

\section{Technical and Bibliographic Notes / Notes techniques et bibliographiques}

The Institute has attempted to obtain the best original copy available for filming. Features of this copy which may be bibliographically unique, which may alter any of the images in the reproduction, or which may significantly change the usual method of filming are checked below.

\section{Coloured covers / \\ Couverture de couleur}

Covers damaged /

Couverture endommagée

Covers restored and/or laminated /

Couverture restaurée etlou pelliculée

Cover title missing / Le titre de couverture manque

Coloured maps / Cartes géographiques en couleur

Coloured ink (i.e. other than blue or black) /

Encre de couleur (i.e. autre que bleue ou noire)

Coloured plates and/or illustrations /

Planches etou illustrations en couleur

Bound with other material /

Relié avec d'autres documents

Only edition available /

Seule édition disponible

Tight binding may cause shadows or distortion along interior margin / La reliure serrée peut causer de l'ombre ou de la distorsion le long de la marge intérieure.

Blank leaves added during restorations may appear within the text. Whenever possible, these have been omitted from filming / II se peut que certaines pages blanches ajoutées lors d'une restauration apparaissent dans le texte, mais, lorsque cela était possible, ces pages n'ont pas été filmées.
L'Institut a microfilmé le meilleur exemplaire qu'il lui a été possible de se procurer. Les détails de cet exemplaire qui sont peut-être uniques du point de vue bibliographique, qui peuvent modifier une image reproduite, ou qui peuvent exiger une modifiration dans la méthode normale de filmage sont indiques ci-dessous.

Coloured pages / Pages de couleur

Pages damaged / Pages endommagées

Pages restored and/or laminated /

Pages restaurées et/ou pelliculées

7 Pages discoloured, stained or foxed /

Pages décolorées, tachetées ou piquées

Pages detached / Pages détachées

\section{Showthrough / Transparence}

Quality of print varies /

Qualité inégale de l'impression

Includes supplementary material /

Comprend du matériel supplémentaire

Pages wholly or partially obscured by errata slips, tissues, etc., have been refilmed to ensure the best possible image / Les pages totalement ou partiellement obscurcies par un feuillet d'errata, une pelure, etc., ont été filmées à nouveau de façon à obtenir la meilleure image possible.

Opposing pages with varying colouration or discolourations are filmed twice to ensure the best possible image / Les pages s'opposant ayant des colorations variables ou des décolorations sont filmées deux fois afin d'obtenir la meilleure image possible.

Additional comments /

Commentaires supplémentaires:

Pages 232, 289 354 are incorrectly nubered pages 32, 28 it.

This hem is filmed at the reduction retio checked below /

Ce documant est filmo au taux de riduction indiquét ch-deseous.

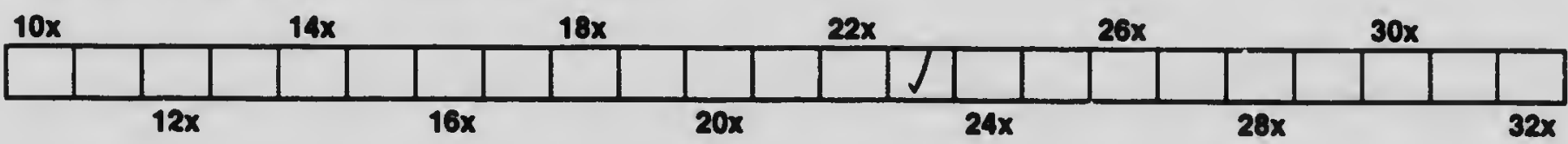


The copy filmed here hes been reproduced thenks to the generosity of:

$$
\begin{aligned}
& \text { Agriculture Canada } \\
& \text { Animal Diseases } \\
& \text { Research Institute Library }
\end{aligned}
$$

The imeoes eppeoring hore ore the best quelity possible considering the condition ond logibillty of the orlginel copy and in keoping with the filming contrect spociflcetions.

Originel copies in prlnted peper covere ore fllmed beginning with the front cover and ending on the lest pege with - prines of illustreted impres. sion. or the beck cover when eppropriote. All other original copies ore filmed beginning on the flrse pege with - printed or illustrated impression. end ending on the lest poge with - printed or illusereted impression.

The lest recorded freme on eech microfiche shell contoin the eymbol $\longrightarrow$ (meoning "CON. TINUED"), or the symbol $\nabla$ (meening "END"). whichover epplies.

Meps. pletes. cherts. etc.. moy be filmed ot different reduction retios. Those too large to be entirely included in one exposure ore filmed beginning in the uppor lott hend corner. lott to right and top to bottom. es meny fromes os required. The following diegrems illustrote the mothod:
L'exemplaire filmó fut reproduit grâce da gónórositó de:

$$
\begin{aligned}
& \text { Agriculturo Consds } \\
& \text { Institut de rocherches viterinatres }
\end{aligned}
$$

Les imoges suiventes ont ott' roproduites ovec lo plus orand soin. compte renu de le condition ot de lo nertote de l'exempleire filmb. ot on conformitó avec los conditions du contrat de filmege.

Lee exemplelres origlnoux dont le couvorture on pepier est Imprimbe sont fllmbs en commencent per lo premier plet et en torminent soit por lo dernibre page qui comporte une empreinte d'impression ou d'illustrotion, soit por lo second plet. selon le ces. Tous los eutres exemplaires originoux sont filmbe en commençent per le premibre pege qui comporte une empreinte d'Impression ou d'illustrotion ot on terminant par la dernibre pege qui comporte une telle emprointo.

Un des symboles suivents apperoitro sur lo dernibre imege de cheque microfiche. sclon le ces: lo symbole $\longrightarrow$ signlfie "A SUIVRE". Io eymbole $\nabla$ signifie "FIN".

Les cortes. planchos, tableoux, otc., peuvent ètre filmbe dos toux de róduction diffórents. Lorsque lo document est trop grand pour ètro reproduit on un soul clicho. il est filmo pertir de liengle suphrieur gauche, de gouche droite. et de haut en bes. on pranant lo nombre d'imeges nócessoire. Les diogrommes suivents lliustrent le mothode.
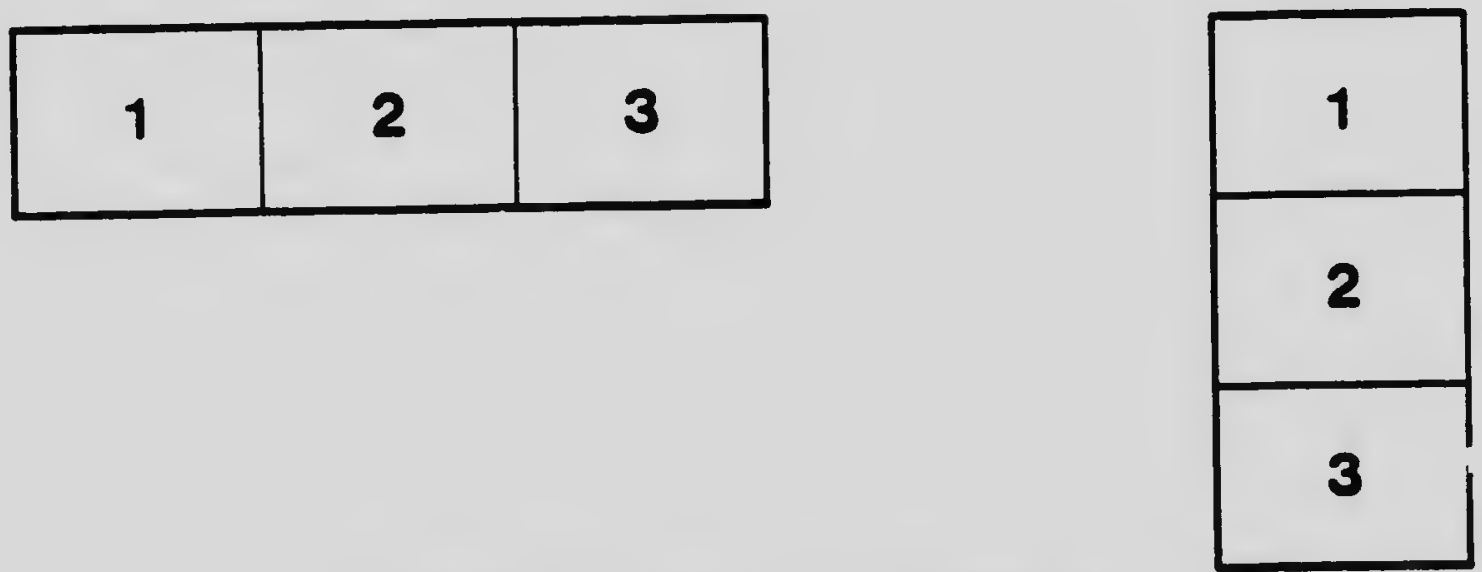

\begin{tabular}{|l|l|l|}
\hline 1 & 2 & 3 \\
\hline 4 & 5 & 6 \\
\hline
\end{tabular}




\section{MICROCOPY RESOLUTION TEST CHART}

(ANSI and ISO TEST CHART No. 2)
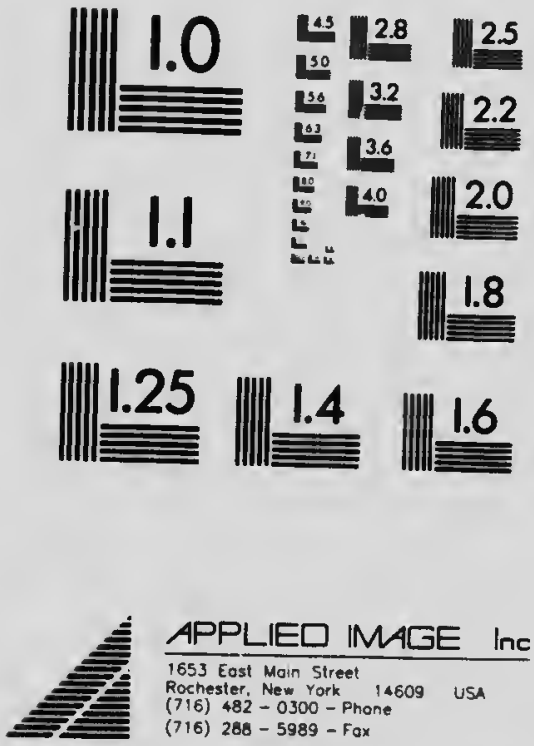


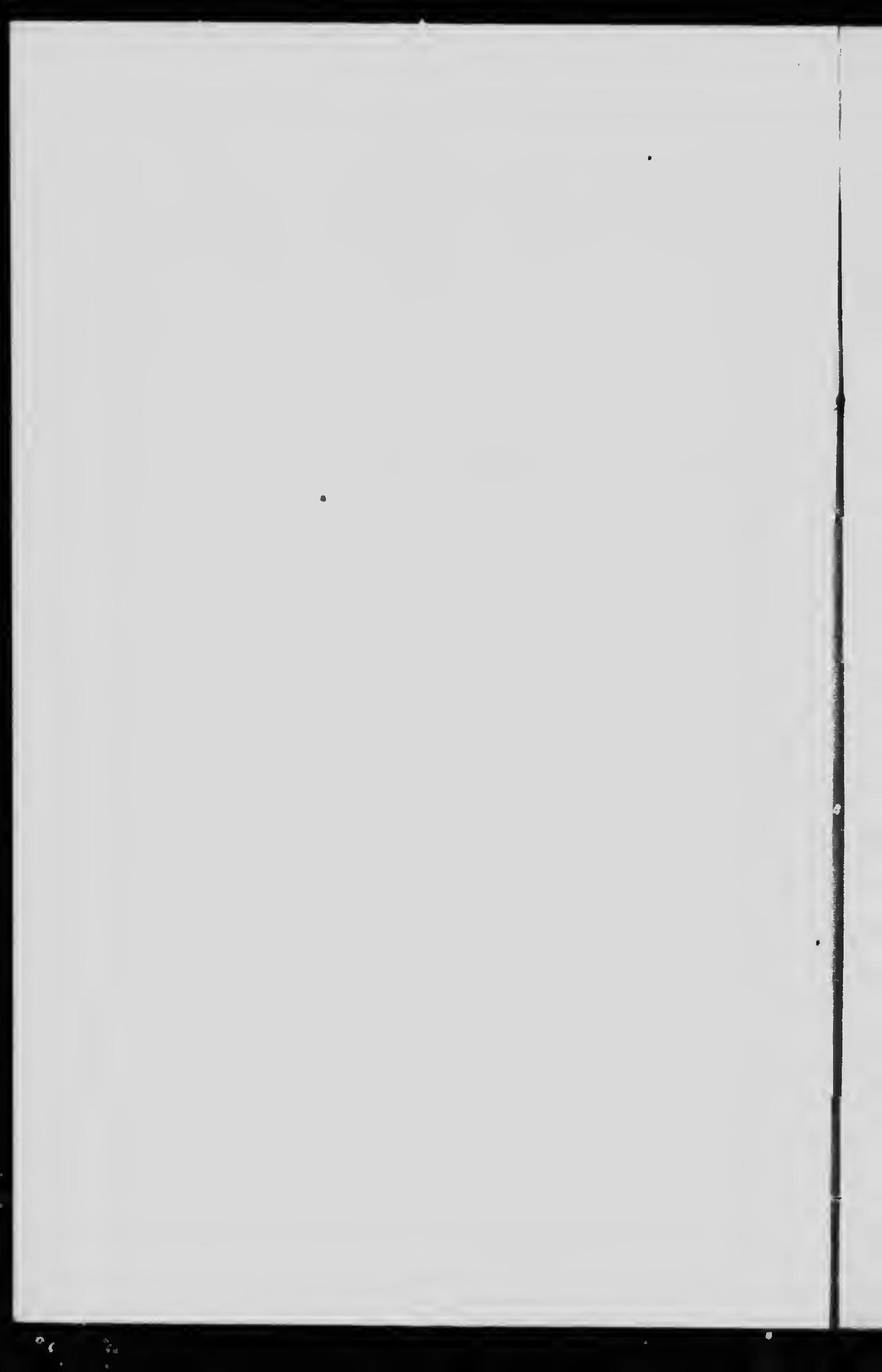




\title{
THE VETERINARY SCIENCE
}

THE ANATOMY. DISEASES AND

TREA'TMEN'T

or

\section{Domestic Annimals}

also containine

A FULL DESCRIPTION OF MEIDICINAS

AND RECEIP'TS.

\author{
wr \\ J. E. HODGINS, V. S., \\ (Homorary Graduate of the Ontario Veterimary Callese) \\ AND \\ T. H. HASKFIT, \\ (Socntary of the Veterinary \& re Company)
}

FIFTY-FIRST EDITION.

LONDON, CANADA :

THF Veterinary Science Company.

190:. 


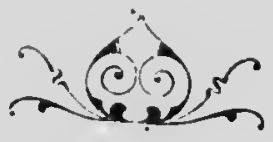

Fotered atccording to Act of the Parhament of Canada, in the year 1896, by . E. Hodgins, V. S., and T. H. HASKFT, a: the Department of Agriculture.

Entered according to Act of Congress, in the year 1896, by J. E. Hovgins, V. S., and T. H. HASKeTt, ig the Office of the Librarian of Congress, at Wash-
ington, D. C.

Entered according to Act of Parliament of the United King. dom of Great Britain and Ireland, in the year 1897 , at the office of the Registrar of Copyrights at Stationers.
Hall.

Copyrights applied for in the following countries: France, Germany, Australia and South Alicica.

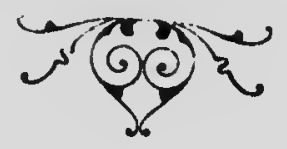

\section{ALL RIGHTS RESERVED.}




\section{PREFACE.}

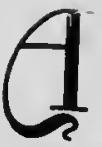

i $1 \mathrm{HE}$ request of some of the leading stockuwners atis prominent farmers of Canada and the United States, and believing that a work of this kind has long been wanted undertaken the publication of THE VETERIs, the authors have simplest English language. Tl.ey have endeavoredence in the profitable and interesting study have endeavored to make it a who, by carefully consulting the stockowners and their sons, contain information of untold value.

The first fifty-eight pages contain the practi conformation of the horse, and should the practical anatomy or

be carefully studied.

Chapter l. lays the plan of the reader proceeds it will how to examine a sick horse, and as Mistakes in ductoring be found to be simple in the extreme. symptoms and treatm can hardly be made, as the causes, that the stockowner has but the diseases are so fully explained in this book.

The comparative anatomy, diseases and treatment of cattle, seginning at page 243, will likewise be found to be as simple and satisfactorily explained as that of the horse.

The diseases and treatment of sheep, found between pages 316 and 337 of the book, are fully dealt with, and it $w$ ill be found by persons who read and study this part of the book that sheep may be asy to doctor as any of the nther animals. The same poultry, found at pags, dogs and

and following pages.

and are a very and receipts constitute Part V. of the book, practically explained. powders, bliste:s, etc., are receipts for making liniments, lotions, those interested in stock, which vable to everybody, especially $i$ may now be said is what the

The index, as you will see, is a prominent featurt of the book, being an index of symptoms as well as of diseases. This makes it very easy for anyone to find out what their animal is suffering from, as they can look for the symptom the animal is chowing in the index, which directs them to the right disease. 


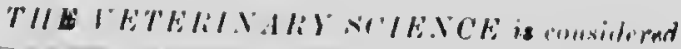

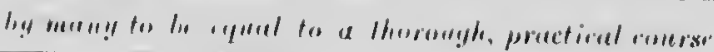

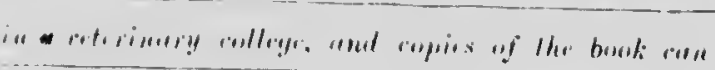

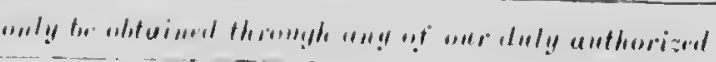
mproxumalitios. 


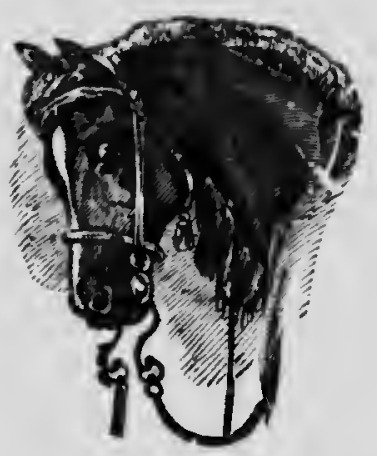




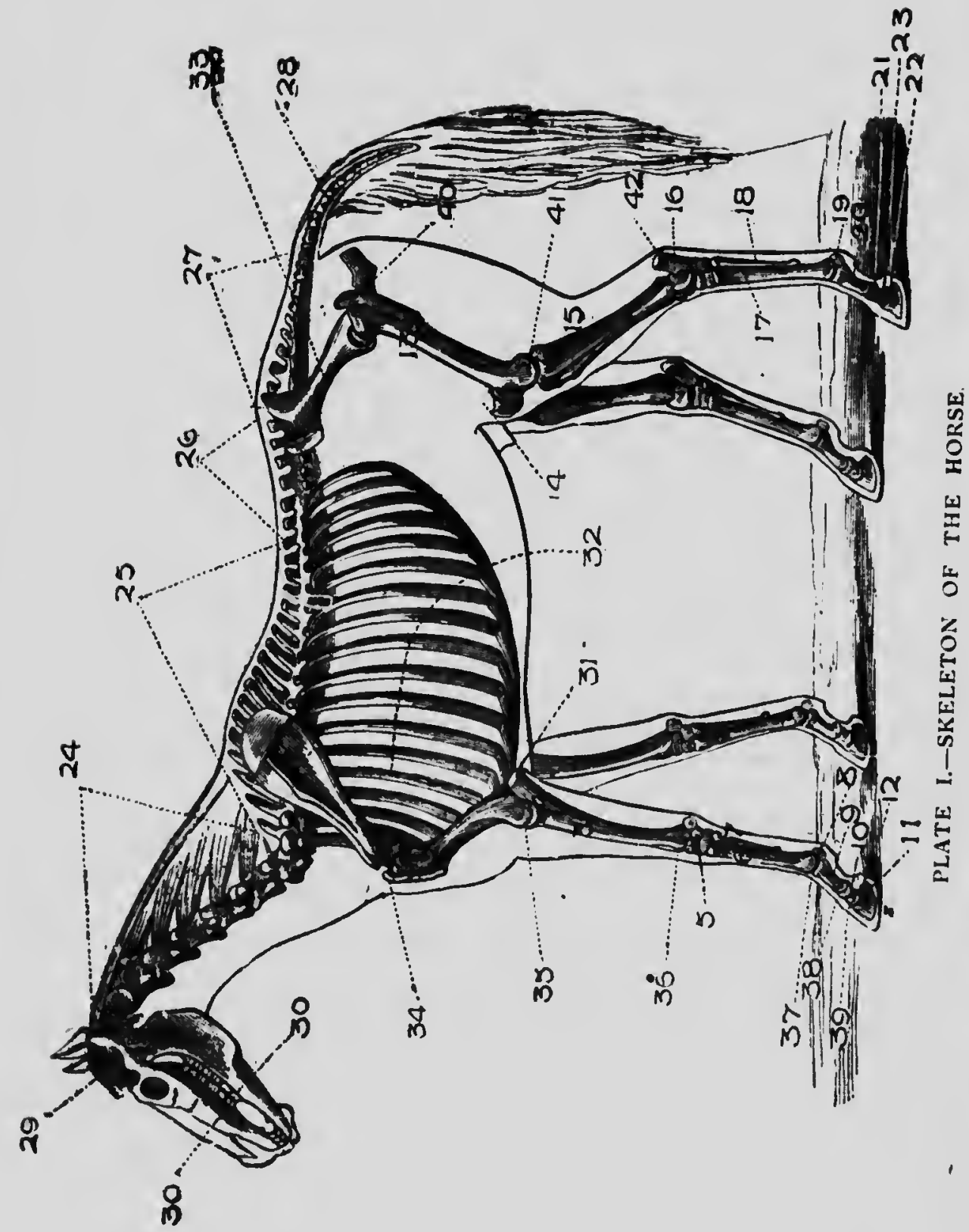




\title{
EXPLANATION OF PLATE I.
}

\author{
SKELITON OF THE HC:ASE.
}

. - ut gives the mames of all the joints and bones in the body, also the number of bones in eact section. Names marked according to numbers.

1. Scapula, or shoulder blade.

2. Humerus, or shoulder bone.

3. Radius, or bone of fore-arm.

4. Ulna, or bone of fore-arm.

5. Carpus, or knee (contains 8 bones).

6. Metacarpal, or large shin bone.

7. Small Metacarpals, or splint bones ( 2 in number) I on each side.

8. Sesamoids, or fetlock bones, 2 small bones at the back of the joint.

9. Os Suffraginis, or large pastern bone.

10. Os Corona, or small pastern bone.

11. Os Pedis, or foot bone.

12. Os Naviculare, or shettle bone, situated behind the coffin-joint, and is the seat of the coffinjoint lameness.

13. Femur, or hip bone.

14. Patella, or stifle bone.

15. Tibia and Fibula, or thigh hones, the Fibala being a small bone ranning down just outside the Tibie.

16. Tarsus, or hock joint (contains 6 small bones).

17. Metatarsal, or large shin bone.

18. Matatarsals, or small shin bnnes (being 2 in number').

19, $20,21,22$ and 23 receive the same names in the hind leg as 8,9 , 10,11 and 12 in the front leg, heing the same from the fetlock down.

24. Cervical region, or neck bone (being 7 in number).

25. Dorsal region, or back bones (being is in number) to correspond with the 18 pairs of ribs.

26. Lumbar region, or small of back bones (being 6 in number).

27. Sacral region, or rump bones (being 5 in number).

28. Coccygeal region, or tait bones (being 18 in number).

29. Craniun bones, or bones that protect the brain.

30. Upper and lower jaw bones.

31. Starnum, or breast bone.

32. Ribs, 18 pairs.

33. Pelvis, or hip bones.

34. Shoulder joint.

35. Elbow joint.

36. Carpus, or knee joint.

37. Fetlock joint.

38. Pastern joint.

39. Coffin-joint, which is situated within the hoof.

40. Hip joint.

41. Stifle joint.

42. Taruu, or hock joint. The joints rearive the same name from the luck down in the lind leg, as from knee down in the front leg. 


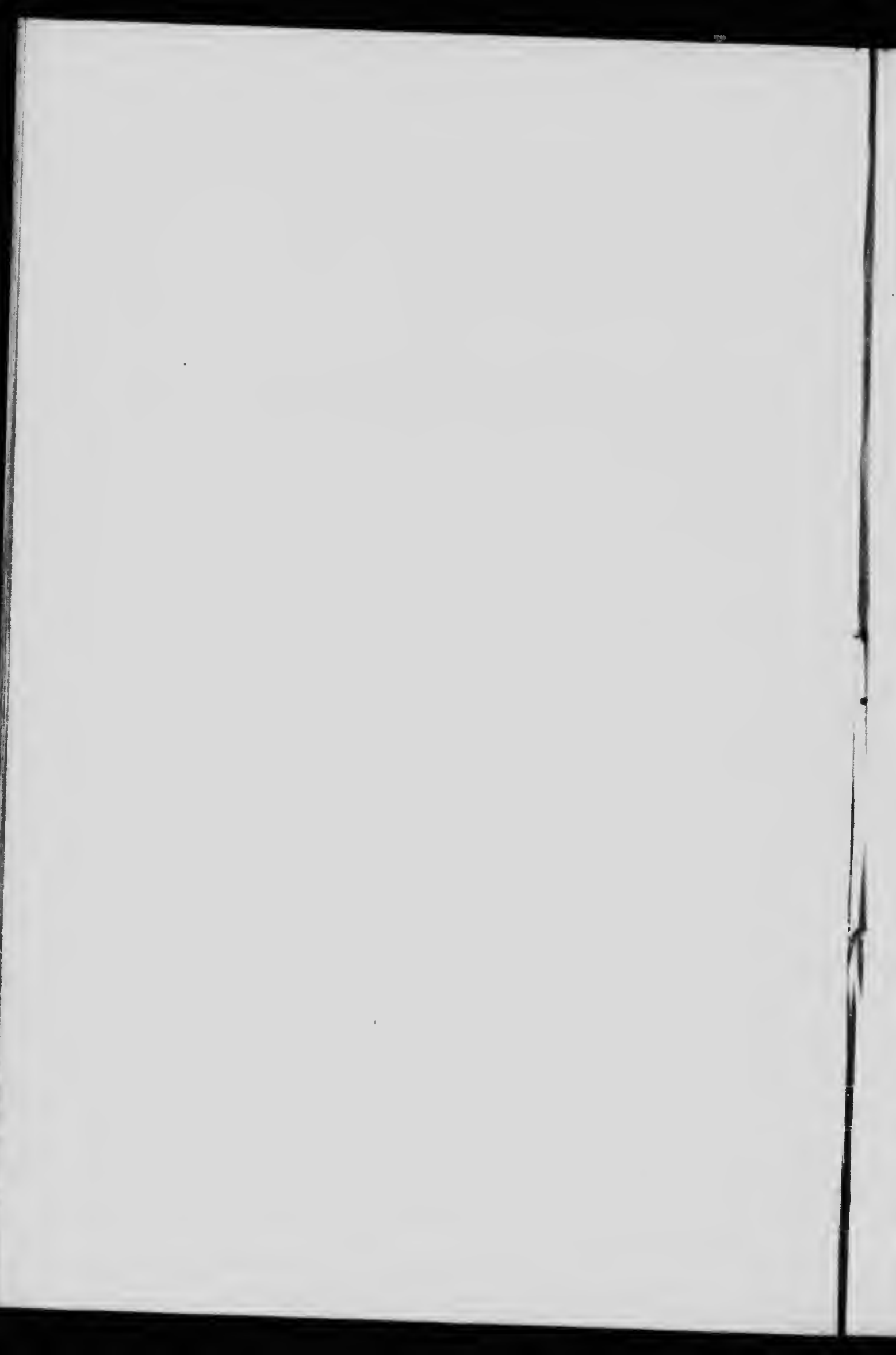




\title{
THE VETERINARY SCIENCE
}

\author{
PART I. \\ ANATOMY OF THE HORSE.
}

CHAPTER I. BONE.

$\mathrm{B}$ ONES are hard, yellowish-white, insensitive objects which form the skeleton of animals. Living bone is bluish pink, insensitive and elastic. On exposure to air if becomes diseased and blackened, and is very sensitive and painful.

Bones are made up of two kinds of matter-animal, which makes the bone tough and elastic, and earthy, which makes it hard and brittle. In young animals the animal matter forms one-half of the substance, which afterwards diminishes to one-third as the animal advances in age. This is why we account for old animals' bones being easier to fracture and harter to mend.

\section{COVERING OF BONE.}

Bones are covered by a tough, fibrous, inelastic membrane called periosteum, which can be seen on examining a bone of an animal which has just died. The only exception we have to this is at the joints where one bone articulates with another, and where a tendon or inuscle plays over a bone; here we find its place taken by articular cartilage.

\section{CONTENTS OF BOKE.}

We find in the extremities or near the ends of bones, red marrow, while in the shaft we find white marrow.

\section{CLASSES OF BONE.}

Bunes are classed as long, that and irregular. Long bones are found in the extremities or legs, and serve as levers for travelliog and pillars to support the body. Always remember, that 
long bones are divided into a shaft and two extremities. Flat bones are found where vital organs need protection. Example: Shoulder blade and ribs, to protect the heart and lungs; pelvic or hip bones, to protect the bladder, rectum and other urinary and genital organs; also the cranial bones, to protect the vital organ called the brain. Irregular bones are found in the spinal column and in the joints, such as the knee or carpus hock or
tarsus, where great strength is required.

HEAD BONES.

In speaking of the different points of importance in connection with the head hones of the horse, in making a cross or longitudinal section of the head, you will notice it is full of cavities or sinuses. The uses of these are to lighten the head and also to warm the air as it passes into the nostrils on its road down to the lungs; you will also tind it is full of foramen or small holes for the nerves from the brain and various blood vessels to pass through to the organs situated in the head, such as the tongue, lips, and the various glands in and around
the head.

Then we have the cavities in which the eyes are situated, one on each side of the head, called the orbital fossa. In examining this fossa you will find a small opening or foramen, through which the optic nerve passes in coming from the brain to the eye. This is the nerve of sight. Then the most important part of all to consider is the cranial cavity in which that very imporvarious functions alled the brain, which controls all the

Then we have anotherments of the body.

drum of the ear. It is si. point, viz.: the situation of the in the whole skeleton, calleded in the hardest bone we find gives the function called hearing the petrosal. The nerve that the petrosal bone and enters comes from the brain down to the dri.m of the ear to give by a small foramen or hole into auditory nerve.

\section{CERVICAL OR NECK BONES.}

first and secuning these bones, we find seven in number. The names. The first ones proceeding from the head receive special is suspended and attached to; the atlas, from which the head a bird with wings out. 
dentata. This is the bone which allows the head to turn in any direction, nence it is sometimes called the axis or pivot of the neck. Between these two bones, on the upper side, is the only plece where the spinal cord is not covered with bone-a spot bout the size of twenty-five cent piece. Here is where the operation of pithing is performed in destroying the horse. It is cone by running a sharp instrument, such as a knife, fairly in the centre of the neck about four inches behind the ears, and passing in this hole through the coverings of the spine into that very vital organ called the spinal cord. causing death instantaneously. The next four bones receive no name, and are about the same in size and length. The last, or seventh hone is only about one-half the length of the preceding ones and receives no special name.

DORSAI OR BACK-BONES.

In considering these bones we find eighteen in number. The chief points of interest about them are the height of the opines on the upper part of the bones. These large spines form the withers of the horse, as you will notice in the skeleton. On either side of these bones we find the ribs attached, eighteen pairs corresponding with ine number of bones in this region.

LOMBAR OR SMALL-OF-BACK BONES.

In considering these bones we find six in number, and they are ctuated immediately above the kidneys.

\section{SACRAL OR RUMP BONES.}

In considering these bones we find five in number in the roung horse, which become united and form, $n$ the adult. These are situated between the upper hip bones i.... nelp to form the rump of the horse. Beneath these bones the bladder is situated.

COCCYGEAL OR TAIL BONES.

In considering these bones we find eighteen in number. The principal points of interest in these are, they become smaller as they proceed towards the point of the tail.

\section{HIP OR PELVIC BONES.}

These are three in number, viz.: Ilium, ischium, and pubis. The largest is the iliun, passing upwards and forwards, the outer part of it forming the pin of the hip or outer angle. The back or posterior part of this bone forms a third of the articular surface of 
the round joint and abe helps to form the upper wall of the peivic or hip cavity. . The ischium passes back from the rcund joint and helps to form the tloor of the pelvic cavity, and can be felt in a horse that is poor in flesh projecting out below the tail on each side. The pubis, the smallest of the three bones, is situated immediately in front of the ischium bone and forms the floor of the palvic cavity.

\section{STERTUM OR BREAST BONE.}

This bone is small and short in the horse and is situated on the lower side of the chest cavity. The principal points of this bone are that it is the softest one in the horse, and the first eight paits of ribs are attached to it on either side. This bone, in the horse, resembles a small, flat boat.

the lateral wall of to the heart and chesty and afford protection region of the back bone. They are attached above to the dorsal to the sternum, or breast Below, the first eight pair are attached the horse; the next ten bone; these are called the true ribs of below, the lower ads being are not attached to the sternum and forwards by a small piee, and are continued downwards slightly attached to the breast of cartilage or gristle, and are just Also remember that, starting until we get to the ninth rib. with the first rib, they get longer last rib is reached, it being a afterwards they get shorter until the

\section{NUMBER OF BONES IN SKELFTON OF HORSE.}

In the head of tha colt is found thirty-eight bones, not including the teeth, but in after life we find a great many bones become
attached to each other by a pacess called ossification.

Head.

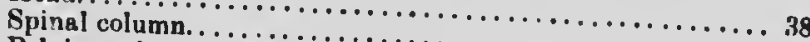

Pelvic cavity or hips, three pair o. . . . . . . . . . . . 54

Ribs, eighteen pair....... pair or six single..........

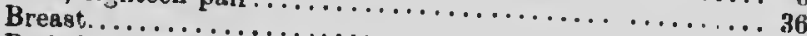

Both front legs............................

Both lind legs. .... ....................... 42

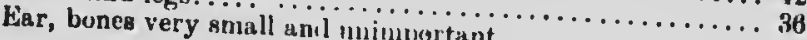

Totul, not inclubling the teeth ........ 216

The teeth sre dealt with semarately in unother seotion of thl bonk. 
CHAPTER II.

\title{
CONSIDERATION OF JOINTS.
}

\begin{abstract}
HE various structures which enter into the formation of joints are the extremities of bone, ligaments, cartilage, and sometimes we have muscles which help to support the joint. All articular joints are supplied with a synovial mem. brane, which secretes the synovia or joint oil for lubricating the joint. Cartilage, or what is familiarly called gristle, are of two kinds, viz.: articular and fibrous. The fibrous is not of much importance and does not need much consideration; it is found in various parts of the body. But the articular cartilage, which covers over the ends of bones where they form a joint, is of more importance.
\end{abstract}

Ligaments are strong fibrous bands found principally around joints. They are of two kinds, capsular and binding. A capsular ligament is a thin membrane, attached around the end of acher which helps to form a joint, and is, as it were, air-tight. The uses of these lig: rents are to keep the joint oil from escaping, and partly helps to hold the bone together. On the inside lining of this ligament we find the synovia membrane wlich secretes the joint oil. Binding ligaments are generally found on each side of of the joint, and are very strong bands of fibrous tissue. The uses of these ligaments are to hold the bones of the juint firmly together.

\section{THE IMPORTANT POINTS OR JOINTS IN THE IEGS.}

Shoulder Joint. - This joint is formed by the shoulder blade, or scapula, and humerus or shoulder bone. This is a ball-andcorlet. joint, and has a strong capsular ligament, and is held to ite plawe also by several large muscles, the most important ono boing the foxor brachii, which passes down over the shoulder foint through a pulley-like process on the bone, and is held down by a bindiag Hgament which is supplied by a synovial membrane, or sack. This is the seat of what is called shoulder joint lameness. The motion of this joint is outwards or inwards, backwards or forwards.

Eloow Joint is formed by the lower part of the humerus and the upper part of the radius and ulua. It has a capsular ligament and binding ligamente, one on the inside and one on the outside. The action of this joint is just forwards and backwards, or flection and extension, but has no side motion. 
carpus, or Inee-This to a very important joint, conal ructed of alght bones, having two rows, four in each, held together by strong, short ligaments. Thus we have three separata articular eurfaces in this joint. The top side of the upper row articulates with the bone of fore $2 \mathrm{rm}$; this surface gives the most motion to the knee. Another articulation between the two rows of bones gives slight motion to the knee, but not so much as the upper articular surface. Between the lower part of the lower row of bones and the upper part of metacarpal, or shin bones is mother articular surface which gives slight motion to the knee. This joint has a large capsular ligament, and has binding ligaments inside and outside. The action of this joint is the same as elbow joint.

Fetlock Jolnt. - This is formed above by the lower part of the shin, or metacarpal bone, and below by the upper part of the large pastern bone. At the back of this joint we have two small bones called the sesams:d bones. This joint has a capsular and two lateral binding ligaments. The motion of this joint is backwitds and forwards, same as knee.

Pasterv Jolnt. - This joint is situated just above the hoof, and is formed by the lower end of the large pastern bone and the upper end of the small pastern bone. It has a capsular and lateral binding ligaments, same as fetlock joint. It also has same motion as fetlock joint, and is sometimes the seat of what is termed a high ringbone.

Comn Joint-This joint is situated within the hoof of the horse. It is formed above by the lower and of the small pastern bone, and below by the upper part of the foot bose, or a pedis. Immediately bohind thls joint, and articulating with the other two bones, we have the navlcular, or shuttle bone-it gote it name from its likences to the shuttle of a sewing machine. This bone is the seat of navicular disense, or otherwice oullad colln-foint lamencas, and aloo is affectud with what is comatimes called a
bondown riagboes.

\section{JOLTS OP HIT LBQ.}

Elp Joint-This is a ball-and-socket joint, similar to shoulder joint. It has a capsular ligament and wl. ligament, in the joint, holdi:g the head of the bone in the socket, which can be soen plainly on examining the joint. This is an important ligament, it often becomes strained, which is the seat of hip joint laneness. It is also held logether by the heavy muscles of the hip. Its motion is similar to that of shoulder joint. 


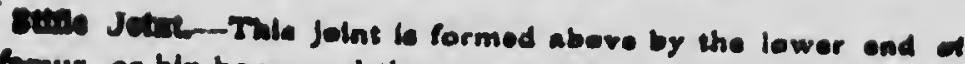
the feour, or blp bone, and the upper end of the tibia, or thigh beas. Thees two bones in front form a pulley-llke lariace on whleh the patelln, or stife bone ls sltuated. This bone, when the folnt in in motion, slides up and down siver the pulley-llke surface. It comotiones becomes displaced, and thls lo tormed dislocation of the stive bona. This is an important polnt to notice about this folot. It has a capoular and lateral, or binding ligaments; also thre very important ligaments, called the straight ligaments, which holds the atifle bone to its place as it plays upon the pulleylike process of thls joint. The motion is backwards and forwards, name as elbow joint.

Hock or Tarsus Joint.-This joint contains six bones. The two upper bones, one of whi-h is a pulley-like bone placed in front, and the other one placed behind, forms that part of the hock which is called the point of the hock to which the muscles of the gamb are attached, which can be easily seen or felt. The upper surface of these two bones articulate with the lowsr extremity of the tibia, or thigh hone, and forms a true articulation of the hock joint. This part is what gives most of the motion to the joint. Below those we find tiree other smali, ant bones, placed one upon the other, having articular surfaces between each one. These are ealled the cuneiform bones of the hock. Immediately behind these three small bones we have what is termed the cuboid bone. This bone also ariculates with the cunoiform bones, helping to form the articular surface of the hock. The lower articular surfaces help to give a small amount of motion to the joint. This joint is the seat of the diseaso tormed spavin. front leg.

Fetlock, Pastern and Coinn Jolnt are dmilar to those in

In spaking of ligamente, there is another very Important one to mention which is called the llgamentum nucha, which supports the head when the muscles are at rest. This extends from the pole of the head backwards under the mane and is attached to the spine of the dorsal vertebra or, commonly called, the withers of the horse. This ligament is chiefly made up of fibro elastic tissue, and will stretch much the sume as a piece of
elastic. 


\section{CHAPTER III. \\ THE MUSCULAR SYSTEM}

COMMONLY CALLED FLIAH.

$M$ USCLES are the chiof organe of motion, each one beine separated from the other by a thin, delicate membrane nade up of connective tissue, which forms a sheath for the muscie. A muscle is divided into two parts, viz.: muscular and tendinous. The muscular part is the larger of the two and forms the larger portion of it, and is sometimes called the belly of the muscle. It is made of muscular tis'sue, which has a reddish meaty color. At both ends of the wiuscle we find a tendinous part, or the hard, white portion of the muscle where it becomes attached to the bone. Every muscie is attached to two or more places on different bones, and, upon their contraction, moves the joints of the body. They are well supplied with nerves, which give strength and feeling, and also well supplied with small blood vessels, from which the muscle is fed. Muscles are found in separate groups, all of which have different actions to perform. There are two kinds of muscles-voluntary and involuntary. The voluntary muscles are under the control of the will of the animal; example-the muscles of the legs, hip, back, heat, and neck. The involuntary nuscles are beyond control of the animal, and will act oven though the animal were asleep-such as the heart, the large muxcular curtain which separates the che.t cavity from the abdominal cavity, which is one of the great muscles of breathing; also the muscles around the chest which assist in breathing.

Voluntary Huscles are In groups. The first one we call attention to, after removing the skin, is a thin muscle almost entiroly covering the body, and is sometimes accidentally removed if not cereful in skinning the animal. The action of this muscle is to shake the skin when flies or something bother the horse. At the head we find a group of muscles which assist in chewing, or masticating $1_{1}$ the fond. Around the throat is another set of muscles, sometimes called the muscles of the gullet, or pharynx, which assist in swallowing. The neck muscles are divided into two groups, one on each side. The action of these are to raise and lower the head, also to turn the neck and head from side to cide. The muscles of the back are generally divided into two 
Grups, one aoove the sponal culumil alla the ulfier belun. Ithe muscles above the spine assist the animal in running, jumping and rearing. The nuuscles below the spine are sometimes called the lumbar, or psox, situated below the lumbar bones, or the bones of the small of the back. Below these muscles are the kidneys. The action of these muscles is to ass he animal in getting up. These musules are important, for when paralyzed the horse cannot use his hindquarters in trying to get up.

The Gluteal Muscles, or the muscles of the hip, are very large, filling in around the hip bones. The action of these is much the same as those of the back, as they assist in jumpixg, running, rearing, and in raising the hind leg.

TLC Abdominal Muscles, or belly muscles, are four large, flat muscles on each side of the abdomen, or belly. The outer edge of these muscles are attached to th. outer ends of the faise ribs, also to the frocesses of the linmbar bones and the outer angles of the hip bones. They unite helow to what is calied the linea alba, which is a hard, white, fibrous cord, and is attached in front to the back part of the breast-bone, passing back in the centre ot the belly, and is attached to the front of the pubic bones, or what is called the lower bones of the hip cavity. About ten inches from where it is attached here, passing forward, we find a small slit, or hole, which is called the navel, or umbilical opening, where the naval vessels pass in and out during the fotus life, or before the colt is foaled. This is a point of importance to note, for sometimes at the time of birth this opening does not close and allows the bowels to come down and form what is known as navel, or umbilical rupture.

Before fniahing the description of thls group of muscles wo will mention very larko, important ligament which is found epread all over the abdomen, or belly, of the horse. It le of a yollowlah color and about one-eighth of an inch thick, attached in front to the back of the breast bune and to the hip bones behind. This is the first structure seen after removily the skin from the belly. This ligament gives great support to the organs contained in the abdominal cavity. The action, or uses, of the abdominal muscles are to support the organs contained in the abdominal cavity, to flex the back-bone and assist in the passing of the faces, or manure. 'In the mare these muscles assist her in foaling, $\infty$ parturition. 


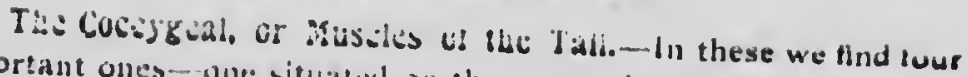
important ones-ane situaled on the upper side of the tail when it is straigltt out, its notion is to raise the tail; two are situated one on each side of the tail. they have the power of drawing the tail to either side: the last sue we montiun is situated under the tail and is the smallest one of the four, its action in to draw the tail down.

The Shoulder Muscles are very large and powerful ones. There are oaly three of freat importance, viz.: The two situated on the outside of the shoulder blade; these are important as they are the seat $c$ the disease called sweeny. The other important one is that which passes down over the shoulder joint through the groove or pulley-like surfice on the shoulder bone. This is a fo.'s, powerful muscle, attached above to the lower end of the s) 'er blade, down through the groove mentioned to the upper part of the bone to the fore arm, or radius, at the front side. Its chief point of importance rests in its action in raising the front leg, where it passes through the pulley-like surface mentioned, when it becomes injured or diseased; it is also the seat of shoulder joint
lameness.

Muscles of Front Leg, from shoulder down, are divided into two sep:arate kinds, viz.: the extensor and flexor muscles.

The extensor muscles are the ones which bring the leg forward. These muscles, above, are attached to the bones around the elbow joint, passing down in front of the arm bones. About three inches atnove the knee they become changed into the tendinous I irt of these muscles, or what is calied the cords of the leg. Some them are attached to the knee joint, while others pass over the front of the joint and are held down to their place by a band or ligament, forming a loop, as it were, for this muscle to glide in when the leg is in action. Each one of these loops, where the muscles pass through, are supplied with a eynovial membrane to secrete the synovia, or oil, which lubricate it durlng action, the same a in the joint. This is a point of importance, as sometimes, on account of injury or strain of thls part of the joint where the muscle plays through, we nind a small puffy enlargement containing oil sccreted by the synovial memorane. This disease is what is called a bursal enlargemert.

The flexor muscles are the ones situated at the back part of the leg, attached above to the back part of the elhow joint, passing duwnwards at the back part of the leg. About two or three 
Inches above the buck part of the knee joint they become tendinous, and from there down to the back part of the foot bone, whore twe of the principal muscles are attached; these form what is known a the back tendons, or cords, of the leg. Some of them become attached to the back part of the knee, same as the muacles on the front part of the leg, while the other two principal tendons pase through a loop formed by ligaments, the same as those mentloned in the front part of the knee. In tracing these tendons down from the knee to the fetlock, they pass through another large loop or sheath formed at the rick of the fetlock, where some of the fibres are attached, while others continue down at the back part of the pastern bones, and are attached to the os pedis, or foot bone. These tendons are important as they are known, when they are strained, as the strain of the back tendons. The action of these muscles is to flex the leg, bend the knee, pastern joints and fetlock.

Muscles of Hind Leg.- These are also divided into two groups, extensor and flexor.

The extensor muscles are situated in front of the hind leg ; attached, above, around the stifle joint, passing downwards in front of the thigh bone, one being attached to the front part of the hock, while the other passes through sheaths, or loops, which is supplied by a synovial membrane, formed by ligaments, to hold the muscles firm in front while the leg is in actinn. In tracing them down, in front of the shin bone to the fetlock, we rind them passing through loops, or sheaths, continuing down in $f$ int of the pastern bones to where they are attached. The action $j i$ these is tc bring the leg forward.

The flexor muscles of the hind leg are attachied, above, around the back part of the stifle joint. In tracing them down it is found they become tendinous. Two of the principal ones pass down to that part of the hock joint, which sticks up behind, known as the cap. These form what is called the gamb of the leg, and are partly attached at the point of tha hock, the other part passing down to the fetlock joint through a loop, or sheath, along the back part of the pastern bones, and are attached to the foot bone. This muscle, from the hock down, forms one of the back tendons of the hind leg.? Another important muscle is found passing down underneath the ones already mentioned, through a loop, or sheath, at the back part of the hock, where it is supplied with a synovia sack. This is a point of importance, for when it becomes 
strained it is the seat of what is callod thoroughpin. It then passes down the back part of the shin bone beneath the other tendon already mentioned, through the loop at the fetlock to the back part of the foot bone, where it is attached. The action of these muscles are to flex or bend the fetlock and raise the hock joint in travelling.

Involuntary Muscles, or muscles which are not under the cantrol of the will. The firat we call attention to are the muscles of breathing, or respiration; they are a group oituated around the chest in such a way as to enlarge the chest cavity and draw the air into the lungs - this action is callod inspiration-while others in acting decreases the size of the chost cavity and forces the air out of the lungs, which is called expiration. The diaphragm is a muscular curtain which separates the chest from the abdominal cavity, and also assists greatly in drawing the air in, when it contracts ; this muscle also assists in passing manure, and in the mare foaling. It separates the heart and lungs from the bowels, liver and stomach. Everyone interested should examine this muscle, which can be seen by opening any dead animal.

There is one muscle which is both voluntary and involuntary. It is situated in the penis, surrounding the urethra, or the tube, which carries the urine from the bladder to the penis in the male animal. Its action is voluntary while the animal is passing urine, or water. It acts involuntary during sexual intercourse, forcing the semen down through the penis. There is what is known by ths name of fat situated between the muscles.

CHAPTER IV.

\section{THE NERVOUS SYSTEM.}

THLs gystom to a very importans ent of organe which stwo motba and foollng to tho boty, and the difisront conces, one acolng, hearing, omolling and tasting. The two prectpal parte of the nervous system are the brain and spinal cord The braln, being the centre of the whole nervous nystom, is situated in the cranial cavity, surrounded by three delicats mombranes, the outer one being attached to the inner wall of the cranial cavity. The brain contain several important 'perves ealled the crania! nerves, which are given off from the brain and panend down through tho various foramen "or opooingen in tho 
head to supply the wifferent organs situated there, such as the optic nerve, which passes down to the eye, giving the sense of sight. The auditory nerve passes down to the drum of the ear to give the sense of hearing. The aulfactory nerves, which give the sense of smell, are situated in the mucus membrane lining the nose. The nerves passing down to the tongue give the sense of taste. Other nerves pass down to the lips, teeth, mouth and face, giving motion and feeling to the parts mentioned; others pass down to the gullet or pharynx, giving it the power of swallowing. In passing from the brain along the spinal cord, which is situated in the opening of the bones of the back, there are numerous small nerves given off to supply the muscles of the neck, giving the neck motion and feeling. About opposite the shoulder blade, or withers, the spinal cord gives off a large bunch of nerves, part of which supplies the heart and lungs with nervous power. This is a point of importance, for if the spinal cord becomes injured in front of these nerves it causes immediate death. The other part of this bunch of nerves supply the shoulder, chest, and muscles of the front legs. Passing backwards along the spinal cord is found the sympathetic system of nerves, which $\mathrm{go}$ to supply the bowels, stomach, liver, kidneys, and other organs situated in the abdominal cavity. Continuing backwards along the spinal cord, to about opposite the hip bones, we find another lot of nerves, one of which groes to supply the rectum, or back bowel ; this gives the power of passing manure. Others go to the womb and bladker; these assist in urinating by contracting the bladder. Other nerves pass to the small organs situated in the pelvic cavity; some of these nerves pass down to the hind legs, supplying them with nervous power. The balance of the nerves of the spinal cord go to supply the tail.

Nerves have the appearance of bunches of white thread lietd together by connective tissue. 


\section{CHAPTER V. \\ CIRCULATORY SYSTEM.}

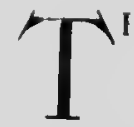

IIIS is an important system to understand on account of it being the means by which the various parts of the body are led or nourished. The principal points to consider are the heart, arteries, citpillary vessels, veins, and the very important fuid they carry, called the blood. Considering the heart, we find this the main organ of circulation; it weighs about six and one-half pounds in the atverage horse; it acts as a force pump to force the blood through the vessels already named. It is made of strong muscular tissue, which acts involuntary, and is situated between the lungs, which are curided by what is known as the mediastinum, which is a division between the lungs and is made up of two folds, the heart being between these. The bottom end, or apex, of the heart is downwards and rests just above the breast-bone; the base, or upper part, being directed upwards and to the left side, the left lung having a hollow on its inside for the heart to work in. There is a covering or sack around the heart which helps to protect and support it in its place, attached above to back-bone and below to the bones of the sternum, or breast-bone. This sack is made up of fibrous tissue and is of a whitish appearance; inside it is smooth, and has numerous small glands which secrete an oily substance called serous fluid, which lubricates the outer wall of the heart and the inner wall of the sack so that in action it does not irritate the walls. The cavity in the heart is divided into two parts, the right and left sicles; each one of these parts are again divided into an upper cavity called auricle and a lower cavity called ventricle; thus we have the right and left ventricle and right and lef auricle. The right auricle comununicates with the right ventricle through an opening in the septum, or partition in the right side of the heart. This opening is guarded by a valve to keep the blood from flowing back into the auricle. The left auricle communicates with the left ventricle, same as on the right side. The right side of the hoirt is sometimes callod the venous; this side only deals with the impure blood. The left side is sometimes called arterial side, and only deals with pure blood; this side of the heart is very much stronger and thicker than the right side. 
In tracing the blood through the heart, commencing at the right auricle, we find the two large veins of the body, called the anterior and posterior vella cavas, which empty the impure blood of the body into the right auricle of the henrt. It is there guarded by two small valves at the mouth of each vein, while the right auricle contracts, forcing the blood down through the hole in the septum into the right ventricle. It is there guarded by a valse to keep the blood from flowing back, while the right ventricle contracts and forces the blood up into the pulmonary artery, which passes only two or three inches abure the neart and divides into two branches, one to the right lung and the other to the left lung. These again divide into uther small arteries, which flow into what is known as the capillary netwolk. This network is situated aro: I the air cells of the lungs, where, by a process, the blood gives off carbonic acid gas, which is breathed out along with the air. The blood lakes in the oxygen from the pure air, which changes the eolor of the blood from a black red to a hright red. This is a point of importance to note as it shows that stables should be well rentilated so that animals can have plenty of pure air. The blood now flows into the pulmonary veins, which carry the pure blood back to the heirt to be empticd into the left auricle. Here these veins are guarded with valves so as not to allow the blood to flow back while the left auricle contrats to force the blood down through the opening inentioned hefore into the left e ntricle. This opening is also guarded by valves so as not to allow the blood to fiow back while the left ventricle contracts, th great force, to drive the blood up into the common aorta, the largest artery in the body, which passes above the heart two or three inches, and, just below the backbone, br aks into branches, one passing forward and supplying the parts of the body in front of the heart, the other brinch passing backward under the spinal bones, supplying the parts of the body behind the heart.

The branch which groes forward runs uncler the spine just a few inches, where it breaks into other branches, some going to supply the shoulder and tront legr the other branches being two large ones, one paming an eatels side of the neck under the juirular vein, which are allud caroid arteries. These rive of small branches, as they pass up the sile of the neck, to feed the muscles and other parts thereof, while juet holu the butt of the ear, this artery breaks into thre large branches, whith gro to supply the brain and different parts of $1 i_{1}, 4, \cdots+1$. In insialering 
the branch which runs backivards from the heart, we find it a very long, large artery, passing just below the spine, between the kidneys, breaking up about six inches behind them into four large branches-two on the left and two on the right side. One on the left goes to supply the left hip and organs in the pelvic or hip cavity, while the other passes down the left leg to supply it with blood; one on the right side helps to supply the right hip and pelvic cavity, while the other passes down the right leg. This large branch, in passing back along the spine, gives off small branches-one to the liver, one to the spleen, one to the stomach, and branches to the large and small bowels, and one
to each kidney.

Arteries are the vessels which carry the blood away from the heart to the different parts of the body. They always carry the pure blood of the body, which is a bright red color. When the reft ventrical contracts it causes a wave, as it were, to pass all down through the arteries. This is an important point in connectinn with the pulse of a horse. The walls of the arteries are macie up of elastic tissue, and after deatl, are always lying open, and, also, you never find and slood in them after death, the reason is because they contract and force the blood all out before they loose the power of contracting.

How to Tell When an Artery is Cut.-The blood comes out in spurts every time the heart beats, and is of a bright red color. Arteries are always found deep-seated and well protected with musclis and bone; as, for instance, the large arteries of the legs always pass down on the inside of the leg very close to the bone, and on account of this we very rarely have large arteries injured. Towards the end of the arteries they are found to break up into very small ones which run into the capillary network of the body. These are numerous very small vessels abnut $\frac{l}{9000}$ of an inch in diameter. Their walls are very thin and cannot be distingrished except under a microscope, and are found in all parts of the body. As the blood passes slowly through these small vessels, the nourishment is absorbed from the blood through the very thin walls to supply the tissues of the body. When the lood passes through this capillary network it again enters into larger vessels called the veins, which carry it on its road back to the heart. In starting at the head to trace the blood back to the heart. we find it carried from the head by two very important vessels called the jugular veins; these are important on account 
of belng the veins which are used to bleed the anlmal from. The veins which run up the Inside of the front leg, carrying the blood back from the leg, unite with the jugular veins, forming what is known as anterior vena cava, which empties into the right auricle of the heart. In tracing the blood back from the hind leg, a large vein is found on the inside of the leg, passing up under the hip, where it unites with the veins of the hip region, forming wliat is known as the posterior rena cava. As it passes forward it takes in veins from the various organs such as the stomach, liver, kidneys, spleen, and small bowels, and finally empties into the right auricle of the heart. This is the complete circulation of the blood.

Blood is that which carries nourishment to all parts of the body, and also carries away all the waste material of the body, where it is thrown off in the form of urine, which is secreted

from the blood by the kidneys. IVe find the waste material also thrown off in sweat or perspiration through the skin, and also by the lungs. The blood varies in color in the different parts of the body-in the arteries it is a bright red, while in the veins it is ark red color.

\section{CHAPTER VI.}

\section{LYMPHATIC SYSTEM.}

This is also known as the absorbent system, and is In connection with the blood vessels, and is made up of very fine minute tubes and glands, which convey from. the tissues of the body a clear fluid known as lymph, and pours it into the blood of the veins as it is on its way back to the heart. These glands are found all through the body; for instance, a large group of these are found inside the thigh or stifle joint of the horse, also another large group inside the shoulder. These are Important points to note as they sometnines become inflamed and the leg swollen; then they are the seat of the disease called weed in the leg, or lympliangitis. 


\section{CHAPTER VII. DIGESTIVE ORGANS.}

HE whole digestive track from the mouth to the anus,
which is situated just below the tail, is sometimes ca!led which is situated just below the tail, is sometimes ca!led
the alimentary canal. The chief parts are the mouth, pharynx, or gullet, œsophagus, or the tube which leads from the gullet to the stomach and the intestines, or bowels. The mouth is an oval cavity at the commencement of the alimentary or digestive canal. In front of the mouth are the lips, one above and one below; at the sides are the cheeks; it is lined by what is known as the mucous membrane, which has several small openings in it from the glands, which are situated around the mouth, through which the saliva is pourea. On the upper part of the mouth the mucous membrane is thrown into ridges, or folds, and are from eighteen to twenty in number. This is a point of importance in connection with bleeding a horse with lampers. Always remember it is not safe to bleed back of the third bar because there is a large artery which runs down through the roof of the mouth and enters up through a role in the bone just before it reaches this bar. The tongue, which has the chief nerves of the sense of taste, is situated in the mouth; this organ also has a very important part to perform in masticating the food and mixing it with saliva. The teeth, which also take a very active part in the masticating of food, are mentioned later on in the book under the heading of "Teeth."

Salivary Glands.-These are the glands which secrete the saliva that is poured into the mouth while the animal is eating. There are only three pairs of much importance. One large pair, one on each side of the throat below the ears, filling up the space between the jaw bone and the neck; this pair has tubes passing around and under the lower jaw and up into the cheek muscles, entering the mouth opposite the fourth molar tooth; these tubes are about as iarge as straws and convey the saliva from the gland into the mouth. The next pair are situated under the pair first mentioned; their tubes enter into the bottom part of the mouth. The third pair are situated uncler the tongue, one on each side; they pour their secretion into the mouth by several small openings near the front under the tongue, which can be seen by examining closely. This is a very important fluid in connection with the digesting of the food. 



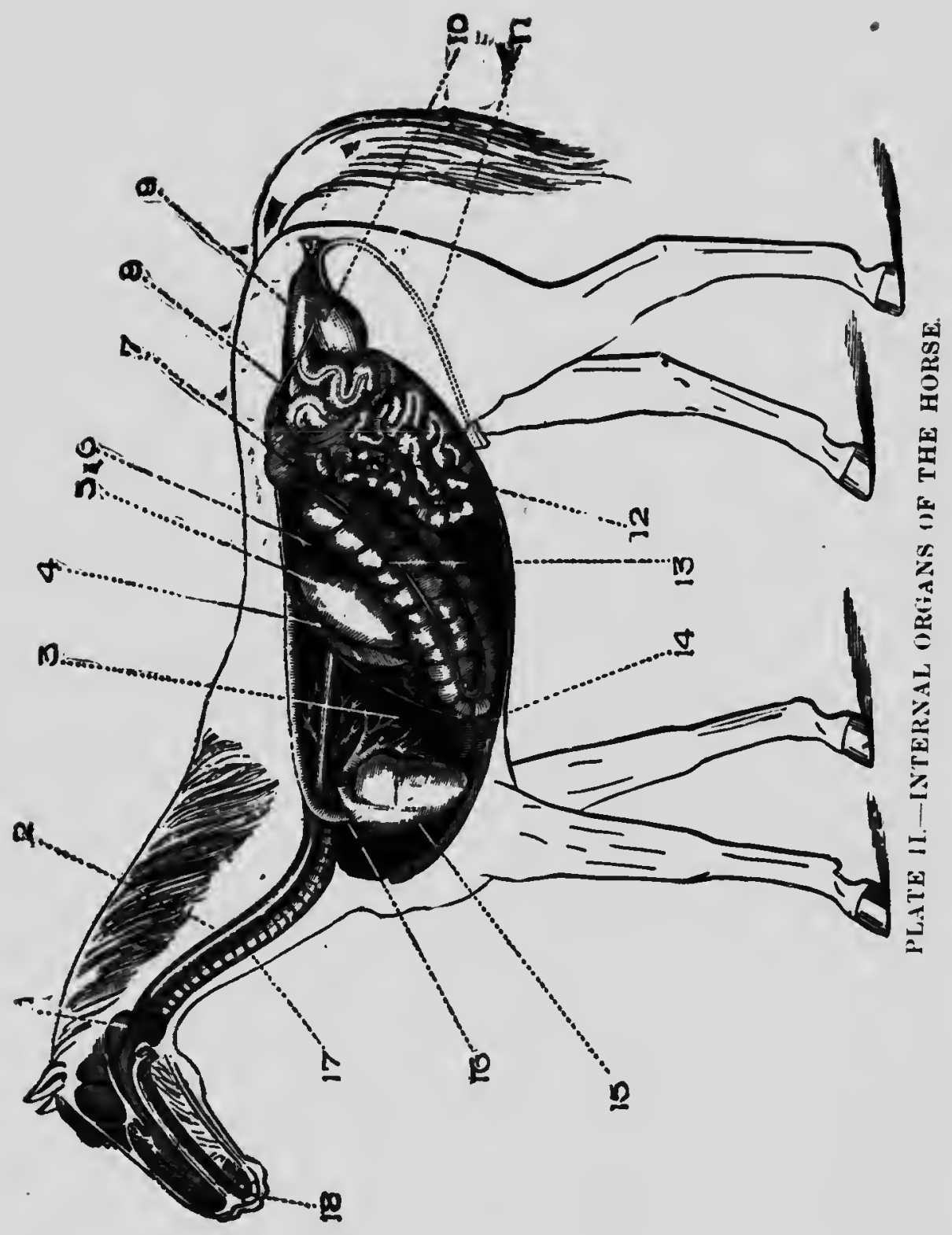




\section{EXPLANATION OF PLATE IL.}

\section{INTERNAL ORGANS OF THE HORSE.}

This cut shuws the position of each organ in the body.
1. Pharynx, or throat.
2. Escyisagus, or the tube which carries the food to the stomach.
3. Right lung.
4. Spleen.
5. Stomach.
6. Liver.
7. Kidney.
a Ureter. This is the tube which. carries the water or urine from the kidnoys to the bladder. There is ene tribe to each Iterey.
9. Rectum, or back bowel. 10. Bladder.
II. Urethra.
12. Small bowels.
13. Large bowels.
14. Diaphragm, or curtain which sep- arates the stomach and bowels from the lungs and heart.
i5. Heart.
16. Common Aorta, which is the largest artery in the body.
17. Traches, or wind pipe.
12. Mours.

SPECIAL NOTICE.-Every place where Tablespoonful is mentioned in this book should read: SMALL, or DrSERT Tarlaspoonsul, which is equal to two Teaspoonfuls. 
The Gullel is a cavity itunted just bolind the mouth. It is chiefly made up of muscles which perform the act of swallowing the food. It is lined with the continuation of the mucour membrane of the mouth.

The Oesophagus, or the continuation of the gullet, which is a tube extenuing from the gullet to the stomach, is used to carry the food to that organ. It is made up of two coats, the muscular and the mucous. The former contains fibres which, when once the tood enters the tube, contracts behind it, forcing it along to the stomach. Its lining is a continuation of tha mucous membrane of the moutii and gullet. In tracing the tube down the neck from the gullet, it passes down the left side of the neck, entering the thoracic, or chest cavity, between the lungs over the heart through the large muscular curtain known as the diaphragm, entering the stomilch an inch or two after passing the diaphragm.

The Stomach.-Th is organ is very small in the horse in com. parison with the ox; it only holds about four gallons, and is situated just hehind the curtain which separates it from the lungs ; it is mostly to the left side. The walls of the stomach are composed of three coats, one on the outside called the serous membranethis is a name applied to membranes which line closed cavities, such as the abdominal, or belly cavity. The inside lining is a continuation of the nucous membrane lining the urgans before mentioned. When the stomach is empty this membrane is thrown into loose folds, and there are also found several small openings through which the gastric juice and pepsine from the glands, situated in the walls of the stomach, enters. These are very important fluids as they assist greatly in digesting the food. The third coat is known as the muscular coat, being made of muscular fibres, and is situated between the two coats already mentioned. Its action is to give the stomach a churning motion, rolling the food around and mixing it with the fuices. The stomach is guarded by a valve where the food enters which prevents It from passing back through the gullet. There is also a valve at the opening of the bowals, preventing any coarse, undigested food from entering them. The stumach is held in its place by five large ligaments, and is well supplied by blood vessels and nerves. Digestion of food takes place very quickly in the horse in comparison to other animals, and if, through a change of food or working too soon after eating, the digestion is interfered with it sets up what is known as indigestion, which is a very 
painful disease in the horss. After the food is acted upon by the Juices in the stomach it changes into what is known as chyme, which pass into the bowols.

The Bowels.-Thay are divided into two parts-the large and small. The small bowels are seventy-two feet in length and about ono inch in diameter, and are made up of three coats, the same as the stomach. Ths serous coat on the outside contains small glands which secrete an oily material that lubricates the outside of the : owels, which comes in contact with the inner walls of the belly, so as to prevent friction when the bowels are being jolted around in the belly. The muscular coat, mude up of muscular fibres, is situated between the other two coats, the same as in the stomach; its action is to contract the bowels, giving it motion to carry the food on through them. The mucous coat is a continuation of the mucous coat of the stomach. Along this coat are found small glands known as villi and lacteal; these are to abscrb the nourishment out of the food as it passes along through the bowels and pcurs it into the blood. This long bowel is found to be attached on the upper side to what is known as the mesentery, which is attached above to the back-bone, and can be seen in any of the smaller animals upon examination. About six inches from the stoniach, in the bowels, are found two openings, one for the hepatic duct, which is a tube used to carry the bile iror. the liver to be poured in on the food as it passes through the bowels. The other hole is for the duct of the gland known as the pancreas. It secretes a clear fluid known as the pancreatic juice, these act on the food in the first part of the small bowels, changing It into chyle. After this, the action of the rest of the bowels is to absorb the nourishment out of the food as it ls passing back. Ths small bowals and stomach, when In a haalthy condition, should be found empty one hour after food has beon eaten. The small bowols ars situated mostly on the left side Just behind the stomach.

Large bowels have three coats the same as the small ones. The first part of the large bowels is known as the blind gut and is about three feet long; this is generally the first thing to fly out in opening a horse's belly. Its use is to act as a reservoir to hold the water and fluid parts of the food; this is where the water and fluid parts are mostly taken up into the system. The next part of the large bowels is known as the large colon; it lays along the floor of the belly, is about nine feet long, and is doubled on itself three times. In this bowel the solid part of the food in found. 
where it is worked about by the entuating of the bowel and the nourishment taken out. After the foud is worked batck out of this howel, and the nourint rent l.1k'n out of it, it enters into what is known as the floating colon, which is ten feet lonv and ahout two inches in diameter, or double the size of the small bowels, in is thrown into folds or pleats, and, as that part of the food that his no nourishment in it passes throwsh, it is worked into balls which pass back and are enptied into the rectum or back gut. This part of the bowels, same as the small intestines, is suspended by a sheet or fold from the back bones, and is situated at the back part of the helly, on the left side, behind the small bowels.

Rectum or Back Gut--It is sometimes known as the straight bowel, which is the last part of the intestines, aid is about eighteen inches long. The cuats of this bowel are a continuation of the large bowels, but each coat is thicker and heavier. Above this bowel, are the hones of the rump; below it, in the horse, we find the bladder and other small glands. In the mare we find what is known as the womb and the vagina, which is the passitye into the womb from the outside, and at the sides we find the hones which help to form the hip cavity. At the back part is found whit is known as the anus, which is situated immediately under the tail. The use of the rectum is to hold the balls as they pass back from the floating culum is nd enipty in here. When the rectum gets full and presses on the sides of the wall, it stimulates the nerves, which cause the muscular coat of the rectum to contract, while the muscle of the anus dialates or opens out, causing the feces or manure to patss out.

The Glands, which assist in digestion, are the liver, pancreas and the splewn.

The Liver is the largest gland in the body; it weighs from ten to twelve pounds in the horse, and is situated between the stomach and diaphraym or curtain which separates the cavities, and is held (1) its place by several strong ligaments; it is of dark brown color, and its use is to secrete the fluid called bile, which is a rreemish color and very hitter to the taste. There is ne gall bladder in the horse, simply a tube which passes down from the liver to the sulall bowel emptying six inches behind the stomach It is along this tuhe where gall stons are sometimes situated. The liver is largely supplied with blond vessels and nerves.

The Pancreas is another :ary important gland situated behind the liver and in front of the kidneys, lying along near the back 
bone. This gland is of a grayish. fatty color and can be found by examining closely in front of the kidneys, its use is to secrete clear, colorless fluid known as the Pancreatic juice. This is an important fluid in connection with digesting the food and enter the bowel just behind where the tube from the liver enters.

The Spleen is situated alongr the left side of the stomach, is long and flat, being about fifteen inches in length, lying along and closely attached to the stomach. This gland is of a grayishred color and is soft to handle; it is a ductless gland, that is, it has no secretion passing from it. The uses of this organ are not clearly understood, but is supposed to regulate the temperature of the stomach during digestion, and also acts as a reservoir for the blood, and is sometimes calied the burying ground of the red corpuscles of the blood, it is largely supplied with blood vessels and nerves and weighs from two to four pounds in the horse.

\section{MEMBRANES OF THE BODY.}

In speaking of the membranes of the body it is found they are of two kinds, serous membranes and mucous membranes.

Mucous Membranes are found lining all open cavities of the body, as for example, the lining all through the digestive organs ; also lining the respiratory or breathing organs; again it is found lining the organs in connection with the urine, also the genital organs or the organs which reproduce the young animals.

Serous Membranes are membranes which line closed cavities, that is, air tight cavities and do not communicate at all with the air, such as are found between the bowels and the wall of abdomen or belly, it is called the peritoneum ; there is also another one found lining the chest cavity and the lungs, this membrane is called pleura. There is also another one found in the brain, but is not of much importanoe. This membrane is always made up of two coats the inner one being attached to the organs contained in the cavity, the other coat is found closely lining the inside of the cavity in which it is found. The inner side of these membranes always secretes an oily flid which lubricates the two surfaces of this membrane, and if it was not for this oily fluid, the walls would become sore from the friction caused by the moving of one coat on the other. These membranes are an important point to note as sometimes they become chilled and get inflamed and set up inflammation. Infammation of the pleura membrane nientioned is called pleurisy, and the membrane in connection with the bowels 
called the peritoneum which wnen inflamed is called peritonitis, a very dangerous diseasi more so than pleurisy.

PROCES; OI: A.'PESTIOK.

In tracing the and from the rin.uth to where it nourishes the

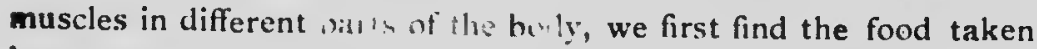
into the mouth by $: \ldots$.... of the lips and front teeth where it is masticated or chewed by means of the tongue and teeth, and while it is being rollcd around and chewed the salivary glands keep pouring in the saliva, mixing the food and preparing it for digestion. After it is thoroughly clicwed it is rolled into a ball at the back part of the tongue, where by the action of the muscles of the gullet it is grasped and forced down into the tube which, by the action of its muscular fii,res, is forced down into the stomach wherc it is rolled about and bcconses thoroughly mixed with the gastric and pepsine juices which act chemically on the food and changes it into what is known as chyme. From the stomach it passes up into the front part of the small bowels where there is the secretion from the liver and pancreas which also act chemically and changes the chyme into what is called chyle. After this the rest of the bowels $h_{y}$ the action of thcsc little villi and lacteals, which are in the coats of the bowels, absorbs the chyle or nourishment from the food, these vessels empty the chyle or nourishment into the veins of the body which is then carried to the heart, where it is forced out from the heart through the arteries down into the capillaries which are all through the body, the nourishment is given through the walls of thesc sınall thin vessels and gives life and strength to the body.

\section{CHAPTER VIII. \\ ORGANS OF RESPIRATION.}

T

HESE are commonally known as the organs of breathing, they comprise the nostrils, chambers in the head or nasal chambers, larynx or sometimes called Aclam's apple. trachea or windpipe, bronchial tubes and the lungs.

The Nostrils are two openings, one on each side of the nose; these are held open by the aid of cartilage or gristle, and muscles. About onc and one-half inches up the nostril on the under side is a small opening about the size of a grain of shot, this is where the tube or duct which carrives the tears down from the eyes empty into the nose. The nostril is lined with a thin delicate skin which after. 
wards changes into the mucous menibrane as it passes up into the chambers of the head.

Nasal Chambers or Chambers of the Head.-These give passage to the air from the nostril into the larynx or Adam's apple. There are two of these chambers divid.d in the center by a thin partition of cartilage called the septum nasi, these comnunicate with the sinuses of the head. The horse cannot breathe through the mouth on account of the formation of the throat, and this compels him to always breathe through the nostrils. This is a point which should be remembered.

Larynx or Adam's Apple.-It is a box made of cartilage, or gristle, gives passage to the air and is also the organ of voice; it is situated in the floor of the gullet. This box has an opening on its upper side, which is guarded by a valve, this valve is always open except when the animal is swallowing food or water. When the food is being swallowed it passes over the valve which closes the opening while the food passes over it. This is important, for if the valve does not close properly and either food or water drop into the windpipe it causes the animal to have a fit of coughing, and is spoken of as the animal to have the food going the wrong way. On the outside of this box of cartilage is found several small muscles attached which help to hold it in its place, it is lined inside by a continuation of the same membrane, as in the chambers of the head. Along the inside of this box is found what is called the vocal chords which come into play when the animal is whinnying. These chords are not nearly so well marked as in the human being, and if they or the cartilage of the larynx become affected by disease it generally gives rise to the disease called roaring.

Trachea or Windpipe. - This is a tube which carries the air down from the larynx to the bronchial tubes in the lungs. This tube is made up of forty or fifty rings of cartilage which are united to each other by strong elastic ligaments which gives the windpipe its flexibility, that is, it can be bent in any direction almost like a piece of elastic. In tracing the windpipe from Adam's apple it is found to enter the chest where it terminates into two small tubes, one going to the right lung and one to the left lung; these are called the bronchial tubes.

Bronchlal Tubes and Air Cells.-These are made up of the same material as that of the windpipe, but are only about half the 
size. These tubes after they pass into the substance of the lung* they break up into other small tubes which pass all through the lungs and terminate into what is known as the air cells. These small tubes and air cells are lined inside by a very thin mucous membrane which is a continuation of the meinbr lining the other organs already mentioned. Just inside th. an mucous niembrane is found the capillary network of the lungs, and while the blood is slowly passing through this network of vesisels it gives off to the air in the air cells carboric acid gas and takes in the oxygen from the pure air while it is in the lungs.

The Lungs are the most important organs in connection with breathing, they are spongy, yellowish organs, two in number, one situated on the right side and the other on the left; the right lung is the largest on account of the left one having a hollow in its side for the heart. The lungs are separited by a partition known as the mediastinum, also by the heart which is in the folds of thin partition and also by the large blood vessels and oesophagus or tube which passes on its way to the stomach. The lungs are made up of light elastic tissue and are full of air cells and tubes, they are very large while the animal is alive and fills up nearly the whole chest cavit"

so large. Bet * membrane called $L_{1}$ after death they collapse and are not nearly - lungs and the ribs is found a serous ara or the lining membrane of the chest. It is made up of two folds, one being attached around the outer part of the lungs while the other is attached to the ribs at the side and at the back to the large curtain which separates the lungs from the bowels. The little glands situated in this membran secretes an oily fluid which serves to lubricate these parts while the lungs are working in the chest so as not to cause friction. When this membrane becomes inflamed from a chill or injury th sets up the disease called pleurisy.

The trachea, or windpipe, bronchial tubes and air cells aro sometimes compared to a tree, the windpipe being the trunk while the bronchial tubes and air cells represent the branches and leaves of the tree. The lungs are largely supplied by blood vessels and nerves.

Breathing in the horse consists of first drawing the pure air in and then forcing the impure air out. These two acts are performed by the muscles of the chest, part of them in contracting in such a manner as to disate or enlarge the cliest cavity and on 
.tccount of the space between the lungs and chest being air tight the lungs themselves enlarge and the air rushes $i$, to fill up space. The act of forcing the air out is performed by these muscles which relax while others cuntract in such a manner as to close the chest cavity and makes it smaller, thu the lungs also become smaller and forces the air out. The act of breathing is performed in a horst in perfect health sixteen times a minute.

\section{CHAPTER IX. \\ URINARY SYSTEM.}

HIS system consists of the kidneys, ureters, bladder and urethra. The action of these organs is to deal with the urine or what is commonly called the water of the animal, which is I watery fluid secreted by the kidneys. It varies in color, according to the condition of the animal's blood.

The Kidneys are two in number-one on the right side and one on the left side, and are situated just below the small of the back-the right one being the furthest ahead. In shape, they are long and narrow, and resemble the liver in color. In cutting one of these kidneys open, it is found to be full of glands and tubes, which secrete the urine from the blood while it is passing through the kidneys. These tubes pass to the centre of the kidneys, where they empty the urine into what is called the pelvis of the kidneys. The glands are largely supplied with blood vessels and nerves. In examining the kidneys, one will generally find a large quantity of fat, which help to hold them to their place. The use of the kidneys are to secrete the urine from the blood, which contains a large amount of what is known as ureaic acid, and if not taken out of the blood by these glands, acts as poison to the system.

The Ureters are the tubes which carry the urine down from the pelvis of the kidney to the bladder. They are two in numberone situated on the right side of the peivic or hip cavity and the other on the left side close to the walls-and they enter one ol each side at the upper part of the bladder. They are only about the size of an ordinary straw.

The Bladder is situated in the pelvic or hip cavity. When it is full it sometimes stretches out into the abdominal or belly cavity. It consists of a body and neck The bedr 
Is the large part, and is placed in front; the neck heing at the back part of the bladder. This is where the urine or wate: passes out of the bladder. The bladder is made up of three coats, somewhat similar to that of the bowels. The serous coat is just a continuation of the serous coat found in the belly cavity lining the bowels. The inside of the bladder is lined with mucous membrane similar to that of the bowels, and when the bladder is empty this is all thrown into folds. Another coat is found, between the two membranes above mentioned, called the muscular coat, and is made up of muscular fibres. Its action is when the bladder is full and presses on the nerves of the coat, these nerves causing the fibres in the coat to contract, thus contractirig the bladder, forcing the urine out. The bladder is held to its place by liganients attached to the wall of the pelvic cavity, and above the bladder is found the rectum. The bladder in the horse rests on the floor of the pelvic cavity. The position of the bladder in the mare differs trom that of the horse. Instead of the rectum or back bowel being immediately above it, as it is in the horse, the womb is found just above the bladder or between it and the rectum. The use of the h!adder is to act as a reservoir to store up the water until the bladder is full; when it is lull it presses on the walls and nerves, giving a peculiar sensation to these parts, and causing the walls of the bladder to contract, forcing the water into a tube which carries it from the body; this tube is called the urethra. The neck of the bladder is simply an opening at the back part of the bladder, and is guarded by a valve which prevents the urine from dribbling out except when the animal is passing its water.

The Urethra is the tube which carries the water from the bladder out of the body, and is sicuated much differently in the mare from that of the horse. In the mare it is very short, passing from the neck of the bl..dder along below the wonb and vagina, which is the passage from the outside into the neck of the womb, it opens up into the underside of this passage about four inches in from the outside. This opening is guarded by a small thin valve, and can be felt by passing the finger along the under side of the passinge which leads into the womh. In the horse this tube is a great deal longar than in the mare, it commences at the bladder, passes long below the rectum or back bowel to just below the anus, here 
this tube biads downwatrds and lor!atrols passing into the penis of the horse and passes down to the end of the penis, where it terminates. This tube is used to carry the urine from the bladder out of the body and is also used in connection with the genital organs, these are the organs which bring forth the young animals. This tube is lined with a continuation of the membrane of the bladder.

\section{CHAPTER X. \\ GENITAL ORGANS.} THESE organs in the horse are those which reproduce
the young animals. To bring forth the young there must be two animals, nne the horse or male animal, the other the mare or female animal, or in other words, there nust be one of each sex, male and femalc. These organs are different in each sex or in the horse and mare and require to be considered separately.

Genital Organs in the Horse are as follows: Scrotum or bag, esticles, spermatic cord, veniculie seminales or the pouches which holds the semen of the horse, urethra, penis and the sheath.

The Scrotum is the siac or bagr which contains the testicles and is situated between the hind legrs, and is covered on the outside by a very fine soft skin. Passing up in the center under the sheath and scrotum or bagr is a well matrac line in the skin called median raphe, this can be platnly seen whon the horse is on his back, and is found to be continued up gradually getting fanter until it reaches under the anus. Under the stin is found layers of white fascia or tissue, which ean be seen on cutting through the scrotum. There is found to be a partition in the scrotum separating the two testicles. The siza of the serotum is affected very much by the weather, the cold weather contracts the fibres in the scrotum causing it to get very much smaller, while in warm weather the fibres relax causing the scrutum to get very much larger. The use of the scrotum is to comtain, stupurt and protect the testicles.

The Testicles are two in number, one situat al on the left side the other on the right, they are ovil in shape, and are attached above to the spermatic cord. Before the animal is horn the testicies are situated in the abdominal or belly eavity and attached to the serous membrane which has alrealy been spoken of in connection with this cavity. At or ahout the time of birth, there is what is hown as the descent of the testicles into the 
scrotum; in their duwnward course, they pass through a slit or small opening at the back pirt of the muscles of the belly, where they are attiched to the under part of the hip bones. These slits or operings are known as the inguinal rings, these rings can be felt in the horse by pressing the fingers well up into the groins. The descent of the testicle is an important point to be remembered for, if it dues not come down into the scrotun he is then called what is known as a rigr or riclyeling horse, in this case the testicle is not found in the scrotum. At the front part of the testicle is found a small ridge called the globus major, and at the back of it is found another small ridgre called the globus minor. Passing between these two ridges there is another well marked ridge called the epididymis, these points can be easily seen upon exanining the testicle after the animal is altered or castrated. The substance of the testicle is made up of small glands and tine tubes, these tubes, as thoy pass towards the back of the testicle, form into larger tubes and finally unite to form one tube, which is used to carry the semen up the back part of the spermatic cord, which these glands in the testicle secrete.

Spermatic Cords, or the cords of the testicles, are attached above to the inguinal ringrs or openings mentioned before, they are about five or six inches long and have the testicles attached to them below. In each cord is found a small muscle which goes by the name of the spermatic musele, the rest of the cord is made up of the spermatic artery, veins and nerves. Running up at the back of these cords is found a tube about the size of a straw, which upon examination is found to be hard and has a small opening passing up through the centre where the semen passes up through it. This tube is called the vas deferens. Around the spermatic cords and testicles is a serous membrane, one layer being attached to the testic: a and cord, while the other is closely attached around the inside of the serotum or bag. In this membrane are small glands which secrete an oily fluid to lubricate the parts, so as not to cause friction when they are jolted around in the scrotum, thi, fluid will be noticed to fly out as soon as the scrotum is cut. This is an inportant point to remember, because sometimes from a slight injury the glands will secrete a large amount of this fluid mentioned, which caluses the scrotum to look large and swollen, this disease is known as hydrocele or water in scrotum or bag. 
Vas Deferens. -These are the tubes which carry the semen up the back part of the cord through the inguinal .ings before mentioned. They then pass backwards ansl upwards, one on each side, to the upper part of the bliclder, where they enipty into two small pouches or sacs, called the vesicule seminales, which store up the semen as it is secreted by the testicles, and when full present the appearance of a pear.

Vesiculæ Seminales.-These sacs or pouches are situated at the upper side, over the neck of the bladider, one on each side, and have the tube which carries the semen emptying into it at the front end, while at the back end of them is a small opening in each one that leads out intu another small tube which passes backward and empties into the urethra, which has been mentioned before as carrying the water out from the bladder. The use of these sacs or pouches is to store up the semen or seed of the horse. While the horse is performingr sexual intercourse, these sacs or pouches contract, forcing the semen through these little tubes mentioned out into the urethra, which is a tube leading down to the penis.

The Penis is the main organ connected in sexual atenourse; its substance is forned of what is known as erectile tissue, which, under certain circunistances, becomes enormously distended with blood. Passing up the under side, there is what has already been mentioned, the uretlira, or the tube, which carries the water or urine out of the body; and also in the act of intercourse, it carries the semen, thus it is noticed this tube is used for two purposes, as we have already mentioned.

The Sheath is a loose process of skin which passes downwards from the scrotum or bag, generally from about four to six inches, according to the size of the animal, and is attached to each side, leaving a hole or opening in the centre through which the penis comes down. The outside of the sheath is covered by a thin, delicate skin, same as that of the scrotum; inside it is lined by a membrane having a lot of small glands, which secrete a thick dark fluid to lubricate this passage. Sometimes this fluid sollects in here and has the appearance of tar. This is an important point to remember, for when it collects to a larse extent the sheath has to be washed out.

The Semen or seed of the horse, when examined under aleroscope, is found to contain snall objects called spermatoson 
which move around, and when in the womb it there meets the ovum of the female, which is secreted by al gland called the ovary. When these two small ohjects mite, they form the fortus, or what might be called the aninal in its first stage.

The Female Genital Organs, or organs of the nuare.-These are rery different from those in the horse, and are named as follows: Ovaries, f.llopian tubes, or the tubes which carry the ovum from the ovaries to the uterus or womb, uterus or womb, vagina, and the vulva.

The Ovaries in the mare represent the testicls in the horse. They are about the sizc of a pigeon's egg, and resemble it much in shape. They are held to their place by ligaments, and at the back part have a tube leading from them calied the fallopian tubes. The use of the ovaries are to secrete the cvum or egg. This is a very minute body, which has to be examined under bo microscope, being only $\frac{1}{150}$ of an inch in diameter.

The Fallopian Tubes ure two canals, one on each side, which pass backwards and upwards, and enter into the front part of the uterus or womb. The use of these small tubes are simply to carry the ovum or egr up from the ovaries and empty it into the womb or uterus.

The Uterus or Womb is a muscular sac situated in the hip cavity, bounded above by the rectum, below by the bladder, and on th: sides by the walls of the hip cavity. It is divided into what is known as a bod: and a neck. The body of the womb is very small, only about four to six inches long and a couple of inches in diameter when the animal is not pregnant, ahd near the front end, at the upper side, there are openings where the ovum enters in. When the animal becomes pregnant, the body of the womb becomes enlarged and passes forward and to the left side of the belly or abdominal cavity, getting larger as the time of pregnancy passes on, until the fotus, or young, has attained its full size. After the ma:e has had her young the womb begins to get smaller until it attains its natural size again. The womb is very largely supplied with blood vessels and nerves, especially so when the animal is pregnant, as it takes a large amount of blood to nourish the fotus, or young animal, before birth. The womb is made up of three coats; the inner one is called mucous membrane, and is found to be in the mare, while pregnant, covered over with numerous small processes about the size of peas, to which the 
placenta or cleaning of the foal is attached. The muscular coat is next to that of the mucous coat, and lies between the outer and inaer coats of the wonly. It is made up of muscular fibres, and is strong and thick in the womb, nuch thicker than it is in the bowels or oth organs already mentioned. The use of this coat is to support and protect the foetus or young while it is being carried in the womb, and at the time of parturition, or what is commonly known as foaling, this coat then comes into use, 2 it cont ratcts the womb very forcibiy on the foal, while the neck of womb lies open, helping to force the foal out of the womb. This is importint to note as the contraction of this coat is known as lahour pains. Lying outside, and covering atound the womb, is fo..... a serous coat, which is a continuation of the serous coat of the nowels. The womb is held to its place by strong ligaments attached to the sides of it, and from there to the hip bones, these are called hroad ligaments. At the back part of the wounb is found the neck. It consists of an openin:- formed by a projection, which is about the size of an egg and has a hard, gritty feeling when the an mo, is not in season and the neck is closed. The neck of the womb is under control of the muscle around it, and this muscle is under control of the nerves of the womb. When the mare comes in season, this muscle is relaxed to a certain extent, thus allowing the neck to open !arge enough for tie passage of a couple of fingers into it; but upon working around it with the fingers it can be forced large enough for a man's hand to pass into it at this period. If the mare is put to the norse at this time, and becomes pregnant or with foal, the muscie in the neck of the womb contracts, firmly closing it, which remains closed until the time of foaling. When, at the time of foaling, the labour pains come $n$, the muscle in the neck dilates, allowing the neck of the womb to open large enough for the foal to pass out. The neck of the womb can be felt easily by oiling the hand and passing it into the passage to the womb, and it will be noticed that the neck spoken of projects into the passage.

Vagina and Vulva.-These two organs together make up the passage which leads into the womb from the outside. In the young mare they are separated by a thin curtain, or partition, made up of mucous membrane. This curtain is found about four inches from the outside, and is known as the hymen. This membrane is destroyed, or should be, when the mare is frst fut to the horae, 
although we often have it broken down In other ways, and In come cases it will disappear of ite own accord. The part of the passage in front of the homen is called the vagina. This passage, in structure, ${ }^{-}$resembles the womb, but is not so strong. There are numerous glands situated along the inner coat or lining of this passage which secret: a fluid to lubricate it. The principal use of this organ is to guide the penis when the aninals are performing stxual intercourse, and also serves at the time of foaling as a passage for the foal to come out through. The part of the passage behind the hymen is known as the vulva. It is aboul four inches long and about two or three inches high, varying according to the size of the mare. In front it is separated from the vagina by the hymen membrane. It resembles the vagina in structure, and also has little glands in its inner cont to secrete - fuid to lubricate the passage. At the back part of the vulva, or around the outside, is what is known as the lips of the vulva, one on each side of the opening. The outside of the lips are covered by very fine skin, and, just below the skin, they are made up of erectile tissue, which is the same kind of tissue as is found in the penis of the horse. This tissue is found more abundantly in the lips of the vulva of the young mare than in the lips of the vulva of the old mare. The opening between these lips is situated just below the anus, or the opening where the back

ei ends. At the back part of the vulva, on the under side, is on opening, or hole, about large enough to allow a man's finger to pass in; this hole is where the tube leading from the bladder comes up into the passage and allows the urine, or water. to pass into the vulva, where it runs out of the body. The clitoris is situated on the under side of this passage, just inside the lips, and can be seen in the mare after passing water when she works the vulva. Just below the clitoris are found two or three small glands which secrete the fluid that passes away when the mare is horsing.

Mammary Glands, or what is known as the mare's bag, are wo glands situated between the thighs, the use of which is to secrete the milk after birth to feed the young animal. In the young mare they are very small, but after the mare is iith ioal a lew months these glands begin to get large, and at iviling time they attain their largest size. These glands are colered outside by a thin, snooth skin. The substance of then are 
made up of small glands and tubes-the glands secrete the milk from the blood, while the tubes retain or hold the milk until it is drawn away from the hag either by milking or the young animal s.cking. Duriug the time of suckling the young, the glands are largely supplied with blood, from which the milk is secreted. On the under sicle of each gland is found the teat, or the part the young animal takes hold of in sucking. The end of the teat is pierced by several small holes, where the milk comes out.

THE FOETUS, OR YOUNG ANIMAL BEFORE BIRTH.

In considering this we nust first speak of the ovum, or egg, which is secreted by the ovary of the mare. Fvery time she comes in season (which occurs every three weeks during the hot weather) this ovum, or egg, passes down the tubes before mentioned into the womb, where it remains a few days and then dies if she is not put to the horse ; but, if during the time this ovum is in the womb she is put to the horse and one of the little bodies which is found in the semen of the horse comes in contact with it the ovum and this little body unites together, the rest of the semen dies and passes away, while the neck of the womb gradually contracts until it is perfectly tight. These two little bodies begin to grow when united and forms the fœtus, or foal. The three parts connected with the fotus, are the fotus, navel string, and cleanings, or placenta. The cleaning, or placenta, is the part which is found covering the foal and is attached to the little pea-like elevations on the inside of the womb. This covering is found to be full of small blbod vessels which run to one point where they unite to form two larger vessels, known as the navel veins, which carry the blood up through the navel opening of the foal where it passes up to its heart; by the action of the heart it is forced out all through the body of the foal and returned to the heart and then forced down another artery which passes it down to the navel opening, along the navel cord, into the cleaning or placenta again, where it is distributed through the small blood vessels. As the blood comes down this cord from the foal it is in its impure state, and while it is passing through these small vessels in the cleaning it comes very close to the small blood vessels in the womb. The blood is cleansed and nourished from the blood of its mother by a process similar to that which was spoken of in connection with the lungs. The fotus, or foal, does not grow so fast the frst month as it does later on; at the age of seventeen wedes 
the Arat halr appears on the llps and the tlp of the tail; between the thirty-fifth and fortieth week the foal begins to show signs of life, and is completely covered with hair. After this tune the foral grows very rapidly and can be seen moving around by watching at the flank. The mare carries her foal eleven months, but in come cases in aged mares they have been know'n to carry their foal over twelve months, and in rare cases in young mares they lack a few days of eleven months.

How to Tell When a Mare is With Foal.-The first thing that is noticed is that she does not come in season at the end of three weeks, and if felt at the flanks she will he noticed to be peevisl and cross, and also ugly to other horses. The mare usually feeds and thrives better at this period, and at the end of three or four months she begins to get larger at the flanks, and gradually continues getting larger until foaling time. Mares that are fed on hard feed and worked do not usually get as large as mares fed on rough feed and not worked. At about the fifth or sixth month the foal begins stirring in the womb, which can be seen at the flank; this is noticed mostly after the mare has had a drink of cold water ; it also can be felt by pressing the hand ayainst the flank on the left sille. At about the sixth month in the young mare the mammary glands, or bag, begrins to get large, and gradually gets larger until the time of foaling.

Signs of Foallng.-The muscles and ligaments gradually become relaxed until there is quite a hollow at each sicle of the tail. The vulva gets quite large at foaling time and wax usually runs irom the teats of the mare a few day's hefore A few hours before foaling she is noticed to be walking around and acting quite uneasy until the labor pains come on, when her restlessness increases to getting up and down and forcing, until what is known as the water bag comes out and breaks; the lahor pains increase, and she lies down, forcing violenty, until tne front legs and head of the foal appear, when it soon slips out, and the cleaning generally comes with it. - Sometimes the foal cones backwards, which is harder on the mare. If the mouth of the foal is examined immeciately it is found to contain what is known as the melt, which looks like a piece of liver. 


\title{
CHAPTER XI.
}

\section{THE SKIN.}

\begin{abstract}
HIIS is the membrane which covers the body, and consists of two layers called the dermis and epidermis. The epidermis is the outer layer of skin, and is made up of injuries, this layer undergoes a continual process of being made up and passing away in dandruff. The dermis or true skin is well iupplied with blood and nerves, part of the nerves being the nerves of touch. What is known as the swcat glands are found in this layer. When the skin is injured, the outside layer being knocked off, this part of the skin is very painful. The skin is attached on the inside to the body by a layer of white tissue which is known as the arcolar tissue, this being the tissue which is cut through in skinn: $r$ an animal. The skin varies in thickness on lifferent parts ut twe body, being thinnest on the under parts.
\end{abstract}

HAIR.

There are three kinds of hair on the horse, the common, which covers most of the body, being the finest of the three. The mane and tail, which is coarse and long. Around the muzzle or nose and the lips are found long hairs, usually black and called sat hairs.

On the inside of the front legs, just above the knee, and on the inside of the hind legs, about the hock, are rough, horny spots which are called chestnuts.

\section{CHAPTER XII. THE HOOF.}

HIS is a very important point in anatomy in connection
with the lameness of the horse. The hoof of the horse
corresponds to the finger nail of the man-it is divided
into three distinct parts, the wall, the sole, and the frog.
The Wall is the part of the hoof that is seen when the foot Is
resting flat on the ground; it is divided into the toe, the quarters,
the heels and the bars. The toe forms the front of the hoof, and
is the thickest and strongest part of the wall. The quarters are
situated at the side of the hoof. The wniis are not nearly so thick
here as at the toe, but are almost straight up and down. The heels 



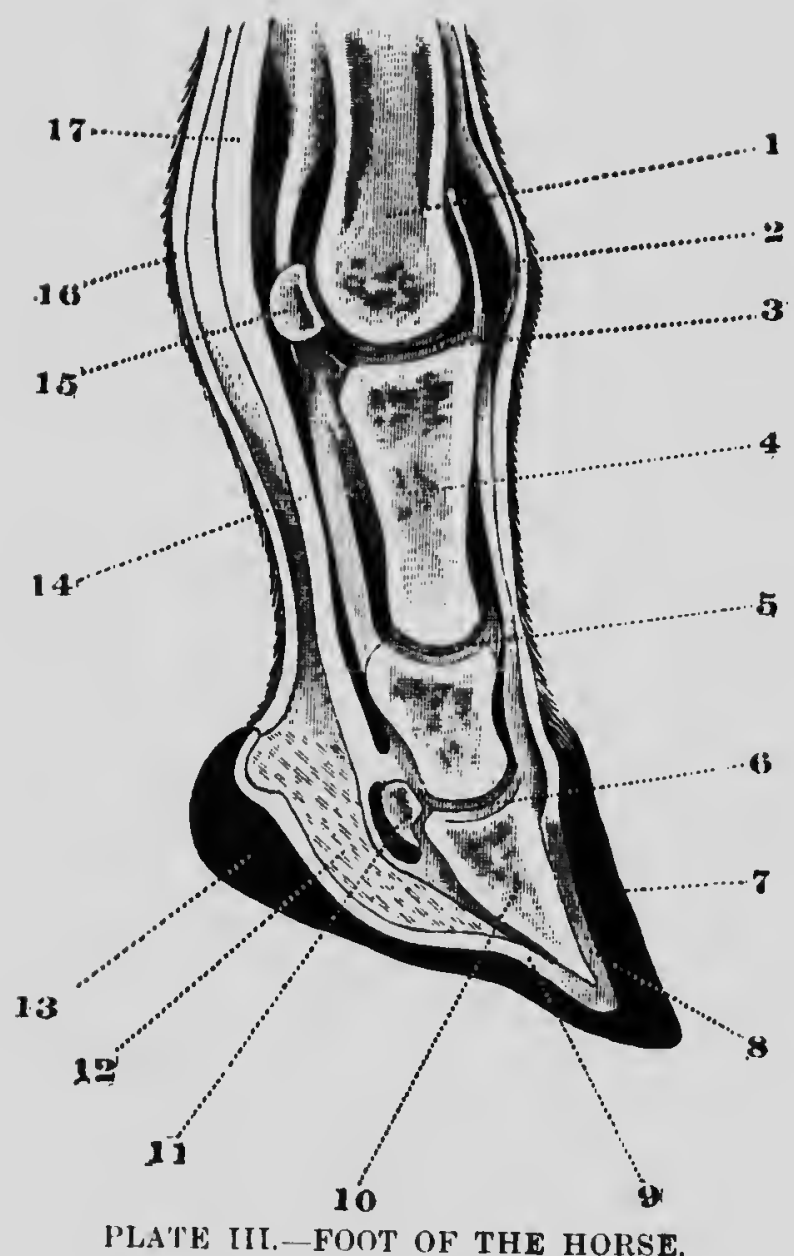




\section{EXPLANATION OF PLATE IIL.}

\section{FOOT OF THE HORSE.}

This cut represents the foot of a horse sawed from above the fotlock down through the centre of the foot, showing the structure of the foot, and giving the names of each part according to number.

1. Lower end of large metacarpal, or shin bone.

2. Bursa, which secretes the joint oil that lubricates the place where the tendon, or cord, on the front of the leg passes down over the front of the fetlock joint. This is important w it sometimes gets injured and becomes enlarged, it is then called a puffy or buraal ealargement, and $b$ of the namo anture as a wiad gall.

2. Fonded jolat.

- Laro pacter bona

C Paver Jeth Thlo jeint b in.

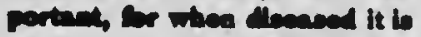

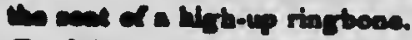

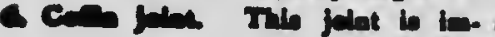

portant for when it is diseased it is the seat of a low-down ringbone.

7. Wall of the hoof.

8. Quick of the foot, or sensitive wall.

9. Quick of the foot, or sensitive sole. 10. Os Pedis, or foot bone.

II. Coffin, or navicular bone. This is inportant for when disensed it is the seat of cotfin joint Inmenese.

12. Fatty Frog.

13. Frog of the foot, or horay fres.

14. Beck tendone below follook

if. Petlock bence (a in number) en 16. Sth. cach aide of the jelat.

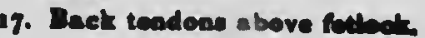

SPECIAL NOTICE. - Every place where Tablespoonful it mentioned in this book should read: SMALL, or DESERT Tanuspoonful, which is equal to two Teaspoonfuls. 


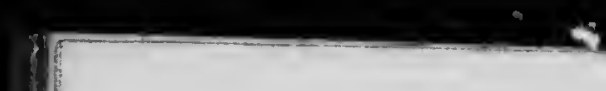


are situated at the back part of the foot. From the heel is a procese of hoof, which looks like a bar, passing forward between the frop and the sole of the foot; this can be seen plainly by raising up the horse's foot. There is one of these at each ide of the frog, and they act as a brace to the heel and the quarters of the wall; these are called the bars. Covering the outside of the wall is a fine membrane which gives the hoof the polished appearance; this is called the periople. This can be best seen when a horse's hoof is well washed off, as it is after travelling through wet grass, which gives the hoof shining appearance. The use of this membrane is to keep the moisture in the hoof and protect it from ivater. This is a point of Importance in conrier:ion with shoeing horses, as it is very injurious to fle the wall too much. Around the top part of the wall, where it unites with the skin, is found a groove which contains white band, called the coronary substance, or band. The use of this is to nourish the wall of the hoot, or, in other words, it is from this the wall of the hoof grows. The under part of the wall, or the part which rests on the ground in the unshod animal, or the part to which the shoc is nailed in the shod animal, is called the spread of the foot. On the inside of the wall, attaching it to the bone of the foot calied the os pedis, is the part called the quick, or sensitive laminæ. This is a point of importance in connection with driving nails in shoeing, so as not to drive the nail into this memurane or even press on it, for it is very sensitive. When a nail has been driven in so as to injure this membrane it is the cominon expression, "you have pricked that horse's foot."

The Sole is a thick plate of horn which helps to form the under part of the hoof. It is situated between the inner border of the under part of the wall already mentioned and the front of the frog. The under part of the sole is concave, or hollowed out; the upper part of the sole is attached to the under part of the os pedis bone, or bone of the foot, by a membrane called the quick, or sensitive sole-this membrane is just a continuation of the sensitive lamina. The outer part of the sole is attached to the inner part of the wall. When pared down a white ring is seen where the sole and the wall is united. At the back part of the sole there is a notch the shape of the letter $\mathrm{V}$; in this notch the frog is situated. An important point to remember in shoeing is never to let the shoe rest on any part of the sule, and, also it is 
not well to pare off too much of the barky-looking substance of the sole as it helps to keep the moisture in the foot. When this is taken off it allows the moisture to escape and it becomes dry and contracted.

The Frog is the prominent spongy horn found in the $V$ shaped notch in the back of the sole. It is wide at the back, helping to form the heels of the foot, the pointed part in the front is called the apex of the frog. The under part of the frog is triangular in shape and has a hollow in it called the clett of the froy. There is a hollow at each side of the frog, between it and the bars, called the commissures of the frog. ' On the upper part is a membrane, known as the sensitive frog, which attaches the frog to the under part of the os pedis, or foot bone. This menbrane is simply a continuation of the sensitive sole spoken of in connection with the sole. The back part of the frog is the widest part and spreads out forming the heels.

To get the best idea of the structure of the foot, get a hoof and the bones of the leg as far up as the fetlock, and saw them down through the centre, which will show you the exact conformation. The shape of the hoot differs in aninals--large draft horses are apt to have what is termed a flat foot, while in the road horses the chief trouble is what is known as contracted feet and weak heels.

\section{CHAPTER XIII.}

\section{THE EAR.}

THE ear of the horse is divided into several parts. The inner part, or drum of the ear, is situated in the hardest bone in the body, called the petrosal. The nerve which passes into the drum of the ear, and gives the sense of hearing, is called the the auditory nerve. From the drum a small opening passes out into the outer part of the ear; this is the portion which is seen on top of the head, and is made up of a membrane known a the cartilage which gives the ear its stiffnes3. This cartilage is covered by a fine, delicate skin, which is covered on the outside by fine, short hair. Situated on the inner side of the outer ear are aumerous long hairs projecting outwards, the use of which is w keep forcign bodies from dropping into the ear. The ear is moved backwards and forwards by small muscles which are atesed around it. 
CHAPTER XIV.

\section{THE EYE.}

$1 /$

HE eye is the chlef organ of sight, and is sltuated in the orbital fossa, which was mentioned in the hones of the head. It is chiefly made up of several coats around the outside and in the centre, by the humoure of the eye. On the inner side of the coats is a thin membrane called the retlna, which contains the branches of the optic nerve, this receives the reflections of objects as they pass through the humours of the eye and they pass along the optic nerve to the brain. The oblong openings seen in the middle of the eye are known as the puplls of the eye. In leading a horse out of a dark stable into the light and watching the pupils of the eje, they will be noticed to get smaller, then on returning it to the stable the pupils will be noticed to dilate or get larger, thus it is seen the pupil does not always remain the same size. The chief use of the pupil is to gauge the sight. At the back part of the eye are several muscles which are attached from around the to the bones in the fossa, the use of these muscles are to move the eye and assist in holding it to its place. Around the front part of the eye are two movable curtains, one above and the other below, these are called the eyelids, the use of which are to open and close the eye, and also to potect it from injuries. Around the free border of the eyelids are what is known as the eyelashes, the use of which are to keep foreign substances fróm falling into the eye. Situated in the inner angle of the eye is what is known as the haw of the eye, this membrane also helps :- protect the eye. In the corner of this angle is a small duct or opening, where the tears of the eye pass down through into the nasal tubes, where it is carried down through the bones of the head and emptied into the under part of the nostril or nose. A small gland is situated on the upper part of the eye, secreting the tears which lubricate the eye. The color of the eye is generally brown, but in some cases it is white and receives the name of a walled eye. 


\section{CHAPTER XV. THE TEETH.}

Yrite

HE teeth are situated in the mouth, in the upper and lower jaws. They are made up of the same tissue as bone, but they contain 10, 2 per cent. more of the earthy salts, this is what malies them so very lard. Unlike bone, they can stand exposure to air and friction without becoming diseased. The teeth are mide up of three hard substances, viz.: dentine, or ivory; enamel; and crusta petrosa. The dentine or ivory is situated in the upper part of the tooth aro: $d$ the pulp or nerve cavity; it is largely supptied with nerves which pass through it from the pulp cavity, and is of a yellowish color. The enamel is the hardest substance of the tooth and covers over the outside of all the exposed part of the tooth, this substance is characterized by its whiteness, and unlike the dentine, there is no blood vessels or nerves in it, and if part of the enamel is broken off it is never replaced again, and the tooth below the part broken off generally becomes decayed. The crusta petrosa is found in the fangs or roots of the teeth and the parts situated below the gum, this substance is the softest part of the tooth. Each tobth is divided into the body or crown, which is the part above the gum, the table of the tooth, which is the part that comes into wear on the top. The neck of the tooth is the part where the gums are attached, and the fangs or roots are the parts situated down in the bone.

The uses of the teeth are to masticate or chew the food, and are also used to tell the age of the animal. There are three kinds of teeth found in the horse, viz.: The incisors or front teeth, which are situated in the front part of the mouth just inside the lips, are twelve in number, six above and six below. The canine or bridle teeth, "which are found mostly in the horse or male animal and are often absent in the mare, are four in number, two in the upper jaw and two in the lower jaw, one on each side, a couple of inches back from the front teeth. These teeth are from a quarter of an inch to three-quarters of an inch above the gum, they are round and pointed and are of no particular use. They resemble the eye teeth in other animals. The molars or back teetli are twenty-four in number, six on each side in the upper jaw, and six on each side in the lower jaw, their use is to grind and masticate the food. 
W02 ners.

The wolf teeth are two small, round, pointed, temporary teeth which vary in size in different animals, and are situated one on each side in front of the molars or back teeth in the upper jaw. They commence to grow soon after the birth of the animal and if not pulled or knocked out usually decay between the ages of five and eight years and drop out. These teeth affect the eye causing it to look dull and run water, and should be pulled out when first noticed.

The horse has two sets of teeth, the milk teeth are temporary and are the ones that the colt sheds, while the ones that come in and remain without being shed, are called the permanent teeth. The cutting of the teeth in the foal varies some, but at or within nine days after birth the foal has four front teeth two in the centre above and two below, and in the back part of the mouth he is found to have twelve molars, at from seven to nine weeks he gets four more incisors or front teeth, one at each side of the two centre teeth in each jaw; at nine months old he gets the last of his milk or temporary teeth, these being the corner teeth, two in the upper side of the jaw and two in the lower side of the jaw. Now he has his full set of milk or temporary teeth, consisting of twelve molars or grinders and twelve incisors or front teeth, six above and six below, making twenty-four teeth in all. As the colt advances in age he must shed all these teeth. After this age the colt commences getting his permanent teeth; when the age of one year is reached he gets four permanent molars. +. - in each jaw one on each side hehind the three temporary ones. is two years old he gets four more back molars, one on each side $o_{i}^{\circ}$ cach jaw. When the age of two years and nine months has been reached the two middle teeth of the temporary incisors or front teeth of each jaw fall out and are replaced by two permanent incisors $n$ each jaw, so at the age of three years these four permanent incisors are up and in wear. At this age, the first eight molars, two on each side of each jaw, are shed and ref lied by eight permanent molars. At four years old he sheds four mure front teeth next to the ones shed at three years old, and ate repliced by four more perminent incisors or front teeth. Also at this age it sheds the four remaining temporary molars or grinclers, which are replaced by rour more permanent molars, and he also grets four more permanent molars at the back of the mouth, thus at the age of 
four yean the colt has all set of permanent molars, consisting of six on each side of each jaw, making twenty-four in all. At five yeare old he sheds the four romaining temporary incisors or front toeth, which are replaced by four permanent incisors, these are known as the corner teeth. It is well to become familiar with the time the colt sheds his different teeth, for sometimes the caps or ahells of the teeth do not fall off when they should; these should bo watched, for they greatly interfere with the animal feeding and should be removed by a pair of pincers. At five years of age the canine or bridle teeth make their appearance, so at the age of five years the colt has all his teeth or what is known as a .ull mouth.

TABLE OF THE TEETH.

Aar.

INOISORS OR FroNt TEETr. MOLARS OR GMiNdere. Temporary or Permanent.

The foal at or soon after birth.... 4
nine woeks.......... 8

nine monthe .........12

The colt at one year. . ......... 12

"two

et three $4 \ldots \ldots \ldots \ldots . . . . . .12$

1 four a $\ldots \ldots \ldots \ldots \ldots \ldots$.

11 five $4 \ldots \ldots \ldots \ldots, \ldots$

0
0
0
0
0
1
8
12

$\begin{array}{cc}\text { Tempurary "r } & \text { Permaned } \\ \text { Milik Teeth. } & \text { Per } \\ 12 & 0 \\ 12 & 0 \\ 12 & 0 \\ 12 & 4 \\ 12 & 8 \\ 4 & 16 \\ 0 & 24 \\ 0 & 24\end{array}$

At five years old he gets his bridle, or canine teeth, which are four in number; thus at the age of five years a horse has a fuli mouth of teeth, numbering forty in all.

How to tell the age of a horse by his teetl is fully explained hereafter in this book in connection with examination for soundness of horses.

It is advisable for everyone to become familiar with the anatomy, or structure of the horse, which has been explained in very simple language, for the better the anatomy is understood the easier diseases and treatments are to understind.

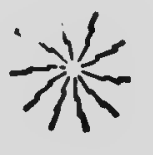




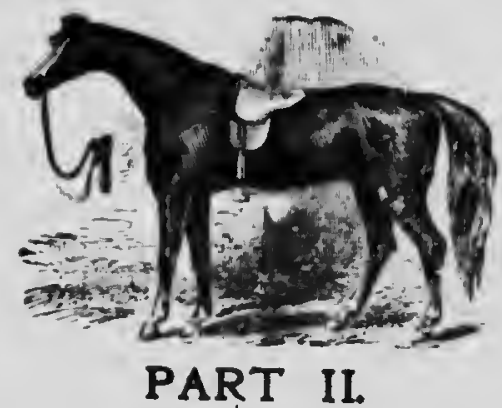

\section{DISEASES AND TREATMENT OF THE HORSE.}

CHAPTER I.

QOESTIONS TO ASK AND HOW TO EXAMINE A SICK HORSB.

$T \mathbf{T}$ IS always well to inquize into the history of the case by asking the following questions before making an examination, as it will help to tell what is wrong with the horse as well as giving an idea as to what part is affected. First - find out how long the animal has been sick. Second-find out how he has been acting. Third-finc out the cause of the trouble if you can. If you find that the animal has been standing with his head hanging down, eating very little, breathing heavily, and coughing. you may come to the conclusion it is some trouble of the breathing organs. Again, if you find out the animal is in severe pain, getting up and down and rolling about in the stall, and slightly bloated, you may conclude it is some trouble of the stomach or bowels. Abain, if you find out the auimal has a straddling gait, attempting co make water often, and allowing the penis to pass out and then draw it in, and sometimes stamping with the hind legs, you may then come to the conclusion it is some trouble of the urinary organs, such as the kidneys or bladder. This will give you an idea, after hearing the history of the case, what set of organs to examine first. In all cases try the pulse; it is generally taken on the small artery which crosses the under side of the juw about the middle; when the animal is in good health it should beat from 38 to 40 times per minute, or, in other words, :his is the number of times the heart beats per minute. The oftener the pulse beats above its regular beat the more serious the case is. It will be necessary to examine ciosely the organs which you have come to the concluaion are afiected. 


\section{CHAPILR I?.}

\section{DISEASES OF THE FEE PIRATORY OR BREATITN; HANS.}

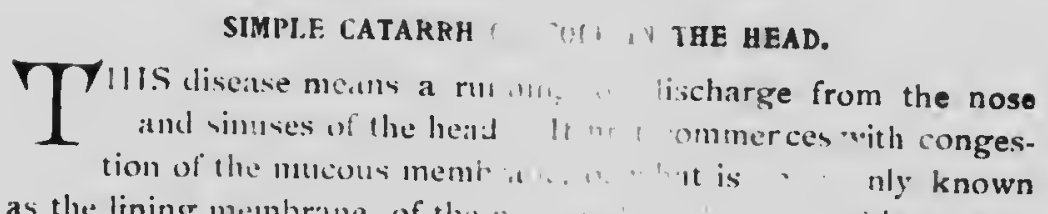
as the lining menbrane, of the ne tion is followed by an inflamm: , at. and in a few days this is follon d by nature, which later on in the dise: e tur (1) this conges if the nembrane, : of a watery whitish or . .cker fluid of a whitish or yellowish color, vill mo accurdin; to the severity of the case.

Causes.-The most common, perhaps, is exposure or sudden changes in the we:ther, such as we isave in the fall and spring; or standing in " Iraft, while warm, after driving. It is generally fuund in horses that are in poor condition, the system being run down by fur teeding or over work.

Symptoms.-The animal is noticed to be dull and not eating very well. The hair is standing out and looks rough; pulse not much affected; throat shows soreness when you press on it; also discharges freely at the nostrils. The breathing is about natural, and usually the animal does not make quite so much urine, or water.

Treatment.-As a greneral thing the treatment is quite simple. Make the horse as comfortable as possible in his stable; see that plenty of pure air can get in, and that his stitl is kept nice and clean. Feed him plenty of soft food such as warm bran mashes, boilcd oats, or scalded chopped oats, and it is a good plan to boil up some flax seed and put a teacupful of the juice and boiled flax seed in with his food two or three times a day, according to how much it seems to loosen the bowels. In all cases of this kind it is well to keep the bowels open with soft food. In bad cases it is best not to work the animal very much-just enongh for good exercise. Give him a :easponnful of the following mixture, three times a day in his food, and if he will not take it in his fuod put it on his tongue with a large spoon, which can be done by draving the tongue out with one hand and putting the spoon well back 
Into the mouth with the other and turning it over; then hold the mouth shut until the medicine gets.wet, so that he cannot spit it out.

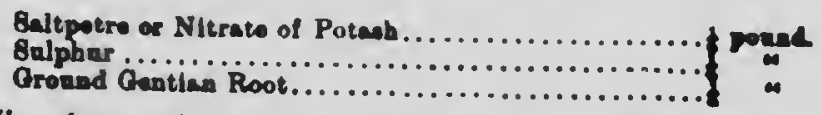

Mix thoroughly and give a teaspoonful three times a day, morning, noon and nlght.

In some cases where the dischargo continues very long it is well to change the treatment and give a teapoonful of ground sulphate of iron twice a day, night and morsing, in his feed uatil the discharge stops. If his throat is sore rub if well two or three times a day with white llniment. In cases where this discharge is not checked it terminates in what is known a chronic catarrh, or nasal gleet.

\section{MASAL GLEET OR CHRONIC CATAKP.E.}

In this disease there is a glary discharge from one or both nostrils. It is a chronic inflamination of the sinuses of the head, and the discharge varies much according to where the disease is situated and the length of time it has been going on.

Causes.-First, neglected catarrn, especially if the animal has not been treated properly and allowed to run out in the cold without being properly fed, such as being allowed to run out at a straw stack. It may be caused by a severe blow on the bones of the head over the sinuses, and also from a bad tonth. Sometimes a tumor will cause it or some foreign substance, sucb as food or a piece of stick hecoming worked up through the nose into the sinuses; or it might be caused by coughing and the food ty up into the sinuses in this way.

Symptoms. - This disease is sometimes mistaken for sandern. The animal at frat may be ln protty cood spirita, but $Y$ the dicease is allowed to run on he will soon get thin and run down on account of the constant discharge from the noee. There is a dlecharge from one or both noatrile of a yellowish color, the lining of the nose will be ellghtly reddened and in some cases is of yellowish color. The way to tell if the sinuses are much affected is to tap on the bone over the sinuses with the finger, if it gives a dull sound like as though the sinuses were full, you may covclude that they are diseased, but if it gives a hollow drumlike sound, you may come to the conclusion that the sinuses are not much affected and there is more hopo of recovery. As the 
disease tuns on, the animal gets very much weaker, the dlacharge has a very bad smell; this shows that the bones of the head are becoming affected. If it is a bad tooth that is causing the trouble, the discharge will only come from one nostril; the animal will not eat very well; sometimes he will be noticed, after taking a bito, to throw the food out of his mouth. The breath has a very bad smell and the horse will soon run down in condition. The way to distinguish this diseses from glanders ls first, that the dischargo in glanders ls of a greenish color and will sink In water, while the dlscharge in nasal gleot will float on water; sscond, by examining the lining inside the nose which, If the animal has glandere, will be found to be covered with small ulcers.

Treatment.-Thls disease is not, as a goneral thing, easlly treated. If the animal is thin and run down in condition, it is well to build him up with good food, regular exercise, pure air and the following mixture:

Ground sulphate of Iron $\ldots \ldots \ldots \ldots \ldots \ldots \ldots \ldots \ldots \ldots \ldots$ pound.

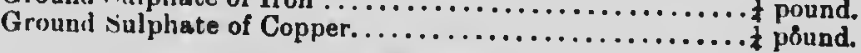

Mix thoroughly and give a teaspoonf:l twice a day, night and morning, on his tongue or in his feed. Wash the nostrils twice a day with warm water. If you conclude that the sinuses are much affected or that some food or foreign substance is causing the trouble, the treatment will then be different. The animal will have to be thrown down and tied with a rope, securely, then strip a piece of skin as large as a copper off the bone with a knife, and take a trephine or an inch auger and bore a hole through the bone in to the sinuses, which can be easily done for the bone is soft and thin and does not cause much pain to the animal, and can be done with very little risk. When the hole is through the discharge will come out of it, and with it will generally come the ceat of the trouble. Keop the hole open a long w you can by pasing your finger into lt, anci aloo injectlng warm water with a fow drope $\alpha$ carbolic acid into It with ayrings once a day; use 10 drops of carbulic acid to the pint of water. If the disesse ls caused by a bad tooth, have the tooth pulled out, and follow up with medicines mentioned above.

\section{ABSCESSES OF THE BONES OF THE HEAD.}

The only trealment is to bore a hole with a trephize or auger through the bone- of the head into the abscess, allowing the matter or dischurie to escape. Inject into the hole with a syringe 
a little warm water with a few urops of carbolic acid twice a day until healed; use the curbolic acid-10 drops to the pint of water.

TASAL POLYPI OR SMALL TUMORS.

These are situated around the nose and chambers of the head, and are sometimes found around the throat, they are usually attached by a neck to the membrane lining these organs.

Causes-They are said to be die to some change in the systom, but the cause of them is not clearly understood.

Symptoms are rather peculiar. The animal has difficulty in breathing, and somatimes acts as though suffocating and may even fall down, and in some cases will get up and for a while appear better, then the above symptoms come on again.

Treatment-Examine the throat carefully by looking into the mouth; have something to hold the mouth open and pass the hand back in the mouth and feel for these little tumors. Look into the nose, and if they are in reach remove them by tying a thin, strong string tightly arounc the neck or roots of the tumor, allowing it to drop off of its own accord. Th, are also removed by twisting them off with the fingers. If you cannot get at the tumors it is then a hopeless case.

LARYNGITIS OR INFLAMMATION OF THE THROAT.

Causes.-They are similar to those of catarrh: Exposure, standing in a draft while warm, or from a number of horses being kept in a poorly ventilated stable; or from injuring the throat in giving a ball of medicine. Sometimes it occures in the form of an epizootic, or where a number of animals become affected at the same time without any apparent cause.

Symptoms.-The animal appears dull, the throat swoolen; if he goes to drink It will be noticed the water will run out through the nostrils when he tries to swallew. When you examine the throat and press on it, it causes hlm pain which is shown by the animal jerking back and if pressed hard will cause him to have a ft of coughing. It will be soen that he swallows frequently and holds hls head in a peculiar position, as if trying to favor his throat. The animal does not care to eat much and what he gets should be soft food, as it hurts him to swallow. If the pulse is very much quicker than natural, and the above symptoms present, you have then a very severe case. The mouth is hot and dry and has a sticky feeling; he is nn-iced to breathe a ittle beavior than natural. The bowels are usually a little costive 
and the urine or water alttle scanty, as in inust all the diseases of the air passages. In two or three days, if the case is going on favorably, it will be noticed he will have a discharge from the nostrils, which is a good sign. This disease usually takes from ten to twolve days to run its course, but after this the animal should not be put to hard work for some time as it is apt to bring on what is known as roaring or bronchitis.

Treatment. - As in all other diseases of the air passages give plenty of pure air; have the stable well ventilated; clothe the body according to the season of the year and if the legs are cold have thom wall hand-rubbed and bandaged, and give the following mixture:

Baltpotre or Nituce of Potanh.

Olerate of Potanh. pound.

Mix the two thoroughly together and give a teaspoonful on his tongue three times a day. Rub the throat well with white liniment three times a day. In sevare cases it is also well to take three tablespoonfuls of mustard, two tablespoonfuls of flour and enough vinegar to make it like a paste, rub this around the throat every night and leave on till morning. Give the animal plenty of cold water, a little at a time but often, feed lots of hot mashes with a little boiled flax seed which will have a laxative effect on the bowels. Instead of putting on mustard a hot poultice of linseed and bran might be used and left on all night. In very severe cases, and when the animal's life is threatened by choking to death, it is well to perform an operation known as tracheotomy, which is done on the windpipe, at. uut six inches from the larynx or Adam's apple, by first cutting through the skin and then cutting three of the ringe in the windpipe and uning the regular tracheotomy tute which can be obtained at almant any drug stora. When this operation is performod it sives the hores immodlate rollof for ho drawe the air through the tube inatead of the nontrile. The way to tell whon to take the tubo out is to place your hand over the tube which makos him breathe through the nose. When he breathes clear onough through his noke to suit you, take the tube out of the windpipe and draw the skin together over the wound by a couple of stitches and then treat as an ordinary wound; of course, this operation is seidom needed except in ex. treme caser. 
DISEAGES AKD TREATMETT OF THE HHORSE. Ji-tii

Tt is colled thenc cour

It is called thls when no other disease can be wen.

Causes.-It may result from laryngitis, or inflammation of the Sroat. Sometimes a horse is noticed to have this kind of cough for some time before he takes heaves, or broken wind. A cough of this kind is generally worse during changeable weather and is sometimes shown more after eating and drinking or after being brought out of the stable.

Treatment-Give the following powder I

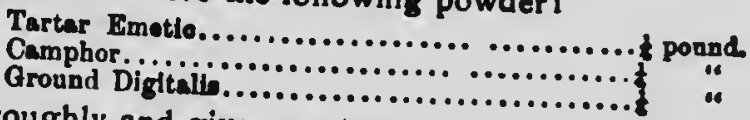

Mix thoroughly and give one teaspoonful night and morning in feed or on tongue with a spoon. A teaspoonful of oil of tar in hi feed three times a day is also recommended.

ROARING.

This disease is breathing with a loud and unnafural sound upon any violent exertion. More air passes into the murrils than can pass into the lungs, and this is due to the wastivip of the muscles of the larnyx, or Adam's apple; this condition caun... passage through the larynx to be smaller than natural. The.... rushing through this small passige into the lungs acts on tho* vocal cords; this is what causes the peculiar sound.

Causes. - This disease sonetimes follows laryngitis, distemper and influenza by being put to work too soon after recovering from. them. It may also be hereditury, that is where the sire or dam of the horse has been affected with roars. It may come on from tight reining. Horses with very long necks and narrow jaws ar. apt to become roarers.

Symptoms.-As long as you flo not excite the animal he io almost free from it, but if he is worked or driven hard he will stino it quickly.

Treatment.-If this disense is once well established it is incurable, but in cases where the disease is just coming on give

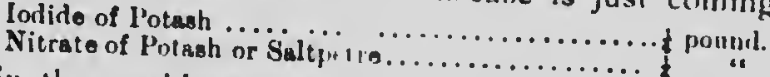

Mix thoroughly and gine a le:iepounful rwice a diny, mi-f.e and morning, in his feed, and blinter the thiditl with

Ground Spanish Flien, or $1,1 \cdot 1.11+\ldots \ldots \ldots \ldots \ldots \ldots \ldots+1,1$,

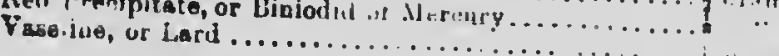


Mix thoroughly tc gether and apply around the throat, rub it in well and grease in three days afterwards. If he is not better in a month, blister ngain.

SPASMS OF THE MUSCLES OF THE LARYNX OR ADAM'S APPLE.

This dissase is not very often met with but we find it cometlmes affecting old horses.

Canses of this disease are not known.

Symptoms. - The animal may appear in perfect health when all at once he will be seized with a violent fit of coughing, will reel, stagger, and sometimes even fall to the ground; after a few minutes it will pass off and the animal will seem as well as ever.

Treatment.-Give the animal a good dose of phyic:

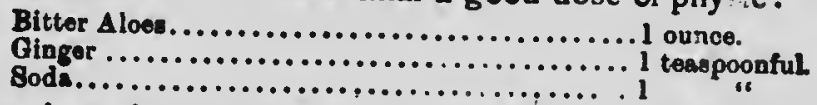

Dissolve in a pint of lukewarm water and give as a drench, and allow the animal to stand quiet the next day after giving this drench; follow up after this with a teaspoonful of bromide of potash every morning in his feed.

BLEEDING FROM NOSE (EPISTAXIS). in man.

This disease is not so commonly met with in horses as it 10

Canises.-It is generally the result of some injury, or in running or fast trotting horses when they are put to violent exertion, rupturing some of the blood vessels in the nose; it is also more frequently met with in horses in high condition.

Symptoms. - How to tell whether the blood just comes from the nose or from the lungs. If the blood comes from both nostrils It is generally from the lungs, while if the bieeding is from the nose it is usually only from one nostril. You can also tell by putting your ear to the windpipe and listening, if it is coming from the lungs you can tell by the gurgling sound heard in the lungs ; if it is in the nose you will not hear this sound in the lungs. When the blood is coming from the lungs the brathing is affected, which is not the case when bleeding from the nose.

Treatment.-If not bleeding very much bathe with cold water until it stops, but if bleeding much plug the nostrils with cotton batting saturated with white lotion and remove in twelve houra.

BLEEDING OF THE LUNGS (HEMOPTYSIS).

This is generally a symptom of some other disease, but it may come on, in a horse in high condition and not nsed to work, by 


\section{DISEASES AND TREATMENT OF THE HORSE.}

putting him to severe exertion when he is not used to it. It is mostly found in trotting and racing horses when they are not properly taken care of. The blood may come from the lining of the air cells or from the lining of the tubes of the lungs.

Symptoms. - As a usual thing it is not very hard to find out where the blood is coming frori. It comes out of both nostrils; the animal als. coughs, breathes quickly, and is generally very weak, and in taking the pulse you will find it beats very quick, but weak. By applying the ear to the windpipe you will hear that peculiar gurgling sound every time the animal breathes.

Treatment.-Keep the animal standing very quietly. Apply cold water or ice to the sides and chest. Be very careful how you drench the animal in this disease for they are so easily choked in diseases of the lungs. Give as a drench -

Turpentine ................. ounce, or 4 tablespoonful,

which acts as a styptic to stop the bleeding; or you might give Mincture of Chloride of Iron........ I dram, or 1 teappoonful.

Mix in a pint of cold water, shake well, and give as a drench every night and morning. If the legs are cold rub well and bandage them. Allow plenty of fresh air to get to the animal and blanket according to the season of the year. In some cases the disease is treated by giving

Sweet Spirit of Nitro........... unnce, or 4 tableapoonfuly, In a pint of cold water, three times a day, morning, noon and night, until the animal has relief. This disease is sometimes followed by inflammation of the lungs.

CONGESTION OF THE I.U:IGS.

This is where the blood rushes to the lungs from a chill or some other cause, filling up the arteries and veins in the lunge and causing them to become gorged with blood. This disease is aiways found before inflammation of the lungs, that is, if the congestion is not relieved it terminates in inflammation.

Causes of this disease are standing in a draft while warm, getting a cold drink of water while the animal is warm, or by putting the horse to severe exertion, such as running, trotting, or drawing heavy loads, when the system is not in proper shape to stand it. It sometimes follows other diseases such as catarrh or intluenza.

Symptoms vary much according to the cause. If from fast or hard work the symptoms are well marked. The animal 
becomes oluggish, trembles at the flank, breathes heavy, nostrils are dilated or enlarged, pulse is quick and weak, the lining around the eyes and nose becomes very much reddened; by placing your ear to the sides of the chest or to the windpipe there is $>$, peculiar gurgling noise; the legs and ears will be cold. If the disease follows a case of catarrh or influenza he then will be noticed to refuse his food, tremble all over the body, ears and legs cold, mouth hot, pulse quick and weak, and by placing your ear at the vides you will hear the peculiar sounds. The animal stands, as he is generally found to do in all lung 'roubles, and if he does go to lie down will get up immediately. If the animal does not soon get relief the disease will run into inflammation of the lungs.

Treatment.-The treatment must be quick. This is not a very fatal disease, but a simple one to treat if taken in time. Keep him well supplied with good, fresh air, and always be careful he does not stand in a draft. Keep the body well covered according to the time of the year, and give

Sweet Bpiritu of Nitre......... I ounce, or 4 tablespuonfuls.

Put in a pint of cold water, shake well and give as a drench. being careful not to choke the animal in giving it. Have the legs weil hand rubbed, if cold, and bandaged; and if the aninal is in high condition and full of blood it is well to give, with the above drench,

Fhoming's Thnoture of Aconite............... in to 15 drope.

Also put a mustard plaster on the sides over the lungs. Take $\$ 1 \mathrm{~b}$. of mustard, with 3 or 4 tablespoonfuls of flour and enough vinegar or warm water to make it into the form of a paste. Rub this well over the cides of the chest with the hand, and in some cases it is well to rab the front of the chest as well as the sides. In some cases we find great benefit in having cloths wrung out of warm water held up to the sides. If he is not relieved in a couple of hours give another drench, same as the one mentioned above; repeat the drench every two hours until the animal has relief. It Is also well to give him only a mouthful of cold water at a time, but give it to him often. Feed him soft food, and after he begin. to get better, exercise him a little by walking around; also givo the following mixture:

Ground Gention Root....................... peund.

Mix thoroughly together and give a teaspoonful three times 


\section{DIBEASER AND TREATMENT ( F, THE, HORSE.}

day in his feed, and gradually bring him back to his natural feed
and work again.

\section{INFLAMMATION OF THE LUNGS (PNEUMONIA).}

This disease is inflammation of the lung substance itself and is quite a common disease. The lungs in their natural state will float on water. In the first stage of this disease the lungs are filled with blood anc serum, and they are of a dull reddish color; at this stage, if the animal dies, the lungs will still float on water. As the disease runs on, if not cured, the lungs change to dark, grayish appearance; if the animal dies and the lungs are put in water they will sink.

Causes-Are much the same as those of congestion of the lungs and generally come on horses kept in a poorly ventilated stable, which has a tendency to weaken the lungs; sudden changes in the weather, such as we have in the fall and spring, are liable to bring the disease on. 'It is also sometimes caused by keeping a horse in a warnı stable and then turning him out to pasture to lie on the cold ground; or, if while he is out, a cold rain storm comes on and ne gets wet and is chilled through; or, if a horse is clipped and exposed to the cold; standing in a draft while warm; inhaling smoke; also by driving against a cold wind too soon after he has had influenza, distemper, or any of those weakening diseases. It also frequently follows congestion of the lungs.

Symptoms.-Are much the same as congestion of the lungs, only plainer. There is, generally, very little trouble in telling the disease. It commences first by the animal shivering, after the shivering ceases heat takes place; the ears and legs will first be hot and then cold; the mouth is sticky and the breathing affected, but not so much as in a pure case of congestion of the lungs; the pulse is quick, ranging from fifty to seventy-five beats to the minute, which is stronger than in a case of congestion; the horse does not care to eat; stands up all the time, with head hanging down and ears lopped over, and in hot weather perspires freely around the cliest; the eyes have a glossy appearance and, around the inside of the eyelids, are very red. As the disease passes on the horse breathes heavier and sometimes is noticed to sigh, as if in distress; the bowels become costive. ana the manure has a glossy appearance; placing your ear to the side of the chest you will hear a grating sound similar to that produced by taking some bair of rour head, just above the ear, and grating it between the 
thumb and finger. If the horse is loose in a stall he will work around till he gets his head to a door or window, which shows that he wants fresh air. By tapping the finger on the chest. over the lungs it will produce a dull sound, which. if the lungs were not affected, should give more of a hollow sound. If the disease is going to terminate fatally the pulse runs up to 100 beats per minute anci is so weak you can hardly feel it; he will breathe very heavy; the nostrils make a flapping noise, and his flank draws in and out almost like a heavy horse : the appetite is entirely gone; the breath smells very bad; he still persists in standing, and notices nothing. As death approaches the mouth becomes cold, the pulse cannot be felt ; he may, near the last, lie down, which will cause him to breathe "ery much heavier; he again staggers to his feet, breaks out into a cold, clammy sweat all over the body, and finally staggers, falls, and dies. If the case, on the other hand, is more favorable, the animal eats a little and notices things around him, and the above symptoms gradually disappear. It generally takes from 9 to 12 days to run its course, and, as a usual thing, is treated with satisfaction if taken in time.

Treatment.-Clothe the body according to the season of the year. If the animal affected is in high condition use sedatives, such as

Flemlng's Tinotnre of Aconite .........8 to 10 drope.

Laudanum...................... t oz. or 2 tablesponfuls.

Mix in a pint of cold water and give as a drench every three hours until the distressing symptoms have ceased and inflammation seems pretty well checked. If the animal seems weak after this give

Wreet Spirite of Nitre........... onnce or 4 tablempoonfule.

Mix with pint of new milk or gruel and give three times a day, morning, noon and night, until the animal seems stronger. After this, when the animal is getting better and he needs a tonic to build up his system and to keep his kidneys in good action so as to relieve his lungs as much as possible, give

Nitrate of Potanh or Saltpetre......... pound.

Mix thoroughly and give a teaspos-ful three times a day. While the animal is sick feed on soft food, mixing a little boiled flax seed with it to keep the bowels regular. If the animal is very thin in condition it is best not in use much of the aconite and laudanum, but commence the stimulants sooner than if the horse was in high 


\section{DISEASES AND TREATMENT OF THE HORSE.}

condition. Apply mustard to the sides and chest and alsh cloth. wrung out of hot water, and be sure to allow the horse h have plenty of fresh air by having the stable well ventilated, hut to not allow any draft to strike him.

\section{PLEURISY.}

This disease is inflammation of the lining found inside the ribs and over the lungs. This is a serious disease if not taken in time and allowed to run on.

Causes are similar to those of inflammation of the lungs, and we often find this disease and inflammation of the lungs coming together. The chief causes are exposure to cold. standing in a draft, washing the body and not properly drying it, iniuries to the ribs in a:.y way.

Symprams.- The animal is first noticed to shiver, the pulse quick and strong-much stronger than with conges:ion or inflammation of the lungs-and is sometimes called a wiry pulse. He seems in great pain, breaths heavily, which is noticed very much at the flanks. At the commencement of the disease he will lie down, but, as a general thing, he will stand up most of me time; if "ou make him cough he will suppress it as much as possible, and instead of coughing out loud, as in other lung troubles, it will be more like a long, heavy groan. The idea of Enis is he tries to keep from moving his chest as much as he can. The ears and legs are cold, but sometimes you will ind one ear hor and the nther cold; he has a tucked up appearanc., and there will be a hollow line right along the bottom of the false ribs and up towards the point of the hip; if you press on his sides it causes him great pain, and in turning him around short he will groan with pain. If this disease is not soon checked it will terminate in what is known as hydrothorax, which means a filling up of the chest cavity witlı a watery fluid.

Treatment. - This disease is treated very much similar to that of inflammation of the lungs. Apply cloths wrung out of hot water to the sides if in warm weather, but if in cold weather mustird is best and easiest kept on. Clotha the body well and wee that he is allowed plenty of fresh air without being in a araft. At the commencement of the disease, if the horse seems to be in much pain, give

Fleming's Tincture of Aconite ......8 to 10 dropt.

Fluid Extract of Belladonna.......... dram, or 30 drock

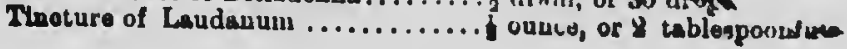


Mix in a pint of cold water and give as a drench. Continue the above drench every two hours until the horse is relieved of the pain. If the horse seems weak after this give

Sweet Spirits of Nitre ............ ounce, or 4 tablespoonfnle.

Whinky $\ldots \ldots \ldots \ldots \ldots \ldots \ldots \ldots \ldots \ldots \ldots$. $\ldots \ldots \ldots$ wine glese full.

Mix in a pint of gruel and give as a drench three times. day, morning, noon and night, until the animal begins to recover nlcely, then use the following medicine to keep the kidneys work. ing freely, as this will have a tendency to keep water from forming in his chest :

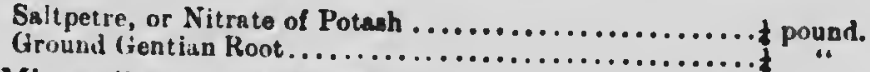

Mix well and give a teaspoonful three times a day. During sickness it is well to fead the animal with soft foods, with a little boiled flax seed in it to keep the bowels free, give a little cold water to drink in small quantities, and give it often-every hour or two.

\section{WATER IN THE CHEST (HYDROTHORAX).}

This generally follows a case of pleurisy. In some cases you will find several pails of a watery fluid around the lungs in the chest cavity. When there is such a large quantity as this it generally ends fatally.

Causes.-Pleurisy.

Symptoms.-After the pain and soreness from pleurisy has passed off the fluid then commences to collect around the chest, which causes him to breathe very heavily, the nostrils becoming large, and sometimes make a flapping noise. He breathes quick, and draws in and out at at the flank worse than he does in a bad case of heaves; the pulse becomes quicker than in pleurisy, and very weak, beating from 75 to 100 beats per minute; the blood in the jugular vein seems to flow back towards the head instead of howing down, causing the vein to move every time he breathes. By putting your ear to the chest you cannot hear anything except above the water. If the animal is loose he will be noticed to try to get to the door or window to get the pure air. In some cases the animal will go on like this for several days, not eating very much, inil gradually getting worse. Near the last his ears and legs get rery cold, and all the other symptoms keep getting worse, and the animal tries to stand on his feet to the very last.

Treatment.-If the animal will take food give him good, strong food, such as oats and hay, and it would be woll to mix a 
little of the bolled llnseed along with the oats to keep the bowde regular; keep the animal quiet; blister the sides well with a strong mustard plaster; grive him of the following .

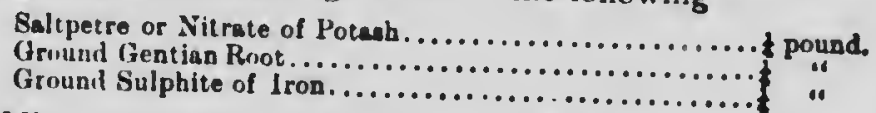

Mix thoroughly and give him a teaspoonful every five hours. It is also recommended in some works to puncture near the bottom of the chest, between the eighth and ninth rib, with a small trocar and cannula, and let the fluid out of the chest, but this operation is not very successful in the horse, and we would not advise it to be done, although it is sometimes successfully performed in human beings.

If the horse dies and you cut into the chest you will find a great quantity of the fluid collected around the lungs, in some cases as much as three pailfuls. tubes.

This disease is inflammation of che lining of the bronchial

Causes.-This disease is sometimes caused by driving a horse fast when he is in a weak condition, inhaling smoke, or from a sudden change in the temperature, choking from food passing down the windpipe, and sometimes it is caused from giving a drench which, instead of passing down into the stomach, some of it goes down the windpipe. This disease is oftener seen in the city than in the country.

Symptoms are a peculiar dryness of the throat, increased breathing, and if you place your ear to the windpipe, you will hear a wheezing noise. The animal seems quite dull, and does not eat as well as he slınuld. If the disease is allowed to run on the pulse becomes quick and weak, and the legs and ears, after a time, become cold; he scems very much depressed and weak, and if the weather is warm perspires freely around the chest and Hanks; on account of not eating very much he will become very wint, and it will be noticed that he does not lie down, and if you wake him stir around it will start him to cough.

Treatment.-If the animal is in good condition and strong, bive the following mixture :

Fleming's Tincture of Aconite...., 5 to 8 demps.

Lwudunum $\ldots$............. the ounce or 2 tableapoonfula.

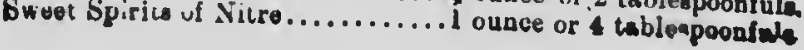


Mix in a pint of cold water, shake well and give as a drellch. Give a drench every two or three hours until he seems relieved. If the animal is very weak, instead of this, it is best to give Whiaky............................ wine glase full

Alo or Beer............................... pint.

Give every three hours until he seems relieved, then pruceed with the foilowing :

Saltpetro or Nitrate of Potanh..................... pound.

Tartar Emetic ............................................

Ground Gentian Ront..................................

Mix thoroughly and give a teaspoonful three times a day. Feed soft feed with a little boiled flax seed to keep the bowels free, give cold water in small quantities, but often, which will have a good effect on the throat; apply musiard or hot cloths wrung out of hot water to the chest, clothe the body well, according to the season of the year, and see that the animal has pure air to breathe without being in a draft. In all lung diseases be careful in drenching so as not to choke the animal.

\section{BROKEN WIND OR BEAVES.}

It is similar to asthma in man.

Causes.-It is generally seen in horses that are ravenous feeders and overload the stomach and are inclined to carry a large belly. This affects the stomach, and the same nerve that helps to supply the stomach with nerve power also helps to supply the lungs; this is how we acrount for it affecting the lungs when the stomach is affected. The kinds of "ood that are apt to produce it are inferior focds, such as musty hay (clover hay being the worst), or musty oats, or it may be caused from a neglected cold. This disease is rarely found in cavalry horses as they are fed on the very best of food.

Symptoms.-This disease is easily detected when it is well established. There is a peculiar way of breathing, a long Inspiration followed by s short expiration and a jerking motion at the flank; the nostrils are enlarged and the muscles of the belly come into play greatly in this disease. On a damp, hot, sultry day the symptoms are greatly increased, and may become very alarming, and you might be led to think that the animal was suffering from inflammation of the lungs; but wher you examine the pulse you will find it beating about natural. In herves there is a loud, hacking, painful, internal cough which seems to come from the lungs; this is noticed more after eating of 


\section{DISEABES AND TLEATMENT WF THE HORSK.}

drinking, and is noticed particularly after being brought out of the stable in the morning, but after working a while will not bo so bad. If you suspect this disease when you ure examining him for soundiness give him a good feed, a pail of water and a good gallop. If affected with this disease you can then notice it plainly. In some cases it can be relieved for a short time by giving a large dose of Fleming's tincture of aconite, 10 to 15 drops in a drench, mixed with a pint of raw linseed oil. This is sometimes done by horse traders to relievo the animal while trading, and in some cases they even pour shot into the animal, which relieves him for a time.

Treatment.-Where heaves once gut well established it is incurable, but it can be helped by careful feeding: By feeding him regularly, and giving him lots of oats to eat and ver? litt'e hay, so as to keep him gaunt: water him oftan-four or five tines a day-not more than a pail at a time, and ne.er a'luw him to get a large feed of hay or a large drink of water at a tine. The best treatment of medicine is give first a physic of tron 8 to 10 drams of bitter aloes dissolved in a pint of water, with a tablespoonful of ginger and soda given as a drench, and allow him to stand in the stable for a day. This will clean his bowels and stomach out ; after this feed him carefully and give of the following mixture:

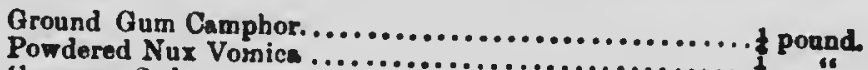

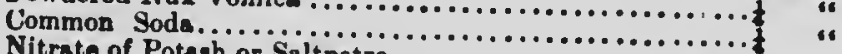

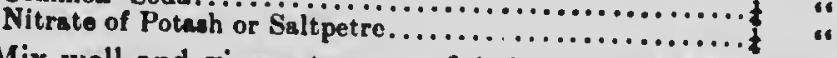

Mix well and give a teaspoonful three times a day in his feed, or on the tongue with a spoon.

\section{PLEURODYNIA.}

This disease is a rheumatic condition of the muscles around the chest. This is not a very common disease.

Causes.- Exposure to cold when the animal is recovering from pleurisy or other weakening lung diseases.

Symptoms.-There is great pain and difficulty in breathing and shows symptoms somewhat similar to pleurisy. In pressing on the sides he shows even more pain than he does in pleurisy, and when you examine his pluse you will find that they are about regular, whereas in pleurisy they would be beating quick and hard. By putting the ear to the animal's side you cannot hear the grating 
Treatment.-If it is warm weather, or in a warm stable, wring a woolen blanket out of hot water, wrap it around hls chest and cover up with a dry blanket to keep the heat in. This blanket would be better heated up by wringing it out of the hot water overy hour. While the blanket is being changed rub the sides woll with white liniment. Give him

Sweet Spirite of Nitre............. ounow, or t tablowpoonfnls.

In a pint of cold water three times a day, morning, noon and nlght, until the soreness has passed off pretty well, then follow up with a diuretic to act on the kidneys.

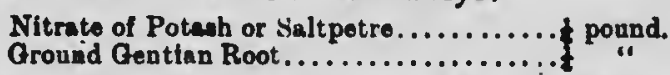

Mix thoroughly and give large teaspoonful three times a day in his feed or on his tongue with a spoon.

\section{SPASMS OF THE DUPHRAGK.}

This disease is sometimes called Thumps on aecount of the peculiar thumping noise the animal makes in breathing.

Causes.-It generally results from an animal being put to very sovere exertion, such as in running, trotting, heavy drawing, or any thing of that kind too soon after eating. It is also said to be caused by buckling the girth of a saddle too tight. This 1lsease is more liable to be noticed shortly after the animal has recovered from some weakening disease.

Symptoms.-It gives rise to a thumping noise which is plainly heard by listening at the back part of the lungs. In most cases you can hear the noise while standing near the animal. This disease is often mistaken for palpitation of the heart, but by examining with the ear along the sicle you will find that the noise made is too far back to be affecting the heart, and you would Imost think by the peculiar noise made that some person was Inside tapping with a hammer. The animal has difticulty in breathing, sweats freely and seems in pain.

Treatment. - In an ordiuary case give an anti-spasmodic.

Sweot Spirits of Nitre $\quad \ldots \ldots \ldots \ldots . .1$ ounce, or 4 tablespoonfule.

Tinoture of Laudanuin ............. " " " "

Mix in a pint of luke warm water and give as a drench every two hours until the animal is relieved of the thumping noise. If warm weather, apply a woolen blanket wrung out of hot water to the chest, with a dry one outside of it. If cold weather it is better to apply a mustard plaster around the bick part of the ahast and cover the body well. In mome cacts, after yiving a few 
DISEAEES AND TREATIENT. UF TEE HORSE.

doses of the above mixture, If he does not get relief, it would be

Bpirite Turpentine.

Rar Linneod O

1 onnce, or $\$$ tableapronfule.

Mix and give as a drench. After the animal is getting better foed well and give regular exercise, and bring the animal gradually back to his regular work.

\section{RUPTORE OF THE DIAPHRAGM.}

This is rupture of the curtain which separates the lungs from the bowels, and if the rupture is large ennugh to let the bowels pass through in on the lungs and heart death soon relieves the enimal.

Causes.-Pulling a heavy load up a steep hill, or by high jumping. Sometimes it occurs when the animal is suffering from acute indigestion, when the stomach is full of gas, and in getting up and down sometimes lies down a little too heavy, causing a great strain on the curtain, which causes it to become ruptured.

Symptoms. - There is a trothy spume comes from the nostrils, breathes very heavy and quick, breaks out in sweat over the body, the pulse runs up very high-sometimes as high as 100 beats per minute-and gets very weak, the animal appears as though it was suffocating, and if the rupture is to any great extent the symptoms gradually get worse, the legs and ears get cold, when death relieves him.

Treatment. - Not much can be done in this case, only give

Laudanum .1 ounce, or 4 tablespoonfuln.

Mix in a pint of water and give as a drench. This muy bo kiven once in a while just to relieve the pain. 


\section{CHAPTER III.}

\section{UISEASES OF THE MOUTH, TEETH, SALIV- ARY GLANDS AND GULLET.}

\section{IRRITATION OF SHEDDING THE MIR TEETH.}

This trouble is generally at its worst when the horse is betiveen three and four years old.

Symptoms.-The horse seems weak at work, sweats easily, his hair is standing and looks rough, he does not feel well and he gets gaunt and thin, his bowels get costive and the oats come through almost whole.

Treatment.-In a case of this kind always examine the teethboth front and back-for shells or caps, and if there is any remcve them with pincers or forceps. Give a mild laxative, such as

Raw Linseed Oil ................................... pint

in a drench. After this feed on soft food, and follow up with the following tonic powders:

Ground Gentian Root................................ pound,

Mix thoroughly and give a tablespoonful twice a day ln bl feed or on his tongue.

\section{LAMPAS.}

This is very common in young horses. 'It is not really a disease itself, but simply an irritation of the gums caused by shedding his front teeth.

Symptoms.-This swelling is found in the rume behlnd the front teeth in the upper part of the mouth. The gum looks red, and if you press your finger on it it seems sore.

Treatment.-Do not use any harsh treatment for, after the horse gets all his teeth shed and his new ones in, the swelling generally disappears of its own accord. It is well sometimes to take a sharp knife and cut the gum in a few places, which relieve the congestion and soreness, then rub the gums a ccuple of times ay with alum water-about two teaspoonfuls of alum to a pint of water. Be careful in cutting the gum not to cut back of the third bar or ridge in the roof of the mouth, for there is danger of eutting the large artery in the roof, which, if cut, will blesd freely. If by accident you should cut this artery, the way to stop it is: Take a large piece of cotton batting, place it in the 
roo: : the mouth over the cut and have it held firmly by windine banduge through the mouth and over the nose, tie the mirnal up so he cannot eat, and leave the bandage on for twerity-four hours, when it can be safely taken off.

\section{PARROT MOUTH.}

This is not a disease, but simply a deformed mouth, whero the upfer jaw is longer than the lower jaw, and the teeth in the upper jaw projects out over the teeth in the lower jaw which generally get very long. It is always well to examine a horse's teeth before buying him for fear of his having sume trouble like this. These horses should never be turned out to pasture for they cannot graze as their front teeth do not come togrether. But in soma cases they make very good work horses if they are kept in the stable and fed on hay and oats. This is considered an unsounaness in horses.

\section{WOLF TEETR.}

These are two small teeth found in the upper jaw in front o: the grinders, one on each side. These teeth have an affect on tne horse's eyes, causing them to run water and look dull, and, if. ome cases, if they are very large, will interfere with the animal s feeding.

Treatment.-Sometimes the teeth are knocked out with a punch, but they are best removed by putting tivitch on the horse's nose and pulling thein out with a forceps.

\section{SHARP EDGES ALONG THE TEETH.}

The grinders on the upper jau are wider than those of the under jaw, and pointed to the outside, while thuse of the under jaw are narrower than those of the upper jaw and pointed in towards the tongue. You will notice these points about the teeth by opening the horse's mouth and drawing his tongue out to one side. From the continual grinding the outer edges of the upper teeth beconie sharp, and will sometimes cut the cheek, while those of the under side will becone sharp on the inside and cut the tongue. If you suspect the teeth are shirp the best way to examine them is to place a twitch on the horse's nose, have an assistant to hold the twitch, and hold his head up slightly. While you take the tongrue out with one liand and hold the cheek aut with the other, then louk back and see if the check or tonme is cut, and also if the edges of the teeth are very sharp, if tho... are, the lorse's mouth needs what is called flouting or tiring the 
teeth, which can be easily done by leaving the twitch on and running a float or tooth rasp along the outer edge of the upper row of teeth and the inner edge of the lower row of teeth. It is not best to file them too much, just enough to take off the sharp edge of the teeth so they will not cut the tongue and cheeks, for if rou file them too much the horse cannot grind his hay so well.

\section{DECAYED TEETH (CARILS)。}

You do not find decayed teeth so often in the horse as you do in the human being. Horses rarely, if ever, suffer from tooth ache.

Causes.-It generally comes from biting some hard substance and either breaking or crackin. the tooth, which then begins to decay.

Symptoms.-The horse in eating his feed will be noticed, all of a sudden, to throw his food out of his mouth, fumble his tongue around a little and then commence to eat again. If in drinking sometimes if the water is cold it takes him a long time to drink, having to stop several times in drinking a pailful. In driving ho is noticed to hold his head to one side, favoring the side that has the decayed tooth in it. His breath smells bad, and he falls off in condition. If the tooth is in the upper jaw, and the roots affected, there is sometimes a running from the nostril over the tooth.

Treatment-O Open the mouth with a speculum or any iron that will answer the purpose, pass the hand back and examine the teeth and tind out which tooth it is. Always in examining the mouth it is best to put a twitch on the horse's nose as it assists in holding him quiet. When you are sure which tooth is affected take a large forceps and remove the tooth. After pulling the tooth out keep the tooth opposite the one pulled out filed down so it will not irritate the gum on the opposite jaw. After the tooth has been removed feed on soft food for a few days until the gum gets healed up. If the horse is run down in condition it would be well to give some of the following tonic powders to build him up:

Ground Gentian Root...........................

Ground Sulphate Iron. .................................

Mix thoroughly and give a teitspoonful twice a day in his feed or on his tongu. 


\section{SPLIT TEETR.}

The teith that become split are generally the nare grinders on the upper side of the mouth, though, in some cases, it might occur in the lower jaw. If the split tooth occurs in the under jaw the split part is generally found on the inside of the tooth and curned in against the tongue. If it is one of the grinders on the upper jaw the split part is on the outside and turns out and cuts the cheek.

Causes.-Generally from getting some hard substance into the mouth and grinding heavily on it, such as a nail or stone.

Symptoms.-The animal can scarcely eat, seems very much afraid when you go to handle his mouth, and will sometimes jerk back. If you run your hand along the upper jaw on the outside where the tooth is split and turned out it will be very sore, and the animal will jerk his head away when you press over the tooth. In eating he is noticed to fumble his food around in his mouth, and after having it in a few minutes he will throw it out halt chewed, stop a few minutes, and then try to eat some again. Place a twitch on the horse's nose and proceed to examine the mouth by drawing the tongue out with one hand and holding the cheek back with the other and look carefully back along the grinders, and if the split is in the upper side of the jaw you will see it worked out, and, in some cases, stuck in to the cheek. If the split tooth is in the under jaw you will find the split part stuck into the tongue.

Treatment.-After you have found where the split tooth is, it is easily treated by taking hold of the split piece with the forceps and pulling it out, which is not hard to do in most ceses. Then take a float or tooth rasp and run it along that side, and if there is any sharp teeth smooth them off. If the borse is vers uin follow up with tonic powders.

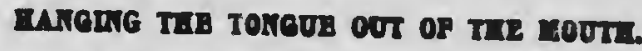

This is not a disense, but a miserable habit, and If it is an formed you cannot cure it.

Cause is generally from the teeth getting sharp and cutting the tongue, or from some injury to the tongue.

Symptoms. - At the first start of this habit the horse just holds the end of the tongue between his teeth while he is at his work. After a time it becomes worse, and while the bit is in his mouth the horse hangs his tongue out three or four inches on either ide 
Treatment.- Examine the mouth as to the state of the reth, if they are 1ound sharp, float or file them so as to stopthem from culting the tongue. If the cause is a soreness on the tongue arem "I with alun water-two teaspoonfuls of alum to one pint of writer. This will generally effect a cure if the case is taken in tıme. There are certain kinds of bits recommended for this habit, but an a general thing they prove a failure.

\section{CRIB SUCKERS.}

This is where a horse takes hold of the manger or anything around him and sucks wind.

Causes. - Sometimes a colt will learn this habit from seeing its mother or other horses doing it. It is also caused by soreness of the front teeth at first, and he commences biting at the manger to relieve him, when afterwards it becomes a regular hahit.

Symptoms.-In examining the front teeth you will find them worn off from biting, and the horse, if you watch him, is continually hanging on to the manger. In some cases he will suck him. self full of wind, and sometimes will take severe colic from sucking so much, while in other cases he will simply hang on to the manger with his teeth.

Treatment.- - When first noticed it is best to put the animal in a box stall and feed him his hay off the foor, and his gram in a pail, which should be removed as soon as the animal is through eating so he has nothing to take hold of with his teeth. Examine the teeth and see if there is anything wrong with them, if they are sharp, causing soreness, file them down, or if it is a milk tooth not properly shed, it is well to remove it. If it is in the spring, and the grass good, he will sometimes get over it by turning him out to pasture. If the animal is old and has been a cribber for come time the best thing to do is to get a muzzlo for him, and ealy leave it of while he is eating.

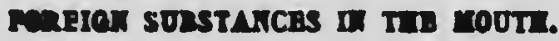

Somotimes wo and a piece of stick cuught across the roof of the mouth, which will ise noticed by the animal not foeding and he will be continually working the tongue around in his mouth, and if this obstruction be not removed the animal will fall off in flesh. In this case examine the mouth well and remove any substance found caught in the mouth with the fingers or with a pincers.

Barley or Wheat Beards. - When horses are fed on harley or wheat straw, or chaff that has beards in it the mouth should be 
examined every week or two, for in a great many cases the bearda get so lodged in the mouth that the animal cannot remove them with his tongue.

Symptoms. - The horse does not feed well, his breath is bad and his mouth seems sore when you handle it; he becomes gaunt and thin.

Treatment.-In all cases where you are feeding this kind of food examine the mouth carefully, and if you find any beards remove them with the finger and wash the sore place with alum water twice a day until it heals up. Use two teaspoonfuls of alum to a pint of water.

\section{INJURIES TO THE TONGUE.}

The tongue is sometimes injured by a person riulling too hard on it when it is drawn out of the mouth, which panizes the tongue. There cannot be much done for this, only give very soft foods, which he can almost drink down, and give him a teaspoonful of powdered nux vomica three times a day on his tongue with a spoon. The tongue is often injured by the horse pulling back when tied by the bit. In some cases the tongue is almost cut off. If you think there is no chance of the tongue healing it is best to remove it with a knife and apply Monsel's solution of iron to stop the bleeding, if any. Afterward bathe the tongue with a iitle alum water three or four times a day for a few days, until the tongue heals up. Use one teaspoonful of alum to one pint of water; also feed the horse on soft food for a few days, while the tongte is healing. If the tongue is not cut enough to remove, treat it same as treatment after removal.

\section{MFLAMUTION OF THE TONGUE (GLOSSITIS/}

This is not a very common disease.

Canses-It is sometimes caused by handling the tongue rough, by pulling too hard when tating lt out of the mouth, or by riving irritating medicines which are not diluted enough with water; by eating polsonous grasees and somotimea by a thorn atiching in the tongue.

Symptoms.-There is a flow of sallva from the mouth ; the animal cannot chew his food well, and there is difficulty in swallowing and breathing, the tongue gets red and is painful when pressed upon, is very much swollen, and in some cases sticks out It the mouth, the horse seems generally feverish, and after a few says there will be seen small boils forming around 
the tongue which have matter in them, the lining covering the tongue becomes dry and cracked in several places. If the animal does not get relief he cannot eat nor drink, and will soon die of starvation.

Tieatment. - If it is a thorn or any foreign substance, remove it and give a dose of laxative medicine, such as one pint of raw linseed oil. Bathe and gargle the tongue with the following ?

Tinoture of Laudanum .............l ounce, or 4 tablospoonfule

Pulroritod Alum.................. t teaspoonful.

Gargle or bathe the tongue three or four times a day, and blister him in the space under the jaws with a mustard plaster. If the tongue is swollen very much it is well to lance it with a knife and allow the watery matter :o escape, also open the little boils that have matter in them and let it escape. Feed the horse soft food with lots of boiled flax seed in it, as it has a soothing effect on the tongue. Follow up with the following povider:

Nitrate of Potash or Saltpotre.......... pound.

Pulverisod Alum......................... "

Mix thoroughly and give a teaspoonful on his tongue three times a day. These are to gargle and heal the tongue, as well as belp the anımal to thrive.

\section{APHTHAE OR TBRUSH.}

At certain times this is a very common disease.

Causes. - Certain kinds of food will cause one kind of aphthre, but the kind we usually see is the infectious kind. This is where the disease is communicated from one horse to another through the air, from stable to stable.

Symptome-The hores is usually firnt notloed to be dull and not fooding wall, has a elight cough, run dowe in ocadiden,

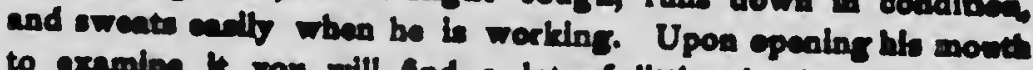

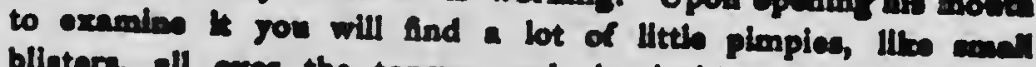
bllotern, Ill crer the tongue and the Insides of the Ipa an cheoks, them pimples or blisters are found all the way through th: lining of the gullet, stomach and intestines, and in some cases the animal gets quite feverish and unable to do any work.

Treatment-Give a half pint of raw linseed oil in a drench to vtart on. This will loosen up the bowels and help to carry off the disease. A tablespoonful of yinger is a good thing to give with the oil, then give the following : 


\section{DISEASES AND TREATMENT OF THE HORSL}

Common sode.

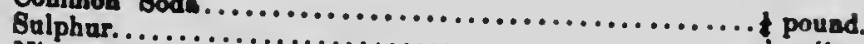

Nitrate of Potain or Saltpetro..........................

Mix thoroughly and give a teaspoonful three tme.t. ree tlmes a day on the two mouth out with alum watertwo teaspoonfuls to a pint of water-with a sponge three times a day until the pimples disappear. While he has the sore mouth feed on coft food, and put a lot of boiled fiax seed in the feed which will keep the bowels loose.

\section{INJURIES TO THE LIPS AND CHEERS.}

The lips and cheeks sometimes become bruised and cut in various ways. If the skin is broken to any extent it is best to stitch it up with a needle used for sewing up wounds, but it may be done with a darning needle. In sewing use carriage trinmer's twine, or a piece of white wrapping twine. Put a stitch about every half inch, and in stitching it is best to tie a separde knot for each stitch, then bathe with warm water two or thret times a day and apply, after bathing, the white lotion. In sewing the wound it is best to place a twitch on the animal's nose to keep him quiet. If the skin is not broken bathe and apply the white otion same as mentioned above.

\section{PARALYSIS OF TEE LIPS AND CHEERS.}

This is not a very common disease, although it is met with occasionally.

Causes.-It is an injury to the nerves which supply the lips and cheeks with motion. For instance, it is done sometimes by using a heavy poke on a horse in the pasture, also in the stable by having him tied with a heavy halter, or any other kind of an injury that would affect the nerve will produce this; cold weather will sometimes bring it on.

Symptoms.-It is first noticed that the animal is not able to use his lips in eating or drinking, or in any other way, and they hang flabby and loose, and in most of cases they look as if swollen, but it is only the looseness of them that gives them that appearance. When the horse tries to drink he $h$ to put his head dexp into the pail so that the water covers up his lips and nose, for this is the only way he can drink.

Treatment. - Keep the horse's strength up as best you can by feeding solt tood which can be easily chewed. In this disease it is pest to keep the animal in the stable and give him the following
medicine: 


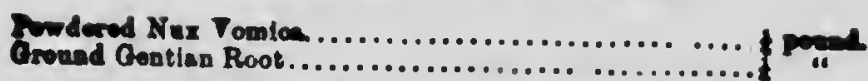

Mix thoroughly and give a teaspoonful three times a day, hand rub his cheeks three times a day and apply the white liniment after each rubbing. This disease generally takes from two to six weeks to recover and in all cases remove the cause of the trouble.

\section{DISEASES OF THE SALIVARY GLANDS.}

\section{SLAVERING OR FROTHING AT THE MOUTH.}

Causes.-It is generally caused from something in the feed that the animal is eating, or a heavy dose of aconite will cause $1 t$, or In fact anything that will stimulate the secretion of the salivary glands.

Symptoms.-A continual dripping of the saliva from the lips.

Treatment.-Change his feed and wash his mouth out with alum water two or three times a day-two teaspoonfuls to a pint of water. If this does not help it give him a good physic:

Bittor Aloen ............................. 8 drame.

Common Boda.............................. I towpoonful

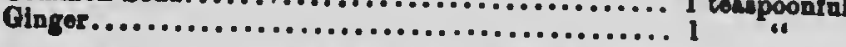

Mix in a pint of water and give as a drench; let the horso otand in the stable the next day. This will generally stop tho slavering.

THICKENING OF THE PAROTID GLAND.

This is usually called thick glands.

Causes.-Tight reining, or sometimes it remains thick after ditemper, or from inflammation of the gland.

Symptoms.-A heavy thickening behind the jaw bone and below the ear.

Treatment.-Blistering is the best way to get rid of thls. Use the following mixture as a sweat blister:

Pulverized Catharides, or Spanish Fly................. dram.

Vuseline, or lard ................................... drancen

Mix thoroughly together and there will be enough to blister the glands on both sides of the hroat. In putting this on always rub it in well, then tie his hcad up so he cannot rub his neck, leave it for three days, then grease it with some lard and keep greasing every third day till the blister is off, and if by this time the swelling has not gone down it would be advisable to repeas the blister. 


\section{IFLAMATHON OF THE PAROTID GLAND.}

This is the salivary gland situated below the ear and betweo the back part of the jaw bone and the neck.

Causes. - Generally from a bruise of some kind.

Symptoms. - There is a large, painfiul swelling just belnw the ear, on the affected gland of either side. It is so painful the hurse can hardly eat or drink, and he stands with his head poked out.

Treatment.-Give it lots of hathing with vinegar, hot water and saltpetre; after bathing, rub dry, and rub well with white liniment, then apply a poultice of boiled turnips and bran, or linserd meal and bran, about half and half. Change the ponltice three times a day, and bathe and rub with liniment each time the poultice is changed. This will check it and drive it away. If it does not check the inflammation the gland will fester, form matter and come to a head. It is well to let it come pretty well to a head before attempting to open it. The way to tell when it is ready to lance or open is, you find a soft spot where the hair generally lalls out, and when you press your finger on the spot and take it off the matter presses the skin back to its place quickly. You can easily tell when it is fit to let. Take your knife or lance and give the skin over the soft spot a little nick, which maly be done without any danger of bleeding. After this is done press the matter all out and keep on bathing and poulticing till the swelling has entirely gone down. After it is healed up, and if the gland remains a litt thick, blister with the following :

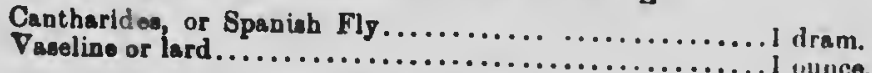

Mix thoroughly together and apply one half of the mixture, rub it well and tie the horse's head up so he cannot rub it, leave till the third day, then grease with some lard, and keep on greasing for a few days until the blister gets healed up, then take some warm water and soap and wash the grease off and, after drying, use the other half of the blister same as first half. During the time the animal is sick with this, feed and water him from $\&$ high manger. On account of his throat being so sore feed him mostly soft feed which would be easily swallowed. Give him the following powder for a tonic and diuretic to act on the kidneys :

Nitrate of Potash, or Saltpetre $\ldots \ldots \ldots \ldots \ldots \ldots \ldots \ldots \ldots \ldots \ldots \ldots \ldots \ldots \ldots \ldots$ pound.

Mix together and give a teaspoonful twice a day in his feed or on his tongue. 


$$
\rightarrow
$$




\section{MACOCONY RESOUTION TEST CHART}

(ANSI and ISO TEST CHART No. 2)
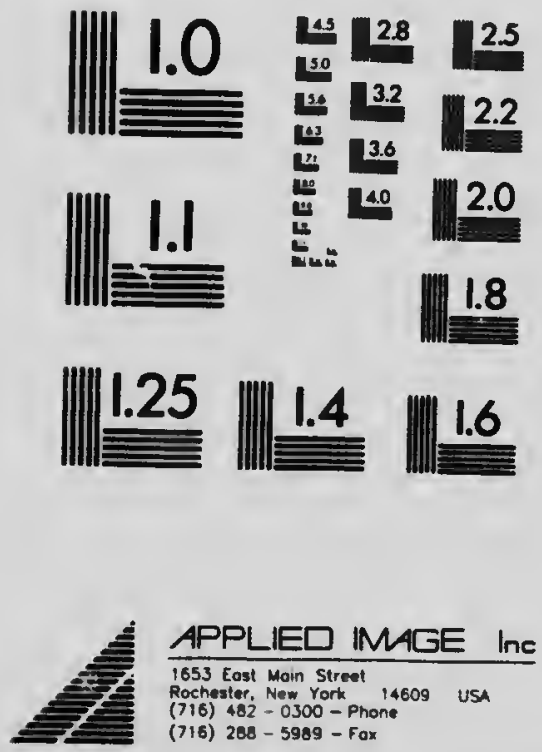


\section{PARALTSTS OP THE GULLET OR PHARTAR.}

Tho is a very serious disease, for the animal cannot swallow nelthe food or water, but fortunately it is not often met with in the horse.

Causes.-It is generally causer by some injury to the throat. Symptoms.-The animal will take food into his mouth, chew it and prepare it for swallowing, and then spit it out, not making any effort to swallow; he will try to drink, but cannot make any ef. rt to swallow it. If you examine the throat you cannot see anything wrong; no swelling, and it does not seem the least bit sore; the horse seems eager to eat and drink, but cannot; he falls off greatly in condition, gets very weak and will soon die from astrvation.

Treatment. - If he is a very valuable animal and worth going to the expense, treat him with a stomach pump by taking the juice got by boiling hay and making gruels made out of chopped oats, new milk and eggs and pumping it down in to the stomach; in this way he is kept alive until the muscles of the gullet have regained their strength of swallowing. In giving the gruels put teaspoonful of nux voinica in it three times a day. This is a nerve stimulant, and will help the muscles to regain their strength; also hand rub the throat well around the gullet and apply white liniment five or six times a day until the animal regains the power of swallowing.

\section{CHOKING WITH OATS.}

This is generally found in old horses that are very greedy feeders and not used to getting oats.

Causes.-Are generally where a horse has been out at pasture and brought in and given a feed of oats and he goes at it so greedy he fills his moutr. and tries to swallow it without chewing It properly.

Symptoms. - The horse is noticed not to be eating his oats, and if you examine there is very little of the oats gone out of the box and the horse is slobbering at the mouth and coughing, and if you watch him for a few minutes he will be noticed to gag and and draw the muscles of the neck stiff and bend the neck down as if he was trying to force it up out of his throat, tmen he will take violent fit of coughing for a few minures, and in some cases he will throw out it frothy substance probably mixed with a few oats. He will keep on doing this until he gets relief 
Treatment In some cases by drenching hlm with $\mathrm{naw}$ lloseed oil the oil will work around the oats and make it slippery and he will be able to cough It out or swallow it down. It is also well to hand rub him along the neck, which will sometimes help to start the oats down to the stomach. He generaily gets entirely over it in a few hours. After a few hours, if he has not got relief, it is then best to put a twitch on his nose, put a gag in his mouth, and pass a probang down his throat (the probang is a long tube used for relieving horses and cattle in choking); relieve him without using the probang if you can. It is advisable, after bringing a horse from pasture, when giving him his first feed of oats, to dampen it with water, as he is not so apt to choke when the oats are damp. After a horse has once choked he is more liable to choke again, and to prevent this, scatter his oats well, and have a few large, round stones put in the feed box so he cannot ge: a large mouthful at a tine. It is very seldom a horse will choke on any kiıd of fruit or vegetables, such as apples, potatoes and carruts, but if he does, use the above treatment.

\section{DILITATION OR ENLARGEMENT OF THE CESOPHAGUS.}

The Oesophagus is the name of the tube which carries the food from the gullet to the stomach.

Causes.-From choking which causes the tube to Lecome enlarged, forming a pouch or sack where the food often becomes lodged and causes symptoms of choking. region.

Symptoms. - This eniargement can be seen if in the neck

Treatment.-It can sometimes be relieved by rubbing on the enlargement with the hand, which causes the food to pass down into the stomach, thus relieving him. It also can be rolieved by drenching with raw linseed oil.

\section{SWELLING AROUND THE HEAD AND THROAT.}

This swelling is noticed around tine horse's head and throat just after he hats been iurned out to pasture for a few days, and looks very alarmingr when first noticed.

Causes. - It is caused by an incratsed flow of blood to the head when the animal hats his head to the ground and not being used to it.

Symptoms. - 1t is loose swelling around the jaws and throat of the horse. When you examine it, it is not at all painful, and the animal seems perfectly healthy in every other way. If the 
animal is brought In for a night, and is fed where he will hold up his head, the swelling will all disappear and will be all right In the morning.

Treatment.-In some cases he does not need any treatment at all, but if the animal's blood seems very bad it would be well to give him a few doses of the following :

Nitrate of Potash or Saltpetre.................... pound.

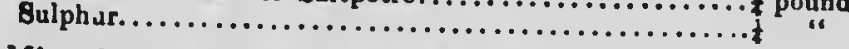

Mix thoroughly and give a tablespoonful in a little grain night and morning.

\section{CHAPTER IV.}

\section{DISEASES OF STOMACH AND BOWELS.}

The stomach of the horse is very small in proportion to that of other animals, and digestion takes place very quickly.

\section{ACUTE INDIGESTION.}

This is one of the most common diseases of the horse.

Causes.-If the horse is not used to being fed very heavy, and he gets a large feed of rich food, such as bran, oats or hay, it is apt to set up the disease; or eating wheat may bring on a bad case of it; it is sometimes caused by a horse being put to work too soon after a large meal. A change in the food will cause it, or even a change of work, such as a horse being used to the farm and then put on the road driving. When a horse is turned in on a field of clover, after a rain or frost, it is apt to bring on a bad case of indigestior.

Symptoms.-We will take a case as we often see it on a farm. The farmer intends to take a journey of fifteen or twenty miles, and the night before he gives the horse an extra good feed, and, if he is used to feeding on cut feed he will probably change the food to hay. The next morning he is up early and gives the horse another good feed before starting on his journey. The horse starts off lively, but after a few miles he becomes dull, oweats freely around the belly and chest, and is noticed to pass manure in small quantities, and in some cases he will even scour; if he is stopped he shows sierns of cramps or pains in his belly, and attempts to lie down, he looks around at his side, and when you examine him he is slightly bloated; as he is driven on, he becomes duller and more bloated, but finally reaches his 
fourney's end, and you can hardly unhitch him from the rig, ho bo in such pain. As soon as lie is taken into the stable he shows violent symptoms by laying down and trying to roll on his back, then he will jump to his feet, look at his flank, and again lie down, and sometimes he is nori-ed to paw first with one foot then the other, and keeps on repeating these symptoms until he gets relief; he perspires freely all over the body from the pain; tapping with your finger on his side it will produce a drum-like sound, showing that there is gas there. If you sound the stomach and bowels with the ear you will not hear much noise, any more than the tinkling of gas. $\mathrm{He}$ is noticed to pass gas per anus, which is a good sign. The heat of the body, the legs and ears are about natural. This is a good point to note, for in inflammation of the stomach or bowe s, the legs and ears are always cold and clammy, his pulse beats from 50 to 75 beats per minute, and beating moderately strong, whereas if there was inflammation it would be beating very strong and wiry ; he is also noticed to breathe heavy and quick, which is caused from the stomach being so distended with gas that it presses lieavy on the lungs. By placing your ear to the botton part of his neck yot will hear him belching wind. This disease generally takes from twelve to twenty-four hours to run its course. In some cases, where the disease is not so bad as the one mentionel, the symptoms will not be so distressing, he will be nuiced to leave his feed and commence pawing, then lie down quiet, probably for a few minutes, then get upon his feet again, take a few bites of feed, paw, and lie down again. In some cases he will seem easy for a few minutes, when the pain comes on again. If you examine his bowels you will hear them working pretty well, but will hear gas passing through them. The pulse will not be changed mucl, probably 5 or 10 beats faster than they should he, and the heat of the body, and of the ears and legs will be abr tuial. In a case of this kind, if the animal does not get reliet he will probably show these symptoms for clays, or even a week, before the syinptoms will get worse. It is not well to allow the animal to suffer too long if he does not get relief himself.

Treatment.-This disease is found more in heavy horses than in light, and also is more fatal in the heavy liorse. In some cases, where the animal does not get relief in this disease, it will terminate in rupture of the stomach, or inflammation. If you are driving 
or working the anlmal, the first thing to be done ls to stop working him and get him to the stable as soon as possible and treat him as soon as you can. Give him the following:

Ppirite of Tnrpentine............. on once or tableopoonfule

Raw Liaseed Oil..................

Mix, shake well and give as a drench. Give an injection of half a pail of luke-warm water and a little soap, with a teaspoon. ful of turpentine in it. Have his belly well hand rubled and apply a mustard plaster. Half pound of mustard, four tablespoonfuls of flour and enough vinegar to make it into a paste, apply this well over the stomach-also clothe the body according to the season of the year, and do not ailow the animal anything to eat till he gets relief, for it will only make him worse. In bad cases it is best to have some person stay with the animal to ke-p him from hurting himself in rolling about; also keep the animai quiet as you can, and never, in any case, run him or keep him walking around the yard, for it is best to keep him quiet as you can. If he does not get relief from the above dose in an hour
and a half, give him the followir $\cdots$

Bitter Aloes.

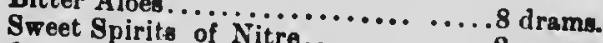

Ginger................... ounces or 8 tableaf oonfuh

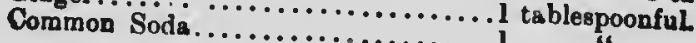

Dissolve in a pint of luke warm water, shake well and give as a drench. If he does not get relief in two hours after this following :

Sweet Spirits of Nitre

Ginger .................. I ounce or 4 tablespoonfalk

Common Soda..................... I tablespoonful.

Dissolve in a pint of warm water and give as a drench every two hours. Also give an injection every couple of hours, and have the belly and legs well hand rubbed.

In severe cases take a half pail of salt, heat mell and put in grain bag, tie half way down, and place it over the a back, then cover him up with this changed by more hot salt evanket to keep the heat in ; keep to keep down the pain and keep

In a case where the horse inflammation from setting in. from work and give him the following slightiy affected, take him 


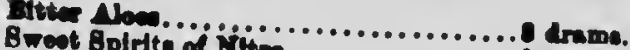

Common 8 ods ...

Ginger ..............................

Dissolve in a pint of warm

follow up with the following drench:

Sweet Spirit of Nitre...

Common Boda..................... il onnee or t tablespoonfule

Gloger. .1

in a pint of wa...........

four hours in a pint of warm water and give as a drench every allow him to antil the animal is relieved. Blanket him well and worked off stand in the stable for a few days, till the physic is food, such in all cases, when he is recovering, feed on sof be will drink. water, as it . In all cases of stomach trouble, warm the drinking where the animal is him any goot to die, and the bloat good, he gradually keeps getting worse, begins to droop over bad and breathe very heavy, and his ears begin to beats per minute, If you examine the pulse, it is up to 90 or 100 not lie down so, and you can hardly feel it. The animal does much all over much, but walks around his box, trembling very cold as death approaches, legs, ears and nose gradually become clammy, and he will be notso the inside of his mouth is cold and something, but nothing noticed to strain, as if wanting to pass die. All through wate: in small quantities, but often. this symptom, for it is caused from You must not be misled by bowels pressing on the bladder. should bo well studied, for it te

\section{Roptons ar ID stomc.}

Ibie disenes is generally caued during the time the noimal is entoring from ac . indireation.

Causes.-A horee sufforing from acute Indlgestion, will, from the pain, scmetimes throw himself down on his side, and the become buing so distended a sollen with gas will cause it to

Symptoms. - The animal ..in be noticed all at once to become very bad-mucl worse than before-the pulse will get very quick and weak, he will perspire all over the body, and in a very short time will show symptoms of approuching death by his bowole and 
stomach becoming very much swoilen, mis legs, ears and nos will begin to get cold, which indicates approaching death, and the animal generally dies very quickly.

Treatment.-There is no treatment that will give him relief, but it is best to give the animal an ounce of tincture of laudanum to relieve his pain till he dies.

\section{CHRONIC INDIGESTION.}

This disease is sometimes called dyspepsia. This is quite a common disease among horses, especially about the time they are shedding their teeth.

Causes.-It may result from a disordered state of the bowels or liver, or from a young horse while shedding his teeth, not chewing his food properly, from being very high fed, from feeding dusty clover hay, and from irregular feeding and watering.

Symptoms. - The symptoms of this case is not alarming, the horse gradually falls off in condition and gets weak, sweats very easily while at work, his coat is dry and dusty, and he does not seem to have any ambition, his manure is of a dark clay color, he is sometimes attacked with little fits of colic or pains in the bowels, and he is noticed to be licking the walls and manger and seems to have a craving appetite.

Treatment.-Give him a change in reed and a dose of physic consisting of the following :

Bitter Aloes. ....................8 drama.

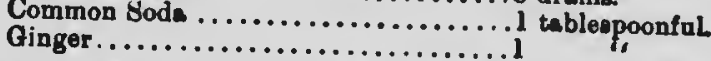

Mix in a pint of luke warm water and give as a drencb, allow the animal to stand In his stall in the stable until the physic passes off ; feed on soft food and follow up with the following mirture as a tonic for him :

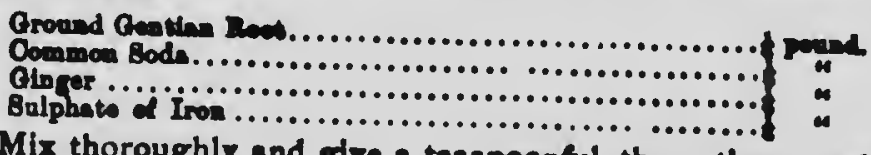

Mix thoroughly and give a teaspoonful thres thes a dry in hle feed or on his tongus with a spoon. This will bulld him up and start him to gain.

Bots.

These are found clinging to the inside of the stomach of the horse, and we have rarely ever examined a horse's stomach but what we found some in it. In some cases they are fourd in the numbers, and in these cases they injure the anings 
Causes. - Bots are caused by the bot-tly stinging and laying its eggs under the horse's head, neck and legs. These fies, whi' they are laying their eggs on the horse, seem to annoy him very much, and he will be seen to jerk his head as if they had stung him. These little eggs are taken into the horse's mouth by him biting and rubbing his legs with his mouth in the fall of the year. They pass from the mouth down into the stomach, where they lodge for the winter by hanging on to the lining membrane of the stomach and develop and grow until spring comes, when they will let go their hold, pass through the bowels and out with the manure, where they soon become developed into a regular bot-fly, and fly off to bother the hore during the summer. This is the way they reproduce.

Symptoms.-The horse will be noticed not to be doing well, and has a ravenous appetite, but the feed does not seem to do him much good. He will also be noticed to hold his head up and be moving and twisting his upper lip.

Treatment.-Give him the following mixture :

Raw Linseed Oil...................l pint.

Spirits of Turpentine.................... punce or t tablespoonfule

Shake :isll and give as a drench. Give this drench once a week until the animal seems relieved, allowing him to stand a day after each drench; also give him a teaspoonful of ground sulphate of iron in his feed twice day.

\section{DISEASES OF THE BOWELS:}

\section{Prsuone courc}

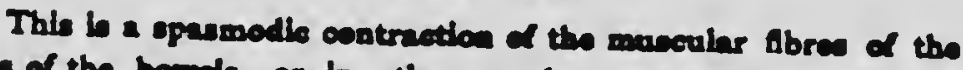

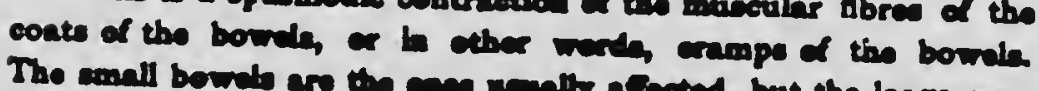
alf tht too, bo criveted

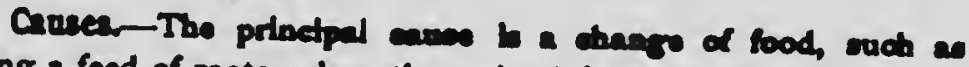
siving a feed of roote when the antinal bo bot uead to it, and oupecially when frozen, or a cold drink of watar whon the animal is hot Sometimes it comes on after giving the horse 4 physic. A sudden change in the weather vill wometimes bring it on. Some horses become, as it were, subjected to this disease, more sspecially if the stomach is not digesting the food properly. Although this disenes is very painful while it lasts, it is not very 
fatal, and usually passes of quickly. If not attended to, the chief danger is, that it will set up inflammation, which then becoines very serious.

Symptoms.-The attack come - on very quickly, in some cases the horse will begin to paw, cringe, iook at his side, and throw himself to the ground as if in great pain, will roll around and try to ${ }^{\circ}$ Vance himself on his back. If the weather is hot, he will sweat vory much. He may lie quiet for a few minutes, get up, and may appear all right, may eat some, then the pain will come on again, and act in the same manner. He will generally pass manure in small quantities, and also maire his water, which is a good sign. On putting your ear to his sicie, the bowels will be working juat about natural, excepi when severe pain comes on. The pulse, when he is at ease, is about natural, but when in pain, it beats vory much faster, probably 60 or 65 beats per minute, while in infiammation the pulse gradually goes up and stays up all the time. If you press on his bowels it seems to relieve him in colic, while in inflammation it gives him more pain. As a general thing it does not last very long probably two or three hours, although, in some cases, we have seen it last as long as ten or twolve boura, but the symptoms in that case would not be 20 severe.

Treatment-A student was once asked at a certain veterinary collene, what he would do if he were sent for in a case of this lind. He said "he would go es fast as he could for fear the case would be all over before he got there."

The favorite reanedy for colle is 8

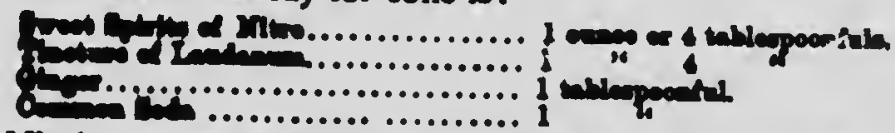

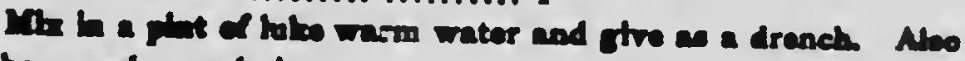
encher rood rundy lis

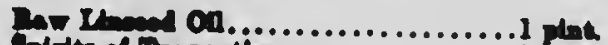

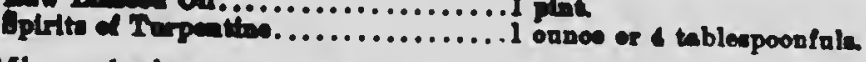

Mlx and give as a drench. Another good remedy is:

Floming's Iloture of $\Delta$ conite .................10 drops. ,

Whiky.................................... I wineglaksful.

Mix In a plot of luke warm water or beer and give as a drench. In cases of this kind it is best to have some person stay with the enimal for fear he would get cast on his back or hurt him. ilf. In evvere eace have the bally well hand rubbed, and have clothe 


\section{DIHEAgEG AND TREATYENT UF THE HURSE.}

wrung out of hot water applied to the belly, or you may hnd good results from a inustard plaster applled over the bowels. Any of the above drenches, except the oi ana turpentine, may be given every hour until the animal gets relief. After the animal has got over the pain, to get rid of the irritation in the buwels, or whatever has caused it, give a dose of physic consisting of:

Bitter Aloes.............................. 8 dram.

Ginger $\ldots$.

Mix in pint of luke warm water and give as a drench.

In each of the drenches mentioned it ls well to put in a tab' spoonful of ginger and common soda.

WIID OR FLATULENT COLIC.

This ard acute indigestion are a greit deal the same. The rtomach is generally affected in this disease as well as in indigestion.

Causes. - This disease is caused from a derangement of the digestive organs, and the food in the bowels forms gas which fills the bowels and causes extreme pain while it lasts; but in the majority of cases it is caused from a change of some kind in the food, and is als. found chiefly in aged horses.

Symptoms.-The symptoms of this disease resemble acute Indigestion somewhat, only that the gas is formed in the larke bowels instead of the stomach. The aninal lays down and rolis, the belly becomes bloated with gas, and if you notice there will be no belching of wind from the stomach as there is in acute indigestion.

Treatment.-Give injections freely of one-half pail of luke warm water, a little soap and a tablespounful of turpentine, an. for a drench give:

Spirits of Turpentine............1 th ouncen or 6 tables zoonfuls.

Tincture of Laudanum............... "f ou

Kaw linseed Oil .............. pine.

Common Soda.................

Shake well together and give as a drench, and follow up witb the following drench:

Sweet Spirits of Nitre............ I ounce or \& toblespono ile

Ginger ....................... I trablespoon u $^{\prime}$

Mix in a pint of luke warm water and give every hour untll the horse gets relief. It is best in this case to have someone to stop with the animal to keep him from hurting himself or frum getting 
cast. Hand-rub the belly well, itn' in severe cases apply a mustard plaster to the bowels, and aho have one-half pail of hot ealt II a bag placed orer the animal's kidneys; this will have a tel dency to move the gas in the bowels and helps to keep down inflammation. After the animal has been relieved, if it has been a bad case, it is best to follow up with a dose of plysic, con. elsting of :

Bitter Alues ..............................8 drams.

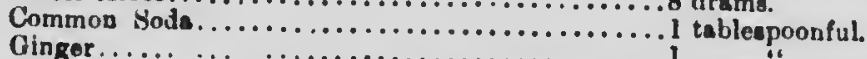

Dissolve in a pint of luke warm water and give as a drench, and allow him to stand in the stable the next day. Feed on soft, light feed. This will generally prevent him from having another attack of colic.

\section{INFLAMMATION OP THE BOWELS (ENTERITIS.)}

This is a very common disease in the horse and is, perhaps, one of the most fatal.

Causes. - The disease sumetimes follows a severe case of colic, where tine animal does not soon get relief. It may be caused from sating food which has clay or sancl in it, which causes an irritation of the bowels. Eating pea straw will cause the disease sometimes; drinking staguant water, exposure to cold after a long, exhausting drive, the animal getting a chill which rushes the blood in upon the bowels and sets up congestion, whic. is followed by inflammation.

Sympioms.-The horse is attacked very suddenly, begins to tremble, paws with one foot and then with the other, and turns the head around to the side, cringes and lies down, and does not get a minute's ease as he does in colli, but will get up, walk around, look: at his side, and if his pulse is taken at this stage of the disease, it will be found about 45 beats per minute, full and bounding. His legrs and ears will !: hotte- ".an natura!. He passte talibure in sinall quantities, which luuns slimy. The pain kecp (iil increasing, the symptoms get worse, and he does not get a linute's $p \cdot: \cdot \cdot$; his pulse is up to about 75 beats, and it is still tu!l and boum.!ing and does not vary as it does in colic, but kecp: I. hy hiritier as the diseisse advances. He sweats freely, altl ti.. " in in his eyes becomes very much reddened and angry looking : ', ers and ears change from hot to cold, and the pain keeps on lucinilitg. At this stage his ears begin to lop over and 


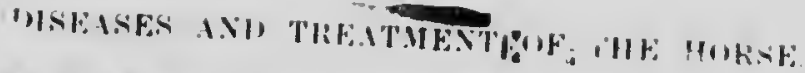

ho gets very nagbard look on hle face, as If in extreme agony. After a few hours he is a pitying sight to see. If you sound his bowels at this stage there is not the slightest $n$ vement to be heard, only a jerking and trembling all through his insides. He begins 10 breathe heavy, and his ears and legr have a cold, clammy feeling. He keeps on in rery great pain, him: down, getting up, and walking around his box, and, if seen to make water, it will be red and bloody lowking, and if there is any passage from the bowels, it will be mostly slime. If he does not gret relief in the course of eight or ten hours, mortificatior then sets in, and the animai becomes quiet and casy, but he ..l keeps sweating and breathing heavy, and in some cases will try to eat and once in a while he will be noticed to walk around his box. In this stage he does net lie down. The surface of his body, his ears, his nose, his lips and legs get colder and have a death-like feeling. If you take his pulso now, It will be up to 100 heats per minute, and so weak you can hardly feel it, showing that his heart is just fluttering, and that was all; the haggard look on his face becomes more marked; he will be noticed to strain a few times, as if trying to pass something, but nothing comes. He will keep on his feet a lung as he can, but will tinally stagger, fall and die. This disea: Eenerally rune a course of from 10 to 16 hours, but in some case we have known them to live as long as two or three days, where there was not much of the bowels affected.

Treatment.-This disease, if taken as soon as the animal is noticed sick, may be sometimes cured, but the treatment must be quick and careful, for, if the diseave ouce gets a couple of houre the start, it is then a hopeless caso. Give the following :

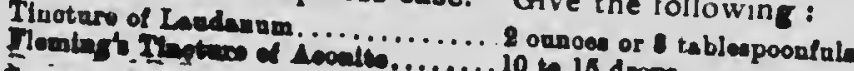

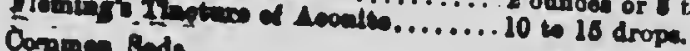

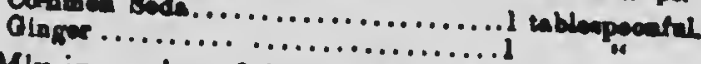

Mlx in a pint of luke warm water,

and give as a drench. mation. This drench the pain and try and check the inflammay be repeated every hour until the animal woolen blankets, wrung of heat to the body in the form of large and hall pail of hot salt in of hot water and held up to t: belly, after rou are through using grain bag to the back. In every case, plaster, consisting of :

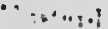

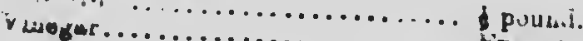

Sinough to make it like pares 
Rub thls well over the belly. Do not give any physic or injection in a case of this kind, for they only irritate the bowels and make the case worse. It is always best to keep the bowels quiet in this disease. IVhere the animal is in high condition it is well to take a half pail of blood, if in the first staure of the disease, but if you do this, do not give so much aconite. If the animal gets relief, it is best to feed him on soft feed with flax seed in it, which has a soothing effect on the bowels. The horse's bowels will be found, after death, to be black and thickened and full of watery fluid.

\section{CONSTIPATION OF THE BOWELS.}

This is where the bowels become sluggish and loaded with food and manure.

Causes.-This disease is often a syınptom of another disease, as in liver trouble, or where the stomach is not doing its work properly. It also may come after distemper or influenza, where the bowels become weak and cannot do their work; also paralysis of the bowels, where the bowels are paralyzed; sometimes from eating over ripe and inferior food, such as pist strilw or barley straw. In some cases it is caused from a large tumor growing on the inside and pressing on the bowels, not allowing them to act.

Symptoms.-There will be very little manure pass, and what comes will be in little hard balls. The animal will look unnaturally full and show signs of pain, but not much. IIe is sometimes noticed to lie down and roll, and look around at his sides. His pulse is not much changed, and when listening at his sicle there will be very little movement in the bowels. He does not ent much and looks dull and dumpy, and his water is of a thick, yeilow color. If you examine his rectum or back bowel by oiling your hand and passing it in through the anus, which ean be eanily done without any danger, you will find it full of hard, dry minure.

Treatment. - To start with give him a good dose of plyysic, consisting of :

Bitter Alues....................8 to 10 drams.

Bweet Spirits of Nitre.............. I ounce ol 4 tablesponnfuls.

Powdered Nux Vomich .............. I teasponful.

Mix in a pint of luke warm water and give as a drusch, then follow up with the lollowing drenches:

Sweet Spirits of Nitre........... Innce or 4 tablespoonfula

Powdererl Nux Vomica.............. l leasponnful.

Common suda $\ldots \ldots \ldots \ldots \ldots \ldots \ldots \ldots \ldots$ i tablespoouful. 
Mix in a pint of luke warm water and give as a drench every five or six hours until relieved of the pain. Twenty-four bours after you give him the drench with the aloes in it. If the bowels have not begun to move, follow up with a drench of one pint of raw linseed oil. Clein the mitnure from the rectum or back bowel with your hand twice a day, and grive an injection of one half pail of luke warm water and a little soap. After the pain is relieved, and the bowels working, it is well to follow up with the following powders :

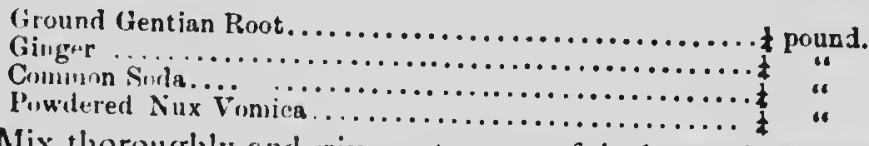

Mix thoroughly and grive a teaspoonful three times a day in his feed. The powders will strengrhen and tone the bowels and start the animal to thrive. Feed the animal on soft feed with plenty of flax sead in it, which will have a good effect on the weak bowels. In cases of constipation, where the physic does not seem to be acting right, a little exercise will often start it to work.

\section{DIARRHCEA.}

This is the very opposite to constipation, and is a disease where the animal passes a large amount of fluid manure, which is due to the congested state of the bowels, and is seen most in horses of weak confirmation, as narrow chested and gaunt looking horses.

Causes.-Where the animal gets a few feeds of rich food after being used to poor food for a length of time. Sometimes from a feed of roots, such as turnips and carrots, especially if they are frozen. Also drinking stagnant water, which acts as a blood poison; and we sometimes lave very bad cases caused by an animal feeding on a sandy pasture, where the grass is short, and in grazing the short grass takes up sand with it which causes an irritation of the bowels. An over dose of physic medicine will cause this, and when it is thus caused the diarrhoa is called superpurgation. Diarrhcea is a disease very easily treated, as a general thing, that is if the animal is in a healthy, strong condition. It is sometimes seen in nervous horses when they are put in races and get excited. It is also noticed in excitable road horses. In these cases it is due to excitement.

Symptoms.-This disease is very easily told. The animal passes a lot of watery looking manure. If you examine the pulse it will not be much affected at first, but if the disease is allowed 
to run on it will become quick and weak. The animal does not eat. and becomes very gaunt and wiak looking, and if allowed to run 'n the legs will become colder than natural; after a time there will be sligrlit pains, caused by the irritation and spasms in the bowels. When the animal berrins to get in pain-if he is not soon relieved-the disease begins to get more serious, for the congested state of the bowels would soon run on to inflammation of the bowels.

Treatment. - In many cases all you have to do is to change the food, clothe the body according to the season of the year and give a little medicine. Endeavor to find out the cause of the trouble, and if it is causei by some irritation in the bowels, such as irritat. ing food or sand, then give the following :

Raw Linseed Oil ................t pint.

Tincture of Laudanum...............

Common Sodi................... I tablesponful.

Mix and give as a drench. In this case give the drench to assist nature in throwing off the cause of the disease. Where the disease is not caused from an irritation of that kind give the following :

Tincture of Catechu.............. ounce, or 4 tablespoonful.

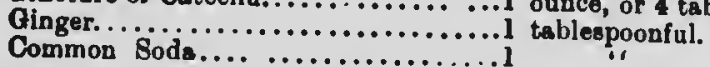

Mix in a pint of coffee about the same strength as what is used at the table and give as a drench, repeat the drench every four or five hours until the animal has relief. The animal will be very dry ; give him the water luke warm, in small quantities, but often, and in the water mix a handful of flour. Feed him on dry feed and keep him quiet. In severe cases it is well to apply a mustard plaster over the bowels and put a half pail of hot salt in a bag and place it over the kidneys.

\section{DIARRHOEA IN YOUNG ANIMALS.}

Causes.-The causes of this disease in young animals are generally exposure to cold, or where the mother's milk is either too rich or too poor, or where the young animal is allowed to lie out on the dimp yround in the spring or fall of the year. This chills the boweis and its up diarrhcea, or in some cases where the mother is workingr hiard and becomes heated and the foal drinks a large
amount of the hot milk. 
Symptoms.-He wili pass a large amount of flum nanure, which will stick around his legs and tail; and will become weak and sickly and very gaunt, and his coat will be staring.

Treatment.-It in a strong foal, give :

Cast or Oil ................... ounce, or 4 tablespoonfula.

Tincture of Laudanum................. 10 to 15 drops.

If the mother's milk is weak try and improve it by giving lots of nourishing food. If it is caused from drinking the milk from the mother when hot, always milk a little out before the foal gets to the maro. If this does not relieve him in five hours, follow up with

Tincture of Laudannm....10 to 20 drope.

Brandy or Whisky........ to to 1 ounce, or to 2 to tablonpoonfula.

Mix with some of the mother's milk and give as a drench three times a day. If in severe cases keep the foal warm and apply a light mustard plaster to his belly.

\section{BLOODY FLUX (DYSENTERY).}

This disease affects the lining of the large bowels, in which large ulcers are fcrmed, which bleed, causing the manure to be streaked with blood.

Causes.-Often from a severe attack of diarrhcea, from pasturing on wet, marshy lands, or from eating hay grown on such lands, or using impure water.

Symptoms. - The passages from the bowels are streaked with blood and have a bad smell; sometimes slime comes away with the manure. He does not feed much, and in some cases his appetite is entirely gone. The pulse will be at about 50 beats per minute and weak, and there will be colicky or cramping pains in the bowels.

Treatment.- This disease is in some cases not treated with success, and in bad cases is considered very serious. Give the following :

Raw Linseed Oil................. pint.

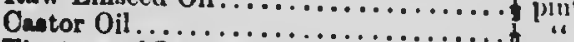

Tíncture of Laudanum................. onnce or 4 tablespoonfuls.

Mix, shake well, and give as a drench; then sllow up with the following drenches :

Tincture of Laudanum............. n nunce or 4 tahlespontale.

Tincture of Catech" $\ldots \ldots \ldots \ldots \ldots \ldots . \ldots \ldots$ " ounce or 4 tahlespont

Mix in a pint of luke warm water and give as a drench three times a day-morning, noon and night-until he gets relief. Slothe the body well, according to the season of the year; feed 
on soft fee! with hots of boiled linseded in it, and take the chill off his drinking water for a few diys. Aiter the first symptoms have passed off some, follow up with the following powder:

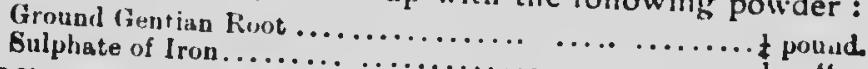

Mix well together, and give a tablespoonful twice a day.

TWIST IN THE BOWEL (VOLVULUS). met with.

This is not a very common disease, althougil sometimes it is

Causes.-It may be due to colic, when the animal is in very bad pain, and the bowels cramped, and the animal rolling about. It is generally noticed in young animals.

Symptoms. - It is very hard to be sure it is this disease, for the animal shows similar symptoms to inflammation of the bowels : there is no passage on account of the twist in the bowels; the animal is noticed to sit upon his t.iunches, and he sweats, and seems in great distress; the pulse runs up and gets weaker and weaker; he is generally slightly bloated, on account of no passage. In two or three hours the bowels, where the twist is, become inflamed and the animal stays in severe pain until he dies.

Treatment. - In a case where you are sure it is this disease, there is no treatment, except to relieve the pain by giving one ounce or four tablespoonfuls of laudanum every hour. If the animal is opened after he dies, there will be found a half hitch on the bowel and for about a foot or so on each side of the twist it will be black and inflamed.

\section{INTUSSUSCEPTION.}

This is where you have one part of the bowel to slip inside of the other. This disease is generally found in foals living on milk. Causes.-It is hard to say just what causes it, but it is supposed to be due in some cases to cramps in the bowels.

Symptoms.-They are similar to those of colic; the anima: will have pains for a few days, will not eat; the bowels do not work very well, and after a few days in some cases the part of the bowel that was slipped inside the other will begin to sluff and pass off in the manure, the bowel will heal and the animal will gradually recover. In cases where you suspect this, give to a
cood sized foal:

Raw Linaed Oil.................... tesoupful.

Tinnture of Ludinum.................. i dram, or 1 teappoonthl 


\section{DISEASES AND TREATMENT OF THE HURSE. 108}

Mlx ln some of the mother's milk and give as arench. The dose must be given in proportion to the size of the foal. After this follow up with the following :

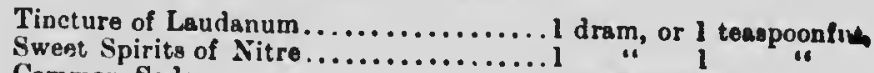

Common Soda........................ teasnoonful.

Ginger .................................... teasnoonf

Mix in a little of the mother's milk and give as a drench every four hours until the animal gets relief.

\section{BALLS FOUND IN THE BOWELS (CALCULI).}

They are chiefly made up of lime, and vary from the size of a marble to twenty pounds. They generally commence by the animal drinking or eating a piece of brass or iton, or anything which will have a tendency to collect the lime.

Causes.-Generally from feeding the sweepings of a mill floor, or such like. It may take the ball a long time to collect befcre it gets large enough to stop the passage, the balls are generally found in the large bowels.

Symptoms.-The first symptoms of this are, for a while, the animal is subjected to wind colic, which afterwards, sooner or later, as the ball gets larger, terminates in a complete stoppage of the bowels, which sets up inflammation and generally terminates in death from twenty-four to fo:ty-eight hours after the compiete stoppage in the bowels.

Treatment.-In a pure case of this kind nothing can he 'ane, only give doses of laudanum, 1 ounce or 4 tablespoon ry couple of hours to relieve the pain while the animal lives. In the first symptoms, give a good dose of physic, and $: n$ all cases where you suspect this disease it is best to examine the rectum or back bowel by oiling your hand and passing it into the rectum, and if you can feel the ball, remove it with your hand.

\section{RUPTURE OF THE RECTUM OR BACK BOWEL.}

This is a very serious injury, but in some cases they will recover, especially if the rupture ison the upper sile of the rectum.

Causes.-Are generally from some foreign substance, such as the shaft of a buggy in a runaway, or any other such cause, entering in at the anus into the back bowel and rupturing it. It has also leen caused from what is known as inal-audress. This is when the stallion, serving a mare, enters into the wrong passage. 
Symptoms are generally stoppage in the bowels, and alce bleeding from the anus after the stillion has served the mare, or if a shaft in a runaway, this will be plainly seen. You can tell the extent of the injury by oiling your hand and passing it into the rectum and examining it.

Treatment - In a case whare it was done from any substance, such as a stick or shaft, it is best to examine and see if there is any sliver or piece of the stick left in the wound, and if there is remove it and clean the mantre out of the rectum by passing your oiled hand up three or four times a day. After you have removed the manure give an injection of a little warm water and soap, which will have a soothing effect on the wound, and also help to keep the bowels regular. Feed on soft food, and only allow him to have a small amount of it, so as to keep the bowels empty as possible, without starviıg the animal, and give him the following

Raw Linseed Oil ................

Tincture of Laudani $i \ldots \ldots \ldots \ldots \ldots \ldots . . .1$ pint.

Mix and give as a drench. After this, if the animal seems in pain, it is well to follow up with 1 ounce or 4 tablespoonful drenches of laudanum every four hours in a little luke warm water. If the animal is very fleshy, it is well to give five to ten drops of Fleming's tincture of aconite to keep down inflammation.

TUMORS OR ABSCESSES IN THE RECTUM OR BACK BOWEL.

This disease is not very common.

Causes.--When the bowels are costive it has a tendency to cause this; or from rudely inserting the hand or an injection pipe.

Symptoms. - The svmptoms are noticed most at the time of making manure. He will be noticed to be in severe pain when passing anything, and in some cases he will lie down from the pain. If the tumor or abscess is large you will notice the animal straining, but pass nothing.

Treatment. - If it is an abscess, and you think there is matter in it by feeling it, take a small knife or lince and pierce it, allowing the matter to escups. If it is a tumor, and can be got at, then remove it with a knife by cutting it out. In some cases the ecraseur (which is an instrument with a chain that squeezes it off) comes in very useful in removing tumors here. The after treatment is giving raw linseed cil, and feeding boiled flax seed in the feed to keep the bowels loose. 


\section{PROTRUSION OF THE RECTUM OR BACK BOWEL.}

This is often met with and is a miserable 'ooking sight, eupecially if it is left out long and it becomes swollen.

Causes,-From a horse jumping a fence and yetting caught and lying on his belly half over the fence; or in cases where the animal gets very much bloated, as in wind colic or acute in-igestion, and the bowels get pressed out. It has been seen in cases of diarrhoea, and one great cause of this is constipation of the bowels, where the animal strains to pass manure and, in so doing, turns the rectum out. It is turued out sometimes when the mare is foaling, and sometimes in castrating an old stallion, where he forces very much.

Symptoms. - You will see from three or four inches, and, in some cases, two feet of the bowel.

Treatment. - Wash the bowel well with luke warm water, and then place a twitch on the horse's nose and have one of his front legs held up so he cannot kick; have the tail held out of the road, then take sweet oil and oil 're bowel all over; commence returning the bowel at the anus, as you have to turn the bowel inside out; shove the parts well back in with the hand and arm, and have someoise to hold his tail down tight for an hour or so until he quits forcing, after the bowel is replaced. It is also well to have his hind end raised, by rneans of straw or boards uncler his hind feet. Give the following dose of medicine to work on his bowels and relieve the pain :

Raw Linseed Oil.................. pint.

Tincture of Laulanum.................

Shake well together and give as a drench. Feed the horse on soft feed $::$ n lots of boiled linseed in it to keep the bowels loose. If the case is caused by constipation of the bowels, give :

Bitter Aloes............................. 8 drams.

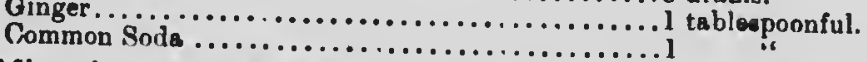

Mix with a pint of luke warm water and give as a drench.

\section{PERITONITIS.}

This is inflamnation of the serous membrane fo:!nd lining the inside of the belly and over the outside of the bowels.

Causes.- It is yenerally caused from exposure to cold after some veakeninis disease. This disease is also noticed to cume after the colt has been castrated and he has been ieft out in a cold rain or walked through a river when warm after castration, 
or left standing in a cold east wind. It may also be caused from the belly being bruised.

Symptoms. - The animal will be noticed to bo in slight pain, will lie down, stretch himself out and moan, sweat freely if the weather is warm, then get up and move around and seems very weak, hreatlies very heavy, almost as heavy as in a casc of inflammation of the lungs. The pulse runs up to 70 or 80 beats per minute. If he is not soon relieved his legs and ears become cold; his ears lop over, and he seems very weak-hardly able to get up wlien he is down. By listening with your ear to his side you will find his bowals do not work very much, and if you press over the bowels it causes him pain. The animal refuses food, and, in some cases, the mancie will have a very glossy appearance.

Treatment.-Give the following :

Haw Linseed Oil.................1 pint.

Tincture of Laudanum.............. punce, or 4 tablespoonfal

Fleming's Tincture of Asonito.........5 to 10 drops.

Mix and give as a drench. Apply lots of heat to the belly in the form of woolen blankets wrung out of hot water, and foiiow up afterwards with a mustard plaster over the bowe!s, and a half pail of hot salt in a bag over his back. Feed on soft tood with lots of flaxseed in it to keep his bowels regular. After the first drench, if the pain is not relieved, follow up with the following drench :

iincture of Laudanum $\ldots \ldots \ldots \ldots \ldots \ldots 1$ ounce, or 4 tablespoonful.

Fleming's Tincture of Aconito........5 to 10 drops.

Mix in a pint of luke-warm water and give every two hours until the pain is relieved. Sometimes this disease is followed by dropsy or a collection of water in the belly.

\section{DROPSY OF THE BELLY.}

This is a collection of a watery fluid in be beliy sround the bowels, and is generally the result of inflar nation of the membrane mentioned above.

Symptoms.-The animal is very weak, the pulse quick and weak, the micles of the body soft and flabby, the belly looks swollen, and : ! ou press on it you can tell it is cansed by some fluid inside. The bowels are constipated, but in some cases of this disease the animal will eat pretty well.

Treament. -Give renedies that will tend to absorb the fluid, encourage his appetite by giving him lots of good food to wh Give the following : 
Iodlde of Potanstum. .......................... pouad.

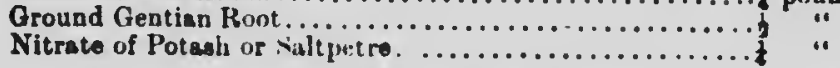

Mix thorou ihly together and give a tablespoonful three times ay. Give the animal a little exercise every day. It is recommended in bad cases to tap the lower part of the belly with a trocar and cannula, but this operation does not prove very successful in the horse.

\section{BORSE EATING TOO MUCB WBEAT.}

This is a very dangerous thing, especially if the horse is not used to getting wheat and eats a quantity of it. The wheat swells and forms gas in his stomaclı and after a time gets like dough which sets up acute indigestion and often terminates in a case of acute founder.

Treatment.-As soon as you have found out the horse has eaten wheat, do not let him have any water or feed to eat for twenty-four hours and keep him quiet, after that give him plenty of luke warm water and soft feed. If acute indigestion is set up, give the treatment given for acute indigestion; if it turns to founder, give treatment given for acute founder.

\section{LONG ROUND WORMS (LUMBRICI).}

Symptoms. - The animal will not do well, will fall off in condition, and every once in a while will pass some long, round worms in his manure. Sometimes when they are in large quantities they will set up spells of colic, and we have known cases where they form a ball in the small bowels and stop the passage, killing the nnimal.

Treatment.-Get rid of the worms by giving :

Raw Linseed Oil................. pint.

Spirits Turpentine ................

Mix and give as a drench once a week. As well as this give a teaspoonful of sulphate of iron in lis feed twice a day. This is the best remedy known for the worms.

PIN WORMS.

These are short, fine worms about an inch or two long and only affect the rectum or back bowel.

Symptoms.-The horse generally feeds well, but will fall off in condition. His coat will be dry and dusty; he will rub his tail and there will be a white, slimy stuff around the anus, 
Treatment - If the animal is in good condition, give a physic of

Commun Sod ............................... . 8 dram.

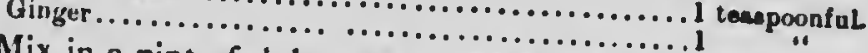

Mix in a pint of luke warm

warm water, and give as a drench. following :

the rectum with your hand and inject the

Quasuia Chipe

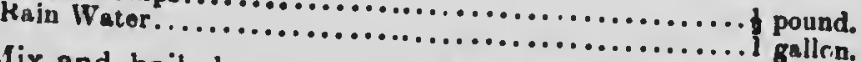

Mix and boil down to one half gallon, then strair off the chips and inject with a syringe. After the injectiun keep it in the rectum one half hour by holding the tail down. Clean the rectum out and give an injection once a week. This is a cheap and sure zure for them. Medicine given by the mouth will not do much good, for it will never reach the worms.

\section{CHAPTER V. \\ DISEASES OF THE LIVER AND SPLEEN. CONGESTION AND INFLAMMATION OF THE LIVER.}

These two diseases are so much alike, having the same causes, symptoms and $t$. 2tment, that we will treat them both
together.

Causes.-It is is:vally caused from feeding very high and getting little exercise, or an abscess in the liver will cause these diseases.

Symptoms. - The animal shows pain, looks around at his sides, lies down, but does not roll as he dces in bowel troubles. He will then get up and stand awhile, breathes heavy and quick, the pulse is quick and the bowels, as a general thing, are costive and the manure is black and slimy looking. The lining of the mouth and eyes are of a yellow color, similar to jaundice. Other ymptoms are that he will be lame in the off front leg; and his urine is green, resembling the bile of the liver.

Treatment.-If the animal is in good condition, give

Bitter Aloes....................8 8 drams.

Twoet Spirits of Nitre $\ldots \ldots \ldots \ldots \ldots$. ounce, or tablespoonfula.

Mix in a pint of luke warm water and give as a drench. Apply a mustard plaster well rubbed in on the under part of the the belly and clothe the body well, according to the season of the year. After this tollow up with the following medicine: 
Iodide of 1 vi..eterutn

Nitrate of Piriash it sill ......................... pound

Mix thorowghly lowether and give a teaspoonful three times a day in his feed or on his tongue with a $s r^{\cdots}$ n. In cases wher the cause is from highi feeding and little exticise, feed light, soft food and give regular exercise.

\section{TELLOWS (JAUNDICE.)}

This ls, perhaps, the most common disense of the liver.

Causes.-From inflammation of the liver, from gall stones stopping up the tube which leads from the liver to the bowels, from weakening diseases, such as influenzii or distemper, from an abscess forming in the liver or from any other disorder of the liver, where the bile is not taken from the blood.

Symptoms.-Th: bowels become constipated and the manure is of a dark clay color, the animal is dull and does not feed well, the lining of the mouth and around the eyes is of yellow color, from which 't gets the name, jaundice.

Treatment.-If it is in the spring of the year, by turning him out on the grass it will often effect a cure itself, if not, and the onimal is in fair condition, give

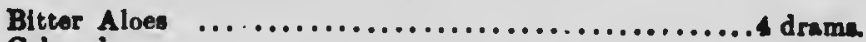

ralomol ........................................ dram.

Mix in a pint of luke warm water and give as a drench, or it is sometimes mixed in the form of a ball (as to how to make a ball refer to the receipts in the back of this book). After this follow up with the following powder:

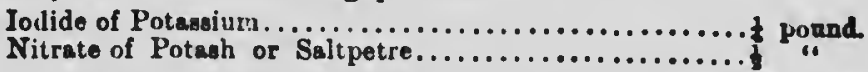

Mix together and give a teaspoonful three times a day. Feed the animal on soft, nourishing food, such as boiled oate, calded chop stuff and bran, with plenty of boiled flaxseed, and allow him gentle exercise every day, this will generally effect a cure.

\section{BILE STONES (BIHARY CALCOLI.)}

This disease is not so common in horses as it is In man, bat they may exist in graat numbers, and if they do they stop the low of the bile out of the liver and cause the bile to be abeortan

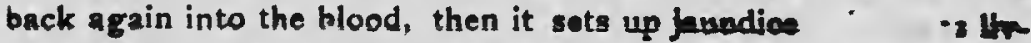
Ing high and taking little exerciss are liable wo stos won This ome rule holds good in horeec. 
Treatment.-Give either a pint of raw linseed oil, or $8 \mathrm{dram}$ of bitter aloes dissolved in a pint of luke warm water to physic the bowels, and give the following :

Diluted Hydrochloric Acid............. \& dram, or \& lemopoonfuL

Mix in a pint of water and give as a drench two or three times a day. Th. action of this acid is to dissolve the stones and get rid of them. Feed the horse light ar'l give regular exercise

\section{ENLARGEMENT OF THE LIVER (B YPER TROPHY)}

7 is usually seen in old horses, and is caused by faulty feeding. This disease is also seen in man, which is generally caused from taking intoxicating liquors.

Symptoms.-The animal falls off in condition, sometimes has diarrhoa, while again he is costive. This continues changing from onc to the other. There will also be yellowness of the lining of the mouth and eyes, and the animal will die a lingering death.

Treatment.-There is no cure, but it may be helped sometimes by regular feeding and regular exercise.

\section{INFLAMMATION OF THE SPLEEN.}

This disease is chiefly found in the southern parts of the United States, where it is very warm.

Causes are unknown.

Symptoms.-Similar to colic, the animal is dull and languld and has a tendency to hang the head and lop the ears. He will lie down and roll, get up, stand easy for a while, will not eat much, an i the pulse runs up and is quick and weak. This is a hard disease to form a positive opinion before death.

Treatment.- If you suspect it is inlammation of the spleen, give the following :

Raw Linneed Oil..................1 piut.

Tinot ure of Laudanum..................1 piut.

Shake well, and give as a drench. Apply a mus'ard piaster over the left side of the bally: opposite the stomach and spleen. Clothe the body well to keep him warm, and give the follow ing drenches :

Tincture of Laudanum............... ounce or 4 tablespounfil

Mix in a pint of water and give every two hour uatl the animal gets relief. 


\title{
Gurter vi.
}

\section{DISEASES OF THE URINARY ORGANS.}

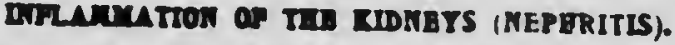 \\ Thlo disease is Alvided into two kinds--acuto infammation \\ and chroalc inflemmetion.
}

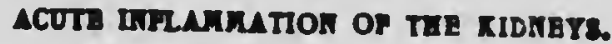

Cuses. Exposure to cold or standing out in cold rain atorms, such as wo have in the fall and spring; lying on the ground when It is cold and damp; by giving large quantities of medicine which acts on the kidneys; from carrying a heavy waight on the back; or In running horses, from violent exertion in racing.

Syr.jtoms. - The animal seems feverish, the puise is full and sunding and runs from 60 to 80 beats per minute, the moutb 6 hot and dry, he sweats freely und breathes heavy, he looks arousd to the sides, and, In some cases, puts his nose right upon the side opposite the kidneys; the animal will sometimes cringo and 110 down easy, stretch out, and will be heard moaning, as if in great distress; sometir.es he will lie for half an hour at a time, but wils lie quiet and will not try to roll on his back as he does in bowel diseases; also, by pressing over the loins it causes him more pain. If you listen at the bowels you do not hear much muvement or rumbling in them, and there is very little passage from tho bowe:c. He will try and make water often, but passes very littlo at a time, and it lo generaily of a red color and tinged with blood. If the animal doen not get relief after two or three daye, all the symptome gradually grow worea and when be trles to make wator bo paness nothing but Mnod; in this cane bo generally dies ba day or 20. Treatment. - The iroaiment must be qulck if you want to are the lle of the anional. Give the following drench ,

gar IInment unl

Tinotnes of 1 . ............. I plnk

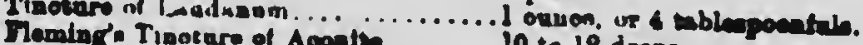

Ii Awate........10 to 12 drops.

Mix and give as a drench. Apply woolen blankow, wrum ax of hot water, over tho small of the back and cover mis ans dry biankets so as to keep the heat ia and anuse to when sweat. Always apply mustard plaster ever the blankets are taken off. It is also recommended to yity a

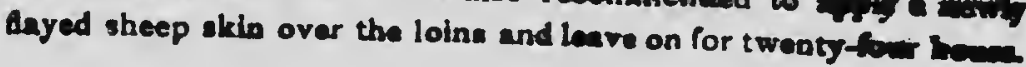


Keep hir: yusel ax you cusl and, wite: libe nret arenco, if ho dow not get reicf, follow up with tho following drench :

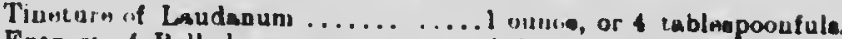

Extract if Belladonan................ dram, or 30 drope

Fleming's Tricture of Aconlto........ 10 dropa

Mix in a pint of luke warm water and give as a drench every two hours until the animal gets relief. Now, always remember in this disease never give any medicine to act on the kidneys, such as saltpetre or sweet spirits of nitre, for the kidneys should be left as quiet as possiblc. After the animal has relief give a teaspoonful of common soda in his feed three times 2 day. Feed on soft food with lots of boiled flaxseed mixed with it. If the bowels are very costive it is well to give injections; two or three times a day, of warm water and a little soap, which will help to regulate the bowels.

\section{CHRONIC LNFLAMMATION OF THE KIDNEYS.}

Causes.-This is caused by using too mucl medicine that has a stimulating effect on the kidneys, or from eating food that has a tendency to act on the kidneys, such as pea or oat straw.

Symptoms.- The horse is uneasy, lies down and gets up, stands with his hind legs spread apart, as far back as he can get them, and they aro generally swollen; his pulse is not much affected : he passes urine but in small quantities, sometimes quite natural and sometimes streaked with blood; he generally walks stiff, and by pressing on his back he wlll show signs of soreness.

Treatment.-Give a pint of raw linseed oil as a drench, and if there is much pain it is well to put in one ounce or four tablespoonfuls of Tincture of Laudanum and five drops of Fleming's Tincture of Aconite, fend on soft food with lots of boiled fiaxseed in It. and give him a cuapoonful of common soda throe times a day in his feod. Place half-pailful of hot salt in a bag over his kldneyn, keep this ahanged every hour until he gets relief. After he gete rellof glve him regular exercise and follow up with the following powders !

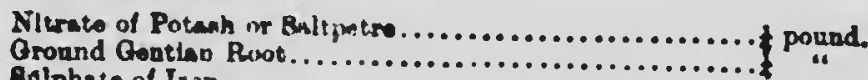

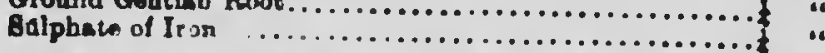

Mix and give a teaspoonful three tlmes a day in feed.

DLABTES.

Thls is where the food if converted lato sugar and passes of trough the kidney. 
DISEASES AND TREATMENT OF THE HORSE. :115

Cuuses-Are from a weakened state of the gytem following come weakening disesse, and it may also be caused from cating
musty feed.

Symptoms,- There is great thirst, the anlmal drinks large quantities of wator. In one case an animal was known to drink thirty-eight gallons of water in tive hours. The hores is dull, foeds poorly and passes an abundant amount of water or urine which is of a clear color; his cont looks dusty, and he becomes hide-bound, and he wlll gradually plne away tlll he dies.

Treatment-Change ble food, and if in summer time, let him have a run to grass; if In any other time of the year give him plenty of cooked feed, wuch as boiled ant or scalded chop stuff ; give him pure water to drink in amall quantities, but often, and give the following :

Tinoture of Iodine.................. dram, of $\$$ teaspoonful.

Mix in a pint of water, give once day for four or five days, until he seems better. After that follow up with the following
powders:

Sulphate of Iron.

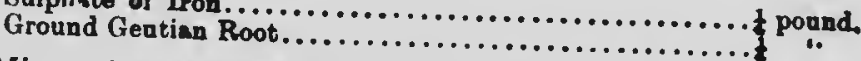

Mix and give a teaspoonful three times a day in his feed or on his tongue with a spoon.

\section{ISCTURIA.}

This is where the horse does not pase urine or water.

Causes.-From the kidneys not acting properly.

Symptoms-The hores will not pase any urine.

Treatment-Glve one ounce, or four tablespoonful doses of -weet spirite of altre thres times a day undl be makes watar, then follow up with the fallowiar powder

Crovad Genthen Rom.

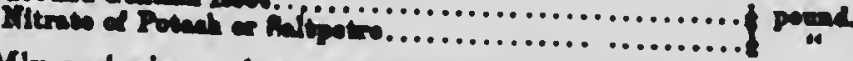

Mlx and cive a larese tonopoonful three those a day ha foed until the animal Is all rithe W. aleo bave the dlscase In another form, the kidneys secrete the urios or water all right, but it is held In the bladder:

Causes-Spasms or contractlon of the neck of the bladder, or calculi or bladder stones will cause it by working up into the neck of the passage, or sometimes from horse holding his water on accolunt of having no bedding under him, boing afraid of splashing his lea 
SJmptoms.-The animal attem;.u to urinate or make water often, but nothing comes; he groans with pain, stamps his hind foet, and will sometimes lie down and get up. In the horse you will notice him passing his penis in and out. In this case, if you are not just sure of it, oil your hand and pass it up into the back bowel or rectum, and by passing - . towards the bladder you will find it greatly distended with water.

Treatment.-If it is a case where the animal has no bedding under him, always shake straw under him, and give the following drench :

Tinoture of Landenam.

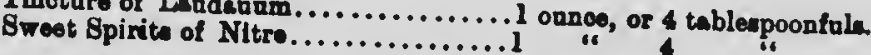

Mix in a pint of warm water and give as a drench. If after half an hour the horse is not relieved and makes water, you will have to take it away, which is very easily done in the mare; oil the hand and pass it in along the floor of the vulva about four inches, when you will feel a small hole on the under side. In some cases, by passing the finger about an inch into this hole, it will cause her to strain and she wil: make water. If this does not have the effect, then pass the catheter, which is a limber tube made for the purpose, down into the bladder. In the horse, take hold of the penis, enter the catheter in the hole in the penis and gently pass it up into the bladder and allow the urine to drain out through the catheter. Put a little sweet oil on the catheter before using it. Generally after taking the water away once it will be all right.

\section{INFLAMMATION OF TBE BLADDER (CYSTITIS).}

Causes. - The bladde is sometimes injured in difficult cases In foaling; Exposure to the weather, being out in cold rains, or lying on the damp ground.

Symptoms-The enimal wilts with a straddling gait, and makes water aften in small quantitien, which is sometimes streaked with blood.

Treatment.-Give the following :

Tincturs of Laudanum ..............1 ouncen \& \& tableppoonfals.

(n).............................. pint.

Mix and give as a drench. Apply heat over the small of the back in the form of a mustard plaster, also apply mustard around the back part of the belly. Keep the animal quiet and feed boiled iinseed to act on the bowels. After the first dose, if the animal has not relief in two hours, give the following drench : 
Tinoture of Laudanum.............1 oonow, or t tablenpocent

Fleming's Tincture of Aoonito................... 8 drops.

Mix in a pint of luke warm water and givo as a drench atro this drench every two or three hours until the animal seems relieved, and then give the foliowing powders 8

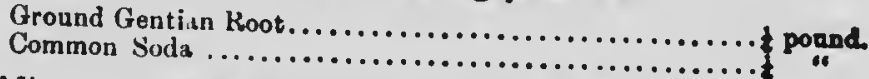

Mix and give a tablespoonful twice a day in his feed.

\section{STONES IN THE BLADDER (CALCULI).}

These ston. are found in the kidneys or in the tubes that lead down to the bladder, or in the bladder, or may be found in ' ' ube that leads out of the bladder, but they are mostly found i. .ne hladcler.

Causes. - Are generally from the kind of food and water tho animal uses, turnips being one of the worst, or drinking water that contains a great deal of lime.

Symptoms.-The animal is uneasy and has colicky pains. He will be in more pain just after passing water. In some cases where there are a number of these stones, the animal after making water will pass blood, and for a few times after this he may make water all risht, and then will pass blood again.

Treatment.-Give lots of soft feed with boiled linseed in it to loosen the bowels and give the following medicine :

Diluted Hydrochloric Acid ......................... dram.

Mix in a pint of water and give as a drench threc times a day. The action of this acid is to dissolve the stones. Continue the use of this until the animal is better.

\section{INVERSION OF THE BLADDER.}

This is only met with in mares, and generally at the time of foaling, when the mare is straining violently.

Symptoms.-In straining, the bladder becomes forced back and turns out through the tube, and hangs out of the vulva inside out.

Treatment - If it is noticed at the time it is done, before it becomes swollen and enlarged, it can generally be turned back to its place by pressing it in with the hands and fingers. After you have returned it, if the animal is in pain, give one ounce or four tablespoontuls of tincture of laudanum every two hours until the animal stop; straining and seems relieved. 


\section{DRBRLITA OF THE ORUNB OR WATER (ENORESIS).}

Causes.-Sometimes from an irritation of the bladder or from the neck of the bladder becoming paralyzed.

Symptoms.-The animal is noticed to have urine dribbling away from it all the time.

Treatment.-Give a teaspoonful of powjered nux vomica twice a day. If the animal's water seems thick it is well to give a teaspoonful of nitrate of potash or saltpetre once day in the feed.

\section{PARALYSIS OF THE BLADDER.}

Causes.-From a weakened state of the system or being exposed to the cold, and is noticed most in animals that are very poorly kept.

Symptoms.--In a pure case of this the urine or water is not passed on account of the bladder not being able to contract, and thus becomes very full, causing much pain. By oiling the hand and passing it in the back bowel or rectum and pressing it down you will find the bladder to be very full of water.

Treatment.-Draw the water off with a catheter (which is a limber tube made for the purpose) every night and morning and give the following :

Powdered Nux Vomica.

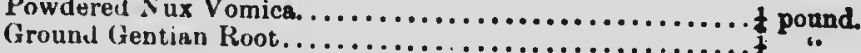

Mix thoroughly and give a teaspoonful three times ay in his feed until he has regrained the strength to pass urine.

\section{CHAPTER VII.}

\section{DISEASES OF THE GENITAL ORGANS OF THE HORSE.}

INFLAMUAIION OF THE TESTICLES.

Causes.-Are somutimes from a kick or blow of any kind, or from their swinging around and striking the legs in the trotting stallion. In some cilses they are bruised in lying down.

Symptons. - The smptoms are very plain, the horse seems in pain, and testicles become swollen and very sore to touch; he walks with a stiff, stritgyling grait and is generally noticed to stand.

Treatment.-Give physic drench, consisting of

Buter Alues..................8 lnitus.

Elemiug incture or Aconite.............. to 12 dropen.

Tincture of Laudautum................ ounce, or tablenpoonfule 
Mix in pint of luke warm water and give as a drench. Bathe the testicles with warm water and then apply a hot poultice to them, consisting of half linceed meal and bran. poultice can be held to its place by means of cords over his tacia. Change the poultice every two or three hours and keep hathing well with warm water. Also clothe the body well and, if he wishes to eat, give him plenty of soft feed with boiled flax seed in it. After the first drench, if he does not get relief, give him the following :

Tincture of Laudanum............ ounce, or $\$$ tablezponfuis.

Mix in a pint of luke varm water and give as a drench since times a day.

\section{DROPST OF THE SCROTUM, OR BAG (HYDROCELE).}

This is where there is a large amount of fluid collects in the scrotum and makes it look large and flabby.

Causes.-It often follows a case of inflammation of the testicles.

Treatment.-Give iodide of potassium-a teaspoonful twice a day in his feed. In some cases it is recommended to draw the fluid off by tapping the scrotum with a sinall trocar and cannula, but it is best to try and absorb it, anyway, by using medicines mentioned.

\section{INJURIES TO THE PENIS.}

Either in the stallion or in the gelding, by being kicked or struck with a whip or stick while the penis is out of the sheath, or it may be caused in the stallion by putting him to too many mares, or handling the penis rough, or sometimes from becoming frost bitten in very cold weather.

Symptoms. - The penis will be swollen and the animal wil! not be able tc draw it back into the sheath, it hangs out and, if sou press on it, it seems sore.

Treatment.-Bathe weil with warm water until the swelling seems to go down, also take a sinall pen-knife and tap the penis where it is swollen a few times and allow the water and blood to run out; this will often reduce the swellit 5 . After this, oil the penis and try and pass it back into the sheath. After the penis is put back, plug the opening of the sheath well with cotton batting, which generally hold. its plate for a faw hours a a time, thus giving the penis the lleat of the indy, which is very helpful to it. Bathe, oil, .. eplace tive puis two or three times a day until it regains its strength, and give the following : 


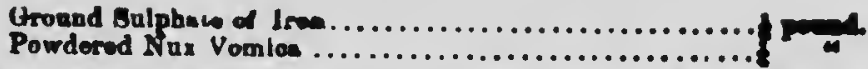

Mix and give a teaspoonful three times a day in his feed until the animal oan draw the penis back into the sheath himself.

\section{SWELLING OF THE SREATH.}

Canses.-This is generally caused from what is known as a dirty sheath, also from bad blood and disordered kidneys.

8 raptoms.- Swelling around the sheath and hind legs, his water or urine is thick and yellow.

Treatment.-Take warm water and soap and wash out the inside of the sheath and grease it with lard. Give the horse a phyaic ball, or drench, mentioned in the receipts at the back of this book, to elean him ont, and give the following powders :

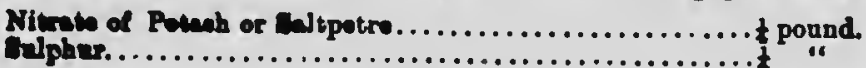

Mix thoroughly and give a teaspoonful three times a day in his foed. Give the horse a little exercise every day and the swelling will soon disappear.

\section{CROWTIS ON TEE END OF THE PENIS.}

These growths are of various kinds and prove very troublosome and painful when the animal is urinating or making water.

Causes.-It is hard to tell the cause, but sometimes from a olight injury not being treated the sore place will throw out arowth.

Treatment-If the growth is not very large wash it off with warm water and soap, then touch the parts with a stick of caustic potash, which will burn it; after the scab falls off, wash, and then burn again, repeat this until you have the growth entirely remored. Dress it every day until it is enticely healed with the white lotion.

\section{WARTS AROUND THE SHEATH.}

We frequently see warty growths around the sheath which can generally be got rid of by tying a small strong cord around the wart very tightly, which will stop the blood circulating; by leaving the string tied tightly the wart will soon drop off. This is the best way to romove them, if it can be done. Another very good method of removing them is to cut them off with a knife and burn the spot with a stick of caustic potash. Warts, as a conoral thing do not bleed much. 


\section{CHAPTIR VII.}

\section{DISEASES OF THE GENITAL ORGANS OF THE MARE.}

\section{DISEASBS OP THE OVARIES.}

Enlargement of the ovaries is the most common disease wo have to deal with in connection with the ovaries.

Causes.-The cause is not known.

Symptoms.-The animal is noticed to be very irritable, falls off in condition, and is continually in season, and if put to a horse does not get with foal, and this is one cause of a mare being bar ren.

Treatment.-If the mare is in good condition give her a physic drench consisting of the following :

Bitter Aloes............................. 8 to 10 dram.

Ginger.....................................1 thblonpoonful.

Common Soda..............................1

Mix in a pint of luke warm water ard give as a drench, allow the animal to stand in the stable a couple of days after the drench, and follow up with the following powder:

Iodide of Potasainm

Nitrete of Potash or Biltpotre........................ pound.

Mix thoroughly and give a teaspoonful throe times a day.

\section{WHITES (LEOCORREOBL,)}

This disease is met with mostly in old mares that are poor in condition and that have ceased to breed. There is a white glary sischarge from the vulva bohind, which looks like curdled milk. this discharge has a bad smell, the animal falls off in condition becoming thin and weak.

Treatment.-Oil your hand and pass it in behind with a cloth or sponge saturated with hot water and soap, wash out the passage thoroughly clean, or this can be done with an injection pump and several pails of luke warm water and wash it out that way. Aiter bathing, wash the womb with the following lotion :

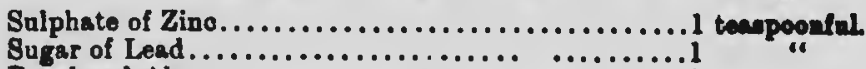

Powdered Alum.................................... "

Mix in a pint of luke warm water, and with a sponge rub the Inside of the womb with this lotion every second day till the dichurge stops, and give the following powders : 
Calphats of Coppor pound.

Balphate of Iron...

Mix and give a teaspoonful twice a day in her feed; feed her on rich food and give regular exercise, and, as a general thing, she will soon be all right. It is 8. very dangerous thing to put the mare to a horse while she has this disease, as the horse is apt to catch it. If she is, and the horse catches, it is called clap or zonorrhoea.

\section{CLAP (GONORRHCEA.)}

Causes.-From a horse being put to a mare that is diseased in some way.

Symptoms.-The horse's penis becomes sore and swollen, and there is a slight discharge of a mattery appearance. If the horse is put to the mare while in this way, he will give the disease to the mare he is put to.

Treatment.-See that the horse is put to no mares until he recovers from this disease. Wash the penis off with luke warm water and a little castile soap and dry with a soft, cotton cloth, then apply the following :

Sulphate of Zino......................2 dram, or 1 tomponful.

Dissolve in a pint and a half of luke warm water and shake well ; saturate the penis well with the lotion by the use of a songe. Bathe and apply every day for a week or so until the animal is all right. Also give the following powder:

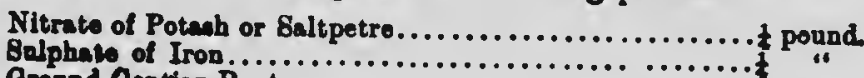

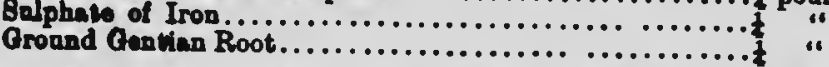

Mix and give a teaspoonful three times a day in his feed.

\section{BARRENNESS IN THE MARE.}

This is when the mare will not breed.

Causes.-From enlarged or diseased ovaries; from a contractlon or closure of the neck of the womb, or from the neck of the womb being twisted off to one side.

Symptoms.-The mare may be repeatedly put to the horse without becoming in foal.

Treatment.-In a case of this, examine the neck of the womb by passing your hand into the passage to the neck of the womb, and, if you find it contracted, or closed, open it by working your fingers around in it until it dilates or opens. If it is a $\mathrm{li}$. hard to dilate, eaturate a sponge with extract of belladonna an. arry 
che sponge into the neck of the womb with your hand and squeezo out the medicine around the neck of the womb. Leave the mare quiet for an hour after this, then pass in your hand and you will find that the medicine has relaxed the fibres in the neck of the womb and you can easily open it with your fingers. After the neck of the womb is dilated, or opened, put the mare to the horse, and you will generally find she gets in foal. If it is case where the neck of the womb is turned off to one side, try and straighten it with your hand and have the mare immediately put to the horse. If it is a case where the ovaries are diseased, there can be nothing done. Sometimes after you have put the mare to one horse several times, F.dd she does not get in foal, by changing the horse will often catch her. Mares will start to breed as young as two years old and will breed as old as twenty years. Some have been known to breed older than this.

\section{CHAPTER IX.}

\section{FOALING (PARTURITION) AND THE DISEASES FOLLOWING IT.}

The mare, after being put to the horse and gets in foal, usually carries her foal eleven months, but some vary a few days lens, while others may go as long as twelve months. The covering around the foal is called the cleaning, placenta, or after-birth, and is atlached to the inside of the womb to the little r-ocesses called villi, connecting the after-birtl, and the foal is the uavel string or umbilical cord. Between the foal and the after-birth is a fluid (the use of which is to protect the foal from being injured while its mother is moving around). This fluid is called the amoniotic fluid.

\section{HOW TO TELL WHEN A MARE IS WITH FOAL.}

The mare becomes quieter in disposition, and thrives better : the belly gradually becomes distended, and at the end of the sixth or seventh month, after the mare has taken a drink of cold water, the foal will move around. On account of the foal lying to the laft side, the moving of it can be noticed plainer on that side of the mare than it can be on the right side. Also, another way to tell is by oiling the hand and passing it into the passage and find out if the neck of the womb is sealed and tight. In some cases 
Yow can feel the foal in the womb, at the anme tlme you are exmining the neck. This is the surest method of telling, especially if the mare is only in foal a short time and it is very mall. During the time of carrying the foal the mare does not come in season every three weeks, although mares have been known to take the horse and still be with foal.

THE WAY TO USE A MARE WHEK WITH FOAL.

Keep her in her natural condition as nearly as possible. Feed fairly well, although it is not well to have her too fat. Kuep her out runing around every day if it is fine, so as to have good ezercise. It does not hurt a mare to work her as long as the work is light and steady, but never pull her too heavy or back her up suddenly, for mares often lose their foal by doing this.

\section{SIGKS OF IMMEDLTE FOALING.}

There is a falling away at each side of the tail very noticeable, and, as a general thing, wax or milk will run from the teats for a day or so before foaling. A few hours before foaling the mare seems to be very u:-sasy; labor pains come on, and with the pains she is noticed to strain. Very soon the water bag appears, and as it comes the pains become worse; she strains and lies down. If the foal is coming as it should, the head and front feet will make their appearance, after this the mare should be delivered of it in a very few minutes. If the mare has much difficulty, it is well to pull upon the legs while she is straining. Generally the cleaning comes away with the foal. The foal has known to be smothered when the cleaning comes away without being broken, so it is better for sumeone to be around during the time the mare is foaling, and if anything should occur like this, break the cleaning, or after-birth, and save the foal from smothering.

NAVEL STRING (UMBILICAL CORD).

If this cord does not break immediately after foaling, take a piece of cord and tie it very tightly one inch from the belly, then cut the navel string off an inch below where it is tied and leave the string on until it drops off; this is to keep it from bleeding.

TIE NATURAL WAY FOR THE FOAL TO COME.

The foal should come with front end first, $\cdots$ the front feet und bead coming together. 



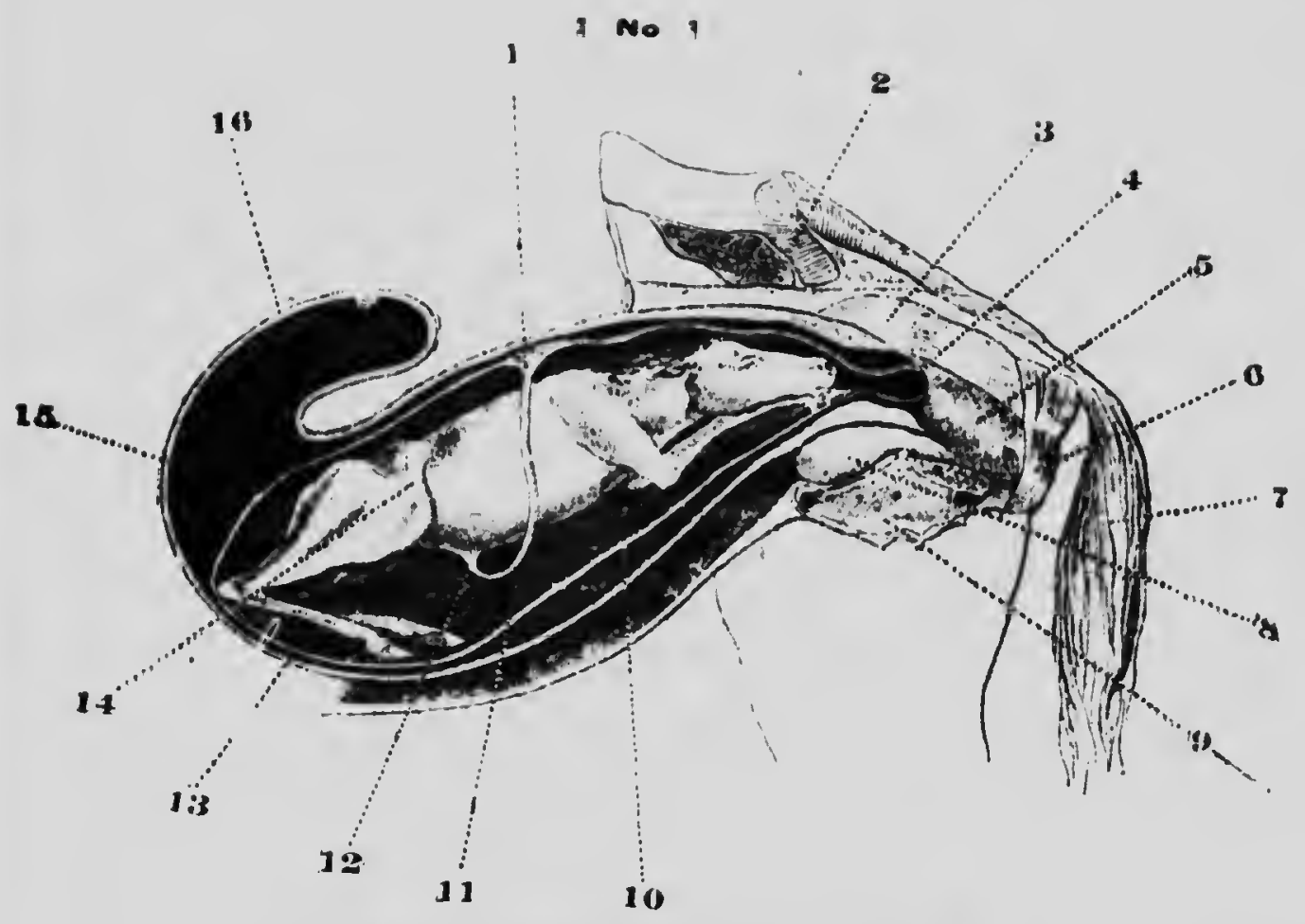

PLATE IV.-POSITION OF FOAl, IN WONB.

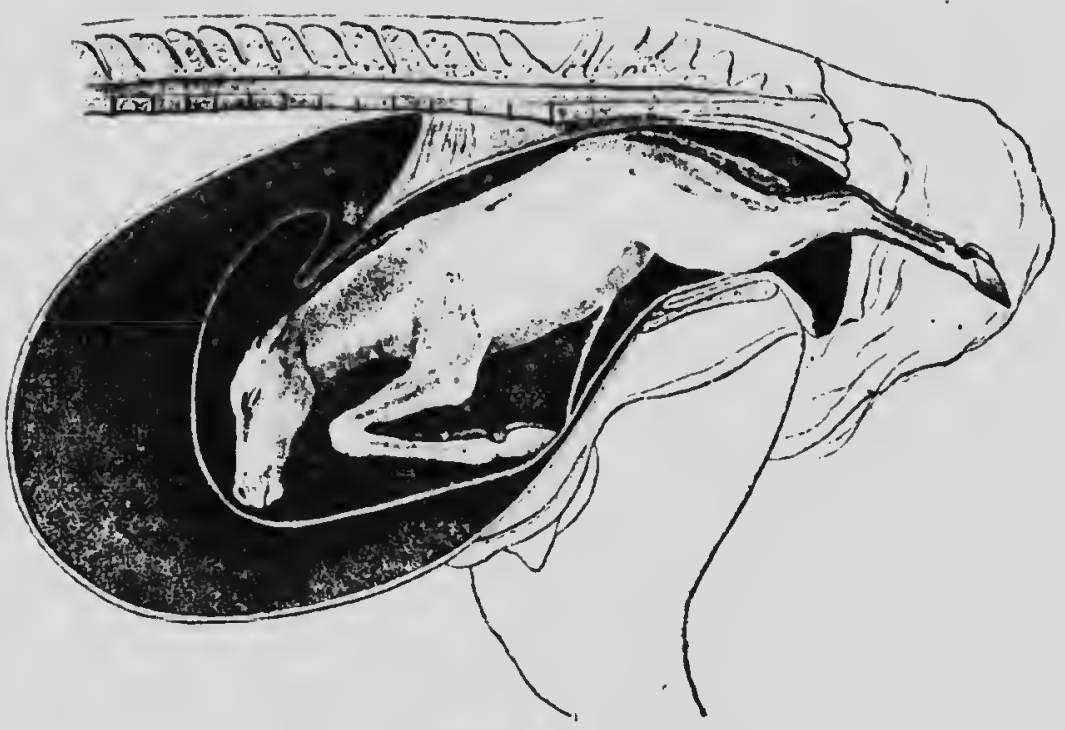

No. 2. 


\section{LXPLANATION OF PLATE IV.}

\section{MOSITION OF BOAL IN WOMB. \\ Ne. 1.}

Thls eut shows the natural position of the foal Iving in the womb, showing the natural way it should come our -froni aegs and head first-when the mare is foaling.

3. Navel string.

2. Rump bones.

3. Back buwel, or rectum.

4. Neck of womb.

5. Vagina, or passage out from womb.

6. Vulva.

7. Tail.

8. Bladder.

9. Mare's milk bag, or Mammary glands.
10. Cleaning, placenta or enerbirth.

11. Fluid, or water around the foal. This is what comes out wner

12. Navel. the water-bag brenks.

13. Womn.

14. Fosd, or fuetus.

15. Cleaning, placenta or afterbirth. 16. Womb.

\section{POSITION OF FOAL IN WOMB.}

No. 2.

This cut shows the position of what is known as a breech presentation; or, in other words, where the mare is foaling and the foal is comin 5 backwards. This is important to note, for ii a mare is foaling and the foal coming backwards, always straighten the hind legs out first, and the foal will come awas all right. When the foal is coming backwards, it is not wise to try to turn ith but bring it away as shown in this cut.

SPECIAL NOTICE. - Every place where Tablespoonful is mentioned in this book should read: SMaLl, or Deames TABLESPOONFul, which is equal to two Teaspoonfuls. 


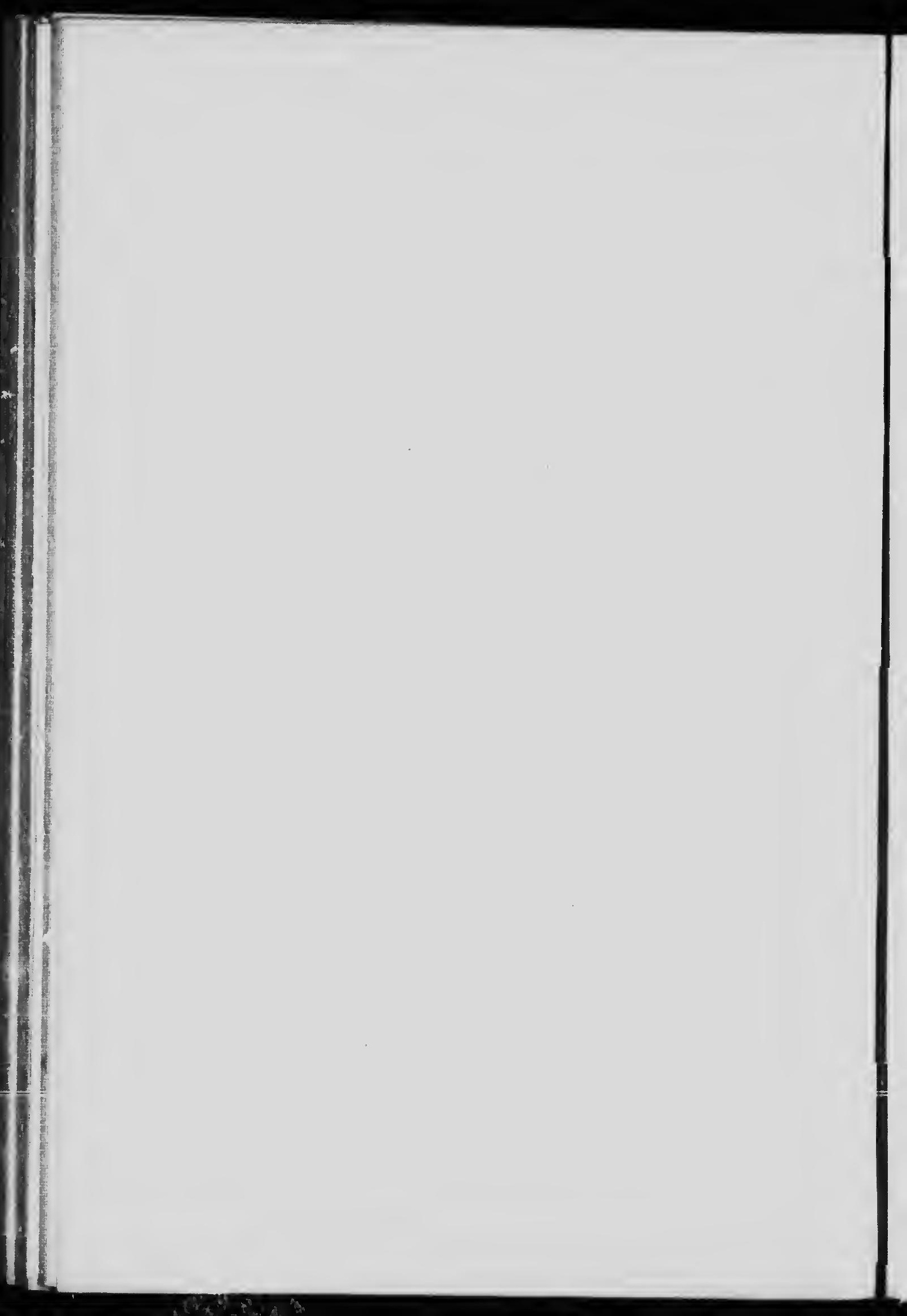


DIFITCULTIES MET :"TH II A MaK" FOALING.

Sometimes the labor pa $s$ inme on al d the mare wants to foal, but the neck of the woril :emains clr ied. In this case, oil your hand, enter it into the passage w the womb and, in some cases, you can open the neck of the womb rery easily by pressing it open with your fingers. If it is hard to open, saturate a sponge with extract of belladonna and rub it around the neck of the womb, leave it for a little while and you will soon find it easily opened. In a case where the front legs and head appear, and the foal does not seem to come any further with her straining, use gentle force by pulling on the legs and head, and if this does not bring the foal you may come to the conclusion there is something wrong. In this case, oil your arm, or take waum water and soap, so as to make your hand and arm slippery, shove the foal back into the womb and give it a thorough examination and find out what is wrong. If it is a case where there is dropsy of the belly (that is where the belly is swollen up with water), take a sharp knife and pass it back in (guarded by the hand so as not to injure the mare) to the foal's belly and then cut a small hole, large enough for the water to run out, start the legs and head again into the passage and she will soon foal if she is given a little assistance.

Sometimes the foal's head is enlarged with water on the brain. In this ease the foal will come out so far that only the legs and the point of the nose will be seen. After using a little force, and it will not come, shove the foal back and feel the state of the head. If it is onlarged take a harp knife and cut a hole in the softest part of the enlargement and allow the water to escape from the brain. Now, by glving the mare a little assistance, you will find it to come all right.

The foal may come in various positions. We sometime have a case where the head and one front leg comes out and the mare cannot foal. In this case shove the foal back and bring the leg that is not up, forward, and you will find she will foal all right. The front legs sometimes come without the head, the head being turned back. In this case shove the foal back, take small piece of rope, four or five feet long, make a noose and slip it over the foal's head onto his neck, have an assistant to pull on the rope while you use your arm and hand in helping to straightes. the neck and head, when this is straight, have the assistant to pull on the rope while you pull on the loge, and you will and in 
foal to come all right. Suinelimes the head and neck will come, and the front legs are turned back. In this case shove the foal well back and catch the front legs and bring them forward, then pull on the legs and the foal will come all right.

Sometimes its four legs will come together and the head turned bact. In this case shove the front legs back into the womb as far as you can with your hand and arm, and then bring the foal out backwards by pulling on the hind legs. Never, under any consideration, attempt to bring the foal head first in this case.

The foal sometimes comes backwards, and if the hind legs come out irst, the foal generally comes out all right. When the foal is coming backwards, and the legs do not come out as they sould, and you fool nothing but the tail, rump and hips of the foal, tho hind legs being turned in under, it is a rather difficult job, but it can be done all right by shoving the hind end of the loal upwards and towards the front of the womb, then slipping the hand down and getting hold of the foot of the hind leg and lifting upward and backward until you can bring the leg out into the passage, then reach down the band and get hold of the other leg and bring it out as you did the first one, then the foal will come away backwards all right.

As well as diferent positions, we meet with what are known e. deformities, or truks of nature. In cases of this kind, on coount of never mecting hardly two cases of the same kind, you will have to make a thorough examination and use your judgment w to the bent way of grting out, and act on the plans given in the difiernat positions.

In eace of having difficulty with twin foals always examine the ane thoroughly, and which ever foal is the nearest to the back deliver hlm irst, and as well as this, before pulling on the logs, always be sure you are not pulling on a leg of each foal. Ater dolivering the first foal the last one comes very easily. In any case where you have to shove the foal back into the womb it is well to raise the mare's hind end up by making her stand on manure or boards, as this has a tendency to help the foal to go forwards. Avoid using hooks and knives, as you are apt to injure the womb. It is always best to use your hands and pieces of fins ropo.

You may always make up your mind that if a mare is not dolivered of ner foal in half an hour, or thereabouts, after the water 
bag has come out that there is sonething wrong; for a nare, is everything is all right, foals in a very few nuinutes. It is best inen, to make an examination, and, if anything is wrong, fix it right away, for it is a great deal easier to do it ther th. . fter the mare has been sick a couple of hours. If aryything $\ldots$ is wrong is attended to at once you often save the mare's life as well as the life of the foal.

\section{TROUBLES AND DISEASES WHICH FOLLOW AFTER FOALING.}

\section{CLEANING PLACENTA OR AFTER-BIRTH.}

In some cases we find that the mare does not clean properly, and part of the cleaning remains attached to the inside of the womb, and it will be left hanging out behind.

Treatment.-Try the following medicine. Give har:

Raw Linseed Oil ................. pint.

Sweet Spirits of Nitre..............

Fluid Extract of Belladonna..........25 to 30 drops.

Shake well together and give as a drench and place a ha!:pail of hot salt in a $F$ 'ag over the kilney, also throw a blanket over this to ke: - heat, and keep the mire quiet for a few hours and she wi, .erally clean herselt "ild save th" bother of removing it with the hand. If this does in't cause it (1) come away, leave it for twenty-four hours after foal $\mathrm{rg}$, and have the mare held by the head and also one of the ir.mt legrs helu! up so she cannot kick, have another assistant to hold the tail out (1) the way, roll up your sleeves and oil your right arm and hand, take hold of the cleaning with your left hand while you pass the right one into where the cleaning is attached to the womb, commence at the top, gradually forcing the cleaning off the inside of the womb. When once you get it started, work it all off by gent'y pulling, and the mare, as a general thing, will be all right.

\section{AFTER PAINS.}

These are the labor pains continued after the foral is out of the womb.

Symptoms. - The mare will be in pain, lie dı1 and strain some.

Treatment.-Keep the mart quict, and waich ter that she does not force her foal bed out, and give the follow' $\mathrm{g}$ to relieve per paine : 


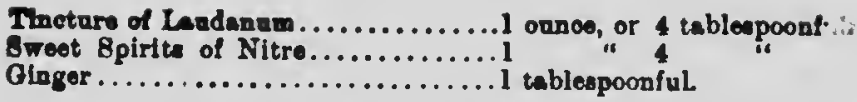

Mix in luke warm water and give as a drench cvery incur and a half or two hours until the mare is relieved. Cuver the body well and place a half-pail of hot salt in a bag over the kidneys and give her a he: bran mash.

FOAL BED TURNED OUT.

This trouble is mentioned in connection with putting out of the calf bed in the cow, where it is specially dealt with. The causes and treatment are the same in both cases. Thic trouble is rarely met with in the mare, but is very common with the cow.

\section{RUPTURE OP THE WOMB.}

This is generalay a very serious trouble.

Causes.-From a mare while the labor pains are on, and she ls in great distress, throwing herself heavily on the ground or floor. This is generally the way this trouble is caused.

Symptoms.--Sometimes, even before the foal is born, you will find the mare's bowels hanging out, and, in some cases, dragging on the ground, and the mare will be in severe pain. While in other cases you will find the rupture while you are examining around the foal in the womb, while again, if you suspect rupture after the mare has foaled, you can find it by examining the womb, it may be large or small. In cases where the bowels are hanging out and she is in severe pain, it is best to destroy the animal to relieve her of her pain as soon as you can, for there can be nothing done to save her life. In other cases of rup. ture, after the foal has been taken away and you put in your hand to seo that everything is all right, you will find the womb to be ruptured. It may be ruptured in any part, or of any size. This Is very serious, but cases have been known where they got better when the womb was torn on the upper side.

Treatment.- Try and keep down the inflammation by applying heat to the body in the way of blankets and hot salt in a hag over the back, and it is well in some cases to apply a coat of mustard over the belly and give the following medicine :

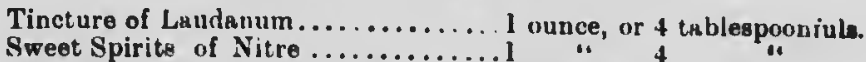

Fleming's Tincture of Aconite...........10 dropa.

Mix in a pint of luke warm water and give as a drencls every d $x$ hours until the mare is relieved. It is well to change the salt 
every hour, so as to keep up the heat. If she wishes to eat, feed her soft feed with plenty of hoiled flax seed in it to keep the bowels loose. In regard to the treatment of the rupti:re, it if best to leave it alone and let rature itself lieal it up, because, in opening up the passage and bathing the womb and putting in medicine, it allows the air to pass through the tear onto the bowels, and also the medicine and the water will leak through onto the bowels, and with these things getting in around the bowels it doss a great deal more harm than good. If the bowels get costive, give raw linseed oil in drenches of a pint, and also give injections of warm water and a little soap twice a day until the bowels commence to work freely.

\section{RUPTURE OF THE PASSAGE.}

Causes.-It generally occurs in foaling and is done by the legs of the foal in coming out through the passage if not coming straight, or where the foal is too iarge for the passage.

Symptoms. - In some cases, where the mare tries to foal herself, you will find the legs out-one out the natural passage, while the other is out through the anus. In other cases, where the mare lias foaled and is apparonly all right, you will first notice the manure coming out through the vulva instead of its natural passage. Oil your hald and arm, pass them into the vulva and examine the passage thoroughly, and if it is ruptured you will find a tear somewhere on the walls of the passage, and it will generally be found on the upper side of the passage, between it and the rectum.

Treatment.-If it is in a case where the foal is coming out, and is caught with one leg in each passage, oil your hand and shove the legs back into the womb and then hring them both out of the right passage. After this keep the mare very quiet and feed on soft feed with plenty of flax seed in it, and if it is in the spring of the year let licr have grass. If the bowels seem to be costive, give her small doses of linseed oil, half a pint at a time, so as not to mike the bowels too loose; also, if the mare seems feverish and swollen behind, give one ounce or four tablespoonfuls of tincture of laudanuin along with each dose of oil Don't try to stitch up the rupture, but simply inject the passage with a halfpailful of warm water and soap with twenty drops of carbolic acid in it. When this is injeced in the rectum, it flows down through the rupture and clesinses and helps it to heal; repeat the injections 
twice a day and feed on soft food. In cases of this kind it is best not to depend on medicine, but allow nature to do most of the work.

\section{INFLAMMATION OF THE WOMB (METRITIS).}

This is inflammation of the substance of the womb.

Causes.-From difficult cases of foaling, where there is a great deal of force used. Exposure after fodling, lying on the damp ground, or it might be caused from a mare getting a chill while she is warm after foaling.

Symptoms.--It usually occurs three or four days after foaling. There is uneasiness, pain, and sometimes straining, and in straining sometimes a dark red fluid will pass from her. She will also be noticed to lie down and moan and will look around at her fanks, her pulse is quick and w-ry, her ears and legs will be hot, and then change to cold, cold sweats will appear around her sides and flanks; the vulva will be swollen, and she will pass urine or water in small quantities.

\section{Treatment.-Give}

Fleming's Tincture of $\Delta$ conite........10 to 12 drops.

Tincture of Laudanum............. ounce, or 4 tablesponfiuls.

Mix in a pint of luke warm water and give as a drench; then apply blankets, wrung out of hot water, over the kidneys; after this is taken off, apply a mustard plaster. If the bowels are costive, give injections of warm water and soap, and give a physic, consisting of one pint of raw linseed oil. Wash the womb out once a day with warm water with a few drops of carbolic acid in it, about ten drops to a pint of water. After the first drench, if she does not seem relieved, follow up with the following drench :

Sweet Spirits of Nitre............. ounce, or 4 tablesponufuls.

Tincture of Laudavum................ ". " or

Fleruing's Tincture of Aconite.........10 drops.

Mix in a pint of luke warm water and give as a drench every three hours until the animal seems relieved. Give her plenty of warm water to drink, feed on soft food, keep her warm, and see that the foal keeps her well sucked out. This disease sometimes terminates in leucorrhcea, or whites.

\section{WFLAMMATION OF THE VAGINA AND VULVA, OR PASSAGE OUT FROI THE WOMB.}

Causes.-It generally comes after difficult cases of foaling.

Symptoms. - The vulva is generally very much swollen, and che inside of the lining is of a red color. 
Treatment.-Give the animal a pint of raw linseed oll to loosen up the bowels, and keep them loosened up well by foeding soft feed with lots of boiled flax seed. If in the spring of the year, feed her mostly on fresh grass. liathe the outside of the vulva with warm water, and tap the lips of the vulva with a sharp knifo in a few places where the $y$ are swollen; this will let the water run out and bring down the swelling. Each time after bathing, three times a day, apply the white lotion.

\section{INJURIES TO THE HIPS DURING FOALING.}

Symptoms. - The mare will be stiff, and there will be a falling away of the muscles on the affected side.

Treatment.-Bathe the muscles of the hip whore it is fallen away, with warm water and salt every second day; rub the parts dry with a cloth and apply the acid liniment. Continue this treatment every second day until the siffness disappears, and the muscles gain their natural size. During the treatment let her run out to pasture as she needs gentle exercise. In this case, it generally takes some time for complete recovery.

\section{INFLAMMATION OF THE MULK BAG (GARGET).}

This is inflammation of the glands which secrete the milk; it is not so common in mares as it is in cows.

Causes.-It is caused from getting cold, by lying on the cold, damp ground in the fall or spring, or from the foal not sucking properly. or from an injury of any kind.

Symptoms. - The bag will be hard, hot and tender, and swollen some, she will be noticed not to be feeding, seems feverish and her bag is very sore when handlud, and the milk is thin, watery looking, and mixed witi curdy looking milk which will come out in jerks when you are milking her.

Treatment.-Give as a drench :

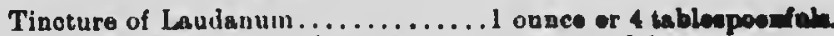

Nitrale of Potssh, or Saltpetre....... I teuspoesful.

Fleming' Tinctnre of A ternite ......5 dinps.

Mix in a pint of luke warm water and give as a dreneh, but If the bowels seem costive, mix in a pint of linseed oil instead of water. Bathe the bag well with warn: water and vinegar, if the weather is warm, and apply the white linument; weaken the liniment down half strength with wator; after applying the liniment oil the bag all over with goose cil. Do thin the ex four times a day, and if the apimal is in moch pain do it efrener. Soe that the bag is kept well milked out, either by the foed or the 
bard. In cases where it is not taken in time it ends up with festering of the bag. In this case the bag will continue to sv.ell, the milk dries "p and the bag will be very sore; matter will form in the bag and it will come to a head. Treat by bathing with warm water and vinegar and apply liniment and goose grease afterwards. This will have a tendency to bring it to a head so it will be fit to lance. The way to tell when it is fit to lance is to feei around until you find a soft spot in the swelling, then open it with ance or sharp knife at the soft place so as to allow the matter to escape. After this keep bathing with warm water and vinegar four or five times a day and use, instead of the liniment, the white lotion. In severe cases of this kind it is best to take the foal away for a while as the milk is not good, and is apt to sicken the foal.

\section{SWELLING ALONG THE BELLY BEFORG FOALING (DROPSY).}

This swelling commences at the bag three or four weeks before foaling and continues gradually swelling forwards until the swelling extends out between the front legs, but the mare does not seem at all sick, eats and seems as well as ever.

Treatment.-If the mare is used to being in the stable, turn her out and let her have lots of exercise every day and give the following powders

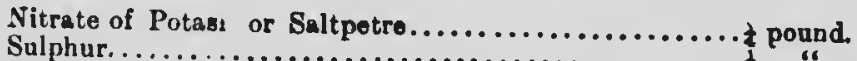

Ground Gientian Root......................................

Mix thoroughly together and give a teaspoonful twice a day in her feed until she foals.

This is not a serious disease, but it is well to look after it before it gets too bad. It generally gets all right as soon as the mare foals.

\section{MARES LOOSING THEIR FOALS (ABORTION).}

This is most often seen in mares before the sixth month of being with foal, but may occur afte inat.

Causes.-From a slip; from drr ving too heavy, or backing a heavy load; or the smell or sight of suod will cause it.

Symptoms. - The mare will be sry restless, get up and down, walk around until the labor pains come on, which soon causes the water bag to come out and break, then the front legs and head of the foal will appear, and she will soon be delivered of the foal.

Treatment. - In case the foal should not be coming straight, straighten it and take it alway, then give the following: 
Raw Unseed Oil ................. plat.

Spirits of Turpentine................ I ounce or \& tablespoonfula

Mix and give as a drench. In case inflammation of the womb ohould follow abortion, refer to the treatment of infammation of the womb.

CHE P IF.R X.

\section{DISEASES AND TROUBLES OF YOUNG FOALS.}

\section{CONSTIPATION WN YOUNG FOALS.}

It is sometimes a troublesome thing in a very young foal to get his bowels to move.

Causes.-Foals of a mare fed or. very dry feed and foaling early are often troubled in this way, or foals not getting their mother's first milk.

Symptoms.-The foal will be noticed to be fuller than usual; he does not seem to care to suck; he will strain as if wanting to pass something but nothing comes. In some cases he will lie down and look around at the side as if in pain.

Treatment.-Get a small syringe and give small injections of luke warm water with a little raw linsced oil in it; give these injections three or four times a day. In cases where the manure balls are hard and large, it is necessary to oil the finger, pass it up into the rectum and remove them. Be a little cautious not to irritate the bowels too much. Du this every time before giving an injection. Give him on his tongue a tablespoonful of raw linseed oil and a teaspoonful of whisky mixed well together; give this three times a day until the boweis move and the colt seems better. You will have to use your own judgment as to the amcunt of oil and whisky given, according to the size and strength of the colt. The above is for a colt a day or two old. Keep him warm and comfortable, and keep the mare milked out so that ho will not get too much milk.

\section{DLRREGAA IN YOUNG FOALS.}

Causes.-From allowing the foal to be out and lie on the damp ground too soon after foaling; exciting the foal, caused from the mare being turned in with other horses and running around a great deal; from the mother's milk being too rich or too poor, or sucking the mother while she is hot, after working. 
Symptoms.-The colt is noticed to pass a thin, watery ditcharge from the anus which sticks around his tail and legs. Ho does not suck much and soon becumes gaunt and dull, and to come cases he will be griped.

Treatment.-Remove the cause if you can find it. Keep the mare and foal very quiet, and if it is from the milk being poor, feed the mare a little heavier, or if ycu think it too rich, feed the mare a little lighter. Give the foal:

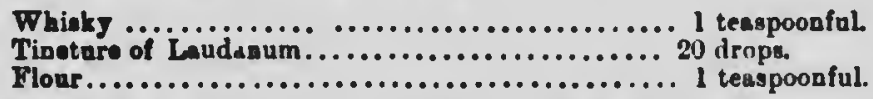

Mix with a little of the mother's milk and give every four or ave hours until the foal is relieved. In all cases of this kind keep the b. warm, as it has a tendency to relieve the congested state of the bowels. This is a dose for a smal! foal two or three days old, so you must use your judgment in giving it to an older colt.

\section{LEANING OF THE MAVEL. AND RHEUMATISM IN YOUF: FOALS.}

Causes.-It is supposed to re lue to a germ getting in at the navel string, while others say it is caused from a cold, a chill or an injury.

Symptoms.-The foal will be first noticed to be lame in one hind leg, and some of the joints will be swollen and sore to handle; when he goes to make water it will come out through the navel string. The next day the swelling in that leg may be moved into one of the other legs. After the rheumatism has moved around from leg to leg for a few days it will be noticed to settle in one of the joints, then it will fester and break, and the matter that runs away will smell very bad and seems to come from the bone. After It ceases to run where it festered and broke, and is healing up, it will be noticed to settle in unother joint, break and run, and will keep on. breaking and running in different places until the colt is so weak that he dies. In other cases the joints swell and dc not break, but there is a continual running from the navel, and on account of this running so much he gets weak and soon dies.

Treatment.-When the leaking is first noticed, if treated properly it can be cured. Apply Monsell's solution of iron to the navel with a foather four or five times a day, this will stop the leaking; and rub the swollon joints four or five times a day with white liniment, and give the foal half a teaspoonful of salicylic acid on the tengue three times a day. If this is taken in time, 
[DISEASE AND TREATM LNT OF IHE HOHSJ . 139 before the joints begin to run, this will invariably effect a cure. After the joints break, bathe with warm water lliree or four times a day", and apply white lotion. Sometimes we have a pure zase of leaking at the navel without rlscumatism; in this case, treat by applying Monseli's solution of iron to the navel with a feather tour or five times a dity until it stops leaking; also kecp the colt very quiet and warm.

\section{WEAKNESS IN THE LEGS AND JOLNTS OF A YOUNG FOAL.}

Bandage the legs to support and strengthen them, and also give them a good hand rubbing. If his is down and cannot get up, raise him up four or five times a day to suck, and give him every chance to strengthen lis legs.

\section{CROOKEDNESS OF THE LEGS OF YOUNG FOALS.}

In some cases they will be ovar on the knees, while in others they will be crooked in the hind legrs.

Treatment.-I.eave the foal alone; do not try to do anything to the legs. Feed hin well, and as he gets strong his legs will straighten.

\section{DISTEMPER IN YOLNG FOALS.}

This is frequently met with in foals, and is fully dealt with in "Distemper or Stran;les."

\section{CHAPTER XI. \\ CASTRATION, DISEASES AND TROUBLES FOLLOWING IT.}

The best age to perform this operation is at one year oldduring the months of Aprit and .1 ay, these being the safest months, after the colt has been turmed to pasture for eight or ten days and is shedding his coat.

\section{PRECAUTIONS BERORE OPERATING.}

Never operate on a colt unless he is in good condition and healthy. See that he has no distemper or any such disease; also have good weather-not too hot or too cold-and avoid east winds and damp weather. Have your hands and instruments thoroughly clean, by washing them in warm water, a little soap and a fiw drops of carbolic acid. It the horse is vider than a year old, it is best to feed very light the day before the operation so his 
oowels will be empty, as it makes it easier on the horve whun he is thrown down and tied. Bafore throwing the colt down, satisfy yourself by examining and asking if the colt has hat any rupturc; if he is ruptured he will hate to 1 = uperated on diflerently. It is also a good plan to examine if both testicles are down hefore throwing the animal. In aged horses, if the sheath is dirty it is best to wash it out and oil it well with larci a li:w days betore operating; it often prevents swelling after castrating.

\section{THROWING OR CASTING THE ANIMAL FOR THE OPERATION.}

There are various ways of doing this-some use the belt tackling, others use Farmer'Miles' tackling-but the simplest and most used in this country is the rope tackling, as shown in cut below. This tackling consists of about iurty feet of rope, inch

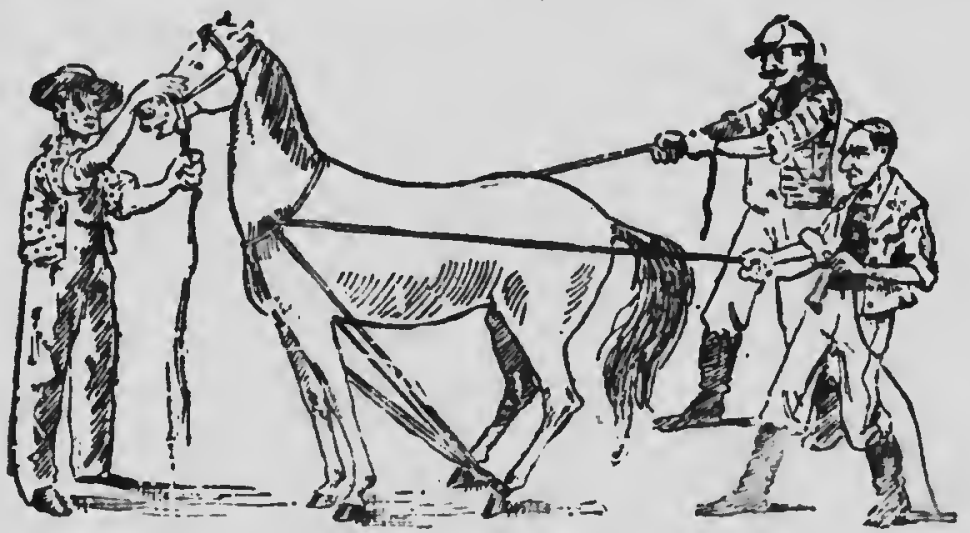

rope will do if good; make a loop by doubling it in the centre, tie a knot and slip the loop over the head, pass the ends of the rope back, one on ench side, and run the rope through the ring in the hind hobble, which is made out of heavy, thick straps, and buckles on the hind leg below the fetlock, and has a ring in front of it to run the rope through. This hobble is better thar putting the rope around under the fetlock, as the rope burns the leg. Pass the rope forward after it is put through the ring in the hobble up to the neck and through the loop at the neck. Have a man hold the head while one on each side pulls on the rope, same as seen in the cut; this will throw the animal. Now tie him securely so that he will not hurt himself, then proceed with the operation. 
The Farmer Milev lackling is not used much for castrating common colts, but is used to cut ridgling or rig colts. This is where the testicles are up in the belly and cannot be found in the bag. This is the only throwing tackling that call be used in this kind of an operation. The belt tackling is a good one, but it is rather expensive for a man who does only a few colts.

\section{OPERATIMG WITH THE CLAMPS.}

The clamps are generally made out of cedar, and are about from 4 to $\sigma$ inches long, hollowed out in the centre and loaded with green salve, the receipt of which is at the back of the book. Tie one end of the clamp with strong carriage trimmers' twine, leave the other end loose. Now, take hold of the testicle with the left hand and cut into the scrotum, or bag, with a sharp knife, clove to the median raphe. Always have your knife sharp, and nake a good large cut so as to allow the testicle to slip out, then take hold of the testicle with the left hand and the clamp with the right and slip it over the cord, draw the cord junt noderately tight and spread it out in the clamp then tighten the clanip at the end that is not tied with a castrating pincers, also tie this end good and tight with the twine mentioned. Now, take off the pincers and operate on the other testicle the same as the first one, then cut off the testivles and part of the cord below the clamps, leaving about half an inch of the cord below the clamps; this will help to prevent the clamps from slipping off. The clamps are considered the best way to operate.

\section{OPERATING WITH THE ECRASEUR.}

This is a new method of operating, and has met with very good results in most cases. There are no clamps used in this method. Let the testicles out the same as if you were going to operate with the clamps. Then slip the testicle through the chain at the end of the ecraseur, and screw it up until it squeezes it off. This closes up the end of the artery in the cord and prevents bleeding. It is always hest to operate on one at it time, although some operators take off hoth at the same time, but there is more danger of bleeding. Pour sweet oil, with a few drops of carbolic acid. into the cuts and let the animal up l'se two drops of carbolic acid to one ounce or four tablespoonfuls of sweet oit. 


\section{OPERATHO BT SBARING.}

This method is used in some places, and is performed by letting the testicles out and putting on an iron clamp in the same place as a wooden one. Cut the cord off close to the clamp, and have a hot iron, dip 1 in oil, and burn the end of the cord and artery ; this sears it and prevents it from bleeding. Now remove the iron clamp and operate on the other testicle in the same way. By oiling the hot iron it keeps it from sticking to the cord and pulling off the scab.

\section{OPERATING WITH LIGATURES.}

This way is not much used for horses, but is a very good mothod for bulls and boars. In this method the testicles are let out in the same manner as in the other ways, and the cords are tied with a strong piece of twine to prevent bleeding, and cut off just below where th . are tied. But of all these methods of castrating we think the safest and best is the clamps. If the colt is ruptured it requires a more careful operation, which will be fully described in connection with scrotal hernia.

\section{HOW TO TREAT THE COLT AFTER CASTPATION.}

If the weather is chilly, damp or east winds, keep the colt in at nights, in a box stall, clean and well bedded, turn him out overy day that is fine and let him have nothing but grass to eat. It the operation was done with the clamps remove them the second day, and in cutting them off cut the string on the front end, spread the clamp well apart in the front so as to allow it to drop off the cord; in doing this be very careful not to pull down the cord out of its place. If the colt swells very much bathe the cuts with warm water until you soften them, then take butter on your fingers and insert it into the cuts and open them up, allowing the discharge to run out. A little swelling on the point of the sheath, as long as it is not too large and the animal feeds well and has a whitish discharge from the cuts, is not considered serious and need not alarm you. These are natural results of castration.

\section{BLEEDING FROM THE CORDS (HEMORRHAGE.)}

The blood may come from the veins of the scrotum or from the arteries of the cords. If it is coming from the veins you can tell it by its dribbling away from the cuts anc its dark color. If it is from the artery of the cord it comes out in spurts, and is of bright red color. 
Treatment-If it is from the vells: of the scrotum east the animal and plug the cut with cotton hatting saturated with Monsell's solution of iron and leave the plug in twenty-four hours when it will be safe to remove without danger of bleeding. The batting can be removed by placing a 1 witch on the animal's nose and take it out without throwing him down.

Bieeding from the artery of the cord is generally after the operation has been performed with the ecraseur and it has failed to close the artery of the cord, and when the animal gets up he will be bleeding. In other cases it occurs from the horse pulling a clamp off by jumping a fence or catching it with his teeth.

Treatment.-Throw the animal and secure him, get hold of the cord and place a clamp on the end of it good and tight, this will stop the bleeding, then allow the animal to get up.

The question has often been asked if a one-year old colt would bleed to death by bleeding from the artery of the cord? The answer is: Yes, cases have been known where animals have bled to death by bleeding from this artery. The animal generally bleeds some after castration, but so long as it does not bleed very freely it need not alarm you, and by keeping the animal quie tit will generally stop bleeding of its own accord.

\section{ROPTURE (ZERTL).}

This is where the aximal has a small rupture that was not noticed before the operation was performed; or, in come cases the animal will rupture himself at the time of operation.

Symptoms. - The bowels will be noticed to be hanging out of the cut; there may be only a little-two or three inches, or a foot, and it has been known to be so much that the animal would tramp it under his feet. If the bowel is out very far, and becomes strangulated and inflamed, the animal will be in great pain and act as if he had inflammation of the bowels. The bowel will be of a bluish-red color, and after a time, if left out, will become mortified. The way this generally occurs is: There will be no eign of the rupture during operation, but in a fow hours the owner will go back to see the colt and find him in the abovementioned state.

Treatment.-1f the bowels are out, and inflamed and brulsed with the hind feet, and he seems in great pain, there can be nothing done but to destroy the aninial. In cases where there ie only a small amount of the bowels out, throw the animal and eacure him of 
your hand with sweet oll and force the bowols back through the hole into their natural cavity, sew up the cut that was made to let the testicle out and this will keep the bowels from coming dowa; keep the animal very quiet and feed on soft food to keep his bowels loose Swelling will take place, and between the swelling and the stitches it will keep the bowels in their place and the hole will heal up, and there will be no more trouble with the rupture. In a case of this kind it is best to keep the clamp on a day or twe longer than you would if the animal was all right.

\section{THE FATTY LINING OF THE BOWELS COMLNG DOWN AFTER CASTRATIOK.}

In some cases where there is a very slight rupture which is not noticed during castration, and after the animal is let up and walks around, in a few hours the fatty lining of the bowels comes out-it may be out from six inches to two feet.

Symptoms. - When you go to see the colt there will be something hanging from the cut, generally of red color, and when you feel it, it is of 2 fatty feeling and the animal does not seem to take any notice of it at all; he feeds away and seems in perfect health.

Treatment.-Take a scissors and cut it off; there is no danger of bleeding or any trouble, and watch that there is no more comes out.

\section{ABSCESSES FORMED IN SCROTUM AFTER CASTRATION.}

This generally comes in a case where the animal is all healed up and seems to be doing very nicely.

Causes.-Some dried matter; a dead piece of the cord or a sliver being left in the scrotum after it is healed. This causes an Irritation, starts it to fester and forms an abscess.

Symptoms.-There will be heat, pain and swelling around the wcrotum or bag, and the animal will walk very stiff in his hiod logs.

Treatment.-Poultice and bathe well, rub with weak whim ilniment. This will bring the abscess to a head, then lance it and allow the matter te run out, or in some cases the poultice on bring it to a beed and it will break of its own accord. 


\section{SWELLING AFTER CASTRATION.}

As we mentioned before, a small amount of swelling is not a bad sign, but when he begins to swell up very bad, especially around the scrotum and cuts as well as in the sheath, the animal seems very stiff and does not want to move nor care to eat; and If the discharge from the cuts is of a red waterish color, the case becomes more serious and needs immediate attention.

Causes.-From lying on cold, damp ground or standing out in cold east winds or a cold rain and he gets cold in the cuts, which sets up inflammation and swelling; or allowing the cuts to heal up too soon and dam back the natural discharge; or it may be from the cuts being poisoned from dirt on the hands of the operator or on some of the instruments, or standing in a dirty stable, or it may be from the colt's blood being very bad.

Treatment. - Keep the bowels loose by giving small doses of raw linseed oil, bathe the cuts well with warm water and tap the point of the sheath in a fow places with a sharp penknife, allowing the watery stuff to keep dropping out; this will help to relieve the swelling. After you give him a good bathing and get the swelling down some; put salty butter on your finger and open the cuts well, this will allow any discharge that is formed above to run out. After the bathing and the opening of the cuts, then apply a poultice of hot linseed and bran, hold this poultice to the cuts by means of strings over the back. It will not be necessary to tap the sheath and open up the cut every time you dress the swelling - once a day will be all that is necessary; but bathe and put on hot poultices three or four times a day, this will allay the inflammation, and if there is poison in the cut, the poultice and hot water will draw it out. Feed the unimal on soft food and five gentle exercise, which has a tendency to take down the swelling. As soon as the colt begins to eat, and there is a good healthy white discharge from the cuts, you may then consider him as going to come all right.

\section{SCIRRHUS CORD.}

This is a growth on the end of the cord.

Causes.-From the cord being pulled down in taking off the clamp, or from the colt when it is ilching from liesing, biting it and pulling it down. The cord is pulled down through the cut and if not noticed at the time and put back into the bag, the cut heals tight around it and bolds it down, and the cord being 
exposed to the air becomes irritated and diseased, and a growth is formed on the end of it.

Treatment.-If this is noticed right at the time it is very easily checked by bathing it with warm water, which softens the cut, then take your finger with some butter on it, break the cord loose from the skin, shove it back into the bag and it will soon get all right. If it has not been noticed in time, and gets very large, it will soon have to be operated on. Cast the animal and secure him, break the skin from the cord, where it is healed to it, with your finger and thumb, as much as you can; the parts you cannot break with your finger and thumb cut with a knife until you get the cord all loose, place a clamp on the cord so you will be able to cut all the diseased part off below the clamp, leave the clamp on two or three days and reınove it, same as after castration, open one end and spread it. The cord may also be taken off with the ecraseur instea $i$ ? of putting on a clamp, and in some cases it works better than the slamp. After the operation, if the animal swells much, bathe with luke warm water three or four times aday, and after each bathing apply the white lotion. If the point of the sheath is swollen much it is well to tap it in a few places with a sharp penknife to let the watery stuff keep dropping out. Feed lots of soft food with boiled flaxseed in it, and give the animal gentle exercise every day. If the case has been allowed to run on until the cord becomes diseased up through the ring in the rim of the belly it is then a hopeless case.

PERITORITIS FOLLOWING CASTRATION.

This is inflammation of the lining of the scrotum and the lining of the abdominal or bolly cavity.

This disease is more fully descrlbed in connection with the diseases of the bowals.

Causes.-From too severe medicino boing used In the clamps; or from a bungling oporation; from the animal standing out in cold east winds or rains; or lying on the damp ground. The inflammation first commences in the lining of the bag or scrotum, and extends up through the ring in the rim of the belly and spreads all over the serous membrane lining-the belly cavity. This generally comes on about the third or fourth day after castration.

Symptoms. - The animal is very dull, will stand around witbout eating, and sooms as if be was cold. The cuts are net 


\section{DISEASES AND TREATMENT OF THE HORSE.}

wollen, but there is a bloody, watery fluid keeps dropping away. As the symptoms gradually get worse the animal seems in pain, will lay down, and keep getting up and down, breathes very heavy, as if he had lung trouble. If in warm weather, he sweat freely, his pulse is weak and fast-from 60 to 70 beate per minute; if he passes anything from the bowels it will be covered with slime, and his water will have a reddish appearance. This is a very weakening disease, the animal gradually gets worse for a couple days, then he dies.

Treatment.-For a yearling colt give the following :

Tinoture of Laudanum............. t ounce, or 2 tablespoontul

Fleming' Tircture of Aconite...........

Raw Linesed Oil................... pint.

Mix thoroughly and give as a drench. If this does not give relief in three hours follow up with the following :

Tincture of Laudanum............. ounce, or 2 tablenpoonfula.

Fleming 5 Tincture of Aconite.......... d drops.

Mix in half pint of luke warm water and give as a drench every three hours until he seems better. If he seems weak after recovery give a wine glassful of whisky in a pint of oatmeal gruel three times a day for a few days until he gains his strength. Keep him good and warm by blanketing him, and apply a mustard plaster over the bowels until he seems relieved, poultice the cut with a hot poultice of linseed meal and bran, which will start a healthy discharge to run from the cuts. Warm his drinking water and feed on soft food. When once this disease gote well otarted it generally proves fatal.

\section{LOCKJAW (TETANUS) AFTER CASTRATION.}

This disease usually comes on from the ninth to the twentyArat day after castration, and generally follows a case that you think is doing extra well.

Causes. - The real cause is not known, but it is liabie to follow any kind of an operation, or even a very slight injury. It is frequently noticed in colts that are exposed to the cold, walklog or standing in a river for any length of time after being casirated, or allowed to run in a wet, marshy pasture. For treatmont and further particulars of this disease turn to "Lockjaw or Totanus," which is dealt with more fully in the diseases of the acrn cos avien. 


\section{BLUDNESS (AMAUROJIS) OCCURR ING AFTER CASTRATION.}

This disease is sometimes noticed to come on an animal after he has been castrated, especially if he bleeds treely at the time. This disease is mentioned more fully in connection with the diseases of iveye.

\section{CASTRATING ORIGINALS OR RIGS.}

This is where the testicles do not come down into the scrotum or bag, but remains up in the abdominal or belly cavity. The cause of this is not fully understood. In a case of castrating a rig it is advisable to have an expert who pays special attention to this branch of castration to do it. If the testicles are not down at a yearling it is best to let the animal run over for a year or so, for the testicles often come down themselves. In some cases one testicle will be down and the other up, while again neither of the testicles will be down.

\section{THE DIFFERENT MEDICINES USED IN LOADING THE CLAMPS.}

Some use biniodid of mercury or red precipitate-2 grains to an ounce of lard or vaseline, but the green salve, the receipt of which is at the back of the book, is what we recommend and un.

CHAPTER XII.

\section{RUPTURES (HERNIAS) AND THE MODES OF TREATING THEM.}

NAVEL OR UMBILICAL IRUPTORE.

This 18 where the navel opening does nut become, properly elosed at the time of birth, and the bowels come down thrcugh the opening in the rim of the belly and forms a pouch or sack in the skin, the size of which varies from the size of a hen's egg to larger than a goose egg. This is a miserable blemish and is best to be treated in the spring of the year, when the colt is a year or two old.

Treatment.-Prepare the animal by starving it twenty-four hours, then throw and secure him, shove the bowel well back and draw the skin well up and put a heavy stiff clamp on it, secure both ends of the clamp with stout cord and run a few darning needles through the skin below the clamp, this will keep the cla.np 
from slipping off, break off the point of the needles so they will not catch in anything; let the animal up and leave "he clamp on until it falls off of its own accord, which is generally from nine to tweive days, by this time the hole will be healed up and the rupture will not be seen any more. After the clamp falls off there will be a raw spot which will need to be watched in warm weather so that maggots do not get into it. In case they do wash it off well with warm water and soap and apply the creolin lotion a few times.

Warning.-Be careful not to catch the bowel in the clamp with the skin.

\section{RUPTURE (VENTRAL HERNIA.)}

This is a rupture anywhere in the rim of the belly, and may vary from the size of a hen's egg to that of a man's head.

It is generally due to an injury from a kick of an animal, or an injury of any kind which strikes and bursts the rim of the belly, or it may be caused from an animal pulling very heavy.

Treatment.- The way to be sure if it is hernia is that you can shove it up through the hole in the rim of the belly, and as soon as you let go it will come out again; you also can feel the hole in the rim of the belly. These ruptures have often been tried to be treated with the clamp and cutting in and sewing them up, but the best plan is to leave them alone and get as much work out of the animal as you can.

\section{RUPTURE IN TKE BAG (SCROTAL HERNLA).}

This is where the bowel and the fatty covering of the bowel zomes down along with the testicle.

Causes.-Some colts are ruptured at bir. and they never get all right. It is also caused by the colt runuing, jumping or any other such violent exercise, or it may result at the time of castrarion in severe struggling.

Symptoms.-The scrotum has a swollen and enlarged appearance, and you can press the bowel and covering up through the hole into the belly, and when you let it go it will come down again.

Treatment.-If it is in a colt that is not castrated, you can get rid of this very easily while you are castrating him. In a case where you are going to castrate and fix the rupture at the same time, have the animal well prepared by starving him a day or so before the operation, then throw and secure him, shove the bowel and fatty lining back into the belly, and in taking up the 
testicle with your left hand, also allow the hand to reat on the hole where the bowel comes out; make a small cut large enough to allow the testicle to slip out, and slip the clamp on over the cord : also draw up the white covering or tunics you cut through in letting the testicle out, and fasten this tight in the clamp as well as the cord; this will prevent the rupture from coming down. A day or so after the operation it will swell some and fill up the hole where the rupture comes down and the rupture will entirely disappear. After four or five days it will be all right to remove the clamp, and there will be no danger of the rupture coming down. In the stallion it cannot be treated except by castrating in the same method as is mentioned above.

\section{CHAPTER XIII.}

\section{DISEASES OF THE EAR.}

\section{DEAFNESS.}

If it is of long standing nothing can be done for it, and it is hard to detect it in some cases.

Causes.-It generally comes on horses that are used where there is a great deal of noise, such as artillery horses, or it may be caused by a diseased state of the drum of the ear or nerve.

Symptoms.-The animal seems stubborn and cannot be taught to obey the word.

Treatment-There connot be very much done to the horse but place a twitch on his nose and pour a little sweet oil in his ear every day; this sometimes helps them.

ITJURIES OR CUTS AROUID THE EAR.

If the skin or cartilage is torn, put a twitch on the horse's nose and take a needle used for sewing skin cuts and draw the wound together with stitches of carriage trimmers' twine, bathe it well with warm water twice a day and apply the white lotion until it is healed.

DISEASES OF THE CARTILAGE OF THE EAK.

Causes.-This disease is generally caused from an injury of some kind.

Symptoms.-It will keep festering and breaking every month or so at the place the cartilage is diseased. 
Treatmenr.-Place a twitch on the animal's nose and with charp knife split the skin and tissues open to the diseased part of the cartilage, scrape the diseased part out and burn around where the diseased cartilage is with caustic potash, which will generally cot up a healthy action, and it will heal up all right.

\section{FROST BITES OF THE EAR.}

This is generally caused by keeping the animal in a cold place and allowing the ear to become frozen. This is not so common in horses as it is in young cattle.

Treatment.-Bathe with cold water, and apply the white lotion after bathing, three or four times a day. If it is taken in time it will save the ear from dropping off. If the ear becomes dead, and drops off, treat the same until it heals up. If you notice the ear just at the time it is frozen, apply snow to it to draw out the frost.

\section{CHAPTER XIV.}

\section{DISEASES OF THE EYE.}

Before studying the diseases of the eye it is advisable to study the anatomy of the eye, found in Part I. of this book.

\section{SIMPLE OPHTHALMLA.}

This is inflammation of the outside covering of the eyes and the lining of the lids.

Causes.-This is often the result of an injury of some kind, such as being struck with a whip in the eye; or extrom . + cold will cause it; being kept in a dark stable, or whers there is foul air around the stable, or from chaff or any other s!iustance getting into the eye.

Symptoms. - The eye is very dull and partly closed, and ometimes the eyelids will be swollen, and water running fron the corner of the eye. The eye is sore to handle and it hurts when the animal is brought into the light, and on account of this lis will keep it closed. After a day or so there. ill be a scum gradually come over the eye and it presents a very irritated appearance.

Treatment.-Examine the eye carefully and try and find out the cause of the trouble. If it is a piece of chaff, or any substance in the eye, remove it; if it is the fault of the stable, sit it fixed. Bathe the eye well with new milk, just from the cow, twice a day and, after bathing it, each time apply the eye wash, mentioned in 
the receipts at the back of this book, in and around the eye. Keep on with this treatment until the animal is relieved. In cases where the eyelids are much swnllen it is well to bleed; this is done by taking a sharp pen knife and raining the vein below the eye by pressingr your fingers on it, then cut it and pllow it to bleed until it stops of its own accord, which takes about half an hour.

\section{MOON BLINDNESS (PERIODIC OPHTHALMIA).}

This is inflammation of the inner structures of the eye.

Causes.-Extreme heat and cold, poorly ventilated stables or dark stables; all these have a tendency to bring this disease on. It also comes on hereditary, that is, where the dam or sice has had this disease. It is very apt to follow up in his or her colts.

Symptoms.-They are generally well marked, and together with the history of the case, you will have little difficulty in telling if it is this trouble that is affecting the eye. The animal may be put in the stable apparently all right at night, and in the morning you notice the eyes to be running water, seems very weak, and the eye partially closed. It generally affects one eye at a time, although if may affect both eyes at once. It is also noticed to change from one eye to the other. The disease gradually gets worse for two or three days, the eye gets weaker and assumes a yellowish or reddish appearance. The animal can see but very little out of the eye. In two or three days more the ye will return back to almost its natural state, but may look a little bluer than usual. It will appear all right again, but after the course of from three to six months it will show again with the same symptoms. This time it may be in the opposite eye, or in the same one. It will keep coming on in spells like this from time to time, each time leaving the eye a little more blurred, until in time it will completely blind the animal. In some cases the animal will go blind in a year from repeated attacks, while in others it takes as long as three years. The first time the disea: attacks the eye you may think it a simple case of inflammation of the eye, but after it comes back a few times you ay make up your mind it is a case of periodic ophthalmia.

Treatment.-The treatment generally terminates very unsatisfactorily in the end, as the animal goes blind, and when c.rce you have made up your mind it is this disease it is best to part with the animal, but you can help to keep back the disease, when every time the eye is nuticed to bo scie, to bathe them well with new 
milk twice a day and apply the eye wash $\ln$ and around the eya. This will help to check the inflammation and keep the sight in the eye longer, but it finally terminates in cataract of the eyes, that is, blindness. In some cases where the eye looks very irritated it is well to bleed from the vein below the eye, but it does not generally do so much good as it does in simple ophthalmia.

\section{- cataract of the fye.}

Cataract is a pearly white deposit across the sight of the eye, and it may be what is known as a complete cataract, that is where it covers all the sight, or it may be a partial cataract, that is where the animal can see a little.

Causes.-It is caused by repeated attacks of inflammation of the eye, the same as we have in ophthalmia; or foals have been born with cataracts on their eyes. This disease may effect one or both eyes. There is a white deposit over the sight of the eye.

Symptoms. - If it is only partial cataract the animal can see a little, but if it is a complete cataract the animal cannot see at all.

Treatment.-Very little, if anything, can be done, unless by an operation, and such an operation is not attended with much success in the horse because you cannot regulate his sight with glasses as is done in people. As for medicine, when the cataract is well formed there can be, nothing given to help him. The only thing we can advise you is when you are buying a horse be sure the is not affected with this disease.

\section{STAR GAZER (AMAUROSIS),} the eye.

This is paralysis of the optic nerve which gives sight to

Cajses. - Standing in a stable that is dark, or by striking the head agrinst something. In severe cases of bleeding, horses have been known to go blind, but as the blood returns he gains

Symptoms. - The eye has a large, glassy appearance, and the pupil of the eye is very much enlarged, and if he is taken out of a darb stable into the light the pupil of the eye does not close up the same as if it was all righi, but remains large all the time. The animal generally carries his head high and steps hirh.

Treatment. - If the case is of long standing nothing can bo done for it; if it comes on from injury by striking the head against something, or from bleeding, it can be trested all right. 
154

TRE VETERUMARY RCIZNOE.

Give the animal a teaspoonful of nux romica in hls feed three times a day, this acts as a stimulant to th: nerve; wash the eye with eye wash twice a day for a few day. In buying horses be particular and watch the eyes close! : is : oundness, for some of the best buyers have been nippe in 11 , 'is ase.

CANCEROUS GROW T.I 'N THi : :YE.

It first commences with an in' $11 \ldots)^{\prime}$, in the eye, after this there will be a growth noticed to br cns iss, wut of the ball of the

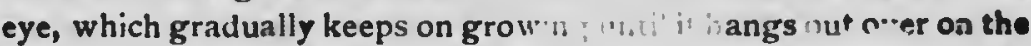
cheek, it looks red and angry, and th $\ldots+\ldots+1, l_{1}+1$, will cause it to bleed frecly, and gives the ar i. . . . . y appearance. In some cases the bones around i e $8, h, \ldots$. sased, and then it smells very bad. This distase is $w^{+}-\mathbf{n}$ met with in the cow than in the horse.

Causes.-The causes of this aro like all other cancerous growths-from cancer germs getting into the blood and settling in the eye.

Treatment.--You may effect a cure in the first stages of the disease by removing the eye, growth and all. Cast the animal and secure him, and have his head held solid, cut around the eye between the eye and the eyelid, and lift the eye up by sticking a hook into it, then out the structures off at the back part of the eye and have a hot iron to sear it, to stop the bleeding, then allow the animal to get up, and dress it the same as you would an ordinary wound by bathing it with warm water and applying white lotion three times a day. After applying the lotion, if the cut looks angry, apply compound tincture of benzoin, or what is called Frier's balsam, with a feather to keep it from growing again.

\section{FULARIA CCULI.}

This is a smal! worm, about che size of a pin, found in the humors of the eye, moving around. It is liable to be found in any part of the body; they have been found around the testicles and bowels.

Causes.-From a microbe, and is mostly seen in horses that pasture on low, wet land; it is taken into the system through water and feed, and from the bowels it gets into the blood and is carried into the eye or various parts of the body through the blood.

Symptoms.-This worm may grow from the size of one halt inch to two inches long, and it sets up considerable irritation in 


\section{DIBRAgES AND TREATMENT OF THE HORSE.}

the eye. The eye has a hazy appearance and seems very weak, and by watching it you can see the worm sometimes in the front, then it will move around to the back. If the worm is allowed to remain in the eye it will keep the eye irritated.

Treatment-The only thing that can be done to save the gye is an operation. Cast the animal and secure him, have his head held solid so that he cannot move, take a small lance or sharp penknife and make a small incision or cut across the sight of the eye, which will let the humors of the eye run out, and with it the worm generally comes. Keep the animal quiet after the operation and put him in a clean, dark box stall for a few days. Bathe the eye with new milk twice a day and apply the eye wash after bathing until the eye is healed. It generally takes a week or so for the eye to heal and the fluid to form in the eye. After the course of two or three weeks all that will be noticed is a slight scar, which will gradually absorb away in time and the eye will get all right.

\section{glaUCOMA.}

This is a hardening of the back humor of the eye.

Causes.-From a severe injury to the eye, or where the eye is pierced by a stick or anything, and it injures the back part of the eye; or sometimes from natural decay in old animals.

Symptoms.-The horse gradually gets blind, and has high, peculiar action in front, the same as seen in all blind animals. If you look into the eye through the pupil you will see that the eye has become hardened and is of a grayish color.

Treatment. In a case where it comes on from an injury, bathe with new milk three or four times a day, and apply, after bathing, the eye wash. It is more frequently noticed in gray horses than in others, and if it comes on in old age nothing can be done to cure it.

\section{INFLAMMATION OF THE HAW OF THE EYE (MEMBRANA NICTITANS).}

This is the diseased or enlarged state of the cartilage in the corner of the eye.

Causes.-Generally from chaff or something getting into the eye and irritating it. This causes it to enlarge and stick out of the corner of the eye and gives the animal a great deal of trouble, end also loots very bad.

Treatment.--When it is first noticed remove the irritation. if it can be found, and bathe with new milk or luke warm water two 
or three times a day, and after bathing apply the eye wash. The cartilage will generally return to its natural size in a few days. If this fails to remove the enlargement, place a twitch on the animal's nose to keep him quiet, take small pincers and catch hold of the cartilage and draw it out of the eye some, then take a scissors and cut it of. This is a very simple thing to do, for it will not bleed and does not hurt the animal very much, for it is only a plece of cartilage. After you cut the cartilage off treat the oye the same way as mentioned above, and in a few days you will hardly be able to tell there was anything wrong with the eye.

\section{MJURIES TO THE EYELIDS.}

This is where the eyelid becomes torn or bruised.

Causes.-It may be caused in various ways.

Treatment - If the eyelids are torn, draw the edges of it together by putting a few stitches in it with a needle that is used for sewing up wounds, and use the carriage trimmers' twine. It is not always necessary to throw the animal for this, but just put atwitch on his nose, but if the animal is very wild it is best to throw him down; bathe the wound with rew milk or warm water three or four times a day; after hathing apply the eye wash, in a few days the stitches will come out and the wound may open up some and look worse, but keep on treating it and it will heal up in a short time. In some cases, where the eyelid is torn and the eye injured, the eye will fall out on the cheek, this may be caused in a runaway. Wash the eye off and set it back to its place and sew up and dress the wound as mentioned above.

\section{INJURIES TO THE DUCTS OF THE EYE}

WHICH CARRY THE TEARS DOWN TO THE NOT.

When this tube becomes injured the tears will flow out over the cheek. It is recommended to take a small syringe and inject this tube or passage with warm water. The best way to inject this is from below by putting the point of the syringe in the small hole found in the bottom part of the nose and force the water up through this until it runs out at the corner of the eye, this will clear the passage-out, and sometimes effect a complete cure, but if the case is of long standing it is best to leave it alone, for the horse might be able to work for years. 
TRAR SIGTHEDNESS (WTOPL).

This trouble is generally found in horses with very full eyes.

Canse.-There is no particular cause for this; the animal was foaled with this disease.

Symptoms-The horse has a very full eye, with enlarged pupils, and will shy vary much, a bo cannot ses objects along the road at any distance.

Treatment-There is none, but alwaya be caroful In buying a hores that be is not a shyer for it is a miserable thing.

\section{CHAPTER XV.}

\section{CONTAGIOUS DISEASES AND FEVERS OF THE HORSE.}

\section{1. - CCNTAgIoUs diseaseg.}

SMULLPOX IN TEB EORSE (VARIOLA EQULA).

This disease is not very often me: with in America, but is quite common in Europe.

Causes.-They are same as smallpox in people, it is contagious, and spreads from one horse to the other by germs. The way the disease is carried from one horse to the other is from the scales, which contain the germs, getting on the groom's ciothes, the saddie or harness, and in this way it is communicated to enother horse, where it gets into the blood and sets up the disease. This discase bes to run a course, and it generally takes from nies days to two weeks before the animal begine to recover. This disenes may be communicated from the horne to the man, cows or other animals, so it is well to be careful when around a cass of this kind and not allow the sales or scabe, which fall off the horse, to sot onto you.

Symptoms-There is more or less fever, the pulse quick and weak, the animal is thirsty and does not care to eat much, red patches appear upon the skin, with a small hole in the center of anch blotch, from which cozes a watery serum. These patches vary in sies and are apt to be found on any part of the body, the skin becomes very sore and tender, the mouth is core and saliva koeps running away from it, the throat also seems sore and it appane dificult for bim to swallow. In the courm of ais to 
fifteen days the red spots dry up and the scales fall off and the animal gradually recovers. It is these scales which fall off that, when they are carried to other animals, spread the disease.

Treatment.-The treatment is simple: Keep the animal from other horses, feed on soft food with lots of boiled flaxseed in it, if in the spring of the year, grass is best. Give

Sulphur ................................ ponnd.

Nitrate of Poiabh or Saltpetre........................

Mix thoroughly together and give a teaspoonful three times a day on his tongue, which is all the medicine he will need internally. Attend to the animal's general comfort, keep him warm and do not expose him to the cold, for this would be liable to kill the animal if it drove the rash in from the skin. Wash him all over where the scabs are once a day with the following mixture.

Creolin........................ bunce, or 4 tublespoonivl.

Rain W ater ................... 1 quart.

Shake well together and apply with sponge or cloth and this will kill all the germs of the disease as they come out on the scabs; rub him once a day and this will keep the disease from spreading. The only danger in this disease is letting the animal get cold and driving the rash in from the skir, which poisons the blood. After the animal gets better it is best to gather all the straw and manure out of the stall he has been in and burn it, then close the stable up and burn sulphur in a dish, which will kill all the germs left in the stable.

GLANDERS.

This is a very contagious or catcuing disease in the horse, and one of the most serious and loathsome diseases the horse is liable to. It occurrs in two forms, chronic glanders and acute glanders. This disease has existed for thossands of years, and has been treated by every kind of medicine known, and nothing has ever effected a cure.

\section{CHROMC GLANDERS.}

This disease was common in this country when it was being cleared up, and is now sometimes found in back townships.

Canses.-It is due to germs poisoning the blood, and it is thought that cases of catarrh and nasal gleet have terminated In a case of glander. Sometimes it has broke out in a severe form while horses are on shipboard during the time of a storm, when the hatches are shut down, but in a case of this kind there must 


\section{DIBEABES $\triangle$ ND TREATMENT. OF THE HORSE. \$159}

have been one of the aumials affected, and when closed up tight the disease began to show itself. If it gets into large, crowded cities where there are large numbers of horses kept in one stable it is sery troublesome.

Symptoms.-It is most often seen in old and debilitated animals. In the chronic form of the disease it may exist for a long time without showing severe symptoms, and might be mistaken for nasal gleet; but if you take the temperature of the animal, you will find it up to from 103 to 105 degrees, while in nasal gleet the temperature will be normal-about 98 or 99 degrees. There is a discharge from the nose; at first it is rather watery, but afterwards it is of a greenish-yellow color and very sticky; it sticks around the nose, and has no smelldiffering from nasal gleet. The discharge in this case will sink in water, while in other diseases it will float. The eyes will have a discharge from them. After the disease has gone on for some time, the inside of the nose becomes full of patches of ulcers which have very little tendency to heal. The lymphatic glands around the head and neck become swollen and hard. The animal falls off greatly in condition; becomes thin and hide-bound, and generally pines away in a lingering death. Man and dogs will take this disease from horses, but other animals are not subjected to it. When it attacks man, it is a terrible disease; so you see the necessity of handling the disease with very great caution.

Treatment.-As soon as there is any suspicion of this disease, put him some place where other animals will not come in contact with him; have only one pail and feed box for him, and allow no other animal to eat or drink out of it; also handle him with care yourself, and be sure there are no cuts on your hands, or do not allow your clothes to touch him, as you might carry the disease to other animals. It is best to send for the veterinary government inspector, and if he pronounces it a case of glanders, have the animal immediately destroyed and burned, and have the stable disinfected.

\section{ACUTE GLANDERS.}

This disease is mostly noticed in Euorpean countries, and not often met with in this country.

Causes.-This is caused from germs getting in and poisoning the blood, the same as in chronic glanders, only that it runs it. course very much more quickly than the chronic form. 
Symptoms.-Fsur or five days after the germs have entered the system the aninal will be noticed to tremble; his temperature will run up as high as 105 degrees or more, and he will run freely at the nose, the discharge being similar to that of cirronic glanders, only it is sometimes streaked with blood. The lungs become affected and inflamed, which frequently causes death. All the other symptoms are the same as in the chronic form.

Treatment and precautions are the same as in chronic glanders.

\section{II. - FEVERS OF THE HORSE.}

They are four in number, as follows: Influenza, purpura hemorrhagica (or what is commonly called button farcy), strangles or distemper, epizootic cellulitis os pink eye.

\section{LNFLUENZA.}

This disease received its name when, at one time, it was thought it was influenced by the stars. It is very common among the horses in America, and is a disease that is liable to affect any organ of the body.

Causes.-It is caused from germs floating in the air ; this is how it spreads so quickly from one horse to another. It is more common in the spring and fall, when the horses are shedding their coats, than at any other time of the year. In 1874 and $187 \varepsilon$ this disease broke out in the form of a regular epizootic, and spread all over the country and caused a great deal wi trouble. Horses that are kept in badly-ventilated stables, especially those that are underground, are more likely to catch this disease.

Symptoms.-The first symptoms are a dull, languid appearance; sweats freely on the slightest exertion; the coat starry and dirty looking; the mouth hot and dry, and there is a slight courh. After these well-marked symptoms set in, by pressing on his throat it seems very sore and causes him to cough. The pulse will be quick and weak, and in some cases will go as high $\mathbf{a} \mathbf{8 0}$ beats per minute. The horse will hang his head, and seems to be suffering from severe headache and nervous depression; and he gets so weak you would imagine you could shove him over. At this stage of the disease, he will breathe heavy and have a peculiar rattling noise in the throat, which you can hear by putting you ear to the side of his throat. His eyes look heary and red; his bowels become costive; and if you take his tompare- 


\section{DIGEABES AND TREATMENT OR' THE HORSE.}

ture It will be up as high as 105 degrees. There will be It is a favorable sign. cettle on the bowels, An this stage of the disease it is apt to may settle on the liver, when inflammation and deith, or, it it will be diarrhoen when the symptoms will vary-sometimes on the lungs and set up inflen costiveness; or, it may settlo necessity of careful nursing during the disease. Thing not allowing the animal to get cold all through this disterists in stanaing which is considered rather a legs and sheath become swollen, to any great extent.

Treatment.-Clothe and attend to the general comfort of the animal according to the season of the year. If the legs are cold, hand-rub and bandage them, and allow the animal to have plenty of fresh air in the stable as long as he does not stand in a draft. Support the system and assist nature to throw off the disease, for influenza will run its course in spite of medicine. Keep the bowels loose by feeding on soft food with plenty of boiled flax seed in it, but never, under any circumstances, give the animal a physic drench. Give him the following medicine:

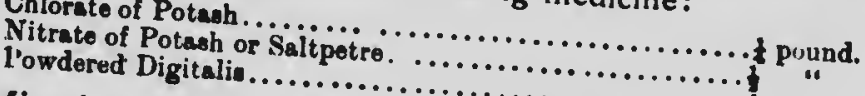

Mix thoroughly together and hours on his tongue with a spoon give a teaspoonful every six small quantities, so he will be able In feeding, give the animal any in his manger; but give able to eat it all without leaving cold water to drink in small it to him often. Allow the alsimal well with the white liniment quantities but often. Rub his throat lungs become affected, applyr or five times a day, and if his sides of the chest every aply a light mustard plaster over the animal seems relieved. In the give a wine glassful of whisky where the animal is very werk, four times a day as a patmeal gruel three or animal; this is a great thing to being careful not to choke the animal is getting better, the eye geep up the strength. When the things about him; the pulse gets clear; he will t.lke notice of stronger-and the appetite gulse gets more naturil-slower and passed off, and the animal seets better. After the disease has following mixtures 


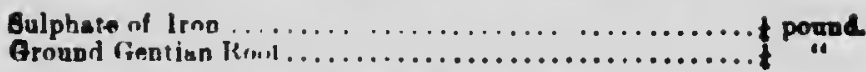

Mix thoroughly and give a large teaspoonful three times a day in his feed. Feed well and give gentle exercise every day. This disease, if treated this way, and allowed to run its course without getting cold, will terminate favorably. But above all things never bleed, or give aconite or a physic in this disease, for it only tends to make the animal weaker and the disease worse.

\section{BUTTON FARCY (PURPURA HEMORRHAGICA).}

This disease is not contagious or does not spread trom one animal to another. It is defined to be some putrid condition or charbonous affection of the blood. The disease mostly affects the capillary blood vessels of the skin, but in some cases it will affect the lining of the lungs and air passages.

Causes. - It generally comes after some other disease, such as influenza, distemper or any other weakening ailment, also in horses that are overworked, thin and run down in condition. When the system is in this state by turning the animal out cold nights or allowing him to be out in a cold rain, and he gets a chill, you need not be surprised to see this disease come on. It is noticed mostly in the spring and fall. The blood gets very thin, almost like water, when the animal is suffering from this disease.

Symptoms. - The disease generally comes on very suddenly, the horse may be apparently all right at night, and in the morning ine will be literally covered with patches of swelling all over the skin. In some cases it affects the animal more in some parts than in others, for instance, we have seen cases $u$ here the eyelids were so swollen the animal could not see out of them, his lips will also be sivollen so much he cannot eat, in other cases his -heath and legs will be badly swollen, or little spots may be seon

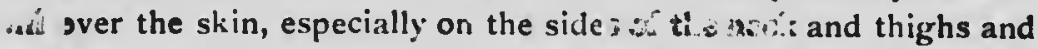
orer the back. The peculiarities about these swellings are that they come on so quickly, and sometimes disappear from one part of the body and come on in another. By giving the animal exercise it will take them down, but afterwards the lumps will come back worse than ever. Examine the lining of the nose, and if it is affected watch out for lung disease. The general symptoms are the animai will seem dull and breathe a little heavier than natural, pulse not much changed, but weak, and he will generally try and 


\section{DISEASES AND TREATMENT OF THE HURSE.}

eat some. Cases have been known where the swelling got so bad that patches of the skin would drop off and leave raw sores.

Treatment.-It runs its course in three to thirty days. Place the animal in a comfortable box stall, attend to his general comforts and keep him warm. Give him the following drench :

Rar linesed Oil..................
Bpirite of Turpentino..............

Mix together and give as a drench, repeat this drench every three days until the animal is relieved. Give him a teaspoonful of chlorate of potash three times a day on his tongue with a spoon until he is better. Feed on good, light, soft food with plenty of boiled flaxseed in it to keep the bowels loose. Do not apply anything externally unless the swelling breaks out; if it does, bathe three times a day, and after bathing apply the white lotion. Never, in any case, attempt to open any of these lumps, for it only does harm. Bleeding is good in the early stages of the disease if the animal is strong enough to stand it. Be very careful in nursing him that he does not get a relapse, for it is liable to cause death. There are cases known where the mouth and nose have swollen so badly that the animal died from suffocation. The after treatment is to build the animal up by regular exercise and good food. Give him the following tonic mixture :

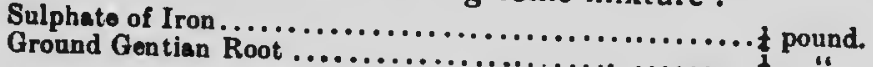
his feed.

Mix thoroughly and give a teaspoonful three times a day in

$$
\text { DISTEMPER (STRANGLES.) }
$$

This is very common among Canadian and American horses. It receives the name of strangles from the peculiar suffocating noise he makes in breathing. It generally attacks young animals from the time they are foals until they are five or six years old, but it may be found in older horses.

Causes.-It is due to germs in the blood, and all coi is are liable to be affected with it. It is seen most in the spring and summer months of the year. These germs float in the air and are taken into the system by th. a animal breathing.

Symptoms. - The animal is dull and languid, and a small amount of work fatigues him. He will probably have a cough and sore throat at first, and there will be saliva running away frum the mouth, the bowels are inclined to be a little costive or dry looking, then there will be a little lump begin to form around the 
throat, sometimes under the throat and sometimes at the sides. This lump gradually gets larger and causes the animal to heve difficulty in breathing, he is dull, hangs his head and soon becomes very gaunt. The disease generally runs its course in from six to twelve days, the abscess or lump around the throat generally breaks and runs, and he nearly always runs at the nose, which is a good sign, in some cases there is more than one lump or abscess forms, and if the poison is in the system it is best to have them brought to a heal and let the discharge out for this gets the poison out of the blood.

Treatment.-This is very satisfactory in most cases : Always allow the disease to run its course, give plenty of pure air, clothe the body according to the season of the year, feed on good food, such as boiled oats or chop stuff with plenty of boiled flaxseed in it to keep the bowels loose. This is a disease that does not require much medicine. Give the following powder :

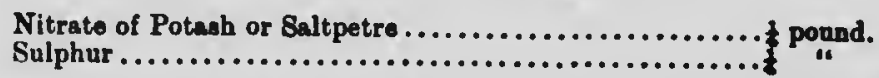

Mix thoroughly and give a teaspoonful three times a day on his tongue with a spoon. Rub the throat and lumps well with white liniment three times a day, apply a hot poultice of half linseed meal and bran to the throat every night, this will draw the abscess or swelling to a head and cause it to break, which is better than lancing. In cold weather it is best to apply a mustard plaster to the swelling instead of a poultice, for after the poultice is taken off the animal is apt to catch cold. Never, in any case, burn sulphur under the animal's nose, because it is apt to set up inflammation of the lungs. In case the lump gets so large around the throat that the animal's life is threatened by choking, you may then perform the operation of tracheotomy, which is performed by cutting into the windpipe on the underside about nine inches down the neck from the larynx (Adam's apple). About thi part of the neck you will find that the windpipe is almost bare-just covered with the skin-cut a hole through the skin about two and one-half inches long, then cut across three of the rings of the windpipe and have the regular tracheotomy tube to put in the hole and keep the rings open so the horse can hreathe through this opening until the abscess or lump breaks and the swelling goes down so he can breathe through his throat, when this occurs take the tube out and draw the skin back to ite 
place by putting two or three stitches across it, then trent it as a common cut by bathing two or three times a day, and after bath. ing, each time apply the white lotion, and the hole will soon heal up. During the time the tube is in the throat it is best to take it out and clean it once a day.

\section{BASTARD STRANGLES.}

This generally follows simple strangles or distemper.

Causes.-Is from the matter in the abscess or lump being absorbed into the system and poisoning the blood.

Symptoms. - Abscesses of the same nature as the one which forms in the throat from distemper are liable to form and break out in any part of the body, sometimes around the shoulder, fiank, neck or hips, but the rest of the general symptoms are the same as in simple strangles. These abscesses will keep forming until the poison is out of the blood.

Treatment.-The :reatment is the same as in a simple case of strangles. Give the same medicine, bathe, poultice and rub the abscesses with white liniment and try and bring them to a head so that they will break themselves, or lance them to get the poison out of the blood, for this is the only way to get rid of the disease. The danger in this discatse is that the abscesses may form inside on the lungs or bowels and cause the animal's death. We have known of some cases where the animal would break out forty or fifty times, depending upon the amount of poison in the
blood.

\section{PINK EYF. (EPIZOOTIC CELLULITIS).}

The disease affects the cellular tissue under the skin, and like the other fevers of the horse, runs a course which takes from six to nine days, and, as a general thing, if treated propcrly, runs its course iavorahly.

Causes.-This disease is due to germs in the air, and when once it starts it sprcials all over the country from one horse to another. There was a yreat outbreak of this disease between 1875 and 1880 , which spread all over the country.

Symptoms. - The animal becomes dull and feverish, and his eyes are red and swollen, and afterwards turns to $\pi$ pinkish color, from which the disease receives its name-pink eye. The animal does not eat well; his temperature runs from a 103 to 105 degrees; his mouth is hot and dry, and he falls off greatly in condition; his manure is hard and dry; there is a discharge from the eyes and a 
*welling of the limbs and belly, and in sume cases he has a cough.

Treatment. - This discase is a very simple one to treat, in most cases, if there is not too much medicine usec. \& Allow the diserse to run its course; keep the body warm; have the stable clean, and allow the animal to have plenty of fresh air. Feed on soft food with plenty of boiled flax seed to keep the bowels loose, and give the following simple medicine to act on the blood:

Chlorate of Potash..............................t pound.

Nitrate of Potash or Saltpetre........................... pound

Mix thoroughly and give a teaspoonful three times a day on his tongue with a spoon. Never mix chlorate of potash and sulphur together, as it will explode and is very dangerous. Give the animal plenty of cold water to drink in small quantities. In cases where the animal is very weak give as a stimulant a wine glassful of whisky in a pint of gruel three times a day, and never, under any circumstances, give a physic in this disease. It is well to wash out the nostrils and eyes twice a day with luke warm water. After a few days you will see the animal began to take notice of things around him and gradually gets better.

\section{CHAPTER XVI.}

\section{DISEASES OF THE SKIN.}

\section{CRACKED HEELS (SCRATCHES).}

This disease is common among horses, and affects the heels, the heels of the hind legs being oftener affected than the front.

Causes.-Anything that will irritate the skin tends to produce this diseasn. In the fall and spring, when there is wet and muddy roads, washing and not properly drying the legs, standing in badly kept stables, or by wearing boots on the legs. Heavy, hairy-legged horses are more subject to it than light horses.

Symptoms.-The affected legs have a tendency to swell and are stift and sore about the heels, the skin becomes cracked and scaly-looking at the back of the heels, and in some cases, when you are driving him, the heels will bleed.

Treatment-The first thing to do is to feed on soft food and give a physic drench consisting of the following :

Bitter Aloes.............................8 drama

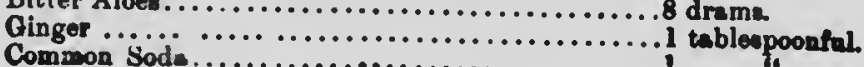




\section{DIGEASES AND TREATMENT OF THE HOKSE.}

Dissolve in a pint of luke warm wiater and give as a drench, allowing the animat to stand in the stable tlie llext dity. After chis give him the following powder:

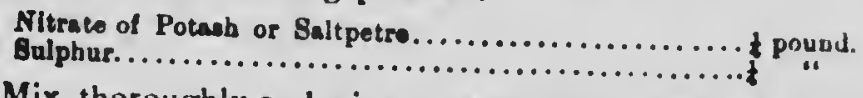

Mix thoroughly and give teaspoonful twice a day in his feed, this will cool his blood and get him in good condition. Bathe the heels with luke warn water and a little castile soap night and morning, after bathing wipe dry with a soft cloth and apply the white lotion. Before you take him out to work rub his heels with vaseline or lard to keef the heels soft and protect them from the dirt and water while you are working him. In cases where the heels are very sore and swollen apply a hot poultice of half linseed meal and bran to them every night for a while until he seems better.

\section{MUD FEVER.}

This is inflammatio, of ihe skin of the legs and the under part of the belly.

Causes are similar to that of scratches, and the disease is seen mostly in the fall and spring during the wet weather, when the cold, muddy water splashes over the legs and belly, or wash. ing the legs with cold water and not drying them properly.

Symptoms.-The legs aro swollen and stiff, the skin is hot and ter.der, and the hair falls off in patches.

Treatment.-Give the same medicine internally as that given for scratches to cool and clean the blood. If the legs are dirty bathe them off with luke warm water and a little castile soap and dry them with a soft cloth; after this don't bathe, but brush off with soft brush and apply the white lotion twice a day, which is sooth. ing and healing to the skin. Keep the animal out of the ret and mud as much as possible. If you have to work him, each time before you take him out, rub the parts affected with vaseline or lard, which will soften and protect the affected skin.

\section{GREASE.}

This disease generally follows cases of scratches that are neglected. It affects the glands of the legs, as well as the skin, and is more common in heavy, hairy-legged horses that have round, fleshy legs. It may be caused from bad blood and swollen legs, and is more often seen in the hind legs than in the front ones. It is also brought on by clipping horse's legs in cold, wet weather. 
188 THE: VETERINARY ISCIENCE.

Symptoms.-There is a thickening and swelling of the legs, the hair stands out on the legs, and they are hot and tender, and there is an vily discharge from around the heels, which has a bad smell in some cases. This is how the disease got its name, greasa When the animal is working the swelling goes down, but comes back again during the night.

Treatment.-It is hard to effect a complete cure, but you can relieve the animal to a certain extent by giving a physic drench, and powders, same as are mentioned in scratches, to cool and clean the blood, feed on soft food, bathe the legs with warm water and sastile soap twice a day; after bathing rub dry and apply the white lotion with a few drops of carbolic acid in it to destroy the smell, poultice the legs every night with hot bran and linseed meal to soothe and draw the oily, stuff out of them. This will generally fix the legs up in good shape for some time. In cases where it is very bad and in the "grapous" stage, and theie is little red growths around the heel, which look like a buncl: of grapes, burn them off with caustic potash or chlorate of zin:. which is in the form of little sticks.

\section{SIMPLE ECZEMA.}

This w...isce is sometimes mistaken for nuange, but unlike mange, it is not caused by germs or parasites working in the skin. It is mostly noticed in hot weather, when the animal is fed on very hot food, which heats the blood, such as barley and other hot foods.

Symptoms.-First there is a dryness in the skin around the head, neck and tail, then little pimples will form, which will break and run a watery-looking fluid. Alter the animal is brought in from work he will be very itchy and rub himself against the manger until the skin is almost raw.

Treatment.-You can relieve the disease at the time, but when a horse once hecomes affected with this disease it will generally break out every summer afterwards during hot weather. Give the animal a physic drench and powders the same as are mentioned for the treatment of scratches to clean and cool the blood, and rub him twice a day with any of the following washes: Corrosive sublimate, one dram to the pint of rainwater, mix together and sizake well before using; creolin may be used, two tablespoonlinls to the pint of water, mix together and shake well before usiny; tincture of iodine may be used, two drams to the pint of water and sliake well belore using. Of the three receipts 


\section{DISEABES AND TREATMKNT OF THE HORSE: U(i!!}

mentioned, the cheapest and favorite one, and the one we use mostly is the creolin, which will cost about two or three cents, and acts as well as any. The way to apply the lotion is firs to take a fine brush and brush all the dust out of the skin and then apply the wash by rubbing it all over the affected skin with a sponge or cloth Do this twice a day until he stops rubbing himself.

\section{KETTLE RASH (SURFEIT).}

Causes.-This is generally caused from feeding hot and overripe food, or giving a drink of cold water when the animal is heated, or from overheating the animal by druing him too fast.

Symptoms. - Small pimples will appear in the tkin around the head, neck and shoulders, but may affect the sikill in $u^{\circ}$ hel parts of the body. This disease is noticed at all times of the ye is.

Treatment.-Give the animal a physic druncin suminting of

Bitter Aloes ............................... to lu trams.

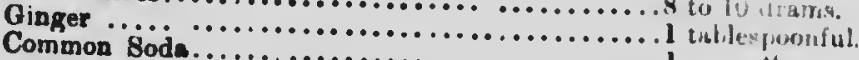

Mix in a pint of luke warm water and give as a drench, allow the animal to stand in the stable the next day, feed on soft food, and follow up after this with the following powder:

Ground Gentıan Root............................ pound.

Nitrate of Potash or Salt petre.........................

Mix thoroughly together and give a teaspoonful twice a day on his tongue with a spoon until the pimples disappear.

\section{WARTS.}

Warts are thickenings or growths on the skin.

Causes.-It is difficult to say what is the cause, but some animals seem to be more inclined to warts than others, and they may be found on any part of the body.

Treatment.--If the warts have a neck to them they are easy got rid of by what is known as cording them, that is tying a smail, strong cord on th: wart as close to the skin as you can tie it ; by tying it very right it will stop the circulation of the blood in the wart and cause it to die and fall off in a short time. If they have a large neck and you cannot cord them cut them off with a sharp knife or scissors, and burn them a little with caustic potash, which will kill the roots and stop them from growing again. They are also nicely taken off with an ecraseur, if you have one. 


\section{MBLANOTIC TUMORS.}

These tumors only affect gray horses, and are found mostly to be arnund the tail, sheath, lips and ears, but may be found on other parts of the body.

Causes.-The exact cause is not known.

Symptoms.-These tumors are generally small, varying irom the size of a bean up to the size of a pigeon's egg, and are in bunches. They are not sore to handle, nor do they break ou', but simply grow until they cause trouble to the parts they are in

Treatment. - As long as they do not interfere with the anima! in any way it is best to leave them alone, but as soon as you fear the! are going to cause trouble it is best to cut them off by using a sharp knife and putting Monsell's solution of iron on them to stop the bleeding; or tie a tight cord around them allowing them to drop off themselves the same as a ivart; or take them off with an ecrasure, which is an instrument for that purpose. After they are off treat the part as a common wound by bathing twice a day with luke warm water and applying white lotion each time after bathing.

\section{MANGE.}

Canses-This is caused from a germ or parasite working down into the skin and sct:ing up the disease. One horse will catch the disease from another, also men and other animals will take the disease from the horse, so you see it is best to be careful if you think the animal has mange. It is most seen in animals that are in poor condition, with long, dirty hair, but it will affect animals that are in good condition. The disease is generally carried from one horse to another by the groom's clothes, harness or brushes.

Symptoms.-The insects burrow down into the skin and set up an irritation which breaks and runs a watery discharge, the hair falls off in patches, and the animal is cxtremely itchy. The dis. ease generally commences around the mane and tail, and gradually spreads over the body. To make sure of the disease being mange examine a few of the scalus under the microscope, and if you find the small germs or parasites in it you will know that it is a case of mange inu have to deal with.

ireatment. - Apply something that will destroy the germe or parasites in the skin. If the horse's hair is long, clip him, ana wash the body off with luke warm water and a little sonp; than apply any of the following wahes? 
Carbolio Acid.................... ounce or 1 tablenpoonful

Sweet Oil..........................

Mix and shake well together; rub it around his head, neck and shoulders the first day; the second rub it around the chest. belly and over the back; and the third day put it over his hind quarters and legs. It is best not to go over the whole body the same day, as too much of the carbolic acid would be absorbed into the system and might cause poisoning. Another very good wash, and one we think better than the above, is:

Creolin.........................2 ounces or 8 tablespoonfula.

Rain Water........................ quart.

Shake well and rub in thoroughly all over the skin twice a week until the parasites are killed. This is by far the cheapest and best remedy known; you can cure a case for ten cents. To prevent the disease from spreading to other animals, wash with carbolic water, everything that he has come in contact with, that is, a few drops of carbolic acid in warm water; this will kill the germs or parasites and prevent the disease from spreading. Feed on suft food and give a teaspoonful of sulphur in his food twice a day.

\section{RINGWORM ON HORSES.}

Causes.-It is caused from germs or parasites working in the skin, but is not so common in horses as in cattle.

Symptoms.-It often attacks the animal around the eyes and nose. The germs or parasites work in circles, which causes the hair to fall off and leaves round, bald spots. If not checked, it will soon spread over the body. Men are liable to take this disease from horses and cattle, and horses and cattle are liable to take it from men.

Treatment.-The best and cheapest remedy, and never known to fail in our experience, is crude petroleum oil as it comes out of the ground. This can be bought at almost any store in the country or city. The way to use this is to paint it over the spot where the ringworm is working, and let it go a half-inch over the edge of ringworm on to the good skin so as to check the disease from spreading. Apply this once a day until the ringworm is gone. If it blisters the skin, stop using it for a day or so and then continue agaill. Another very good remedy is to paint the spot where the ringworm is with tincture of iodine every two or three days until the ringworm is gune. 
LICE ON HORSES.

The lice may be common horse lice or hen lice. The hen lice are very small and reddish looking, and travel very fast. They get on the horse from being too near a lolisy hen house, or from hens roosting in the stable. The horse lice are larger than the hen lice; they have a long, brownish body and travel very slowly, and they are generally found on horses that are turned out and have long, dirty hair.

Symptoms.-The horse's coat looks rough; he does not thrive well, and keeps rubbing his sides, neck and tail until he has the hair worn off, and he seams in perfect misery. By examining the hair closely you will see there is lice on him.

Treatment.-Kill the lice by washing the body off well with luke warm water and soap, then dry him off by rubbing him with cloths, and apply the following wash:

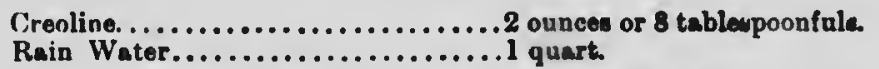

Shake well and apply all over the body every third day by rubbing it well into the skin. Keep the treatment up until you have all the lice killed. Another very good remedy is a plug of "black-strap" chewing tobacco well cut up and steeped in a gallon of rain water and rub well in all over the body every third day until the lice are killed.

CHAPTER XVII.

\section{DISEASES OF THE BRAIN AND NERVOUS SYSTEM IN GENERAL.}

\section{INFLAMMATION OF THE BRAIN AND ITS COVERINGS (PHRENITIS).}

This is not a very common disease, but is sometimes met with. Congestion first sets up, which is followed by infammation.

Causes.-From a tumor growing around the brain; or a severe injury to the skull, with or without fracture; or continued exposure to the heat by being out in the hot sun will cause it; it is also sometimes caused after a case of distemper or strangles, where there is an abscess formed in the brain; also from other causes we cannot account for.

Symptoms.--The first symptoms are marked dullness. If the animal is standing in the stall, he wil! rest his head against the manger; the pupil of the eye will be very large: his pulse will be 
beating quite strong, but will beat slow sometimes-orly twenty times por minute-and there will be a peculiar snoring noise made in breathing. After this dullness passes off, then there will be the reverse takt place. The animal will be greatly excited-seems perfectly mad, and acts like a mad horse; the pulse, in this stage, becomes a great deal quicker, and the breathing louder; the animal reels around in his box with his head very high, and in some cases will rear up and put his front feet in the manger; and at times he moves like a piece of machinery. Sometimes he will be noticed to be walking around in his box with his head to one side; this is caused from the brain being affected on that side. In some cases, if you try to lead him he will fall down; but at times he will have quiet spells, after which the exciting symptoms will again return and be more alarming than at first. We have seen cases where the animal would twist his head down between his front legs and hold it in that position.

Treatment.-It is dangerous treating an animal with this disease, and you have to be careful in going around him. Give him a good physic drench consisting of:

Bitter Aloes............................10 tn 12 drsms.

Ginger................................ I tahlenpoonful.

Common Soda............................... 1

Mix in a pint of luke warm water and give as a drench. One hour after the above drench give the following:

Bromide of Potassium.............. 2 drams or I leasponful.

Fleming's Tincture of Aconite.............. 10 ilmps.

Mix in a pint of cold water and give as a drench every two hours, and apply cold water cloths and ice to his head until he frets relief; cover his body up nice and warm with blankets. In a case where the animal is in good condition, and you notice the disease coming on, bleed him; take a half or three-quarters of a pail of blood from him. If you bleed him, follow up with the above treatment, but only give him about eight to ten drams of hitter aloes and not so much aconite.

\section{SUNSTROKE.}

"This disease is common to all animals, and more especiall! " man. It generally attacks hard-working horses in the hot mon..,s of summer It is a congested state of the bluod vessels of the brain, with loss of power and feeling.

Causes.-Exposure to the hot sun, as a general thing, and - opecislly so if the horse has heen hich ted and bept in a poorly 
ventilated stable. It is often seen in taking a horse out of a pasture field and giving him a hard day's work in the sun when bo is not used to it.

Symptoms.-The first symptoms are duliness and dryness of the skin, and if the horse is working he will not be sweating as much as he should; he will also be noticed not to take his food very well, and have a staggering gait when he is walking. These symptoms may be noticed two or three days before the disease sets in. If he is working he will finally stagger and fall down, he may then struggle for a short time, but, finally, will lie quiet, with complete loss of power and feeling; if you prick him with a pin or knif he does not feel it, the pupil of the eye is very much enlarged, the pulse quick and weak, he breathes heavy, and when yoi try to get him up he will not be able to help himself at all.

Treatment.-Apply cold, wet cloths and ice bags to the head around the brain, and keep these on until he gets relief, and also give

Swoet Spirite of Nitro...............1 ounoe or \& thblespoonfule.

Whinky......................... I wineglassful.

Mix in a half pint of cold water and give as a drench. Repeat this every hour and a half or two hours until he gets relief. Be careful in drenching him while in this state for fear of choking him. As well as the above drench give a dose of physic consisting of

Bitter Aloes............................. 8 to 10 drarna.

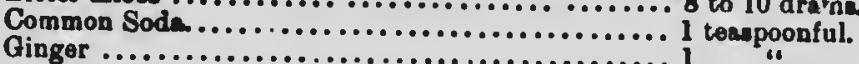

Mix in half pint of luke warm water and give as a drench. If the animal seems to take notice to things around him and wants to eat, give him soft food with boiled flaxseed in it, and give plenty of cold water to drink, in small quantities at a time, but often. If the horse lays for any length of time turn him over two or three times every day, this will prevent his lungs from becoming affected, and he will lie easier. Keep the body very warm with plenty of blankets, this will have a tendency to draw the blood away from his head. In this case, as in others . Asis i... animal is down keep plenty of dry bedding under hir.. As soon an be wants to get up, and seems able, help him to his feet.

\section{CONCUSSION OF THE BRAIN.}

Causes.-It generally occurs in a horse when he is running away and strikes his head against something, or in rearing up and falling back and striking the pole of the head. In some cases he gets better quickly, while in other cases he may die very suddonly. 
Symptoms.-In a pure case of this the animal looses all motion and feeling, he becomes completely paralyzed, and may lie wirhout much signs of life. The pupils of the eyes will be very large, his pulse will be very weak. If there is no sign of fracture of the skull bones there is hopes of recovery. He will first begin to show signs of consciousness hy trying to get up, but will rise on his hind legs first, and it may be some time before he will be able to rise on his front legs. In some cases the animal gets better quicker than in others, according to the amount of injury to the brain.

Treatment.-Same as that yiven for sunstroke.

\section{STOMACH STAGGERS (MEGRIMS).}

Causes.-It may be caused in various ways. Anything that will interfere with the flow of blood to the brain, such as heart disease ; from indigestion; from horses working in a tight collar; or from a small tumor growing and pressing on the brain. Very nervous animals are more subject to this than others of the opposite temperament.

Symptoms.-The horse will be attacked suddenly; he staggers and becomes unmanageable and falls to the ground. These symptoms may pass off in a few minutes, and the animal apparently seems as well as ever. A horse once affected with this disease is unfit to use for single driving, for he may take one of these fits at any time and fall down without showing the slightest sign before it.

Treatment-Dash cold water on his head until he comes to, ?nd afterwards give him a physic drench consisting of

Bitter Aloes ............................. to 10 dram

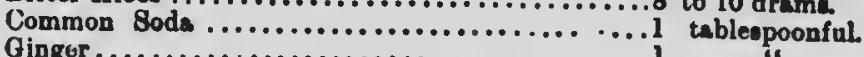

Gingur.....................................1

Mix in a pint of luke warm water and give as a drench. If there is anything wrong with his stomach this will generally relieve him, and it might be he would never have another attack of it. If it is from a tight collar, put a large one on him. In some cases it is recommended to give after the physic a teaspoonful of bromide of potassium in his feed twice a day, for a while, to act on his nerves.

\section{INFLAMMATION OF THE SPINAL CORD AND CUVERINGS (SPIMTIS).}

Causes.-It is sometimes caused from the animal injuring its back by falling over a bank while ruaning away, by severe exertion from nervous excitement. We have seen a case where a colt, running in a pasture field, fell and hurt himself. It may alse by brought on by throwing an animal. 
Symptoms.-At first the symptoms may not be so well marked, but they gradually come on. The animal seems very feverish and weak, has a staggering gait, and will sometimes bo noticed to strike his hind fetlocks in walking, and, in some cases, if you go to turn him around he will fall down, and, as a general thing, if the disease is allowed to run on, it soon causes paralysis and death.

Treatment.-Give a physic drench of

Bitter Aloes............................ . 8 dram.

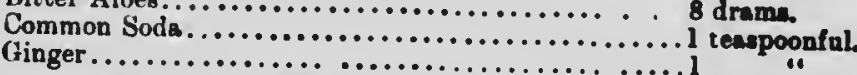

Mix in a pint of luke warm water and give as a drench; also, give the following powder :

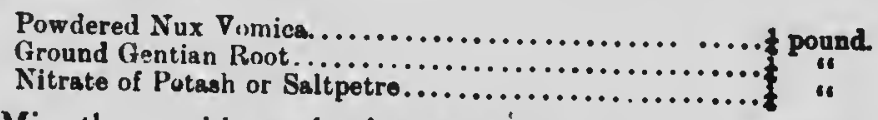

Mix thoroughly and give a teaspoonful in his feed or on his tongue with a spoon every night and morning. Keep the animal very quiet in a comfortable place and blister him along the back with a mustard plaster-quarter of a pound of mustard and enough vinegar to make it into a paste, put this .plaster on every day for a few days. When the horse is getting better and his back very sore where you blistered him, oil his back with sweet oil, lard or goose oil. Feed the animal on soft food with plenty of boiled flaxseed in it to keep his bowels loose. If the animal gets down always assist him in getting up, for when once be gets off of his feet entirely there is very little hopes of recovery.

PARALYSIS.

Paralysis may be in the complete or partial form. Complete paralysis is when there is loss of motion and feeling all over the body, and in cases of this kind death soon comes on. Partial paralysis is where there will be one part of the body affected, such as the hind quarters, or he may be paralyzed in one side. If the spine is affected all of the parts behind the affected part will bo paralyzed.

Causes.-From an injury to the brain or from tumors growing around the brain or spinal cord. Nervous excitement and intoxicating liquors cause this disease in man. In stallions it is caused by being put to too many mares, or frum a horse getting cast io the stall and hurting his back; throwing an animal for an operation may hurt him ; in hunting horses, or other horses, it may be caused from slipping and straining the muscles under the spine, or from a fracture of the spinal bone. Sometimes, 
when a horse has fractured his ribs he cannot ret up. Thes disease is more often seen in cows than in horses.

Symptoms.-If it is a case where the paralysis affects the one side of the body, the animal cannot walk straight, but goes around in a circle, and has not the proper use of that side. In a case where it affects the hind quarters, the animal. when he lies down, cannot get up; he will raise on his front leirs, but cannot get up on his hind legs, and if you do not help him onto his feet, he seems very uneasy; but during the time he is down he will eat and drink fairly well. If you prick him with a pin in his hind part he cannot feel it. In cases of complete paralysis, when he cannot move at all, he soon dies.

Treatment.-If you think that he could bear his weight on his legs if he was up, raise him with pulleys or slings. Apply a mustard plaster over his back if the weather is warm, but if the weather is very cold, instead of applying musta:d, put a half-pail of hot salt in a bag over his kidneys and blanket him so he will be hot, for what you need is heat to the back in these cases. In cases where the animal can stand fairly well, when he is up, keep him on his feet as much as you can, for a horse can stand a couple of weeks without hurting him. If you allow him to get down, and he cannot get up, he will only flounder around and may hurt himself. Give the following drench :

Bitter Aloes................... \& drams.

8weet Spirite of Nitre ............. ounce, or \& Lableapoonflata

Common Boda...................... tablenpoonful.

Gingor ........................... "

Mix in a pint of luke warm water and give as a drench; thi will get the bowels and kidneys acting; then give him the follow lat powders to strengthen the nerves:

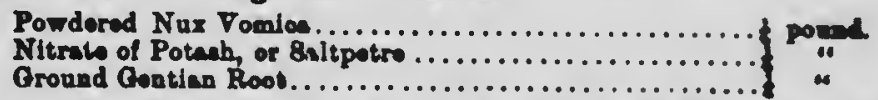

Mir thoroughly and give a teaspoonful three times a day oo his tongue with a spoon, or in soft food with plenty of boiled fas seed in it, and if he is able to walk give him gentle exercise every day.

\section{INFLAMATION OF THE BRAIN AND SPINAL CORD AND TBEIR COVERINGS (CEREBRO-SPINAL MENINGITIS).}

This is congestion of the brain and spinal cord and their coverings, and if, in this state, they do not soon get relief, it curns into inflammation. This is, comparatively, new diseasa and is not known in any other cointry but ow this continent 
Cansen-From horses being kep't in m iruwded stable that is poorly ventilated and badly drained, or from eating certain klnds of grasses that contain too much narcotic properties, such as are grown in swamps.

Symptoms.- They vary according to the parts most affected. There will be trembling noticed in the different parts of the body; the animal seems very dull and does not feed. As the disease goes on, the animal will have a peculiar jerking in the limbs, and then he will stagger, fall down and be unable to rise; the pulse will be quick and weak; the bow sis usually costive, and his water is of a dark brown color. At first he generally lies in a dull, stupid manner, breathing heavy, and sweats freely if it is very warm. After a time the dullness passes off and the animal becomes delirious. If you give him water to drink, he will try, but he cannot, as there is paralysis of the gullet. These symptoms gradually get worse until he dies. Wherever you see one horse affected there is apt to be more affected, for the same cause that brought it on him will bring it on the others.

Treatment.-If noticed before the animal is too had, there is hope of recovery; but if the animal is down and cannot swallow before he is noticed to be sick, the chances are against him. As soon as the disease is noticed, take one half-pail of blood from him and give the following drench :

Bitter Aloen $\ldots \ldots \ldots \ldots \ldots \ldots \ldots \ldots . .8$ dramm.

Sweot Splrits of Nitre ................. unace or 4 tablenpoonfale

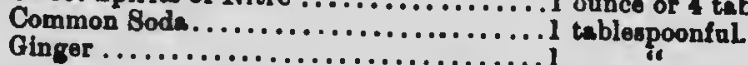

Mix in a pint of luke warm water and give a drench, then follow up with the following powder:

Powdered Nux Vomica

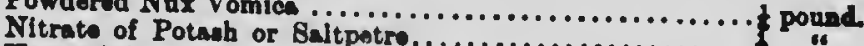

Hyponulphite of Boda...............................

Mix well together and give teaspoonful on hls tongue every three hours until he gets relief. Apply a mustard plaster and hot cloths along his back rand cover the body warm. If the animal gets down turn him over from side to side three times a day, and be very careful while drenching for fear of choking him. Feed on soft food, with plenty of boiled flax seed in it, and give plenty of cold water to drink.

\section{CHOREA.}

This is an affection of the nervous system, where the horse loses the power to back up. 
Causes, - It is due to some injury to the spinal cord, and sometimes comes on a colt after castration, but we think he must have been injured while throwing him.

Symptums. - The horse will be useful, and as long as he is going ahead he will be all right. He can pull or do anything in the shape of work until you go to back him up; as soun as you try to, you will find that he cannot back; the muscles of the hind quarters will begin to shiver, his tail will rise up, and, no matter how much you force him, he cannot back up. This disease is more common in nervous animals.

Trestment-If you notice it when it is coming on, gives

Pordered Nox Vmic . No.............................. pound.

Mix thoroughly and give a teaspoonful three times a day in soft food. Rub him over the back and hips with the white liniment twice a day. If he is in good condition, give him a physic drench of

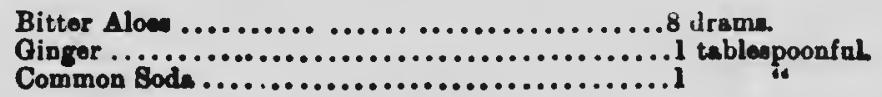

\section{STRITGHALT.}

This receives its name from the way the animal acts.

Causes.-This is caused from some affection of the nerves which go to supply the part affected, but really what parts of the nerves affected has never been found out. This disease is more often seen in highly nervous animals, and is caused from applying severe blisters to the legs, which irritates the nerves, or clipping the legs and having him out in the cold. It is noticed to follow after castration, elther from the buralng of the rope on the fetlock or the irritation of the cutting.

Treatment-If this dlsease is once well establishod it is incurable, but if noticed at the time it is starting give the animal a physic of

Bitter Aloes .......................... to 10 drame

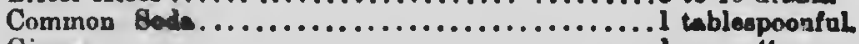

Ginger ..............................

Mix in a pint of luke warm water and give as a drench. Leave the animal in the stable the next day, and follow up with the following powder, which acts on the nerves: Bromide of Potassium, two drams or a teaspoonful, twice a day in his food, or on his tengue with a spooks 


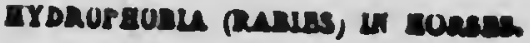

This disease novor oecurn in a bores unlose bo has bes bitu by a mad dog or cat.

Symptoms, - He shows restlesenese, will bite and rub where he was bitten. These symptoms are followed by brain disturbance, and the animal will act somewhat as if he was suffering from inflammation of the brain; but in this disease the animal is wicked, and will bite at you in a peculiar way, just like a vicious dog. The animal becomes more excited, turns round and round in his atall until he gets weak and falls down, and gradually keepe getting worse until he is relieved by death.

Treatmant. - If the horse is showing the above symptoms, and he has been bitten by a dog, have him destroyed at once; but if you were called to see a horse after he was bitten by a mad dog, and before he shows the above symptoms, take a sharp knife and cut away the flesh arcund the bite, then burn it with a stick of caustic, potash or nitrate of silver. If you have not these, burn it well with a red hot iron or anything to destroy the poison.

\section{LOCKJAW (TETANUS),}

This is purely a disease of the nerves and receives its name by the way it acts on the muscles of the jaw. Sometimes they become so set that you could not pry the animal's mouth open. There are two forms of this disease, one is known as the traumatic form, this is where the disease follows an injury or operation, which can be seen; the diopathic form of the disease comes on the animal without any visible injury or operation. In this case it is thought to be brought on from worms or bots in the stomach or from being exposed to axtrome cold.

Causes.-The general causes of this disease are when a nal runs In the horse's foot, it may follow a stake or cut just about the time the wound ls heuled up, and somes on from eight to twenty-one days after being injured. It may also come after wound which seem to be healing extra fast. It follows operations, such as docking, nicking horse's tail or cestration; it sometimes occurs after very severe blistering. In referring to the disease following castration, it is more apt to come on when a borse is allowed to run through a river or spring creek, or being left out in cold winds. As an example, twenty-four horses were castrated and bathed in cold water a few days after, and sixtea 
of of the twenty-four died of lockjaw. Thls shows you the meessity of having the operation done in fine weather aid the colt kopt away from damp plitces. The disease is noticed to come on just about the time the colt is healed up, the same as in other wounds.

Symptoms.-There is not much difficulty in telling a case of this kind. At first there is a peculiar stiffness of the body, and he walks with his neck high and his head stuck out as if he was vuffering from sore throat, he has a peculiarly high action, and if he is on pasture he cannot get his head down to eat, except in a very mild case of the disease. The horse, in most cases, will tiy to eat if he can, especially at the commencement of the disease. If you walk up to him and suddenly excite him he will almost groan, as if in pain, his head will fly up and the haw of the eye will fly over the eye so that you can hardly see it. When he is excited his tail will raise up and the muscles all over his body seem hard, drawn and set, and the animal will almost fall down. In a case of this kind examine the mouth and you will find that it can only be opened a little. If it is a severe case these symptons will gradually gro worse, and in a few days he will get off his feet and will be unable to raise them; he will have fits of severe struggling and be in terrible agony, and the only thing that gives him relief is death, which soon comes.

Treatment.-In a very light case of the disease, if in the spring and the animal is able to get down and eat grass, it is best to leave him out in a level pasture field where there is noihing to disturb him. In a case of this kind do not go near him to give him medicine, but watch him to see that nothing turns up that you are not expecting, because catching a wild colt in the patsture to give him medicine would only excite him so much that it would do more harm than good. There hats been all kinds of tréatment tried for this disease, but the best is to give the animal, as soon as noticed, a dose of physic consisting of

Blttor Aloes.......................8 drams.

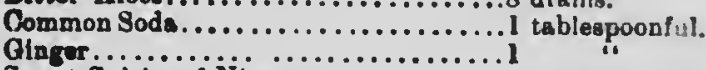

8 reot 8pirit of Nitro................ I ounce or 4 tablesponnfult.

Mix in a pint of lal:e warm water and give as a drench, being careful not to excite the animai inuch while giving it to him. In case it is caused from a nail in the foot, pare the hole out well where the nail went in and poultice with hot linseed poulsices, 


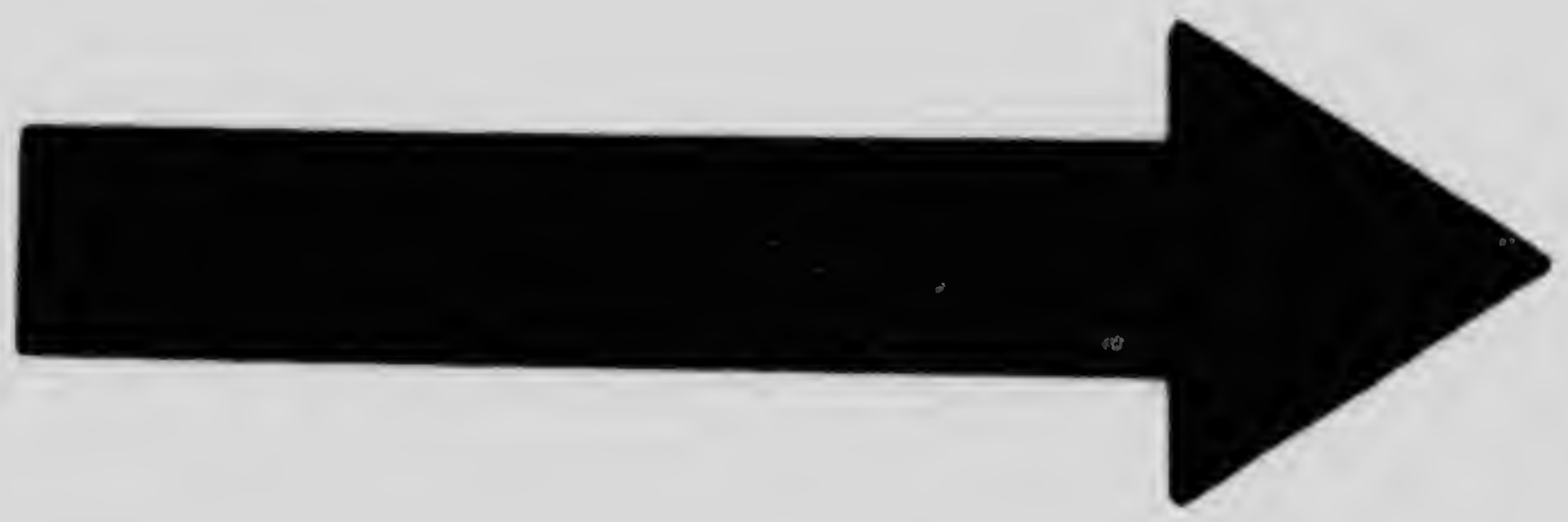




\section{MICROCOPY RESOLUTION TEST CHART}

(ANSI and ISO TEST CHART No. 2)

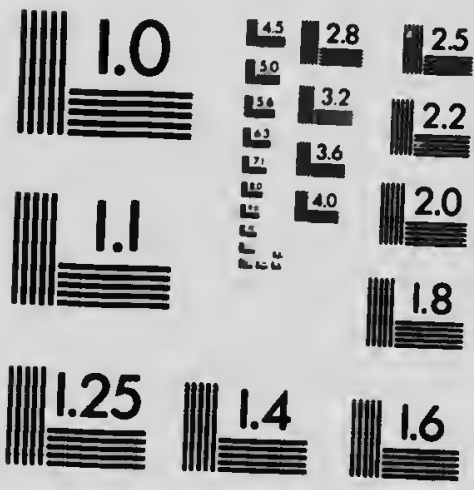

APPLIED IMAGE Ine 1653 Eost Moin Slreet

Rochester, New York 14609 USA

(716) 482 - 0300 - Phone

(7i6) 288 - 5989 - Fax 
changing them often to keep them hot. Keep the foot poulticed until the animal seems reliever. If it is from a wound bathe well with luke warm water three or four times a day, and paint the foot over with fluid extract of belladonna after each bathing. Keep the animal in a comfortable stable, free from noise or anything that will excite him, as perfect quietness is what is wanted in treating this disease. Give one dram, or one teaspoonful, of fluid extract of belladonna on his tongue with a spoon three ti.ies a day, and feed on soft, easy cliewed food, such as gruels of chop stuff with boiled flaxseed in it-make the gruel so he can drink it down-if in the spring give him grass, if in other times of the year scald his hay and make it as soft and easy to eat as you can. It generally takes from three weeks to thirty days for the disease to run its course. It is best not to rely too much on medicine, for it takes time for it to run its course. Good nursing is better than medicine in this disease. As a general thing, before the end of the third week, he begins to get better.

\section{CHAPTER XVIII.}

\section{DISEASES OF THE LYMPHATIC SYSTEM.}

\section{WEED IN THE LEG (LYMPHANGITIS).}

This disease also gets various other names, such as water farcy, big leg and Mlonday morning fever. This is a very common disease now in this country, and is liable to be more so, on account of horses beingr better fed and cared for than they used to be. The disease generally affects the hind legs, but sometimes affects the front legs.

Causes. - It is common in hard-worked and highly-fed horses, by letting them stand in the stable for a few days without exercise after being accustomed to working every day and feeding them the same as if they were working; this is why it is seen so often on Monday morning. The direct cause of the disease is from horses getting too much nutriment in the blood, which over stimulates and sets up inflammation in the lymphatic glands in the legs; then when these glands are inflamed they do not absorb the lymph and carry it off as they should when all right, thus the leg becomes very largely swollen with lymph. It is also caused by a horse getting a prick of a nail in the foot, and the soreness extends up the legs and affects the gland: and sets up inflamma. 
tion in them. It is also caused from a horse having bad blood with too much fbrime in it. Heavy horses with sluggish circulation are more liable to it than lighter horses.

Symptoms.-The first signs are the animal will quit feeding, tremble and be feverish, which is followed by lameness and swelling along the inside of the 1-m-usually the hind leg-just inside the thigh. The swelling, at tirst, will be along the line of the lymphatic vessels in the shape of a hard cord; if you press your hand on this cord the animal will immediately throw his leg out and up and seem very stiff and sore; after this stage the leg becomes greatly swollen all the way down and around it, in sore cases as large as a stovepipe, ard it wili be very sore to handle, and is so painful that the horse will lift it from the floor and look around at it. The symtoms of a case in the front leg are simiar, only the swelling starts at the chest and extends down the inside of the front leg. The pulse will be quickened, and the animal breathes heavier than natural. After an animal has once been affected by this disease he is more liable to have it again, and after he has been afflicted with it several times it terminates in what is known as elephantiasis, or big leg.

Treatment-Get rid of the nutriment of the blood as soon as possible, by bleeding; take a half pail of blood from him if the animal is strong and fat, and give him a physic drench :

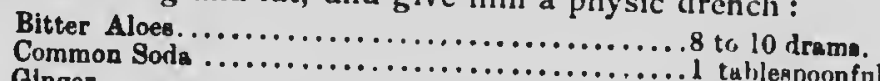

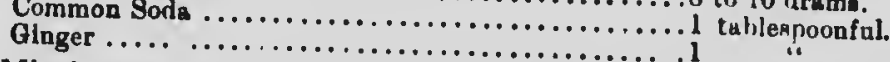

Mix in a pint of luke warm water and give as a drench ; If you bleed, just give 8 drams of aloes, and give the following
powders:

Nitrate of Potesh or Saltpetre....................... pound.

Gruund Gontian Root....................................

Mix thoroughly and give a teaspoonful three times a day on his tongue with a spoon or in his food. Feed on soft food, with plenty of boiled flax seed in it, to keep his bowels loose. Bathe the leg with luke warm water, as warm as you can bear your hand in it, with some saltpetre and vinegar in the water, for nearly an hol - at a time, three times a day, and after wiping dry, rub well with white liniment weakened down nearly one-half by adding more water to it. If in very cold weather, bandage the leg to keep him from getting cold in it after the bathing. Allow him to stand quiet for three or four days until you get the 
Inflammation checked in the gland, then commence to exercise him some every day, and gradually bring him back to his natural habits again. The more he is bathed with warm water the sooner he will get relief.

\section{BIG LEG (ELEPHANTIASIS).}

This is a thickened state of the leg from repented attacks of lymphangitis or weed in the leg. The swelling becomes oryanized and you cammot effect a complete cure in any case.

Treatment.-- (iive the animal . egular exercise, also give him a good physic drench once in a while to keep his bowels rignt. consisting of

Bitter Aloes............................. 8 to 1018 rams.

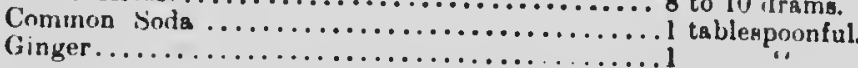

Mix in a pint of luke warm water and give as a drench, then give him the following powder to act on his kidneys and blood:

Nitrate of botash or saltpetre. .................. pound.

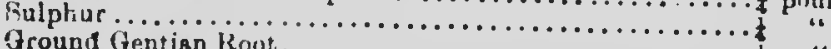

Ground Gentian koot............................ "

Mix thoroughly together and give a teaspoonful in his food twice a day, this will help him more than anything you can do for him. Any time you notice the leg swelling repeat the above treatment, and by keeping his blood in good condition he may make a good work horse for a long time.

SWELLING OF THE LIMBS (ANASARCA).

Causes.-This is caused Irom the lymphatic glands of the legs working slugrrish and not carrying the lymph off. It generally occurs in the hind legrs, and is commonly called stocking of the legs. The nost commion cause we have is where a horse is accustomed to standing in the stible during the winter months and then putting him to hard work in the spring before he gets used to it. After resting during: the nighi his legs will be swollen the next morning. Or, it maly be calused from giving a horse a long journey when he is not used to it; the ne:t morning his legs will be swollen. Also a horse's blood being in bad condition will cruse it.

Symptoms.-There is swelling of the legs during the night, and in the morning when he is taken out the swollen legs will be quite stiff. This swelling will go down after he is kept moving for some time, but will return again the next night, perhaps worse than before. If this disease is not attended to, it is apt to terminate in a case of scratches or grease. 
Trutuent.-Keep the animal from work for a fow daye and tro him a physic consiating of

Bitter Aloet ....................8 drama.

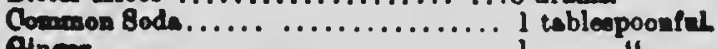

Oinger .................................. 1

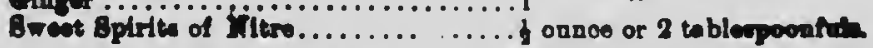

Mix in a pint of luke warm water and give a a drench. Peed on soft, light food, and allow the animal to stand in a stable a fow days after giving the drench. In case the animal is very weak, and you think it is not safe to give him the aloes, give him

Raw Lineed Oil................. 1 pint.

Sweet spirits of Nitre..............

Mix and give as a drench,, and use him the same as if you gave him the aloes; then give him the following powder to act on his kidneys and blood and build his system up :

Nitrate of Potash or Saltpetre...................... pound.

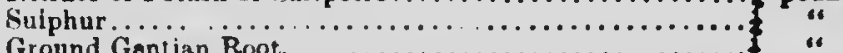

Ground Gontian Rnot............................. "

Mix thoroughly and give a teaspoonful every night and morning in his feed. After he stands a couple days put him at gentle work, not too hard, atso hand rub his legs at night and bandage them, which will keep the swelling down and strengthen the leg. Never leave the bantage on longer than three hours, for if you do it will do more harm than good.

CHAPTLR XIX.

\section{DISEASES OF THE HEART, ARTERIES AND BLOOD.}

\section{I. - HEARI DISEASES.}

These diseases are very uncommon in the horse, but sometimes we have what is known as rupture of the valves and palpitation of the heart.

RUPTURE OF THE VALVES OF THE HEART.

Causes.-1t is hard to tell just what the cause is, but the valves are diseased in some form before the rupture takes place.

Symptoms.-When rupture takes place the horse dies almost inst:unly. for it stops the circulation in the system. In some cases the horse may be subjected to weak spells byfore rupture talies plate, while other times this symptom will not be noticed.

Treatment. - There is monc; and the only way to tell if this caused death is to examine the heart, which will be clotted with 
blood. caused from the rupture of one of the valves in the heart, and also you will see the ruptured valve.

\section{PALPITATION OF THE BFART.}

This is weakness of the heart.

Causes.-It generally comes after weakening diseases, such as the fevers of the horse, lung troubles, or dropsy of the heart.

Symptoms. - The animal will be very weak, and you can hear the heirt thumping in its cavity; the symptoms will be greatly increased when the animal is excited. His pulse will be very quick and weak, and in this state the animal will be unable to do any work.

Treatment.- Keep the animal quiet and strengthen the system as much as you can by good food, and give him the following tonic medicine which acts as a tonic to the heart and system in general :

Pulverized Digitalis

Ground Gentien Root............................ . ponnd.

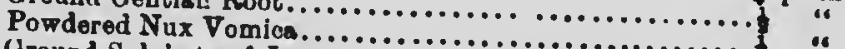

Ground Sulphate of Iron ................................

Mix thoroughly and give a teaspoonful three times a day in tis feed or on his tongue with a spoon.

\section{1. - DISEASES OF THE ARTERIES. TUMOR (ANEURISM).}

This is a disersed state of the walls of an artery.

Causes.-The causes are unknown.

Symptoms.- Tilis dicease often goes on in the artery unknown until the diseased part of the artery will give way ; if it intern. ally, and a large artery, he will bleed to death very quickly; if it is a small artery in the muscles he will not bleed to death, but you will notice a large swelling appear suddenly around the diseased part of the artery, and the artery will bleed until it is stopped by clotting and pressure trom the muscles and skin. The animal w.il be a little weak, but the swelling will not be sore, and pressing on it you can tell there is a fluid in it.

Treatment.-Allow the fluid to remain in the swelling two or three days until you are sure the artery has stopped bleeding, .hen, with a sharp knife, open into the lower part of the swelling : make a big cut into it, and remove all the clotted blood, then take a largo syringe and wash out all the blood with luke warm water with fow drops of carbolic acid in it. After this, bathe 
the parts well with luke warm water twice a day, and inject in the hole each time, after bathing, with the white lotion. Keep the animal quiet and it will heal up in the course of two or three weeks all right.

\section{RUPTURE OP AN ARTERY.}

Causes.-It is sometimes caused from straining while the mare is foaling; drawing heavy; severe extrtion of any kind; or a severe bruise.

Symptoms. - Same as a tumor or aneurism of an arıery, only you wi! not find the artery diseased.

Treatment-This dicease is treated the same as tumor or aneurism of an artery.

\section{III. -DISEASES OF THB VEINS.}

INFLAMMAIION OF A VEIN (PHLEBITIS).

Thls disease is mostly noticed in connection with the jugular relns.

Causes.-Usually from bleeding a horse with a rusty fleam; using a rusty pin or your hands having dirt on them while putting in the pin (so you see the necessity of having everything clean when bleeding); sometimes from a horse rubbing his neck against something after bleeding; from turning the horse out to grass right atter bleeding and allowing him to have his head down, rhis interferes with the circulation of the blood, causes swelling and clotting of the blood, which sets up inflammation.

Symptoms. - There is swelling along that side of the neck you hled him from, and if he is allowed to have his head down that side of his head will also be swollen. The swelling will be hard and paintul when you touch it, and, in a tew days, the clotted blood iormed in the swelling will start to fester and break out in little boils or abscesses along the side ot the neck.

Treatment.-Keep the animal's head well tied up and bathe the sides of the neck with warm water and vinegar four times a day for half an hour at a time, and each time, after bathing apply white liniment. If the neck beals or festers, open the places up with a knife and allow the matter to escape. When you do this, change the treatment to white lotion instead of liniment. Do this until you get all the swelling and inflammation out and the braling places all healed up, then blister, using the following 1 


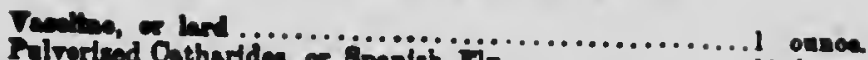

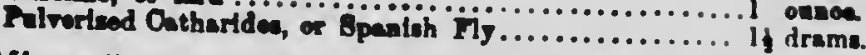

Mix well together and rub the blister along the swollen part of the neck iie the horse's head short so he can not rub it. Rub the blister in well and grease the place where you blistered in three days after; allow lt to remain two or three weeks, or until lt heals up, and if the swelling is not down, blister again and follow out the same directions in this as in the first blister. In after treatment do not turn the animal out to pasture for a year or so, for his head will swell up on account of his not having the use of this vein; keep him in the stable and feed him out of a high manger, and by doing this he will be just as useful as ever, for after a while the other jugular vein will enlarge so it will do the work of both the veins. In buying a horse look at both sides of his neck to see that the veins are all -ight.

\section{IV. -DISEASES OP THE BLOOD.}

\section{BAD BLOOD.}

This is when the blood gets very impure ana the h-rsc does not thrive well.

Causes. - From working very hard and feeding very high, or from turning the animal out to a straw stack and allowing the system to run down.

Symptoms.-The animal will get weak, and will not thrive well, and gets hide bound. The hair will be rough, dry and scruffy; and, if the blood is hot, there will be pimples form over the body; and when he stands in the stable over night his legs will swell; and if he is out in wet weather scratches will come on; and the animal is dull and unfit for work, ard no matter how much you feed him he will not thrive.

Treatment.-Get his blood in good shape by giving a physic drench to start on, consisting of:

Bitter Aloov .....................8 drame.

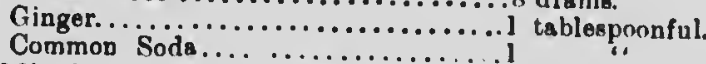

Mix in a pint of luke warm water and giva as a drench. Allow the animal to stand in the stable a couple of days, and feed on soft food with plenty of flarseed in it to keep the bowels loose, then give the following powd :

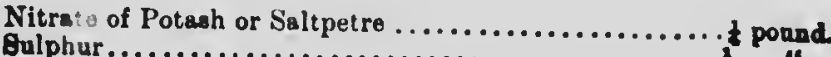




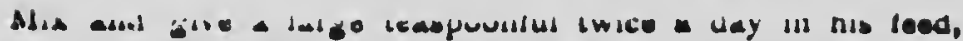
after you have given him this, follow up with the following tonic powder to make him strong:

Grunod Gonthen Root ............................. pound.

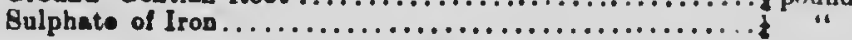

Mix well together and give a teaspoonful twice a day in his feed; if in the spring of the year and you can turn the horse on grass, bleed him, taking half a pail of blood, then turn him out, and this will cure him as quick as anything. When you are treating a horse for bad blood, if you have him in the stable, give him a little exercise every day.

\section{AZOTURIA.}

This disease, at one time, was not very common, but is getting more so all the time.

Causes.-From allowing a horse to stand in the stable and feeding him well for a few days without any exercise, the blood gets too full of albumen, and then, by taking him out and driving him, brings on the disease. When you drive the horse the blood gets heated and he takes in a great deal of oxygen from the air into the blood, which unites with the albumen in the blood and changes it into acids, which are known as hippuric and urea acids; these acids stop the action of the kidneys and then act on the muscular system, and cause the muscles of the back and hips to become swollen and paralyzed. This is the only disease that is noticed to come on horse very soon after starting on a drive. It is more common in the winter months, on account of the animal standing in the stable more, but is liable to come on at any time of the year.

Symptoms.-On taking a horw out of the stable, he will go off full of life for a quarter of a mile to a mile, or even a longer distance in some cases, then you will notlce him break out into a sweat; he becomes stiff in the hind quarters and not able to trot. If you examine him he will be breathing heavy, his pulse quick and weak, and will be trembling about the flanks. Look over the back and hips and rou will notice the muscles swollen and as hard as a board. If $y_{-}$attempt to drive him still further, ne will get so stiff he will not be able to go, and will fall down and not be able to rise, and all the symptoms mentioned above will be increased greatly. His urine will be of a dark red color and very little at a time, for the kidoege are sot acting much. If you 
catch some in a dish, and allow It to stand, the acids will come to the top. In severe cases the lega and ear are very cold.

Treatmeat.-As soon as the symptoms aro noticed, stop driving him and take hin :o the nearest place, for If you keep on driving him be will only fall down and be a great deal more bother to you. When you get him into the stable, cover him well with blankets and let him have a good awoatlng; this will relieve the kidneys, give him a good rubbing all over the back and hipe with white liniment; if you have not got the liniment along with you apply a cont of mustard and vinegar over the back, or even a half pail of hot salt in a bag would be good, for you must get heat to the kidneys to start them to act. Give the following :

Swoet Spirite of Nitre.............. ounce, or \& tableopoonfale

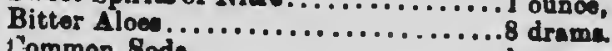

Tommon Boda...................... tempontel

Gingor.............................

Floming's Tinsture of $\Delta$ conite..........10 drope.

Mix is = pint of luke warm water a.ld give as a drench; thls is th get the bowels and kidneys acting. As a general thing, if this treatment is given as soon as noticed, he will be able to work in three or four hours. If it is a severe case, and the horse does not get ralief in three or four hours follow up with the following drench:

Sreet Spirlts of Nitro............. ounoe, or t tablenpoonfule.

Common Boda ................... tablespoonful

Fleming' Tincture of Aconite...........10 drope.

Mix in a pint of luke warm water and give every three hours until the animal gets relief; aiso, keep the heat applied to the back. If the animal is so bad he gots down, tu- him over from side to side, twice a day, and as soon $a$ he abis J get up, help him to his foet. It is well to use slings for a short time every day after he begins to get strong. We eaw oas can whore horse had lain nine days and afterwands got up and was all right again by means of the above treatment without the allings. Feed on soft food and give all the luke warm water he can drink; tend to his general comfort, such as a comfortable stall with good bedding. Watch if he makes water, and if be does not, take it away with a catheter. When the animal is getting better give the following powclers to get his kidneys working 1

Nitrato of Potach or Sultpetro....................... pound.

Mix and give teaspoonful twice a day in his feed. After an animal has suffered from this disaase once be is more apt to be 
Huwles afars. Watch that his kidn re are in good shape, and hitle the animal exercised every lay. If you have fear of a horse becoming attacked with tl:is disease when you are going to drive him let him walk easy for the first mile or so, and then he will bo
all right.

\section{CHAPTER $\mathbf{X} \times$.}

\section{DISEASES OF THE BONES.}

\section{BIG HEAD (JSTBO-POROSIS).}

This disease is more common in some localities than others; it is not met with much in Canada or Great Britain, but is frequently seen in the United States and Mexico. It is a disease which attacks horses from one to four years old, and rarely attacks old horses, and it gradually comes on as the animal grows, without any sigus of soreness, only the bones of the head and legs get larger and lighter and become very brittle, that is, easy to break. Thus it gets the rame "big." It more often affects the bones of the head than those of any other part of the body.

Causes.-It is difficult to say what is the real cause of this disease, but it is supposed to be caused from an animal feeding on pasture land deficient in the salts of lime. Some think it is wholly caused from animals grazing on low-lying, swampy land, where the giass grows long and does not contain the full amnunt of nourishing substances.

Symptoms.--At first the symptoms are not very well marked, but the animal is noticed to be dull, fall off in condition, and hi: muscles get very soft. The animal may run along this way for four to six months, then the true nature of the disease will show itself. The animal will seom stiff in travellng, his.boll; becomes very gaunt, and the bones of the bead will be noticed to be getting larger than natural; then, aftor thls, he bones of the legs may also become enlarged, and as the disenes goes on the bones will continue getting larger, and the animal keeps gradually going down in condition until he dies. In sume cases the bones become so brittle that while he his walking along one of his legs rould reak and he would have to be destroyed.

Trevtment-The treatment is not very successful, and if the disease .las been running on for any length of time it is best to destroy the anima:. If a the carly stages, and he is on low 
puxture, move him to a good, hlgh pasture hold, and give en soonful of culphate of iron in some oate twice a day to build the system up and overcome the disease.

SPLITIS.

This is a bony enlargement on the inside of the leg, between the knee and fetlock, and is sometimes noticed to affect the outside of the leg, and it is noticed to affect the bones of the hind legs, below the hock joint, either on the inside or outside. Any enlargement of the bone along the places mentioned comes under the name of splint.

Causes.-Certain breed of animals are more liable to splints than others. For instance, horses with small, weak bones below the knees, or colts that are very fat, and heavy on their legs, are the most liable to splints. Driving or riding colts on hard roads, or working them on hara roads. Horses that are driven on the pavements of large cities are very apt to have splints, from shoeing too heavy; or from the animal striking his foot against the other leg in traveling. In all of these cases, whether it is due to hard roads, or from striking the leg with anything, inflammation will set in between the bone and the covering of the bone, then there is a deposit of bony matter, this is what causes the enlargement and soreness. When the splint affects both sides of one leg
it is called a double splint.

Symptoms.-At first it is a llttle hard to detect, but when the spint gets any size It is very easy to tell what is wrong, and when a young horae goes lame on the hard road it is well to examine for splinte. The lameness has a peculiarity about $i t$, when the animal is wilkine bo walk. -erfectly cound, and he also stands on the log an if notblog we wrong, but when you come to trot him he will be very lamen and he will drop and raise his head to a sreat extont. Nwase bar in mind thot when a lame horse is trotting hls head zoes down when he atrikes his weight on the sound $\mathrm{sg}$, he does thl In trying to favor the lame leg, and in all cases, no mattor how sure you are about the part the horse is lame in, examlne the foot to see there is no nail in it.

Treatma- - As a general thing it is successful. Keep the horse fr... work as much as possible, and if in summer time bathe the leg in cold water with a little salt in it; do this a couple of times a day, and after rubbing dry, apply the white liniment; teep at this treatment until you cet the infammation and yore- 


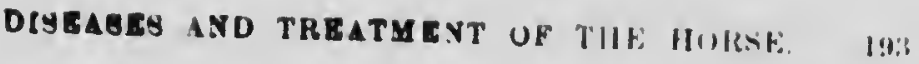

nesa wut of the splint, after this blistor to remove the enlargement.
Cise flie following blister:

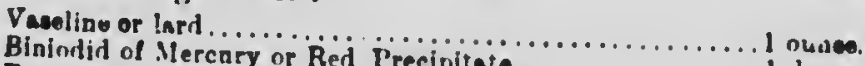

Binindid of Mercney or Red Precipitate...................

Mix thered Camharides or Spaniah Fly...............

an ordinary splint together and there will he enough to blister solint clip it off nnd apply one-third of the is much hair on the rub it in the bettur the hlister works i the more you ; tie his head a little short for aw hours so he cannot get down to bite the blistered part ; lol this stand for three days, then grease the blistared part witb vaseline nr lard, then let it go for two or thre. eks after the first blister and blister again, and follow out ! : se direction as in the first blister, and, if it is not all gonc, saster the third time in two or three weeks more.

\section{SORE SHINS.}

This is inflammation of the covering of the shin or metacarpal bones and nearly alw: ys affects the front legs, but somtimes affects the shin or meta arsus bones in the hind legs. This i more commor in some parts of the country, and is generally sese in young race or trotting horses that are put to severe exertion.

Causes.-It is from hard and continual driving in training young horses for races; from a continual steady strain on the legs, it sets up an infammation in the covering of the shin bones; or fron taking a colt out of the pasture field and putting him to too liard work when he is $n$, used to $i t$; or from running and striking the front of the shil "rainst anything.

Symptoms. - They are $w y$ plain. The colt is very lame $a$ first, and in examining him, if you run your hand down over tha shins, you will find them very sore and lot. He will flinch and jump away from you when you press on the parts affected; and in trutting he drops his head similar to splint lameness. If it in sllowed to run without being treated, a thickness will soon appeas in front of the shin bones where the soreness was.

Treatment.-Give the animal as much rest as you can. If in the summer, bathe with cold water and salt. If in the winter, bathe witl: warm water and salt. After bat!ling twice a day, rub dry and apply white liniment. After you get the soreness and inflammation out by bathing and using the liniment, blister him to take down the enlargement. Use thr same blister and directions as is given in treptment of ap nta. 
SDE SONE.

Thls is ossification, or turning into bone, of the lateral cartilages of the foot; these are two cartilages, one situated on each side of the foot, and by pressing on them at each side of the foot, just above the hoof, you can move them in and out, that is when they are in their healthy state, but when they become diseased or changed into bone, they become enlarged and you cannot move them at all. This disease is more often met with in heavy breeds of horses, but it is sometimes met with in light horses, when it is harder to treat and more of a detriment to thein on account of being used for fast work.

Causes.-From hard work, as a general thing.

Symptoms.-In heavy horses, they are not lame in some cases, just the enlargement at each side of the foot, just above the hoof, but in severe cases there may be lameness. In light horses, used for drawing, the first symptom noticed is lameness, afterwards followed with the enlargement at the sides of the foot, just above the hoof.

Treatment.-Rest the animal as much as you can, and, if in the summer, bathe the foot well with cold water and salt twice a day; after bathing each tine, wipe dry and apply the white liniment. If it is in the winter, bathe with warm water and salt, and also poultice with half linseed meal and bran; put the poultice on as warm as you can without burning the animal, and each time after bathing and poulticing, rub with white liniment, the same as mentioned above. After you get the soreness and lameness out by the above treatment, blister with the following receipt :

Binlndld of Mercury or Red Precipitata..............2 dram

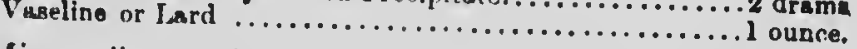

Mix well together and there is enough in this receipt to blister a small side bone four times. Apply quarter of the blister and rub in thoroughly, leave it for three days and then grease with lard, and allow it to go for two or three weeks, then wash the par:s clian with luke warm water and soap, and blister again, just the sime as the first time; repeat the blisters untif the lameness is antrely grone and the side bone stops growing. In buying a horse alwatys examine him closely for side bones, especiaiv if it is a heary horse. In cases where you want to vurk the aninial slive hitn with a bar shoe 
DISEASES AND TREATMENT UF THF HUKE: 19, RIMGBOKE.

There are two kinds of ringbones-the high-up ringbone and the low-down ringbone. The high-up ringhone affects the pastern joint, the low-down ringbone affects the coflin joint. A ringbone is a bony growth around the pastern or coffin joints. They may affect the front legs, but are more often found on the hind ones, same time.

Causes.-Like most other bone diseases, it runs in some breeds of horses to be affected with ringbones, that is to say it is hereditary, so you see the necessity of breeding sound animals. But there are other well-marked causes, such as hard or fast A comm; or an injury or severe sprain of the joint will bring it on. or, in foals, by allowing them to follow their mother when she is working, which is very hard on foals; sometimes by a horse running a nail in his foot, and if it runs up far enou, th to wound the coffin joint, it will cause the joint to become iseased and hrow out a ringbone; or it may come on by a horse standing on one leg while he is very lame in the other.

Symptoms.- They are very plain. There is lameness, followed by an enlargement around whichever of the joints are be ffected. Now, if it is the pastern joint, the enlargement will be about half way between the fetlock joint and the hoof; this is the form known as high-up ringbone. If it affects the coffin joint, boof, and this form of the disense is known as a low-down ringbone. The parts around the ringbone will be hot, and the lameness will increase as the disease goes on. The peculiarity of ringbone lameness is that the animal takes a longer step on the affected leg and puts his heel down fist; also, that he is more lame when starting of than aftor be is driven a piece and get
warmed up.

Treatment.-The treatment, in some cases, is not attended with very great success, although, in others, It is very successful, depending, of course, on how much disense there is going on in the joint. - The treatment is similar to spavin-the main object that is, to have what is known as anchylosis of the diseased joint, w ench other. As coon forming the joint become united solid 
soreness leaves, and this is what is called cure. Of course, after it is cured, the motion of that joint lo gone, and the anmial does not have quite as free action as before the leg was affected, but will be very useful for years after. In order to get a real good idea about this, examine some ringbone, after a horse dies, that was cured, and it will give you an idea how the bones unite. In all cases first have the foot pared down to its natural shape, and have the toe cut off very short and keep it cut short after. wards; this throws the strain off the joint. Cut the hair off the enlargement, if it is long, and blister with the following:

Biniodid of Mercury or Red Precipitate ................2 drame.

Vaneline or Lard...................................

Mix well together. There will be enough in this receipt to blister an ordinary ringbone two or three times, according to the size of it. Apply one-third of the blister and rub in thoroughlythe more you rub the better it will work-and grease the third day after blistering, and keep on blistering every three weeks until it is cu ed and follow out the same directions as the first blister; each time before you blister wash off the parts with warm water and soap. If, in the course of a few months, this does not help him, "fire" him. Use the same kind of a firing iron as that used in firing a spavin. Place a twitch on his nose and have one of his front legs held up, and when your irons are red hot burn all around the ringbone in streaks--running up and down-threequarters of an inch apart; don't burn too severe, just enough te leave white seam where you run the iron. In doing this take your time and do not lean heavy on the iron. After you fire, leave it six days and blister the same as above mentioned anc follow out the same directions. If the horse will not stand, throw him the same as you would if you were going to castrate him. Don't get discouraged if he does not get better right away, for it generally takes from six months to a year, and even longer in bad cases. In colts the treatment is just the same, only not quite so severe. and will vary according to the size of the animal.

BONE SPAVIN.

A spavin is a disease affecting the bones of the hock joint, and generally throws out a bony enlargement on the inside of the hock joint. When the spavin is inside of joint and does not show itself outside in the form of an enlargement it is then called an occult spavin. They are divided into high-up spavins and lowown, or what is comm only called jack spavins. 


\section{DISEASES AND TREATMENT OF THE HORSE}

Causes.-The sante as in rumgbone, certinn hreeds of horses are nearly all spavined, for it come; on in a hereditary folm, that is where the dam or sire is affected with spavin and their colts become affected with spavin, and so on for grenerations of horses. A great many horses have spavins in this way, therefore you will see the necessity of breeding good, sound horses, although when a spavin comes on from some well marked cause, such as from hard work, or from a severe sprain of tla joint or an injury, such as a kick from another horse, it is all righlt to breed from these.

Symptoms.-Are very plain and easily noticed as a general rule. Inquire into the history of the case; how long the animal has been lame and how he acts when travelling. If the horse steps shorter than natural and strikes the toe first in putting down the foot. If he is noticed very lame in starting off aftar standing for a while, or from being kept in tle stable over night, and gets better after he groes a mile or so, and the further he groes the less he shows the lameness, then look for a spavin; if there is an enlargement you can easily see it, but if it is an occult spavin there will be no enlargenent, juat heat and soreness in the pirts. When the above symptoms are present you may be sure it is a spavin. After a time the muscles of the lip on the sicle he is lame or will waste away from not being properly used. You must not let this symptom mislead you as to where the latmeness is. As the enlargement grows the lameness will increase.

Treatment is the same as in ringbone. Try and get the diseased joint to become united and form what is called anchylosis of the joint, then the soreness and lameness will disappear; but on account of there being no movement in the joint, the aninal will not have as free use of the leg as he had betore he got the spavin, but may be very serviceable for a number of years after being cured. High-up spavins are very much harder to cure than the low-down or jack spavin, for they affect the largrest articulation in the hock joint, but they are treated just the same. It is always best to first try a blister on spavins before firing, for in some cases a blister will cure them all right. Blister with the following receipt :

Binindid of Mereury or Red Precipltate. .............2 dramm.

Mix the

receipt to broughly together. There will be enough in this receipt to blister an ordinary sized spavin twice. Apply half of it over the inside of the hock where the enlargement is; rub in 
thoroughly and grease the parts three days afterwards. If it is an occult spavin, or if the enlargement groes right through the joint, put ill the blister on at once, that is, half on the inside and half on the outside of the joint; then let it alone for three weeks and wash off the parts with warm water and soap, and blister agrain just the same as the first time. Repeat the blister a few times, and, if not somewhat better, fire it with the feather iron, the same as shown in the cut. Have three of these irons and get

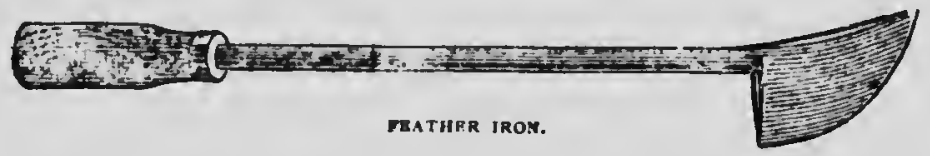

them red hot, then place a twitch on the horse's rose; also have one of his front legs held up, and proceed to fire. Draw the lines the same as seen in the cut, and always have them a good half-

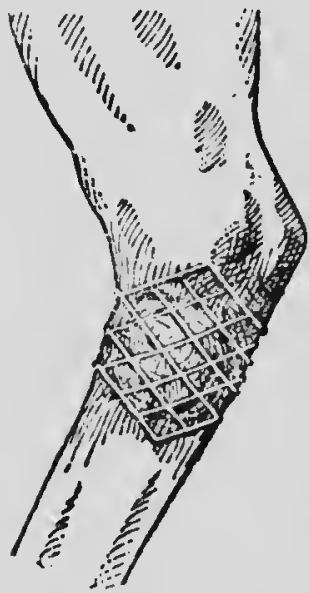
inch apart each way. Run the iron lightly over the lines (same as shown in cut) until there is a white line appears, then that is plenty deep enough. The best place to heat your irons is at a blacksmith shop, and if the horse is very ugly you may have to throw him in the same way as if you were going to castrate him, and then fire. Keep on firing and blistering until you effect a cure; it may take from six months to a year or two to effect a complete cure. After firing do not blister for six or seven days. It is all right to work the animal a little between times, it will help on with the cure, but when you are working the horse, shoe him with a high healed shoe, this helps to throw the strain off the hock joint. After firing and blistering, always keep the animal out of the water, for getting the leg wet acalds the hair and skis and makes it very sore. 
CIIAPIER X.I.

\section{WOUNDS AND TREATMENT.}

Wounds are of virious kinds, as follows:

(1) An Incised Wound. - This is a womnt caused by a clean sutting instrument whete it lengrth is greater than its depth.

(2) A Punctured Wound. This is a louml cillsed by some sharp or blunt instrument, and its lepth exceeds its length.

(3) A Lacerated Wound. This is a wound where the flesh is both torn and cut, as in a case where one horse kicks another.

(4) A Contused Wound.-This is a wound where the skin is not broken, but the tissues under the skin are very much bruised, as, for instance, a man with a black eye. This is one of the best examples of this kind of a wound.

\section{GENERAL TREATMENT FOR ALL RINDS OF WOUNDS.}

If the wound is blecding, stop it in any of the following ways: By applying cotton batting orer the wound and a tight bandage over the cotton batting, and latre it on for twenty-fol: - hours; or, by putting on astringent medicine. The best medicine for this is Monsell's solution of :run; apply it with a feather. Another very good way is to tie the end of the artery tightly with a small itring, that is, if you can gret hold of the artery. A common sewing needle that is used for sewing up wounds comes in very handy in some cases, by just running the needle in under the urtery or vein that is bleeding, and tic up some of the muscle along with the artery, and leare it ticd until it comes off of its own accord. If the lound is deep, and you camnot catch the artery, plug the hole with collon bitting and leate it in for twenty-four hours, then exampi- we wound to see if there is any pieces of stick or anythiri,s it. If it is a lacerated wound, sew it up after washing the wound out with a little luke warm water to make it nice and clean. The best wy to sew the wound is to place a twitch on the horse's nose and have one his front legs held up, and put in the stitches with a comm piving needle used for sewing wounds, which can be grot at an, wholesale drug stcre, and use the small carriage trimmers' whine to sew it up with, which can he got at any hardware sture. Before starting to sew up a bad cut, exannine as to where you should put in your first stitch, so as to bring the edgen of the wound evenly together. Put in the stitches one-half inch apart, tying each stitch separately 
until you have the whole wound sewed up. Just draw the stitch:s moderately tight, they will stay in longer than if they were drawn 100 tight. In case it is a wild animal, throw him down the same as if you were going to castrate him, then sew it up. Aftor stitching up the wound, bathe well with luke warm water twice a day until the stitches come out; after bathing each time apply the white lotion, this is to keep down the inflammation and swelling. Allow the stitches to gradually rot out of their own accord, then the wound will open up again; still continue to bathe and apply the white lotion. After applying the white lotion each tine after the stitches come out and the wound is opened up some, paint the wound ivith compound tincture of benzoin or Friar's balsam; this will keep any proud flesh from growing in the wound. When the wound is just about healed up, and is hard, then change the treatment. Quit bathing and apply the lotion and benzoin. After this, use the green salve twice a day, every night and morning. The best way to apply this salve is to melt a little of it in a spoon by holding it over the lantern blaze until it is thin enough, and then apply it with a feather all over the wound. The idea of using this salve is that it not only heals, but it keeps the skin soft around the wound, and allows the edges to draw well together, and makes the wound look nicer when it is healed. If the wound is deep, and there is not a very large hole in the skin, do not sow it up, but treat it just the same way as you would after the stitches have come out of a wound you have sewed up, only work the medicine up into the wound by using a feather or a syringe. The main thing in this kind of a wound is to get it to heal from the inside first. If you have a wound where the skin is not much torn, mostly bruised, give it lots of bathing with luke warm water two or three times a day. After bathing each time, wipe dry ar: apply the white lotion to take down the swelling. If you have a case where the wound is of long standing and does not seem to heal, burn it a little with caustic potash, and then treat it the same as an ordinary wound. Sometimes, in treating a wound, the inatter forms a pocket and does not run out. In this case you must cut a hole at the bottom of the pocket or sack, where the matter is lodged, and allow it to run out; after this treat, and you will find it will heal up all right. The above treatment will do for wounds on any part of the body except around the eyes or feet. You will find separate treatment 
for these wounds given along with the diseases of the parts. Look in the index.

\section{MODES OF HEALING WOUNDS.}

There are two ways of healing: 1st, "Healing hy the first intention;" 2d. "Healing by the seciond intention." Healing by the first intention is the way which is mostly used by the medical doctors. This is when the wound is nicely brought together and kept in an antiseptic state and heals from the start without suppurating or running matter. Healing by the second intention is the way that wounds are mostly treated in veterinary practice, for you cannot keep the horse quiet, and the wound soon becomes irritated and begins to run matter, which is good sign as long as the discharge is of a nice white color. After the wound begins to run matter it gradually becomes knit together. In all cases of wounds keep the horse quiet and feed on soft, light food with pleniy of boiled flaxseed in it, this will keep his bowels regular while he is standing so quiet. If there is a thickening left after you have the wound healed up give it a light blistering with the following :

Pulverized Catharifes or Spanish Fly.............. It dranis.

Lard or Vaseline................................

Mix thoroughly and apply a little of it, according to the size of the enlargement, rub it in well and let it go for three days and then grease the blistered part. In the course of two or three weeks, if it is not gone complete'y down, wash the parts with luke warm water and soap, then dry and apply more blister. After blistering treat the same as above mentioned; keep on blistering till :ou get the thickening all out.

\section{INFLAMMATION OF A WOUND.}

This generally follow's deep punctured wounds, but might follow other kinds of wounds.

Symptoms.-The wound becomes ver: much swollen and terder, the animal seems feverish and in pain, and the cut discharges watery-looking blood.

Treatment.-Keep the animal quiet and warm, and give a teasponful of nitrate of potash or saltpetre in his feed twice a day, alio feed on soft fond to keep his bowels loose. Bathe the wound three times a day with hot vinegar and water-half and half-hathe for half an hour or more, rub dry and apply the white lotion. Swab out the wound by means of a sponge or syringe with the following: Carbolic acid, 25 drops to 1 pint of water. Swab out each time after bathing. 


\section{DLCOD POISONING.}

Causes.-From a wound being handled with dirty hands or dirty or rusty instruments, or anything that wili poisun the wcund.

Symploms.--The wound becomes very sore, and commences swelling and lestering, and he is apt to break out and run matter in different parts of the body.

Treatment.-Give the animal

Hyposulphite of Sorla.................... teasponful.

Give three tin :s a day on the tongue with a spoon or in his feed. This is to kill the poison in the blood. Bathe the wound with hot water three or four times a day and poultice between the times oi bathing with hot linseed meal. Swab the wound out by means of a sponge or syringe with carbolic acid and water-25 drops to 1 pint of luke warm water. This is to lean the wound. Any place that the animal breaks out treat it same as the wound.

\section{CHAPTER XXII.}

\section{INJURIES AND DISEASES OF THE HEAD, NECK, SHOULDERS, BODY AND HIPS.}

\section{1. - INJURIES TO TIE IIEAD AND NECK. \\ POLL EVIL.}

It gets its name from affecting the poll of the heard.

Causes.-It is caused by an injury of some kind, as a horse striking his head against the top of a low doorway when going in or out of it, or from pulling back on his halter. It is also caused by putting on a heavy poke to keep the animal from jumping.

Symptoms.-Are swelling and soreness of the parts, and the horse carries his head stiff, for it hurts him to move that part of his neck. Now, if he does not get relief soon, matter will form and work Hown around the bones, and then the bones themselves become disersed.

Treatment.-If it is treated as soon as it is noticed it is easily done. Just remove the cause and bathe the parts well with warm water and a little vinegar twice a day, and after bathing rub dry, and each time apply the white liniment; also, keep the animal rery quiet and feed him out of a high manger. This is to keop 


\section{DIERA8DG AND TREATMENT OF THE HORSE:}

the sore parts as quiet as possible until the so:eness and swelling is all gone. In a case where natter forms open it with a knife at the lowent part so as to allow the matter to run out. After opening bathe well twice a day and melt green salve and pour it into the cut each time after bathing. In a case where the bones become diseased you will have to throw the animal and cut into it and scrape out the dead bone before it will heal, then treat the same as above mentioned. In case where poll evil gets very bad it generally leaves the horse's neck stiff, and he will not be able to eat off of the ground. In cases of this kind, if the animal is ugly to handle, always put a twitch on his nose while you are dressing it. After you get the parts healed up all right, and if Is thickened, sweat it down by rubbing the parts with the acid liniment, apply every third day after bathing with warm water and sal. until the thickening has gone down.

\section{INJURIES TO THE VIUSCLES OF THE NECR.}

Causes.-Are froin pulling back on the halter, or from getting cast in the stail. In some cases it is caused from having been bit
by another horse.

Symptoms.-Are stiffness of the neck, also swelling and soreness of the parts. In some cases he will carry his neck to one
side.

Treatment. - Is to bathe well with warm water and salt two or three times a day. After bathing wipe dry and apply the white liniment until the soreness and swelling is all gone. In cases where matter forms open it at the bottom of the lump and allow it to run out, and afterwards treat it as an ordinary wound by applying the white lotion.

\section{FRACTURE OF THE BONES OF THE NECK.}

Causes.-Are generally from falling on his head while running away, or in stumbling. It nıay be done in other ways, as jumpIng over anything that is high and falling on his head. It unay his neck.

Symptoms.- If the fracture causes the bones to press on the opinal cord it causes death immediately by stopping the t.eart's action. If it is only a piece off of one of the bones the horse will be very sore around the part, and will carry his head to $t l e$ side the fracture is on. If you go to straighten his neck he will almost 
Treatment.-Kiep the animal as quiet as you can and feed him out of a high nanger. Bathe the parts well with warm water twice a day and apply the white liniment each time after bathing, and the bones, after a time, $v$ ill unite together. If it does not heal together the part broken w." fester and form matter in it, then open up the parts with a sharp knife and remove the piece of broken bone, then treat as a common wound and you will find
it woon heal up.

\section{SORE ON THE TOP OP THE NECK FROM THE COLLAR.}

Causes.-Are from a bad fitting collar irritating the neck, or from sometimes taking a horse that is not used to a collar and working him too hard hefore his neck is hardened to the collar, causing his neck tu become scalded and sore.

Symptoms.-Are very plain, the top of the ner's becomes sore and raw looking, and the horse is afraid to let you handle that
part of his neck.

Treatment.-Is to wear a nice fitting collar on hin and have a regular pad for the top of the neck; dry and clean it every time after using it; clip off the mane around the sore and waslı it every night with cold water and salt, then dry it well and apply th white lotion, also apply the lotion every morning, without washing, before you take him out to work: sometimes it is necessary to liy him off work for a few days to get it healed.

\section{II.-INJURIES AND DISEASES AROUND THE SHOULDERS AND WITHERS.}

\section{FISTULOUS WITHERS.}

This disease resembles poll evil, and also gets its name from the part it affects.

Causes.-Are from riding a horse with a poor-fitting saddle, which bruises the withers; from a horse rolling or getting cast on his back, and in this way bruise the withers and bring on this
disease.

Symptoms,-Are swelling and soreness of the withers, and if allowed to run on without being treatec soon forms mat:ar, which wilt burrow down around the bones; if it is not attendeci to soon alter it affects the bones the matter that comes from it will have very bad smell, and little pipes will form which will run down to 
Treatment.-If you notice it as soon as it begins to form matter, bathe well two or three times a day, and each time after bathing rub the parts with white liniment; if matter forms, open the swelling up at the very lowest part so as to let the matter run out, then bathe, as above mentioned, and pour hot green salve right into the hole. In a case where the discharge of matter smells very $b$ and you think the bone is diseased, throw the animal, cut down to the diseased bone and scrape it, then treat with Both this dis pouring it into the cut twice a day after bathing. In dressing the wolind always put a twitcl on the horse's nose if he is very ugly. If there is a thickening after you have the parts healed up, rub the parts with acid liniment; apply the liniment every third day after bathing with luke warm water and salt until the thickening is all gone down.

\section{SWEEKY (SHOULDER SLIP).}

This is a common occurrence in young horses.

Causes.-It is more likely to occur in young horses than in old ones. It may be caused in plougl.ng, when the plough strikes solic against anything, causing a sudden jerk; or in horses that are used on a tongue and the wheel passes over a stone or rough piece of ground, swinging the end of the tongue around, causing the neckyoke to jerk and bruise the shouller. it on.

Symptoms.-They are well marked. As soon as the horie receives the injury there wiil be a slight swelling and soreness of the part, afterwards there is a wasting away of the muscles thit are injured. It is generally the muscle. lying over the shouldi $r$ blade that become affected with this disease, and in some cases the muscles fall away until there is a large hollow over the shoulder blade. In some cases the horse is not very lame, but goes a little stiff.

Treatment.-If the animal is at very heavy work, change it to light work, and if you can allow him to run without work so much the better. Bathe the parts well with cold water and salt every night if in the summer; after bathing, wipe dry ard hand rub and pull the skin out on the hollow; this is to get the skin loose from the muscle. Every third day after bathing apply tlie acid liniment in and around the hollow part of the shoulder; this 
Is the best remedy known. Continue this treatment until the muscle becomes its natural size and the shoulder is filled out. It sometimes takes the muscles a long time to fill out to their natural size, but, as a general thing, it gets all iight in the course of time. If you can, turn him out to pasture, then blister in and around the hollow place with the following :

Pulverized Canthariden or Spanioh Fly............... I drame

Vngeline or Lard . ............................ ounce.

Mix well together and rub it all in to the parts, and grease three days after with lard, and repeat blister every three weeks
until cured.

\section{SCALDED OR GALLED SHOULDERS.}

Causes.-Generally from the collar getting hard from the weat drying on it; or from a bad-fitting collar-either too big or too small. Sometimes, in the spring of the year, when the horse's shoulders are tender and not usea to work; by putting the horse to hard work scalds and makes the shoulders sore.

Treatment.-Use a good-fitting collar, and keep it clean by brushing or scraping the dirt off it before using. While you are working your horses, if you are going to allow th. . to stand a few minutes, raise the collars so as to allow : he air to get to the shoulders, also keep the mane from getting under the collar. Every night, after working, bathe with cold water and salt, and after wiping dry, if they are sore, apply the white lotion; this will heal and harden the skin.

\section{BRUISES OF THE SHOULDER.}

Causes.-This is caused from a bruise of any kind.

Symptoms.-A swelling appears around the bruised part soon after it is done, and when you come to examine it, it is tound to contain water, or serum.

Treatment.-Cut into the swelling at the bottom part of it and allow the water to run sut; make a hole large enough for you to put in your finger; after opening, bathe well with luke warm water twice a day; after bathing, wipe dry, and apply the white liniment arourd the swelling, and, as well as doing this, dress the insidf of the swelling, to get it to heal from the inside, with compound tincture of benzoin or Friar's balsam, or you might use green salve instead or the benzoin to put in the wound; insert it us into the hole with a feather. 


\section{DIRFARES ANU TREATMFAT UF THE HMRE.}

TOMORS OR LUMPS ON TBB SHOULDER.

Causes.-From the animal receiving a bruise of any kind on the shoulder, and not heing properly treated afterwards, it turns into a hard, callous lump.

Treatment. - The best treatment is to take a sharp knife and skin the lumps right out; atter this, sew up the skin with a needle and twine, and treat them as a lacerated wound. There is not much danger in cutting around the $\mathrm{s}^{\prime}$ ' 1 lder, for there are no large vessels where these lumps are gen dily found.

\section{SHOULDER JOINT LAMENESS.}

This is very bad lameness, and the seat of the trouble is generally situated where the large muscle of the shoulder passes down through the pulley-shaped part on the bones on the front of the shoulder joint.

Causes.-From a severe sprain of the joint, and is generally caused by a horsi becoming cast in his stall; or fron going througl deep snow; or from lalling on his shoulder; or from a kick from another horse; and sometimes it is caused from a kind of rheumatic: iflanmation settling in the joint.

Symptons. - When the animal is trotting he will step short on the affected leg, and will often strike the toe and stumble, on account of not being able to lift the leg up properly. In standing, he will bring the foot well under him, resting on the toe, allowing the knee to bend forward; this is to give the shoulder a rest. If you pinch him around the shoulde, he will flinch from soreness.

Treatment. - If the case is : suwed to run on for a long time, and the bone beconses diseased, it is incurable; but if taken in time, you may effect a cure by bathing the shoulder with luke warm water and salt twice a day. After bathing, wipe dry and rub well with white liniment. Keep the animal in the stable and keep the shoulder as quiet as you can. After the soreness is pretty well out, blister with the following blister:

Powdered Cancharide or Spanish Fly................t drame

Vameline or Lard. 1 ounca

Mix and apply half of this mixture around the front and side of the shoulder joint; rub in well and allow it to stand for three days, then grease with lard. After two or three weeks, if the enimal does not seem bctter, wash the shoulder off and blister crain, following the same instructions as given before. 
Causes.-From a bad-fitting harness; or from the backing of the harness rubbing on it.

Treatment.-In all cases remove the cause, and, if in the summer time, bathe with cold water and soap; if in the winter, use warm water and soap; do this twice a day. After batling each time, wipe dry and apply the white lotion.

\section{CHRONIC SORES ON BACK OR SHOULDERS (SIT-FAST).} back.

Causes.-From working and neglecting a sore shoulder or

Symptoms.-The sore spot has no tendency to heal and keeps raw all the time while working.

Treatment.- Burn the sore with caustic potash and afterward treat by keeping the animal from work, bathe with like warm water, and, after bathing, apply the white lotion twice a day until it is bealed.

\section{BROKEN BATK.}

Causes.-From an animal receiving a fall of some kind.

Symptoms. - If the break is near the front of the bones of the back it will cause instant death, but if it occurs further back it will cause paralysis of the hind quarters.

Treatment. - There is none but to destroy the animal.

INJURIES TO THE MUSCLES OF THE BELLY.

Causes.-Sometimes when a horse steps on a sharp piece of itick it turns up and catches the muscles of the belly, or from the holk of a cow, or from the kick of another horse.

Treatment.-If it is a lacerated wound, stitch it up, and treat it same as given for lacerated wounds; if it is a punctured wound, and only has a small hole in the skin, exumine to sce that there : nothing in it, and then use the same treatment as that given for punctured wounds. If the wound is serere enough to allow the bowels to come out, then it is a more serious case. If the bowel, are out to any great extent, and are injured by the horse trampinds on them, it is best to destroy him at once, but if the bowels are only out a litic, and are not injured or blackened, throw and secure the animal, and wath the howels off with a little luke wam water and sibove them back into their place, then stitch "1j) the wound good and tight, afterward bathe the wound twice a say with luke warn water and apply the white lotion each time atter bathing. If the opening is very latoe it is well to wrap a bandoge 
of factory cotton around the body to belp to support the sticten Keep the animal quiet and feed on oft food until the wound
heals up.

STAEED.

This is a very common occurrence among horaes.

Causes.-The animal steps upon a piece of stlck and turne up and catches him, or from jumping a fence and getting crught, of running against a stake sticking up in a Asld, or a plow handle or anything that the animal will run against.

Treatment.- Pull the stake out if it is still stuck in the horse, and examine it to see that there is no pieces of the rood left in the wound. There is never much bleeding in a case of this kind, but if it does, stuff the hole with cotton batting and leave it in for twenty-four hours; after this time it will be safe to take it out, then treat same as for punctured wound. Keep the animal quiet until it begins to heal, and feed on soft food with plenty of flaxseed in it to keep his bowels loose.

HIPPED.

This is when the point of the hip bone is knocked down.

Causes.-From running through a narrow doorway and striking the side of it, or from falling on hard ground, or anything that will strike the point of the hip hard enough to break a piecn off the bone.

Symptoms. - At the time it bappens there will be swelling and soreness around the point of the bip. After It gots well you will notice that the injured bip is pot a large as the other, and it is o aasty eye-sore on a horse.

Treatment.-The only thing to bo done after it b inoched down is to bathe and apply the whito liblment after bathlof entit you got the awelling and sorones oot, then leave to alone If is b a case where the hlp awelle up and begine to fecter around the broken piece of bone, cut into lt and take the pices out, then tren same as lacerated wound.

\section{FRACTURE OP THE HIP BONES.}

This is generally caused from a horse slipping and falling lce, or may be done in any other way when the animal receive lnjury enough to fracture the bones.

Symptoms.-There is severe Inmencas, and 16 you exasm elosely by twisting on the boxes you wifl baer the broken coll an 
the iunes grind on each othor. In s othurt time the purts around the irature hacome greatly wollen.

Treatment.-If the fracture is very bad it is best to destroy the animal, but if you want to try to save it, all that can be done is to keer the animal very quiet and bathe the parts well with luke warm water and vinegar, after rubbing dry, rub well with white liniment twice a day, and in some cases this will affect a cure in the course of a few weeks.

\section{BALLING AWAY OF THE MUSCLES OF THE HIP AFTER FOALING.}

Causes.-The muscles become injured, while the mare is foaling, by throwing herself down or striking herself against anything and Lruising the muscles on either hip.

Symptoms.-The mare will be noticed to be stiff and sore after foaling, and after a few days there will be a falling away of the mu ses of whichever lip was injured. The lameness varies, in some cases it is worse than others.

Treatment. - The best and only treatment for tr. ; to let the mare run out and apply a fly-blister to the wasted 1 . scles. Use the foliowing blister:

Pulverized Cantharides or Spanish Fly.............1 drams.

Mix well and apply all over the wasted muscles, rub in well and tie the mare so she cannot bite or rub the blistered parts for a few hours, then turn her out and grease in three days afterward, allow it to go for a month, and if she is not better blister again, and keep on blistering every month until she is better.

\section{SORB TAL. PROM THE CRUPPER.}

Causes.-From reining the horse too high, which draws the crupper too tight, or from the horse sweating and allowing it to get dry and hard on the crupper, or anything that will trritate the tail.

Treatment.-By not using the crupper under his tail for $a$ few aays you will have removed the cause, and to heal it wash the parts off with luke warm water and soap; after bathing it once apply the iwhite lotion twice a day, without bathin, until it is healed up.

FRACTURES OF THE BONES OF THE TAIL.

Causes.-Usually from a horse rearing up and falling back a his haunches. 
Treatmento-Keop the animal quilet, aod if $t h$ to tho coscon for Wies, cover the animal so it will not have to wee lte tall in trying to keep them off; if the tail is much swollen rub witb white liaimont twice a day until the swelling is gone down, then leave the animal quiet until the bones unite. If there is not $m$ " swellins bandage moderately tight and leave the bandage or. ' ' ys at - time, while the bones are uniting.

\section{HIP JOUTT LAYENBSS.}

This is a sprain of the round ligament in the hip joint.

Causes.-The way this disease generally occurs is from a horse stepping on a small, round stone, and the stone turns and throws the leg forward, or from slipping on ice, or falling in other ways and striking the hip.

Symptoms.-The horse steps short on the affected side, and in trotting he goes kind of three-cornered, and every time the horse raises his leg the hip raises with it, showing that he is trying to keep the hip quiet; he will also flinch when you press around the hip joint. If the disease is allowed to run on for some time there is a wasting of the muscles around the part.

Treatment.-If it is an old standing case, and the joint is diseased, it is incurable, but if taken in time the animal may be cured by keeping him quiet and bathing the parts well with luke warm water and salt twice a day; after bathing, each time, wipe dry and apply the white liniment. Keep on with this treatment until you get the soreness and swolling out, then blister with tho following :

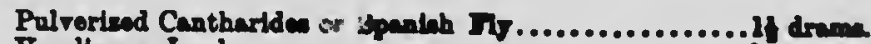

Vacoline or Lard.....................................

Mix well and there will be enough to bitater the hip three times, each time rub the blister in well, allow it to 50 for three days, then grease with lard; let it so for thrse or four woeks, then blister again; repeat the blleter this way woth the animal is over the lameness.

\section{SPRAIN OF THB MUSCLES OP THE EOP.}

This is more common than hip joint lameness, and is usually caused in heavy horses by slipping while pulling a heavy load; or while driving light horses, you pull them up suddenly, causing them to slip, and in this way they sometimes spralo the muscles of the hip. 
Symptoms. - There la ewelling and soreneas of the muecles which will be best noticed while standing behind the animal, and there will be great difficulty in bringing the leg forward.

Treatment.-Keep the unimal quiet; bathe well with luke warm water and salt two or three timos a day; aftor bathing. wipe dry and rub the parte woll with white liniment. Follow this treatment until the animal is botter.

\section{CHAPTER XXIII.}

\section{DISEASES OF THE FRONT AND HIND LEGS.} CAPPED ELBOW.

This is a thickening at the back of the elbow joint.

Causes.-From shoeing and leaving a long heel on the shoe, which catches the animal in that part while he is lying down; or from wearing a heavy belly band on the harness, which rubs against and irritates the elbow.

Treatment.-If it is caused by the shoe, have him shod with a short-heeled shoe, and, for a time, tie an old bag around the foot, so when he is lying down the foot will not irritate the elbo::. Treat with the following as oon as noticed: Bathe wei! with like warm water and vinegar twice a day. $n$ it is not raw, only swollen, use the whit liniment after bathing; but if it is raw, use the white lotion; this will generally bring it all right. In some cases it festers and matter forms in it; in this case open it up with a knife at the lowest part of the sivelling, and treat it the same as above mentioned, only melt a little green salve and put it in the hole each time after dressing it until it heals. If it is of long atanding, and there is a large, hard lump formed on the cap of the elbor, the only treatment is to throw the animal and secure him, and skin the lump out carefully, which can be done without much bleeding. After you cut the lump out, draw the akin together with a few stitches and treat the same as a lacerated wound, by bathing with luke warm water and applying the white Lotion twice a day until it heals up.

FRACTURE OF THE BONES IH THE SHOULDER.

Causes.-Generally from falling, or from running against somethirg.

Symptoms.--There will be swelling and soreness of the parts and the animal will be very lame, and, on moving the shoulder, vou will hear the ends of the bones grating on each other. 


\section{DISEASES AND TREATMENT OF THE HORSE}

Ireatment-In most cases $k$ b best to destroy the animal, but if you attempt to treat it, keep the animal quiet and bathe with luke warm water twice a day. After bathing, apply the white liniment; this is to keep down the swelling and inflamma. tion. The treatment in this case is of very little success. The parts become badly swollen and the animal is in severe pain, and it is best to have him destroyed.

\section{INJURIES ATD SPRAINS OF THE KNED.} knees.

Causes.-Generally from the animal falling and hurting the

Symptoms,- Tke animal cannot bend the knee in walking, and when you handle it, it seems very sore.

Treatment.-Keep the animal quiet, and bathe twice a day with luke warm water and salt, and after bathing apply the white liniment; but if the knee is cut, use the white lotion after bathing. If the cut is large, put a few stitches in it, and treat as above mentioned.

\section{STRIKING THE RNEE (SPEEDY CUT).}

This is where the animal strikes the knee with the oppc ... .

Causes. - This is caused generally by bad shoeing, or usii.g too heavy a shoe on colts; some horses with high action have tendency to strike the knees.

Symptoms.-There is swelling on the insice of the knee; it is very painful, and as soon as you go to handle it the animal will jerk his knee away from you. In some cases it becomes very much swollen and forms matter in it. When the horse is walking, in bringing his leg forward he will swing it out and can hardly get along, it being so sore; while in other cases, where he does not strike it so severe, the inside of the knee becomes thickened and hard.

Treatment.-Leave the animal off work, and bathe the parts well with luke warm water and salt two or three times a day; the more bathii:g the better. Each time after bathing, rub dry and apply the white liniment. If there is matter formed, open it up with a sharp knife to allow the matter to run out, then treat as above mentioned. After it is healed up, if there ia a thickening, blister the thickening with the following :

Pulverized Cantharides or Spanish Fly ............... drams.

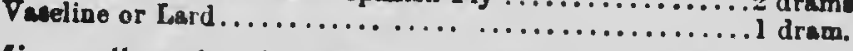

Mix well and rub what you can nicely get on over the owelling; rub in well and grease the third day; let it go for a souple of weess, then blister again, and repeat the blistering 
until the thickening is gone. After this, be careful how you have the animal shod, and if he is inclined to strike, wear a knee boot on him.

\section{FRACTURE OF THE BONES OF THE ENEB.}

Causes.-From falling on the knees.

Symptoms.-The animal will be very lame, the knees become swollen and is hot and tender.

Treatment.-Keep the animal quiet and bathe well with luke warm water-the more the better-after bathing, each time apply white liniment. It generally takes a case of this kind four or five weeks to get better. After the soreness and swelling has gone down it is well to blister a few times with the fly blister to get the soreness and thickening out of the knee.

\section{PUFFY ENLARGEMENTS AROUND THE RNEES AND FETLOCKS (BURSAL ENLARGEMENTS).}

Causes.-From striking the knee against the manger while pawing, or from lying on the hard floor, or anything that will bruise the knee or fetlock.

Symptoms.--There is a puffy enlaryement, but not sore to handle, and it feels as if it was full of oil.

Treatment.-Bathe well once a day with cold water and salt, rub dry and bandage for three hours. After you remove the bandage-every third day-apply acid liniment, which will make, as a general thing, a complete cure. Never attempt to open a Bursal, for it will allow the oil that is in it to run out. In all cases, if you find the cause, remove it.

\section{SPLINT AFFECTING THE RNEB.}

This is where the splint is very high up on the bones and affects the knee.

Treatment.-Use the same treatment that is given for splint, but in some cases it is very hard to effect a cure.

\section{KNEE SPRUNG.}

This is when the knee is bent forward.

Causes.-From hard and fast work, or from standing in a stall that has a big slant, high in front and low behind, or from feeding out of a very high rack, or from a sprain and contraction of the back tendors, or a horse being shod with high heels wil cause it. Horses with weak, small knees are more subject to this than horses with good, strong straight knees. An animal may be very badly knee sprung and still be a good work horse. 


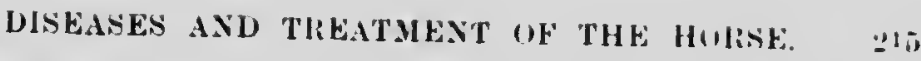

Treatment.-If you want to work the animal and ireat it, first fx the floor, see that it is level and also feed him off the floor. Bathe the legs with cold watter and salt twice a day, after bathing rub dry and apply the white liniment every night, after the liniment is dried in; bandage for a few hours, shoe the animal with a flat shoe, if the roads are not slippery. If you do not want to thie the horse turn him out and blister the back cords once a month with the following :

Pulverized Cantharides or Spanish Fly............... drams.

Faseline or Lard.....................................

Mix and there will be enough in this to blister h.th legs once, rub in well and tie his head short so he can he cin alot hite it for a few hours, then in three days, grease it and let him run for a montl, and repeat the blister until he is bettar.

\section{CALF-KNEED.}

This is not a discace but a fault in the formation of the knes, this is where the animal stands with his knees bent bask.

Treatment.-There is none; only in buying a horse watch that he is not calt-kneed for they are bad stumblers.

\section{SPRAIN OF THE BACK TENDONS.}

There is more or less swelling around the sprained tendons, the animal will be lame in travelling, and if you press on tlie cords he will flinch.

Treatment.-Batlie with cold water and salt if in summer, but if in winter bathe with luke warm water and sait twice a cilv, rub dry and apply the white liniment, and an hour or so after arp'?ing the liniment, bandagre, leaving the bandage on for three hiurs. After he is pretty well over the lameness, and if there is a thickisning left, blister with the following :

Pulverized Cantharides or Spanish Fly .............. 2 dran॰q.

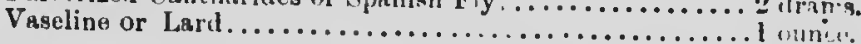

Mix and rub enough in to blister him well, and grease the third day. Keep the animal quiet while treating hin.

\section{SPRAIN OF THE FETLOCK JOINT.}

Causes.-From tile horse stepping crooked or turning over on his ankle.

Symptoms. - The animal will be very lame, the joint ill be swollen and sore to handle.

Tratmant.- Use tha same troitment as given in sprain of the back tendons. 


\section{ENOCKLINO.}

Causes,-From hard and fast work. Horses that stand uraight on the fetlock are more apt to knuckle.

Symptoms.-There will be a jerking forward of the fetlock every time the animal steps, and in standing the animal stands with his fetlock joint bent forward instead of tack.

Treatment.-If it is a case of long standing there can be nothing done, but if it is only coming on blister him around the fetlock and turn him out. Blister with

Powdered Cantharidew or Spanimh Fly................2 dramm.

Vaseline or Lard................................ oúnce.

Mix and apply around the fetlock, rub the blister in well and allow it to stand for three days, then grease and let it go for a few weeks and blister again; repeat the blistering until the joint gets strong. There will be enough in the above prescription to blister two fetiocks.

\section{ENOCKLING IN COLTS.}

Causes.-From being left in the stable without getting much exercise during the winter and in the spring he will be knuckled in the fetlocks.

Treatment.-Before turning, him out blister around the fetlocks well with the above blister, and in three days afterwards grease and turn him out to pasture.

\section{INTERFERING, OR STRIKING THE FETLOCRS.} shod.

This trouble is mostly met with in coits when they are first

Causes.-Sometimes from shocing with too heavy a shoe and putting the horse on a long trip before he is used to it. Some horses naturally travel so close behind that they brush the legs together.

Symptoms.-Soreness on the Inslde of tive fetlock, and somstimes the hair and skin will be knocked off, and in severe cases will swell badly When the norse, in travelling, strikes himself he will hop on three legs with pain for a little piece, then be all right until he strikes again.

Treatment.-Bathe the leg well with luke warm water and a little castile soap twice a day, if it is swoolen, after bathing rub dry and apply the white lotion. Have the shoes changed and mrde light. If the animal is in poor condition, feed liim well and do not work him too hard until he gets strong and in good shape for his work. While you are driving, it is well to wear an interfering boot on the 
les, and by caroful shoelns and gotting him strong and ablo bi mork, he generally gets over it all right.

\section{WIND GALLS.} pint.

These are little puffy swellings at the back part of the fetlock

Causes.-From hard driving, in some horses it comes on easier than others.

Symptoms.-It does not generally lame the animal, but it is an eye sore. These little puffy sivellings are full of oil, which comes from the bursal that secretes the oil which lubricates the back tendons where they work over the back of the fetlock.

Treatment.-If in the summer, bathe the legs well every night with cold water and salt, then rub dry and put on a bandage; leave this on for a couple of hours every night after bathing, and every third night give the leg a good rubbing with acid liniment after taking the bandage off. If this does not zure him in a few weeks, blister with the fly blister used in knuckling, and treat him the same after blistering.

\section{THICKENINGS AROUND THE FETLOC.}

Causes.-This is generally from hard work and from sprains of the joint, and is often seen in livery horses.

Treatment.-Blister the same and use the same treatment afterwards as is given for knuckling, only blister heavier.

\section{FRACTURES OF THE BONES BELOW THE KNEE.}

Causes.-Driving a horse fast along a very hand road when he is feeling good, will sometimes fracture these bones, or in iumping a feace, or in running away, or getting the leg caught, or anything that will give the leg a blow hard enough to fracture the bones.

Symptoms. - The horse will be very lame and will hold the leg up with pain, and by taking hold of the leg and twisting it, you will hear the ends of the fractured bones grate together.

Treatment.-If it is in an old animal destroy him at once, but if $i^{*}$, is a colt or young horse, keep him quiet in slings, after you get the leg straight, then apply a starch bandage, which is a bandage wrung out of starch, put a good lot of the bandage on and hold the leg straight until the bandage hardens, after that it will holu the broken leg straight; leave it on for four or five week: until you are sure the bones are well knit together. 
BRDaE DOWT.

This is where the tendons and ligaments at the back of the fetlock give way and allows the fetlock to drop down almost on to the ground. This is mostly seen in running or racing horses where they are put to very severe exertion.

Treatment.-You cannot restore the fetlock back to it. natural state, but blister once a month with the following:

Powdered Canthardies or Spaniah Fly............. 2 drame.

Vaseline or Lard..... ........................... 1 ounce.

Mix and rub about half of this in along the back of the fetlock, allow it to stand for three days and let the animal run out to pasture. Repaat the blister until you get him pretty well over the lameness. If he is very lame, better keep him in the stable for a while, and bathe with warm water and salt twice a tay after bathing, apply the white liniment until he is pretty well over the laineness, then blister and turn him out.

SPRAL OF THE STIFFLE JOINT.

Symptoms. - The animal cannot bring the leg forward, and it is very sore when you press around the joint.

Treatment. - Bathe twice a day with hot water and vinegar, with a little salt in it, after bathing wipe dry and apply the white liniment. Keep the animal quiet to give the sprainfd parts rest.

\section{DISLOCATION OF THE PETELLA OR STIFFLE OUT.}

This is where the petella or stiffle bone slips out of th a pulleylike process of bone in front of the stiffle joint, alid as soon as this slips out it locks the joint so the animal cannot m.-ve it.

Causes.-It generally occurs in young colts or young horse. that are worked hard and get down thin; it comes on by the animal slipping off the end of a plank, or slipping while in the act of getting up.

Symptoms. - The horse will act like an animal with its foot nailed to the foor; it cannot get it forward or back. When you feel around the joint it will be drawn and hard, and you can see the joint bone is out too far, and when it is left out for a long time the joint becomes swollen.

Treatment.-It is very simple to treat in most cases. Have an assistint to hold the animal's head and a nother to pull the affected le: rell firward while you place your hand against the joint and shwe it in toward the animal as hard as you can, until the bone groes into its place, after which the animal can move his 


\section{DISEASES AND TREATMFNT OF THE HORGE.}

leg; soon as it is in walk the animal on a level piece of $g$ round until the affected parts regain their strength. If it slips out the second time it is easier put in, by pressing it the same way. Bathe the parts with warm water and salt, after bathing rub dry and apply the white liniment twice a diy until the joint gets strong and the soreness is all out. If the animal is in poor condition feed well and try to get his strength up.

\section{Partial dislocation of the stiffle.}

This generally occurs in yourig foals when they are running over a rough pasture lield, or in colts in the spring of the year when they are very weak. At first, when noticed, the stiffle will alip out and the leg will be locked for a hop or \$wo, then it will alip in and he will go on all right again. The stiffle keeps slipping in and out for some time until the bones gets diseased and wea'sened, and then the bone gets about hatt way out and stays there. After this the joint will be larger than natural and the animal will never have proper action arsin.

Treatment.-As soon as it is noticed is the time to treat it. Place the animal in a lisel place where he can not run around much and feed well to fret him stroner as soon as you can; apply a light blister around the siffle joint made of the following:

Pulvesuzed Cantharides or Sipunish Fiy................ th drams.

Vaseline or Lard............................. l ounce.

Mix and apply a light coat of the blister over the joint, rub in well and grease the third dily Let it go for a month then blister again and repeat this every month until the stiffle is good and strong.

FRACTURE OF THE THIGH BONE.

Causes.-Generally from a hick of another horse, and, although the bone itself is fractured, the coverings will hold the bone to its place in some cares.

Symptoms.-For a fow days after the kick the animal will seem lame and you may not suspect a fracture of the bone, but all at once the covering of the bone gives way and the horse will almost fall, and when you come to examine it you will see the leg is fractured, for you can swing the legr around.

Treatment.-Wlien the bones give right away, destroy the horse, but if the horse gets a severe kick and is a litlis lame and you are afraid of fracture, keep the animal perfectly quiet, bathe with warn water and salt and after bathing apply white liniment, 
to get coroness and inflammation out. By doing this, the covering of the bone is so strong that it will hold the bones together until it knits together and he gets all right.

SPRAIN OF THE YUSCLES ON THE FRONT OF TEE GIND LEG, BBTWBEN TBE EOCS AND STIFFLE JOINT.

Causes.-Similar to other sprains.

Symptoms. - The muscle will be swollen and sore in moving the animal forward, when he lifts the leg and goes to bring it forward-instead of it going forward it will fly backwards and upwards. The muscle that is affected is called the fexor metatarsi muscle.

Treatment.-Keep the animal very quiet, bathe well with luke warm water and salt three times a day, and after bathing rub dry and apply the white liniment.

SPRAIN OF THE MUSCLE ON THE INSIDB OP THE HIND LEG RUNMTIO OP PROM THE HOCX. drawing.

Causes.-From severe sprain of the leg by slipping in

Symptoms. - There is thickening of the muscles above the hock, and the animal will be stiff for a few days, the stiffness will soon disappear, but it will leave a thickening if not treated.

Treatment.-Leave the animal off work and bathe the parts twice day with luke warm water and $s+1$, if in the winter, but, If in summer use cold water and salt; after bathing rub dry and apply the white liniment, after the animal gets over the stiffness and soreness, blister to get the thickening out, using the following:

Pulverized Canthardies ...........................2 drams.

Vaseline or Lard ................................. I ounoo.

Mix and apply about half the amount, rub it in well and let it go for three days, then grease. Repeat the blister in three weeks and repeat it every three weeks until the thickening is all gone down. Turn the animal out while you are treating it.

BOG SPAVIN.

This is a puffy enlargement partly on the inside and partly on the front of the hock joint. There is an over amount of joint oil secreted in the joint, and this bulges out the capsular ligament at this part of the joint.

Causes.- Horses with round, meaty joints are most subjected to this. Kecping young colts in the stable and feeding them high without much exercise, or fast work or strain of the joint will cause it. 


\section{DIETABES AND TREATMENT OF TEE HORST.}

Symptoms. - There is a puffy enlargement on the inside and fron: of the hock joint sometimes larger than others, by feeling it you can tell it is full of oil. If it comes on from a sprain the animal will be lame for a fow days, but this pases of and loaves en onlargoment.

Treatment-If the animal is lane, bathe with luke warm water and oalt twice a day, in warm woathor use cold water, and in cold weather use warm water, after bathing rub dry and apply the white liniment. Keep up this treatment for a few days until he is over the soreness and lameness, then blister with the following, and turn the animal out.

Pulveriead Canthardiee or Bpanibh Fly ................2 drame.

Vavoline or Lard...$\ldots \ldots \ldots \ldots \ldots \ldots \ldots \ldots \ldots \ldots$. I unce.

Mix and there will be enough to hlister two or three times according to the size of the bog, rub in well and in three days grease. Repeat the blister in a few weeks as soon as the skin is nicely healing up. It needs to be blistered several times before you get it all down. Often where there is a bog spavin there is a thoroughpin in connection with it. For further particulars rofer to last paragraph under the heading of capped hock.

THOROUGHPIN.

Causes.--Similar to those given for bog spavin and the enlargemeuts are on each side of the hock near the back.

Traatment. - The treatment is the same as given for bog opavin. Never, undor any circumstance open either a bog spavin or a thoroughpin, for if you do, you will have a case of open joint to deal with.

\section{CAPPBD EOC.}

This is a common disenes. It is a owolling or thickening on the eap of the hock.

Cunser_From en Injury of soms hlod, wuch as from kicking In the stabis and striking the hock against the atall, or some horses will do lt in taying down.

Symptoms.-Swolling on the cap of the hcck, which is generally soft but not sore to handle, and is of a puffy nature, for it is mostly oil that causes the enlargement on account of the little bursa being injured, it secretes too much oil and that is what causes the enlargement. It does not lame the horse or interfere with his usefulness, but it is a bad eye-sore.

Treatment-If it is caused from kicking the stall, place the

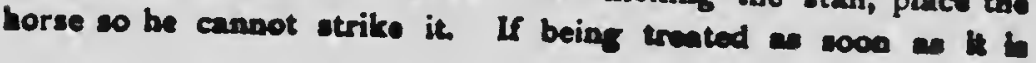


tone, bathe with luks warm water and salt, rub dry and apply the white liniment. Koep this treatment up until the soreness and swelling in all siat, then blister the thickening with the following :

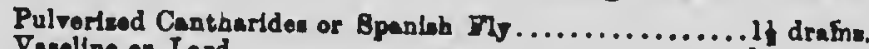

Vanollo or Lard.................................. I diuce.

Mix thoroughly and there will be enough to blister one cap four or five times; blister light and blister about every two weeks; grease the third day after each blister. In case you want to use the animal bathe the parts once a day with cold water and salt, rub dry and apply the acid liniment every third day after bathing. The acid liniment is also good when used in this way for bog spavins and thoroughpins when you want to work the horse.

SPRAIN OF THE HOCK JOINT.

Symptoms. - The horse is very lame and does not use the hock right in bringing the leg forward. There is swelling and heat around the joint.

Treatment. - Bathe well with is $t$ or cold water, according to the season of the year, after bathing, each time wipe dry and apply the white liniment; bathe twice a day and keep the horse quiet.

FRACTURE OF THE BONES OF THE HOCK.

Fractures of these bones do not occur very often.

Symptoms. - The animal vill be very lame, and will hold the leg up with pain; the joint will become swollen and very sore to touch, and by working the joint you can hear the grating sound made by the broken bones.

Treatment - If it is a very bad fracture destroy the horse, but if not, and a young animal, keep him quiet and bathe well with luke warm water and salt three or four times a day after bathing, rub dry and apply the white liniment, this is to keep down the inAammation and welling. It is always best in treating auy kind of a fracture to keep the animal in slings, but do not sling him entirely of his feet, just enuugh to ease the weight off his legs. After a rew weeks the bones will hecome united, but there will be lameness and coreness in the jint, which is best relieved by blistering with

Palverized Canthardies or Spanioh Fly.............. dram.

Biniodide of Mereurs - Red Precipitate................ dram.

Vaseline or I aril ............................ drum,

Mix thoroughly and there will be enough to blister twice, rub a littlo in on each side of the joint, rubbing it in well. Erease the 


\section{DIBEABES $\triangle N O$ TREATMENT OFI:TBE/ BORSE.}

why das and let it alulle iut t..... (n) tour woeks, then bister as worv. Lot the animal have a good rest by turning him out to pastura.

\section{DLOOD SPAVU.}

This is an enlargement of the voin which runs down in front of the hock joint.

Cris ises. - From a weakened state of the wall of the vein.

Syptoms. - There is an enlargement of the vein, but the anima is not lame, nor It does not hurt the animal for any kind of ark. but it is an eye sore.

Treatment. - There is no treatment for it.

\section{OPEN JOLNT.}

This may affect any of the joints of the legs or body, and from some injury the joint becomes panctured, allowing the joint oil to leak out.

Causes.-Generally from a kick, or prod with a fork, or running against some sharp obstacle.

Symptoms. - There will be lameness and swelling around the injured joint and leaking from the hole, of an oily looking substance which is the synovia or joint oil. If the leaking is not stopped, inflammation gets into the joint and destroys the joint, and if the horse does get better, it leaves him with a stiff joint.

Treat nent. - The larger the joint the more troublesome it is to treat, and the more danger there is of loosing the animal. Do not bathe or apply any liniment, for it only increases the flow of the joint oil. If the case is taken in time by applying Monsell's solution of iron in and around the hole every couple of hours with a Peather, In most cases it will completely check the running of the oil, and the animal will recover all right. This is the best treatment knowa for open;oint. In cases where the hole is very large and the bono injured, it la best to deatroy the animal. Keep the animal quilot and feed on soft food with plenty of boiled flaxseed in It to keep the bowels open. Sometimes after the joint seems healed up for a couple of weeks it will break out again; treat this the same as at the first time until it closes the hole up. After the joint is healed up and it is still swollen, bathe with cold water and salt once a day, and bandage for a couple of hours after bathing, and every third day, after taking off the bandage, rub the joint well with acid liniment. 
They are very rare in the horse but are fully described in tumors and cancers in cattle.

\section{CURB.}

This is rupture and onlargement of the ligament that runs down the back part of the hock joint-thie ligament receivee the name of calcanoocuboid ligament.

Canses. - Horses that have crooked or curby lege are more liable to this than horses with straight legs. It generally comes on from a severe sprain by slipping while drawing or driving, or, from rearing up or backing the animal forcibly with a heavy load or in deep snow.

Symptoms. - It is easily detected by looking at the hind leg at the side, you will see the enlargement at the back of the hock, or by running the hand down over the back of the hock joint you can feel it. When the curb is first sprung on, the animal will be lame, and, in travelling, he will step long, somewhat similar to ringbone lameness. After the animal rests a day or two, and is driven, at first, he will not be very lame, but after driving a while he becomes very lame, and when allowed to stand he rests the leg by standing on his toe and throwing the fetlock forward. After a time the animal will get over the lameness if not treated, but the onlargement will remain.

Treatment. - Get the coreness and lameness out of the ligament by bathing with luke warm water and salt twice a day, if in winter, but if in summer cold water and salt; sfter bathing rub dry and apply the white liniment. When the sorenese and swellby is all out of the ligament, blinter with the following to reduce the thickeaing.

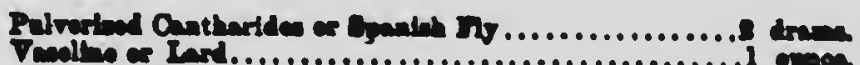

Mix, and there will be enough in this to bilster three times. Cat the hals af around the curb and rub one-thind of the mixture in woll, in three day grease and let it go for a couple of weeks, then wash the leg of with luke warm water and soap and blister again, then grease as before, repeat this blistering every three weeks until the enlargement is all gone. During the treatment do sot work the animal, but if you sonet work him keop him wei: chat co to will ant ath 


\section{DIYEABEg AND TREATMENT OF THE: HoliNF.}

This is a kind of chronic inflammation in the tendons and ligainents around the joints, and may affect any joint of the body.

Causes. - It often follows weakening diseases wher the animal is allowea to run out and lay on the cold, danup ground or from bad blood, when t! is too much acid in it.

Symptoms.--There slight soreness, suelling and lameness in the joints, changing from one joint to the other, and is noticed to be worse in damp weather.

Treatment. - Rub the affected joints well two or three times day with white liniment; also give the following :

Salicylic Aoid

Nitrate of Potain or Saltpetro.................. prund.

Common Sods

Mix thoroughly and give a large teaspoonful threc times a day. This medicine acts like a charm in rheumatism.

\section{CHAPTER XXIV. DISEASES OF THE FEET.}

\section{ACUTE + JUNDER (LAMINITIS).}

This is inflammation of the sensitive part of the foot, or whit. is commonly called the quick of the foot.

Causes.-This disease is very aisily brought on by driving $\mathrm{O}_{2}$ working a horse hard and then griving him a cold drink of walle. or allowing him to stand in a draft while he is warm. $1 \%$ h. checks the perspiration suddenly and drives the blood to the feel. which sets up inflammation in them. Sometimes by kiving at. animal a small feed of wheat it will first cause acute indigention. and then turn to a bad case of founder. It may affect mares a few days after foaling, especi,lly if they do not have their natura, flow of milk, or if by catching cold after foaling it should settle $i$, their feet. Hard driving and b.id shocing will also cause it Lung troubles sometimes rermili.ite in founder.

Symptoms. - Founder generally affect the front feet, hit may affect the hind feet and the symptoms are plain. The pulie beats

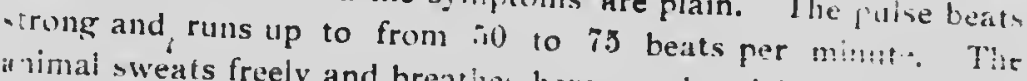
"himal sweats freely and breathe heary and quick: he funerally atands on his fect for a few days at the first of the distise; he

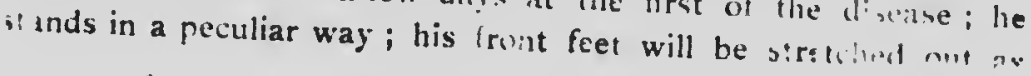


far as he can put them, and atanding on the heels trying to relieve the feet, while he has the hind feet drawn forward and well under him to throw as $m$, h weight as he can on his hind legs to relieve the front feet $H_{1}$ feet are very hot and feverish, and the horse can hardly move forwards or backwards. On account of the innammation ining inside the hard resisting hoof where there is no room for swelling ; it is one of the most painful diseases that the horse is liable to, and if he does not get relief in a few days the quick of the foot becomes destroyed, and the bone will get loose from the inside of the wall and drop down on the sole, and when it does it will cause the sole to become bulged out in an unnatural way, and then it is known as club (pumiced) foot.

Treatment.-Give a dose of physic consisting of

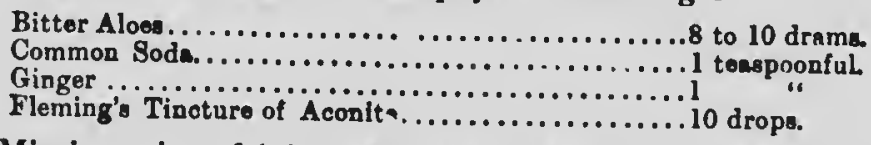

Mix in a pint of luke warm water ar $\downarrow$ give as a drench. If he is in high condition take half a pail of blood away from him, then take off his shoes and place his front feet in a tub and bathe them for two or three hours at a time with luke warm water-hot as you can bear your hand in it-two or three times a day; after each bath rub dry and apply white liniment around the feet and legs, poultice the feet with hot linseed meal and bran and leave the poultice on till you are ready to bathe again, repeat this treatment until the inflammation is checked; give the animal plenty of cold water to drink-a little at a time-and if he wants to eat give soft feed and the following drench :

Nitrate of Potash or Saltpetre. . ................. teaspoonfuL

Floming's Tinoture of Aoonit ........................10 tropen.

Water..................................... plnt.

Mix and give as a drench three times a day, continuing the drenches until the animal gets relief. Clothe the body well and have the stall well bedded to induce him to lie down for it will help to relieve his feet. The after treatment is, blister with the following and turn him out to pasture:

Pulverized Canehurides or spanish Fly............. It drame

Lard or Vavelin $\ldots \ldots \ldots \ldots \ldots \ldots \ldots \ldots \ldots \ldots \ldots \ldots \ldots \ldots \ldots$ it drame

Mix well and apply all of it around the tops of both the feet, rui in well and grease three days after, then turn him out to pasture. 


\section{SORE FEET (CHROIIC FOUNDER).}

This is a soreness or a chronic inflan..nation of the feet.

Causes.-From hard work, especially driving on hard roads. Horses with small or flat feet are more subject to this than other horses, but any of them dre liable to it; had shoeing, letting the shoe rest too much on the sole will cause it ; stancling on a dry floor and the fect becoming dry, hard and contracted.

Symptoms.-It generally affects the front reet; they become hot, dry and very hard, and, in soms cases, become contracted at the heels, which is caused from the fever und soreness in the foot. The horse has a peculiar stumbling action, and he tries to step on the heels first; if you press around the feet with a pincers or your hands the animal will flinch. After a time, from trying to favor his feet, the muscles of the chest will gradually waste away and leave the chest hollow. This must not mislcad you and make you think there is anything wrong with the chest. :ometimes when the chest falls away some call it chest founder, bu, this is a mistaken idea, for there is no such thing as chest founcler, the whole trouble arises in the feet.

Treatment.-The treatnient is not very satisfactory in somo cases. If it a valuable animal soak the feet well in warm water and salt, in a tub containing six or eight inches of water; leave the feet in the water two or three hours at a time, twice a day; every night put on a hot poultice of half linseed and hran, leave it on all nlght. After the soreness is pretty well out blister around the top of the hoof with the following:

Powdored Cantharidow or Spaniah Fly.

y............... dram.

Mix and apply all of it around the tops of bo... I ounce. turn the horse out to pasture for the third day. work again let himer the horse is afl right and he is brought in to affected with him stand on a ground floor, for an animal once careful in shoeing: liable to be affec.. 1 again. Re you want to keep she recommend the bar shoe. If it is a horse on a ground floor and, and he is not of much value, keep him biue clay, or anything pack the feet every night with cow manure, in very bad cases by bili keep the moisture in the foot, and while witl help it. 
This is when the foot bone becomes separated from the inside of the walls of the foot and drops down on the sole and frog of the foot This disease is generally the result $\Rightarrow$ acute founder when it is allowed to run on too long. This disease spoils a horse for road work, but he may be fixed up so he will work pretty well on the farm at slow work by blistering him around the tops of the hoofs, same as is done for chronic founder, and turn him out for some time and shoe with a heavy shoe well corked up, and have it well beveled out so it will not bear any weight on the sole of the foot; have the whole weight to come on the wall, also have the shoes set regular about once a month

\section{CORNS.}

Corns are generally found affecting the front feet, but may be found in the hind feet, and are also inore frequently found on the inside heel of the front foot, but may be found in either or both heels.

Causes.-Horses with weak, flat heels are more subject to it, and it is generally brought on from bad shoeing, and by the shoe resting too heavy on the heel and bruizing the horn between the bar and quarter of the wall; driving on hard roads has a tendency to bring on corns; steady driving will also cause them.

Symptoms. - The horse is more or less lame in most cases, and is more so just after he bruises it. When standing, if it is in one font, he will be noticed to point that foot out, if in both feet, he will first point one out and then the other, changing from one to the other every little while. The animal will go pretty well on soft ground, but will be noticed to get lame as soon as he strikes a hard piece of road. On raising the foot and tapping or pressing on the affected quarter, he will ainch. In taking the shoe off and paring down the quarter there will be a red spot in the corner of the sole. In case the corm becomes bruised and festers, the symptoms will be more sevore, he will hold up the foot and in walking he will step long, and will step on the toe, then hop on the other foot to get along. The affected quarter will be hot and tender when pressed on, and if he does not coon get relief it will fester and break out at the top of the hoof.

Treatment. - In many cases of corns it is not necessary tc lay the asiinal off, but shoe him so the shoe will not press on the beels and arply a poultice of hot linseed and bran to the foot for a 


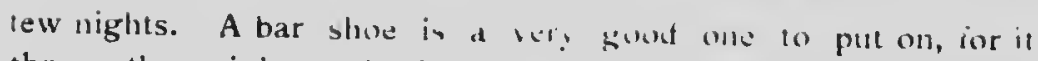
throws the weight on the frog and relicves the lieels and yuartor. In case it is a festering corn remove the shoe and pare down into the corn until you strike the matter, allow it to escape, this will give him relief, then poultice as above mentioned and allow the animal to rest a few days, and when you are going to use him again shoe him with a bar shoe, and see that the shoes do not press on his heels and quarters, and if the soreness continues, blisier around the affected quarter with the same blister that is used for chronic founder. The after treatment is to keep the animal shod regular and see that tlie shoes do not press too much on the heels.

\section{THRUSH IN THE FEET.}

This is a disease that affects the frog of the foot, and is mostly seen in the hind feet, but often affects the front feet.

Causes.-From standing in wet and filth, or anything that will rot the frog. Heavy horscy are more subject in this disease than light horses.

Symptoms.-They are vey plain, the animal may be just a little lame, but if he steps on anvthing very hard he 1 ill Tinch, and by examining the foot you will find that the centre of the frog is eaten out by the disease, and there is a discharge that comes from it which has a very had smell.

Treatment.-Keep him out of the wet and dirt, and keep the table very clean. Cut off the dead horn from around the frog and wash out line diseased part of the frogr with warm water and a little soap, after it is cleaned well poultice with a hot poultice of haif linseed meal and bran for a few days until the foot is nice and soft, after this clean the poultice out of the frog and dust in some dry calomel about twice a week until it is better; another cheap remedy is to pack the foot full of conmon salt a couple of times a week; another is to pour a fow drops of butter of antimony into the diseased foot once a week. Do this until all the discharge and smell is gone from the frog, after that leave the frog alone until it goes down itself.

\section{NAILS IN THE FEET (PUNCTURES).}

This is a very comınon thing, especially in large cities. This is where a horse steps on a nail and it runs in to the bottom of his foot. When a horse is lame always examine the bottom of the foot to see that there is no rail or anything in it. 
Symptoms. - If it is in the hind foot the animal knuckles ovet and becomes lame very suddenly. If in the front foot he points it out while standings and when he steps on it will put as little weight on it as possible and hop on the sound leg. If y,d examine the foot you may find the nail itself; if not, by tapping around the foot with a small hammer you will find where the tender spot is, then pare around it and you will find a small, black spot where the nail went in.

Treatment.-If you find the nail pull it out and pare out the hole where the nail went in almost down to the quick, after this drop in a few drops of butter of antimony, which will kill any poison or rust that may be left in. After this keep the animal quiet and apply a hot poultice of half linseed and bran for a few day's until he is entirely over the lameness before you work him. The danger of these punctures are that they may start to fester, which is a very painful thing, and also very dangerous. If it starts to fester, the animal will hold the foot up with pain; it will be swollen around the top and very hot. Cut down well into the hole and allow the matter to escape; bathe with hot water and poultice to relieve the pain and draw all the matter out. In cases where you cut a large hole and the quick bulges out, burn it with butter of antinony once a day. After the animal is able to walk nicely blister the foot around the top of the hoof with the same blister used in chronic founder and turn him out to pasture till the soreness is all out.

\section{PRICKS IN THE FOOT.}

These are injuries which are caused in shoeing by driving nails too close to the quick.

Symptoms. - At the time of driving the nail the horse will give a sudden jerk, showing that the nail struck the quick.

Treatment.-Remove the shoe and keep the horse quiet for a day or two; if he is lame poultice the foot with hot linseed. It he continues- to be lame, pare around the nail hole and give it the same treatment that is given for punctures of other nails. In any of these cases, if you want to work the animal when he is getting better, plug the hole with tar and cotton batting and put a leather under the shoe to keep the dirt out. 
QUARTER CRACK.

This receives its nane on account cf the part of the foot it effects ; it generally affects the front leet, and is more often seen to affect the inside quarter of the foot.

Causes.-Certain breeds of animals are more subject to this than others, especially if the feet are of a brittle nature, and it : often seen in road horses, more especially if they have high knee action and strike the ground heavy.

Symptoms. - At first a small crack appears is the quarter of the foot just below the hair; if the animal is kept to work he will get lame, the crack will get larger and longer, and will 'ometimes bleed. If the animal is kept working, it will sometimes faster on account of the irritation being kept up.

Treatment.-Remove the shoe, pare out the hotiom of the affected quarter so the shoe will not rest upon it, then shoe with a bar shoe; as well as this, pare out the crack all the way down on each side-almost to the quick-from the top to the bottom of it so it will not be pressing on itself. If the animal is a little lame poultice the foot for a faw days until the soreness is all out. After this apply a little of the same blister that is used for chronic founder just above the crack in the hair. This is to stimulate the growth of the horn and make the hoof grow and draw out all the soreness.

\section{CaUlKs.} shod.

This is common in the fall and spring when horses are sharp

Causes.-From the horse or his mate stepping on his foot and cutting around the top of the hoof.

Treatment.-If it bleeds freely apply Monsell's solution of iron, and if you have not this apply a pad of cotton batting and bandage tightly over it, leave it on for twenty-four hours. The danger in caulks is that sometimes hair and dirt gets worked down into the caulk and it begins to fester and works down into the foot. In all cases where the animal shows any signs of lameness, pare out the hoof around the caulk to the bottom of it, then poultice for a few days, change the poultice twice a day to keep it hot and each time the poultice is changed, pour a little hot green salve into it. 
OVFIHI:Aill.

This grenerally ocilles in tast horses where they atre spocted vithout having on quarter hoots, by stepping two lar with their nind foot and catching the heel of the front foot.

Treatment. - Trea! the same as a lacerated wo.ml, and in ail cases where you are speeding fast horses, wear boots on them to prevent them from catching their quarters.

\section{BRUISES OF THE SOLE OF THE FOOT.}

Causes.-From steppinz on a stone or any hard substance or trom the shoe pressing on the sole.

Symptoms. - The animal in travellialy stops very long on the affected foot, and by tapping the sole of the foot with a hammer he will flinch when the bruised spot is struck. If the bruise is allowed to run on without being treated it will commence to festes and the symptoms will be more severe; the horse will hardly be able to put his foot to the ground, and it will be hot and swollen around the top.

Treatment.-Remove the shoe and find the affected spot by tapping on the sole with a hammer, and if you to not think it is festering poultice with a hot poultice of halt linseed meal and ar change the poultice twice a day to kee, it hot until the bureness is all out, but if you think it is tortering pare a small hole in through the sole to the festering part, to allow the matter to escape, after this poultice as ahove inentioned untii the animal is better. Each time, when charying the poultice, melt a little green salve and dop it into the hols you cut.

\section{CUTS OF ANY KIND AROUND THE FEET.}

Refer to the treatment of Wounds.

\section{FALSE QUARTER.}

Causes.-From a cut around the top of the hoof which somedimes causes a false growth of horn, in the form of a ridge, to grow down the hoof as it grows out.

Treatment.-File the ridge down level with the wall of the foot with a rasp.

\section{COFFIN JOINT LAMENESS (NAVICUL.1.? DISEASE).}

This is getting to be a very common dincase, and is seen mostly in driving horses.

Causes.-From tard and fast work. Animals with short, upright pastern joints, short, stubby action, or horses will bigh 


\section{DISEABE AND THEATMENT WF THE HURSL. 2:3}

poinding action are more often affected with thm Isiase; alluw. ing the toes to grow too long and cutting down the lucks when shoeing them will cause it.

Symptoms." There is usually more or less lameness; in some cases :t cumes on sudden and sivere, while in ofliers it gradually comes on for weeks. and sometimes for months, before it is much noticed. While standing the horse will point the feet out, and in some cases this is the first symptom that will be noticed. If lowh feet are affected the horse suffers pain and while standing will first throw the weight on one foot and then on the other. In travelling he has what is known as a groggy action. Another well marked symptom is a wasting of the muscles of the chest. On examining the feet the heels will be found to be contracted and hard, and by raising the foot up and pressingr with your thumb on the tack part of the heel the horse will flinch. 1i you notice the shoe the horse has been wearing it will be found to be worn most at the toe.

Treatment.- If it is a bad case of long standing it is incurable, hut if taken in time, by resting the horse and by balling the feet twice a dily for an hour or two at a time (if in the winter batle with warm water, if in summer use cold water). After bithis is apply white liniment around the top of the loof and every night poultice the foot with hot linseed neal and bran, half and halt. Cintinue this treatment until he is pretty well ov the lameness, then blister the foot same as in chronic founder anu iet him out to nimlure. If it is of long standing and you want to use the horse, have him stand on a ground floor and pack his feet every night with cow manure or blue clay or anything that has a tendency to suften the foot. Shoe him with hish heeled shoes and have it low in front. In some cases neurotomy is performed, that is, where the operation of nerving the foot is performed, this is done with a view of taking the feeling away from the foot. The way this is purformed is by throwing the animal and securing him, then make a cut along the inside and the outside of the leg between the knce and fetlock about half wi!s, make the cut about two inches ?ong lengthwise in the groove batween the shin bone and the back tendons, in this groove you will find the nerve, artery and vin which runs down the leg, then cut about an inch out of the ner.: so it will not unice together aysin, do this on botls sides of the affected logr or legs, then stitch the cut up, bandige the legr and 
treat a common wound, bithe and apply the white lotion twice ang. After this is performed the horse will gret up and go off as though there was nothing wrong, but after this uperation be careful in shoeing him and examine the foot every night, for if anything went wrong with the feet they would rot off before the animal would show any lanneness. This operation at one time was performed to a great extent, but is not so much done now. In examining a horse if you think that he his been nerved in this way, prick him with a pin around the fect and if he has been uperated on he will not feel anything, but if he has not he will show signs of feeling.

\section{CHAPTER XXV. \\ MISCELLANEOUS INFORMATION.}

Horses that are wide between the oyes with a nice tapering muzzle and a nice bright eye shows a good disposition and a kind horse. Nice large ears, and in travelling they should be carried forward, this also is a good indication. The neck should be good and leng and bowed upwards, and well cut out under the jaws. The shoulders should be long and well slanted forwirds with nice high withers, also a short strong back with long round well developed hips and rump. Also a good round deep chest with a tidy belly not too small; it is also a good point to have him well ribbed up, that is, not to have too much space between the last rib and the hip bones; also look to the legrs that the bone is fiat and clean with good shaped feet.

\section{HOW TO EXAMINE FOR SOUNDNESS.}

Give the horse a quick trot or gallop to see that he is not lame, and as sooll as he stope put your ear to his nose to hear that his wind is not affected. Then examine his nostrils and mouth, at the same time look to see the agre of the animal, which is told by his teeth; then look closely into the eyes to see that there is nothing wrong with them, pass the hand up around his ears and the pole of the head to see that they are all right; then examine one side of him first by starting at the neck, running the hand over it to the withers, then over the shoulder, down the outside and inside of the front leg, and watch carefully for splints, sidebones, ringbones and such tike; then raise the foot and see if it is a well 


\section{DISEASHS AND TREATMENT UF THE HORSF E:ii}

formed one, witl good, strong heels; look back along the belly for warts and rumning sores caused from cantration, then pass the hand down the back of the hips and see that the hip bones are both the same size, then follow the hind leg over the hock and hind fetlock and look for sp vins, wind gills, curbs, splints, sidebones and ringhones, also look at the stiflles and see that they are all right; examine the foot as you did in the front, then examne the other side sume as side mentioned; after this stand back and take a look at him to see how he stands on his legs, and, also, how he holds his head and neck; notice if he stands with his front feet well under him, for this is a good sign; at the same time see if he is inclined to be weak in the knees and fotlocks. Beware of calf-kneed horses for they are always stumblers; see that he stands neither too stritight nor too crooked on his hind legs. After this take a walk around to the front and see that he has a well formed breast, and that he does not toe in nor toe out too much; then make an effort as if you were going to strike him with a stick or whip over the side, if he grunts examine close to see that he is not a roarer, then give him another good, sharp trot or gallop to see that he carries his front and hind legs nice and straight and that he has good action, also notice whether he carries his tail straight or not. Step up yuick and place your ear to his nostril to see if he makes any noisc, ant be sure that he is all right in his wind. To make sure that the horse is all right put him in a stable for an hour or two, giving him a pail of water and a feed, for in some cases of lameness the animal will not show it until he has stood for a while. After this go into the stall and take the horse out yourvelf, watching how he steps over and how he backs out of the stall for fear of strit.s hitt ind corea. After this trot him again and test him for lameness and soundness in his wind.

\section{HOW TO TELL A HORSE'S AGE BY HIS TEETH.}

Commencing at the time the colt is foaled: At nine days old he gets two centre nippers, or front teeth, two above and two below ; at nine weeks old he gets four more front teeth, one on each side of the other two palirs, these are called the lateral teeth; at nine months old he gets four more front teeth, called the corner teeth, one on each side of the two pair below, and one on each side of the two pair above. So, at nine months old, the colt has a full mouth of milk, or teinporary front teeth. At the age of 
two years you have to judge from the general appearance of the colt as to his age, as there is no clange in the front teeth. At three years old he sheds the four centre nippers or front teeth, two above and two below, and grets in permanent ones; at four years old he sheds the four litteral teeth, two above and two below, and gets in permanent teeth in their places; at five years old he sheds the four corner, or outside teeth, and gets in permanent ones. So, at this age, the horse has a full mouth of permanent front teeth.

Each one of the front teeth has a black ring on it at five years old; at six years old the ringrs on the two centre teeth in the bottom row disappears and only a black spot is left on each; at seven years uld the rings on the lateril teeth, or the ones next to the centre in the lower row, disappears and only a hlack spot is left on each tooth; at eight years old the rings on the corner teeth of the lower row disippears and only a black spot is left on each tooth; at nine years old the rings on the two centre front teeth on the upper row disappears and a black spot remains on each tooth; at ten years of anc the rings on the lateril teeth, or the ones next to the centre pair in the upper row, disappears and a black spot is left on each tooth; at eleven years old the rings on the corner teeth of the upper jaw disappears and a black spot is left on each tooth. At twalve years old we come agrin to the bottom row, and looking at the front of the teeth the two centre ones will be found to be much narrower and longer than the others ; at thirteen years the lateral, or teeth next to the centre pair-one on each side-become much longer and narrower; at fourteen years old the corner teeth in the lower row become much longer and narrower; at fffteen years old the two centre teeth on the upper row become long and narrow; at sixteen years old the lateral teeth on the upper row become long and narrow; at seventeen years old the corner teeth of the upper row become longer and narrower. At eighteen years of agre we look agrain to the botton row and the two centre teeth will be much shorter than the others; at nineteen years old the lateral teeth of the bottom row have become much shorter; at twenty years old the corner teeth have become much shorter; at twenty-one years of age look agrain to the teeth in the upper row and the two centre ones, will be much shorter; at twenty-two years old the lateld teeth will be shorter, and at twenty-three years old the corner teeth of the unper row will be short. After twenty-three years old the age can no. be told accurat=-1y. 


\section{DISEASES AND TREATMEN'T OF THE GOMSE. \\ HOW TO DRENCH A HORSE.}

Have a halter on the horse and take him some place where there is room for his head to be held up high, then place a twitch on lis nose. A twitch is a handle of some kind, about three feet long, at the end is a hole through whlch is a small rope tied to form a ring. This rope is slipped over the horse's nose and twisted up pretty tight, then hold the horse's head up high by lifting on the twitch. This is to keep the medicine from runnin: out when poured into his mouth. Have an assistant to hold the twitch while you, with a black bottle which euntains the drencl,, slip the neck of the bottle into the mouth from the side where there is no teeth; only pour a little out of the hottle at a tine, as you might choke the horse. If he goes to cough let his head down immediately until through coughing, then continue the drenching, but don't be in too big a hurry to empty the bottle.

\section{HOW TO BLEED A BORSE.}

Place a small rope, or plow cord, in the form of a slip-knot, over the horse's neck and draw it tight enough to swell the jugular vein on the left side of the neck, moisten the hair over the swelling and hold the fleames-which must be clean-lengthwise with the vein; have an assistant to hold the rope, and also cover the horse's left eye so he cannot see you. When you are satisfied the fleames set over the vein strike them a quick, sharp blow with a stick of some kind, which, as soon as the vein is cut, will send a stream spurting out of the hole. Continue holding the rope tight until it has bled enough. Always catch the blood in a pail so you know how much you take away. When it has bled encugh iet the rope slack, which will stop the bleeding. Then take a bright new pin and run it through the two edges of the skin bringing them together, then wind a string around the pin so it cannot get off; leave the pin in for twenty-four hours after bleeding; tie the horse's head up and do not let hi.lt out to grass or eat anything that will cause him to keep his head down to the ground until the vein is healed. Be sure your hands, the flims and the pin are clean, for dirt or rust will set up infianumation of the vein.

\section{A CHILL.}

Causes. - It is often noticed after a horse las heen working hard and takes a cold drink of water, or is atlons to siand in the cold afterwards, or anything like that, will bring on a chill.

Symptoms. - The horse will be shivering, lovks very dull, hus 
back will be humped up a little, he breathes heavy and refuses his feed. This is not looked on as a disease itself, but a symptom of some other sisease, and if allowed to run on without being checked is liable to set up inflammation of any of the organs of the body, so you see the necessity of checking a chill in time.

Treatment.-Put the animal in a warm stall and put an extra blanket or two on, to get hin heated up, if his legs are cold rub them to get the circulation started. Give as a drench:

Sweet Spirits of Nitre ............. 1 ounce or 4 tablespoonfuls.

Fleming Tincture of Aconite................. 5 to 10 drops.

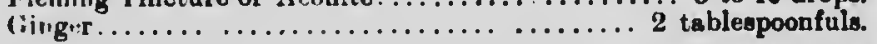

Mix in a pint of luke warm water and give as a drench, repeat the dose every hour until he is better. If you have not the sweet spirits of nitre give a wine glass full of whisky. As soon as the horse will eat give him a hot drink or a bran mash.

HOW TO FEED AND TAKE CARE OF A HORSE.

Always water the horse before feeding if he is not too warm. Feed regular, that is, set certain times for feeding him and feed as near that time as possible. Give him a certain amount of exercise every day that the weather is fit to take him out, if not working him allow him to run out around the yard, and always remember that good cleaning and a clean stable is half the feed. A good plan to cleanie the stable is to throw a little lime around the stalls every week or so, also in the summer when the horses are all out of the stable, close up the doors and burn sulphur in the stable, this will kill all the germs of distemper and all other diseases that are in the stable. Always have a little box of salt kept in front of the horse so when he wants it he can have it, and by doing it this way he will never take more than is good for him; rock salt is the best if you can get it. Whitewashing the stable about once a year is a good plan to keep it clean.

\section{NOTICE.}

All the doses of medicine which are mentioned in this book in the diseases and treatment of the horse, if not specially mentioned for the age of the animal, is intended for the averag size horse, so in giving deses to colis or very small horses you must regulate the dose to the age and size of the animal. Yearling colts would take one-third of the dose mentioned for a horse. A two year old could stand one-half the dose nientioned for a horse. A three year old can stand nearly as large a dose as is mentioned for a horse. Four year old and upwards take the full dose. 



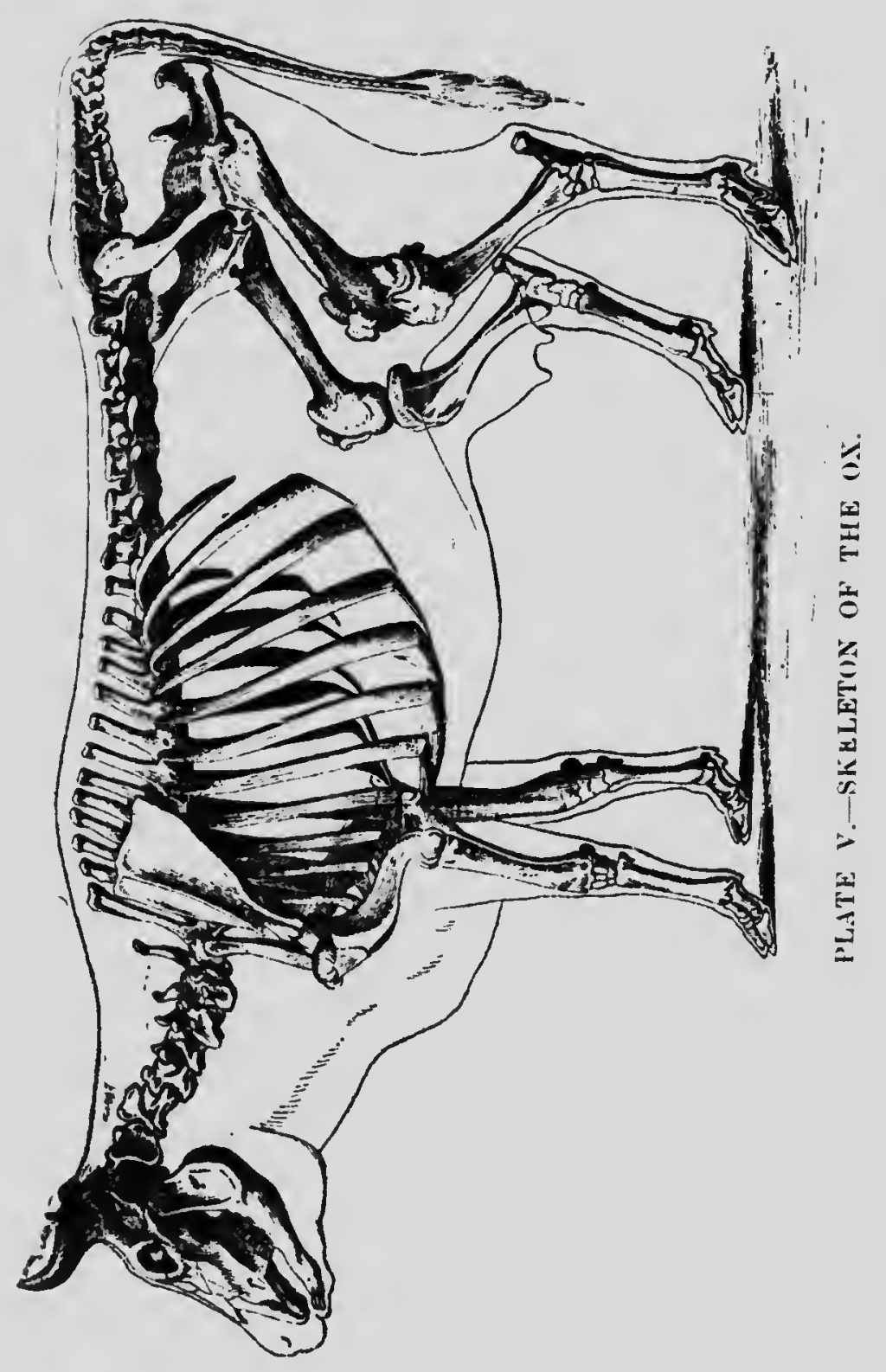




\section{EXPLANATION OF PLATE $V$.}

\section{SKELETON OF THE OX.}

This cut shows the position of each of the bones and joints in the frame of the ox. For particulars in connection with this cut refer to the anatomy of the ox--the part which deals witb the bones.

SPECIAL NOTICE.-Every place where Tablespoonful is mentioned in this book should read: SMALL, or DESERT Tablespoonful, which is equal to two Teaspoonfuls. 


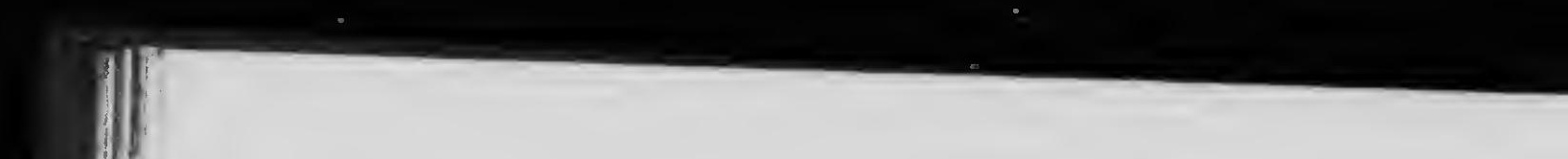




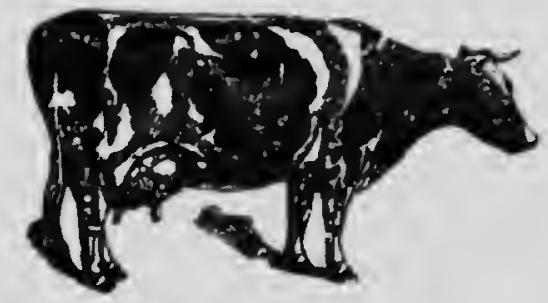

\section{PART III. ANATOMY, DISEASES AND TREATMENT OF CATTLE.}

CHAPTER 1 .

\section{ANATOMY OF THE OX.}

Each of the bones and joints of the ox receive the same name as those of the horse. There are a few important points of difference in the structure of the skeleton of the ox and horse, viz.: There are only thirteen pairs of ribs in the ox while the horse has eighteen pairs. The breast bone or sternum is much larger and flatter in the ox than it is in the horse. This is important to remember because when there is anything wrong with the lungs or chest of cattle they always lie down, for the breast bone and the ribs are so formed that when they lie on the breast bone it expands the chest, giving the animal more relief than if it was atanding. while the horse always stands in lung trouble, for ble breast boes and ribs a. 20 formed that it contracts the chent and dives the more pain while lying down. The bowes of the hand $\alpha$ the ex differ from those of the borwe by being vary beary and wide on the upper part of the skull and bas a projection $\alpha$ boas at ach deb on the upper part of the skull called the core of the born. Thl $b$ important.on account of dehorning, and overy one interested sbould become familiar with it. This projestion or the core of the horn is hollow inside which is a continuation of the sinuses or cavities in the bones of the head. Attached to the core of the horn and covering it, is the horn itself. Another point of difference between the ox and the horse, is that there a re two small bones found in the heart of the ox called the cardiac or heart bosah while in the horse's heart there are no bones at all to be found 


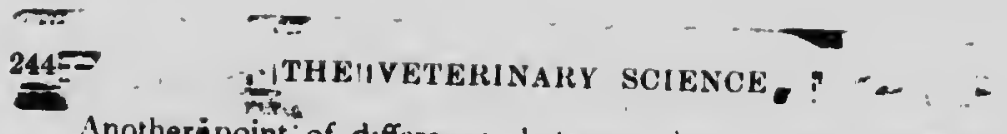

Anotheripoint; of difference between the ux and horse is/that the bones in the $\log$ of the ox are divided from fillink wun., i.... wo parts, while in the horse they are not divided.

DIGESTIVE ORGANS OF THE $0 X$.

The Lps of the ox are thick and hard, the upper one in front has no hair on it and varies in color with the color of the animal. and when cattle are in good health this space is always moist.

- The Cheeks on the inside are covered by numerous little rough processes which give the cheeks a very rough appearance.

The Tongue of the ox is stronger than that of the herse and is more movable, it is very tl:ick and heavy at the back; it is pointed at the front end and the upper part of it is very rough; it is by means of the tongue the ox takes most of the food into his mouth. the horse.

The Glands which secrete the saliva are similar to those of

The Teeth differ very much from those of the horse, the ox has no front teeth in the upper part of his mouth, their place being taken by a pad of cartilage or gristle. This pad takes the place of the upper row of front teeth for the lower row of teeth presses against it when the animal is cropping grass; on account of this pad it can be seen why cattle will not do as well on short grass as horses. The front teeth in the lower row also differs from those of the horse, they are eight in number, chisel-shaped and are loosely set in the gum. The molars or back teeth are similar to those of the horse only they are smaller and not so smooth on their upper surface. The ox has twenty-four molars or back teeth, and oight incisors or front teeth, making thirty-two in all.

The Phnrync, or gullet in the ox is much larger than that of the horse.

The Casophagus, or tube, which carries the food down from the mouth to the stomach is well developed, the fibres in it are very strong and have a double action. When the animal is eating they carry the food from the mouth down to the stomach, and during the time the animal is che ving its cud they act the very opposite, they carry the food from the stomach back up into the mouth.

The Stomach is a very important organ to understand, for cattle suffer a great deal from diseases of the stomach. The stomach of the ox has a capacity of sixty gallons, and is divided Into four divisions. The first department is the rumen or paunch; the second is the reticulum, or honey comb; the third is the omasum, or manyplies, and the fourth is the abomasum, or true 
digestive part of the stomach. The first three departments of the stomach prepares the food for digestion, while the fourth digeste it. The rumen or paunch is very large, and in an aged animal it fills' up three-quarters of the belly cavity, it lies up against the left side of the belly, 'where it is attached and held to its place by liga. ments ; its situation is important to remember, for in many diseases of the rumen, or paunch, it is first noticed on the left side, and in tapping for bloating it is always done on the left side because the paunch lies right up against the left side. The walls of the paunch of an ox resembles the stomach of the horse, but is not nearly so sensitive, and will stanu a great deal of abuse before inflammation will set in. The paunch has two openings, both of which are at the front, one is where the food enters the stomach, while the other is where the food passes out into the next division of the stomach called the reticulum, or honey comb, which is the smallest division of the stomach, and resembles a honey comb in appearance. This part of the stomach has not very much to do in preparing the food; it has two openings, one in front, where the food enters into it, the other at the back, where the food passes through into the third part of the stomach called the omasum, or manyplies, which is the second largest division of the stomach. When this is full it is ovoid in shape and placed just behind the second division of the stomach and at the right side of the paunch, and if you examine the inside it will be found to be full of folds, or layers of membrane. The use of this part of the stomach is, while the food is passing through it to draw into its folds all the coarse parts of the food and roll it about in the layers until : gets it fine and well prepared to mo- - the last part of the stomach, where it becomes digested. viven this part of the stomach becomes deranged and the food beicmes dry and hard between the folus it then sets up the disease $c_{i}$ iled impaction of the manyplies, or dry murne. When the food passes out of this third division it is emptied into the fourth part of the stomach called the abomasum, or the true digestive part of the stomach. This is where the food is digested. The walls of this part of the stomach is redder in color the : the three first divisions and has the glands which secrete the acids and gastric juices of the stomach which assist greatly in digestion. This stomach, also, has two openings, one where the food enters and the other where the food goes out of it and enters into the small bowels. 
The Bowels, or lntestlnes, of the ox are divided Into large and omall bowels, same as that of the horse, the structure and action of them resemble those of the horso. The small bor is are only half the size of those of the horse, they being about one-half inch in diameter, and about 150 feet in length. The large bowels are not nearly so large as those of the horse, and are 86 feet in length.

The Liver of the ox resembles that of the horse only it has a gall bladder which resembles a pear in shape and it acts as a vessel to store up the gall during the time there is no digestion going on. But during the time digesiton is going on the walls of the vessel contracts and forces the gall down on to the food. The other two glands, the pancreas and spleen resemble those of the horse. These juices have the same action in cattle as they have in the horse.

\section{HOW RUMINATION OR CHEWLNG OF THE CUD IS PERFORMED IN THE OX.}

The ox takes the food into its mouth principally with it. tongue, it is then roughly chewed and swallowed and passes into the rumen or paunch where it is rolled about by the action of the walls of the paunch and mixed with the juices which are secreted in the paunch. After the animal has finished eating, it then, as a general thing, lays down (but may stand up) and commence chewing its cud, the way this is ferformed is, the walls of the rumen contracts and forces the food up into the bottom part of the asophagus, which then takes on a reverse action and forces the food up into tue mouth where the food 's all thoroughly chewed over again, and in swallowing it $t$ time the end of the cesophagus, instead of opening out ar. allowing the food to drop into the paunch, keeps closed and pa es the food right into the second stonjach, thus you see the ox first roughly swallows its food and is held in the paunch until the animal has time to bring it back to the mouth and chew it over araiı. After it enters into the second stomach or reticulum, which is the honey comb part, the food is shifted around for a short time and mixed with the juices secreted i1. that part, then it passes back into the manyplies or third division of the stomach where the fine parts of the food pass izht along to the abomasum or fourth stomach, while the coarser parts of food are drawn between the folds of membrane in the third stomach, here it is worked about between the folds until it is fine and ready to pas $;$ into the fourth stomach, where it becomes 
fally digested by the action of acids and gastric fuices which are secretud in this part of the stomach, then it passes into the small bowels, and is acted upon by the bile from the liver and the pancreatic juice from the pancreas, these juices are emptied into the first part of the small bowels by little tubes or ducts, which lead from the glands down to the bowels, just on the same principle as that of the horse. After this, throughout the rest of the bowels, the nourishment of the food is taken up in:n the system by means of little glands or villi which are situated in the coats of the bowels, and the nourishment when once in the blood goes to supply the different parts of the body, while the part of the food there is no nourishment in passes off through the back bowels in the form of manure.

The Feet of the ox and bones below the fetlock are divided and receive the name of trotters.

\section{THE RESPIRATORY OR BREATHING ORGANS.}

These organs in the ox work on the same principle, and resemble in structure those of the horse, only they are not, as a general thing, so liable to diseases as the breathing organs of the horse.

\section{THE URINARY ORGANS.}

The chief point of difference in these organs are the kidneys. In the ox they are larger, and instead of being smooth, like those of the horse, they are rough, and resemble a bunch of grapes. The bladder and the rest of the urinary organs resemble those of the horse.

\section{THE GENITAL ORGaNS OF THE COW.}

The Ovaries in a cow are smaller than those of the mare, but resemble them in structure.

The Womb in the cow somewhat resembles that of the mare, but the inside lining is different, for it is covered with button-like processes about the size of a pigeon $e \mathrm{f}$, only more flattened out. These processes receive the name of cotyledons; this is what the cleaning or afterbirth is attached to and is a very important point which every person interested should become familiar with by examining a womb after calving or by opening a cow that dies soon after calving. The passage out of the womb of the cow is shorter than that of the mare, but is formed on the same principle.

The Bag, mammary glands, or udder, is very important to understand in the cow. It is first divided into two halves by 
$1+$ rtuion or division in the center of the hag. Fach one of these $1.010 .$, are agiain divided into two parts, each part is known as a quartie of the bag, each quarter having a mammary, or nilk gland and a sinus, or pouch to hold the milk where it is secreted until tho cow is milked. This sinus or pouch is situated just $\therefore$ : ve passagre of the teat.

THE GENITAL ORGANS OF THE BULL.

r.e Testicles are ovoid in whape and well developed. The "ne?....'it rord and artery are small conipared with those of the lure: : $\because$ penis $i$, long and pointed, and has an $S$ shaped curve

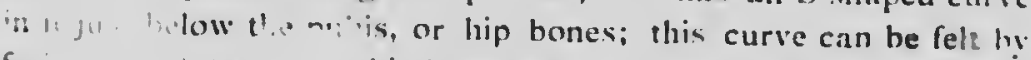
foe a wehind the batr: the sheath is long and rum. a the belly and has a tult of hair on the point of i. is. of the pe: the bull is serving a cow the $\mathbf{S}$ shaped part itens out.

\section{CHAITER II.}

\section{DISEASES AND TREATMENT OF CATTLE.}

\section{CATARRH OR COLD IN THE HEAD.}

Cattle do not suffer so much from this disease as horses. This is an inflanmation set up in the lining membrane or the sinuses of the head.

Causes.--It is generally brought on from exposure or a sudden change in the weather.

Symptoms.- The nose is rough and dry and has a mattery discharge from it; the animal has a slight cough and makes a rattling in the head when it is breathing.

Treatment.-Give a mild dose of physic consisting of

ripom salts.................... t pound.

Sweet Spirits of Nitro................. I l vunce, or 4 tablespoonfule.

Mix in a pint of luke warm water and give as a drench; keep the animal dry and warm and feed on mashes and good hay until it seems better. After the first drench follow up with the tollowing medicine :

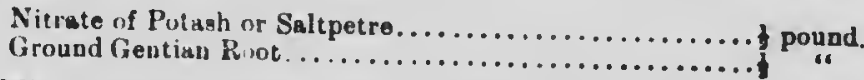

Mix together and give a teaspoonful three times a day until the aninal is better. In cases where the discharge continues from the nose and becomes chronic, it is then called nasal 
cleet, same as In horses; the treatment then in to give a teaspoonful of ground sulphate of iron three times a day in its left or on its tongue with a spoon, and this will soon stop the vischarge.

SORE THROAT.

This is a kind of inflammation affectins the larynx, or Adam's apple ; it may also affect the pharynx. or fiultet.

Causes.-Exposure to cold ant sidslen clanges of the weather, or from clioking, when some-thing loclges in ind irnutien the throat, or from roughly passing a jerohilly down the throilt and bruising $i t$, or from giving nedicines that are nut properly diluted witl water.

Symptoms. - Difficult breathing, the thro:t will he swnlen, and it hurts the animal when you press on it, the nose will he dry, and the animal will be noticed to keep swallowing, it refuses its feed and does not chew its cud, it also holds its head poked on" trying to ease its throat.

Treatment.-Give the following drench :

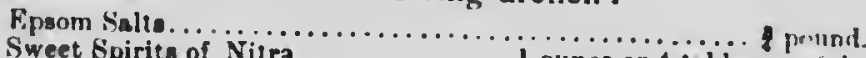

Sweet Spirits of Nitra............... nunce or 4 tablenpesntuls.

Mix in a pint of luke warm water and give as a drench. taking care not to choke the animal, as well as this follow up with

Nitrate of Potash or Salt petre................... pound.

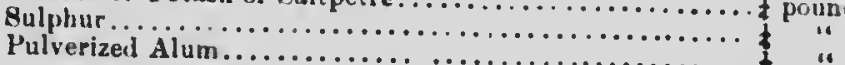

Mix and give a large teaspoonful three times a day on his tongue, this is to gargle the throat, give until the animal is better. Rub the throat three times a day with white liniment and in bit! cases apply a mustard plaster to the throat or you might use a hot poultice every night on his throat.

\section{FILARIA BRONCHITIS.}

This disease affects young cattle and sheep and is caused from mall germs or parasites getting down into the lining of the bronchial tubes; these germs receive the name of strongylus micrurus and they get into the system by being takes into the stomach in the water or food, then they pass from the stomach into the bowels, from there they get into the blood and pasy around until they get to the bronchial tubes where they lodge and set up this disease. This disease is most conmon where animals ure yrazing on low pasture fields.

Svmptoms. - The animal makes a wheezy noise while breathing and has a dry husky cough with a slight discharge from the 
nose and by examining the discharge with a mlcroscope you will find those little germs or parasites in it. The animal gradually runs down in condition and if the affected one is not soon separated from the rest the other young cattle will become affected.

Treatment.-Kill tine germs or parasites by giving

Raw Linseed Oil................................. plnt.

Bpiritu of Turpentine................. t ounow or 2 tableapoonfule.

Mix and give as a drench once week. The turpentine has a special action in cases of this kind for it gets into the blood and therefore comes in contact with the germs or parasites and kills them. If this should fail, drive the affected cattle into a stable, then take a pan of sulphur, throw some live coals in it and let the animal's breath the fumes of it, stand in the stable with the cattle and just give them as much of the fumes as you can stand yourself and then turn them out, this is the best wav to tell how much to give them. Do this every day for a week or so until they are better. By breathing the fumes of the burning sulphur it comes In cohtact with the germs or parasites in the bronchial tubes and destroys them and stops the disease. The main thing in burning culphur is not to strangle the cattle by letting them inhale too much of the fumes, as well as this feed them well to get them up in condition.

INFLANMATION OP THE LONGS IN CATTLE (PNEOMONL),

Causes.-They are similiar to the causes of inflammation of the lungs in horses; catching cold in some way, such as being out in cold rains or standing in a cold draft or catching cold after calving.

Symptoms. - The animal refuses to eat, has a slight cough and the nose is sometimes dry, then wet, changing frequently; he breathes heavy and quick and in breathing makes a groaning noise similar to impaction of the stomach, and care must be taken that you do not mistake one for the other. By placing your ear over the side of the chest a sound is heard similar to that made by rubbing some hair of your head just over your ear between your thumb and finger. If it is a milch cow she will be noticed to drop off scme in het milk. By pressing on the ribs over the lungs with your hand the animal is noticed to he sore, also feverish and very thirsty and from the fever of the lunirs the bowels are often a little costive, the pulse is quick and strong at first but after a couple of days, if not better, the pulse gets yuiclier and weaker, sometimes running as high as one hundred beats per ninute. In this diserse catle lie almost all the time, und lie well upon the breas bonte for this position seeris to , ite them relief. 
Treatment. - If the bowels are not very free and the animal b in fair condition, give

Fpsom Solt $\ldots \ldots \ldots \ldots \ldots \ldots \ldots \ldots$ pound.

Sweet Spirite of Nitro................. punce, or 4 tablespoonfula

Fleming Tinoture of Aooniti............16 dropa.

Mix in a pint of luke warm water and give this drench three lim s a day, onitting the salts after the first drench. Rub the sides wlth white liniment three times a day, and keep a half pail of hot salt over the lungs, changing it about every hour during the day, and at night apply a mustard plaster; take half a pound of mustard with enough vinegar to make it into a paste and rub well in over the sides and cover the animal up warm. Keep this treatment up until relief comes. When the animal seems to be getting better quit the above drenches and give the following :

Nitrate of Potash or Saltpetre ...................... ponnd

Ground Aniseed....................................

Mix together and give a teaspoonful three times a day on his tongue. Keep the bowels regulated by giving one-half pound drenches of epsom salts once or terice a weok and feed on soft food with plenty of boiled flaxseed in it.

\section{BRONCHITIS In CATTLE.}

This disease, when it is the result of a cold, comes from causes similar to that of inflammation of the lungs; the aymptoms are same as those of inflammation of the lungs, only by listening with your ear at the windpipe you will hear more of a wheezin noise. lunge.

Treatment.--1s the same as is given for intlammation of the

\section{PLEURISY IN CATILE.}

This is inflammation of the coverings of the lungs.

Causes.-They are similar to those of inflammation of the lungs, and this disease is very often found in connection with it.

Symptoms.--They are similar to those in inflammation of the lungs, only that when there is pleurisy there is more of a grating sound heard when you place your ear to his side and the animal's sules seem sure and he flinches more when you press on it then in inflammation of the lungs.

Treatment.- The treatment is the same as for infammation of the lungs. In this disease. as well as in all other lung troubley 
be very carefui in drenching so as not to choke the animal, and give him plenty of fresh air without being in a craft and keep him as comfortable as possible.

CHAPTER III.

\section{DISEASES OF THE DIGESTIVE ORGANS} OF CATTLE.

\section{SLAVERING.}

This is a dribbling of saliva from the mouth.

Causes.-From a wound, or something being caught between the teeth, or from eating wild mustard or poisonous grasses.

Treatment.-Give the following :

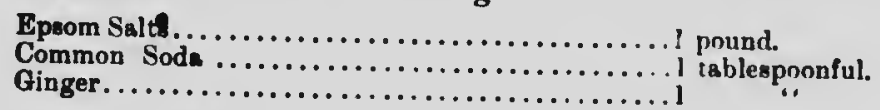

Dissolve in a quart of luke warm water and give as a drench. Sponge the mouth out with the following lction once a day :

Powdered Alum........................ tablespoonful.

Water.................................... pint.

After the medicine has operated and you have washed the mouth out two or three times the slavering generally disappears. In all cases of tixis kind examine the mouth thoroughly by looking into it, and if you find anything cauglit between the teeth remove it at once.

\section{SHARP MOLARS OR BACK TEETH.}

This is where the edges of the teeth are sharp and cuts the tongue and cheeks. When the animal is feeding it wili sometimes stop and spit the food out of its mouth and does not thrive well. The best way to fix this is to run a tooth rasp a few times over the outside edges of the upper teeth and the inside edges of the lower teeth.

\section{DECAYED TEETH (CARIES) IN CATTLE.}

Symptoms. - The animal does not thrive well, will stop eating and spit the food out of its mouth; on examining the animal's mouth you will find the breath smells very bad; if you put a clevis in its mouth and run your hand back you will find the c...aycu tooth.

Treatment.-Tie the animal up short and have the tongue lield out of the mouth by an assistant; if the animal scems ugyt place a small sized clevis crossways in its mouth, then pass your 
and b along the toots untll you and the affected tooth. Then remove the tooth with a large pincers or forceps for that purpose. In drawing the tooth, if the animal is ugly, throw it down and ecure it by the same process as is given in castrating a bull.

\section{CAPS ON THE TEETH.}

This occurs in cattle from two to four years old when thes are shedding their milk grinders; instead of the milk teeth dropping out, as they should, caps hang on the new teeth and cause them to fester at the roots, causing a lump on the jaw bone.

Symptoms. - The animal will be noticed to hold its head to one side, have difficulty in eating and sometimes spit the food out, will fall of greatly in condition and if allowed to run on for some time a lump will form on the jaw opposite the festered tooth.

Treatment.-Examine the mouth carefully till you find the sooth whicl has the cap on it which can be easily told by its being stuck up higher than the other teeth, as soon as you find it remove the cap with a pincers or anything that will knock the cap off the tooth, a cold chisel and hammer will do, by tapping it gently until you knock the cap off. If this is done in time it will save a lump from forming on the jaw.

LUMPS ON THE JAW BONES FROM THE TEETH OR FROM AN INJURY.

These lumps are hard and immovable.

Treatment.-If it is caused from a cap stayiug on the tooth too long, causing the roots of the tooth to fester, remove the cap but do not pull the tooth at first, try a blister on the lump of the following :

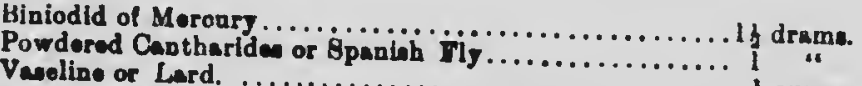

Mix and apply one-third to one-half of this amount, according to the size of lump, rub in well and grease in three days; between two and three weeks after, wash off the lump with soap and water and blister again, greasing in three days after. If this treatment does not stop the lump from growing throw the animial and secure it and pull the tooth with a large forceps used for that purpose. If the cause is from an injury blister same as mentioned above. For other information of lumpy jaw see actinomycosis.

INFLAMMATION OF THE PAROTID GLAMIDS. chroat.

This is inflammation of the rlands situated at the side of the 
Canses.-Fron 1 injury of some kind such as another animal hooking it; or by striking an animal with a stick or stone while driving them.

Symptoms.-The affected side of the throat will be swollen and vory sore, and the animal will walk about with its head stuck out, and will fall off in condition, for on account of the throat being so wore it is unable to bend its neck down to eat, and it also hurts it to swallow.

Treatment.-Apply hot poultices to the throat of half linseed meal and bran; change the poultice every three or four hours to keep it hot, and each time-when you are changing it-rub the gland well with white liniment, this will either check the inflammation and bring down the swelling, or if it festers, will bring it to a head, and then if it does not break of its own accord lance it in the softest part. After you have lanced it and let the matter out, poultice every night and apply white lotion before putting the poultice on and after taking it off. While you are treating the animal keep it in the stable and feed it out of a high manger so it will not have to lower its head to eat; give it plenty of slops and boiled feed, or anything that is easily chewed and swallowed so as to keep its strength up until it gets better.

\section{ChokINa.}

This is a very common thing amorig cattle.

Carses,-From the animal att'smpting to swallow something that is too largo for ite throat, such as an apple, potato, vlice of turnip, mangel, or carrot, and sometimen from a bone whon the animal has a fachlon of licking or chowing thom, and by miatake

Sjuptoms - The animal will stop eating, alaver at the mouth, cough, breath heary, and after a time will become bloated in the paunch, which is noticad at the loft slde, and $\boldsymbol{Y}$ the animal does not seon wot reief it becomes so blonted it will drop down from aufocation and will coon dle. Bleating is genorally worse whon it is an apple or potato, for they act just like a cork in a tube.

Treatment-Examine the mouth and throat, or gullet, and seo If you can tell what is chcking the animal; also examine along the left side of the neck to try and find out where it is lodged in the tube. If you en fool or see whatever is choking the animal, and you think you on reach it, put a clevis crossways in it mouth and rue your tand down the throat and bring it up 
yeu cannot resch it pour halt a plnt of linseed oil down as a drench, then move the obstruction by working it with your hand from the outside until the oil gets worked around it and it may slip down when you get it started. If you have no raw linseed oil any other kind of oil will do. If this faile pass down a probang, which is an instrument for that purpose; there is a small wooden gag goes with the probang; the wooden gag is placed in the mouth crosswaye; bave a man to stand on oach side and hold $a$ horn and one end of the gag, keeping the cow's head In line with the body; oil the probang and pase it through the hole in the gag, on through the center of the mouth into the gullet or throat, down into the tube leading to the stomach, pass it gently down until you strike the obstruction, then press on it until you force the obstruction down into the stomach. In cases where the animal is badly bloated, and you cannot press the obstruction down into the stomach, tap her on the left side to let the gas out with a trocar and cannula, or with a penknife, then you can easily shove the obstruction down and the blcating will soon disappear. Do not, under any circumstances, go to shove down a broom-handle, or anything of that kind, to remove the obstruction, for you are apt to burst the tube which leads to the stomach, and you will then lose the animal. Probangs cost from $\$ 1.00$ to $\$ 1.60$, and can be got at a wholesale drug store or veterinary instrument store, and is something that every stock owner ahould
have.

\section{BLOATHE (TYMPANITES)。}

This is ges forming in the paunch, or rumen, and it a common occurrence among cattle.

Canses.-Frow choking, ruddes change in the food wot clover, or eating frosen roote of any tolod.

Symptoms-The laft dde will be greath swolles with one and in eovere cases the whole belly will be distencied, by tappins with your fingers on the left slde, over the paunch, it will make a hollow, drum-like sound, and on account of the stomach being so much swollen it presses on the lungs, causing the animal to breath very heavy. In severe cases the eyen will bo bloodshot, and if it does not soon get relief will otagger, fall and die, actually smothering to death.

Treatment.-The treatment must be quick in severe casen fiva the following dreoch s 


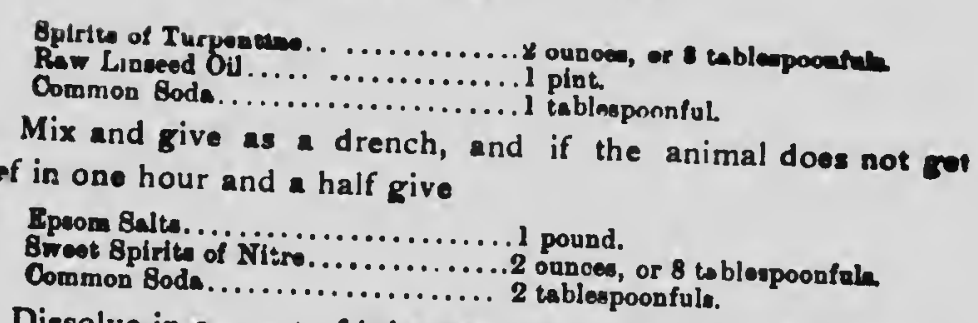

theonfuls. after this give the following drench water and give as a drench, gets relief:

Bwoet Bpirit of Nitre............... ounce or 4 teblempoonfule.

Common Soda........................

Apply plenty of heat to the body by means of blankets, and hot salt over the kidneys. The after treatment is to feed light, give luke warm water to drink and principally mashes to eat for a few days, so as to allow the stomach to have a rest. Where the animal is very much bloated and in danger of its life, perform the operation of tapping. The way this is done is to cut a small hole in the skin on the left side, midway between the point of the hip, bone and the last rib, and about four inches down from the back bone. After the hole is cut in the skin :ake a trocar and cannula and run them downwards and inwards, then pull out the trocar and leave the cannula in, which lets the gas come spouting out of the cannula ; leave the cannula in for an hour or so until the bloating is all gone down, then pull it out and let the hole heal up itself. A trocar and cannula can be got at a wholesale drug store from 50 cents to 75 cents, and is a very valuable thing to have on hand. If you have not one of these Instruments take a sharp penknife and stick it in the same place as you did the trocar and cannula.

IMPACTION OP THE RUMEN, OR PAJNCE, WITH FOOD.

This is when the rumen, or paunch, gets full of food and is unable to work it out.

Causes.- From feeding on poor food, such as straw and such like, and the animal takes a large feed of it, and on account of the walls of the stomach being weak it is unable to work the lood out of it as it should, or trom a large feed of over-ripe grass, or from the animal getting loose and getting a large ieed of corn, hrall, oats, wheat or nther grain, or from a large leed of any kind of toud the animal is not lised to. It is also caused by feeding latlemwg 


\section{DISEABES AND TREATMENT OF CATTLE.}

$\because 5 ;$

Symptoms.-In some cases the anlmal is slightly bloated while in other cases there is no bloating at all; the animal seome uneasy, and makes a peculiar grunt or groan nearly every time it hreathes. If it is a cow, and milking, the flow of milk will fall away in one night, the nose will be dry, breathing and pulse will be quicker than natural, and the animal will keep getting up and down once in a while, and will not take much food or water. By pressing on the left side, over the paunch, or rumen, it will be found hard and full of food, and where you make the dent in it with your finger the dent will stay in it some time. By tapping over the stomach there will be a dull, heavy sound. The bowels ure costive, and the passage is dry, slimy looking, and hac bad smell.

Treatment.-Give a dose of physic consisting of

Epeom Salts...............................t th ound

Bitter Aloes ....................................

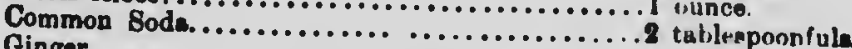

Ginger................................ I tublespoouful.

Dissolve in a quart of luke warm water and give 85 a drench. After this follow up with a stimulant to help the physic to work through the bowels.

Whisky.

Ginger..................................2 wineglnosfuls.

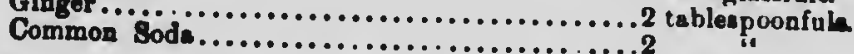

Mix in pint of luke warm water and give as a drench 11 ree times a day until the animal is better. If the physic has not i" as. ated in twenty-four hours after giving it, walk the animal a quirier of a mile, the exercise often starts the physic to work, hut if it does not operate wait twenty-four hours more before giving any more physic, at the end of this time, if the physic has n... operated, give a stronger physic consisting of

Bitter Aloe.

Gamboge. . . . . . . . . . . . . . . . . . . . . . . ...2 ouncen

Mix in a pint of luke warm water and give as a drench, tli.". at the end of another twenty-four hours give the animal a shor. walk, and this will generally work the physic; if this has na. operated, after walking it, give

Ran Linseed Oil

...I pint.

Give this drench every day until the physic does operiote Keep the animal well blanketed and warm, and plitce a half pais of hot salt over the back, for heat helps the stumach to act. (iive the animal all the luke warm water it will drink: give it slonu. 
feed, but no hay. In the course of a week or so after, if the physic has operated without carrying off the load of food out of the rumen or paunch, then, as the last resort, perform the operation of rumenotomy.

\section{BOW TO PERFORM THE OPERATION OF RUMENOTOMY.}

The animal, when sick, is generally very easy held; shove it up against the side of the stall or partition, then fasten it there by means of a long rope, any way at all so you get it solid, and tie the animal so the left side will be out, tlien, with a sharp knife, make a cut four or five inches long, right through the skin and muscles to the stomach, commencing the cut two inches below the back bone, and half way between the last rib and the front of the hip bone, then pass your hand into the cut and take hold of the stomach, drawing it well out, then make a large enough cut in the stomach to pass your hand in and out free, then have some person to hold the stomach still out through the cut in the side so the food will not fall down between the wall of the stomach and the belly; remove all the hard food in the paunch or rumen, then sew the cut you made in the stomach up with a needle used for sewing wounds; use carriage trimmers' twine, and put the stitches half an inch apart, then wash off the cut which was made in the stomach with a quart of luke warm water and 10 drops of carbolic acid in it; after it is washed off nice and slean shove it back to its natural place and sew up the outside cut, putting the stitches in half an inch apart. The treatment for the outside wound is to bathe the cut twice a day with luke warm water, and, after bathing, apply the white lotion until it is healed up. The a!ter treatment is to give the animal a iew drenches of stimulants, such as are mentioned in the treatment of impaction of the rumen, or paunch. Feed the animal on soft food imade into the form of soft gruels for a few days and keep it quiet until the cut is healed up.

\section{VOMITING.}

This is sometimes met with in cattle, but never in the horse. C.auses.-Generally from some irritation of $-?$ s fourth, or true A : :stive part of the stomach, or it may be $c_{a}$. sd from eating - ile bones, old clothes, or a boot or something of that kind. ionteli nes it is caused from nails being taken into the rumen with coud. Often after an animal is slaughtered there ase nails and rub. bish tound in the stomach. 
Treatment. -Give a physlc consisting of

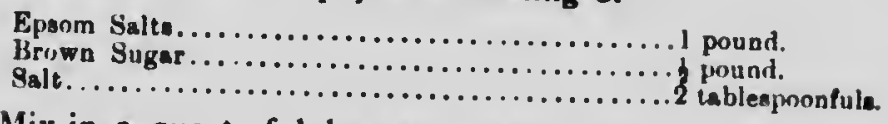

Mix in a quart of luke warm water and give as a drench. This will generally give relief, but if it does not, give:

Raw Linseed O11

8weet Spirits of Nit................ pint.

Nitre.............. ounce, or 4 tablespoonfule

2 tablespoonfula.

Mix and give as a drench every second day until the animal gets relief. Feed on soft focd and give luke ivarn water to drink for a while. In cases where this does not give relief and you are sure there is something in the stomach, perform the operation of rumenotomy and take it out.

EAIR BALLS IN THE ROMEN OR PAUNCE.

Causes.-They are caused from animals licking oach other in the spring when the hair is loose, and this hair collects in a ball in the stomach.

Symptoms. - The anımal soon stops chewing its cud, and has slight spells of bloating; it does not feed well and soon falls off in condition.

Treatment.-Give a physic of

Bipsom Salto.

Common Bod ......................... I ponnd.

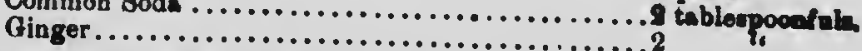

Mix in a quart of luke warm water and give as a drench. Give this drench once a week, and if it does not help the animal, and you think thore is a hair ball in the stomach, then, as a last resort, perfolm the operation of rumenotumy. There has been cases known where snakes, from three to four foet long, have been found in the stomach of the ox; there are also cases known where nails have worked their way through the stomach into the heart and killed the animal.

\section{BINDER TWLNB IN THE RUMEN OR PAONCE}

Causes. - From eating straw that has been bound with binder twine, and the twine collects and rolls up in the form of a ball in the rumen or paunch.

Symptoms.--Sane as that given for hair balls in the ramen or paunch. or paunch.

\footnotetext{
Treatment.--Same as that given for hal bell in the nowa
} 


\section{IMPACTION OF THE MAKYTLIES OR THIRD PART OF THE STOMACH.}

This also receives the name of fardelbound, or dry murrain. This is when the food in the third part of the stomach gets hard and dry between the folds and cannot work out. In some cases it gets packed in hetween the folds as hard as a board.

Causes.-From the animal eating dry and over-ripe food that does not contain much nourishment. A common cause is when the cattle are turned out too early in the spring, before the new grass has grown much, and in trying to get at the new grass they fill themselves with old, dry grass, which lodges in third part of the stomach and sets up impaction of it.

Symptoms.-First there will be diarrhoea, followed by costiveness and stoppage in the bowels, and anything that does come away is hard and slimy looking. The animal will fall off in condition, and if it a milch cow she will nearly go dry. The nose will be dry and hot, the pulse quickened and breathing increased, and sometimes there will be slight moaning and grating of the teeth; the belly has a tucked up appearance, and on account of the animal not eating much it does not chew its cud. If the disease is allowed to run on without being relieved it affects the brain and the animal becomes delirious, which is followed by convulsions and death.

Treatment.-Give the following drench :

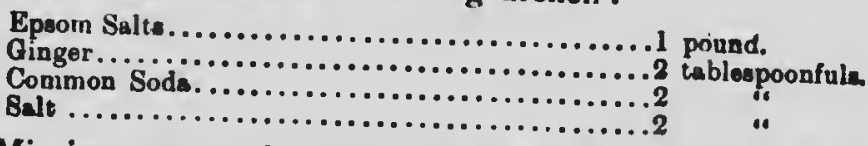

Mix in quart of luke warm water and give as a drench. After this give the following stimulating drenches :

Whisky

Ginger .................................. wineglasofnle.

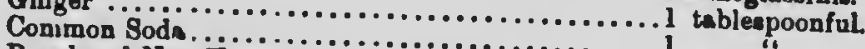

Powdered Nux

Balt.... Nux Vomica....................... I teappoonful.

Mix in a pint of luke warm water and give as drench; repeat this drench three times a day until the animal is better; keep the bowels open by giving pint doses of raw linseed oil every three days ; by keeping the bowels open and giving these stimu. lants it will generally work the food out of the stomach in a few days. Give the animal plenty of luke warm water to drink, and feed on suft fuod. Salt is given to get the animal to drink, which helps to work the food out. 


\section{DISEASES AND TREATMENT JOF: 'ITTIE}

INPI.AMMATION OF THE FOURTH PART OF THE SIOMACE.

This is infammation of the fourth, or the true digestive part of the stornach, and is more often met with in calves than in oldor
cattle.

Causes. - In cattle it is caused fium eating frozen roots or grass, also over-ripe food. In calves it is caused from changing too suddenly from sweet to sour milk, especially when the calf is young this irritaies the stomach and sets up the disease.

Symptoms. - First diarrlicea, "then constipation, and keeps changing from one to the other every day or so; the animal breathes quick and groans with pain; the nose is hot and dry, and the belly has a tuckeci up appearance and is sore whon you press on it ; the legs and ears will be cold.

Treatment for Calves. - Give the following drencb :

Raw Llneeed Oil .................... piut.

Tincture of Landanum.................... I drum, or 1 teaspoonfal.

Mix and give as a drench. Give its belly a good rubbing with mustard and vinegar; blanket to keep it warm, also place some hot salt in a bag over the back, after this give a teaspoonful of laudanum in half a cup of milk three times a day until it grets relief, and if it will drink give it small quantities of new milk, and In its drinking milk put one teaspoonful of common soda every time you feed it.

Treatment for Larger Cattle. - Give the following drench :

Raw Llnseed Oil................. pint.

Tinotare of Laudanum................. vunce, or 4 tablesponnfals.

Mix and give as a drench, afterward give the following:

Tincture of Laudanum............ sunce, or 4 tablespoonfula.

Fleming's Tincture of Aconice.......... I5 irops.

Mix in a pint of water and give as a drench three times a day until it gets relief. Clothe the body well and keep hot salt in a bag to its back. Give luke warm water to drink, and feed on soft food.

\section{DIARRHCEA IN CATTLE.}

Causes.-From drinking impure, or tgnant water, eating frozen roots; a sudden change of food, or from excitement by being chased.

Symptoms. - There are large passages from the buwcls of a fluid nature, and the animal soon grets gaunt and falls off in condition, and in bad cases will not eat, but seems very thirsty.

Treatment. -Give the fo' 'owing drench : 
Raw Linseed Oil.................. pint.

T'incture of Gatochu................ I nunce, or 4 tableuponnfule.

Mix and give as a drench. Clothe the body well and place hot salt to the back. Keep the animal very quiet; give very little water to drink, and take the chill off it; feed on soft, hot mashes and very little other food. In severe cases also apply a mustard plaster over the belly to heat the bowels. If the animal does not get relief in five hours after the first drench then give the following :

Tinoturs of Cateohu. ................1 ounoe, or 4 tablempoonful.

Ginger.........................2 tablespooofule

Common Borla...................... "

Mix in a pint of luke warm water and give as a drench even five hours until the animal gets relief. This disease, after it runs on for some time, is apt to terminate in bloody flux (dysentery).

\section{BLOODT FLOX (DYSENTERY) II CATIR.} with blood.

This comes after diarrhoea, when the manure is streaked

Treatment. - The treatment is the same as given for diarrhcea, only in each of the drenches put a teaspoonful of ground chalk.

\section{COLIC AN CATTLE.}

Causes. - This is generally caused from taking a cold drink of water or a change of food especially if it is green or frozen.

Symptoms. - This is very painful while it lasts, the animal is very uneasy, lies down, gets up, stretches out, strikes the feet against the belly and moans, and looks around at the side with pain and in some cases is slightly bloated on. the left side.

Treatment.-Give the following drench:

Epsom Solte.......................1 ponnd.

Tinoture of Ludenum................ ovnow or tablespoonful

Mleming' Tincture of Aconit...........10 drope.

Mix in a quart of luke warm water and give as a drench, keep the animal warm by blanketing and repeat this drench every hour until the animal gets relief, but after the first dose leave out the epsom salts. Another good drench is

Kaw L'nseud Uil................. pint.

Spirits of Turpentine.................. 1 t ounces or 6 tablespoonfuls.

Mix and give as a drench, after this follow up with the above drench every hour. Aflother good drench is

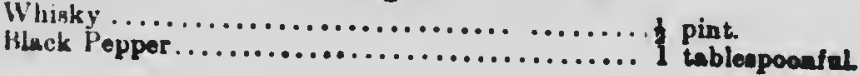




\section{DISEASES AND TREATMENT OF CANLLE}

Mix in a pint of luke warm water and give as a drenct. The danger of this disease is that it may terminate in inflummation of the bowels.

\section{INFLAMMATION OF THE BOWELS (ENTERITIS:}

This is not so common in cattle as it is in horses. It geres ally affects the small bowels, in severe cases the animal dies b four or five hours.

Causes.-It sometimes follows cases of colic or from the bowels getting twisted and stopping the passage, from being out in cold rains; or a sudden change in the temperature and the animal gets a chill which settles in the bowels or from eating musty or frozen food, or from drinking ice cold water when it is hot or anything that will chill the body.

Symptoms-There is dryness of the muzzle, loss of appetite and on accusut of not eating does not chew its cud, it seems very restless and is in severe pain. pawing and getting up and down and does not scern to have a minite's ease. Its urine or water is of a red color and he manure that it passes is covered with slime, the legs and ears are cold, the aninual keeps gritting its teeth, and on listening at the side there is no movement to be heard in the bowels, the pulse is very quick but after a short time gnts very weak, so weak you can hardly feel it.

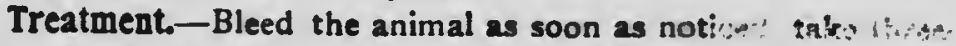
quarters of a pail of blood from it, if it in fair sistition a medium sized animal; after this give

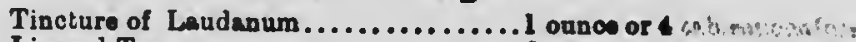

Linneend Tea....................... pint.

Mix and give as a drench every four hours, wict th the well, place hot salt over the back and a mustard piaster in

CONSTIPATION OF THE BOWELS IN CATILE.

This is not so common in cattle as it is in horses and is nors likely to occur in cattle that are feeding high on strong feed such as corn, shorts and mill sweepings or any other rich food is apt to cause it especially if the animal is not getting few roots alons with it to keep the bowels loose.

Symptoms.-The animal seems dull, does not care to ent or drink, the muzzle is dry and there is no passage from the boweln

Treatment.-Give the following:

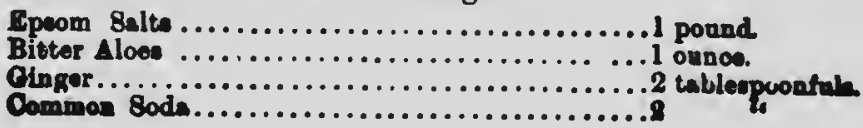


Mix in a quart of luke warm water and give as a drench. II this has not operated in twenty-four hours walk the animal for quarter of a mile and if it has not operated in twenty-four hour after the walk give it the following:

Gamboge.......

Bitter Aloes. 2 drams or 1 toanpoonful.

water and give as a drench: not operated in last drench has not operated in twenty-four hours give

Raw Linseed 0

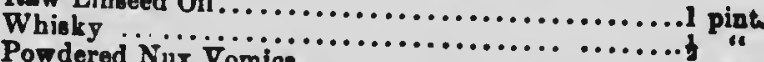

Vomic......................... 1 teaspoonful.

Mix and give as a drench, and give this drench every day antil there is a passage; keep the body warm with blankets and hot salt in a bag over the back.

INFLAMMATION OF THE LINING OF THE BELLY CAVITY (PERITONITIS),

The causes, symptoms and treatment are similar to those in this disease in the horse. It is rarely met with in cattle.

\section{DROPSY OF THE BELLY.}

This follows cases of peritonitis, and the symptoms and treat. ment are similar to that in the horse. This disease is rarely met with in cattle.

\section{TAPEWORMS IT CATTLE.}

This is about the only kind of worms the bowels of the ox are subject to. This complaint is rarely met with in cattle, but in cases where it is there may be from twenty-five :o one hundred feet of the worm found in the bowels.

Symptoms.-The animal runs down in condition, but still keeps feeding and seems always hungry. The only way to be sure that it is a tape worm is to watch the manure and you will find joints of the worn coming away with the manure.

Treatment.-Get rid of the worm hy starving the animal for four days, that is, just give it enough to keep it from starving to death. Give the following drench :

Oil of Male Fern................ t ounce, or 2 tablespoonfule.

Now Milk 1 pint.

Mix and give as a drench. Give this drench three times a day during the four days you are starving the animal, and at the end of that time give one pint of castor oil, which will bring the worm away all right. Young calves are more often affected than 
cattle; treat them the same, only give quarter of the dose. As soon as the worm pisses away bring the animal back to ite regular feed and habits agrain.

\section{JAUNDICE OR YELLOWS.}

Causes. - This may be caused from congestion or inflamma. tion of the liver, or from bile stones forming in the duct of the liver, damming back tlie bile. It is most often seen in stall-fed cattle.

Symptoms.-By pressing on the right side of the belly it causes the animal pain, its appetite is poor and it does not want to drink much ; the white of the eyes and the lining of the mouth and nose is of a yellow color. If it is a milk cow the milk falle off in quantity, and has a bitter taste like bile; the animal will sometimes cough a very painful cough, and will soon run down in condition and have a very dull appearance.

Treatment.-Give the following :

Epsom Sults........................... pound.

Salt.................................... tablesponfule.

Mix in a quart of luke warm water and give as a drench, but before giving it to the animal put one dram of dry calomel (which acts on the liver) on the tongue with a spoon and wash it down with the drench. Repeat this drench once or I vice a week until the animal is better. Feed on soft food, give plenty of water to drink and gentle exercise every day.

\section{FLUKE DISEASE IN CATTLE AND SHEEP.}

This oecurs in cattle and sheep pasturing on low-lying lands, and is more often met with in rainy seasons.

Causes.-Animals drink tive eggs of the flukeworm out of pools of water, or take them in along with the grass; after they get into the stomach in this way they get into the blood along with the nourishment, and pass around in the blood until they come to the liver, where they lodge and for in into flukeworms, after this they lay eggs, w!:ich pass down out of the liver along with the bile, then out of the system along with the manure; they bocome dry and are blown into pools of water and over the grass, where the animals again take them up. This is the way they generate.

Symptoms.-At first, when the eggs are taken into the liver, they seem to stimulate the action of the liver, and the animal seems to thrive better than ever for a time, but after the worm be 
come full grown the liver hecomes diseased, which stops the secretion of the hile, and the animal soon falls off in condition, hecomes very dull and weak, and has dropsical swellings uncler the jaws, throat, chest and belly, and these symptoms are soon followed by death.

Treatment.-There is nothing that can be be done but to destroy the diseased animal to keep the disease from spreading, and move the unaffected cattle to a higher and dryer pasture. This disease does not affect horses, so horses can be turned on the pasture the cattle are taken from. On examining the liver after death you will find it diseased, and you will also find worms which are from one-half to one inch long, and have round bodies. In some cases you will find them in great numbers.

\section{WHITE SCOWERS IN CALVES.}

This is a form of diarrhcea in,calves.

Causes.-Is from an inflammation of the lining of the fourth part, or true digestive stomach, and is generally caused from changing the calf's milk by taking the milk of another cow to feed it on, or from giving it cold or skimmed milk when it is not used to it.

Symptoms.-The manure it passes is very thin, and is of yellowish white color; the calf is in pain, breathes heavy, and groans in spells, keeps gritting its teeth and looking around at its sides.

Treatment.-Try and find out the cause of the trouble, and if caused from a change in the milk, or from giving it too cold, give guod, warm milk to drink, and follow with the following:

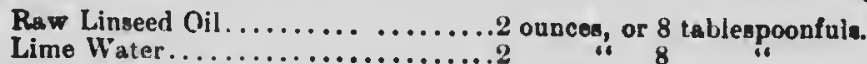

Tincture of Laudanum..............

Mix and give as a drench, and if this does not give relief give the following :

Tincture of Laudanum............. dram or 1 teaspoonful.

Lime Water.................... 2 ounces, or 8 tablespoonfuim.

Mix and give this three times a day in a little milk as a drench. Keep this treatment up, and see that the animal is kept dry and warm until it is better.

\section{BLOODY URINE (RED WATER) IN CATTLE.}

Causes. - It is caused by the animal eating some weeds that act on and irritate the kidneys, or it may oe caused from stones in the bladder or kidney's, or from a severe strain to the back. 
Symptoms.-The urine or water is of a smoky, red color, and the animal will pass water often, and strain atfer making it, and, in some cases, makes a great lot of it.

Treatment,-Give as a drench :

lilauber Salto. .1 to 1 t pounds.

Mix in a quart of luke warm water and give as a dreach, and follow up with the following powders :

Giround Gentian Root.............................

Silphate of Iron ............................

Mix well together and give a large tablespoontul in a mash twice a day, night and morning.

CHAPTER IV.

\section{TROUBLES IN CALVING AND DISEASES FOLLOWING.}

HOW TO TELL WHEN A COW IS WITH CALF.

During the hot months of spring and summer a cow will come bulling every third week, and occasionally a well-fed cow kept in a warm stable will come bulling during the winter. After she takes the bull and is with calf she ceases to comc bulling or running, and will thrive and feed better, and is of a quieter dis. position than before. After a few weeks she commences to get larger at the flanks, which is more noticeable on the right side on account of the calf lying mostly $c$ that side. The calt gradually grows, and at the fiftl or sixth month becomes alive, and can be seen moving at the side after the cow has taken a cold drink of water. A few months after the cow has been to the bull you can, by pressing your hand in quickly at the right flank, feel the calf, which is easily told by the shape and hardness of the object you teel. Springing commences in young cows about four months previous to calving, and the bag gradually keeps getting larger until calving time, while older cows generally commence to make a bag from four to six weeks before calving. During the tirne she is making a bag the vulva gradually keeps getting larger. Near the end of the ninth month, when calving time approaches, the ligaments at the sides of the tail and hips relax and leaves a hollow at each side of the tail, this hollow is well marked a day or 10 before calving. A few days before calving the cow bas a wild 
expression in her eye, and is cross to other animals, and will try to get auay by herself, after this the labor p.ins come on and she is noticed to be straining, then the neck of the womb opens out, the water bag appears and breaks, and if the calf is coming ratural and everything all right, the front legs and head appears. The cow generally lies down, and after a few minutes of severe straining the calf is delivered, and the cleaning, placenta or afterbirth generally comes away at the time of calving, or very soon after.

\section{DROPSY OF THE WOMB BEFORE CALVING.}

This is due to some derangement of the afterbirth, and there is an nver abundant amount of fluid secreted around the calf, in wme cases several pailfuls collect in the womb around the calf.

Symptoms.-The belly keeps getting larger and larger until the cow seems almost as broad as she is long, and on account of so much fluid forming she becomes weak and has difficulty in getting up and walking around.

Treatment. - There cannot be much done in this disease only keep the strength up, give a teaspoonful of nitrate of potash or saltpetre in a mash every third day until she calves, this is to act on he: kidneys, which helps to get the water out of the womb. Feed plenty of good, strong, nourishing food to keep her strength up and she will be all right after calving.

\section{PARALYSIS OF HIND QUARTERS BEFORE CALVING.}

This disease is generally noticed in poorly-fed, unthrifty cows, especially if they are exposed to cold or wet, and is caused by the calf in the womb pressing on the nerves that go to supply the hind quarters with power.

Symptoms.-The cow appears healthy-is eating and chewing her cud, but is not able to rise on her hind parts.

Treatment.-Give half-pound doses of Epsom salts once or twice a week, according to how it acts on the bowels, and give the following powder:

Ground Gentian Root $\ldots \ldots \ldots \ldots \ldots \ldots \ldots \ldots \ldots \ldots \ldots \ldots$ p. pound.

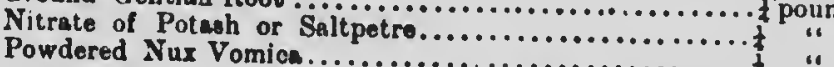

Mix and give a tablespoonful in a slop twice a day. Give plenty of good food; keep her warm; have good beddingr under her, and turn her from side to side twice a day until she calves, then she generally comes all right. Never attempt to put her in ulings, just let her lie until she is able to get up. 


\section{DIBEASES AND TREATMENT OF CATTLE.}

TROUBLES MET WITB IN CALVING.

Troubles met with in cows when calving, such as deformition, or calves coming in unnatural shapes, is fully explained in connection with "Difficulties met with in a mare toaling." The deformities and positions are about the same, and the principle laid down to take foals away is used in taking calves away. Always, if the calf is coming front end first, have the front feet and head coming together, and if the hind end is coming first, do not attempt to turn the calf, but bring it out with hind feet first. Never be too eager to use hooks, because small ropes are better and there is less danger of tearing the womb; and in cases where there has to be any cutting done, it is best to get an experienced hand, for the parts of the calf have to be skinned inside, com. mencing at the legs and skinning to the shoulder blade, and then taking it off with the leg; then take out the ribs and insides, and $s 0$ on, with the other parts until you have enough of the calf cut away so that you can get it out all right.

Closore OF THE NECK OF THE WOMB at CALVING TME.

This is where calving time has come, and labor pains are on the womb, but the neck of the womb keeps contracted or closed, and will not allow the calf to come out of the womb.

Treatment.-Give the following drench:

Epwom Salt $\ldots \ldots \ldots \ldots \ldots \ldots \ldots \ldots \ldots$ pound.

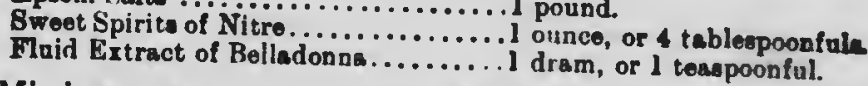

Mix in a quart of luke warm water and give as a drench. Koep the body warm with blankets and half a pail of hot salt, in a bag, over the back. On examining the neck of the womb with your hand you will find that you can only get one or two fingers worked into it. Take a small piece of sponge or cloth and saturate it with fluid extract of belladonna, then shove it well inte the neck of the womb as if it were for a plug; change this two or three times a day to put more of the fluid extract of belladonna on it. Do not use any rough treatment, for the belladonna in a dzy or so will dilate or open the neck of the womb enough so that she will calve herself. In case this treatment should fail, take a penknife and nick around the inside of the neck of the womb in several places on the upper side, then use the belladonna an described above-und this will open it. 


\section{RUPTURE OP THE WOMB OR THE PASSAGE OUT FROM THE WOMB.}

This occurs at the time of calving in the same way it does in the mare when foaling, and for symptoms and treatment look at rupture of the womb, or the passage out from the womb, in the mare.

\section{TURNING OUT OF TEE VAgINA OR PASSAGE LEADING FROM THE WOMB.}

Causes.-Both in cows and mares is from standing in the stall with their hind feet too low before calving or foaling, and while lying down, on account of being so full, the wolisb presses back against the passage and turns it out; it is liable to come out in cows a few days after calving from straining, or it may be caused from constipation, in either cows or mares where they strain in making manure.

Symptoms. - There is a bulging out of the passage about the size of a man's head.

Treatment.-Bathe the parts well with luke warm water until it is nice and clean, and shove it back to its place and stitch the edges of the vulva together by putting in a couple of stitches, just leaving space enough at the bottom for the mare or cow to miake water. Put the stitches deep in the vulva and allow them to come out of their own accord, which generally takes a week or so. II it is a cow, give a pound of Epsom salts and a tablespooniul of ginger in a quart of luke warm water, and raise her stall two or three inches higher at the back.than in the front; feed on rich food, as, it will not make such a bulk in her stomach. If it is a mare, give her a pint of raw linseed oil, and raise her stall two or three inches higher at the back than in the front; and in either case be careful until after they foal or calve. In either case, if they are about to have their young, watch them close, and if the labor pains come on, cut the stitches out and give her assistance, and after she is delivered of her young shove the parts back and stitch up the vulva again for a few days, then she well be all right.

\section{WOMB, CALP OR FOAL BED TURNED OUT.}

This is where the calf or foal bed is turned inside out, and hangs down from the vulva. This is not often seen in mares, but is a common occurrence in cows.

Causes. - lirom the animal lying with her hind end too low, and while the womb is in its dilated or enlarged state, after calving or foaling, the body being low behind, the bowels and 
stomach presses the womb back up into the pelvic, or hip savity, and as soon as it gets up in this part it causes the animal to have pain and strain, which soon turns the womb inside out. To prevent this from taking place, it is always well to keep the animal standing for a few minutes after having her young, so as to allow the womb to go back into its place, and after this, if she lies down, see that her hind end is not too low.

Symptoms.-The animal seems very weak and has a large, red mass hanging out behind, sometimes larger than a largre wooden pail.

Treatment.-In all cases, as soon as it is noticed, return it, for the sooner it is done the easier it is put back and the less danger there is of losing the animal, for the longer it is out the more it swells. If the cleaning is still attached to the womb-as it is in some cases-remove the cleaning, which is easily done, before returning the womb, by separating it from one button at a time. After this bathe well with warm water, and when it is nice and clean, place a clean sheet or blanket under it and have it held up by two men, one on each side, while you are returning it; after everything is ready for returning it make the cow, or mare, get on her feet, and have her stand so that her hind end is a few inches higher than her front end, then have the men who are holding the sheet raise the womb a little higher than the vulva, this makes it easier to shove in. After this begin turning the womb in, commencing at the edge of the vulva, returning it gradually until all of it is in the passage, then, with your hand closed, press it against the end of the womb and shove it right back 10 its place and hold it there for a few minutes with your hand and arm. During the time you are returning it be careful not to run your fingers through it. After you draw out your arm place three or four good, solid stitches across the vulva, leaving a little space at the bottom for" the water to come out. Cover the animal so that she will be warm and keep a half pail of hot salt in a bag to her back. If it is a cow give the following :

Rpeom Salt..................... pound.

Bweot Apirite of Nitie.................

Mix in a quart of water and give as a drench, after this give one ounce or four tablespoonfuls of tincture of laudanum and ten drops of aconite in a pint of water every three lwurs until slie stope straining, also keep her standing on her feet for 9 few hours, 
with ber hind and raised three or four inches higher than her front end. In two or three days after the pains are gone take the stitches out and allow her to stand on the level floor again. If it la a mare give one pint of raw linseed oil instead of the Epsom calts, but the rest of the treatment is the same. In both cases remove the stitches in two or three days, when the animal quite straining and seems all right.

EOW TO TAKB AWAY THE CLEANING FROM A COW.

Cause - Is from a congested and swollen state of the buttons 11 "hich the cleaning is attached to the womb inside.

Treatment-As soon as the cow is noticed not to clean give the following drench :

Bpporm Saltu......................1 pound.

Fuld Extra ot of Beilia donna............. I dram, or 1 teappoonful.

Sweot Spirit of Nitro.................1 ounce, of 4 tablespoonfuls.

Mix in \& quart of luke warm water and give as a drench. Blanket well and keep half a pail of hot salt in a bag to her back ; cive her a hot bran mash and leave her quiet, and when the medicine operates she will generally clean all right, in thirty hours after you have given her the medicine, if she has not cleaned you will have to take it a way with your hand. Roll up your sleeves and oil your right hand and arm, then take hold of the piece of cleaning that is outside with your left hand and pass your right hand into the womb, and by gently pulling the cleaning it will come away quito easy after getting the medicine, it being held in only by the neck of the womb being tightened on it, not allowing it to slip out. In cases where the cleaning has not loosened off of the buttons, keop gradually pulling with the left hand and loosen the cleaning with the right hand off the buttons until it is all worked off. A littlo practico in removing cleanings-soon makes a person perfect at it. When the cleaning is green and too tight on the buttons allow it to remain in another day and give her another drench of the same kind as the first one mentioned, which will make it all right for taking away. Cleaning should never be taken away without first giving the medicine to loosen it from the buttons.

ITFLAMMATION OP THE WOMB (METRITIS).

This disease generally comes on two or three days afte1 calving.

Causes.-From getting wet, standing in a draft or anything that will give her a sudden chill, will bring it on. 
sympioms,-Slight shivering; the hurbs, ears and lege ane cold, the pulse and breathing quick, she loses her appetite and stops chewing her cud and seems restless on her hind lega, a it in pain; she seems sore on the right side, her vulva is swollen, and she passes bloody looking stuff from it; frequently, after making her water, she seems very thirsty; her bowels are coative, and the urine is of a reddish color; the bag is hot, swollen and and tender, and she does not give as much milk 25 she should.

Treatment.-Give the following :

Kpeom Selt .................... pound.

Tincture of Landinum ...............1 pound.
Fleming's Tincture of Aconito......10 drope.

Mix in a quart of luke warm water and give as a drench; keep ner body warm with blankets and half a pail full of hot salt in a bag on her back, and keep it hot by changing it every bour. After the first drench give

Tincture of Laudannm.

Sweet Spirit of Nitro............... ounow, or \& tablempoonfale

Fleming Tinoture of Aconito.........10 drope.

Mix in a pint of luke warm water and give as a drench every four hours until she is better. Feed on soft food with boiled fls $x$. seed in it to keep the bowels loose. Give her cold water to drink in small quantities, but often. After this disease has passed of there is sometimes a nasty discharge from the womb of whitish color, which has a bad smell. This is called whites (Leucorrhoea).

\section{W.ITES (LEUCORRHCEA)}

This disease frequently follows inflammation of the womb, but may be caused in other ways, such a handling the womb rough in taking the calf, or cleaning away, or returning a cal bed; anything that will irritate the womb will set up this dises-:- : or it may be caused from the cow being put to the bull too onen.

Symptoms.-There is a naty, whitish dischargo, which na a bad smell, passes from the vulva, which is often noticed after she makes her water, from the effects of this the cow runs dowa in condition, gets poor, weak and hide-bound.

Treatment.-Give her half-pound doses of Epsom salts dissolved in a pint of luke warn water, twice a week to keep the bowels free. Oil your hand and pass it through the passage to the neck of the womb, then gradually open it up with your fingers until you get it large enough to prss your hand into the womb, then with a pail of luke warm water, soap and a sponge wash the womb and pae 
ano cut entll you got It nlce and clean, then with a terspprontu $\boldsymbol{\alpha}$ culphate of sinc dissolved in a pint of water bathe the womb woll. This will heal the womb and dry up the discharge. In the course of a week, if the discharge is not stopped, dress the womb again the same as above mentioned. Keep giving her the salts once or twice a week, according to how much it acts on the bowels, and, if in the spring of the year, let her out to grass.

\section{PARALYSIS AFTER CALVING.}

This is when the cow apparently seems healthy, only she cannot rise up on her feet, and is generally caused from an injury to the muscles or nerves of the back when she is straining while calving. This disease need not alarm you for, as a general thing, she gets all right in a few days.

Treatment.-Give the following:

Epenm Balta.....................1 pound.

8weet Bpirite of Nitre................ I ounce or tableppoonfals.

Mix in a quart of luke warm water and give as a drench. Keep her body warm with blankets, and apply a quarter of a pound of mustard, mixed in vinegar, over the back every second day. Feed on soft food, with boiled flax seed in it. Milk her out twice a day, and also turn her over from side to side twice a day, but never, under any circumstances, put her in slings.

\section{WIL FEVER (PARTURIENT APOPLEXY),}

This is one of the most fatal diseases cows are subject to, and mostly affects well-fed, fat cows that calve during the hot months of spring and summer, but may affect poor cows. It is also noticed occasionally to affect cows at almost any time of the year; even in the winter, I rare cases, it is noticed.

Causes.-The exact causes of this disease are not clearly understood; but it is supposed that on account of the hot weather, and the cow being fat and full of bluod, it sets up a fever which affects the nerves, and when the nerves are affected, the milk glands also become affected, and do not secrete the milk, and the milk not being secreted as it should be, leaves the blood charged full of material which should go to form milk, and when the blood becomes full of this material, it affects the brain and nerves, soon causing paralysis. This disease is usually noticed to come on in from one to eight days after calving. The sooner it comes on after calving, the more fatal the disease is. Cows taking it io 
one or two daye after calving seldom get better, but after the time there is more cnance of recovery.

Symptoms.-At first there is a wild, glary appearance of the eyes, and when you go to milk her there will be very little milk iv the bag, which, in most cases, seems soft and flabby. In trying to walk she has a staggering gait. These symptoms will gradu. dly get worse; saliva will run from her mouth, and she wlll wa Ereatly excited; keeps staggering, and acts like a drunken man. Finally she gets down, and is unable to rise; her head is tume around to her side; her ears are lopped over, and her eyea now have a peculiar, dull, glassy appearance; the pupils of the eyen are enlarged; she breathes a little heavy; her nose is dry, anc she does not take any notice of things around her. If you go $\mathrm{k}$ milk her only a little will come out at a time. There is very littl or no passage from the bowels, and if you prick her with a pia we cannot feel it A few hours after this, if she does not get relief, she becomes delirious, moans heavy, lies stretched out, and keepe tossing her head about. The bag keeps getting softer, and after a while, when you try to milk her, you cannot get any. She gradually gets worse and soon dies. We will relate a case where a cow was stricken with milk fever, and owing to the diotance we had to go, when called to treat the case, it took four houre to reach her from the time she took sick, and on arriving abe was breathing her last. This shows the necessity of overy; stockowner underntanding this disease thoroughly, so he can trant thom a coon as they are noticed sick; for this is the only wer troat aill fover accessfully.

Treatment. The treatmeist must be quick in uruer 10 be effective. If the cow is on her feet and able to swallow without difficulty, give the following drench :-

Epsom Salts. 1 pound.

Bitter Aloes......................................

Nitrate of Potash, or Saltpetre............... large teaspomful.

Common Soda and Ginger.................... 1 tahlespoonful oach.

Mix in a quart of luke warm water and give as a drench. Put the cow in a cool, airy stable, and tie a bag, with broken ice, to the bead between the horns, keeping the ice to the head until she is relieved. Milk her dry, and sponge the bag thoroughly with warm water so as to soften and clean it. Take a pint of clean boiling water, allow it to cool down to luke warm, to this add fifty grains of iodide of potassium and stir until thoroughly dissolved. By the aid of a 


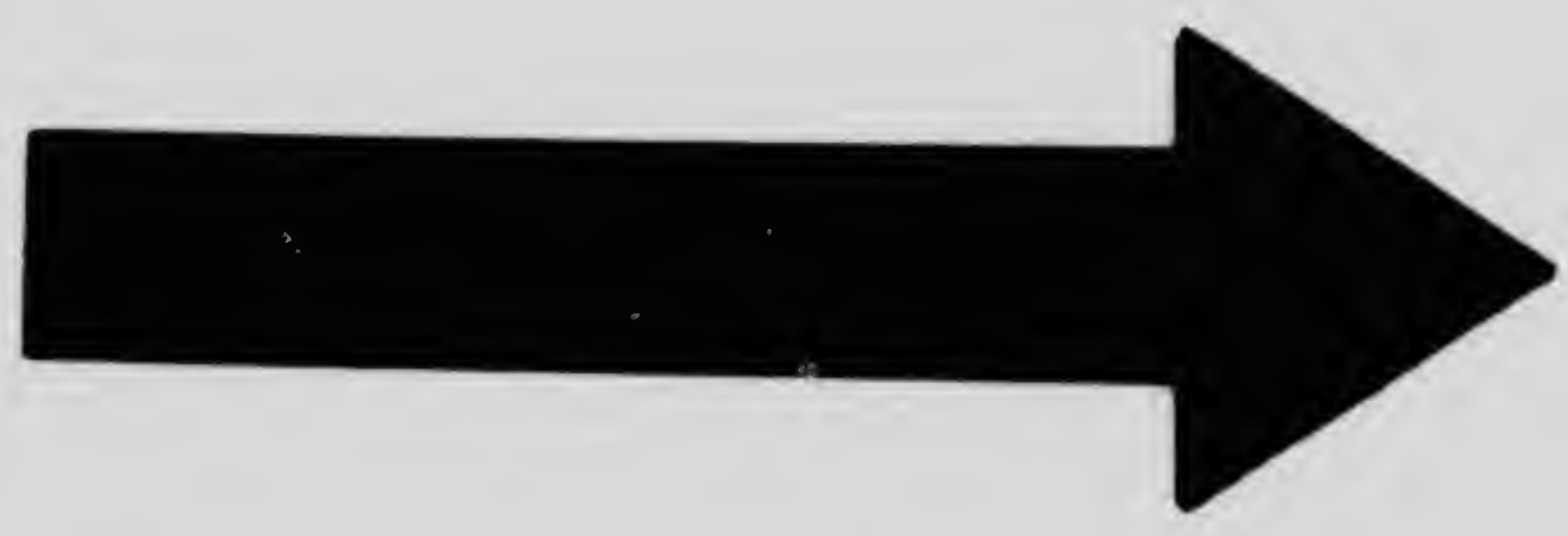




\section{MICROCOPY RESOLUTION TEST CHART}

(ANSI and ISO TEST CHART No. 2)
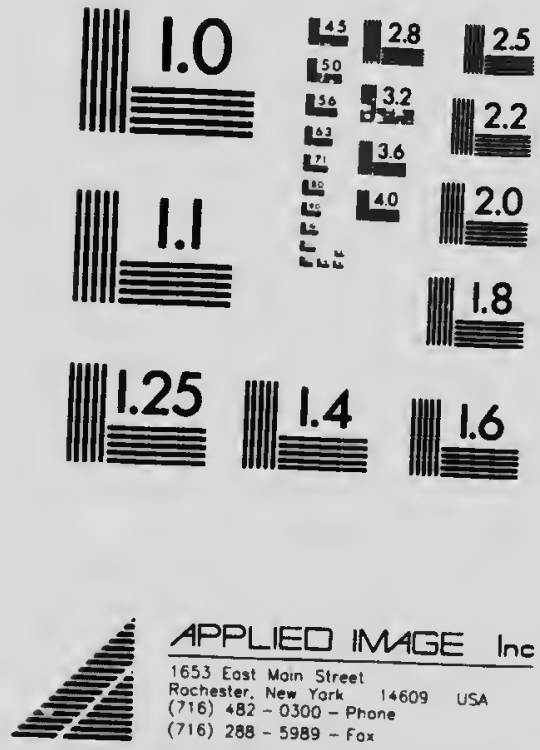
teat syphon and small rubber syringe (which can be got at any drug store) inject one-quarter of this mixture through the passage of each teat up into the bag. After injecting, give the bag a thorough band rubbing in order to work the medicine well up around the milk glands. In case the cow should get off her feet watch her rarefully so she will not injure the bag by lying on it, and turn her from side to side every four hours, keeping her lying up well on her breast bone. If her bowels are not free give her balf a pail of luke warm water injections every four hours. If she does not make her water within twelve hours after injecting the bag, take it away by means of a catheter, which is an instrument for this purpose, and can be got through a drug store. This is done by passing the point of the catheter, guided by the finger, along the bottom part of the vulva about four inches in, where you will find a small opening. Into this pass the catheter gently downward and forward until the water comes through the catheter. Guarding the opening mentioned is a little valve, and sometimes by slipping the finger in and raising the valve the water will come without using the catheter. Do this twice a day if necessary. Six hours after injecting the bag, if the cow is not showing signs of recovery, milk her out and repeat the same injectior. into the bag. Repeat this every six hours until the nilk returns to the bag and she shows signs of recovery in other ways. During treatment offer her frequently small drinks of cold water and gruels. Milk often until she is well. When recovering, give her 2 small quantity of such foods as she seems to relish best, and leave the calf with her for a week or so. If the cow is not going to recover, the paralysis become more marked. She becomes dull and quiet, which is tollowed by a delirious state before death.

The treatment of this disease is one of our latest discoveries, and has proved to cure over 90 per cent. of the cases.

\section{HOW TO PREVENT UIK FEVER FROY COITNG OT.}

If the weather is hot and the cow is in good condition, and you are afraid of milk fever, turn the cow into a shady place every day for a week or 20 before she calves; feed very light and allow her to run out at night, and give her the following medicines

Epaom Saltu..................... 1 pound.

Bweot Spirits of Nitre................. ounce or 4 tablespoonfule.

If she has a very large bag before she calves, milk her every day; after she calves, keep her in during the day and let her out at night for a week, and keep her well milked out. Repeat the above dose and she will generally be all right.

INFLAMMATION OF THE MILK BAG (GARGET).

Causes.-From getting cold in the bag; from an injury; from too great a flow of milk at calving time; from a lump in the teat: or from anything that will stop the milk from being milked out $\alpha$ the bag. 
Symptoms. - The cow seems feverish; the bag is swollen, hot and tender; she is very thirsty, but does not care to eat; the bowels are a little costive; when you go to milk her it causes her pain; there is very little milk in the bag; and, in severe cases, nothing but a little water will come out. This disease may affect one quarter, half the bag, or all of it. It is most often seen in cows, just after calving, that are kept in high condition. If it is allowed to run on for some time the bag may fester and break, while in other cases, where there is a great deal of inflanmation in the bag, mortification may set in, and th's part mortifiel will drop off. The mortification may extend up into the body and
cause her death.

Treatment.-Give the following:

Epsom Salte................... pound.

Sweot Spirit of Nitre. ............... punce or 4 tablespoonfule.

Nitrate of l'otash or Saltpetre.......... I teaspoonful.

Mix in a quart of water and give as a drench, and repeat this every second or third day until she is better. This will carry off the fever out of her system. Bathe her bag well with warm water and vinegar three times a day; after bathing, apply white liniment, and as soon as the liniment is on, oil the bag with lard or goose oil to keep the liniment froin blistering and also to soften the bag. Milk her three or four times a lay and feed light until all the soreness is out of the bag. In cases where the milk stops coming entirely, and the bag is festering, watch for a soft place in the swelling, and, as soon as it forins, lance it and let the matter out. After you lance the bag. if it smells bad, put a few drops of carbolic acid in the water that you bathe it with; this will kill the smell and clean the wound or hole. The rest of the treatment is the same as given above. In case the bag inortifies, give it lots of bathing with the hot carbolic water, as above mentioned, three times a day, then apply the white lotion, and give the drench mentioned above once a week instead of every second day; the mortified part of the bag will gradually rot away and heal up.

SMALL ROUND LUMPS IN THE PASSAGE OF THE TEAT.

Causes.-From a bruise or injury to the passage of the teat in some way, and whan it is healing the thickening or lump forms.

Symptoms. - There is a small lump in the teat which can be felt between your finger and thumb when you are handling the teat. These lumps may be anywhere along tbe milk passage of 
the teat. The first summer the cow is affected with these lumps in the teat they interfere greatly with your milking her, but if she is bred again when she calves these lumps will entirely block the teat and give you a great deal of trouble for you cannot get the milk down, and the bag becomes swollen and inflamed, and in a great many cases she loses the affected quarter.

Treatment. - Generaliy, the first season they are affected with it, you can get the milk out all right, but it is advisable not to breed the cow agair but let her go dry and fatten her, for she will be worse next summer. When you cannot get the milk down with your fingers pass a teat syphon or milk tube up the passage of the teat through the lump far enough to reach the milk, and then the milk will run till the quarte: is milked out. Use the tube each time yos are milking the other teats. These teat syphons can be got at almost any drug store or veterinary instrument store for about 10 or 15 cents. The way to use the tube is to first tie a colored string in the small ring at the side so you won't lose it if it drops out in the straw, then oil it; take hold of the teat with your left hand and with your right hand pass the teat syphon up through the passage to the lump, and when you come to it gradually force it through, which is easily done; continue passing it gently up until the milk runs out, and leave it in until all the milk is out. Bathe the bag twice a day with warm water and vinegar, after bathing apply white liniment and then oil the bag with lard to keep it soft. It is advisable in very bad cases to let that quarter of the bag go dry as soon as you can.

\section{BLOODY MILK.}

Causes.-From any injury to the bag, getting cold in it, or from eating irritating weeds.

Treatment.-Give the following :

Fipnom Salts............................. pound.

Nitrate of Potash or Saltpetre................... teap poonful.

Mix in a quart of luke warm water anci bive as a drench; give a teaspoonful of saltpetre in a mash every night. After milking bathe the bag with warm water, wipe dry and apply white liniment, then oil the bag with lard or goose yrease, and the milk will soon get all right. If you think it is caused fron eating irritating plants put the cow in another pasture. 


\section{BLUE MIL.}

This is where the milk is watery looking and very blow

Causes.-From little grerms, called bacillus cyanogenus, gottine' up into the teat. The only way to be sure it is caused by these germs is to examine the milk with a microsiope.

Treatment.-With a small glass syringe inserted into the passage of the teat inject some of the following each time after milking :

Hyposulphite of Soda $. . . \ldots \ldots \ldots \ldots \ldots \ldots \ldots \ldots \ldots . \ldots 1$ dram

Shake well before injecting, and after a few injections the milk will be all right.

\section{STRINGY MILK.}

Causes.-From swallowing small germs while drinking out of stagnant pouls of water.

Symptoms. - A few days after the germs are swallowed the cow's milk will be curdy and stringy looking, mixed with water, and will come out in jerks when milking. It will be like this for a few days, then get all right for a week or so when it will como on again. Generally two or three cows out of a large herd will be affected in the same way.

Treatment.-If it is caused from drinking out of low springs or pools keep the cows away from the water by fencing it off, and give two drams, or one teaspounful of bisulphite of soda in a mash every night, which will soon make the milk all right, and the dissase will not come back on her again.

\section{CHAPPED OR SORE TEATS.}

Causes. - This is caused from milking with rough hands; or from the cow running through long grass and wetting and irritating the teat; or it may be caused from flies.

Treatment.-Eac's time before milking wash the teats off with luke warm water and a little castile soap, then after you nave milked her rub the teats with the followirg salve :

Vaseline.

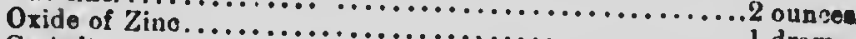

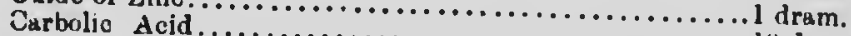

Mix well together and put in a box large enough to hold it. This is a cheap and a grand healing salve for any kind if sores around the bigy. 


\section{SWALL WARTS ON TED TIATS.}

These are very troublesome when you are milklng, but ars very easily got rid , $f$ if you take the right plan.

Treatment.-After the cow is put dry is the best time to treat. Tie the cow up and hobble her two hind legs together abovo the hocks with a strap so she rannot kick you, then with a pair of large, sharp scissors clip all the warts off as close as you can to the teat. By cutting them off with scissors they will not bleed. After they are taken off dress them once a day with the same salve used for chapped teats and they will not come on again, but if they should come on the next year use the same treatmient again.

\section{CUTS AND FISTULA OP THE TEAT.}

This is when the teat has been cut deep enough to cut the milk p. ssage, which allows the milk to keep dripping out through the hole.

Treatment.-If the cut is big sew it up witi a needle used for sewing wounds; bathe with warm water and apply white lotion every time after milking. The best way to milk a cow while the teats are sore is to insert a teat syphon, or milk tube, up into the teat, and this will let the milk run out without irritating the teat; sometimes after it is healed up there will be a small hole in the side of the teat, which will allow the milk to leak out while you are milking. The best way 'o fix this is after she has gone dry burn the hole with a pointed stick of caustic potash, which destroys the fistula, then while it is healing up the hole will disappear and be all right the next time she calves.

\section{COW POX.}

This is often seen in cow, and affects herds in all parts of the world. It is somewhat similar to smallpox in people only it is not nearly so fatal. This is an infections disease, that is, it can be carried from one cow to ancther. For instanr, one man milking eight or ten cows and only one has the disease at first, he will carry the disease to all the others by milking them.

Symptoms.-The cow seems feverish and does not give quite so much milk. In a few days, little red, piliple-like spots appear around the teats. In a day or so more, these red spots will rise up in the form of a blister, which contains a watery fiuid. If these are not broken during milking, they dry up themselves and form scabs, which, in a few days, drop off, leaving the teat 


\section{DSBEABEg ATD TREATMENT OF CATTLE.}

natural. It generally takes this disease from eight to ten days to run its course; but sometimes, when the blisters on the teats are broken by the milker's hand and kept irritater by milking, or from flies, it takes a long time to heal them up.

Treatment.-Keep the cow separate from the others, and allow only one person to milk her, and no other, so as to keep the disease from spreading, if in the spring, only let her have grass; if in any other time of the year, feed on soft food with boiled fax seed in it, and give the following powders for her blood and kidneys:

Nitrate of Potash or Saltpetre.....................t pound.

Ground Gentian Rort................................... "

Mix thoroughly and give a teaspoonful night and morning in a mash. Each time before milking her, bathe the teats with luke warm water and soap, then milk her carefully and use the following preparation:

Sweet Oil....

Mix and apply to the sore parts of the teats each time after milking.

\section{COWS LOSING THEIR CALVES (ABORTION)}

Causes. - This generally occurs from slipping on ice; being chased by a dog; or from the hook of another animal.

Symptoms. - Labor pains come on; she will get up and down; the water bag appears and breaks; and if the calf is coming straight, it soon appears and comes away all right.

Treatment.-If the cow keeps on straining, and the calf does not come, oil your hand, pass it up into the womb and straighten the calf, and it will come away all right. After the calf is taken way, cover her up warm, and if she does not seem very well give ber the following:

Sweet Spirits of Nitro................ ounce or 4 tablesponnfuls.

Epsom Eslts....................... pound.

Mix in a quart of luke warm water and give as a drench. If the eleaning does not come away, use the same treatment as is given in "How to take away the cleanings from a cow." After this, feed on soft food, keep her warm and milk her twice a day; this will bring her back to her milk.

\section{BARRENNESS IN COWS AND BULLS.} Jerseys.

This is comnion thing in well-bred cows, especially in

Causes.-From their being kept in too high condition; fro'n a diseased state of the ovaries; contracted or diseased state of the neck 
of the womb; the womb being deformed, such as the neck being twisted to one side; or where there is twin heifers one or the other will be barren. Bulls or cows that are too closely inbred in the same line of breeding for several generations may become barren, or what is known as run out; it is also caused in bulls sometimes from fatty degeneration of the testicles-mostly seen in old bulis-and, also, rig bulls (that is, where only one or neither of the testicles are down in the scrotom) are sometimes barren. This rule also holds good in horses.

Treatment.--If it is caused from being in high condition bleed her, take a half pail of blood away the day before taking het to the bull, or give her a physic of one and a half pounds of Fiprom salts in a quart of like warm water as a drench. The idea of this is to cool her blood. Examine her, and if it is from contraction of the nerk of the womb, pass your hand up gently and open it by working your fingers in it; if is from the neck of the womb being to one side, straighten it. In doing this have your laand and arm oiled. In either of these cases put the cow to the hull im. mediately after fixing it. If it is fium inbreeding try a:ıd start her to breed by putting her to a mongrel bred bull. There cannot be much done for a barren bull.

\section{CHAPTER V. \\ DISEASES OF THE GEPJTAL ORGANS OF THE BULL.}

ONFLAMMATION OF THE TESTICLES (ORCHITIS).

Causes.-It is generally from an injury, or from serving too many cows.

Symptoms.-The bull moves stiff and has a straddling gait, the testicles are swollen and very tender.

Treatment.-Give the following :

Epsom Salt. .......................

Nitrate of Potash or Saltpatre..................

Ginger .......................... tablesponful.

Mix in a quart of luke warn water anc grive as a drench. Batre the testicle well with hot water and rinegar and..pply a poultice of not linseed meal and bran, about halt and hatf. Have the poultice held up to the bag by means of strings tied up uver the back and it will give steady heat to the hag and draw the inflammation out: it 


\section{DI8ב.ABE8 AND TREATMENT OF CATTLE.}

will also support the testicles and ease the pain; keep the poultices hot by changing them twice a day : keep this trealtmelut up until the bulı is better, and do rot let him get cold afterward. Juring the time you are treating him feed on soft food and he will a,wn be all right. If, after he is well, you find that the inflaminulion has lestroyed the seed part of the terticles-which can be told by putting him to cows and if they do nut get with calt castrate hin, for he will be of no further wie for breeding purposes.

\section{INJUR!'ES TO THE SHEATH AND PENIS.}

Causes.-From jumping over a fence and being ciunght on it, or being caught in any way that will injure the sheath anl penis.

Symptoms. - There is swelling and soreness of the sheath and penis. If it is a bull he will be unfit for service until he is hetter.

Treatment.- Examine to see that there is nothing in th: end of the sheath, and if there is anything remove it at once. Bathe well three times a day with luke warm water, wipe dry and thon apply the white lotion. Keep this treatment up until tho swellngy is all out. In very severe cases give him a pound of Epsom salts.

\section{CLAPP IN BULLS (GONORRH(EA).}

This is inflammation oi the lining of the passage of the penis. Causes.-From too frequent service, or from serving a cow that is affected with whites (leucorrhoa).

Symptoms. - There is a wi,itish fluid discharge from the end of the penis and sheath, and they are also very sore to handie, and in making his water it scalds him and causes him pain.

Treatment.-Give him one pound of Epsom salts in a quart of luke warm water as a drench to cool the blood; bathe the shealh well with luke warm water twice a day, wipe ciry, and inject into the sheath a little of the following mixture :

Sulphate of Zino................2 drams or 1 teaspuonful.

Water ..........................

Mix and shake well before using. This is a cheap and effective cure for this disease. Keep the bull away from cows until he is better, as he would give the di rase to the cows.

\section{CASTRATION OF BULLS AND CALVES.}

Secure him, either by standing him in a firm stall or throwing him down, which can be easily done by taking a rope about thirty feet long, make a loop in the centre large enough to slip over his head and neck and then tie a knot in it; after the rope is put over nis bead and fitted on the neck, pass it back between the front 
legs and bring the ends of it back one on each slde around the outsids of the hind legs, and back around the inside just abuve the hock, then bring them forward on the outside of the front legs through the loop; have a man on each side to pull on the ropes, "which will soon throw him down, then tie him up solid. This is the best method known for throwing cattle. As soon as you have secured him, take a sharp knife and make a cut along the side of the bag large enough to let the testicle out; be sure the cut extends to the bottom of the bag so it will not form a pocket.. As soon as you have let the testicle out, draw it well uf ard you will notice a white covering attached to the back part of it, cut this off close to the testicle with your knife, then you can. ull up the testicle and cord free; after this, pull the testicle and cord well up, and if the bull is over a year old, tie the cord with a strong, fine piece of string about four inches above the testicle, leaving the ends of the string six or eight inchcs long so they will hang out of the bag and not heal up in it; leave this string on until it drops off itself; cut the testicles off below the strings; fill the holes full of salty butter and let him go. The reason the string is tied on the cord when the animal is one year old and upwards is because there is danger of him bleeding to death from the cords. The operation of castrating a bull standing up is done by securing him in a solid, narrow stall and operating in the same manner as you woulci if he was lying down.

The way to castrate $n$ calf is to tie him or have some person hold him; make the cuts in the bag the same as for castrating bulls; when the testicle is out, separate the covering attached tc the back part of the testicle with your knife; then draw the cord and testicle well up, and with your knife scrape up and rown on the cora until it is scraped off, this will stop the bleeding; fill the holes full of salty butter and let him go. The main thing after castrating bulls, bull calves, boars and dogs is to keep them away from dampness, and if they swell, bathe witti luke warm water and soup and open up the cuis with salty butter on your finger. If it swells very much, bathe with luke warm water and salt ihree times a day, and after bathing apply white lotion. Scrn'times, a few weeks after the cuts are healed up, the bag swells and becomes very sore and hot; in this case you may know there is matter forming in the bag. Bathe well three times a day with luke warm water; after bathing apply white lotion and put on a hot poultice of half linieed meal and half bran; fasten the poultice on by means 
of etrings over the back; this is to brumg the isven...g iv a its Change the poultice every time you bathe the bag. As soon an you fird a soft spot in the bag, lance it to let the matler out: make a good sized hole in it, large enough to r:on yuur liager up into it to clean it out. After this, treat by hathing with luke varm water and soap and applying the white lotion twice a lay; keep the cuts open by putting butier on your finger and running it up into the hole once a day until it commences to heal.

\section{RIG OR ORIGINAL BULLS.}

This is when one or both the testicles ncver come down into the scrotom, or bag. These kind of bulls cannot be castrated like horses, and after they get a little age on them they become a perfect nuisance.

Advice. - When you go to castrate a calf and find only one or neither testicles are down, fatten and get rid of it, for it very rarely comes down afterwards. It will save you a lot of trouble if you get rid of it while young.

\section{HOW TO RING A BULL.}

Secure the animal by throwing him, or havirg him in a solid, narrow stall; take a piece of sharp-pointed, clean, hard wood, or a sharp piece of bright steel large enough to make a hole for the ring; put the hole through in the suft part of the none, just in front of the hard cartilage that separates the noufrils, which is easily felt. After the hol: is thrru, ${ }^{2}$, open and oil the rin slip it through, close it and put in the screw. After tha ring is turn it every day until the wound is healed. These rings cal e got at any hardware store.

SWELLING OP THE POINT OF SHEATH IN STEERS.

Caises.-It is mostly seen where they are grazing on - "ufield where there is a lot of limestone, or when there is $\pi$ in the water they drink, and on account of the steer no out his penis while making water, just letting it dribble a of the sheath, the lime in his water collects and forms a al limestone which soon gets large and irritates the sheath, cau it to swell.

Treatment.-If he is a quiet steer, let him stand, and his someone to hold him by the horn and nose, while you, with you angers oiled, pass one of them up into the sheath, and by working the stone around you can soon remove it, then oil the "shea!! inside and outside with lard and it will be all right. In case ycu eannot do this with the steer standing up, throw him down and secure him as for castration and remove it in the same way. 
CHA!'l:1! 1\%.

\section{DISEASES OF THE EAR AND EYE.}

Diseases of the ear of the ox are very ritrely met with, and are similar to those of the horse, and for any information concern. ing them refer to discases of the ear in the horse.

\section{CANCER IT THE EYE.}

The eye of the ox seems to be favorite place for cancers and is very often met with.

Causes.-The causes of it are the same as ether cancers, tha: is, the cancer germs get into the blood, for the disease first begins in the blood, but afterward locates and shows itself in the eye, although some say it will come on from an injury.

Symptoms. - The first symptom is dullness of the eye, with tears flowing from the corners; there will be a bulging out of the eye, and if you look close you will see in the back part of the eye a small growth; the animal may thrive fairly well for a while, but will fall off in condition as the growth corres on account of the pain in the eye; soon the growth gets so largre that it will destroy the whole eye and hang down on the clseek; it gets very angry and red looking, and will bled freely if the least thing touches it; the cancer keeps on growing, and in a short time the bones around the eye become diseased, and when they become dis eased iey also beccme enlarged, and have a very bad smell.

a reatmeat.-By removing the eye in the early stages of the disease you can effect cure. This is done by throwing and securing the animal have the head held solid, and with a knifo cut around the eye and loosen it from the eyolids, then stick a amall hook into the eye and pull it out a far as you can, then take a piece of carriag trimmers' twioe and slip it around the back part of the eye and tie it tight-this will stop the bleedingthen cut the eye off in front of whore you tied the string; saturate a piece of cotton batting with Monsell's solution of iron and insert it in the hole where the eye came out of ; take the batting out the next day and bathe the eye twice a day with luke warm water and coap, after bathing apply white lotion; if the parts are raw and angry looking touch the spots with caustic potash every day. This may effect a cure, but in a case where it grows again, or where the growth is very bad befure operating, or the bones diexed, have the animal destroyed immediataly. 


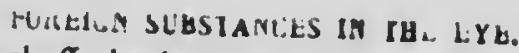

Sometimes claff, barley-beards or small pives ."l atick get inte the eye and become lodged there.

Symptoms.-Th animal sutrers very inuch ; tears run down sver the cheek; the eye becomes very much infl.mmed and dim, and if allowed to run on the sight will soon beenme covered with a white scum. If you catch e animal and examine the eje closely you will find out what $i$, :

Treatment. - In ail it:; catch the animil and examine the sye closely, and when you hnd out the cause of the trouble remove 1t, then bathe the eye every day with new milk or luke wirun water; wipe dry and apply, in and around the efe every time after sathing, the eye wash mentioned in the receipts at the back of his book. Keep this treatment up till the eye is better.

A GROWIH ON THE HAW OF IHE EYE.

This is a red growth in the imer corner of the eye, caused by iume irritation of the haw of the eye, which is a piece of cartilage or tougls membrane that fits across the inner corner of the eye.

Syilptoms. - At first the eye looks sore and angry in the inner :orner and runs water freely, afterwards followed by the red, angrv looking growth growing out of the corner of the eye. The Grov may vary from the size of a marble to a small hen's egg. ment atment.- Sciure the animal by throwing it the same as zround, a to castrating bulls. Have the head held firmly on the hat you can hold it with. enough s usually she eye with new milk wash.

SORE OR INFLAMED EYAS I CATIL.

Causes. - From getting cold in the oyes or trom an infury.

Sympioms. - Tears run freely, and the oyes are vary weat and red looking, and if not relieved a scum soco form over the sight
of the eve.

Treatment. - Bathe well twice a day with now milk or luke warm water, and each time alter bathing wipe dry and apply the
eye wash.

\section{CATARACT OF THE EYE IN CATML.}

This is very rarely met with in cattle, and for information carding it look up cataract of the eye in horses, for the caucea
symptoms and treatmeat are the same. 


\section{DNUKIBS TO THB EYELLDS.}

It may occur in a good many ways, as a kick from a horse, book from a cow, or from catching on something.

Treatment.-If they are torn much stitch them up with a cewing needie, used to sew up wounds, and carriage trimmers' twine, which is the best twine for this vrork, and treat it afterward by bathing with new milk or luke warm water and applying the eye wash. Do this twice day and it will soon heal up and the stitches will work out themselves.

CHAPTER VII.

\section{FRACTURED BONES, WOUNDS, SPRAINS OF JOINTS AND TENDONS.}

FRACTURED BONES.

Fractures occur in various ways, from the kick of a horse, gotting caught on a fence while. jumping, falling, being chased by dogs, or being struck with anything hard enough to fracture a bone. As a rule, when the fracture is so bad that the bone is shattered, or a piece of the bone is stuck through the skin, it is beat to destroy the animal, and if it is fat enough it makes good beaf, provided it is killed in time.

FACTURE OP THE LOWER JAW.

This is a fracture that generally occurs from a kick or a blos a come kiad, and is first noticed by the animal not being able tn at, and the mouth will seem crooked. It is recommended in ances of this lind to set the jaw in place, and have it held there with wire factenod around the teeth in the jaw. This can be done botter if it $i$ the front of the jaw that is fractured. When you have set the jaw with wires feed on soft food, such as gruels, tlin the animal can drink down. If the animal is fit to kill it is bist to butcher it.

BROKEN KECK OR FRACTURE OP THB IBCK BONES.

To show how simple this may occur we will relate a case that camo under our own personal observation. A cow that had been kept in the stable during the winter and fed well was let out one day by the owner, and she, feeling good, was playing about when tho dog was put aftor her, and while running away from tho der 


\section{DISEABES AND TBEATMENT OF CATTLE.}

the kicked up her hind feet and lowered her head, In doing this she caught her nose on the ground, which threw her over onte her head and neck. We heard the bone snap, and by the tume we got to her she was dead. On examining her we found that one of the bones of the neck was broken in the fall, which caused her death instantly. In any case where the bones of the neck are fractured enough to press on the spinal cord in will cause death instantly.

\section{FRACTURES OF THE BONES OF THE BACK.}

This may occur from something falling on the animal, or by slipping and falling, or from another animal jumping on it while
standing crooked.

Symptoms.-There is paralysis of the hind quarters, attended with pain; the animal will moan and refuses to eat anything. In severe cases the back will be swollen, and the mark of wha
caused the fracture can be seen.

Treatment.-It is best to kill the animal, but if you wish to trv to treat it, keep it quiet, feed on soft food and keep the bowele regulated by giving small doses of salts; turn it from side to sidtwice a day, and be careful while turning it not to hurt its back.

FRACTURE OF THE BONES OF THE HIP.

In some cases we have a hip knocked down from a blow, from running through a narrow doorway and striking the hip This is not dangerous, only it spoils the look of the animal when its hip is knocked down. If it is sore after being knocked down bathe twice a day with luke warm water and apply white liniment until the soreness is out; if the bone heals all right do nothing more to it. Sometimes we have a case where the broken piece of bone does not heal to the other; it soon begins to fester around it, and the parts become swollen and sore. You must then opeit with a sharp knife and remove the broken piece of bone. Frao ture of the under part of the hip bones generally occurs from the animal slipping on ice when the legs straddle out. As soon as in gets up it walks off very stiff, and the legs are straddled out be hind while walking or standing. The treatment for this is to keep the animal very quiet by tying it in stall until the bomunite, which generally takes four or five weoks. 
FRACTURES OE THE RISS.

This is aiways the result of a kick or a blow of some kind. In a severe case the animal cannot raise to its feet; there will be a dinge in the side, and on shoving it in and out you can hear the bones grating on each other. In slight cases the animal will be able to get up all right, but will be stiff and sore. In most of these cases the animal will cough a little, and breathe short and quick.

Treatment. - All that is needed is quietness, good care and food. If the animal is not able to raise turn it over from side to side twice a day. If the rib is broken so bad that it penetrates the lung and sets up inflammation there is no hope of recovery.

FRACTORE OF THE SHOULDER BLADE OR SHOULDER BONE.

Fracture of these bones is indicated by the extreme lameness and pain it causes the animal, and on moving the leg you can hear the bones grating on each other. In a caşe of this kind it is best to destroy the animal, but if the fracture is not so severe, and it is a young animal, keep it very quiet and feed well, and it will come all right in the couse of time. The less you bother with it the better.

\section{FRACTURES OF THE BONES BELOW THE KNEE.}

There is crooker ness of the leg, lameness and extreme pain, and when you move the leg you can hear the bones grating on each other.

Treatment-Get the animal in a quiet place, set the leg in shape, and have some one to hold it while you bandage it with a starched bandage, which is a long strip of cotton dipped in starch used for starching clothes. On drawing the bandago out of the starch draw it between your fingers to clean out as much of the starch as you can, then wrap it moderately tight around the leg, put lots of the bandage on, and have some one to hold the leg and bandage straight for an hour or so until the starch hardens the bandage. After that the bandage will hold the leg to its place. Leave it on four or five weeks until the bones are healeci. Keep the animal quiet until the bones are well knit together. If the leg should swell with this bandage take it off and put it on looser.

Fractures above the knee are sometimes treated by this method, but not nearly so successfully. 
PRACTURES OP THE DONES ABOVE AND BFLOW THE STIFFLB JOWT. The animal may not able to stand, but if it is the leg will bo hanging loose. By moving the leg you can hear the broken bones grate on each other.

Treatment.-In very severe cases it is best to destroy the animal, or, if is a fat animal, kill it for beef. If you attempt to treat it you will not be able to do anything for it only keep the anima! quiet, and leave it lying down or standing up, whichever it prefers.

STIFFLE OUT IN CATTLE.

For this disease we refer you to dislocation of the patella (stiffle out) in horses, for the causes, symptoms and treatment are the same in both. This does not occur so often in cattle as it does in horses.

\section{FRACTURES OF THE BONES BELOW THE BOCK.}

For this we refer you to fracture of the bones below the knee, for the causes, symptoms and treatment are the same in both cases.

\section{SPAVIN.}

This is generally seen in working oxen, or cows. There is lameness and an enlargement on the inner side of the lower part of the hock joint, similar to spavin in horses. Blister with the following :

\footnotetext{
Biniodide of Mercury or Red Precipitate ..............2 drama.

Powdered Cantharides or Spanish Fly............... "

Mix thoroughty and clip of the hair on the inside of the
} $y$ and clip off the hair on the inside of the hock well, and thement, and rub on half of this bler, rubbing it in well, and tie the animal short so it cannot lick it; grease the blistered part the third day after blistering, then let it go for a month, and then wash it off with warm water and soap and keep repeating the blister until the animal is over the lameness, which generally takes three or four months.

\section{SPRAIIS IN ANY PART OF THE ANIMAL.}

Causes.-Generally from the aninal stepping crooled, or a dog worrying it, or from fighting.

Symptoms. - There is heat, swelling, pain and stiffness, or lameness according to the part of the body it is in.

Treatment.-Bathe the parts well with luke warm water and vinegar three times a day; after bathing wipe dry and apply th. 
white liniment. If the sprain is in a joint of the legs, by bandag. ing it each time after bathing will help to relieve the pain and support the joint.

\section{WOUNDS OF ALL KINDS.}

For wounds we refer you to the explanation of wounds giver In horses, for they happen in a similar manner and are treated. the same; but, in sewing the skin in cattle you will find it toughes and a little harder to sew than in the horse.

\section{AIR UNDER THE SKIN CAUSED FROM $\triangle$ WOUND.}

Sometimes from a very small wound in the ox, air gets undes the skin into the tissue which connects the skin to the body. The amount of air which gets in varies greatly, sometimes only a mall amount works in just around the wound, while again we have seen cases where so much air would work in that it spread all over the body under the skin and make the animal louk double its natural size. The way to be sure it is air, is to rub your hand ove? the skin and it will make a peculiar crackling noise.

Treatment-The main thing to be done in this, is to tap the akin in several places around where the air is with a penknife and let the air escape; rub the skin to get all the air out, and after this give the skin a good rubbing once a day with white liniment, then give the wound the treatment given for wounds, and in a few days the air will all disappear. This disease is sometime met with in the horse and is treated the same.

\section{MGCOTS U IVGLECTED WOUNDS.}

Symptoms.-.The wound smells bad, is dirty, and if you stir it, the maggots can be seen moving around in it.

Treatment.-Give the wound a thorough cieaning, by washing it out with luke warm water and soap, after this apply creolin lotion, this will destroy them. In very bad cases, if this does not sffect a cure, give the wound a good dressing with spirits of turpentine, and afterwards bathe twice a day and apply the creolin lotion.

\section{RAEUMATISM.}

This 18 a kind of inflammation that affects the joints and tendons.

Causes.-From bad blood where there is too much acid in it; from getting wet or from lying on the damp ground in the spring of the year, will cause it. 
Symptoms. - There is swelling anc so:eness in the joint affected; it may affect one joint for a while, then move to another,
and so on.

Treatment.--Rub the affected joint well with acid liniment once a day and give the following :

Nitrato of Potash or Saltpetre..................... pnund.

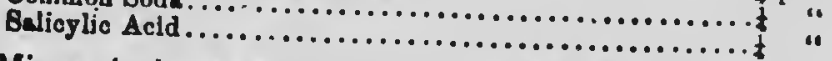

Mix and give a tablespoonful twice $a$ day in its feed.

\section{CHAPTER VIII.}

\section{DISEASES CF THE SKIN.}

\section{WARTS AND SMALL GRJWTHS ON THE SKIN.}

Some cattle are more subject to warts than others. If the warts have a neck the best way to get rid of them is by tying a small, strong string tightly around the wart, as close to the skin as you can, and by leaving the string tied tight on it it will stop the blood circulating in the wart, which will cause it to die and drop off. If the wart is flat and has no neck that you can tie the string on cut it off with a sharp knife and burn it with a stick of caustic potash. Small lumps, or tumors, in the skin are very common in horses and cattle, but are easily got rid of. If it is a 1orse put a twitch on his nose and have one of his front feet held up; if it is a cow tie her up solid, then cut a hole in the skin over the lump anc skin around it, then lift it up and cut it off at the bottom. There is not mur' ianger from bleeding so long as you do not cut into a large vei nich you can see right in the skin. The after troatment is to b. . e with luke warm water twice a day and apply the white lotion after bathing until it heals up

\section{IICE ON CATTLE.}

They may be cattie lice or hen lice.

Srmptoms.-The animal keeps rubbing itself until it rubs the hair off in places, and if you examine closely you will sce them in the hair. Cattle affected with lice do not thrive well.

Treatment. - The treatment is very simple and cheap. Hero to the most effective remedy known if it is properly used:

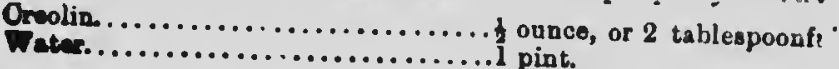


Mix and shake well and there will be onough in this to go over a cow twice. Before applying it give the animal a good brushing with a stiff brush; pour the wash into a flat dish where you can get at it, and with a brush or sponge, dipped in the wash, rub it all over the animal. Do this : wice a week until the lice are all killed. Twenty cents will buy enough creolin to kill the lice on twenty head of cattle.

\section{MANGE IN CATILE.}

For this disease refer to mange in horses, for the causes, symptoms and treatment are the same.

\section{RINGWORY.}

This is a common disease in young cattle and calves.

Canses.-From a parasite, or germ, getting into the skin and working around the bottom of the hair, causing it to fall out in round patches. This disease affects young cattle more than older ones, but may affect them at any age.

Treatment. - The cheapest and best remedy for this is c: ude petroleum oil painted over the spot and a little over the edges of the ringworm, in the sound skin, to keep it from spreading. Paint this on with a feather every day, or every second day until the ringworm disappears. Be careful in handling ringworms on cattle, as you are liable to get them yourself from the cattle.

\section{HORN FLY.}

These are also called Austrian flies and are a small, black, hard fly. They first started on this continent in the Eastern states in the year 1887, and since then have spread all over the country. They start to bother the cattle during the $\mathrm{v}$, in days of May and continue bothering them until the frost comes in the fall. These flies become very numerous on the cattle, and they pierce holes in the skin and suck the blood. While they are resting they light on the horns, and sometimes the base of the horn is literally covered with with them.

Treatment. - Apply wagon grease, tar, or sonie oily substance around the base of the horn every few days to keep them from resting on the horn. Wash the animal's body twice a week with creolin wash, which is very cheap and effectual.

Creolin...........................2 onnove or 8 tablespoonfule.

Water...............................1 gallon.

Mix, shake well and rub them over twice a week with a cloth or sponge dipped in this wash and it will keep the flies from bothering them. 
WARBLES.

This trouble is only found to affect cattle, and is caused by a large fly, called the gadfly, stinging the animal around the back; this fly lays an egg down in the skin each time it stinge
which develops into what is known as the warble.

Symptoms.-Small lumps appear in the skin, principally over the animal's back, and coming on spring, these lumps, which contain the grub, or warble, becomes pierced, and the grub gradually works out and falls on the ground and in a few days matures into another gadfly which flies off to sting cattle again during the
summer. Treatment.-As soon as you notice the lump, cut the skin and
squeeze the grub out. By killing the grubs in this way you will
soon get rid of the pest.

\section{SNARE BITES.}

The bite of some snakes is very poisuncus and causes the animal to have grnat depression; it becomes very weak and come culd, and in severe cases death soon comes on if and legs beIf you see the animal as soon as it is bitten cut the piece onteat. burn the wound with a hot iron to kill the poison; give half-pint doses of whisky or brandy mixed in a pint of water every three or iour hours to stimulate the animal and counteract the depression
and weakness causer by the poison in the system.

BITES OF I ECTS, SMALL SNAKES, HORNETS, BTC.

After the bite, or sting, there is nuticed a soft swelling, which is sore. Rub the parts with white liniment three or four times a day; which will soon draw the poison out and take down the swelling.

\section{FROST BITES.} horses.

Frost bites in cattle are treated the same as frost bites in

\section{BURNS AND SCALDS.}

Burns and scalds on any animal are treated by applying carbolic oil to the burnt or scalded part, take four ounces of sweet oil with ten drops of carbolic acid in it. Put this on twice a day and 
CHAPTER IX.

\section{DISEASES OF THE FEET-HOW TO DEHORN, BLEED AND DRENCH.}

\section{LAMUNITLS (FOUNDER).}

This is infammation of the sensitive structures of the foot, ot what is . 'mmonly called the quick of the foot.

Causes.-Are from verfeeding, overheating, or from driving long distance on a haru, stony road.

Symptoms.-The animal persists in lying down; the f-et are not and sometimes swollen around the top of the hoof anc sore to press on; the animal is greedy to drink on account of being feverish, buit does not care to eat much, and if you force the animal to move it just slides its fee' along, seems very stiff and its belly is all drawn up from trying to favor its feet.

Treatment.-Keep the animal as quiet as possible, and poultice the feet with hot linseed meal and bran-ahout half-andhalf. The way to do this is to take an old grain bag, cut about a foot off the bottom of it and pack the hot poultice in the bottom; place the foot in it, and then tie it up around the fetlock and foot so it cannot fall off. Do this to all the feet and chango the poultice twice a day; keep this up until the animal gets all right. As well as this, give a pound and a half of Epsom salts in a quart of luke warm water; also give a teaspoonful of saltpetre, or nitrate of potash, in a mash night and morning. Sometimes, If the weather is warm, by standing the animal in a stream of water with a mucky bottom, for a few hours every day, will soon bring them all right without anything else.

\section{SORENESS OF THE FEET FROX ANY CAUSE.}

Treat just the same as you would for founder, by poultices and keeping the animal quiet. If the toes are too long, cut them off with a chisel and mallet.

FOUL IN THE FOOT (FOOT-ROT).

This is an inflammation of the skin and parts between the srotters or toes, and after this there are ulcers or small boils form and break out all around the top of the foot and between the trutters. The foot becomes very much swollen in some cases ani causes the trotters to spread wide apast. The animal suffers great 
pain and can scarceily put the foot to the ground, and if allowed to run on is thout being tre'sted at once, it becomes very tedious and hard to treat. The hind feet ar. more often affected than the front ones.

Causes. - Are from something becoming wedged in between the trotters or toes, such as hard clay, manure or a piece of stick, bone or any such like substance, it is more often seen where cattle stand in a filthy place or have to walk through a dirty, soft place.

Traatment. - As soon as no: :ed examine the foot and remove any substance found between ihe trotter or toss, wash the foot th roughly with luke warm water and soap, after this apply a good warm poultice of linseed meal, poultice every night and keep the animal in a nice dry place and after you take the poultice of in the morning and before you put it 011 at night give the foot a good dressing with the following:

Carbolic Acid................. I dram, or 1 cearpoonful.

Water........................ pint.

Shake well together each time before using and apply as mentioned, when applying get it worked in between the trotters or toes as much as you can. Keep this treatment up until it is better, in very bad cases it takes a long time to get better, bui keep at it. Another very gooc wash to use in place of the carbolic water is

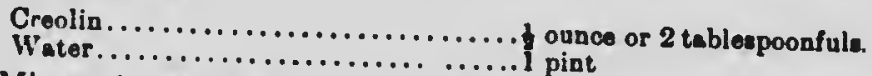

Mix and use the same as the carbolic water, if one remedy hould fail try the other; during treatment be sure and keep the animal quiet and in a dry place, and feed well to keep its strength up.

FISTULA OF THE FOOT.

No matter what part of the foot is affected it is just the sarive, it is caused by a bruise or from something running into the foot and dirt getting up in the hole or from diseased bone.

Symptoms. - There is lameness ard a discharge from a small hole which has no tendency to heal, and if it is from a small piece of diseased bone the discharge smells very bad.

Treatment.-In all cases pare out the hoof or horn around the sore spot, so as to allow whatever is in it to have a chance to run out, and then poultice until you draw out whatever is in the hole causing the trouble. The best poultice for this is hot linseed meal. After you get it out, the hole will soon heal up of its owa leourd. 


\section{NAIL RUN IN THE FOOT.}

This generally occurs where cattle are running around old buildings where boards with nails in them are lying about.

Symptoms.--There 's severe lameness which comes on all of a sudden; the animal appears to be in great pain cnd can scarcely touch its foot to the ground.

Treatment. - Pull the nail out, pare out around the hole made by the nail and poultice with hot linseed meal; keep the animal quiet until ilie soreness is all out; change the poultices twice a day. If it should fester tion pare down around the hole until the matter comes out and then poultice well to draw it all out ; keep the animal quiet until the hole heals up. After you quit poulticing stuff the hole with tar and cotton batting to keep the dirt fron working up into it.

\section{DEHORNING.}

This is an operation which is carried on to great extent in Canada and other countries, and is gaining the favor of stock owners rapidly. It is a very simple, although a painful operation while it lasts, and is, as a general thing, attended with very good results. While this is a painful operation sc are all other operations, such as castration and docking, but as long as it is done with a view to benefitting the lives of the cattle themselves, and also their owner, it is not considered inhuman. It is best not to perform this operation on cattle under one year old for the horns will often grow again, and before that time they never do much harm. The best time to dehorn is in the spring, during the months of March and April, so that the horns will be well healed up before the flies come to bother them, or in the fall of the year, just after there has been frost enough to kill the flies. The operation is a simple one, and is performed in this way: Build a stanchion, similar to the old way of tying cattle, in a solid doorway, or any other such place where you can run the cattle into it, one at a time. Have the stanchion built good and strong, also have the sticks in it good and tight together, just large enough for the animal's neck to fit in when it is closed; have a narrow stall, built out of good strong plank, at the side of the stanchion where you can $r \cdot \eta$ the cattle in, this will keep them from swinging the body around while you are dehorning them. When you have the animal fast in the stanchion put a rope halter over its head, and have the head and neck well pulled frrward by means of a double 
pulley so as to get good purchase to hold the animal in its place while operating; have the pulleys attuched to something ahout eight or ten feet straiglat in front of the animal, and as near the ground as possible, this will hold the head in better position; have a man take hold of the nose and ear at one side while you saw the horn off with a stiff-backed, fine-tooth carpenter saw, takiug about one-eighth of an inch of skin of with the horn, then take off the other horn in like manner. By taking the horn off in this place it is easier sawed, bleeds less, heals nicer and there is no danger of it growing again. As soon as you are through with this animal put in another. In cases where you only have one to dehorn throw and secure it, and tale the horns off in the same manner. Another way by which they may be taten off is to use large dehorning clippers. These clippers can be got at a hardware store, and the directions how to use are along with them. We recommend sawing the horns off, except in cases of very young rattle. After two or three years of age the horns be. come brittle, and in pinching them off with the clippers liase is danger of fracturing the bones of the head. Always keep the animal from being chased before and after the operation, for there is more danger of bleeding when they are excited. If they bleed much apply a little of Monsell's solution of iron with a feather, which will stop the bleeding. Keep the animal quiet and do not allow it to be out in any cold storms, and be careful when feeding it not to throw dust or chaff on the head so it will get in the holes, which would be apt to cause festering. If you want to kill the horns \& 1 calves it must be done when they are about a week old. When the little horn first appears take a stick of caustic potash, dip it in water and rub it well into the skin around where the little horn is coming through. One burning generally kills the horns; if not, repeat it heavier in a few days.

\section{HOW TO BLEED A COW.}

Tie a small rope around the neck, just in front of the houlders, so it will raise the jugular vein, then take the largest blade of an ordinary fleames, hold it lengthwise, fair in the centre over the vein, then hit the fleames a sharp tap with a piece of hardwood; hit hard enough to cut the vein, and catch the blood in a pail Take from half a pail to a pailful of blood away. Vhen you have enough blond away, let the rope slack, run a pin through the two edges of the cut and wind a string around the 
pin in the form of a hgure eight and tie it there. Keep the animal in the stable, and feed out of a high manger, for twenty. four hours, then remove the pin and allow the aninial to go. In this operation, as in all others, have everything clean for fear of blood-poisoning.

\section{IOW TO DRENCE CATTLE.}

In catile always mix your drenches in a large quantity of water, because it will wash out of the paunch quicker, and have a quicker and better action when given this way. Have an assistant to hold the horns while you take hold of the nose with your left hand, and hold the head a little above a level; with your right hand put the bottle well back into the mouth and allow it all to run down without taking the bottle out of the mouth, unless the animal should cough; if it does, let go of its head until through coushing, then continue the drenching. Be careful in drenching, especially in lung troubles, for they are easily shoked.

\section{CHAPTER X.}

\section{DISEASES OF THE NERVOUS SYSTEM.}

\section{CORI STALI DISEASE.}

Causes.-From eating corn stalks which have minute germs underneath the leaves; these germs are so small that you cannot see them without the aid of a microscope. Corn stalks that are affected with these germs do not grow so well, and ripens long before the other corn.

Symptoms.-There is first, symptoms of impaction of the third part of stomach or manyplies, after that the brain becomes affected and the animal becomes delirious, this is followed by atupidness; the animal will shove its head forward against the stall and pay no attention to anything, and after a few days, dies.

Treatment.-Give the following :

Epeom Salta .... ......................1 pound.

Bitter Aloew............................. ounce.

8veet Spirits of Nitro....................1 ounce or 4 tsblespoonfule.

Fleming : Tincture of Aconite ...............10 to 15 drops.

Mix in a quart of luke warm water and give as a drench, and efterwards follow up with :

Jleming's Tinoture of Aconite........10 to 15 drops.

\$weet Spirite of Nitie............... I unce, or $\$$ tablespoonfeln.

Glnger...................... I tablespoonful. 


\section{UIUKANES AND TKEATMKNT WF CATTLE.}

Mix in a plnt of water and give as a drench every four hours until it is better. Give luke warm water to drink and feed on soft food, keep the body warm, and if the animal's head is affected, keep ice to its head in a bag. Smut on corn is very bad feed, as it is apt to deranf the stomach and cause diarrhcea, and if the animal gets too muc inut it will set up a disease similar to ergotism.

\section{INFLAMMATION OF TEE DRAIN (ENCEPBALITIS)} in horses.

This disease is not so often met with in cattle as it is

Causes.-From a 'severe blow on the head, or from falling and striking the head; irritation of small tumors growing around the brain and pressing on it; certain kinds of food containing ergot or narcotic principles will cause it, or from eating grains from a distillery.

Symptoms.-The first symptoms are the animal will be dull and drowsy and stands with its head pressed up against a wall or fence; its legs keep moving as if it was roing to walk right through whatever its head is pressed against; when walking it has a staggering gait; its bowels are costive and its urine is of a dark-red color. After these symptoms pass off the animal gets delirious and acts as if it were mad, it bellows, stamps its feet, grates 1 teeth, froths at the mouth, runs about wildly, and, if in the strule, rears up into the manger.

Treatment. - In the first stages, when the animal is dull, bleed it, taking a half pailful of blood away, and give

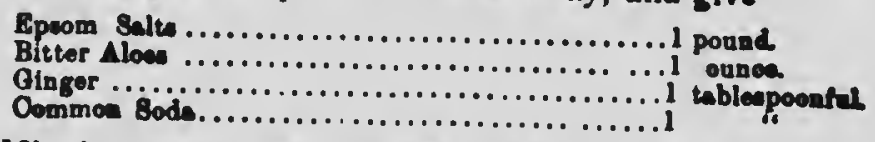

Mix in a quart of luke warm water and give as a drench. Keep the animal in a quiet, shady place; apply a mustard plaster to the back; keep the body warm and apply ice to ite head in a bag. Give

Srreot Bpiritu of Nitro.

Memin the Tineture of Aoopita. 1 eance or 4 tablempeonfin 10 to 18 drope

Mix in a pint of cold water and give every five houre, untll the animal is better. Give plenty of cold water to drink in small quantities and feed on soft food. Give an injection into the anus of half a pail of luke warm water and soap twice a day to help to start the bowels. 


\section{SUNSTROKE.}

This very rarely occurs in cattle. The causes, symptoms and treatment are the same as those of the horse, only in giving a physic use one pound of Epsom salts along with the bitter aloes.

\section{LOCKJAW (TETANUS).}

This disease is rarely met with in cattle.

Causes.-Following operations, or wounds of uny kind, and sometimes it comes on from causes unknown.

Symptoms.-If it is from a wound just when it is healing up the nuuscles all over the body is contracted and hard; the animal has a stiff way of walking ; the tail will be stiff, and keeps working like a snake; the jaws become partially set; the animal cannot reach diwn to the ground; the eyes have a peculiar look and seem to be turned back in the head and set. In some cases the animal can eat, while in other cases it cannot, according to how much the muscles of the jaws are affected.

Treatment.-This is one of the diseases that does not need much medicine because in giving the medicine it excites the animal and does more harm than good, and, anyway, medicine does not seem to do any good in this disease. Give the following:

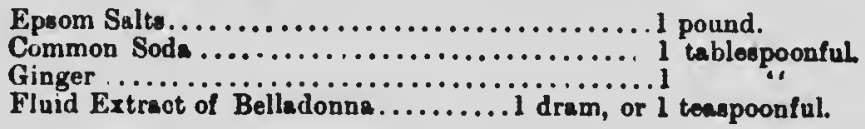

Mix in a quart of luke warm water and give as a drench once a week. Keep the animal perfectly quiet and free from noise. Feed on food made into gruel, so that it can drink it down. If it is caused from a wound, bathe the wound twice a day and fill the place full of green salve. If the wound is where you can poultice it, poultice it every night with linseed meal. This disease generally takes three or four weeks to run its course, and if you can keep the animal's strength up till then it will pass awas, while in severo cases they die in a week or so.

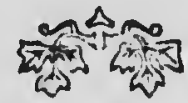




\section{CONTAGIOUS DISEASES IN CATTLE}

This disere contaglods PLEURO-PNEUMONIA.

of the name. This disease was mor the lungs; this is how it gets its common at one time than it is England in 1841, and Ansia in 1804, disease in cattle, but never aff in 1843. It is a very contagrious once gets over this disease affects other animals. If an animal is an outbreak of again. When there germs of the disease it spreads very rapilly, by the

Symptoms being carried about in different ways. feverish; the temperature goes as high as 105 degrees. animal will remain feverish for a week or so, and also have a cough, as if from a slight cold. After this the lungs become inflamed and sets up inflammation of the lungs and their covering. By listening at the sldes you will hear the peculiar grating sound that is heard in inflammation of these parts. The animal breathes heavy and quick, falls off rapidly in condition, refuses to eat, becomes hide bound, and there is a discharge from the nostrils of a whitish color, which has very bad smell. The pulse runs up higher and becomes weaker; the nose is dry, and the animal lies on its breast bone most of the time. Sometimes there is diarrhœa. then costiveness; the eyes become dull and the animal soon dies. When one animal in a herd becomes affected with this disease the whole herd will soon become affected and die, and if it is not checked in this herd it soon spreads all over the country.

Treatment. - If there should be several animals die in the same dlstrict, and you suspect this disease, send for one of the government veterlnary inspectors, who looks after all contagious diseases that break out ln America. The treatment he will follow, after he is sure It is this disease they have, is: He will have the affected herd Immediately destroyed, and, the people who have been attending the cattle and those who are on the farm, will not be allowed to leave the farm for ninety days, and all the stables where the cattle have been will be disinfected and no other cattle will be allowed on the farm for ninety days after the slaughter. Medical treatment is of no arail in this disease, and you are not 


\section{CUNSUMPTION LN CATTLE (TUBERCULOSIS)}

This disease is a contagious one, caused by germs called the bacillus tuberculosis. This disease has been known for centuries back, and there has been laws passed calling for the destruction of affected animals, and also forbidding the meat to be used as food. This disease is known in all the civilized world. It may affect the lungs, bowels; liver, kidneys, bladuer, brain or spinal cord, or any part of the body. The germs in the affected cattle come away from the lungs by coughing, o: flows away in the saliva from the affected animal's mouth, tl fall on the grass, in mangers, pails and such like, and other animals following them up may breathe the germs ir the lungs by eating or drinking out of the same pail or $n$ zer, or off the grass where the diseased cattle have been, and this is how the disease is communicated from one to the other. These germs may also pass out of the system into the milk, and animals or people that drink this milk are liable to take the disease, so you see the danger of baving a diseased cow around.

Symptoms.-At first the disease comes on very slowly after it is taken into the system. If the disease affects the lungs there is a short, dull cough which may be noticed more in the morning, after exercise, or drinking, later on in the disease the cough becomes more troublesome, the animal runs down in condition, the breath has a bad smell, there is a dribbling of saliva from the mouth, the animal becomes hide bound, the hair stands out and it is a pitiful looking sight, and in a few months pines away and dies. The time it takes the disease to run its course varies from three months to a year. This disease is noticed more in thoroughbred cattle than it is in grade cattle. If it affects the bowels the animal will run down in condition, will have diarrhea cometimes, then costiveness changing every few days; the other nymptoms are the same only when the disease does not affect the lungs the animal has not such a cough. If the disease affects the brain or spinal cord It causes paralysis, and death coon follows. If any of the other parts or organs of the body are affected it causes symptoms peculiar to that organ when affected, and the animal slowly pines away and dies. The way to test cattle to find out whether they are affected with tuberculosis or not is to use the test known as the tuberculine test, which is done by injecting uberculine into all tile herd of cattle that are supposed to be affected with the disease ?and having them starved for twenty-four 


\section{DIBZAGES AND}

TMENT, OF : CATTLE.

huurs alter the injection. temperature of the cattle

cake their tomperature. The normal, while the temperature of ected with the disease will be two or three degrees. In case of the affected ones will be raised herd of cattle it is best to send you suspect this disease in your inspector to come and use the test, for hovernment veterinary how to test them, and the thoroughly understands this way you prevent the affected ones will bo destroyed. In of cattle, and by doing this you also proteading in your own herd vourself and those around you also protect the lives of your family, ciated from cattle to meat of affected to people by drinking the milk or eating the this disease the cattle. In opening cattle that are affected with with the disease, and its is affected will be found to be eaten away inclosed in a membrane, and if you cut into a lot of small lumps to be full of other little cheesy lumps about them they are found very bad cases tumors will sometimes a the size of a pea. In matter.

\section{HYDROPHOBIA, MADNESS OR RABIES IN CATTLE.}

This disease originates spontaneously in dogs and cats and can be communicated to other animals or man by the poison citi:igd from the bites of these animals while they are mad. The saliva of the mouth contains the poison and this is how it is caused from a bite. Every animal that they bite does not go mad, but about one-fourth of the animals bitten do go mad.

Symptoms.-A few days after being bitten the animal loses its appetite, is very restless and anxious looking, then there is increased restlessness, loud roaring at times, bunting at things and pawing with its feet; saliva keeps dripping away from the mouth, there is a peculiar wild look in the eyes, and the animal keeps continually straining to pass manure, but very little comes, and in a slort time it becomes paralyzed in the hind quarters, lalls down and death soon relieves it. If the above symptoms are present, and a mad dog has been through that section of the country, you may as well destroy the animal, for it is mad
and is dangerous to have around.

Treatment-If the disease has set in, destroy the animal, and in going around it be very careful not to let it hook or bite you; but if you go to treat the animal just after it has been bitten by a mad dog, take a sharp knife and cut a piece right out of the 
wound, then take a stick of causilc porash. "Ir nitrate of silver, and burn the wound well with it ; but if you have not got these, burn the wound well with a red hot iron, which will also kill the poison.

\section{LUMPY JAW (ACTINOMYCOSIS).}

This disease is contagious and spreads among cattle. It lo caused by germs known as "actinomycosis." This disease gencrally affect the upper or lower jaws, but may affect the tongue and other parts of the body. The way this disease is comnunicated from one animal to annther is from the affected animals slavering on the grass or over feed and other animals take it up when eating or drinking. These germs pass down into the bowels, wh.re they are taken up into the blood and caried around until they locate in the jav. They may also be taken into the system from the slaver getting into the wound on another animal, and it is thought that this disease may be carried to and affect man by eating the flesh of an animal affected with this disease.

Symptoms.-If it affects the jaw there will be a hard, bony lump form opposite the roots of the teeth, either in the upper or Icwer jaws. The disease gradually works in the jaw, the lump grows, and in the course of time the disease gets so bad that the teeth loosen and fall out, and on account of the disease being so bad that the animal eannot eat, it falls off in condition and dies. If it affects the tongue, it is generally the thick part at the back that is affected. It thickens and hardens the tongue so much that when this is affected, it sometimes receives the name of wooden tongue; in thls case the animal will fall off in condition, from not being able to eat, and will soon die.

Treatment.-If more than one animal in a herd becomes affected with lumpy $\mathrm{jaw}$, and after examining the teeth you find nothing wrong with them and you cannot see the mark of any injury outside around the jaws, and if they are not sore to handle, then be suspicious of this disease and treat in the following manner 1 Separate the affected animals from the sound ones; treat the affected ones by throwing and securing them, then skin a piece of the skin off the upper part of the lump, and take a quarter-inch auger or a trephine, which is an instrument used for boring into the bone, but an auger will do just as well; bore two small holes well into the bone, wh; the bone is diseased; pour tincture 0 . and let it soak well around the diseased easily done when $e$ into the wias ...2; let tise anioual 


\section{DISEASES AND TREATMENT OF CATTLE.}

up, and in a few days afterward catch it again and fill the holes with iodine, and keep putting in the iodine every fourth day until the holes heal up. If this treatment fails to kill the lump destroy the animal and burn it, for it is dangerous to have it in your herd, and its meat should not be used for food, as it might set up the disease in man.

\section{ANTHRAX.}

This is an infectious disease caused by germs, called the anthrax bacilli, getting into the blood. This disease affects cattle in all parts of the world, and is only noticed in cattle that are grazing on low, swampy land that have pools of stagnant water on it. When once the disease gets into a pasture field it will remain there for years, and the only way to get rid of it is to break the field up and drain it.

Symptoms-It more frequently affects young cattle than older ones; the attack is very sudden, the night before will be found dead 1. the morning. In sone cases as soon as the animal is affected it drops down, goes into convulsions and dies. In other cases it will last longer, the pulse will run up to from 80 to 100 beats per minute; the animal will not eat; the whole surface of the body, legs and ears are cold, and it is very dull, stupid and weak. In short time this dullness gives way to uneasiness, it champs its jaws, kicks and paws the ground and appears to be in terrible agony; it has very much difficulty in breathing, the nostrils are onlarged and the mouth open; the lining of the mouth, nostrils, rectum or back bowel and vagina are of a blue color, the manure is first thin and water looking, then covered with slime and blood; the aymptoms gradually get worse, and in a few hours it dies a misorable death. Tho germs are taken into the system from eating grase around a swamp or drinking the water from stagnant pools. They find their way from the bowels into the blood, and work around until they locate themselves in the bowels or tissues under the skin. When an animal dies from this disease it bloats up, decomposition setting in very quickly, and there is a blood-stained fluid flows from the mouth, nose and anus. If you have had an animal or two die while pasturing on this kind of land, and showing the above symptoms and appearance after death, send for the government veterinary inspector, he will examine the blood, and if the germs are found in it you will then be cure it is anthrax. Burn the 
araseces of the dead cattie and remove the sound ones from the pasture; drain the hold and break lt up lo the best way to get rid of the germs. Sheep are also subject to thie dienace and have the arme aymptoms.

Treatmant.-There is no treatment for this disease.

\section{BLA?: QUARTER.}

This is an infectious disease and is very fatal, and affecte cattio from six months to three or four years' old. It is caused by germs getting into the system. This disease is noticed mostly in cattle grazing on low-lying, swampy lands.

Symptoms.-About three days after the germs get into the system the animal becomes dull and feverish, the temperature rises as high as 107 degrees; there is lameness in some of the legs, generally in one of the front ones, which is caused from a swelling which usually forms just behind the front leg, but may be in any other part of the body. The symptoms gradually get worse; the animal acts as if it had severe spells of colic, but keeps looking around to where the swelling is; breathes heavy; becomes very weak and soon dies. The swelling, after it is first noticed, grows very fast, and when you rub your hand over it, it makes a crackling noise as if it contained air. If you cut into the swelling the animal does not feel it, and nothing comes out only a dark red, frothy looking substance, which has a bad smell. If you skin the animal where the owelling is, there will be dark brown, dark red and yellow colored patches, and the parts around where the swelling is will be soft and easily torn.

Treatment. There is no treatment for this disease, only remove the sound animals, deatror and bum the affected ones, and drain and break up the pastura.

\section{TEXAS FBVER}

This dicease affects cattle all through the southern parts of the states, and is caused from germs getting into the blood. The germs are carried from one animal to another by cattle ticks.

Symptoms.-At nirst there is dullness, loss of appetite, and the animal will leave the herd and stand or lie down alone. The temperature at this stage will be up from 105 to 107 degrees, and stays about that all through the disease. The bowels are constipated, and anything that is passed is covered witlı bile, and near the end of the disease the urine or water is of a dark red color. 


\section{DISEASES AND TREATMENT OF CATTLE.}

The pulse and breathing are both quickened; the animal hecomes very stupid and lays down most. of the time, and in a few days death relieves it In some cases they die in three days, while in others they live for several weeks, and if an animal does recover it takes it a long time to do so.

Treatment. - In order to keep the disease from spreading do not allow cattle that have these ticks on tliem to go into other herds, and cattle affected with this discase should be put on a pasture by themselves, and the ticks should be picked off and killed, then give the animal the following: Fifteen grains of sulphate of quinine three times day, either in a drench mixed with a pint of water, in a capsule or on its tongue with a spoon

\section{CHAPTER XII.}

\section{DISEASES THAT ARE LIABLE TO AFFECI ANY ANIMAL.}

TUMORS.

Tumors are growths which are not inflamed nor sore to handle, and are of various kinds; they do not fester and break, and run matter as abscesses do, but simply grow; they may affect any part of the body in any kind of an animal, and n some cases there will be a small amount of matter in the center of the lump. Tumors, as a general thing, grow very slowly, and are very hard when you feel them.

Treatment.-At first they may be stopped growing and abcorbed by blistering

For Tumors on Cattle-Use the following blister :

Powdered Cantharides or Spanish Fly...............2 dram.

Mix and rub in w......................... ounce.

Mix and rub in well what you can get on the tumor; tie the inimal's head so it cannot bite the blister; grease the blistered part in three days, and in two weeks blister again, and continue sntil you have blistered it three or four times, and then if this loes not stop the growth of the lump ard reduce it down it is best to cut it out. Tincture of iodine is also good to use in some cases. Rub the lump well with it once. day till you get it well blistered, then grease and let it go for a few days, then wash the grease off with luke warm water and soap and commence using the iodine again. 


\section{For Tumors on Borses.-Use the following blister:}

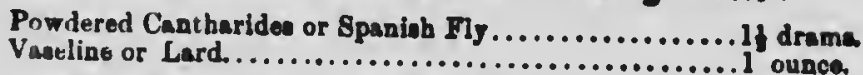

Mix and apply with the same directions as is given for the blister on cattle, if tisis does not fix it try the iodine the same as for cattle. In case you have to cut the lump out, throw the animal down and secure it, make a good, long cut in the skin over the tumor and cut around it until you have it cut out, after the tumor is out and it is bleeding, take a large piece of dry. cotton batting about the size of the tumor and shove it in where you took the tumor out, then sew up the skin the same as sewing a wound, and leave it sewed up for twenty-four hours, then take a couple of stitches out of the lower part of the wound and take the batting out and dress it by bathing it off with luke warm water and soap twice a day, after each bathing dress the wound by inserting melted green salve with a feather up in the wound and app'ying white lotion around the outside and inside of the cut. Keep this treatment up until it is healed. If the tumor lies near a large :ein such as the jugular vein, and you cannot cut it out, keep blistering it, and it this does not help it, paint the lump over with tincture of iodine every day the same as above mentioned. This treatment will du for tumors either in the horse or in cattle.

\section{CANCER.}

Cancers are angry looking growths generally, affecting cattle, sheep and dogs, and is sometimes noticed in horses, around the head and neck, but may affect the other animals in any part of the body.

Symptoms.-At the first appearance of the cancer-before it rats into the blood-it does not hurt the animal's health, but after the cancer once gets settled in the blood the animal falls off in cot.dition, the growth grows very rapidly, and the least irritation auses it to hleed. In some cases the d sease graclually eats the surrounding tissue until it kills the animal, and if it is near a bone it gradually works into it, and when the bone becomes affected it has a very bad smell. When the disease has arsived at this stage it is called hone cancer.

Treatment.-In the first stagres of tha, lisease cut it out good and clcan, and by doing this you can sometimes prevent its -preading. It is best to throw the animal and secure it before vou attempt to cut the camer out, and as soon as you have taken it 
out burn the place good with a red-hot iron, then bathe it twice a day with luke wa:m water and apply the green salve and white lotion after each bathing. If, at any time afterwards, there should appear to be a red spot growing, tie the animal up and give the spot another good burning with the red-hot iron,- and keef this treatment up until it is healed. In some cases when the disease has run on too long before it has been cut out, or after it is cut out, it grows again worse than at first, or where it has been entirely neglected and allowed to run on so long that the bones hecome affected and smell bad destroy the animal and burn the carcass, as it is not fit for bet and would be very apt to communicate cancer to anyone eating the meat.

$$
\text { , }
$$

\section{ARSCESSES.}

Abscesses are of two kinds, one festers and has matter in it, while the other, which is called a serious ahscess, is only a bruise containing water, or serum. These kind of abscesses are generally found around a horse's shoulder, but may affect any part of the body.

Symptoms of a Serfous Abscess.-About twenty-four hours after the bruise there will be a swelling varying in size from an egg to that of a man's head, and when you press on it you can tell there is fluid in it, and on opening it you will find a watery looking fluid mixed with blood.

Treatment of a Serious Abscess. - Cut a whole in the bottom part of the lump large enough to run your finger in and clean all the fluid out, then bathe the part well with luke warm water and salt, and insert melted green salve up into the lump through the hole with a feather twice a day, also run your finger into the hole once a day to keep it open until it heals inside, each time after bathing rub the outside of the swelling with white liniment to help get the thickening out and keep the swelling down.

\section{ABSCESSES THAT CONTAIK YUTTER.}

Causes.-From distemper; from bruises; or from a cut healing up and there being some substance left in the cut which afterwards festers.

Symptoms.-Abscesses differ from tumors, as they fester and form matter $;$ are hot and sore to handle; cause the animal to be feverish and in pain, and after a time they come to $a$ head and either break or have to be lanced. 
Treatment.-Bathe well with hot water and salt, or vinegar, twice a day, and where it is very sore poultice it once in while to help to bring it to a head. Each time after bathing sp.ly white liniment around the swelling; this also helps to bring it to head. When the abscess is ready to open there will be a soft place on it where the hair is falling off and pulls out ensily; take a sharp penknife or lance and make a cut in it large enough to put your finger in and clean all the matter out, and treat with green salve, bathing and applying white liniment the same as is given in the treatmient of serious abscesses.

\section{RONNLIG SORE (FISTULA) \\ Running sore, or 6stula, may form io an animal or in any part of the body.}

Causes.-From the animal getting a deep wouna and some substance being left in the wound after it is healed which shoul.t have been taken out before the wound healed up. It is also caused from discased bone, or a small piece of broken bone which
keeps testering.

Treatment.-In all cases where it has been a wound that is healed up and then turns to a running sore, you may come to the conclusion there is something at the bottom of the wound that is causing the trouble, and if it is in a place you can operate on it without throwing the anima' down, by twitching it, do so (this can generally be done in the horse), but if not, throw it down and secure it, then take a gonse quill and probe into the hole to see which way it goes and the depth of it, then with a sharp knife cut a hole large enough for your finger to go in; cut the hole to the bottom of the wound and clean out whatever there is in there, then treat the wound by bathing with warm water twice a day. After bathing each time put melted green salve up in the hole and apply white lotion in around the cut; keep this treatment up until it is healed. If it is caused from a diseased or fractured bone, cut down same as above and take the piece of bone out. If it is a diseased bone, scrape it out well with a hard steel spoon, and then treat the wound the same as given above, and it will soon be all right.

\section{STRUCK BY LIGETNING.}

The shock is instantaneous, and affects the brain and nerves. If the shock is heavy enough it causes immediate death, but if it is not severe enough to cause death it leaves the animal prostrate, 
Symptoms. - When it does not kill the animal it falls paralyzed and unconscious, the muscles relax and are soft and fabby, and in some cases there will be twitching of the muscles, the animal will breathe hard and slower than natural, and in most cases there will be spots of hair singed off the body.

Treatment. - Dash cold water on the head, rub the body and legs well to get the circulation up, then apply a thin mustard plaster on the back of the head and sides of the neck; blanket the animal well to keep the body warm, and keep the head cold by applying cold cloths, and as soun as it is strong enough to swallow, if it is a co:s or horse, give it half a pint of whisky in a pint of warm water; if it is a sheep, dog, or pig give a wine glassful of whisky in half a pint of warm water, pour the drench down slowly so as not to choke the animal; give a drench every hour, and turn it over from side to side every once in a while, and attend tc its general comfort until it is better. After the sloock has passed off, if the animal seems to be paralyzed, for a cow or horse give a teaspoonful of powdered nux vomica twice a dity on its tongue with a spoon, or in its feed, this is for a nerve stimulant. Give a sheep, dog, or pig one-quarter of a teaspoonful of powdered nux vomica twice a day until it is strengthened.

THE APPEARANCE OF AN ANIMAL RILLED BY LIGHTNING.

If a thunder-storm has just passed over, and the animal, which was previously healthy, is tound dead shortly afterwards, the muscles are soft and flabby and you can move its legs any way you like, and in some cases there will be spots of hait scorched off the body, this indicates that the animal was killed by lightning.

\section{ERGOTISM.}

This disease is most often seen in cattle, and shows itselt mostly in the winter and spring of the year.

Causes.-From eating ergotized grass, which is nothing more than diseased grass. (Ergot also affects rye wheat). The diseased grass is cut along with the hay and other food, dried and brought into the barn and fed during the winter with the good hay and other parts of food. This is how the arimala get it. The ergot affects the grass, etc., on the same principle is smut does the corn. Ergrot is mostly seen in grasses and rye wheat, but may affect other kinds of grain that is grown on low, rich land in wet, hot seasons. 
Symptoms.-After cattle have eaten it and it gets into the blood it has such a peculiar contracting action on the heart, arteries and other vessels that it weakens the circulation of the blood so much that in some cases it stops it entirely in the legs, ears and tail, and as soon as circulation in these parts stop they die, rot and drop off, and later on in the disease the brain becomes affected and the animal goes into convulsions and dies.

Treatment.-Change the food entirely, batl the affected parts with luke warm water twice a day, rub dry and apply white lotion to them after bathing. Give the following powder:

Nitrate of Potah or 8altpotre....................... pound

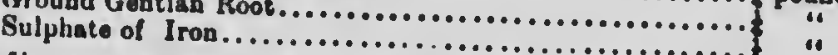

Mix and give a teaspoonful three times a day to a horse or cow; to smaller animals give one-half of the above dose.

BOW TO DRY AN ANIMAL THAT IS GIVING MILX.

For a cow, give her a pound of Epsom salts in a quart of luke warm water as a drench, then bathe the bag once a day for a week with luke warm forge water (this is best obtained at a blacksmith shop where they cool the irons). After bathing, milk out a little of the milk once a day, on the ground, for a few days, then milk a little out every second or third day for a few days, then once every week or so for a while, and then stop milking. The last time you milk her, milk the bag out dry. During the time you are $\mathrm{pi}$ 'ing the cow dry, feed on dry, hard food. For a mare, give eight drams of bitter aloes and a teaspoonful each of ginger and common soda, dissolved in a pint of luke warm water, as a drench. After you give the physic drench, let her stand in the stable for a day or two, bathing the bag and milking her the same as is given for the cow. In drying a sow give a teaspoonful of sulphur in her feed twice a day, and if it is a quiet sow bathe the milk glands with luke warm forge water once a day for a week, and allow her to run out. In drying a ewe give a tablespoonful of Epsom salts dissolved in a half teacupful of luke warm water, once a day for a week, and bathe her bag with forge water, and milk her out in the same way as is given for the cow. Why forge water has such a good effect in drying up the secretion of milk is on account of the iron in it, which gets into it while cooling the irons in the water, and this iron has an astringent action on the milk glands. The reason the physic is given is to clean the milk out of the blood. 
DISEASES OF THE HEART, ARTEHILS AND BLUUU.

These diseases in cattle are the sime as in the horse, and for causes, symptoms, and treatument we refer you to the pages ir Part 11. of the horse where they are fully explained.

\section{NOTICE.}

All the doses of medicine which are mentioned in this book in the diseases and treatment of cattle, if not specially mentioned for the age and size of the animal, are intended for an average sized cow, steer or bull, so in giving doses to young cattle you must regrulate the dose to the age and size of the animal. Calves under one year old would take about one-third of the dose; two-year-olds would stand one-half the dose; three-year-olds and upwards take fult dose mentioned, and cattle over the averagp size, such as large bulls, cows or steers, can take a little more than the dose mentioned.

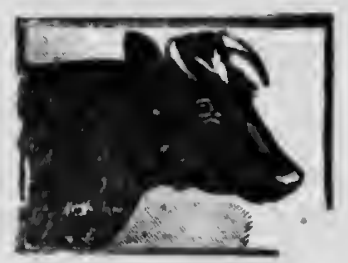




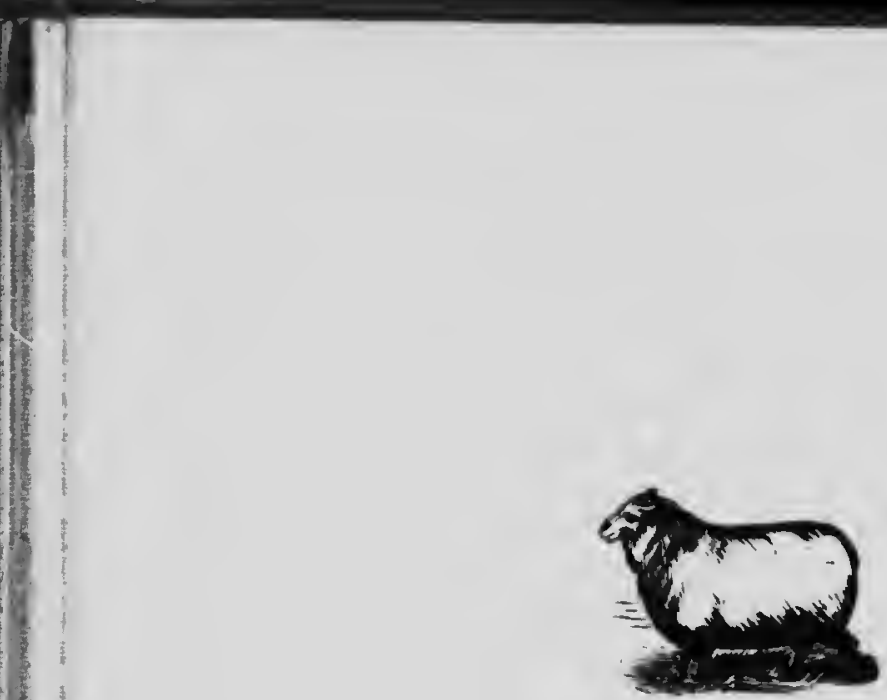

\section{PART IV. DISEASES AND TREATMENT OF SHEEP, PIGS, DOGS AND POULTRY.}

CHAPTER I.

\section{DISEASES AND TREATMENT OF SHEEP.}

Sheep belong to the clgss of animals called ruminants, which means animals that chew their cud. In regard to the structure of sheep, they are on the same principle as that of cattle, only smaller. The skin of the sheep is different to that of the ox, as it grows wool instead of hair, and has in the skin numerous small glands which secrete oil, which is used to lubricate and soften the wool.

COLD IN THE HEAD (SIMPLE CATARRH).

This is a common disease in sheep, and consists of an inGamed state of the lining of the nose and the cavities of the head.

Causes.-From being left out in a cold rain and exposure to cold weather, and is mostly seen in the fall and spring, during the seasons of cold rains. It is often seen during washing and shearing time.

Symptoms.-There is a discharge from the nose, and the affected sheep keeps suuffing, sneezing and coughing; does not feed well and seems very dull.

Treatment-The treatment is very simple in most cases. Keep the sheep dry, warm and clean, and this often effects a cure in a few days without any medicine; but if the disease does nol pass off, give the following mixture: 
Nitrate of Potwh or Baltpotre.................... poun

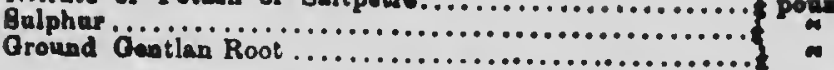

Mix thoroughly and give a teaspoonful twice day on the tongue with a spoon, in its feed or as a drench; feed hot manher and take special care to see that it does not get wet, for the disense might settle on its lungs. If the discharge from the head gots clogged around the nose wash it off with warm water and soap. In some cases, where the above treatment does not stop the disease, change the treatment to half a teaspoonful of ground sulphate of iron three times a day in its feed, or on its tongue with a spoon. Iron acts on discharges of any kind in helping to stop them, and also builds up the system, for it is a great tonic.

\section{SORE THRDAT.}

Causes.-The causes are similar to those of catarrh, only the throat being the weaker part it settles there instead of elsewhere.

Symp:oms.- There is swelling and soreness around the throat, and the animal holds its head and neck poked out, and when it :oughs it seems to try to save itself all it can. The animal is dull, eats very little, and when drinking the water runs out through its nose.

\section{Treatment.-Give}

Nitrate of Potash or Saltpetro $\ldots \ldots \ldots \ldots \ldots \ldots \ldots \ldots \ldots \ldots$ pound

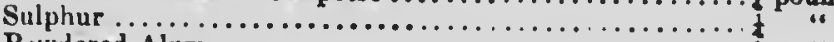

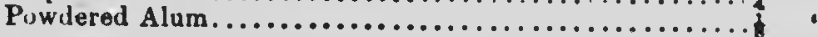

Mix thoroughly and give small teaspoonful on its tongue witl a spoon three times a day. As well as giving the powder rub the throat three times day with white liniment. Feed on soft food raised high so it will not have to bend its head over to eat. Give all the cold water it wants to drink in small quantities at a time; also take good care of it, not allowing it to get wet or sold, and it will soon get all right.

\section{BRONCEITIS.}

This is inflammation of the lining of the bronchial tubes.

Causes.-From being chased by a dog; inhaling smoke, or getting wet are the principal causes of bronchitis in sheep.

Symptoms. - The affected sheep will be dull, breathe heavy and quick, the ears, will lop over, and, like the ox, they will lio lown most of the time while suffering with lung trouble. If you listen at the bottom of the windpipe a wheezing noise will ve heard. 
Treatment. - Keep the animal very quiet in an airy place and give the following :

Swoot Spirite of Nitre

Fleming' Tincture of Aconito.......... ounce, or 1 tablespoonful

Mix in a teacupful of tuke warm water.

drench. drench. In drenching do not raise the head too high, and be very careful not to choke he animal. If the sheep wishes to drink give cold water in s.isall quantities; also, small, hot mashes and grass, or hay to eat. Give the sheep the above drench three times a day for a day or so until it gets relief. If the sheep seems very weak then change the drenches to something more
stimulating.

Whisk

Ginger............................... vine glaseful.

Mix in alf pint of very carefully. Give this druel and pour this down strong; also, be sure to times a day until it gets have plenty of have plenty of fresh air without being in a draft.

\section{FILARIA BRONCHITIS.}

Causes.-From small germs getting into the system and settling in the lining of the bronchial tubes and inflaming them. This disease is not very common, but sometimes we have an out. break of it where the sheep are pasturing on a low-lying pa- - e, and, as a general thing, if one of the flock gets affected nearly all the herd will be showing symptoms of the disease.

Symptoms.-They have a dry, husky cough ; fall off in cundition, and with the slightest exertion the animal will breathe heavy, and on placing your ear to the bottom of the windpipe you vill hear a wheezing noise, the sheep.will not feed well, scarcely ever chews its cud and lies down most of the time. If you have several sheep showing the above symptoms, and they are pasturing on a low-jying pasture you may come to the conclusion it is this disease they have.

Treatment.-Turpentine seems to have special action in cases of this kind, because as soon as it gets into the blood it spreads through the system and has a tendency to kill all kinds of rerms. Give the following :

Bpirit of Turpentine.............. ounce or 1 tablespoonful.

Ran Linseed Uil................... teacupful.

Mix and give as a drench every third day until the disease disappears. Another good treatment is to burn sulphur in a stable 
where the sheep are and allow then in nswitite ins tumes of the sulphur. Do thi. twice a week and it will kill the germs and stop the disease. The way to tell when they have as much as they can bear is to have a man stand in the stable with them, and when he has all he can stand let the sheep out of the stable. Sheep can stand about the same amount of the fumes of sulphur as a man.

INFLAMMATION OF THE LUNGS AND ITS COVERING.

Causes.-This generally comes after sore throat when the sheep gret cold, or from a neglected cold in the head, or from getling chilled from being in a cold rain. Sometimes it is caused from a sheep getting cold after lambing.

Symptoms. - The sheep lies down with its ears lopped rver, breathing heavy, its legs and ears are cold, and it does not eat nor chew its cud, but seems feverish and greedy to drink. Somelimes it will cough. If you separate the wool on its side and listen with your ear you will hear a peculiar grating sound in the lungs, and the affected sheep will moan once in a while as if in distress. The sheep gets very weak, falls off in condition and will die in a short time if it does not get relief. In some cases the sheep will linger nine or ten days.

Treatment.-Put the sheep in a dry, warm, well ventilated box-stall or stable. If the sheep has just been shorn cover the body well with blankets, but if not just keep dry. Give the following medicine :

Sweet Spirits of Nitre............. onnce or 1 tablespoonful.

Ginger.......................... tenspoonful.

Fleming Tincture of Aconite.............

Mix in a half pint of water and give as a drench. Give this three times a day, being careful not to lift its head too high and shoke it, and give plenty of time for the animal to swallow the drench. In a day or so, when the animal is better, but seems weak, give the following drench, as a stimulant :

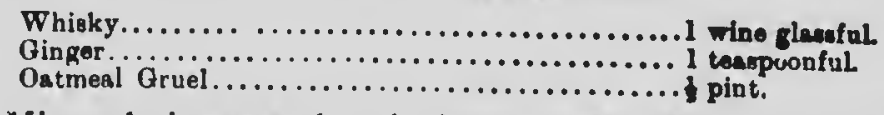

Mix and give as a drench tinree times a day until the sheep gel; strong and commences to feed all right again. During the time the sheep is sick give cold water .o drink in small quantities, but often. If it will eat mashes with flaxseed in it give that, but if not give any other kind of grain it will eat. 
TRCUBLES OP THE TEETH.

Sometlmes, when the sheep is a year or two old, there will be cap of one of the grinders, while shedding the teeth, stick on the new tooth and not fall off; this causes the animal difficulty in eating.

Symptoms. - The sheep does not do well; would like to eat; takes food into its mouth and chews it, but throws it out again and goes off, and although it seems to be failing and does not eat, still it does not seem sick. It will sometimes be noticed to be working its tongue around its mouth.

Treatment.-Catch the animal and examine the mouth, and if it is a cap you can tell it, for it will be higher up than the other teeth in the row. Remove the cap with a pincers and the animal will soon be al, right.

PIECES OF WOOD OR ANY SUBSTANCE LODGED UN THE TEETH.

in eating, the sheep gets hold of a piece of stick or some other substance and it gets caught between the teeth or around the lips or gums, and it cannot work it out with its tongue.

Symptoms. - The animal is not eating and keeps its tongue working around in its mouth as if trying to work something out.

Treatment.-Examine the mouth, and if you find anything caught in it, remove it, either with your fingers or a pincers.

\section{OLD SHEEP LOSING THEIR TEETH.}

Sometimes an old ewe that has lost some of her teeth gets with lamb; you want to keep her over another year, and she only has two or three front teeth, which interfere greatly with her eating, and she runs down and gets so poor that you think she will not pull through.

Treatment.-Catch the ewe and pull out the remaining front teeth and let her gum it, and as soon as the gums heal up she will do well and be able to eat, and will be good for a year or so. The reason why the sheep did not do well was because all the food she could get to eat was merely what she could catch with the few stubs of teeth that remained in her mouth, and when they are pulled out she can take the food in all right with her gums and chew it with her kack teeth, which a re generally all right at this age.

CHOKING II SHEEP.

This is not nearly so common in sheep as it is in cattle, but eomotimes it occurs when they are fed on sliced roots. 
Symptoms.-The animal stops feeding, froths at the mouth, coughs and keeps working its tongue, and in some cases is bloated and the eyer bloodstiot.

Treatment. - Pour down a little raw linseed oil as a drenchi in some cases this will start whatever is lodged In the throat causing th trouble. Feel along the bottom of the neck, and if you can find the obstruction try to work it up or down with your hands, but be sure you do not mistake the larynx or Adam's apple for the lump. If this treatment fails, get a probang that is used for choking In cattle and pass it down in the same way as is explained for chokirg in cattle, being very careful in passing it down, for the sheep is a more tender animal than the cow. Oil the probang well before passing it down.

\section{BLOATING (TYMPANITIS) IN SHEEP.} paunch.

This disease in sheep affects the first part of the stomach e?

Causes,-From a chang $=$ of food of some kind; getting a feou of wet clover; getting a feeil of grain; by chilling the stumach with a big drink of cold water; or by eating frozen rcots or grase.

Symptoms.- . The sheep is uneasy; keeps getting up and down and seems in pain; breathes heavy and keeps moaning; on examining the sheep it is found bloated on the left side; if you separate the wool on the left side over the paunch and tap on it, it gives a hollow, drum-like sound, showing that there is ges inside.

Treatment-The trealment must be quick. Give the follow ing mixture:

Epeom Balta.

Bwcot Bplriti if i................. pound

Common Bode Nite............. onnos, ar 2 tablespoonfele

Ginger.................... I teenpounful

Dissolve in a plnt of luke warm water and give a a drene. If this does not give relief in one hour, give 1

Raw Lingeed OU................. I tenouplul

Splritu of Turpentine.. ... ........ ounoo, or 1 tublewpoonful

Mix and give as a drench. If this does not give relio two hours, follow up with the following:

Sweet Spirits of Nitre.............. ounce, or \& tablespoonful.

Clinger.......................... teanpoontul.

Mix in a half pint of luke warm water and give as a drenct every two hours until it gets relief. Ia very urgent cases, whow 
the bloating is so bad that it endangers the sheep's life, tapping is performed by measuring first half way between the point of the hip and the last rib, and about three inches down fron the back bone, then clip the wool off that space about the size of your hand and cut a small hole in the skin just large enough to allow the trocar and cannula to go in; the one used for tapping cattle will do for the sheep by oiling it first and pressing it through the hole that you cut in the skin downwards and inwards right into the paunch. Leave tha cannula in and pull the trocar out, and the gas will all escase thrmgh the hole in the cannula and save the sheep's life. As swon as the gas is all out, draw out the cannula and let the hole heal up itsolf. If you have not a trocar and cannula, run penknife in the same place as described; this will let the gas out.

\section{IMPACTION OF THE FIRST PART OF THE STOMACH WITH FOOD.}

Causes.-From the sheep getting at some food that it is not used to eating, such as grain, or being turned into a good pasture nfter feeding in a poor one. Feeding a poor quality of peas, straw or clover hay, especiaily if it is a little musty or over ripe, will sometimes cause it.

Symptoms.--The sheep will not be eating, looks dull, grates ts teeth, does not chew its cud, and has a short, quick grunt while breathing, caused from the food in the stornach pressing on the lungs. The animal walks about in a stupid manner, and has very little passage from the bowels, and what does pass is hard and ary. B: pressing on the left side over the stomach it is found to be hard, and by tapping on it, it makes a dull, heavy sound, showing that there is food lying in the first part of the stomach or paunch.

\section{Treatment.-Give the following:}

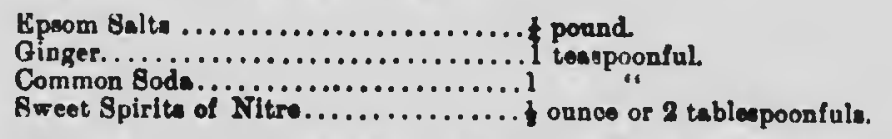

Mix in a pint of luke warm water and give as a drench, then wait for twenty-four hours to see if this dose will physic and clean out the stomach; if it does not physic in that time, give:

Raw Linseed Oll................ pint.

Spirits of Turpentine.................. ounce or 1 tablespoonful.

Mix "and give as a drench. Atter the physic operates, to otrengthen the animal give: 
Whitky............................. wineglansfur

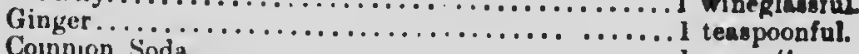

Cornnıon Soda...................................

Oatmaul (irue!, ......................... pint.

Mix and give as a drench three times a day until the sheop gets strong.

\section{COLIC IN SHEEP.}

This is cramps of the bowels.

Causes.-From eatung frozen grass or roots; from taking a cold drink of water; or from eating anything that disagrees with the bowels.

Symptoms.-The sheep will lie down, moan, strike its feet up against its belly, jump up and seem quite easy for a few minutes, and then the pain will come on again. This is the only disease where the sheep acts like this.

Treatment.-Relieve the spasms by giving

Tincture of Laudanum.............. $\neq$ ounce or 1 tablospoonful.

Ginger...........................

Common sida.....................

Mix in a half pint of luke warm water and give as a drench every hour until the animal gets relief. In some cases, after you give a few doses and it does not get relic:, try this drench :

Raw Linseed Oil................... pint.

Spirits of Turpentine.................

Mix and give as a drench and this will sometimes give immediate relief.

\section{INFLAMMATION OF THE BOWELS.}

This is a common disease in young sheep.

Causes.-From eating a lot of snow; from eating dirty pea atraw; or from a severe chill caused from being out in a cold rain and getting the wool very wet.

Symptoms.-There is severe pain, the animal gets up and down and keeps pawing first with one foot and then other, the legs and ears are cold, and when you press on its belly it causes it to inoan with pain. This disease differs from colic for the sheep does not get easy spells but the pain continues all the time.

Treatment.-Give the following as soon as noticed :

Tinoture of Laudanum.............. ounce or 1 tablespoonful.

Floming' " Tincture of Aconite..........3 drops.

Mix in a half pint of raw linseed oil and give as a drench. Turn the slieep on its back and rub in one-quarter of a pound of mustard, wet up with vinegar, on its belly where the wool is short. If it is a ram be careful that you do not get any of the 
mustard around the point of the sheath, for it will cause tha sheath tu be sore and irritate him, afterwards grease where you blistered: keep it very dry, and na comfortable, warm place, and give the following drench every hour after the fist one until the sheep gets relief :

Tinoture of Laudenum............... ounce, or 1 tablespoonful.

Fleming'ه Tineture of Aconite............ 3 drops.

Mix in a half pint of luke warm water and give as a drench.

TAPE WORM IN SHEEP.

Tapeworm usually affect young sheep, but may affect old ones. The disease is generally seen in sheep that are pasturing on low, rich pasture fields, where dogs that are affected with tapeworm often run across and leave their droppings, for this is the way the disease is carried, and spreads from one flock to the other. When one sheep becomes affected with tapeworm, the worm grows rapidly until it assumes the length of trom ten to filty feet, and is made up of flat joints about half an inch long. Aiter the tapeworm gets large, frequently these joints become broken off and pass away with the manure, this joint is alive when it comes away and remains alive and crawls about on the grass, and very often another sheep comes along and picks it up, and as soon as it reaches the bowels it begins to grow and forms a new tapeworm, this is the way the disease spreads among the flock of sheep.

Symptoms. - The animal falls off in condition, and the eyes have a peculiar, dull look. The animal has a good appetite, but what it eats does not do it much good, for the nourishment all goes to nourish the tapeworm. As soon as these symptoms are noticed in one or more young sheep, look out for tapeworm and watch their droppings very closely, and if you see joints of flat worm about half an inch long coming away, you can be sure that they are affected with tapeworm. This is a dangerous disease, and sometimes before the owner is aware, he will lose a lamb or two, and it is best treated as soon as first noticed.

Treatment.-Separate the diseased sheep from the ones that do not show the symptcms and put them in a stable, not allowing them to eat anything for twelve hours; at the end of this time they are ready for treatment. Give the following:

Oil of Male Shich Fera.............. I drum or I teaspounful.

Raw Linfeed Oil..................... teacupful.

Mix and give as a drench to each of the affected sheep. After this drench feed them light, keeping them in the stable so 
you can walch therr druppungs, and it it llorks on ally of them as it generally does, you cammot miss it, for there will be a bunch of worm as lirge as your two hands come away. If it should not act on the sheep. starve it again lor twelve hours and repeat the dose, and if it is a large sheep, rive a teaspoonful and a half of the oil of male shield fern. K.-p this treatment up until the worm has passed away. Watch the other sheep to see if any ol them become affected. The dose for a small lamb is:

Oil of Male Shield Feru................ dram or teaspoonful.

Kaw Linneed Uil........................ theacupful.

Note. - This discase affects steep and lambs far more than stockowners have any idea of. Often these pieces of white, flat worm are seen coming away with the manure, without considering the danger the flock of sheep are exposed to; they allow it to run on, not treated, until a few lanbs or sheep die, then treatment is ziven to the balance after there is a hear! loss; so you see the importance of watching things like this. A trifling cost and a little trouble will orten save heavy losses in your flock.

\section{HLUKE DISEASE IN SHEEP.}

This is a disease of the liver and is very common in Fingland, but not very common in this countri, not so much so as it is in the cattle of this country. This disease is fully described in connection with fluke disease in cattle, for the causes, symptoms and treatment are the same. You will find a thorough explana. tion given there.

\section{GRUB IN THE HEAD OF SHEEP.}

This is a common disease in some localities, especially if the sheep are pasturing on low-lying swampy lands where there are pools of stagnant water.

Causes. - The way this cisease spreads is by allowing a sheep that has died of grub in the head to lie and be eaten by dogs of the neighborhood, and when they are going across pasture fields they leave their droppings, which contain the grub, in the pasture. The grub, being still alive, crawls onto the grass, and the sheep, while eating the grass, takes the grub int the stomach, and in this way it gets into the blood along with the nourishment and passes around in it until it comes in contact with the brain, where it settles itself in the upper side $c^{\text {t }}$ it as near the centre as it can lodge.

Symptoms. - The symptoms are very peculiar. The sheep bolds its head to one side and a little higher than natural, and for 
a few days will go around in thit mannor acting very strange. The symptoms become worse; the animal will take spells of running, and if there is a fence in its road it will run up against It, or if there is a ditch, It will run into it as if it were blind and fall over, then take a fit of jerking for a minute or so, then get up and be apparently all right for half an hour or so, when another fit will come on. In other cases, if the grub settles a iittle to one side of the brain the animal will keep running around and around in a circle. These symptoms gradually get worse, and the fits come on oftener, and if not relieved will die in a few weeks.

Treatment_As soon as first noticed the grub can be killed and absorbed away by giving

Spirits of Turpentine................ t ounce or 1 tablespoonful.

Raw hineed Oil..................... tescupful.

Mix and give as a drench every second or third day for a week or so. This will kill the grub, which will gradually absorb away itself, and the sheep will soon be all right. During treatment, keep the sheep in a small fieid where it cannot hurt itself; catch it every day a ieel around the top of the head for a soft spot in the bone over the brain by pressing hard on it, and when you find it take a sharp knife and cut the skin off the soft spot about the size of a twenty-five cent piece, and then cut the diseased bone, being careful not to touch the brain. As soon as you have cut around it, raise the piec $f$ soft bone out and leave it out. This soft piece of bone, l. . will at once give the sheep relief, for the grub will bulge up in the hole and take the pressure off the brain. Do not attempt to remove the grub, for natuse will remove it in a few days itself. The only thing to be done after the bone is cut out is to keep the sheep in a cool place where flies will not bother it and cause maggots. If they should, wash it out clean with luke warm water and soap, then apply the white lotion with a few drops of carbolic acid in it once or twice a day and it will be all right. The hole in the bone will soon heal over. Providing you should lose a sheep with this disease, bury it deep so the dogs will not get at it and carry it to other sheep. Never, in any case, pour spirits of turpentine in the nostrils, for it will do no good, is cruel, ana sometimes kills the sheep itself. Always give the turpentine as above mentioned. 
SCAB IN SHEEP.

This disease somewhat resembles mange in horses. It is a very serious disease in some countries, but is not muct: seen in Canada or United States.

Causes.- It is a contagious disease and is caused from little germs or parasites getting down into the sikin. The disease spreads by these germs or parasites getting from one sheep to another.

Symptoms. - There is extreme itchiness, and the sheep it continually rubbing itself against something. The wool, on account of the germs or parisites working in the skin, falls off in patches, the sheep falls off in condition, and if you examine the scab, with a microscope you will see the minute germs or parasites. When one sheep is affected in a flock it soon spreads and affects them all. Be careful in handling them, as you are apt to get the disease yourself.

Ireatment.-Clip the remaining part of the wool off short enough to get the medicine down to the skin. A very cheap and effective remedy is creolin water, made by adding two teaspoonfuls of creolin to a pint of rain water. Shake well and rub in all over the body with a brush. Do this every second day until the disease stops and the wool starts to grow. If this should fail, there are regular sheep is for this disease which can be bought at drug stores; it is done up in package and it contains the full directions how tn use it. As soon as you notice the disease among your flock, separate the affected sheep from the sound ones, and thoroughly clean the stable out and burn sulphur in it with the doors closed.

\section{WOOL FALLING OFF SHEFP IN TBE SPRING.}

Causes.-From feeding on hot food, such as pea or wheat meal, and keeping them in a place that is too hot.

Symptoms. - In the spring, just about lambing time, the wool will become loose and fall off in patches. The animal does not seem itchy to any great extent, but will rub some.

Treatment.-As soon as noticed, change the feed and put them in a cooler place, being careful they do not catch cold, and, instead of the rich food, feed roots of some kind to get the blood cool. In very baul cases give:

Nitrate of Potash or Saltpetre.................... pound.

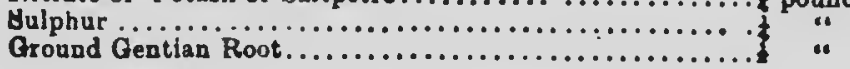


Mix well together and give a teasponnful on the tongues if the affected sheep every night. To prevent sheep froin loosints their wool, keep them in a cool place, feed chupped oats and plenty of roots, such as mangels, to keep the blnod cool.

\section{SHEEP TICKS.}

Sheep ticks are best got rid of about shearing time, by catcliing the lambs and sheep and giving them a good rubbing itil over with creolin water, using two tablespoonfuls of creolin to a pint of water, by rubbing it in well with a brush one dressing will generally cure the whole flock. If in other tumes of the year, it is best to use a regular sheep dip which call be bought at almust any drug store, the full directions are given in the package.

\section{MAGGOTS IN WOUNDS ON SHEEP.}

Maggots are a very common thing in sheep when they have a zound that has been neglected, or they will in some cases form around their bag when it has festered or bealed.

Treatment.- IVash the parts well with suap and warm water; then apply creolin lution, containing creolin, two tablespoonfuls to pint of water. The first time you apply the lotion put a good lot on to kill the maggots, then bathe twice a day and apply the creolin lotion to the parts each time after bathingr, until healed.

\section{DIARRHCEA IN SHEEP.}

This disease does not occur so often in sheep as it does in cattle.

Causes.-From a very cold drink when the animal is dry; trom a sudden change in the feed, or from eating anything that is frozen or very green, will sometimes cause it.

Symptoms.-- The sheep will be dull; will not eat much, and passes a thin, watery manure often, and the hind legs and tail gots wet and dirty looking.

Treatment.-Give the following :

Castor 0il $\ldots \ldots \ldots \ldots \ldots \ldots \ldots \ldots \ldots \ldots$ teacupful.

Tincture of Laulanum ............... ounce or I tablesponfunf.

Ginger ..........................

Comrion Sods...................

Mix in a half teacupful of luke warm water and give as a drench, then follow up with :

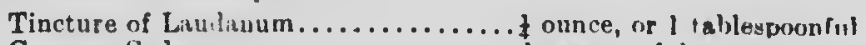

Common Soda......................

Mix in a half pint of luke warm water and give as a drench every three hours until the diarrhœa stops. In very bad cases 
add une-yuirter onnce, or one tablespoonful of tincture of catechy in each drench and this will make a sure cure. live luke warm water to drink with dry flour dusted in it to make a sort of a thin sruel.

\section{BITES FROM DOGS WORRYING SHEEP.}

Bathe the wound off with luke warm water and soap wice a day each time after bathing, then wipe dry and apply the white lotion and this will roon heal it up.

\section{SORE EYES IN SHEEP.}

Causes.-From something getting into the eye; from an injury to the eye; from getting cold in the eye, or anything that will cause it to be irritated.

Symptoms. - The eye is partly closed and water runs from the corner, and when you open the eye it is found to look red, very sore, and infimed, and may have a scum over it.

Treatment.-Catch the slieep and examine the eye, and it there is anything in it, remove it. To get the soreness and in. flanmation out of the eye, bathe twice a day with new milk or warm water, and then apply the eye wash mentioned amung the receipts in the back of this book in and around the eye. Keep this treatment up until it is all right.

\section{BROKEN LEGS IN LAMBS OR SHEEP.}

Causes.-From being run over by anjthing on the road, or from a kick or an injury of any kind that will cause a fracture of the bones. Providing that the fracture or break is so bad that the bones pierce through the skin, it is best to kill the sheep. If it is fat, butcher it and use it for meat. But if the fracture is not so bad and the sheep is young and you want to save it, set the bones to their place and apply a starch bandage, which is a bandage saturated in starch, and in drawing it out of the starch, draw the bandage between your fingrers, so as to scrape as much of the starch out of the bandage as you can, for it will harden quicker and better; then wrap it moderately tight around the leg over the place where it is broken, being sure to have the bones set straight, then have someone to hold the sheep and keep the leg utraight until the bandage hardens, after this the bandage will nold the leg to its place; leave the bandage on for a month or six weeks. Keep the sheep as quiet as possible during treatment. Watch the sheep's leg where the bandage is on for fear it would make the leg sore or be on too tight; if it should, change the 
ondage. Leave the bandage on until the sheep can walk on the leg all right, then cut the bandage off.

INFLAMMATION OF THE TESTICLES IN RAMS.

This is sometimes seen in rams and is caused from an injurg of some kind, such as the bunt of another sheep or a kick of some kind.

Symptoms.-This disease is very painful. The ram walks stiff; the bag will be swollen and sore to handle; he will not eat much, and lays down most of the time to relieve the testicles as much as possible. If the inflammation is allowed to run on the bag and testicles will become blackened and mortified; it will pass up the cords of the testicles into the belly and soon kill the ram.

Treatment.-As soon as the trouble is noticed, separate him from the rest of the flock; keep him in a quiet, cool place and poultice the bag with a hot poultice of half linseed meal and hran, change the poultice every three hours, and each time while changing the poultice bathe the bag with hot vinegar for a while before applying the next poultice. If the ram is fat give the following :

Epsom Salts ................... pound.

Tincture of Laudanum..................

Mix in half a pint of luke warm water and give as a drench. In cases where the bag festers and fo.ms matter, which you can tell by the feel of it, you can tell when it is ready to open by feeling for a soft spot in the bag, and as soon as you find the soft spot lance it to let the matter out, and continue poulticing until all the matter is drawn out and the ram seems better. After the inflammation is pretty well out poultice only about half the time.

HOW TO CASTRATE RAMS.

Throw the ram down and have him held firmly, take a sharr knife and make a cut lengthwise near the bottom of the bag so $i$ will not form a pocket afterwards, cut the hole large enough for the testicle to slip out, as soon as the testicle is out you wil notice where the covering is attached at the back part of th testicle, separate the covering from the testicle with your knife, pull the testicle up three or four inches and tie dtrong siring around the cord, tie it tight enough to stop the blood, leaving the ends of the string four or five inches lnng so they will hang out of the cut and not heal up in the bag, in a few days they will rot off the end of the cord and drop out themselves; 
as soon as this is done cut the cord off halt an inch below the string, then operate on the other testicle in a similar manner. As suon as both testicles are cut off fill the holes up with salty butter and let the sheep up. If he swells gfterwards bathe the hag and cuts with luke warm water and open the cuts by putting salty hutter on your fingers and run them up into the cuts. The main thing after castration is not to let the sheep get wet. In castrating young ram lambs, perform the operation in the same manner as in rams only it is not necessary to tie the cord, hat cut it off with a sharp scissors and this will stop it trom bleeding and be better than tieing. As soon as the cords are hoth cut off fill the hole up with butter and let the lamb go, and if it swells afterwards give it the same treatment that is given for swelling in rams after castration.

\section{CUTTING LAMBS' TAILS.}

This operation is generally performed on ewe lambs and on ram lambs that are being kept for breeding purposes; the operation is best done in the latter end of May when the lambs are from two to six weeks old. The best way to do this is, catch the lambs and have someone to hold them while you take hold of the tail to find the second or third joint; after deciding at which joint you wish to cut, place the knifo at that joint and cut it right off with one stroke, which is very easily d.nne. They usually do not bleed much, but if they do put some of Monsell's solution of iron on, with a feather, and if you have sot this, burn with a red hot iron by touching it to the end of the tail.

\section{LAMBING.}

Sheep are usually put in with the ram in the month of November, and a good way to tell when a ram has served a ewe is to shake dry red paint on the ram's breast and when he has served a ewe the paint will be on her back. The length of time the ewe carries the lamb from the time the ram served her till she is delivered is five months.

\section{SIGNS OP LAMBLNG.}

In the young ewe about the third month she commences to to make a bag; in the old ewe it is about the fourth month whe she begins to make a bag; after this time the bag keeps getting larger until a day or so before she lambs; her bag and teats get hard and full for a few hours before lambing; she is very cross to dogs and 


\section{THE VETERINARI SOIENOE.}

other animals; her eyes have a wild look and she tries to get away by herself; finally the labor pains come on and she seems in Ereat pain, the water bag soon appears and breaks, then if the lamb is coming all right the front legs and head will come out and she will soon be delivered of her lamb.

\section{TROUBLES MET WITH IN LAMBING.}

Sometimes the lamb will bo coming with the front legs out and the head turned back. In a case of this kind, raise the ewe's hind end up high, then oil your hands and shove the front legs back, and pass your hand inside and turn the head straight, then draw on the head and legs and it will come all right. Sometimes a lamb will be coming with only its head and neck out, the front legs being turned back inside, in this case raise the ewe's hind end up high, oil your hands and shove the head and neck back into the womb and straighten the legs, then draw gently on them and the head and it will come, all right. Sometimes one front leg and the head will be out; the lamb cannot come in this position; raise the ewe's hind end up high and shove the leg and head back in to the womb and straighten the leg that is bent back and bring it up with the other leg and the head, then it will come all right. Sometimes in a case where there are twin lambs, a leg of each will be out, in this case watch when you shove them back and be sure you get hold of the two legs that belong to the one lamb, because sometimes a mistake is macie and they draw on a leg of each lamb and injure both the lambs and ewe. Sometimes the ewe will try to lamb but nothing will come-the only thing you can feel in the passage is the tail and rump of the lamb; the trouble in this case is, that the lamb is coming backwards with the hind legs turned forward under it. In this case raise the ewe's hind end up high, oil your hand and shove the lamb upwards and forwards in the womb, ther. slip your hand down along the hind leg of the lamb until you can hook your finger around it, then draw it upwards and then backwards until it sticks straight out in the passage, as soon as you have this leg up do the same to the other, and when you nuve both of them up, draw the lamb out backwards. When you find a lamb coming backwards nover attempt to turn it, for this is impossible in the ewe, but take it away backwards. As soon as a ewe has lambed get her on her feet to allow the lamb-bed or womb to go back to its place, also try to got her to lick the lambs. Sometimes in young ewe whero 
the passage is so small you cannot get your hand in, you will need a boy with a small hand to turn the lamb, while you instruct him. Sometimes the ewe will try to lamb and the neck of the womb will remain closed, not allowing the lamb to come nut; in this case medicine will have to be used. Give the following:

Epoom Balt .............................. pound.

Fluid Extraot of Bolladonna.......................... 15 drops.

Mix in a half pint of luke warm water and give as a drench, then follow up wi: he following :

Fluid Extraot of Lelladonna ....................15 dropa.

Mix in a half pint of luke warm water. Gi a this drench every two hours until it acts on the neck of the womb and opens it so she can lamb without difficulty.

\section{THE CLEANING NOT COMING AWAT AFTER LAMBLIG.}

In a case of this kind give the ewe a hot drink, and then leave her alone, allowing her to lie down, and if it does not come way then, give :

Epoom Salts...................... pound.

Sweet Spirits of Nitre................ 1 ounce, or 1 tablerpoonful.

Fluid Eirtract of Belladonns..........15 drops.

Mix in half a pint of luke warm water and give as a drench, and as soon as the medicine operates it will lousen the cleaning and it will come away all right.

\section{LAMB BED TURNED OUT.}

Causes.-From a ewe, after lambing, lying with her hind parts too low, and the womb gets shoved up in the pelvic or hip cavity, which causes her pain, and on account of this she commences straining and does not stop until she turns the lamb bed inside out.

Symptoms. - The ewe seems very weak and will generally be lying down with the bed out behind. The bed is about as large as a man's head and is covered all over with little processes like buttons; it is to these little buttons the cleaning is attached.

Treatment-As soon as noticed, if there is any cleaning attached to the button-like processes, take it off, then bathe the bed well with luke warm water and place a sheet or clean bag under the bed to keep it up and also keep it clean. Have a man on each side to hold the hind end of the sheep up, and, having your hands well oiled, start to turn it in. commencing at the vulva and keep turning it in until it is all in the passage, then shove the womb back to its natural place with your hand before you leave ic. With a needle and twine used for sewing wounds, put two or 
three good stitches in, leaving only enough space for her to make her water through, and in a day or two, when she is all over the straining, take the stitches out. After the womb has been returned she will likely strain some; to relieve this, give the following :

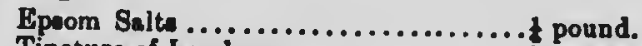

Tincture of Laudanum.................

Fleming's Tincture of Aconite.........3 dropa.

Mix thoroughly and give as a drench. After this, givo a warm bran mash, and give the following drench overy hour until she is through straining:

Tincture of Landanum............... ounce or 1 tablenpoonful.

Fleming's Tincture of $\Delta$ conite............ dropa.

Mix in half a pint of water and give as a drench.

INFLAMMATION OF THE MILK BAG (GA RGET).

Causes.-This is generally noticed after lambing by getting cold, or from an overfiow of milk; from an injury; or sometimes, when a ewe loses a lamb, from not being milked enough will cause it.

Symptoms.-The bag becomes largely swollen with milkis hard, hot, tender and inflamed. The ewe seems feverish and is in pain; if you try to milk her this stage, only a watery, curdy milk comes out. If it is not checked now, the inflamed part of the bag will commence to fester and form matter, and will either break or have to be lanced. Sometimes, instead of the bag festering, it becomes mortified, and if not checked, the mortification will go up into the belly and kill the ewe.

Treatment.-It is always best, if a ewe loses a lamb, or when the lambs are being weaned, to watch the bag and milk her out once in a while until she goes dry. When the bag is swollen and inflamed, milk her out once or twice and bathe her bag three times a day with warm water and vinegar, and in a day or so she will come all right. When it has been neglected until it festers, watch the bag and keep bathing it with warm water and vinegar. As soon as a soft spot comes in the bag, lance it to let the matter out, then continue buthing and applying the white lotion twice a day until all the swelling is gone and the bag is healed up. In cases where the bag becomes mortified, give it lots of bathing with warm water and vinegar, ald keep applying white lotion three times a day, each time after bathing, until the mortification is checked, and then the mortified part will separate from the 
healthy part in the course of time, and drop off, then bathe well with warm water and soap twice a day and apply white lotion each time after bathing. As soon as it is healed up it is best to fatten the ewe and butcher her. During treatment, feed well and take extra care of her to keep her strength up until she gots botter.

\section{DISEASES OF YOUNG LAMBS.}

WEARNESS.

Causes.-Sometimes, where the ewes have been poorly fed, not getting any grain, and has a couple of lambs, the lambs will naturally be weak and unable to stand, and seems very dumpish; or this weakness may be caused from a lamb coming on a cold night and getting a chill; or where a ewe has bother lambing and the lamb has to he pulled away.

Treatment.-If it is a cold night, take the lamb where it is nice and warm, and give it a good rubbing until it is perfectly dry, and pour down with a spoon the following:

Whisky ................................ I tempoonful.

Mix in a tablespoonful of its mother's milts. Give this amount every hour or two until it is strong enough to suck.

\section{CONSTIPATIOK.}

This is where the young lamb's bowels got stopped.

Causes. - Sometimes from a lamb getting cow's milk in its full strength. Cow's milk should be weakened down about onethird by adding water and sugar before giving it. It in noticed in lambs sometimes, when no causes can bo given.

Symptoms. - The lamb seems to be a little fuller at the sides than natural, is dull in appearance and keops straining occasionally as if trying to pass something from the bowals-but nothing comes. Soon it gets in pain and refuses to suck.

Treatment. - Give the followine:

Raw Linseed Oil .........................., I tablepecahl

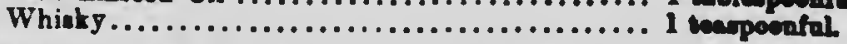

Mix this in a tablespoonful of the ewe's milk and pour $t$ down with a spoon once a day until the bowels seem all right. Give an injection of half a teacup of luke warm water and a little soap into the back bowel with a small syringe three times a day until the bowels move, also keep the lamb good and wan 


\section{DLARRBCEA.}

Causes.-Sometimes from a chill, or from the milk not agree. ing with it.

Symptoms.-The lamb will often pass a vatery manure from the anus, and the tail and hind legs soon gets wet and stick:" The lamb will not suck and seems quite dull, and soon becomes very weak if the diarrhcea is not checked.

Treatment.-Give a teaspoonful of whisky and one of castor oil in a tablespoonful of its mother's milk, mix and shake well and pour it down with a small spoon. If not relieved in four hours, give five drops of tincture of laudanum and a teaspoonful of whisky mixed in a tablespoonful of the ewe's milk. Give this with a spoon, being careful not to choke the lamb; repeat this dose every four hours until the diarrhoa is checked, also be sure and keep the lamb in a warm, comfortable place until it is all right. As well as attending to the lamb in those cases, see that the mother's bag is kept milked out so it will not become inflamed.

FOOT ROT II SHEEP.

In some parts of the country this is a very common disease and resembles foul in the foot in cattle

Causes.-This disease is sometimes brought on from the feet growing too long and splitting up and setting up inflammation in the feet. Sometimes when they are pasturing on a low, damp, pasture from continually getting the feet wet, it irritates the foot and sets up the disease. It may be caused from the sheep walking through mud or dirty places, and the mud or dirt getting up between the trotters and getting hard, which irritates the foot and sets up the disease. In some localities this disease is of an infectious nature, that is to say, where the matter from the feet of an affected sheep gets on another sheep's feet it will set up the disease.

Symptoms. - The sheep are lame and stiff when walking, and if the disease runs on the feet will swell and little boils will form around the top of the hoof, which break and run matter, and the sheep will become exceedingly lame. If the disease is allowed to run on for a time, the hoofs become loose and fall off, and the sheep will then die from exhaustion. When one sheef becomes affected, the same cause will usually affect more; so you see it is advisable to try and find out the cause and remove it, for the same cause that brings it on in one sheep is likely to bring it on io all of them 
Ireatment.-Separate the atfected sheep tron the suund unes and put the affected ones in a quiet, dry place, and if it is caused from the sheep being in a wet place, remove tho sound ones to a dry field. Catch the affected sheep, lay them on their sicle, and bathe the feet well with luke warm water and soap, cleaning all the dirt from between the trotters. As soon as you have bathed the leet, poultice them with a hot poultice of half linseed meal and bran; leave the poultice on all night, and poultice every night until the sheep is better. Each time before putting on the poultice, and after taking it off, dress the foot with white lotio: with a few drops of carbolic acid in it. If this does not effect a cure, then try the following mixture:

Sweet Oil

Carbolis

as...............2u drops. poultice an the lotion before putting on the poultice and after taking it off.

\section{CHAPTER 11.}

\section{DISEASES AND TREATMENT OF PIGS}

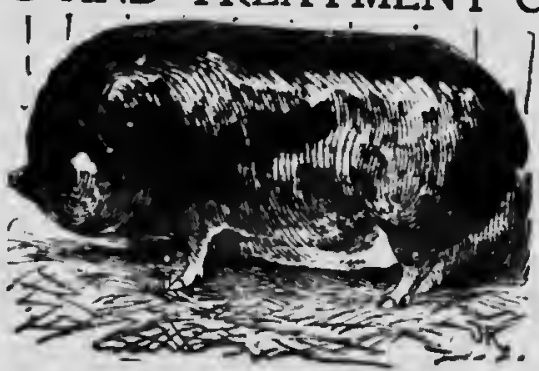

nys are not whject to as ms.ly diseases as cattle or shoep CBorung.

This is not very common thing in pigs, but is sometimes met with when they try to swallow some hard substance which i, too large for the throat.

Symptoms.- The pig keeps coughing, and saliva runs from the mouth; when it tries to eat or drink, the food or water wili run back out of its mouth, and if it does not get relief will soon die.

Treatment.-Pour down a little raw linseed oil. and then il you can feel the obstriction in the tube along the neck, try and work it around with your hand to get it to slip down. If th. 
obotruction is caught in the back part of the mouth, remove it by prying the mouth open with a stick and u urking it out with another stick or a long pincers. If the obstruction is so solid that you cannot get it out or rub it down after giving the oil, take a probeng, which is used for cattle when choking, and pass it back through the throat into the cesophagus, and push the obstruction down into the stomach. Before attempting to pass the probang. cie rope around the upper part of the mouth and have the head held up, then place the gag across the mouth (the same as is done when cattle are choking) and run the oiled probang down.

SORE THROAT.

This is more often met with in young pigs from three to six months old, but may occur at any age.

Causes.-Generally from getting cold; by changing from a warm to a cold pen; or from getting wet in cold weather.

Symptoms.-The pigs will sneeze and cough; in drinkiug, the water will run out through the nose; the throat will be swollen and sore to press on. When one pig becomes affected others generally get it from the same cause.

Treatment.-Make the pigs as comfortable as possible, by having the pen dry and lots of bedding in it. Feed on soft, warm food, with a large tablespoonful of sulphur in it, which will be enough for six small pigs. Give the sulphur twice a day. When the pigs get so bad that they do not even attempt to eat, take a quarter of a pound each of sulphur and nitrate of potash or saltpetre, mix together and throw half teaspoonful back on the tongue three times a day; this will gargle the throat. Rub white liniment around their throats each time you give the medicine, and if it is a valuable pig, and a bad case, poultice the throat with hot poultices of half linseed meal and half bran. Change the poultice every couple of hours until the pig is better.

\section{ACUTE INDIGESTION.}

This is where the stomach is distended with food and gas. It is mostly seen in pigs six to twelve months old.

Causes.-Generally from a pig that is poorly fed getting into a field of peas or grain and getting a big feed, or sometimes when the pigs are not used to grain and on being brought in to fatten they are given a large feed of peas or wheat which will sometimes sot up this disease. 


\section{DIERAGT AND TREATMEAT OF PIGS.}

Symptoms. - The pig refuses to eat, seems bloated, very un. easy, and in pain. If the sickness is after any of the above causes, you may then be sure it is acute indigestion.

Treatment.-The dose for a pig from six months to a year old is as follows :

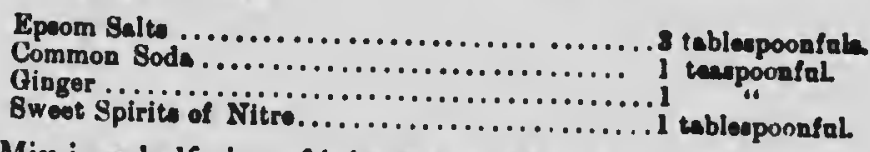

Mix in a half pint of luke warm water and pour down the pig after it has been caught and turned on its back. Five only luke warm water to drink and no feed until the medicine operates. If it is not better the next day repeat the dose. In giving the drench do not pour it down too fast for fear of choking the pig. If the cause is from getting a large feed of wheat or peas it sometimes swells so much that it ruptures the stomach, in this case nothing can be done. As soon as the rupture takes place the pig soon dies; if you want to be sure of it being a rupture, open the pig and you will find a hole in the stomach.

\section{STUNTED OR CHRONIC INDIGESTION.}

This is a common thing in young pigs where they are being weaned and started to feed and before they get used to it they are fed on strong food such as peas, wheat and corn ; this is too much for the young pig's stomach and sets up indigestion. It is also caused from worms. or thrive.

Symptoms.-The pig seems to ent plenty but does not grow

Tratment.-To prevent this disease from coming on pigs, when they are being weaned they should nover be fed on hard, hot "ed, but should get milk and swill until about three months old, th. in bring them gradually to hard foed by giving a lixtle at a tim: In young pigs, they are so much troubled with worms that they should get a handful of hardwood ashes and charcoal put in the feed twice a week, one handful being enough for six young pigs, also give them plenty of salt, for pigs getting ashes, charcoal and salt in this way seem to thrive half as well again When tho pigs are stunted change the feed from har: * and for six pigs give ot:

Buiphur

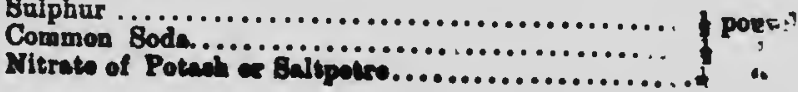


Mix thoroughly and giv 1 tablespoonful in thelr feed night and morning until they begin to thrive, also give them plenty of handwood ashes, charcoal and salt in their feed, as is explained above.

\section{CORSTIPATION.}

Thlo lo llable to affect pigs at any age, but is more often noticed to affect sicurited pigs.

Causes.-In young pigs it is generally caused from chronic indigestiol:, or worms in the stomach, while in older pigs it is caused from feeding on dry food without getting exercise, that is, being kept in a small pen.

Symptoms. - The pigs are very dull; refuse their food; lie down most of the time, and seem fuller than natural; they will strain to pass something but nothing comes. In young pigs, they will not thrive well; the rectum, or back bowel, will be bulged out, and in some cases will be turned out entirely; they seem full and do not eat as they should, and if not attended to will become stunted and pine away until they die.

Treatment.-In young pigs, catch them and pour down a tablespoonful of Epsom salts and a ha!f teaspoonful each of ginger and common soda dissolved in half a teacupful of luke warm water; give this every day until the bowels get nice and loose; after the physic, continue the treatment by giving the hardwood ashes, charcoal, sulphur and ealt, as recommended in chronic ind: * stion. In older pigs, give:

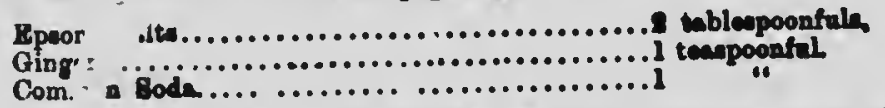

Dissolve in a teacupful of luke warm water and pour dowe as a drench, after catching the pic and turning it on its back; also give the hardwood ahes, charcoal, sulphur and salt a mentioned in chronic indigestion. In aged pigs (that is where they are two or three jears old) use the same treatment as in riven for medium aized pigs, only give a larger dose. They can stand about a quarter of a pound of Epsom salts with a teaspoonful of common soda and ginger dissolved in a pint of luke warm water; repeat this dose every second day until it works the bowels. As well as giving the medicine, give them exercise every day which will help the physic to operate. 


\section{DIARRHCEA.}

This is the very opposite of constipation.

Causes. - It is generally caused trom a sudden change In the food; from eating something that is frozen; or from excitement by being chased.

Symptoms.--The manure runs away like water; the pig is dull and refuses to eat its food, but is very thirsty and greedy to drink.

Treatment.-Change the food, and give a gruel drink of

Dry Flour. ............................... teacupful.

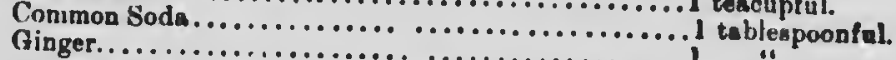

Mix in a half pail of luke warm water and give as a drink three times a day. The above is the proportion to give six small pigs. In a case where it is in young pigs sucking a sow, give the sow

Dry Flour............................... teacupful.

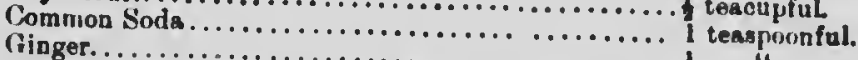

of

Mix in a half pail of luke warm water and give three times day. As well as the above treatment, keep the pigs warm, dry and clean, and they will soon get all right.

\section{WORMS.}

This is mostly seen in young pigs.

Symptoms. - The pig eats plenty but does not seem to thrive "ell, and sometimes you will sce small worms pass away in the manure.

Treatment. - Give a handful of charcoal and hardwood ashe: in the food twice a week; also give halt a tealspoonful of sulphur lor each pig twice a day in their food and this will generally kil the worms.

TURNING OUT OF THE RECTUM OR BACK BOWEL.

Causes.-This is genertly caused in young pigs by getting dry food to eat, and the bowels become costive, and while straining to pass manure, it turns the back bowel out; or where pigs rise on their hind legs with their front feet upon the front of the pen every time you go to feed them; or from going to jump a low fence and getting cauglut, and whle lying with the belly over the fence, the back bowel hecomes turned out.

Symptoms.-- There is a bulging unt of the back bowel from half the size of a hen's egg to even larger than a hen's agc, 
which will be red and angry looking, and after a time become bleckened.

Treatment.-As soon as noticed give the back bowel a oyringing out with luke warm water and soap so as to clean any hard manure out of it, then wash it off clean and oil the bulged out part of the bowel and shove it back to its natural place. As soon as this is done, if it is a small pig, give a tablespoonful of epsom salts mixed in half a teacupful of luke warm water and pour down as a drench, and give one-half teaspoonful of sulpl:ur mixed in sloppy feed twice a day, this will keep the bowels free and the pig will generally be all right. Have the pig fastened in its pen so it cannot jump up on its hind legs; in a case where the bowel is blackened or comes out two or three times after purting it in, do not return it but leave it alone and the piece of dead bowel will drop off of its own accord, and the pig will be all right in a week or so, but give the physic and sulphur as mentioned to keep the bowels loose.

\section{BLIND STAGGERS.}

This is a disease that affects the brain and nerves.

Causes.-From pigs being kept in a dirty, ill-ventilated, poor. ly drained, small pen. The blood gets in such a bad state that it becomes stagnant. This disease is mostly seen in pigs under a year old.

Symptoms. - The pig will be dull, stands in a corner with its ears lopped over, will not eat, and when it goes to walk will run against anything in its way. In a short time, the ears, nose, and around the head turns to a blue color which is caused by the stagnant blood. The bowels are costive, and the pig becomes duller and duller, until convulsions come on-and it dies. When one pig becomes affected in a pen where there are thirty or forty pigs kept, what caused it in that one will cause it in the other pigs, and we have seen cases where farmers would have lost half a dozen pigs in a few hours, so when you find the disease is affecting your pigs, let them out of the pen where they are kept into open air, and clean out the pen thoroughly.

Treatment.-As soon as one pig becomes affected let them all out of the pets intustre open air for a few hours, and afterward put them in a clean pen. In treating the affected one, drag it out into the open air and rub it well with cloths to get the circulatios started, and give the following : 


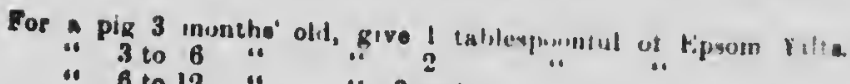
"6 to 12 " " $310+$ ".

As well as this put from a teaspounful to a L I-spoconful or two (according to the age of the pig) of good, andy. also a teaspoonful of ginger and common soda in the drench. Dissolve in half a teacupful of luke warm water, and pour dint $n$ the pig as a drench after turning it on its back. As soon as the drench operates it will relieve the pig. In some cases persons hale been known to cut off the ears and tail with a view 'o greting the circulation of the blood started, but the hand ruboing is better and is not so cruel and does not disfigure the pig.

\section{FOUNDER OR SORE FEET.}

Causes. - This is a very common thing in $P \mathrm{gs}$, especially when fattening them and feeding them on hard, Iry feed, when they are in a small pen with very little straw we heor. Driving them on a hard road or from getting a feed wheat when not used to it will cause it.

Symptoms.-The pig will be dull and lie most of the time and when it moves around it is so sore on its front feet that it walks with its hind feet well under it with the front feet stuck out ahead of it, in some cases the feet are so sore that the pig squeals when it is forced to put its weight on the front feet. From the severe pain of the feet and not being able to get around to eat its food it soon falls off in condition and becomes very gaunt.

Treatment. If it is in the summer time, turn the affected pigs out where they can root in the ground, and pour water in the hole where they lie every day to keep the ground wet, as this will help cure the sore feet, as well as this mix half a pound each of sulphur and nitrate of potash or saltpetre, and give a ter. spoonful of the mixture in a slop twice a day to each of the affected pigs. If it is in the winter time, keep the pig in a warn, dry place. Give it a physic of Epsom salts (use the propurtion given in blind staggers), feed light and give the mixture is ove mentioned, also poultice the front feet every night and the pig will soon get all right.

WÖUNDS.

Canses. - From a bite of a dog or other pigs ; frew. golng through a barb wire fence and getting caught on a barb, or froir running against a nail and tearing itself. 
Treatment.-Where it is a very bad rip or tear, it is best to catch the pig and sew it up with the same kind of a needle and thread as is used to sew up wounds in horses. Put the stitches three-quarters of an inch apart, then fill the wound up with green salve; let the pig go and it will soon heal up, for pigs' flesh heals very quickly; but watch the wound that maggots do no get in it, if they do, wash the wound out well with luke warm water and soap, then apply the white liniment to kill the maggots, and fill the wound up with green salve and it will soon heal up.

\section{castratukg.}

Old boars can be castrated at almost any time of the year, but it is said that the colder the weather the better, as long as the weather is dry and they are kept in a dry place. Catch the boar, turn him on his back and tie him securely with a rope so he cannot get up or hurt you, then take hold of the testicle with the left hand, and with a sharp knife in the right hand make a iut in the bag large enough to allow the testicle to come out; make the cut in the underside of the bag so it will not form a pocket afterwards. As soon as the testicle is out, separate the covering from the testicle, where it is attached to the underside, by cutting it off. Pull the testicle and cord out three or four inches and tie a strong string tightly around the cord to prevent it from bleeding; leave the ends of the string four or five inches long so they will hang out of the cut. As soon as the cord is tied, cut the testicle off half an inch below where it is tied, then operate on the other testicle in the same manner. If it is a young boar you are castrating, instead of tying the cord with a string, cut it off with a sharp scissors and this will stop the bleeding. In very young pigs, after the testicle is out scrape the cord with a knife until it is worn off, or cut it off with a sharp scissors. In all cases after you are through castrating the pig, and before you let him up, fill the cuts where the testicle comes out of with salty butter. If the cuts swell much and the pig seems stiff and sore in a few Jays after he is castrated, catch him and open up the cuts with come butter on your finger and allow the matter that has formed in the bag to run out; this is one thing that should never be coglected after castrating any, animal. 
BOW TO CASTRATE PIGS THAT ARE RUPTURED IN THE BAG.

Causes of Rupture_-Generally from a young pig standing on Its hind feet with its front feet up on the front of the pen when you go to feed them; in other cases it is noticed as soon as it is pigged.

Symptoms of Rupture-The bag is enlarged by the bowels coming out into it, and when you catch the pig and press on the enlargement, you can press the bowel back into its place, but as soon as you let go it will fly out again.

How to Operate.-It is best to castrate ruptured pigs when they are young-about five or six weeks old. If it is a large boar, starve him for twenty-four hours before operating, so his bowels will be empty, for they will slip back to their place easier while'you are castrating him. Have help enough to hold the hind end of the pig well up while you press the bowels back, which is easily done when they are empty, and his hind end being higher than his front they will stay back better while you are operating on him. Take the testicles out in the same manner as you would a pig that was not ruptured, only make the cuts as mall as you can. After each testicle is out, sew up the cut with a needle and thread (the same as used for sewing up wounds); put the stitches in about one-quarter of an inch apart, so the bowels cannot slip out. If it is a small pig, let him run with the others; but if a large pig, keep him in a quiet place and do not give him much to eat for few days until the cuts swell, which will keep the rupture back. Leave the stitches in until they rot out of their own accord.

\section{BLACK TEETH IN TOUKG PIGS.}

These are very small black teeth which are found in the sides of the mouth when young pigs are pigged, and continue growing for some time, but after the pig gets larger they drop out of their own accord. These teeth sometimes grow in such a manner that they cut and poison the tongue and make it so sore that they cannot eat, and in a little while, if not attended to, the tongue becomes so badly swollen that often the pigs will die from starvition and blood-poisoning. We have seen cases where three or four piuss in ane litter died from black teeth.

Treatment. Citch the young pigs and examine each one of then, and if they have hlick lecth, pull them out with a pincere and they will soon be all right. It is a grood practice to catch and 
examine a litter of young pigs, for if the black teeth are taken out in time it will often prevent some of them from dying before you notice them sick.

\section{LICB OI PIGS.}

These lice are large and resemble ticks on sheop, only they can run very fast. We have seen cases where the pigs were literally covered with them. Pigs that have lice on them do not thrive well, and they are a great preventive to fattening pigs, because they irritate and cause them to be continually rubbing and scratching themselves.

Treatment.-Wash the pig well with creolin water, which is a sure, cheap and simple remedy. The strength of creolin to be usad is two tablespoonfuls to a oint of water. Rub the creolin water in all over the pig with a stiff brush. It generally takes two washings to make a complere cure; the second application is to be put on about a week after the first one. As well as this, clean the pen thoroughly, shake lime around the floor, and put fresh, clean straw in for them to lie on.

\section{FRACTURE OF A PIG'S LEG.}

Causes.-This may be caused in various ways, such as being hit by a stone, being kicked, or from getting the foot through a loole in the floor and giving the leg a wrench.

Symptoms.--The pig cannot use its leg in walking; it will hang loose. If you take hold of the leg and twist it you can hear the ends of the broken bones grating on each other.

Treatment.-If it is a fat pig, and about ready to kill, it is best to butcher it. If it is a pig you want to save, and the ends of the broken bone are not out through the skin, try and treat it. Take a long bandage, soak it in starch (same as is used for starching clothes), when you are drawing the bandage out of the starch, draw it between your fingers and scrape it with a knife to get as much of the starch out as you can, so it will harden quicker; roll the bandage up so it will be handy to put on the leg, then set the broken bone to is place, and put the bandage on the leg moderately tight. After it is on, hold the leg and bandage straight until the bandage hardens, after that it will hold the bene to its place. Keep the pig very quiet, and feed it so it will not have to stir around. Leave the bandage on for three or four weeks, until the pig can use the leg all right, then remove the bandage by cutting it off. If tle break is in the hip, or sunie 
place where you cannot bandage it, leave the pig in a very quiet place, and sometimes the broken bone will knit together itself.

\section{BROKEN BACK IN PIGS.}

This is very often seen in sow's when they are very thin and weak after suckling pigs. It will happen very easily sometimes; a very little tap on her nose will sometimes break a sow's back; getting hit over the back, slipping, or from snmething falling and hitting her over the back will sometimes cause it. It may occut in other pigs in the same manner, but they are not so liable to be hurt as weak sows just after you wean the little pigs.

Symptoms.-All at once she will loose power of her hind quarters and drag them after her. If you prick the hind parts with a pin she cannot feel it, and will lie there quite helpless.

Treatment.-Put the sow in small, clean fen with good bed, and feed her so she will not be hungry and try to move around. Give one or two teaspoonfuls of sulphur a day in her feed to keep the bowels loose. Keep her as quiet as possible and she will probably get well in the course of time.

\section{HOG CHOLERA.}

This is an infectious blood disease, and is sometimes called anthrax; it is noticed to break out in herds of hogs all over the country.

Symptoms - The first symptoms are dullness, drooping of the head and ears, loss of appetite, and the pig will go away by itself to lie down; the pig seems very feverish, hot, and in some cases will lie quiet and die very suddenly, while in other cases, as the symptoins advance, the pig has pains in the bowels, will lie on its side, moan with pain, then jump up, run around, squeal and grunt in a very painful manner. The pig at times gets easy spells and becomes quiet; if you catch and examine it you will find that the skin of the belly, thighs, front legrs, throat, and around the nose will be of a purple color, and in some cases on account of the high fever, the skin breaks out in a rash. In the last stages of the disease there is diarrhœa, and the manure which is very thin, is of a black color and has a veiy bad smell. The pig rapidly loses strength, gets a cough, berins breathing very heavy, and in a few hours is so weak it can hardly stand. In sume cases the pig dies in from six to ten hours after being smitten with the disease, while in other cases it lives for a few days. The rash that comes 
sut on the skin soon causes it to slough, and the skin will drop of in places, giving the animal a bad appearance-and will soon die. Although this is a very fatal disease and most of the pigs die that are affected with it, occasionally we have a case get better when the treatment is taken in time.

Treatment.-As soon as any of the pigs are noticed sick, separate the sick ones from the others that are not sick, and put them in a dry, clean pen, and give the following medicine to each pig, using your own judgment as to the proportion to give the different sized pigs :

Epsom Salts . .................... \& to tablespoonfuls.

Sweet Spirits of Nitro.............. teaspoonful to 1 tablespoonful.

Sulphur......................

Mix in half a teacupful of luke warm water and pour down a: a drench after turning the pig on its back. If this drench operates on the bowels before the disease gets too bad, it will often save the life of the pig. If this disease breaks out in you herd of pigs, send for the government veterinary inspector; he will come and examine the pigs to make sure about the disease and help you to prevent the disease from spreading.

\section{UIFFICULTIES net WITH IN SOWS PIGGING.}

Th: average time it takes a sow, after being put to the boar, before she has pigs is three months, three weeks and three days. In a month and a-half after being put to the boar, she begins to get larger and continues getting larger until pigging time. Just before she pigs she is noticed to be uneasy, and starts to make het bed: if anything disturbs her she makes $a$ fuss and seems excited. After her bed is made she seems sick and lies down for a short time, then the labor pains come on-she will strain and the water bag will appear and break, if the pigs are coming all right, she will soon be delivered of one; the front feet and head should come first but sometimes they come with the hind feet first; in a few minutes more she will strain again and another pig will be delivered, and so on until they are all delivered. After this there is "1sully no trouble unless the sow has too much bedding and she s thers the little pigs. Sometimes, when a sow is pigging, a pig will conie crooked and get lodged in the passage and she cannot pig without "Ittle assistance. The pig inay be coming head first with the front feet turned back, or coming with its hind end first and its legs turned in under it, and all you can feel while examin- 
Ing is the tail and rump. If the sow is large enough for you to pass your hand into the passage, oil your hand and pass it up; If the front legs of the little pig are turned back shove it back into the womb; catch the legs with your finger and bring them up even with the head, then pull on the legs and it will come all right. If it is coming backwards, and the hind legs are turned under it shove the pig back into the womb and straighten out the legs so as to have the hind feet coming first. In case the sow is too small for a man's hand to $g \circ$ into the passage, get a boy that has a small hand and have him oil it and pass it up into the pasage, and by you telling him what to do he can bring it away all right. In working with sows lways keep your hand well oiled, and try and not bruise the passage, for it will swell and make it worse for you to work at.

\section{FEVER IN SOWS.}

This disease is occasionally met with in sows, but the causes of it is not clearly understood.

Symptoms.-They are generally noticed as soon as the sow is through pigging, when the little pigs go to suck they cannot get any milk; if you try to milk her no milk will come; the teats are soft instead of being full and hard, showing that there is no milk being secreted in the teats, the sow seems very sick, is feverish and does not take notice of her little ones, nor eat, b: it is very thirsty and will drink great deal if she can get it to drink.

Treatment. -Give the following for a large sow :

Epeom Salt ..................... pound.

Sweet Spirite of Nitro............... onnoe, or 1 tablenpoonful.

Ginger.......................... thenponful.

Mix in half pint of luke warm water and pour down as a drench, arst turnlng the sow on t back and prying her mouth open with a otick to get the drench du wa. After giving the drench follow up with the following powder:

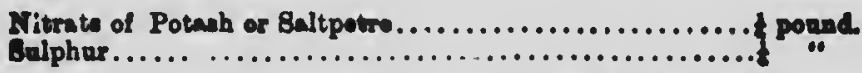

Mix thoroughly, and for a large sow, give a teaspoonful on ber tongue with a spoon twice a day, or in soft feed. Give her plenty of luke warm slops to eat, bathe her milk glands three times a day with luke warm water, rub the parts dry each time after bathing and keep the little pigs sucking to try to bring her back to her milk. By attending to her in this way for a few days she will get all of While the sow is sick keep the little pigs alive by feeding 
Them milk from a newly calved cow: weaken the milk down onethird with luke warm water and weeten it with sugar, pour this down with a spoon, or let them suck it out of a bottle, also keep them sucking the sow as much as you can.

\section{INFLAMMATION OF THB MILI GLADS IN $\triangle$ SOW (GARGBT)}

This is generally noticed right after pigging.

Causes.-From catching cold, or from losing some of the pigs and not having enough left to keep the bag sucked out, and on account of this the glands get so full of milk that they swell become sore and inflamed.

Symptoms.-The sow seems dull, feverish and does not care to eat, and when the pigs go to suck her it causes pain and they do not get much milk. On examing her the milk glands will be found swollen, hard, hot and tender.

Treatment.-Give the same medicine invardly with the same directions as is given for the treatment of milk fever in sows, besides this bathe the milk glands well th-ee times a day with luke warm water and vinegar, each time after bathing rub the glands dry, and in severe cases where the young pigs are not sucking lier, rub the glands with white liniment, and after putting on the the lininent oil the paris with oil or lard to soften the glands and keep the liniment Irom blistering. In cases where the disease runs on, and the glands fester and form matter, they will have to be lanced to let the matter out; then treat by bathing with luke warm water and soap twice a day, and apply the white lotion each time after bathing until the glands heal up. In bad cases it is best to wean the young pigs.

PIG BED OR WOMB TORNED OUT.

This is generally noticed right after pigging, where the sow is left lying with her hind end lower than her front, which causes the pig bed to work back into the passage, and when it does, it causes her pain, and she starts to force and forces the pig bed inside out.

Symptoms.-The womb, or pig bed, is turned out behind, which is larger than a man's head, and in a very short time becomes very red and swollen, and is a miserable looking sight; it should be put back as soon as noticed before it swells much.

Treatment-As soon as noticed, bathe the womb well with luke warm water to take the swelling down and make it clean and 
wru, then aswe a cusuple ul IIIen to raise the sow's husul end straight up while you start turning the womb in at the passage, and keep turning it in until it is all in the passage; then oil your hand and arm, if the sow is large enough for your hand to pass into the passage, but if not, get a boy with a small hand, and press the pig bed right hack into its place. As scoon as you have done this, sew up the vulva or the opening of the passage to the womb; put two or three stitches across it; put them in good and leep, just leaving space enough at the bottom for her to make water. Leave the stitches in for a day or two until she stops straining, then cut the stitches, pull them out and she will be all right. After you have put the bed back, if she keeps straining, give her the following:

Tincture of Laudanum...............t onnce, or 1 tablespoonful.

Sweet Spirit of Nitre................... onnce, or 1

Fleming : Tinctura of Aconite. ........2 to 3 drops.

Mix in a teacupful of luke warm water and pour down as a drench, after turning her on her back and prying her mouth open with a stick. If she does not get relief in two hours, repeat the drench, and keep repeating it every two or three hours until she is all over the straining.

HOW TO RITG A PIG.

The object of ringing pigs is to keep them from rooting. The best way to ring them is to first make a noose on the end of a small rope, slip the noose into the pig's mouih, draw it tight on the upper jaw, and have the rope over a beam or something to draw the pig's head up tight; have a pincers and ring, which can be obtained at any hardware store, place the ring in the pincers, and while the pig is pulling back, close the ring on its nose so as to catch about one-quarter of an inch of Eristle; this is done by pressing on and closing the handles of the pincers. Be c"riful not to put the ring back farther than one-quarter of an $: . c h$, ali: see that there is no rust on the ring before putting it in. Put i:l from one to three rings, according to the size and age of thi pig. If the nose should fester after ringing, it is best to take the ring out.

\section{FITS IN YOUNG PIGS FROM WORMS.}

Symptoms.-The pig is first noticed not to be thriving well, and after a time is noticed to take fits, its legs begin jerking, its head and neck bends back and it keeps champing its teeth, and afor working in this manner for a while, falls over as if it wero 
dand, but in a short time gets up and seems all right ior a llttlo while, then another fit comes on. The pig keeps on taking thoas fits every little while for a few days, but finally gets $s 0$ bad it dien Trentment. - For a pig two months old give

Ran Unceed OA...................... thosouptul.

Splrit of Turpentine..................... I dram or I teapoonful

Mix well and pour down as a drench. Repeat this dose ones a day until the bowels move and the pig seems relieved, afterwards feed lots of charcoal, hardwood ashes, salt and sulphur, the same as is given to stunted pigs to get rid of the worms.

\section{CHAPTER III. \\ DISEASES AND TREATMENT OF DOGS.}

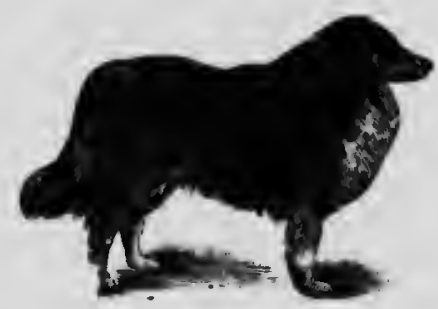

MANGE,

This is a very common skin disease among dogs.

Ciuses.-From parasites, or germs, getting down into the sk!n, and as soon as they do they commence $\omega$ breed and spread al. over the body, mostly affecting the skin on the back, head and neck. This disease, ill soon spread among dogs and to other animals, even to the : man being.

Symptoms.-Th. og becomes extremely itchy, keeps rubbing and biting himself until the hair falls off, and in some cases the skin gets so sore and irritated that it will bleed; the hair is dry and scruffy-looking, and the dog soon falls off in condition To make sure of this disease examine the scales under a microscap and you can see the parnaites or cormb. 
Treatment-If the weather is warm lip the hair off the dog good and short, and give him a thorough good washing with luke warm water and soap, after this rub him dry and apply the creolin wash by rubbing it well into the skin all over the body: use two tablespoonfuls of creolin to the pint of water and apply is once a day until the dog stops rubbing himself, the skin heals and the hair starts to grow out; as well as this, give a teaspoonful of sulphur in his milk twice a day if it is a large dog; give the sulphur in proportion to the size of the dog; if it is in the wintes time just clip the hair off and apply the creolin wash, but do not wash him with water.

\section{PLEAS.}

Fleas are a very common thing in doga, especially if they aro kept tied up and not properly taken care of.

Treatment.-Clean out the place where the dog is kept and whitewash it to get it thoroughly clean and put in fresh bedding. then, if it is in the summer time, wash the dog with luke warrs water and soap, then rub him dry, after which rub him thoroughl, with creolin wash every third or fourth day until the fleas are killed. One washing is usually enough to kill the fleas. I'so two tablespoonfuls of creolin to the pint of water to wash him wi:b

CANRER IN THE EAR.

Causes.-This is a common disease in dogs that run througt long, wet grass.

Symptoms. - There is a discharge of matter from the ear which has a bad smell; the dog holds his head to one side, and is you go to catch him to examine the ear he will be very much ofraid, showing that it is very sore.

Treatment.-Bathe the ear well with luke warm water und castile soap once a day; wipe dry each time after bathing and inject a little white lotion into the ear with a syringe and be will soon get all right.

\section{DEAFRESS.}

This is very common in old dogs.

Symptoms.-The dog seems stupid, and when you call him he does not hear you.

Treatment.-If it is an old dog, and the cause is from age there cannot be anything done; but if it is a young dog, and the deafness is caused from wax in the ear or anything like that, wash the or out with luke warm water and soap, after which drop a few droos 
of sweet oil into the ear; do thls every eecond day and in a short time it will effect a complete cure.

\section{SORE BYES.}

This is an inflammation of the eye and its covering.

Causes.-From something getting into the eye; from a bite or scratch, or anything that will irritate the eye.

Symptoms. - The eye is very red, sore and inflamed, and after a time a little scum will form over the sight. The eyelids, in some cases, are swolien and tears keep running from the corners.

Treatment.-Catch the dog, examine the eye, and if there is anything in it, remove it at once; after this, bathe the eye with new milk twice a day, and each time after bathing apply the eye wash mentioned in the back of this book until he geto all right. While treating him keep him in a cool, dark place.

\section{ENLARGEMENTS OR GROWTHS II THE EYE.}

In some cases the eye itself will become so enlarged that it will bulge out of its socket, which gives the dog a very unsightly appearance. In other cases cancerous growths affect the eye, and the cancer grows until it hangs out of the eye onto the cheek

Treatment.-In either of the above cases treat by removing the eye. First, put muzzle on him or tie his mouth with strong, small rope 20 he cannot bite you, then tie his legs firmly. When you have the dog securely tied, stick hook into the affected eye and pull outwards and upwards, then with a sharp knife cut around the eye and separate it from the eyelid and draw the eye up as far as you can. You will find the eye attached at the back by the muscles, nerve and artery of the eye. Tie a ctring tight around the back part of the eye, so it will prevent bleeding, then cut the eye off in front of the string, leaving the string on. The after treatment is to bathe the parts with lukewarm water and castile soap once a day; each time after bathing apply the white lotion and it will soon heal up. Keep the dog in a dark, cool, quiet place during treatment.

\section{WOUNDS OR COTS OF ANY RIND.}

If the wound is torn much, tie the dog's mouth with rope or muzzle him so he cannot bite you, also tie his legs to hold them firmly, then stitch the wound up with a needle and twine (the same as is used for sewing wounds on horses). There is no necessity for using medicine on it afterwards, but just leave the dog in a dark. 
quiet place, and allow him to liek the wound, which is the hest medicine you can use. It the wound is where the dog cannot get at it to lick it, batle it twice a day with luke war.n water and castile soap, and each time after bathing wipe dry and apply the white lotion.

\section{TUMORS OR GROWTES ON THE SRIN.}

As soon as they are noticed it is best to cut them out clean. First secure the dog in the same manner as is given in the treatment for "enlargements and growths in the eye." then take sharp knife and skin the lump right out; let the dog go and do nothing more to it, only let the dog lick it, for it is dangerous to put medicine on cuts or wounds where the dog can lick it, for the medicine might poison him.

\section{CONSTIPATION IN DOGS.}

This is where the bowels have stopped working.

Symptoms.-The dog wili not eat, seems very dull and Jumpish; the belly seems fuller than natural; he is often noticed to strain, but does not pass much, and anything that does some away will be hard and dry.

Treatment.-For a small or young dog give

Syrup of Buckthora.............. ounce or 1 tublespuonful.

Pour this down twice day, night and morning, until t/e bowels are moved. For a large dog give one-half ounce or two tablespoontuls of syrup of buckthorn twice a day until it acts on him. Castor oil is also recommended to be given in the same propurtions as the syrup of buckthorn. As well as giving the medicine mentioned give an injection of a teacupful of luke warm water with a little suap in it twice a day. Give the dog gentle exercise once day and see that he has nothing but new milk to drink Juring the time he is sick.

\section{DIARREGEA IN DOGS.}

This is not a very common disease in dogs, but is sometimes teen, and is generally caused from a change in his food.

Treatment. - Keep the dog ver; quiet, and in some cases by riving him br..s new milk with a little dry flour in it, it will :heck the diarrhoes without any medicine. If this fails, give to a imall dog lialf a dram or half a teaspoonful of tincture of laudanum and a teasponiful of whisizy in a tabiespounful of new milk as a drench. For a large dog give one dram or a teaspoonful of lincture of laudanum and a tablespoonful of whisky mixed in liaff 
a teacupful of boiled milk and flour and give as a drench. Ropeat the drench three times a day until he gets all right. During the treatment keep the dog very quiet and give very littlo to oat except boiled new milk with a little dry four sifted in it.

\section{WORXS.}

Symptoms. - The dog has a good appetite, but does not thrive well, his hair is dry looking and dusty. Occasionally there will be a worm noticed to pass away in his manure. Sometimes dogs affected very badly with worms will take fits.

Treatment.-For a medium-sized dog give one dram of oil of male shield fern mixed with four tablespoonfuls of new milk. Pour it down by putting it well back in the mouth with a spoon or bottle and holding his head until he swallows it. Give this dose every third day until the bowels are moving free and the dog is relieved of worms.

\section{DISTEMPER II DOGS.}

This is a very common disease in dogs from three to six months o:r, but may affect them at any age, and is mostly seen during the fall, winter and spring. This disease somewhat resembles distemper in horses.

Causes.-It is caused from parasites, or germs, getting into the blool and setting up the disease in the same manner as distemper in horses. By allowing the affected dog to be with other dogs they will catch it from him.

Symptoms. - The dog is very dull and sleepy looking, tries to get in a quiet, dark place and refuses to eat, his eyes keep running water, and after a time they become very sore. In a few days his hair becomes dry, there is a discharge from the nose, eyes, and sometimes from the penis, the bowels are costive, the dog falls of in condition, the symptoms gradually get worse, and if he does not get relief he will go into convulsions or fits and soon die. Like other diseases of this kind it must run its course, which should lats about nine days.

Treatment.-The treatment is very simple. Give the affected dog nothing to eat but new milk and the following medicine:

Nitrate of Potanh or Saltpetre ..................... pound.

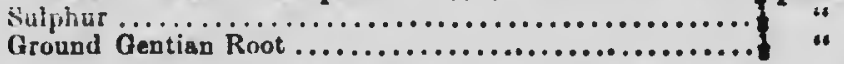

Mix thoroughly together, and for a large dog give half teaspoonful of the mixture three times a day on his tongue with a 
spoon or in his milk. Regulate the dose in proportion to the size of the dog. Keep the dog in a quict, clean place; wash off the discharge from his eyes and nose with luke warm water, and afterwards wipe dry with a soft cloth. If his bowels are costive, hive from a teaspoonful to a tablespoonful, according to the size of the dog, of syrup of buckthorn unce a day until the howels move freely; after that give a dose once or twice a week to keep the bowels free, and in a week or so the dog will begin to gret bette. Be careful not to let him get cold until he gets all right.

\section{MAD DOG (HYDROPHOBIA OR RABIES).}

This disease originates spont.aneously in dogs and cats with. out being bitter, and is mostly seen in very hot weather and in hot clinistes. It may also be caused by dogs or cats being bitten by another mad dog or cat.

Symptoms. - The affected dog is first noticed to become crited; runs about and bites at everything that comes in his way; riva keeps running from his mouth and his eyes are blood. hot. Alter this, the dog will take a spell of quietness, and will go and lie down in an nui-of-the-way place. He seems to lave a depraved appetite; wilt thy and all sorts of dirt. Suddenly, he will again socome everything that comes is , dog rarely, if ever, $r_{s}$. ... In running about he

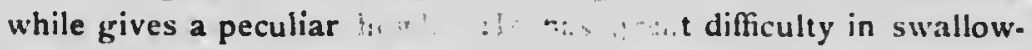
ing, and in some cases $c \quad n \quad, \quad$ all. These symptoms gradsally get worse until the or tir: ine time the discise affects a dog after being bitte: vi:

Treatment.-As soon as the log is noticed to be mad, have him destroyed, for he is very dangerous to have around, and, besides, there is no cure for it. In cases where a dog has been bitten by a mad dog or cat, cut the piece out where he was bitten and burn the hole with caustic potash, nitrate of silver or a red hot iron, which will destroy the poison before it gets into the system.

\section{CHOREA.}

This is a disease that affects the nerves, causing the affected part to keep jerking.

Causes. - It is very often noticed after a dog has had a very severe attack of distemper, or it may be caused trom an injury. 
Symptoms. There is a contlnual jerking of the musclea around this affected part when the dog is resting.

Treatment. There cannot be much done for it after the disease has unce set in, but by giving from one-quarter to one-half a dram of bronide of potassium twice a day on his tongue with a spoon or in a little new milk, according to the size of the dog, as soon as the disease is noticed, it will nearly always effect a cure.

DOGS POISONED WITH RAT POISON, STRYCHNINE OR ARSENIC.

Symptoms.-. All at once the dog seems in great pain; takes fits; slobbers at the mouth; the eyes are bulged out and bloodshot, and he keeps trembling all over. If the dog shows the above symptoms, and you have had poison around the place, or he has been anywhere that he could possibly get it, you may conclude he has been poisoned.

Treatment.-The treatment must be quick. Give the dog an emetic to make him vomit; this is the only way you can save his life. The idea is to get him to throw up the poison out of his stomach before it gets absorbed into the blood. Give him one tablespoonful of salt dissolved in a half teacupful of luke warm water as a drench, or one teaspoonful of mustard dissolved in a half teacupful of luke warm water as a drench; either of the above will cause vomiting. But the best of all, if you have it, to make him vomit, is to give him from half a teaspoonful to a teaspoonful of sulphate of zinc dissolved in a half teacupful of luke warm water and give i: as a drench. If you can get him to vomit soon enough it will generally save his life.

\section{FRACTURES OR RROKEN BONES IN DOGS.}

Causes.-Fractures of bones in the dog may occur in various ways, such as a kick or being struck with anything.

Syniptoms.-The symptoms vary according to the part affected. If it is a fracture of the neck bones the dog dies instantly; it in the back it causes paralysis of his hind quarters; if it is in the hip or hind leg it is easily told, for the dog cannot use the leg and hops along on the other three while the broken one will be dangling; if it is a fracture in the front leg, he acts similar to when the fracture is in the hind leg. To make sure it is a fracture, catch the dog and move the affected par's and you can hear the encis of the broken bone grinding on each other.

Treatment.-If the fracture is in the hack, there can be nothing done but to destroy the dog, to put him out of pain. If it is 
the hup or shoulder bone that is fractured and it is a young dog, kecp him perfectly yuict and the bones will soon knit together, but if it is a very old dog there is not much chance of the bones knitting torether, although they might. If the fracture is down on the leg set the broken bone to its place and have a long, starch bandage (which is a bandage soaked in starch and then wrung out as dry as possible), roll the bindage around the fractured leg letting it go two or three inches above and below the fracture, wrap it moderately tight and hold the leg and bandage straight until the bandage hardens. Keep the dog quiet and leave the bandage on for three or four weeks until the bones are healed and he can use his leg all right.

\section{BREEDING PUPS AND TROUBLES MET WIITH AT PUPPING TIMR.}

Bitches usually come in heat about twice a year, but some come oftener than thac. She is nine days coming in heat and nine days going off, during that time she will take the dog about nine or ten days. It is best to keep the bitch shut up during the eighteen days, so that no other dog but the one you want to breed to can get at her. If you want to get bitch pups, let the dog ic her as soon as slie will take him; while if you want to get dog pups, let her go for seven or eight days after she would have taken the dog, before you let the dog to her and you are almost sure to get dog pups. The bitch carries her pups nine woeks. At the end of that time, and a few hours before pupping, she will try to get a wa, to some quiet place and make nest. As a genoral thing after she once starts to pup, it does not take her long to have them all. Sometimes we have cases where she cannot pup alone, that is, wher one of the pups is coming wrong-sometimes head first with the front legs turned back, and it gets caught at the shoulders. In this case shove the pup back a little, slip your finger in under the front legs and bring them forward, and it will then come all right. If the front legs are coming out and the head and neck are turned back, shove the pup back a little, and straighten the head and neck up along with the front legs, and the pup will soon come all right. Sometimes the pup comes backwards with only his rump and tail up in the passage, in this case shove the pup back and straighten up the cwo hind feet, and bring the pup away backwards. Before stitting to work at a joh of this kind, have your fingers and hands oiled so as not to irritate the hitch, inmetimes a small hook will be of some use, but if you une me be very curefi:! not to tear her. Bitches are not very liable to disease after 
pupping and the only thing to be done is to see that she is dry and warm, and that the pups are sucking her all right.

BOW TO CUT PUPS' TAILS.

This is usually done when the pup is ibout a month old. The length of the tail to be left on varies with the breed of the pup ; find out the length you want to leave it and then find the joint, and cut it through with one stroke of a sharp knife. They do not usually bleed, but if it should, touch the spots with Monsell's solution of iron, or if you have not got that just touch it with a red hot iron which will stop it, but in most cases it will be all right without anything.

\section{BOW TO CASTRATE $\triangle$ DOG.}

This operation is done at all ages-but like other animals it is best done when he is young; it is very simple. Catch the dog and roll him up in a blanket, turning his front legs back and his hind legs forward so as to catch them in the blanket, and have him held on his back with his hind end stuck out of the blanket enough to get at the bag. Take hold of the testicle with your left hand, and with a sharp knife in your right hand, let out the testicle by making a cut in the bag large enough to let it out, separate the covering which is attached to the back part of the testicle with your knife, as soon as this is cut draw the testicle well up, and it he is a young dog cut the cord off with a scissors which will stop the bleeding, but if he is an old dog, tie the cord tight with a piece f strong string, leaving the ends long enough so they will hang out of the bag, then cut the testicle off about one-half an inch below where it is tied, operate on the other testicle in the same way, and fill the holes with salty butter and let him go.

\section{HOW TO SPAT A BITCB.}

This operation is taking the ovaries away from the bitch, to prevent her from coming in heat and getting with pup. It is best to perform this operation when the bitch is between six and nine nonths old and before she comes in heat for the first time, but it can be done at any time, and we have even done it when she was with pup, and be all right, but, if it is done when she is with pup she will generally lose her pups. It is best to have the bitch thin in condition, not griving her anything to eat or drink but milk the day before the operation. What is needed for this operation is a sharp knife, a sewing needle and string (the same as is used for wew:ing up wounds), and a probe, which can be made out of a 
Another thing to bear in mind in this operation, as well as in other operations, always have everything perfectly clean. When this precaution is taken the operation is generally successtul.

CHAFTER IV.

\section{DISEASES AND TREATMENT OF POULTRY.}

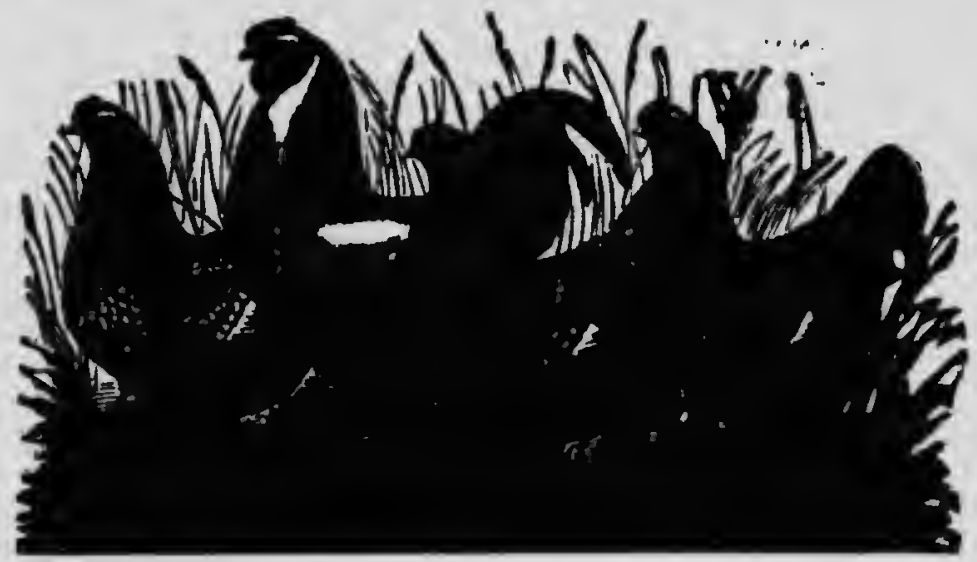

ROOP.

Roup is considered by all poultry men the worst and most dreaded disease that can aftict poultry.

Cause.-From germs settling in the throat, or it may be caused from neglected colds.

There are many remedies for roup, but we think the following as is given in "Success With Poultry," is one of the very best :

Treatment.-Pen the fowl in warm, dry quarters, and keep out all drafts of cold and damp air. Feed hot bran, mashed potatoes and meat, and medicate the throat, mouth and nostrils with cloride of sodium or common salt, as follows: Take a bucketful of warm water; put a teacupful of salt in this amount of water ; then catch the fowl, examine the throat and nostrils, removing all mucous matter out of the nostrils, and then filling a pint cup for each afflicted fowl, hold it by the feet-head down, choke it until the mouth is wide open and then insert the head into the solution. Comb down, so the medicated water may enter the clift in the palate and go out at each nostril and into the throat. Each 
hould be separately treated. Kerosene injected into the nostrils is gerud: alsn ammplunated sweet oil. Ten elrops of coal oil or kerosune ackled to two Irope of wate for a thak of twenty fowls will often effect a curs. But when this remedy is applied, do not attempt to prepare one of the Hock for table use for three or four weeks thereafter, as the entire carcass will be tainted with coal oil.

lupokrt.it. - In treating roup, be careful to remove any discharge from the nostrils that may collect on the feathers under the wings or on the breast. Be sure and protect the sick fowls from all drafts and feed easily digested food. When the fowls look stupid and droopy, feathers rough and no appetite, reduce their food to even fasting.

\section{HEN LICE IN A HEN HOUSE AND ON HENS.}

When once hen lice get started they increase very rapidly and become a perfect nuisance to the hens and the owner, and in some cases they will spread to other buildings and get on the stock. Hen lice are very small and have a reddish appearance.

Treatment. - The first step to be taken to get rid of the hen lice is to drive all the hell out of the hen house, close up the windows and doors, put a pround of sulphur in a pot, put some coals in it to start the sulphur burning, and keep it burning for about half a day. The funes from the sulphur will go into all the cracks and thoroughly tumigate the place and kill the lice : - 'ler this open the donrs and windows and clean the place out thoroughly and put plenty of hardwood ashes and coal dust in the hen house for the helss to roll about in; this kills the lice on the hens. In the course of a week drive the hens out of the hen house again and burn sulphur as you did before, this will rid you entirely of the pest, and by watching the hens and giving them plenty of ashes and coal dust to roll in, will keep the lice off them after this. it in also a grood plan to feed the hens lots of sulphur and new milk, give every night, two tablespoonfuls of sulphur to a quart of new milk, this would be about the proper dose for twenty-five hens. The sulphur passing off through the pores in the skin helps greatly to kill the lice. Whitewash the walls, ceiling, roosts and nests of the hen house, and put clean straw in the nests; this will effect a complete cure. If the lice are in other buildings treat just the same way as mentioned for a hen house. This treitment for killing the hen lice will also kill the 
garms of other diseases such as roup, etc., and is a process that a hen house should have every fall and spring to keep diseases from the fowl.

\section{CHOLERA.}

Cholera is very contagious. The cause of it is overcrowding, bad sanitary management, unwholesome or irregular food, etc. Chicken cholera is not very well understood by poultry raisers, and we believe it is a fact that a great many diseases are called cholera simply because it is not understood. Everyone who keeps fowls should be able to tell cholera from other diseases, for without such knowledge it is impossible to treat the disease properly.

Symptoms.-The fowl has a very sleepy, droopy appearance; it is very thirsty and has a slow gait and gapes often. Sometimes the fowl staggers and falls down from great weakness. The comb and wattles lose their natural color, generally turning pale and sometimes they are dark. There is diarrhoa with a greenish discharge, or like sulphur and water. The crop fills with mucus and wind, and at last the food is not digested. Breathing is heavy and fast, the eyes close, and in a few hours the fowl dies.

Treatment.-The first thing to be done when cholera makes its appearance is to give the coops and yards a thorough renovaling; disinfect with carbolic acid, 40 drops to the pint of water. Remove all affected fowls and burn the carcass of dead ones. The best and most effective remedy for cholera that we have ever used is coal oil or kerosene. The coal oil should be given about four times a week, as follows : Take a feeding of corn and wheat and let it soak in the oil a few hours, and then feed it to the fowls, or mix it in soft fond, one teaspoonful of oil so every two quarts of corn meal. While treating do not give much water to drink.

\section{CANKER.}

Canker is caused by filthy quarters and musty or unwholesome food. Canker may be noticed by running sores on the nead, in the mouth or throat accompanied with a watery discharge from the eyes.

Treatment. - Take warm water and a little salt and wash the nead and eyes, also swab out the throat and mouth. Remove 
alcers with a quill and apply powdered borax to the places ief oare. Repeat this treatment twice a day and a cure will be afected.

\section{CROP BOUTD.}

The most usual cause is that the fowl has swallowed something that it cannot digest. The foreign substance may be a piece of bone, or anything that obstructs the natural passage.

Treatment.-The best treatment for crop bound is castor oil. Give the fowl two teaspoonfuls in one dose. If this does not clear the crop in 24 hours it cannot be cured, and the best remedy is to apply the hatchet just back of the comb.

\section{GAPES.}

Gapes in fowls is caused from drinking dirty water, exposure to wet, damp places, and want of nourishing food.

Symptoms.-The symptoms of gapes, as the name implies, consists of constant gaping, coughing and sneezing.

Treatment.-Give the bird, daily, unless it recovers, a small niece of camphor, about the size of a grain of wheat, and a few drops of turpentine in the drinking water, or mix in the food about Io drops to the pint.

\section{LEG WEAKNESS.}

The principal cause of leg weakness, in most strain of fowls, arises from inbreeding or breeding the same strain of fowls for too long a period. It is also cilused from overfeeding, which increases the weight of the body out of proportion to the muscular strength of the limbs and usually oicurs in the larger breeds.

Treatment. - In the first stages, give:

Sulphule of Jron.......................... pound.

Sulphate of Lime... . . ........................

Mix and give the fowl about the size of two peas of the mixture on its tongue twice a day. If, however, the bird is unable to walk it is incurable.

\section{SCALY LEGS.}

This disease is contagious, and one scaly legged fowl will affect the whole flock. The disease is caused by a small insect which burrows under the scales. The best and most effective remedy is to dip the fowl's feet and legs in kerosene or coal ad 
clear up to the feathers. Some people an thet this is severe and think kerosene will burn and make the flesh sore. This is great mistake, and to satisfy yourself, just take some kerosene and put it on your own flesh, and you will find it will not hurt you at all.

\section{BIC BEAD II TURKETS.}

This is a disease mostly seen in turkeys, but occasionally is seen in other fowl. It may affect turkeys at any age, but is seen mostly when they are young.

Causes.-This disease is caused from small germs or parasites getting into the system and affecting the head. When one turkey becomes affected it generally spreads through the whole flock.

Symptoms.-The first symptom noticed is swelling around the head, usually in front of the eyes. In some cases the swelling only affects one side of the head, and keeps swelling until it closes the eye right up, and the turkey goes around with its head to one side, while in other cases both sides become swollen at the same time, and closes both the eyes. Although these swellings are mostly seen in front of the eyes, it may affect other parts of the head, and even the feet in some cases. If not treated, the swelling gradually increases around the head until it works into the throat and kills the turkey; if in the foot, it swells and becomes so bad that it finally dies.

Treatment.-When this disease gets into a flock of turkeys, if it is not treated it will kill nearly all the turkeys in the flock before it stops. Separate the diseased turkeys from the sound ones, and give to a medium sized turkey three drops of spirits of tupentine mixed in a teaspoonful of raw linseed oil. The best way to give it is to pour it down with a spoon. Give this dose once a day and rub around the swelling with white liniment once a day; this will gradually cure the turkeys if taken in time. If the swelling is very large before you start to treat it, split the lumps open with a sharp knife and squeeze the cheesey matter out of it, then fill the hole and rub the swelling with white liniment; keep this treatment up until the turkey is all right. Be careful not to let the liniment into the eye while applying it to the head. 


\section{PART V.}

\section{Medicines and Receipts.}

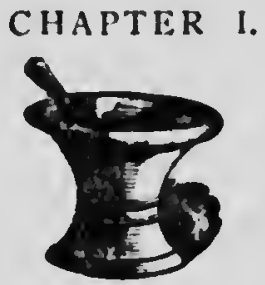

MEDICINES.

11. Alicines are got trom three great sources, viz.: The animal, vegetable and mineral kingdoms. This part of the book is very important and should bc carefully studied by persons interested, as it grives the llames of the medicines, the sources they are got trom, their action and use, the dose to each of the animals and how long it takes to operate.

\section{ACONITE.}

Aconite is grot from a plant that grows in cool, mountainous countries. The form of aconite we recommend and use is Flem. ing's Tincturc, which is got from the root of the plant.

Its Action and Use.-Aconite acts on the heart and blood rcisels, causing the heart to beat slower, and in this way lowers blood pressur: "n the system, thus it is good in most kinds of inflammation where the animal is in good condition, and is used now in nearly every case in place of bleedir.

Dose.-Fleming's Tincture of Acsite. Fon horses, 8 to 10 drops; cattle, 8 to 12 drops; sheep, 2 to drups; pigs and dogs, 1 to 2 drops.

\section{ALCOHOL.}

Alcohol is got from certain kinds of wou, wpis beets, potatoes, etc. It is not used much in its pure state tor dons -ing stock, but is used in the form of liquors for medicius. One preparalion, known as methylated spirits of alcohol $i$ used in making hniments. 
Its Action and Use.-Its action is as a stimulant, and it also acts on the kidneys as a diuretic, and is mostly used in the form of liquors, such as whisky, gin, beer and ale. For external use see where methylated spirits of alcohol is used in making up white and acid liniments among the receipts.

Dose.-For horses (whisky), 1 to 2 wine glassfuls; cattle, 8 to 1 wine glassfuls; sheep, I wine glassful; pigs and dogs, 1 to 2 tablespoonfuls. For horses (gin), 1 wine glassful; cattle, 1 to 2 wine glassfuls; sheep, 1 to 2 teaspoonfuls; pigs and dogs, 1 teaspoonful. For horses (beer and ale), t to 1 pint; cattle, 1 pint; sheep, $t$ to $\$$ pint; pigs and dogs, 1 wine glassful.

\section{ALOES.}

Aloes is got from a plant grown in the West India Islands. There are three kinds of Aloes: Barbadoes, Socotrine and Cape. The Barbadoes is the best, and is the kind mostly used for stock. It is a liver-brown color, bitter to taste and is usually bought either in the form of a powder or lumps.

Its Action and Use.-Aloes acts as a physic and blood purifier and is used in a great many diseases, especially in the horse.

Dose-For horses, 8 to 10 drams; cattle, 1 to 2 ounces; sheep, 2 to 4 drams; pigs and dogs, 1 to 2 drams. In preparing aloes for a drench it must be dissolved in water that is just h. ie warm, for if the water is too warm it spoils the action of the aloes, and if it is too cold it will not dissolve properly. In giving it as a ball, see receipt of physic ball in the back of this book. It takes aloes twenty-four hours to operate on the bowels in horses and cattle, and after giving them a dose they should always be left standing quietly for forty-eight hours after giving them the medicine.

\section{ALOR.}

Alum is got from the alum salts, which is a mineral.

Its Action and Use-It is mostly used externally in the form of washes for healing wounds. It is also dusted onto wounds in the form of a powdar, and is very drying and healing. It is also used in gargle powders for sore throat, influenza and aphtha or sore mouth.

Dose. - The way it is used internally is best seen in the receipt for gargle powders at the back of this book. For making a wash It takes a tablespoonful of alum to a pint of water. 
Amumuiat is obtained from plants and anmuls. There aro several forms of ammonia, but the one mnstly used in the prictice is strong liquor ammonia, which is used mostly for mak. ing liniments. For how to use it see the receipt of white linirnent at back of this bouk.

\section{ANISEED.}

Aniseed grows in the form of berries on bushes that grow in Spain, Germany and Southern Russia. The berries are dried and ground, this being the form we get them in.

Its Action and Use.-It stimulates digestion, sweetens tha stomach, and in cases where the stomach is deranged it relieven the gasses that form. It is a splendid thing for animals that are recovering from weakening diseases to give them an appetite and ouild them up.

Dose.-For horses, 1 tablesponniul; cattle, 1 tablespoonful: theep, I teaspoonful; pigs and dogs, to 1 teaspoonful.

\section{ARNICA.}

Arnica is got from a plant that grows in mountainous coun. ries in Central Europe, Asia and America. The form we use is :he Tincture of Arnica, which is taken from the root of the plant.

Its Action and Use.-It is not used much internally, but if ssed externally in the form of a cooling lotion for sprains, wounds, stc. -one ounce or tablespoonfuls of arnica to a pint of water and applied twice a day. It is also used to rub race horses' legs oefore and after bandaging to keep them from getting atif and sore.

\section{ARSEMIC.}

Arsenic is got from the mineral kingdom. In its pure form t is not much used in practice because it is too strong and powor. iul. The form that is used is known as Fowler's Solution, whleb is prepared from arsenic, and is in the form of a liquid.

Its Action and Use.-It is a powerful tonic for the stomacb and system in reneral, and is especially used after weakening diseases, such as distemper, and will often start the animal to thrive when everything else will fail.

Dose.-For horses, ounce or 2 tablespoonfuls; cattle, ounce or 2 tablespoonfuls; sheep, 1 dram or 1 teaspoonful; pigs and dogs, $\frac{1}{2}$ drim or $\frac{1}{2}$ teaspountul. Give this medicine combined 


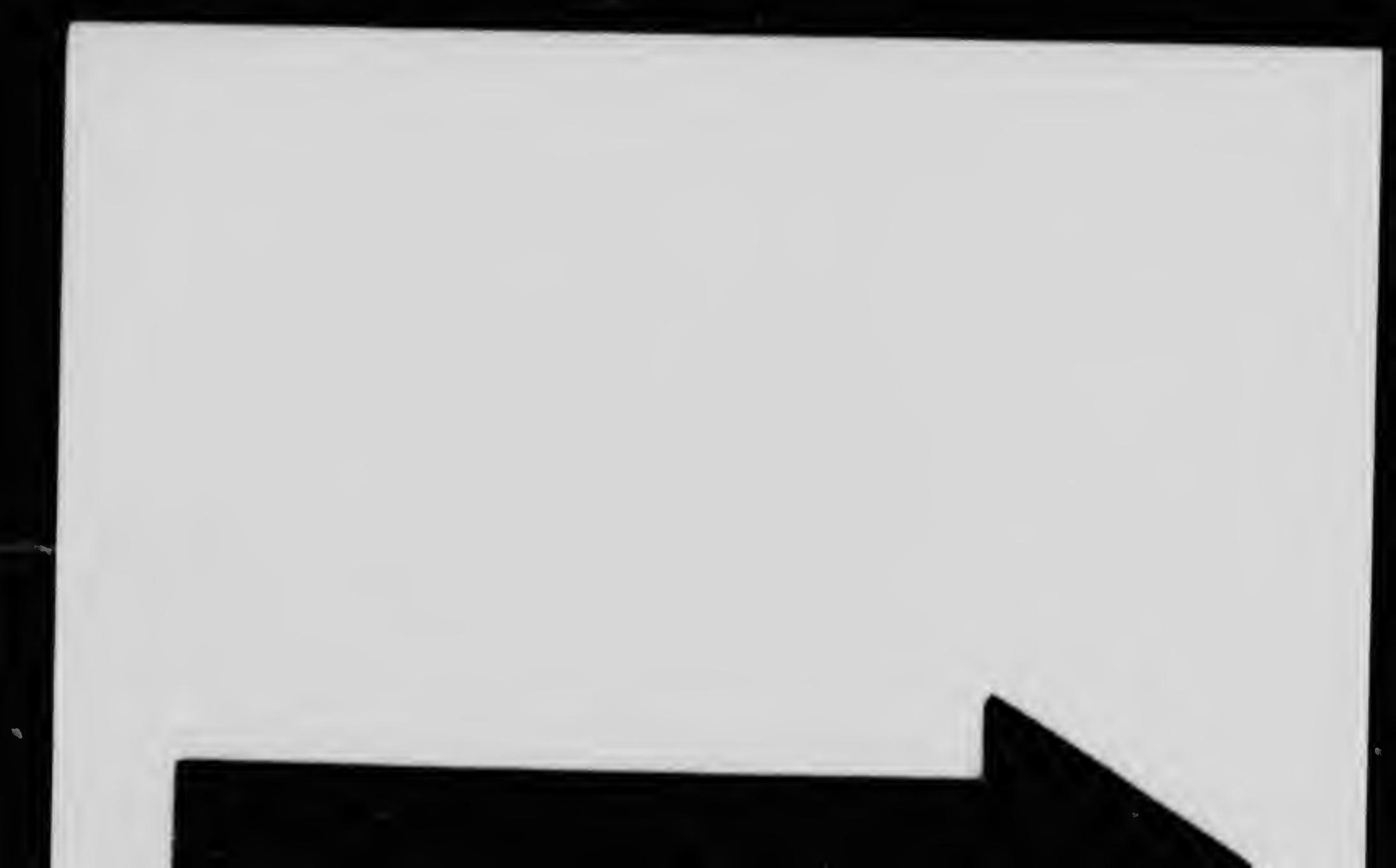




\section{MICROCOPY RESOLUTION TEST CHART}

(ANSI and ISO TEST CHART No. 2)
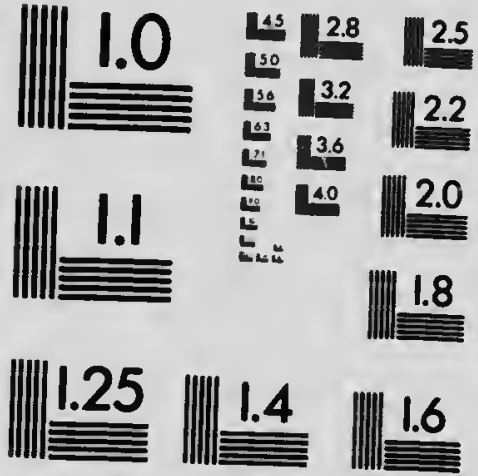

APPLIED IMAGE Inc
1653 East Main Street
Rochester. New York 1 4609 usa
(716) $482-0300-$ Phone
(716) $288-5989 \rightarrow$ Fax


with an ounce of whisky and half a pint of gruel twice a day until the animal gets better and is strong.

\section{BELLADONNA.}

Belladonna is got from a plant known as Deadly Nightshade. It grows wild in some parts of Great Britain, and it is also cultivated to a great extent. The form that is used mostly in practice is the Fluid Extract of Belladonna.

Its Action and Use. - It soothes, softens and relaxes the parts applied to, and is greatly used where there is inflammation and pain in aimost any part of the body to relieve the pain and check the inflammation. The Extract of Belladonna is strong and must be used carefully.

Dose.-Fluid Extract of Belladonna-For horses, 1 dram or 1 teaspoonful; cattle, 1 dram or 1 teaspoonful; sheep, 10 drops; pigs and dogs, 3 to 6 drops. Belladonna is greatly used for diseases of the eyes in the form of an eye wash. For further information look at the receipt for eye wash at the back of this book. It is also greatly used for dilating 0 : opening the neck of the womb, in any animal, where it remains closed when they are ready to be delivered of their young. It is used a great deal for this trouble in cows.

\section{BLACK ANTMONT.}

Black antimony is got from the mineral kingdom, and the form we get it is in a black, heavy, grayish powder that has neither smell nor taste.

Its Action and Use.-It is not used much in the way of medicine, only to color condition powders, etc., but should not be used, as it is very irritating and injurious to the system. When it is used as a coloring material for powders it is in this porportion: one teaspoonful of black antimony to a pound of whatever you want to color.

\section{BUTTER OP ANTRYITI.}

Butter of antimony is also got from the mineral kingdom, and is used in the farm of a brown liquid.

Its Action and Use.-It is never used internally, for it is an irritating poison, but it is used externally for curing thrush in horse's feet, and for burning growths off around the feet that 'ume from the quick of the foot. It is also good in cases wher. 
a nail has run in the foot, after the nail is pulled out and the nail-hole pared out, to drop a fow drops in the bole to kill the rust and poison of the mail.

\section{BENZOM.}

Benzoin is got from a tree called styrax benzoin, which grows in the southern part of Asia. It is got by cuttir:g a hole in the bark and catching the sap whlch afterwards soon becomes hard and brittle.

Its Action and Use.-The form we use this in is known as Compound Tincture of Benzoin, or Friar's Balsam, which is prepared from the gum. Its chief action is for healing wounds by painting the wound over with a feather twice a day, and is especially useful for caulks, or where a nail has run in the fool, to kill the poison. it is not used much internally.

\section{BROMDE OF POTASSIOL.}

Bromide of Potassium is prepared from seawater, and the form we usually get it in is in a white crystal powder, which has a salty taste.

Its Action and Use.-Its chief action is to quiet the nerves in nervous diseases, such as lockjaw (tetanus), or in convulsions, chorea and other painful diseases.

Dose.-For horses, 1 teaspoonful; cattle, 1 teaspoonful; sheep, $1 / 2$ teaspoonful; pigs and dogs, $1 / 4$ teaspoonful. The dose can be given three or four times a day, according to the severity of the case.

\section{BINIODID OF MERCURY (RED PRECIPITATE).}

Biniodid of Mercury is got from the mineral kingdom. It is bought in the form of a heavy, bright-red powder.

Its Action and Use-It is chiefly used for blistering bony enlargements, such as spavins, ringbones, sidebones, splints, etc. The proportions in which it is used is 1 to 2 drams to the ounce of vaseline, or lard, according to the breed of the horse and thickness of the skin. Have the morcury and vaseline, or lard, thoroughly mixed before using, and three days after applying the blister grease the part with lard. For further information look at mercury blister among the receipts.

\section{BUC'THORN.}

Buckthorn is got from the ripe berries of a shrubby bush that grows along the North Pacific Coast. The form we use it in is known as Syrup of Bucktborn. 
Its Action and Use.-It is principally used as a mild phyaie for dogs.

Dose-For a dog give 1 to 2 ounces; cats, $1 / 2$ ounce. A very good plan is to give a tablespoonful of the syrup every night and morning until you get the desired results.

\section{CAMPHOR.}

Camphor is got from a tall, evergreen tree known as the Laurel Cainphor, which grows in Japan, China, and different parts of Europe. The branches are cut and boiled in water and the camphor rises to the top in the form of a gum.

Its Action and Use.-It is mostly used in mixtures for coughs, sore throat and heaves. How to use it is hest seen in the receipt for chronic cough, and heaves or broken wind.

\section{CANTHARIDES OR SPANISH FLY.}

Cantharides are got from flies which receive the name Spanish Fly on account of so many of them coming from Spain. The flies are of a green color, and an inch in length, and are captured in nets, then killed by pouring boiling water or vinegar on them, after this they are dried in the sun or by artificial heat, and are then ground and made ready for use in practice.

Its Action arld Use.-Its chief action is as a sweat blister and is one of the principal ingredients in sweat blisters which are used for sweating thickenings or lumps on any part of the body, that are not on this bone, such as curbs, tumors, thickenings left after a wound has been healed up, etc. As to how to use Powdered Cantharides see the receipt for sweat blister at the back of this book. Cantharides can also be got in the form of a tincture, but is not much used. The proportion to use Powdered Cantharides for a sweat blister is, 1 to 2 drams of the Canthardies to an ounce of vaseline or lard according to how heavy the skin of the hores ic. For cows use it a little stronger than for the horee.

\section{CARBOLLC $\triangle C D$.}

Carbolic Acid is got from coal tar and petrolcum. The pure Carbolic Acid is got in the form of a crystal, but the way it $b$ generally bought is in the form of a liquid.

Its Action and Use.-It has a very cleansing effect on a wound, and is qreatly used for that purpose and is also used for fumigating stables by sprinkling a little around on the floor. It is 
very rarely, if ewer uned internilla. The strength Carlolic Acid should be used in bathing a 1 muml is 10 drops to half a pail of water; for a lotion une 20 drope to 1 pint of water; for making Carbolic Oil use 2:5 droph of Citrhule Acicl to a halt pint of olive or sweet oil, that is about two or thee drops of ach to the ounce of sil. It is a mistake to put tow much acis! in a wash or lotion, for instead of it having a cleamsing eflect it will burn the wound and stop the healing action. A very good healing salve is made out of 5 drops of Carbolic Acid to an ounce of vaseline.

\section{CASTOR OIL.}

Castor Oil is got from the seeds of a shrubby tree that grows n Africa, Southern Europe, and Suth America.

Its Action and Use.-It is a mild physic, similar to raw linseed ail. It is not much used for horsers or cattle, but is sometimes riven to dogrs, pigs, and young animals.

Dose.-For horses, 1 pint; cattle, 1 pint ; sheep, $1 / 4$ pint; jigs and dogs, 1 ounce or 4 tablespoonfuls. In liorses and cattle it takes about twenty-four hours to operite on the bowels, while in sheep, pigs and dogs it only takes about twelve luurs to operate on them. The best way to give Cistor Oil to pigrs and dogrs is to give 2 tablespoonfuls every night and morning until you get the action required.

\section{CATECHU.}

Catechu is got by boiling the chips from a tree that yrows in Africa and Southern Asia. The form that it is mostly used in practice is known as Tincture of Citechu.

Its Action and Use.-It acts as an astringent on the bowels or diarrhued. Thus it is used in cises of diarrhea, and it clecks it in most animals. It is also used for coloring the White Lotion, tnd a few drops makes it a nice dark color.

Dose.--lincture of Catechu-For hornes, 2 to 4 drams or 2 to 4 teaspoonfuls; cattle, 4 to 6 drams or 4 to 6 teanpunfuli; sheep, 2 drams or 2 teaspoonfuls; pigs and dogrs, 1 dram or 1 teaspontul. These doses may be given in gruel or a pint of luke warın water three or four times a day intil the diarrhcea is stopped.

\section{CALOMEI.}

Calomel is got from the mineral ':inglom. It is prepared for medicine in the form of a heavy ivlite powder.

Its Action and Use. - Its chicf action is ats a physic, and also clears the bile from the liver. It is given in cases of jaundice and 
other liver troubles. It is also used for drying up thrush in the feet of horses, where it is explained how to use it.

Dose. - The way to give it to a horse is to combine tram of calomel with 4 drams of bitter aloes and give it in the form of a ball. For how to mix a ball look among the receipts at the back of this book. For cattle give 1 dram of calomel with I pint of raw linseed oil.

\section{CROTON OR.}

Croton Oil is got from the seeds of a tree that grows in the southern parts of Asia.

Its Action and Use.-It is a very severe physic when given internally. It is sometimes given to cattle and horses when the bowels are stopped and you cannot get a passage, but is never given until all the milder physic medicines fail.

Dose. - For horses, 15 to 20 drops; cattle, 50 to 40 drops; sheep, 5 to 10 drops; pigs and dogs, 2 to 3 drops. For horses and cattle, give it in a pint of raw linseed oil; ur sheep, give in a half a pint of oil, and for pigs and dogs, give it in two $t=2$, lespoonfuls of castor oil.

\section{CELORATE OF POTASH.}

Chlorate of Potash is got from mixing other medicines together, and is b. glit in the form of crystals or in a white powder.

Its Action and Use.-Its princinsi action is to thicken tie blood in diseases where the blood is too thin, such as in button farcy. It is also very soothing in cases cf sore throat.

Dose-For horses, 2 to 4 drams or 1 teaspoonful; cattle, 2 :a 4 drams or 1 teaspoonful; sheep, 1 d:am or teaspoonful; pigs and dogs, $\frac{1}{2}$ dram. The way it is used for sore throat is to put a teaspoonful on the tongue three times a day.

\section{CAUSTIC POTASR.}

Caustic Potash is got from pearl ashes. It is put up in white pencil-like sticks.

Its Action and Use.-It is never given internally, but is used to burn warts and growths by wetting the stick and rubbing it over them. It is also used for burning poisonous wounds to kill tho poison, such as dog bites. The sticks must be kept in a corked bottle, for the air dissolves them. While using the stick wrap a piece of paper around the end you hold in your hand so it will not burn your fingers. 
CHLORIDE GF ZINC.

Crloride of $Z$ inc is got from the mineral kingdom. Thi: medicine is generally bought in the torm of round white pencit lit.$^{\circ}$..

lis Action and Use-Its principal action is as a powerful caustic for buraing off growths, warts, etc. It is not used in ternally.

\section{CREOLIN.}

Creolin is one of the many products of coal tar which is gin from the mineral kingdom. It is buught in the form of a thick. dark fluid and smells like tar.

Its Action and Use.-It is used in the form of hea'ng lotions for wounds, scratches, grease and such like diseases. The etrength to use it in the form of a lotion is $1 / 4$ ounce or 1 table. spoonful to the pint of water, shake well before using. It is alsu I rery effectual remedy for killing lice, ticks or fleas on an! animal; also used in mange and scab in sheep; the strength to us: it in cases of this kind is $1 / 2$ to 1 ounce $6 r$ from 2 to 4 tablespoon. fuls to the pint of water, shake well before using. Creolin is a very cheap medicine, it is used a great deal now and is still gainin: in favor. It is best to buy the Creolin in its pure state and mix it into washes and lotion as you want to use it, for when it is mixed with water for some time it loses its strength, so you see the necessity of buying it in its pure state and mixing it as you want to use it.

\section{CRUde petroleum OIl.}

Crude Petroleum Oil is got from the mineral kingdom and is the oil as it comes out of the ground.

Its Action and Use.-It is principally used for oiling horses' ieet in the form of hoof oils; it is also a great remedy for killing ringworm on cattle, horses and other animals; the way to use it in: cases of this kind is to paint it around the ringworm; it is a very cheap aud effectual remedy. See ringworm on cattle.

\section{DIGITALIS.}

Digitalis is got from the leaves of a plant that grows in many parts of the country. The leaves are died and ground, and this is the form we buy it in.

Its Action and Use.-It is a heart and :ung tonic. It is used mostly mixed in powders that are given in weakening diseases, euch as influenza, distemper, and lung troubles. It is also some. times mixed in powders that are given for heaves. 


\section{GAMBOGE.}

Gamnoge is grot from the s.lp of it tree that grows in Southern Asia. The form gimboge is used in is a yellow-white
powder.

Its Action and Use.-It is a powerful physic, mostly used for cattle where mild physics, such as salts and linseed oil, fail. In griving it to caltle it is combined with other medicines in this form:

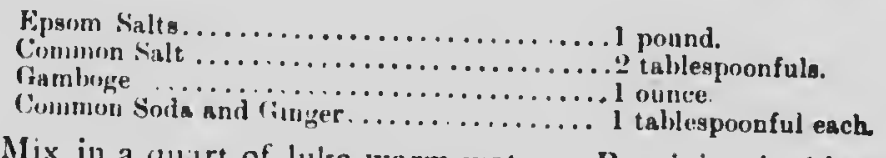

Mix in a quirt of luke warm water. By giving it this way it makes a powerful physic; it very rarely fails, and is used in bad cases of constipation of the bowels and impactions of the stomach.

\section{GENTIAN.}

Gentian is got from the root of a plant that grows in the mountainous parts of Europe. The root is dried and ground, and this is the form it is used in.

Its Action and Use. - It is a bitter tonic for the stomach and system in general. It is used in all kinds of powders that are given to animals that are weak and run down in condition and require a ton $\mathrm{c}$.

Dose.-For horses, 1 tablespoonful; cattle, 1 tablespoonful; sheep, 1 teampoonful; pigs and $\operatorname{dogs,} 1 / 2$ teaspoonful. These doses may be given twice a day in food or on their tongue with a spoon.

\section{GINGER.}

Ginger is got from a plant grown in South America and the West India Islands. The plant is dried and ground, and this is the frrm it is used in.

Its Action and Use.-It acts as a stimulant, relieves the gusses and sweetens the stomach, and is used to a great extent with physic drenches to keep it from griping; and is also used in medicines used for colic, indigestion and a great many other diseases.

Dose.-For horses, 1 large teaspoonful; cattle, 1 tablespoonful; sheep, 1 small teaspoonful; pigs and dogs, $1 / 2$ teaspoonful. These doses can be given every two or three hours. 
HYPOSULPYIIE OF SODA.

Hyposulphite of Suda is go: from the mineral kingdom, and is used in the form of a white powder or crystals.

Its Action and Use. - It is a great blood purifier and is combined with equal parts of gentian, and is used to ciean the hlood and build up the system after weakening diseases. The way to use it is to take lyposulphite of soda one-half pound and gentian one-half pound, mix well together and give of the imixture as follows:

Dose.-For horses, 1 tablespoonful; cattle, 1 tablespoonful; sheep, I teaspoonful; pigs and dogs, $1 / 2$ teaspoonful. The above dose can be given two or three times a day according to the case.

\section{IODINE.}

lodine is got from sea plants, and is used in the form of a dark brown tincture.

Its Action and Use.-It is not often used internally, but is used externally for a sweat blister, for blistering thickened glands by painting it on the lump witl 1 a feather once a day until it blisters, then grease the parts and let it go for two or three days until it heals up, then wash it off with luke warm water and soap and blister again as before mentioned.

\section{IODIDE OF POTASSIUM.}

Iodide of Potassium is got from the mineral kingdom, and is used in the form of a white crystal powder.

Its Action and Use.-Its chief action, when given internally, is an absorbant, $i . e .$, it is given in dropsy of the belly and chest to absorb the fluid; it is also used where there is a thickening around the throat, legs or milk glands; but is not used to any great extent on account of it being sery expensive.

Dose.-Mix it with equal parts of ground gentian root and give a teaspoonful to a cow or horse twice a day; one-half teaspoonful to other animals.

\section{LIME.}

Lime is got from the mineral kingdoin. Internally it is used in the form of lime water, and is sed where the stomach is deranged, also in cases of diarrhoea, and is a good thing to sweeten the stomach.

Doses,-lior horses. 1 onnce or 4 tahlespoonfuls; cattle, 1 ounce or 4 tablespoonfuls; sheep, $1 / 4$ o:ance or 1 tablespoonful rims and dogs, 1 teaspoonful. Lime water is sometimes used for 
neavy hurses by throwing 1 ounce or tablespoonfuls into theil drinking water twice a day. Unslacked lime is used for disin. fecting stables, etc., by dusting it in its dry form around on the floor.

\section{LLWSEED.}

Linseed is used mostly in the forms of linseed meal and raw linseed oil, which is got from flax se :d.

Its Action and Use.-Raw linseed oil is given as a very mild physic, or what is called a laxative. The dose of the oil is one pint poured down as a drench In all cases, after giving it to horse or cow, allow them to stand in the stable the next day and feed light for a few days. Linseed meal is used mostly, when given internally, for fattening cattle and for animals recovering from weakening diseases; but the flax seed itself boiled up is better for feeding young and sickly enimais than the linseed meal. Linseed meal is also used cor drawing poulticss, and is one of the best that can be got, and should alvays be mixed with boiling water.

\section{LAUED ANUD.}

Laudanum is usec in the form of a tincture, and is a prepara. tion from opiu..., which is got from a plant that glows in warm parts of Asia.

Its Action and Use.-It is sometimes used extern lly for rubbing on painful swellings. In using it this ivay use one-third tincture of laudanum and two-thirds white liniment, apply three times a day after bathing. It is used internally in almost every disease where there is pain (which can be seen by looking through the diseases and treatment of this book), it relieves pain and spasms, and in this way helps greatly to check inflammation.

Dose.-For horses, 1 to 2 : $\because$ nces or 4 to 8 tablespoonfuls : cattle, 1 to 2 ounces or 4 to 8 tas:sspoonfuls: sheep and pigs, 2 to 4 drams or 2 to 4 teaspoonfuls; dogs, 20 tu 25 drops. It is given in a pint of luke warm water as a drench, and may be given as often as every two hours in severe cases.

\section{MONSILL'S SOLUTION OF 'RON.}

Monsell's Solution is a preparation of iron which is got froin the mineral kingdom. It is used in the form of is brown, sticky liquid.

Its Action and Use.- Its chief action is for stopping Mlood in a wound of any kind, and also , or scahbing the wound over. It is a great remedy for open joint and leaking of the navel in loals. it is applies to the parts with a featler lour or tive simes in dity. 


\section{MARSHMALLOWS.}

Marstmallows is got from a plant that frows is, this :ountry, generally in the neightiorhood of rivers.

Its Action and Use. - It is chiefly used i foultice, mixed hall and half with linseed meal. It makes one of the most effectual trawing and soothing poultices there is. It is also used when boiled, the tea f:om it is mixed with luke warm water for bathing the milk-bag, to g.rget, milk-fever, etc.; it also makes a very soothing bath for sore or irritated wounds or swelling. Use one teacupful of the tea to a pint of luke warm water.

\section{MUSTARD.}

Mustard is got from a plant which grows in most parts of Europe. The seeds are dried and ground, and this is the form we use it in.

Its Actlon and Use.-It is chiefly used for mustard plasters which are applied over the bowels in severe casee of colic or inflammation to relieve the pain and check the inflammation; also in lung troubles, applied over the ribs and chest, and also the back in disease of the kidneys, and around the throat for sore th-oat. To make a mustard plaster of ordinary strength for a thin-skinned horse take a quarter of a pound or mustard, two tablespoonfuls of flour and enough vinegar to rrake it in the form of a paste. In very severe cases use the mustard and vinegar without the flour on catt!e and horses with a very thick skin. Instead of applying it to an animal with a cloth just rub it into the hair over the parts you want blistered.

\section{NUX VOMICA}

Nux Nomica is got from the seeds of a small tree that grows in India and Australia. These seeds are dried and ground, and it is used in this powdered form.

Its Action and Use.-It is a nerve stimulant, and is usea in all cases of paralysis where the nerves have lost their power to st. angthen them. The way to use it is to take equil parts of gentian and powdered Nux Vomica, mix thoroughly, and as a dose for horses and cattle give one teaspoonful three times a day in the feed or on their tongues with a spoon; for sheen, pigs o. dogs give one-half teaspoonful.

\section{NITRAIE OF SILVER.}

Nitrate of Silver is rot from the mineral kingdom, and is used in the form of whit pencil sticks. 
Its Actlon and Use.-It is used for hurning off warts, proud flesh in cuts and growths in any part of the body hy just wetting the stick and rubbing it to the parts. Keep the sticks corked in a bottle for they dissoive when exposed to the air.

\section{NITRATE OF POTASH OH SALTPETRE.}

Nitrate of Potash or Siltpetre is got from the mineral kingdom, and is used in the form of a white crystal powder.

Its Actlon and Use.-Its chief action is on the kidneys and blood, it causes the kidneys to secrete an extra amount of urine. It is used a great deal in practice in almost all lung troubles, also in cases where the blood is bad and where the sheath and legs are swo len.

Dose.-For horses, 1 tenspoonful; eattle, 1 teaspoonful; sheep and pigs, teasponntul. If given for the kidneys, give once a day; if for lung troubles, see diseases of the breathing urgans.

\section{OLIVE OR.}

Olise Oil is got from the seeds of an evergreen tree that grows in Southern liurope.

Its Action and Use.-It is not used internally to any extent, but is used externally for soothing and healing irritated wounds. It may be used in its pure state or be mixed with carbolic acid10 drops of carbolic acid to 4 ounces of olive oil.

\section{OIL OF TAR.}

Oil of Tar is a product of the pine tree, and the form it is used in is of a dark, thick, sticky liquid with a tar-like smell.

Its Actlun and Use.-It is chiefly used cases of ch:onic cough and is a very effectual remedy. Give a teaspoonful three times a day in the horse's feed, or on his tongue with a spoon.

OXIDE OF ZINC.

Oxide of Zine is got from the mineral kinglom, and the form we get it in is of a white, fine powder.

Its Action and Use.--It is mostly used in making up healing salves, and is used in the same -roportion as the receipt that is given in chapped or sore te c cows.

\section{OIL OF MALE SHIELD FERN.}

Oil of Male Shield Fern is got from a shrub that usually grows along the sille of the road in most temperate countrict. Is is got in the form of a dark, thick, oily liquid. 
Its Actlon and Use.- This medicine is a most effectual remedy for worm-, especially tapeworins, in all animals.

Dose. - For horses, 3 to i drams; cattle, 3 to drams; sheep and pigs, : to 2 Irams; augrs, to I Jram. In giving it to cattle a.ld horses have $11 \mathrm{am}$ starved for twenty-four hours, then give the above mentiunes jose mixed in a pint of raw linseed oil or gruel; feed very light for three day and if the worm has not come away repeat the suse every thud day until it does. In giving it to sheep and pigs, give it in the same manner, only in half the quantity mentioned of raw linseed oil or gruel. In giving it to dogs, give it in half a teacus 1 of new milk, in the same manner as tor horses dind idtle. Fin lurther particulars how to use it look at tapeworm in the different anımals.

\section{PEPPER.}

Black pepper, wisch is the kind mostly used for animals, is got from the berries of a climbing plant that grows in the West Indi-s.

Its Action and Use.-lt is used internally as a stomach stimulant to heat the stomach and bowels, and in this way helps to relieve the pain in colic, indigestion, etc.

Dose. - Fo horses, I tablespoonful: cattle. I tablespoonful ; sheep and pigs. I teaspoonful, dogs, teaspoonful. In mixing up this drench it is often combined with wisky, and makes a good coli drench.

00ASSIA CBIPS.

Quassia Chips are got trom a handsome tree at grows in the West India Islands. It is odorless but bitter to taste.

Its Action and Use- It is used mostly es in injection for pinworms. To prepare if for injection refes to pisworne in horses.

\section{SULPHORIC ACTD.}

Sulphuric Acid is a product of the mineral kingdom, and is got in the form of a light brown liquid.

Its Action and Use.-At one time it was used a great deal as a caustic for burning warts, etc., but is not so much used now as it is too irritating, its place being taken by better caustics, such as chloride of zinc, nitrate of silver and caustic potash. It is used externally in the form of liniments. How to mix and use it, refer to the receipt for acid liniment in the back of this boak. 
SULPEURIC ETHER.

Sulphuric Ether is prepared from sulphuric acid and rectified spirits of alcohol, and is used in the form of a clear liquid with a very strong odor.

Its $\Delta$ ction and Use-It is used a great deal for putting animals asleep for operaticns, especially for dogs. As to how to use it, refer to "how to spay a bitch." It is sometimes given for indigestion or colic, both in horses and cattle, to relieve the pain and gases.

Dose-For horses and cattle, 1 ounce or 4 tablespoonfuls mixed in a pint of luke warm water, and can be given every two hours. Where the $p$ in is severe, it is a very effectual remedy.

\section{SULPHATE OF COPPER.}

Sulphate of Copper, blue vitriol or blue stone is got from the mineral kingdom, and is got in a blue crystal form.

Its $\Delta$ ction and Use.-Its chief action when given internally is for checking discharges, such as nasai gleet or chronic catarrh, and whites or leucorrhcea. When used for this purpose, refer to the receipt to be used internally in the above named diseases. When used externally, it is used for wounds that are not healing well and have proud flesh in them by grinding it fine and dusting it on the wound every two or three days according to how much it burns it.

\section{SULPHATE OF IRON.}

Sulphate of Iron, or commonly called green vitriol, is got from the mineral kingdom, and is used in the forin of a crystal, similar to sulphate of copper, only of a lighter shade in color.

Its Action and Use.-It is one of the best mineral tonics that we have, and is used combined with gentian, in equal parts, for almost every case where the system is run down and needs building up. For horses and cattle give a teaspoonful three times a day; for sheep and pigs give one-half a teaspoonful. It is also used in the same form for killing long round worms and pinworms in horses. For full directions as to how to use it in this case refer to the receipt of worm powders given at the back of this book.

\section{SULPEATE OF ZINC.}

Sulphate of Zinc is got from the mineral kingdom. It is used in the form of a white crystal puwder, and resembles Epsom salts in appearance. 
It Action and Use.-When used internally it is in the form of an emetic that is to cause vomiting. As to how it is used refer to "dogs poisoned with rat poison, strychnine and arsenic." When used externally it has a healing action. How to use it, refer to the receipt of white lotion at the back of this book. It is also used as a drying wash for clap or gonorrhcea in horses and whites in mares. As to how to mix it refer to those diseases.

SUGAR OF LEAD.

Sugar of Lead, also called Acetate of Lead, is got from the mineral kingdom.

Its Actlon and Use.-It is not much used internally, but is used outwardly for healing washes, such as white lotion and eye wash, which are fully explained at the back of this book.

SALICYLIC ACID.

Salicylic Acid is got from a plant. It is used in the form of - white powder.

its Action and Use.-It has a special action in cases of rheumatism. As to how to use it, refer to the receipt given for rheumatism in horses and cattle.

SALT.

Common Salt is got from the mineral kingdom.

Its Action and Use.-It is an essential article of food, and something every animal should have regularly. Horses, cattle, sheep and pigs should have it in front of them all the time for, it should be remembered, stock cannot thrive well without it. Rock salt is the best form in which to have it as the animals can lick it whenever they want it. It is used externally by throwing a handful of salt in a pail of luke warm water, and in this form it makes a very effectual wash for bathing swellings and wounds.

SWEET SPIRITS OF NITRE.

Sweet Spirits of Nitre, or Nitrous Ether, is chiefly a preparation of alcohol. It is got in the form of a clear liquid which bas a sweet taste and smell.

Its Action and Use.-In small doses it acts on the kidneys and skin. For this purpose give horses and cattle a quarter of an ounce or one tablespoonful in drinking water once a day. For sheep, pigs and dogs give teaspoonful in their drinking water or food once a day. In large doses it acts on the bowels and stomach to relieve pain and gases. Thus it is good in the differ. ent forms of indigestion and colic. 
Dose.-For horses, 1 ounce or 4 tuilespuontuls; cattle, 1 ounce or 4 tablespoonfuls ; sheep, 1 ounce or 2 tablespoonfuls ; pigs and dogs, $\downarrow$ ounce or 1 tablespoonful. Mix in a pint of luke warm water and give as a drench. For how often to give it refer to the different diseases it is used in. This is a medicine that is used a great deal in practice, as you will see all through the book, and should be thoroughly understood.

\section{SPIRITS OF TURPENTINE.}

Spirits of Turpentine, also called Oil of Turpentine, is got from a tree. It is used in the form of a clear, oily looking liquid.

Its Action and Use.-Internally for horses and cattle it is used in one ounce or four tablespoonful doses mixed with a pint of raw linseed oil in severe cases of acute indigestion and colic to relieve the pain and gases; it is also used in this proportion for killing the long round worms and bots in horses. For further particulars turn to bots and long round worms in horses and other diseases it is used in. Internally for sheep and pigs the dose of turpentine is one-quarter of an ounce or one tablespoonful mixed with half a pint of raw linseed oil. It is used for the same purposes as it is in horses and cattle. Outwardly it is used for making liniments, and for how to use it refer to the receipts for making white linement and acid liniments at the back of this book.

\section{SALTS.}

Salts are used in two forms; Epsom and Glober. Both kinds are got from the mineral kingdom, and are in a white crystal forr.

\section{EPSOM SALTS.}

Its Action and Use.-Its chief action is as a physic for cattle, sheep and pigs, and is used to a great extent, as you will notice on reading the treatment of the above mentioned arimals. Although salts is a good physic it should not be given to horses, aloes being far the best physic for them.

Dose. - Cuttle take from one pound to one and one-half pounds dissolved in a quart of luke warm water with a tablespoonful each of ginger and common soda and given as a drench. This physic takes twenty-four hours to operate on the bowels. It is alwaye best after giving a dose to wait twenty-four hours for an action before giving any more. Sheep and pigs take one-quarter of a pound dissolved in a pint of luke warm water with a teaspoonful each of ginger and common soda and given as a drench. 
Wait from twelve to aixteen houre for an action on the bowele be fore giving any more.

$$
\text { GLOBER SALts. }
$$

Its Action and Use.-It is not so much used as the Epsom Salts, but is used in borses and cattle for their blood by grinding it up fine and giving a tablespoonful in a hot mash every night.

\section{SULPHUR.}

Sulphur, or Brimstone, is got from the mineral kingdom. It is used in a yellow powdered form.

Its Action and Use.-It is a great medicine, when given internally, to ect on the blood and clear it. It also acts on the skin and helps to kill parasites or germs in the skin, thus it is good in mange and other skin diseases.

Dose-For horses, 1 tablespoonful; cattle, 1 tablespuonful; sheep, 1 teaspoonful; pigs and dogs, 1 teaspoonful. Give every night in a hot mash or soft food; hut it is best given combined with gentian root and nitrate of potash or saltpetre as is explatined in the treatment of swelling of the limbs (anasarca) in horses.

\section{VASELINE.}

Vaseline is got from the mineral kingdom and is used in the form of a yellow salve.

Its Action and Use.-Viseline has a very healing and soothing action on wounds or irritated parts, and is used in nearly all kinds of healing salves, also for mixing blisters, etc.

\section{VERDIGRIS.}

Verdigris is a preparation got from the copper salts, and comes from the mineral kingdom. It is used in the form of $a$ blue, fine, heavy powder.

Its Action and Use-It is not much used now internally, a sulphate of iron and copper take its place. It is used for making up healing salves for wounds, etc. For how to une it see the receipt for greon salve. 


\author{
CHAPTER 11. \\ RECEIPTS.
}

WHITE LINIMENT.

Proportions to make one quart of the liniment. Use either a quart hottle or a quart self-sealer to mix it in:

FIRST. - Put in one-half pint of hard water.

SEcoND. - Put in two ounces or eight tablespoonfuls of spirits of turpentine and shake thoroughly for five minutes.

THIRD. - Beat up one hen egg and put it in and shake thoroughly for five minutes.

FourTH. - Put in two ounces or eight tablespoonfuls of methylated spirits of alcohol and shake thoroughly for five minutes.

FIFTr.-Put in two ounces or eight tablespoonfuls of strong liquor ammonia and shake thoroughly for five minutes.

Sixth. - Put in enough hard water to make up a quart, then shake thoroughly and the liniment is ready for use.

This is one of the most effectual remedies known for all kinds of sprains and bilises where the skin ie not brotren. The longer this liniment stands (if the bottle is kept corked) the stronger and better it gets for using. For making larger or smaller quantities of the liniment add to or take from the proportions given for one quart.

\title{
WHITE LOTION.
}

Proportions to make up one quart of White Lotion. Use either a quart bottlo or a quart self-sealer to mix it in.

Put in one-half ounce of each of the following: Sulphate of zinc, sugar of lead and pulverized alum, add enough water to make a quart and shake thoroughly.

This makes a most effectual lotion for hoaling all kinds of wounds and bruises where the skin is broken, also where the skin Is irritated, such as scratches, grease, otc.

\section{ACID LINMENT.}

Persons getting this liniment that are not experienced in handling drugs had better get the druggist to mix it for them, a it is a little dangerous mixing the sulphuric acid with othor drugs and it requires to be carefully handled. The following are the pro portions lor one quart which is best mixed in a quart bottle or a quart self-sealer: 
First. - Put in two cances or eight tablespoonfule of spirite of turpentine.

SRCond. - Put in one-half ounce of sulphurlc acid; pour this very slowly into the bottle by letting it run down the inside of the bottle which is better turned sideways. Take about fve minutes to pour lt in.

Thind.-Pour slowly into the bottle two ounces or eight ublespoonfuls of methylated spirits of alcohol.

FouRth.-Pour in enough cider vinegar to make a quart, then shake well and it is ready for use.

It is most effectual sweat blister for removing puffy enlargements, such as bog spavin, wind galls, thoroughpins and other puffy swellings around the legs, by apiying it every third day. It is also an effectual remedy for sweeny, curbs, etc., wbrre you want to work the horse. This is also an effectual remedy for rheumatism by rubbing the affected joints every third day. It is also used in various other ways as you will notice through the book.

\section{CREOLIS LOTION.}

The following proportions are for one pint of Creolin Lotion:

First.- Pour in one-quarter ounce or one tablespoonful of creolin into a pint bottle.

- SzCond.-Pour in enough hard water te make a pint, shake well and then it is ready for use.

This makes an excellent healing lotien for wounds, and by making it double strength it makes a most effectual wash for destroying germs, parasites, lice or ticks on all animals. It is used In various other places wo you may see in this book.

MTE WAS

The following proportions are to make an eight-ounce bottle of aye wash:

Bulphate of Zine.

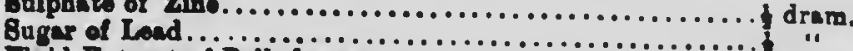

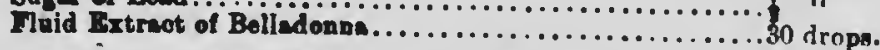

Add onough hard water to make eight ounces, shake thoroughly and the wash is ready for use.

This makes a very cheap and effectual wash for sore eyes, or sores around the oyes in all kinds of a nimals by applying tuice day after bathing with luke warm water or new milk. 
CARBOLIC UIL.

The following proportions are for $\$$ four-ounce bottle: Olive or Sweet Oil ............................ unrices. Shake well together and this makes a splendid application
for healing wounds. PHYSIC DRENCE FOR HORSES.

Bitter Aloes

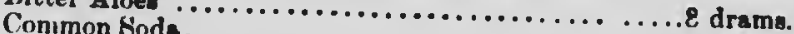

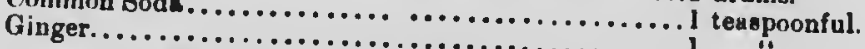

Dissolve in a pint of luke warm water and give as a drench, always allowing the horse to stand in the stable a day alter giving it.

This is one of the best physics known to clean out a horse's stomach and bowels, and also to purify his blood.

\section{PHYSIC DRENCH FOR CATTLE.}

Epsom Salts ............................

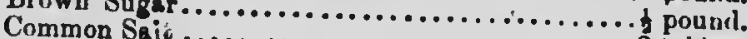

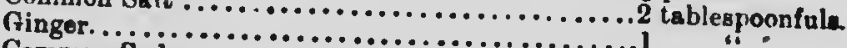

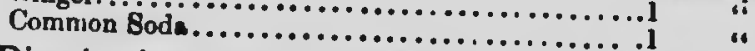

Dissolve in a quart of luke warm water and give as a drench. This makes good general physic for a cow that is not thriving well.

\section{PHYSIC BALL FOR BORSES.}

This contains the same ingredients as the physic drench, only it is prepared in a different way, as follows:

FIRST.-Grind up eight drams of bitter aloes good and fine. rolled.

SECOND. - Add a few drops of water to make it sticky when

THIRD. - Roll it In a teaspoonful of ringer into the form of a long ball, so it will be about one-half inch in diemeter and two or three inches long.

Founra.-Roll it neatly in a piece of papor, and hofore giving It to the horse oil the paper, so it will elip down easily; shove it well back into the mouth and hold the horse's head up until he swallows it. The action of this ball is the ame as the action of the physic drench.

BALI TO $\triangle$ CT ON THE LIVER AND WORMS.

First.-Grind up four drams of bitter aloes, moisten it and roll it into the form of a ball.

Sacowo.-Make a hole in the end of the ball and drop in one-half dram of calomel, wrap it in paper, oil the paper and give it so you would a physic ball. 
CRED SALTE.

The following are the proportions for making green salve:

First.-Take mutton tallow, one-hilf pu:md; lard, threequarters of a pourd; beeswax, two ounces; put in a pot and siir over a hot fire until it is melted.

Sacond.--Keep on stirring, and puur in one-half ounce of verdigris. Keep stirring it over the fire for fifteen minutes.

THIRn. - Then take it off the fire and add one ounce of spirits of turpentine and keep stirring it until it is cold, then it is ready for use.

This is one of the best healing salves known, especially when a wound is nearly healed up, for it keeps the wound solt, draws the edges together and allows the hair to grow over better. The way to apply it to a wound is to melt it in a spoon and apply it with a feather.

\section{MERCURY BLISTER.}

Binlodid of Morcury ar Red Precipitate ................ it drame.

Vaneline of Lard....................................... d ounce.

Mix thoroughly and this is one of the best blisters for blister. ing boriy enlargements, such as splints, spavins, ringbones, sidebones, etc. Rub inis the part well, grease it three days after, and in thre- weeks repeat the blister, and repeat in like manner until you have the required action. In case you want a heavier blister add another half dram of the biniodid of mercury. For further directions look at the separate diseases $a b c \%$ mentioned.

RLT BLISTER.

Rowdored Contharides or Bpaninb Fly................ it drams.

Vusoline or Lard................................... I ounce.

Mix thoroughly, and this is one of the best sweat blisters for blistering thickenings or enlargements in any part of the body where they are not on the bone. Use the same directions as a. given in the mercury blister.

\section{POWDERS TO ACT ON THB KIDNEYS AND BLOOD.}

Nitrate of Potanh or Saltpetro.....................t pound.

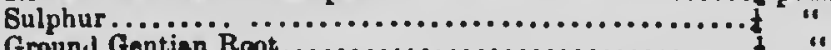

Ground Gentien Root.............................. "

Mix thoroughly and give a teaspoonful three times a day in the horse's food or on its tongue with a spoon. If it is a cow, give a tablespoonful twice a day; if a sheep, give a teaspoonful iwice a day. This is a good powder for starting an aninual to thrive, but before giving it, it is best to give a physic drench. If it is a horse, give aloes; if a cow, give salts. 
Balphate of Iron...... WORM PIIWDERS.

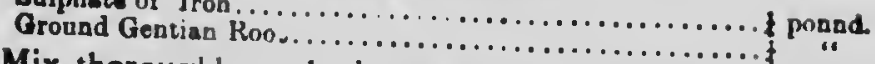
Mix thoroughly and give a teaspeonful three tincs a day in
the animal's food or on its tongue witlı a spoon. This powder is only intended for bots, round worms and pin worms in horses. It is also good tonic powrler. Before and after using tie
powder give a physic drench.

\section{COUGH POWDERS.}

Sulphur.

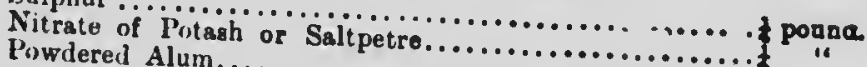

Mix thoroughly and $\ldots \ldots \ldots \ldots \ldots \ldots \ldots \ldots \ldots \ldots \ldots \ldots$

a horse or cow's tongue with a teaspoonful three times a day on give half a teaspoonful with a spoon, if $i$ is a sheep, pig a $\mathrm{i}$ 's. spoon. This is a splendide times a day on the tongue witt a throat, or sore mouth, and alsor for a gargle in all cases of sore good cough powder.

GENERAL CONDITION POWDER.

Nitrate of Potash or Saltpetro................... pound.

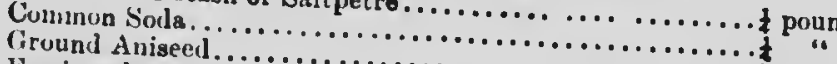

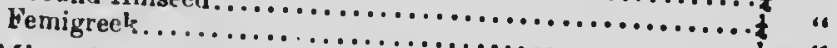

Mix thoroughly and give bran mash, but if in a case whereonful every night a in a hurry, rive a tablespoonfulten the animas horses that are night in a bran give a tablespoonful every Saturday

\section{RECEIPT FOR COLIC AND INDIGESTION.}

Eweet Epirits of Nitre

Tincture of Laulauum.............. ounce or 4 tablespoonfuls.

Flching's Tincture of Aconite...........

Common Suda... of Aconite......... 10 drops.

Ginger ............................ teas poonful.

Mix in a pint of luke warm water 1

two hours in cases of colic, wive as a drench every further particulars refer to dindigestion and inflammation. For

\section{HOOF OINTMENT}

Ruw Linseed Oil

Crude Petroleum (Oil.....................................

Neatsfoot Oil $\ldots$

Pino Tar.............................................. "

Mix well and apply every night with a brush all over and under the hoof-even a little in the hair above the hoof. Clean out the hoof before applging. 


\section{UST OF MEDICINES TO BE KEPT ON HAND.}

The following is a list of medicines that every stockowner should keep on hand for cas,s of emergency, that is, where he has an animal take sick with infammation, colic, indigestion, or alyy other disease that requires his immediate attention, he can give these medicines, while if he harl to go to a drug store for them at the time, he might lose the animal:

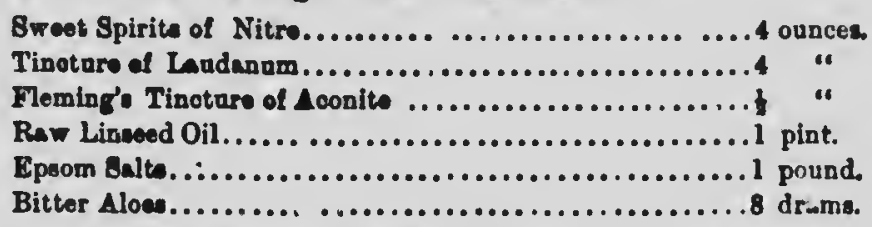

It is also advisable to have a bottle of white liniment and a bottle of white lotion on hand for, as they do not cest much when mixed by the quart, they are very handy to have on hand for sprains, sore shoulders, cuts, etc. As for the other medicines in the book they can be got at a drug store any time, as the cases they are used in are not so urgent. The cost of the list of medicines given is trifling, and by having them on hand and able to give it at the time the animal is noticed to be sick will often save the animal's life, whereas, if you had to go to a drig store at the time, the delav would cause the loss of the animal.

NoTE-In buying fluid medicine alwass take your botile to the drug store, for the new bottle often costs you more than the medicine.

\section{TAKE NOTICE.}

All the doses of medicines which are mentioned in the section of the book, dealing with Medicines and Receipts, are intended for an average sized animal, unless othernise mentioned, so in giving doses to smaller animals you nust regulate the dose to suit the animal. 


\title{
CONSULTATION AND ADVICE FREE OF CHARGE.
}

\begin{abstract}
Any person buying a copy of The Veterinary Science from one of our authorized agents will have the privilege of free consultation on any disease they do not understand, or anything in the hovis lhey want nore information about. In cases where a new dincise should break out, by sending the symptoms of the cane in full, and causes of the trouble as near as you can tell, We will furnish you by return mail, advice and prescription in fu!l-iree of c'. rge. Parties living in Canada should enclose a three isul hamp; if in the United States, five cents in silver, for relurn pinige. Alvice given on all kinds of operations, (cavirating rigs or original hornes a specialty). Address all mail unjer this heading to J. E. Hodgins, V. S., or to T. H. Haskett, secrolary of tice Veterinary Science Company, Lordon, Canada
\end{abstract}




\section{INDEX.}

\section{PATTI.}

\section{ANATOMK OF THE HORSF.}

livir.

Abrtominal Muscles........... 17

Bluduer, the ............... 34

Bone.....................

Bowels, the................ 3:

Breathing ................ 37

B. sachial Tulve or Air Cells..... 36

Carpus or Knee............... It

Cervical or Neck Bonew......... 10

Circulatory Syatem........... 24

Classes oi Bona............... 9

Coccygeal cr Muscles of the Tril. . 18

Coecygeal or Tail Bones. ......... 11

Coffin Joint ................. 14

Considerntion of Joints......... 13

Contents of Bone............... 8

Covering of Bone............... 8

Digeative Organe.............. 26

Dorual or Beck Bones............ 11

Ear, the..................... 54

Elbuw Joint................ 13

Eye, the.................. 55

Fallopian Tubes, the........... 43

Ferale Genital Organs, the..... 43

Fet lock Joint. ................. 14

Fetlock, Pastorn, Coffis Joints.... 15

Foetu or Young Aninisl Before

Birth.................. 46

Frog, the.................. 64

Genital Organm................ 40

Genital Organ of the Horne...... 40

Glands, the. .............. 33

Glutesl Muscles.............. 17

Gullet, the.................. 31

Hair ...................... 48

Houd Bones ,................. 10

Hip Joint ................. 14

Hip or Pelvic Bones............ 11

Hock or Tareus Joint............ 15

Hoof, the.

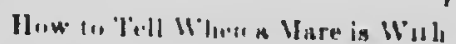

Fual..... $\ldots . . \ldots \ldots$ t7

llow to Till When an Artery is

Cut .......... . .... थ

Impurtant l":iuts of loints iu leckn 1.3

Involuntary Munclem.......... :0

Joints of Himl l.te........... If

Kidneys, tlue............... 3r

Larynx or Alamis Aple...... . 30

Liver, the................ 33

Lunibar or Sinall of li,w $\mathrm{k}$ liones. I]

Lungs, the. ................ 3 ;

Lyniphatic Systein ..........

Mammary (ilanda............ i;

Membranes of the Budy......... 34

Mucous Membraues........... 34

Muncle of Front Leg.......... It

Muecles of Hind Lcg.......... 19

Muscular System............ 10

Nasal Chambers or Cluambers of

the Head.... ............ 36

Nervous Symtem............ :

Nostrils, the............... 35

Number of Bones in Skeleton of

Horee.................. 19

Oesophagus, the............ 31

Organs of Reapiration......... 35

Ovaries, the ............... 43

Pancreas, the... ............ 33

Yastern Joint............... I4

Penis, the................ 1y

Process of Digestion........... 35

Rectum or Back Gut.......... 33

Ribs..................... 12

Socral or Rump Busus.......... II

Salivary (ilands ............ 26

Serotum, the .............. 40

Semen, the................ 42

Baroos $\quad \quad-8 \ldots \ldots \ldots \ldots \ldots$ : 


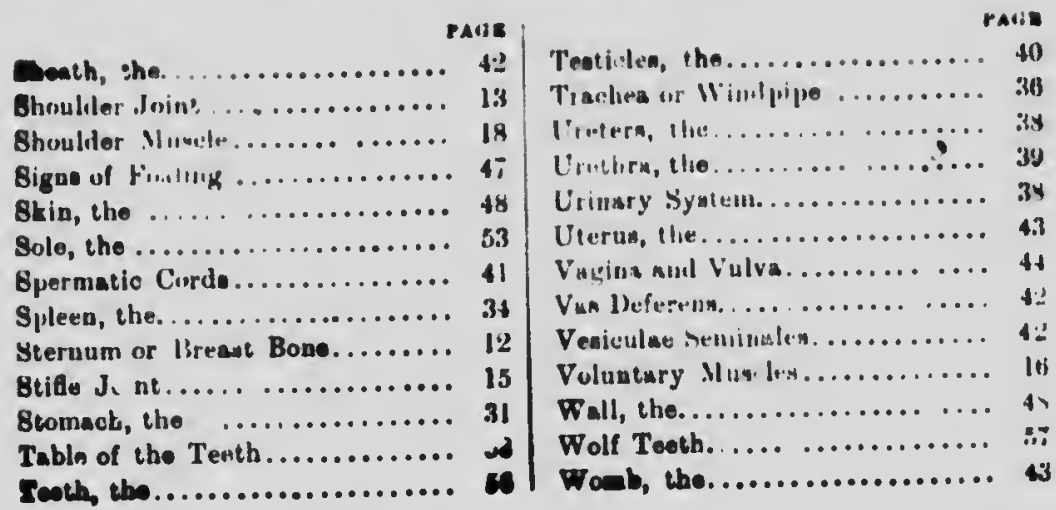

\section{INDEX PART II.}

\section{DISEASES AND TREATMENT OF THE HORSE.}

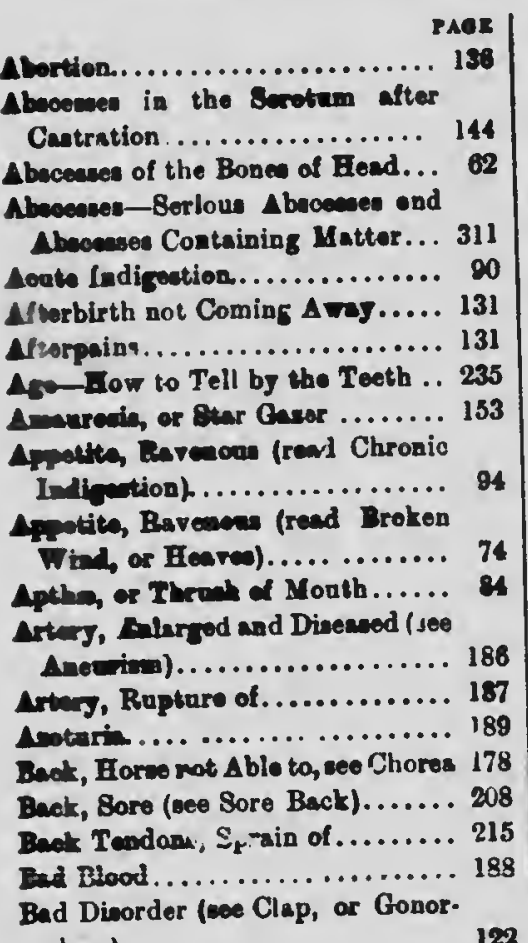

Bag, Enlargement of (see Rupture in Bar)................. $1+1$ Bag, Pentering in, After Cistra. thon, (see Abscesses in).... . . . . 144

Bes, Swelling or Dropsy of..... . 119 Barb. Wire Cuts (see II ounds anil

Trestment)... . . . . . . . . . 199

Eurrenes in the Mare......... 12!

Batard Stranglea............. iki

Baily-A che from Indigeation. ..... 94)

Ball-Ache from Infimmation .... ys

Belly.Aehe, or Colic......... 9; 4;

Belly, Dropey of. ........... I0.4

Bary-Muscles, Injuries of .......

Bis Head (Oateo-Porosis)........ I!)!

Big Leg................... 184

Bil Stones................. 111

Binding Up of the Bowels, or

Constipation .............. 100

Bladder, Inflammation of. . ...... 116

Bladder, Paralggis of.......... 11 s

Bladder, Btonet in........... 117

Bladder, turring Out of, or Inversion................ 117

Bled . Horan, How to........ 237

Bleeding at the Nose..........66 60

Blowding from Lunge.......... 6d 


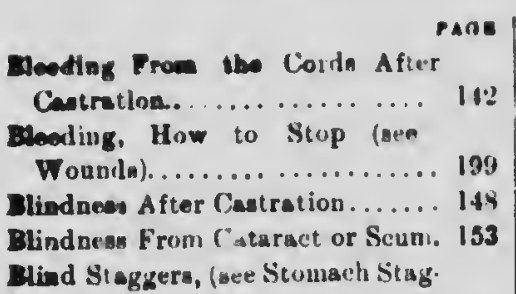

gere)... .............. 175

Bindnesw (nee Star (hazer)....... 153

Bisters in Mouth (see Aptlis or Thrash)............... 84

Bloating From Colle.......... 87

Blonting From Indigeatinn....... 80

Blood, Bsul................. 188

Blood, Barl, After Distomper (nee Butard Strangles).......... 105

Blood, Blot (see Nettle Rash)..... 169

Blood Poimoning. . . . . . . . . . ... 202

Blood Spavin. ................ 223

Bloody Mux, or Iysentury ....... 103

Blow on Head (see Bruin-Con.

contion of .............. .... 174

Dody, Disesses of ............. 202

2os Bpavin. . . . . . . . . . . . . . . 220

Bone Spavin............ . . . 186

Bone Below the Knec, Fracture of 217

BCres, Diveases of ............. 191

Bones of Hip Fractured.......... 209

Bones of Shoulder, Fructure of. . . 212

Bote....................... 94

Bound Up, or Constipation in Yonng Fonl................ 137

Bowels and Stomach, Diseases of. 90

Bowrels, Balls in..... .... .... 105

Bowels, Consing Down After Cas. tration (see Rupturej......... 143

Bowely, Coritug Down After Cas. tration (see Fatty lining).. . . 144

Bowels, Cunstipation or Stoplyage of ..................... 10n

Bowels, Jnflummation of ........ 98

Bowels, Intussusception of ..... . 101

Bowels, Protrusion or Turning Out of .............. 107

Bowels, Ruptnra of the Rectam or Pack buwel.............. 105

Bowels, Tumors or Abscesses in Bactam. 106
Rom

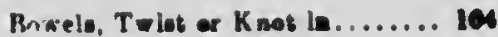

Hrasw, Cuncuasion of. .......... 174

firmu, Inflummation of......... 17

Brenkilown................. 18

Bresthing, Dificult (ees Ploner dynin)................ 7

Brentlung Organs, Dlecanes of.... Breaking Out After Dintemper (co

Busturil Stranglea)............ 10 Hreeding-Mares that Will $\mathbf{k}$

Breell ............... 12

Broken Back.................. 20

Broken Neck (nee Fracture of the

Bones of the Nect. . . . . . . . . . 803

Broken Wind or Heaves......... 74

Bronchitis.................. 73

Hruises of the Shunlder.......... 200

Bruises of the Nole of the Foot... 232

Bursal Enlargentents Around the

Koee and Fetlock............ 214

Button Farog................... 162

Caked Bag (see Infammation of

Milk Bay) .................. 185

Calf-kneed .................... 215

Cance ....................... 310

Canceroun Growthe in the Eye. .. 154

Cancers..................... 224

Capped Elbow............... 212

Cupped Huck. . . ... ........... 221

Care of a Horse, How to........ 238

Curies, or Lecayed Te t7....... 80

Cartilage of Ear, Dize "sd . .... 160

Casting un Aninal for an Operation 140

Castrating, Absoessen or Festering After. ................. 144

Castration, Bleeding After....... 148

Castration Blindness After..... 148

Cantration, Diseases and Troublo Following................. 139

Castration, Fatty Luning of Bowels Comiug Down After.......... 144

Castration, How to Treat Colt After................... 149

Castration, Inflammatlon of the Lining of the Belly, or Peritoni. tis, After................. 140

Castrution, Lockjow After....... 147 restration, Original ar Bip....... Ms 
Caulks................... . 231

Cereloro Spinal Mcningitis....... 177

Cheeks and Lips, Injuries to..... 85

Cheeks and Lips, Jaralysis of.... 85

Chest Founder-

See Coffin Joirt Lameness.. 232

Soe Sore Feet. .. ........ 227

Chest, Water in............. 72

Chill..................... 237

Choking with Odts............ 88

Chorea.................... 178

Chronic Founder.............227

Chronic Indigestion............ 94

Clamps, Cutting With......... 141

Clamps, Mediciney Used in....... 148

Clapp ('xunorrbca) ............ 122

Cleaning Not Coming Away...... 131

Club Foot................... 228

Coffin Joint Lameness.......... 232

Cold in Head................. 60

Colic-from Balls in the Bowels.. 105

Colic-from Indigestion.......... 94

Colie-spasinorlic ............. 95

Cilic-W Wind or Flatulent....... 97

Collar Galls (see Scalded or Galled

Shoulders)................. 006

Colt 111 (sec Distemper)......... 163

Colt-How to Treat After Castra-

tion.................... $1+2$

Cnncussion of Brain............ 174

Contagious Diseases -

Sinall Pox.............. 157

Glanders ...............158.159

Influenza.............. 160

Button Farey............ 162

Distenper............. 163

Bastard Strangles......... 165

l'ink kye............. lii.

Cont racted Feet (ste Sore Feet). . ‥2:2

Luntractell Heels-

Siee Coftin Joint lameness ... .

See Curw .................

Cord in the Bag Diseased After

Castration .................. 145

Corns..................... 2428

Costiveness from Tnmor in Bowel 106

Costiveness or Constipation...... 100

Cough, Chronic.............. 65

Cough from Bronchitis.......... 73

Cough from lieaves........... 74

Coughing (seo Spasms of the Mus.

cles of the Laryux)......... 66

Crack in Meel (see Quarter Crack) 231

Cracked Heels............... 166

Cramps of the Bowels (see Colic). . 95

Cráziness (see Inflammation of

Brain).................. 17\%

Crib Suckers................. 8

Crookedness of the Legs in Young

Fuals ................... 139

Curb.......................24

Cut by sharp stick (see Staked)...2219

Cut or Wound, l'oisoning of..... 20:2

Cuts of any kind (see Wounds and

Treatmeut).............. 199

Cuts of any kind around the Feet. 2032

Cuts of Eyelids.. ........... 15t

Cuts or Wounds (real how to

sew up)............... 199

Cuts or Wounds, Intlammation of. iut

Cuts or Wuunds, Modes of Healing :U1

Cuts or Wounds, swelling of (see

Inflammation of Wound)........ 201

Cutting by Searing.......... 14:2

Cutting Colts (see Castration).... 139

Cuttiny with Ligatures......... 1+2

Cutting with the Clamps........ 141

Cutting with the Eeraseur....... 141

Decayed Teetl. .............. su

Diabetes .................. 114

1)ialhragm, Spasms of........ To

1)iaphragm, livpture of ..... . . 77

liastrher.6............... 101

1harrlee. in Young Animaly..... 10.2

Inorritues in Soung Funls........ 137 


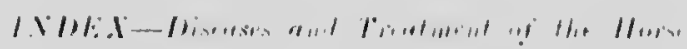

Disinfect Stahlo, How to (read How to Feed and Take Care of

- Unrse).

Disiocstion of the Stifle Bone.... 218

Jistemper................. 163

Distemper in Young Foal ....... 139

I) Irench Horse, How to.......... 237

1)ripping of U rine or Water..... 118

Drnoping Head (see Inflammation of Luugs)................. 69

Dropping Dead (see Rupture of Valves of Heart)........... 185

Dropsy of Belly.............. 108

Dropsy of the Belly Pefore Foaling 136

Dropsy of the Scrotum or Bag.... 119

Dymentery. .............. 103

Diveases of ............ 150

Running Sores of ........ 150

Desfness............... 150

Far Injuries or Cnts......... 150

Frost Bites of .......... 15l

Diseased Cartilage or Gristle of ................ 150

Eating ton much Whest........ 109

Ecraseur, cutting with........ 141

Eczems, simple............. 168

Elcphantiasi ............... 184

Elbow Joint, Lump at the Back of (see Capped Elbow).......... 212

Enlargement of Liver.......... 112

Enlargement of Navel.......... 148

Enlargement of Gaophagus or

Gullet.................... 89

Fralergement of Bag (cos Dropay of) 119

Knlar wunt - Pafy or Soft

Around the Knes or Fetlock. .. 214

Epirootio Collulitio............ 165

Ergotium ................. 313

Eye, Blinulness from Cataract .... 153

Eye, Canoerous Growth in ...... 154

Eye, Disenes of. ........... 151

Eye, Browth in Corner (see Infam. mation of Haw)........... 155

Eje, Inflammation of $\mathrm{Haw}$ in Cor. ner ................. 1nin

Bve, Injury to Tear Dnote....... 156

Bye, Lide Infured or Cat....... 156

D. Inemithtoding......... 187
Eyo, Bcum on (Cataract)........ 153

Kye, sore (Monnblindnees)....... 152

Eye, sore (Simples Ophthalmin;... . 151

Eye, Worm in (see Filaria Oculi) . 154

kyes, Yellow from Knlargement of

Liver .................... 112

Eyes, Yellow from Inflammation of Liver................ 110

Eyes, Yellow From Jaundice..... 111

Falling Away of the Muacles of the Hip After Fosling ........ 210

Falling Awsy of the Muscles of the Shoulder (see Sweeny) .... . 205

Falling Down (see Stomach Stag. gers)................ 175

Fulse Quarter.............. 232

Farcy, Button ............. 162

Farcy, Water (see Weed in Leg).. 182 Fatty Lining of the Rowels Com. ing Down After Castration..... 144

Feet, Club or Pumiced......... 2:28

Feet, Cuts of Any Kind Around

Them................. 232

Feet, Digeases of ........... 225

Festering in Scrotum or Bag After

Castration............... 144

Fetlock 1)ropping (see Breakdown) 218

Fetlock Joint, Sprsin of....... 215

Fetlock, over on (see Knuckling). . 216 Fetlock, over on in Colts (st:

Knuckling in Colts) ......... 216 Fetlock. Thickenings Around .... 217

Filstis Oculi............... 154

Firing, read.............. 19s

Fistule................ 31:2

Fistalons Withers............. 20144

Flagged liag (tee Garget)... . . . . 13.;

Fonl Bed Turned (lut........... 1:3:

Fosl, How to Tell When . Hure is in ................ . 1:3

Fosling, Difficulties Met With while................ 129

Fnaling and Disenses Following .. 1:33 Finling, Immerliate Signs of . . . . 1:24

Fuling, 'l'rnubles Following ..... 1.31

Foaling, l'ains After.......... 131

Fouling, Swellung of the Mare's Bully Befors............... 130 
race

real-The Natnral Way to Come. 124

Fosla, Constipsted or Bonnd Up. . 137

Fosls, Cronked in the Iegs....... 139

Foals, Diarrhoes or Scowers in

Young.................137

Foals, Diseases and Troulbles of . . 137

Foals, Distemper in.......... 139

Foals, Rheumatism and leaking of Navel................ 138

Foals, Weak in the Legs and Joints 139

Foot, Bruises of the siole... . . . 232

Foot, Cluh or Pumiced..... . . . . . . 228

Foot, Cut Froin Horse Stepping on (see Caulks)............... 231

Foot, Nail Run in......... . . 229

Foot, Pricks of in Shoeing ...... 230)

Fonnder in Chest (see Sore Feet), . 227 Founder-

Acute.................. 225

Chronic................. 227

Franture of the Bones Below the

Knee..................217

Eracture of the Bones of the Hock Joint. . . . . . . . . . . . . . . . 2222

Fracture of the Bones of the Knee 214

Fracture of the Bones of the Shoulder................ 212

Fracture of the Bones of the Tail.. 210

Fracture of the Hip Bones.. . . . . . 209

Fracture of the Neck Bones...... 203

Fracture of the Thigh Bones.. ... 219

Frog, Thrush in. . . . . . . . . 229

Fint Leg, Diseases of. . . . . . . . . 212

Frost Bite of the Ear......... 151

Frothing at Mouth......... . 86

Frothing at Vostrils, (see Rupture of Diapl. .gin)........... 77

Galled Back (ses Sore Back)...... 208

Galled or Scalded Shoulders...... 206

Garget................... 135

Genital Organs of the Horte, IDis. eases of ............... 118

Genital Orgun of the Mare, Dis. eases of ............... 121

Glanders-

Acnte................. 15?

Chronic............... lis

Glandera (see Nanal Gleet). . . . . 6 61
Glancoms ............. Pm

Gleet, Nasal . . . . . . . . . . . . . 6 61

Gunorrhea (('lap).............. 122

Good Puints About a llorse...... 234

Grease.................... 167

Growth in Eye............. 154

Growths, Angry Ionking (see

Cancer).................. 224

Growtis on the linil of the Penis.. 126)

Gullet, Diseases of $\ldots \ldots \ldots \ldots$ 78

(jullet, Paralysis of ........... 88

(iums, Sore (see Lampas)........ 7x

Hair Falling Off in Circles (see

Ringworm)............ 171

Head and Throat, Swelling Around 89

Head, Big (scon Big Heall) ... . . . . 191

Hear, Hlow on (see Concussiun if

Brain................. 174

Head, Disease of .......... 2112

Head, Drooping (see Infl:mın เtion of Lungs)................. 69

Heel, Cut From Overreaching (see Uverreach). . . . . . . . . 2:2:

Hearing (sce Deafuess). . . . . . lin Heart, Arterics and libul, Diseases of ............... 18.i

Heart, Rupture of Vulves....... 18.i

Heart, Palpitation of ... ... 180;

Heart, Palpitation of (sec sposma of Diaphragin)........... if

Heares, or Broken Wind....... it Heels, Cracked (zee Scratches) . . . I lifi Heel, Crack in (see Quarter Crark) 2:31 Hernis, After Castration. ....... 143

Hernis, Ventral. ............. 149

Hernia, Umbilical .......... 144

Hernia, Scrotal . . . . . . . . . . .. 149

Hind Leg, Diseases of .......... 21:

Hidebolund (see Bud Blood)...... Is

Hip Muscles, Sprain of ........211

Hip Musclen, Falling Away After

Fonling .............. 910

11ip .J oint Lamentegs........... 211 Hip, loint Knockel ()if (seo

Hipperl) ...............209

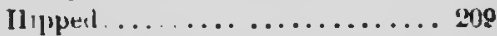

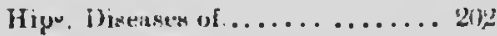

Hipu, lajuries to During Fnaling.. 135 


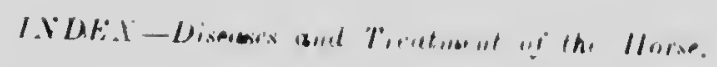

Hock Bones, Fracture of . . . . . Pari. Hick, Capped (nee Cinpled Hoek). 2321 Huck .Iolnt, Sivrain of . . . . . . . . 2...] Hof, Kough After a (ut Around the Top (see Fulke (uarter) ... 23:2 Horse, How u I)rench. ........ 235 Horse. How to Bleed. . . . . . . . . 237 Horse, How to Feel and Take Care of ................ 234

Ilorse, Less of Appetite (rea)

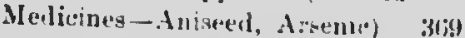

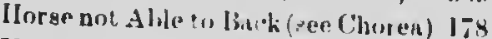

Horse not Alle to liet Up (sec Paralysis

Horse not Able to Get Up (see Broken Back) . . .......... 208

Horse Drolping lead (sev IIcurt Direase)

Horse not lloing Well (ste)-

Bad Bloul ............ 189

Chronic Indigestion........ 94

Worms. ............. In

Bots................ 94

Horse, Miscellaneous Informution. 234

Horse's Age, How w Tell by II is

Teeth................ 23.

Horse Stepping on Fuot (sce

Caulks)................ 231

How to Bleed a Horse. . . . . . . 237

How to Drench a Inrse......... 237

II tow fecd and lake Care of a

Horse................. 2.38

How to Examine a Sick Horse... 53

How to Tell a Horse's Age by II is

Teeth .............. 23.5

Hydrocele (aee Iropsy of the

Scrotum .............. 119

Hydropbobia............... Isit

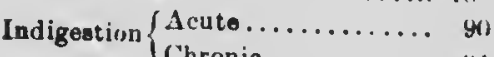

Intlammation (resd How to Tell

From Colic).............. gh

Inflanimstion of liluriler .......

Infimmation of $\left[B_{1}, w \cdot\right]_{s} \ldots \ldots \ldots$. . g

Ioflammatron of lBrain ....... 17:

Intlamanation of II aw of Eye .... 1.5.

Iuflunnialus of Kiilneys....11:3114

lottammation of Luuga........ 6 s
Infiturmation of tiver. PAls

Inflatrion of Liver. . ..... 110

Intiammation of l'arotid liland. . 87

Inthemination of Spleen........ 112

Intummation of Lining of Belly

(see l'critovitis)............ 107

Inthammation of Lining of Belly

After Castration (see I'eritonitis) 1.16 Infaumution of Spinal Cord..... I7: In Hitnmation of the Mllk liag ... I:3:1 Intisnumation of Tongue....... $\times$.3 Inflanmation of Tlirust. . . . . . $6: 3$ Intl anmation of Vein........ I87 Influmanation of Vugine, or Pas.

mage From Womb. ......... 1:14

In.tunntion of $\mathbf{W}$ umb. . . . . . 134

Intl mmatms of Wounds....... 2:1]

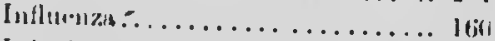
I ujurieg and Sprains of the hisee. $\because 13$ Infurits to Ducts of bise....... 156 Injuries to Ejclids........... 156 Injurieg to lijes and Cheeks..... s. Injurtes to Hips louring Fualing. . 1.3.; Injuries to the Var ......... Iix Injurins to the Penis.......... I19 Injurics to the Viacles of the Beliy 2418 Injuries to the Muscles of tlute Neck 20,3 Itujurieg (o) the Tungue........ 83 Int.rfering (Striking the Kuee . $: 13$ Initriking the Fetlock. 2l6 Inversiou of $: 1$, Bladler........ II7

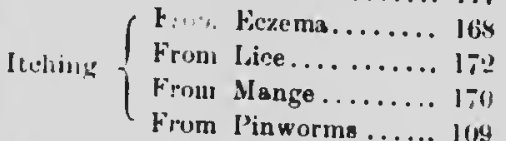
Jaundice, Frou Bilestones. ....... 111 Jaundice or Vellow. ......... 111 lerkıng of L.oks (sore Sitring'lalt) . 179 Joint (O) Kul,ming Our (swe Open

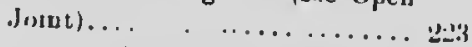

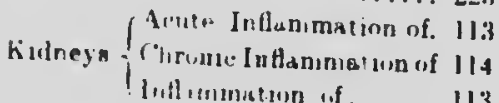

Killeol by Jightmmp. Apleataluce uf un Ammu . ...... ... 31.

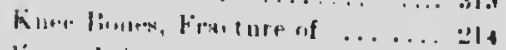
line, Injuा and viraina of .... 21:

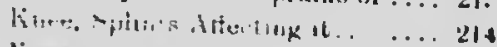
Kue $\operatorname{sprung}_{k}, \ldots \ldots \ldots \ldots \ldots \ldots$ \&! 


\section{PAGE}

Knee, Brelling on the Innide of (aee Striking the Knee).......2 213

Knuckling............... 216

Knuctling in Colte........... 216

Lamenes, Hip Joint. . . . . . . . . 211

Lameneas (see Rheumatiam). . . . . 225

Lamenees, Shoulder Joint...... 207

Lanteness, Stepping on Toe (see

Nail in Foot)............. 229

Lameness, Sudden (aee Nail in

Foot) . . . . . . . . . . . . . . . . 229

Laminitis................. 245

Lampas................... 78

Laryngitis............... 63

Leaking Joint Oil (see Open Joint) 223

Leaking of the Navel or Rheuna-

tism in Foals ............. 138

Legs and Joints, Weakneas of in

Foals . . . . . . . . . . . . . . . 139

Legs Ciorked in Young Fosls.... 139

Legs Swelled From Grease....... 167

Lega Swelled From Bad Blood.... 188

Legs Swelled From Big Leg...... 94

Legs Swelled From Stocking..... 184

Legs Swelled From Weed in the

Leg ........ . ........ 182

Legs Jerking (see Stringhalt). . . . 179

Leucorrhoe or White.......... 121

Lice. . . . . . . . . . . . . . . ... 172

Ligatnres, Cntting $\Pi$ ith........ 142

Lightning, the Appoaramen of 1 Animal Killed by ........... 313

Lips and Cheots, Injurten to..... 86

Lipe and Cusata, Perrlyd of .... \&

Liver and Bplese, Dteanea of..... 110

Liver, Bnlargenent of . . . . . . . 112

Liver, Inthementian and Congent.

lon af................... 110

Lockjer.................. 180

Lockjsw, After Centration....... 147

Lnnips About Threst (wo Dis. temper)............... 163

Lnmpe at Back of Babor Joint (soe Cepped Bubov).......... 212

Lnmps, Band (wa Tumort and Cancers).

Lumps, Elard ( $100 \Delta$ bocenas).... 811

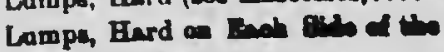
the gib
Lamps in Nose (uee Neal Polypi). Lumps on Shonlder ( 6 Bruises on Shoulder)............. 200

Lumps on Shoulder (see Tumorn or Lumps) . . . . . . . . . . . . . 207

Lumps on Grey Hornes (see Molsn. otic Tumors) . . . . . . . . . ... 170

Lumps Swollen and Sore (nee Abscesses) ............... 311

Lungt, Bleeding From........ . 66

Lungs, l'ongestion of ......... 6 \%

Lungs, Influsnmation of . . . . . . . 69

Lymphatic Syotem, Diseases of .. 182 Lymphatio System, Weed in the Leg. . . . . . . . . . . . . . ... 182

Lymphatic Syatem, Big Leg... . . . 184 Lymphatic System, Swelling of

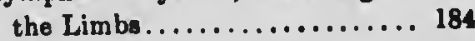

Lymphangitis................ 182 Mad Dog, Bite of (noe Hydro. phobia). . . . . . . . . . . . . . . 180 Madnesa (cee Hydrophobia) . . . . . 180 Mange..................... 170 Mare, Barrennesd In, or Not Breeding. . . . . . . . . . . . . . . 122

Mare, Diseanes of Genital Organs. 121

Mare Fosling, Difficulties Mot With .................. 129 Maro Foaling and Diseaser Following ................. 131

Mare Foaling the Natnral Way... 124 Mare, How to Tell When with Foul. . . . . ............ 123

Mare in Foul, How to Uea...... 124

Mare Lasing Their Foul. ........ 130

Medicine Uned in Loading the Clempe.................. 148

Metritie, Inflammation of Womb. 134

Melsuotic Tumor........... 170

Milk Bag, Inflammation of. . . . . 135 Milk Teeth, Shedding of ........ 78

Mode of Hesling Wounds.... . . 201 Mondey Morning Fever (see Lym. phangitis) . . . . . . . . . . 182 MoutK, Blisters in (see Aptha)... 84 Muuth, Can't Open (sce Lockjaw). 180 Mouth, Deformity (nee Parrot Month.................. 79 
Mouth, Foreirm Subtancen in .... 82

Myopis.................. 157

Neal Oleet, or Chronis Catarrh. . 61

Nasal Polypi, or Small Tumora in Nose.................. 63

Nail in the Foot ............. 229

Navel 8tring................ 124

Navel, Laking of, and Rheumat.

inm .................... 138

Navel, or Umbilical Ruptare.... 148

Navioular Diseane. . . . . . . . . . . . . 232

Nearrightednem .............. 157

Neok Bonen, Fract ure of. . . . . . . . 203

Neok, Divereve of. . . . . . . . . . . . . . 202

Neok, Lampa Under (ces Dietemper) ................. 163

Neck Mojoles, Injuries of . . . . . . 203

Neot, Sere a Top frum Collur. . 204 Needle (read How to Sw Dp Wonada). .................. 199

Nervous 8yetem, Divenes ol..... 172 Conousion of Brain......... 174 Cenobro-8pinal Meningitic... 177 Chore................... 178 Inflasmation of Brin, ota... 172 Hydrophobik ............. 180 Lockjas ................. 180 Parclyai ................ 176 Stomach Staggers......... 175 Stringhalt.............. 179 Bunstroke............... 173

Nettle Rauh.. ............... 169

Nose, Bleeding at............. 66 Nose, Frothing at (ses Ruptnre of Diaphragtn.............. 77 Nowe, Lumpa in (Nesal Polypi)... 63 Nose, Running at, From Cutarrh. 60. i: None, Running at, From Distemper 163 Nose, Runaing at, From Infuenzs. 160 Nose, Ruaning t, From Soro

Throst................ 63

Oats, Choking With........... 88

Dil, Leaking From Joint (oee Open

Joiut) ................... 223

Operating With the Clamps...... I4l Uperating With the Eeraseur..... 141 Opo 'o With Ligatures....... 142 C \& By Sewring........... 142

ral,

Open Joint................ 22

Orchitis (see Inflammation of Tes. ticles) ................... 118

Original, or Rig llorges, Castruting. 149 Osteo-Porosis (see Hig Heal).... I I:11 Ovarien, Dineases of. .......... $1: 1$ Over Driven (see Chill) ........ 2:3; (Over on Fetlocl:s (see Knuckling) : 19 Over on Fetlucks in Colts (see Knuckling in Cults).......... 210 Overreach................. 232 Palpitation of Heart........... I86 Palpitation of Heart-Thumps (see Spasms of Diaphragm)........ 7t

Paraly

Paralywis From Azoturia. . . . . . . . 189

Paralyais From Sunatroke........ 179

Paralysis (aee Cerebro.Spinal Mfeningitis)................... 177

Paralysis of the Bladder........ 118

Paralyain of Hindquarters (ace

Broken Back). . . . . . . . . . . . . . 208

Paralysis of Lips and Cheeks. .... 85

Paralyais of Pharynz and Gullet.. 8.9

Parotid Gland, Thickening of .... 80

Parotid Gland, Inflammation of .. 87

Parrot Mouth............... 79

Partial Dislocation of the Stiffle.. 219

Parturition, or Foaling, and Dis. esses Following. ............ 123 Pasage, Kupture of, Out From Womb ................. 132 Penil, Growthe on the End ...... 120 Penis, Injuries of. .............. 119 Peritoniti .................. 107

Peritonitis After Castration . . . . . 140

Pharynx, Paralyais of........... 8

Pink Eyo.................... 168

Finworms................. 109

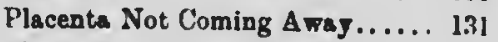

Pleurodynis................ 75

Pleurioy .................. 71

Pleurisy (see Pleurodynı

Pneumonis, or Inflammation of the Jungs. . . . . . . . . . . . . ... क

Polut of Hip hnocked Off (see Hipped)................. 20 roll Evil .................. ne 
rACtr.

Pox, Small.

Precantions Before Cutting or Cas.

trating ................ 13!

Pricks ill the Fout Fronı Shneing.. 230

Puffy Fulurgements Aronnl the

Knees unl Fetlocks......... 214

Pumicent Fot.............. 228

Punctures in Foot From Nail..... 229

Quarter Crack............... 231

Questions to Ask About Sick

Horse.................. 59

Rabies.................... 180

Rash, Nettle. . ............. 169

Ravenous Appetite (see Chronic

Indigestion)

Ravenous Appetite (see Broken

Wind or Heaves ............. 74

Rheumatism................ 225

Rheunntism and Leaking of Navel

in Foals.................. 138

Rig Horses, Castrating......... 148

Ringbone................ 195

Ringwor ${ }^{\prime} \ldots \ldots \ldots \ldots \ldots \ldots \ldots, 171$

Rosring................. 65

Rotten Frog (see Thrush)... ... 229

Rubbing (see ltching in Index)

Rubbing Tail (nee l'ulwurms)..... 109

Running at the Nise (see Cold in

Head). .................. 60

Rtnning Sures............... 312

Running Sores Alout. Far........ 150

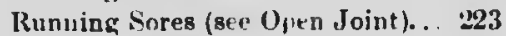

Rupture at Nitel........... 148

Pispture of the Wonb......... 132

Ruprure After Castration........ 143

Rupture in the Bag or Scrotum... 149

Rupture in the lim of Belly, Ven.

tral Hernia.............. 149

Salivary filumks, llispasps of.....78.86

Scalded or Galleil sliunlifer ..... 206

Scrotal Hernis................ 140

Scirrbus Cird. ............ 145

Scrotum Frstering After Castra. tion ................... 145

Scowers ir Young fuals (ane l)iar. rhurg) $\ldots \ldots \ldots \ldots \ldots \ldots$ 137

Gurntches................ 166

Stum on lije (seo Cataruct)..... I5s
P40?

Scrotem, Dropsy of. .. ........ 119

Searing, Cutting by............ 142

Sewing Up * Wound or Cut..... 199

Sharp Edges of Teeth........., 79

Sheath, Swelling of, Dirty....... 120

Sheeth, Warts on............. 120

Shivering (see Chill)........... 237

Shivering (see Congestion)....... 67

Shivering (Bee Inflammation).... 6y

Shivering (see Pleurisy)......... 71

Shoulder Bones Fractured....... 212

Shoulder, Diseases of .......... 202

Shoulder, Swelling of (see Bruises

of) ..................... 206

Shoulder Joint Lameness ........ 207

Shoulder, Scalded or Gulled ...... 206

Shying (see Nearsightedneas) .... 157

Sick Horse, How to Examine .... 59

Side Bone.................. 194

Sight, Near (see Myopia)....... 157

Signs of Immediate Fualing...... 124

Sitfast on Shoulder (see Tumors or

Lumps) .................. 207

Skin, Diseases of ........... 166

Cracked Heels or Scratclies.. 166

Grense.................... 167

Lice .................... 172

Mange................... 170

Melanotis Tumork......... 170

Skin, lliseanes of-

Mud Fever............. 167

Nettle Rash.............. 169

Ring Worn............. 17

Sinule kczema........... 1.69

Slobbering (see Inflammation of

Tongue) $\ldots \ldots \ldots \ldots \ldots \ldots \ldots \ldots, 83$

Slobbering or Frothing at Month.. 86

Smalipox .................. 157

Sore Back.... ............. 208

Sore on Top of Head (sce Poll Evil) 202

Sore on Top of Neck From Collar. 2')4

Sore Eyes (see Simple Ophthalmia) 151

Sore Eyes (see Hoon Blindiness) . . 152

Sore, Running............. 312

Sores, Running About Ear (see

Cartilages of Ear)..... . ... 150

Sores, Rnnning (see Open Joint). . 223

Sore Throat................. 63 
Bore Eeet................... 227

Bore Fest (co Corn) .......... 228

Sore Shine..................... 193

Boundnesa, How to Rrumine for.. 234

Bparin, Bos................. 220

8parin, Boee................... 196

Bparin, Blood ................. 223

Speedy Cnt................. 213

8piasl Cord, Inflummatlon of..... 175

Spinitia.................. 175

Bpitting Out Food (nes Paralyto of Gnllet)................. 88

fipitting Out Food (nes Dinemeen of

Toeth)....................78.81

Bplit Toech.................. 81

Bplint Afrecting the Knet....... 214

Bplints...................... 192

8pleen and Liver, Diveasen of..... 110

8pleen, Inflemmation of ........ 112

8prain of the Beok Tondons...... 215

Sprain of Knce............... 213

8prain of Fotlock Joint.......... 215

Sprain of Bock Joint............ 222

Sprain of Muscles of Bip........ 211

8prain of Muscles on the Front of Hind Leg Between Bock and Stitilo.................. 220

Sprain of Minoles an Indde of Hind Leg Running Up Brom Eock.. 220 Sprain of Stiffle Joirt.......... 218 Btaggeriog, From Atomeah 8tag. gern...................... 175

Btagserieg, Irem Carobro-8pind Menin ritt................. 177

8taggering, From 8ptrill....... 175

Btaked...................... 200

Btar Garor.................... 100

Buble, How to Clean Dimmero Ost of (resd How to Roed ond Tho Care of . Horwel ................ 258

Btin. Ost.................... 818 8tifle Partly Out Partial Dirloontion of) ................... 219

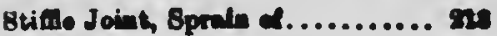

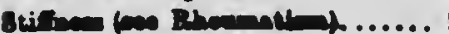
Stiffnew (nee Atotnria) ......... 189 Stiffnese (nee Plenrioy). ........ 71 Stiff Neck (see Injurien wo Mancles of) ................... 303 Stif Neck (see Poll Eril) ....... 201 Striking the Fetlock.......... 216 Striting the Knee............ 213 Stocking laee Swelling of the Limbol. ....................... 184 Stomech and Bowels, Disesen of. 9 Storrach, Ruptnre of ........... 93 Stonew in the Bladder. ........ 117 Stonea, Inflammation of. ........ 118 Strongles.................. 163

Strangles, Bestard........... 165

Stringhalt............... 179

Stnmbles (oee Call Kneed) ....... 215

Snnstroke ................. 173

Surfeit................... 169

Swallow, or Gullet, Paralyot of the 89

Swallow, or Gullet, Enlargement of 39 Swallow, Being Unable to leee

Paralyois of)............... 98

Sweens .................. 205

Swelling A round Head and Throst. 59 Swelling Over Back, see Asoturts. 189 Swelling Along Belly Betore Fosl.

Ins ................... 136

Swelling After Cantration........ I45

Bwolling From Ruptured Artory IC7

Swelling on the Ifuscles of Bip

(see Spraine of)............ 211

Swelling on Inside of Kneo (seo striking Knee).............. 213

Swelling, Sore (see Abrcessed)... . 311

8velling of the Milk Bag....... 135

8walling of the Valva and Vagine 1,34

8welling of the Sheath......... 120

Swelling of the Teaticter (6ee In. Anmotion of $\ldots . . \ldots \ldots \ldots . . .118$

8welling of the Teaticles (60e Dropay of ................. 118

8trolling of Log (wov 8welling of Limbs)................ 18

Brrelling Under the Ear (ses P. rotid Gland . ..............86.87 
xail, Sore, Frem Crex....... 210

Tail, Rubbing (cee Pinworm). ... 109

Teeth, siseases of............ 78

Teeth, Decayed or Rotten...... 80

Tceth, Sharp Edgea........... 79

Teoth, Split ............... 81

Toeth, Wolf Teeth........... 79

Tear-Ducts, Injuries to.......... 156

Teaticlew, Inflammation of. . . . . 118

Tetanus, or Lockjaw . . . . . . . . . 180

Tetanus, or Lockjaw, Nter One

tration................... 147

The Appesrance of an Animal

Killed by Lightnlng . . . . . . . . 313

Thlrat (cee Diabetce) ........... 114

Thiokening Under Ber, Perotid

Gland..................... 80

See Fintulou Withert....... 204

See Poll Evil . . . . . . . . . . 202

Thickening Around the Fotlock .. 217

Thickening at Side of Hook Joint

(see Thoroughpin) .........221

Thickening on Point of Hock twee

Capped Hock) ............. 221

Thigh Bones, Fracture of ........ 219

Throat and Hesd, Swelling of.... 89

Throat, Lumpe About (660 Dis.

temper.... ............... 163

Throat, Sore, Inflanimation of. . . 63

Throwing an Animal for Castration 140

Thrush, or Apthæ, in Mouth.... 84

Thrush in Feet............. 229

Thoroughpin............... 221

Thumps (see Spasms of Disphragm) 76

Thumping of Heart (see Palpita. tion). .................. 186

Tongue, Injuries to. . . . . . . . ... 83

Tongue, Inflammation of ....... 83

Trestment of Wounds.......... 199

Trembling From Congestion of

Lungs. .................. 67

Trembling From Chills ......... 287

Trembling From Infammation of

Lungs.................. 69

Trembling Fron Heur:sy....... 71

Tumor ................... 309

Tumors and Cancera........... 224

Tomor, or Lumpa on Shonlder... set
Tumors in New (cee Nassl Polypi) 63

Tumert, Melnootio, ween in Gray

Horees . . . . . . . . . . . . . . . . 170

Turning Ont of the Bladder, or In-

vervion of .............. 117

Twise for Sewing Up Wounds. . . 199

Uddor (no Milk Bag). . . . . . . . . 135

Urine, Bad, Receipt for (cee Fow. der for Kidneych . . . . . . . . . . . 38

Urine, Bleody (6e0 Indammation of Kidneys) ............... 117

Urine, Bloody (cee Btones in Bladder) ........................ 117

Urine, Bloody (wo Inflammation of Bledder)............... 116

Urine, Dribbling of . . . . . . . . . 118

Urine, Excentive Flow of (see Din. beted)...... ............... 114

Urinary Organe, Disenses of. . . . . 113

Urine, Stoppage of (wee Inflamma. tlon of Kidneyt). . . . . . . . . . 113.114

Urine, Stoppage of (ine Ischuria).. 115

Orine, Stoppage of (eee Paralyaia of Bladder)............... 118

Vagin and Vulva, Inflammation of. ..................... 134

Vein, Inflemmation of. ......... 187

Warta....................... 169

Warta Around the Sheath....... 120

Wating $\Delta$ way of the Hip Muscles After Fosling. . . . . . . . . . . . 210

Water, Bad, Receipt for (wee Receipt of Powder for Kidneys). . . 389

Water, Bloody (wee Infiammation of Bidneyu)............ 113114

Watar, Bloody (ceo Infismmation of Bladder................ 116

Water, Bloody (ees Stones in Bladder) ................ 117

Water, Dribbling of.......... 118

Woter, Bxcenive Flow of (see Diebetes)................. 114

Water In Cheat.............. 72

Water in the Bag (see Dropsy of Scrotum)................ 118 Water, Farcy (wee Weed in Leg). 182 Water, Stoppage of (see Inflam. Ention of Kidney 4 )........113-116 
Womh, Inflammation of........ lit

Ww' Teetl.................. ig

Water in Bolly (noe Dropery of

Belly)..................... 108

Weakneas of the Loge and Joint

is . Foal ................... 139

Weaknees (see Kneo Sprang)..... 214

Woed in the Leg.............. 182

Wheat, Horne Eiating Too Muoh.. 109

Whoezing (nee Nasal Polypi)...... 63

Whoezing (eve Bronchitis)....... 73

Whiten. ................... 121

Wind, Broken (Heaves)......... 7t

Windgalla.................. 217

Withers, Sore 'meo Fistulous

Withers..................... 204

Womb or Foel Bed Turned Uut... 132

Wemb, Rupture of............ 132

Worm in the kige (nee Pileria

Oculi)...................... 1iil

Worme, Pinworms............ 109

Worms, Long Round ........... IUP

Wound and Treatment......... 190

Wound by Sharp Stick (seo Slaked) '2109

Wounds, How to Sew Up........ I:n

Wounds, Modes of Healing ...... थ.

Wounds, lnflammation of........ : vill

Wounds, Swelling of (nee Inflam.

mation of)................. 201

Wounds, Poisoning of........... 201:

Yard or Penis, Growths on the End 1:20

Yard or l'enis, Injuries of ....... 119

Yell.ow's From Bilestones......... 111

Yellows From Liver. ....110, 111, 112

Yellnws or Jaundlco. ........... 111

\section{INDEX PART III.}

\section{ANATOMY, DISEASES AND TREATMENT OF CATTLE.}

Abortion ..................... PAB

Abacessea That Only Contain Water 311 dbsoseme That Only Contain

Master..................... 311

Actinonyconin................ 306

Afterbirth or Clenning-How to

Take It $\Delta$ way............. $\mathbf{9} ; 2$

Alr Under the Bkin Caused From

. Wound................... 292

Animal Killod by Lightning ..... 313

Anatomy or Structure of the Ox.. 243

Angry Growtho (see Cancer)...... 310

Anthrax...................... 307

Apple, Choking From.......... 254

Arteries, Disenses of........... 315

Austrian Fly (see Horn Fly)...... 294

Backbones, Fractnre of......... 289

Back Teeth, Sharp............ 252

Bad Disorder in Bulls (see Clap).. 283

Bag of Cow.................. 217

Balls of Hair in the Rumen or

Paunch .................. 259
Barley Beards in kye (see Foreign

Substances in) ............ 287

Barrenness in Cows und Bulls.... 281

Bellyache (see Colic)...........

Belly Very Large (see Dropsy).... '264

Binder Twine in the liumen or

Paunch .................. 259

Bites Frcm, Frost............. 205

Bite 'ronı Insects, Snall Snakes,

Hornets, etc............. 295

Bites From a Snske .......... 29.5

Black Quarter............... 31,

Bleed, How to............... $: 299$

Bloating..................... 255

Blood, 1)iseases of . . . . . . . . 315

Bloody Flux....... . ....... . . 266:

Bloody Mlilk............... 27s

Bloody Urine................. 2tite

Blue Milk.................. , 279

Bone, Choling From.......... 25t

Bones, Fracture of ............ 288

Bunes, Fractured Above the Stille

Joint . .................... vil 
Bones Fraotured Below the Stifle Joint ...................291

Bowoln.................... 246

Boweln, Inflammation nf. . . . . . . '263

Bowolv Not Working (see Cunatlpetion) ...................263

Brain, Infemmatlon of ......... 3)1

Breat hing Heavy After Being Driv. on or Chaved (nee Bronchitio)... 251

Breathing Organa............. 247

Broken Neck................. 288

Bronchitio.................. 25l

Bronohitin, Filaria........... . 19

Ballo, Barren............... . 281

Bullo, Hor to Custrete.......... 283

Bulls, How to Ring............. 245

Buras and Scalds.............. ‘ 403

Caked Bag (see Infammation of Milk Bag)................ 276

Calf Not Coming Right (see Trouble Met With at Calving Time..... 269

Calves, How w Cantrate........ 28:3

Calf Bod Iurned Oat.......... 270

Calving, Diseases After......... 26

Calving, Trouble Met With..... 20 $26 i$

Cancer...................... 310

Calicer in the Eye ............ 286

Caps on Teeth ................ 253

Caries-Decayed Teeth......... 252

Carrot, Choking From.......... 254

Castration of Bulls and Calves.... 28.3

Cutaract of the Eye............. 287

Catrrrb, or Cold in the Head...... 2t's

Cattle Bitten By Mad Dog (read

Hydrophobia).............. 305

Cattle, Contagious Direases nf.... 303

Cattle, Uisessos and Treatment... 248

Cattle Killed by Lightning. ...... 313

Cattle, Lice on Them........... 293

Cattle, Madness in ............ 30J

Cattle Rubbing Themselves (see

Lice..................... 293

Chaff in the Eyes (see Foreign Substances .................... 28;

Chipped or Sore Teats.......... 259

Cheeks...................... 24t

Chewing Cud, How It I Yerformed : $4 t 6$
Choklng. . .................. 2is

Clap..................... 283

Cleaning of Cor, How to Take

Away.................. 272

Clogging of Food In Paunch (nee

Impaction of). ............ 250

Closurn of the Neck of the Womb

at Calving Time............. 269

Cold in Hest or Catarrb........ 248

Cold in Throst !eee Sore Throst). 249

Colic...................... 262

Constipatlon of the Bowoln....... 283

Contagious Diseases ............ 303

Contugious Pleuro-Pnenmonia.... 303

Consumptlon.................. 304

Cough (read Sore Throst)....... 249

Cough (read Oonsumption)....... 304

Cough (read Infimmation of

Lungs..................... 250

Cough (read Plouriay) ......... 25l

Corn Stalk Diseave............ 300

Cow Oalving, Tronblen Met With. 269

Cow, Barren ................ 281

Cow, Discharge From Wound (see

Whites)................ 273

Cow, Giving Milk, Bow to Dry

Har Up................... 314

Cow, How to Blood ............ 299

Cow, Falling off in Condltion (see Impaction................. 260

Cow, How to Tell When With Calf $26^{\circ}$

Cow in Severe Pain (see Colic).... 262

Cow Louing Her Calf. ......... 291

Cow, Mad (see Hydrophobia).... 305

Cor Not Ablo to Get Up (vee

Parelyuis Before Calving ...... 268

Cow Not Able to Open Her Mouth

(soe Lockjaw).............. 302

Cow Not Cleaning Right, How to

Take It A way ............... 272

Cow Pox ................. 280

Cow Yellow Around Eyes (see

Jaundice) ................ 265

Cramps in Bowels (see Colic)..... 262

Cud, How It Is Chewed......... 246

Cud, Throwing It Up (see Vomiting) $. . . \ldots \ldots \ldots \ldots \ldots \ldots . . . \ldots 258$ 


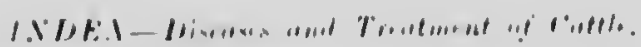

Deceyed reeth.............. 252

Uehorning ................ 285

Diarrhos................. 281

Uiarrhes in Carves (sec White Scowers).................. 206

I igentive Organs, Disersen of .... 252

Digestlve Orguns of the Ox ..... 24

Diwcharge From the Womb (cee Whited)................. 273

Disenes After Calving. . . . . . . . . 967

Urencb, How tu. ............... 800

Dropsy of the Belly............. 204

Dropey of the Womb Before Calv.

ing ................... 288

Jry Murrain (nee Impmotion of Manjplies).................260

Dyantery.................. 262

Fir and kye, Dircuese of ....... 286

Encephalitis ................301

Enteritis ................... 263

Urgotinn................... 313

Kye and Ear, Disemen of. ....... 288

Eye, Cancer in. ................. 286

Eyolide, Injuries te... . . . . . . . . . 288

Fardelbound (eec Impaction of

Manyplies).................... 260

Feet, Sureness of $F_{1}$ uns Any Cause 296

Festering Below the Ear (see In.

fummation of Parotid Gland) . . 253

Filati. Hronchitis............... 249

Fintule of the Foot............ 297

Iisbula, or Running Sore ....... 312

livttllu of the Teat............ 280

Flibg'? Bag (see Inflammation of Mlil Bag).................. 276

Fluke Uisease in Cattle and Sheep 265 Fiy, Litule Flies About Horns and Body (xue Horn Fly)..... . . . . . 204

Fual bud Turued Out.......... 270

Fuod Crming Out of Mouth (see Vomiting)... ............ 258

Foot, Fistula of . . . . . ........ 297

Foot, Nall Itun iu. . . . . . . . . . 245

Font, liut ................. 296

Eardigu Sulatences in the Eye. .. 247

Fuurth l'irt of Stomach, Intlan. mation ol. ............... 281

Fractured Bones, Wound, Spraine of Joints and Tendone......... 28

Fractured Bones............... 288

Practure of Loter Jaw.......... 288

Fracture of the Back Rones...... 289

Fracture of tho Bones Abore and Below the Stifle........... 291

Fractnre of the Boned Belr's the Hook Joint. . . . . . . . . . . . . 291

Freoture of the Bonet Belon the Kne ..................... 290

Frectnre vi tixe Botien of the Bip.. 280 Fracture of the Bones, Nect Bonen 288 Fractare of the Hones, Ribs..... 200 Practure of the Bones, Shoulder Blede, or Shoulder Bone.. .... 290

Garget................... 276

Genital Organn, Dusenses of . . . . 282

Genital Orgere of the Cow ...... 247

Genital Organn of the Bull ....... 248

Glands Around the Throat. . . . . 244

Gonorrben.................. 283

Growtha, Angry Leoking (nee Cancer) .................... 310

Growths in the Corner of the Eyo (see Haw)............... 287 Grow the on the Haw of the Eye.. 287 Growths in the Eye (see Cincer in Eye) ................... 298

Grunting (see Impaction of the Rumen or Paunch)........... 456 Gullet, or Throst (see Pharyux) ... 244 Guts (see Boweln)............ 246 Hair Balls in the Rumen. . . . . . . 259 Hair Falling Off in Circles (see Ringworw) ................ 294

Hard an Láfi Side (see Impaction of Paunch)............... 256 Haw of the Eye, Growths on .... 257 Heart, Disenses of ............ 315 Hide.Bound (is not a Disease but a Symptom of Impaction of Manyplies) .............. 260 


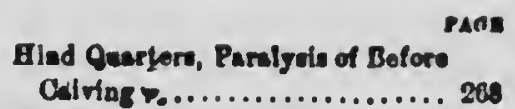

Hip Bowen, Fracture of ......... 298

Hallow Horn (is nut $a$ Ulesese, is

enmes Impaction of Mnasplies) 200

Horn Fly ..... ............... 224

Horen, or Blonting............. 265

How to Biced a Cor ............. 299

¿40 to Drench . Cor.......... 800

How to Dry as Anlmal That Is

Giving Milk................ 314

How to P'orform the Operation of

Rumenotomy................ 258

How to Provont Milt Fover Frow

Coming Oa................ 276

How to Ring $\bullet$ Bull ............ 285

How to Take the Clowing $\Delta$ waj.. 272

How to Toll When a Cor Is With

Calf........................ 287

Gow Rumlanti:n, or Chowing the

Cud, Io Performed ........... 246

Gydrophobia In Cettlo.......... 805

Impactlon of the Manyplles, or

Third Part of the Stomach.... 260

Impactlon of the Rumen, or

Paunch .................. 256

Infiammation of the Bowels...... 263

Infiamenation of the Brain........ 301

Inflammation of the Lining of the

Belly Cavity................. 264

Infiemmation of the Lining of the

Chest Cavity (see Pleuriny) .... 251

Inflammation of the Lunga....... 230

Inflammation of the Milk Bag.... 276

Infiammation of the Parotid Gland 253

Infiammation of the Teaticle in

Bulls.................... 282

Influnumation of the Womb ...... 272

Injuries to the Eyelide..........288

Injuries to the Sheath and Penis.. 293

Intestines (see Bowels).......... 248

Jaundice In Cattle ........... 265

Jaw Boue, Lump On (see Lumpy

Jaw.................... 306

Jaw Bone, Lunıps On, From Teeth

or an Injury............. 253

Kidnegs (see the Urinal Organa). 217 ?
TKü:

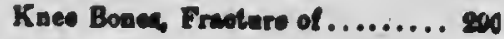

Laminltia..................... 400

Loucorrhaea, or Wbites.......... 275

Idee on Cattle ............... 203

Lightniag, Struck By............ 312

Wightaing, Kulled, tho Appeenence

of After.................... 812

Llniag of the Bolly, Infiummatton of 204

Lipt ........................... 24t

Lrer....................... 240

Liver, Dienaned (wes Muks Dienen) 206

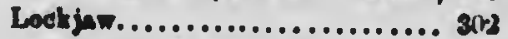

Lowor Jan, Freoturs \&L......... 20

Lump on Indts of Ecak Joint

(nec spavin) ................. 298

Lampo In Puacage of Tant....... 277

Lumpe on the Ju- Bone From the

Tweth of an Injary........... 253

Lumpy Jaw ...................,

Langen Intlommation of.......... 250

Lange (cen Reuptratory Organa).. . 247

Madnew In Cottle .............. 30s

Mazzots In Neglectud Wounde.. 292

Mammary Glands................ 247

Mange In Cattlo............. 294

Mangol, Ohoking From.......... 254

Mesyplles, Impaction of........ 200

Motritio or Inflammatlon of Womb 972

Milk Bag..................... $\mathbf{2 4 7}$

Milk, Bloody ................. 278

Milk, Blue................... 279

Milk Foror................. 274

Milk Feror, How to Provant It

Coming On................ 278

Milk, Falling Of In Ono Night

(sec Impection of Rumon)...... 256

Milk, How to Dry Up \& Cow..... 314

Milk, Stringy.............. 279

Milk, Stopped (no Small Lumps

in Teat).................. 277

silk, Stopped (eee Infinmmation of

Milk Bag)............... 276

Milk, Stopped (nee Impactlon of

Rumen)................... 258

Milk, Stopped (will Eover)... 274

Mouth, Not Able to Open (600

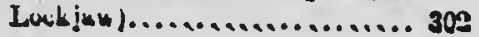


Nall Rug in the Poot o. Pant

Neck of the Wumb Closerl at Vialv.

Ing Time................ $\mathbf{9 n !}$

Nervew, Dimenaes cl. . ......... 3n)

Nuts, liulds (see Teaticles). . . . . . . 2IK

Easphapus, or Swallow......... 284

Orchucis, Inttamnation of Tostleles 282

Urigan of Digeation in the Ux.... 244

Ovarten .................. 247

Ox, Anstomy of. ........... 24:3

Ox, llow It Chew Its Cud ..... 246

Ox, 8tseleton of ............ 24)

Panting Ater Heing Chened or

Uriven (woo Bronchikis)....... 251

Paralyais After Calving ........ 274

Paralyain After Colving (see Milk

Revor)..................... 274

Paralyui From Any Cause It

Trested Same es Paralyais After

Celving ................ 274

Puralyuis (ece Suntroke) ....... 302

Paralyaiv of Bind Quartera Bofore

Culvies .................. 268

Parturitat Apoplezy or M $11 \mathrm{k}$ Derer..................... 274

Pamege Out From Wound, Ruptere of ................... 2\%0

Pacing Blood (nee Bloody Flux).. 262

Pusuob, Bair Ball in .......... 259

Peunch, Impuctios of With Food. 250

Peosch, Twine Ball in... . . . . . . 259

Penis, Ball (read Genltal Organ of Bull) . . . . . . . . . . . . . . 248

Penib, Injuries to ............ . 293

Peritonitit .................. 264

Pharynx. Gullet or Throst. ... . . . 244

Phyio (seo Dlarrhas) .......... 261

Pink Eye in Cattle (asme as Pink

Eyo in Hornes).............. 165

Plenring.................... 251

Plecenta, or Cleaning, Not Coming

Arsy, Eow to Take It Awey. 272

Potate, Choking From.......... 254

Pneumonis, Infemmation of Lungs 250

Quater Il (ace Black Quarter) .. 398

Babie ...................... 305

Red Water. ................ 266

Repiratery or Breathing Organs, 247
Rheumatiom o.......... rit:

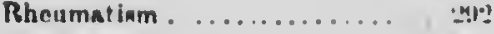

Kilsw, Fracture of .......... 2001

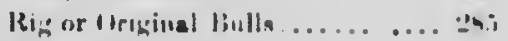

Ringworm. ............... :

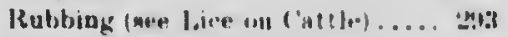

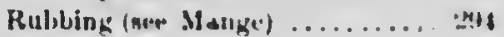

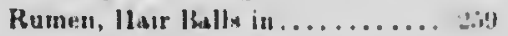

Rumen, Twine Bulla In ....... . :

Rumen, lupaction of With Foml. Lide

Rumillation, lfow it is lect.

formed ................ \&

Rumenotomy, Luw to Porfuru It. 2is

Running Sore. . . . . . . . . . 312

Runaing Sore in Foot (see Fintula) 297

Ruptare of the Woub or l'unage

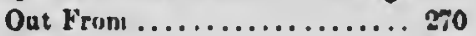

Scalds.................... 295

Scower (see White Scowers in

Culves) ................... 266

Scowcrs in Cattle (cee Diarrhoes). 261

Soum on the Kye (wee Sore Kyed). 247

Scum (ave Cataract of the Kyo)... 287

Sovere Pain in Cattlo (see Colic).. 26:

Sharp Molsrs, or Back Teeth. ... . $2: 2$

Sheath Swelling in Steer. ....... 285

Shoulder Bladc, or Shoulder Bone

Fractured . ............. 290

Shoulder, Bruises of (nee Abacesses) 311

Steleton of the $\mathrm{Ox} . . . . . . . . .240$

Stin, Air Undor, Caused From *

Wound................. 202

Skin, Disessen of .............. 293

Shvering. .................. 152

Small Growtho on the Skin ...... 293

Souall Lumpo in the Skin (see

Warbles)................ 295

Small Round Lamps in the Pas.

sage of the Teat.......... 277

Small Warts on the Teat........ 280

Snake Bites................. 295

Sore Eyes in Cattle From Any

Cause (aee Foreign Subotances in) 257

Sorenese From the Feet, From Any

Cwuse.................... 290

Soreness From the Feet (nos

Founder)............... 290

Borenes Around Cheat (aee Pleur.

iv) 
Bore Throat............... 249

Sore Teats (see Chapped Teats). . 279

Sore Teats (see Cow.Pox)....... 280

Sore Teats (see Cut on Teats)..... 280

Sore, or Influmed Eyes ......... 287

Soro, Running . . . . . . . . . . 312

Spavin .................. 291

Spitting Food Out of Mouth-

See Decayed Teeth......... 252

See Shsrp Molars ........... 252

See Caps on Teeth. ......... 253

Spraing in Any Part of Animal. ... 291

Steers, the Yoint of the Sheath

Swollen .................. 295

Stiftle Out in Cattle........... 291

Stomach of Ox.............. 244

Stonach, Fourth Part, Inflamma-

tion of. . . . . . . . . . . . . . 261

Stones, Bulls (see Testicles)...... 248

Stonen, or Testicles Not Down (see

Rig Bulls).................. 285

Stoppage in the Stomach (8ee Im-

pebtion of) ............... 256

Stoppage of the Bowels (see Con.

stipation)................ 263

Stringy Milk................ 279

Struck With Lightning......... 312

Btructaro (see Anatomy of $\mathrm{Ox}$ ).... 243

Swallow, or Esophagus. ........ 244

Swelling Around Shoulder (soe

$\Delta$ bucesees).

311

Swelling, Crackling When You Kub it (neo Air Under Skin) ... 292

Swelling Below the Ear (see In. Aammation of Parotid (fland).. 253

Swolling of Milk Bag (nec Inflam. matien of Milt Bag).......... 976

Swelling of Point of Sheath in Steors.................... 285

Bwollen on Loft Sido (wee Blouting) 255

Swollen (ee Impection of Stom.

ach) .................. 256

Bunntroke ................ 302

Tail Dropplng Off (see Ergotism).. 313

Tepeworm in Cattle ........... 284

Tapping for Bloating (read Treatment for Bloating) ..........255

Teats, Small Lumps in Passage... 277

Teata, Warts an.............. 280

Teoth................... 244
74

Teeth, Caps on ............... 245

Teeth, Sharp (see Nharp Molars).. 25:

Testicles Not Iown (see Kig Bulls) 285

Testioles of Bull ............. 248

Tetanus.................... 308

Texa Fever................. 308

Third Part of the Stomach, Im.

pactiou of ............... 200

Throat or Pharynx........... 244

Throat Sore, Cold in .......... 248

Throwing Up Food (nee Vomiting) 268

Tongue................... 244

Tronbles Met With While Calving 269

Troubles in Calving. ........... 267

Tuberculosis................ 394

Tumors . . . . . . . . . . . . . . . . 309

Turning Ont of the Vagine or Pas.

arge Leading From the Womb. . 270

Turnip, Choking From ......... 251

Twine Bull in the Rumen or

Puunch ................. 258

Tympanitis or Blosting......... 255

Udder (gee Bag). ............ 24

Urinary Organn............. 247

Urine Red (see Red Water). . . . . 266

Uterus or Womb.............. 247

Voniting. ................ 258

Warbles. . . . . . . . . . . . . . 295

Warts on the Skin ............. 293

Warts on the Teats ........... 280

Water, or Urine, Red (see Red

Water).................... 266

Wheezing (see Filaria Bronchitis). 249

Wheezing (see Bronohitis)....... 251

White Scowere in Calres ........ 266

Whited, Leucorrhan...........273

Womb, Dropay of Before Calving. 268

Womb, Neck Closed at Calving

Time. ................... 209

Womb of Cow............... 247

Womb, Passage From Turned Out 270

Womb, Rupture of........... 270

Womb Turned Out After Calving. 270

Worms in Liver (see Fluke Disease) 265

Wound, Muggots in. ........... 292

Wounds of All Kinds........... 29.

Yard, Bulls (read Genital Organ

of Bull) ................ 248

Yellown................... 265 


\title{
INDEX PART IV.
}

\author{
DISEASES A $:, \because 1 \%$ MT OF SHEEP, PIGS, \\ WGS AN" ?UULTRY.
}

\section{SHE.EP.}

PAQE

Afterbirth Not Coming Away (see

Cleaning Not Coining A way)... 3.33

Bag Mortitied (see Intlammation of Milk Bag)............... 334

Bag Swollen in Ramb (see Inflain. mation of Testicles). .......... 330

Bag Swollen (aee Inflamnition of Milk Bag) . . . . . . . . . . . . . 3:4

Bellyache (see Colic)........... 3:3

Bloating ............... 321

Bowels, Intammation of . . . . . . 323

Breathing Heavy (see lironchitis)

Breathing Heavy (nee Intamination of Lungs) . . . . . . . . . . . 319

Broken Legs in Lambs and Sheep. 329

Bronchitiv................ 317

Bronchitis, Filaria ........... 318

Caked Bag (see Inflammation of Bag).................. 334

Caps on Teeth.............. 320

Catarrh, Simple............. 316

Chased by Dags (see Bronchitiv). . 317

Choking in Sheep..... . . . . . . 320

Cleaning Not Coming A way...... 333

Cold in Head. . ............. 316

('olic in Sheop.............. 323

Cinstipation in Young Lambs.... 3335

Coughing (see Choking)........ 320

('oughing (see Sore Throat) ...... 317

Cramps (see Colic)............ 323

Lud, Not Chewing (see Impaction of First Stomach). .... . . . . . 322

Cutting Lamb's Tail........... 331

Diarrhøa in Lambs. .......... 336

Diarrhce in Sheop........... 328

Dcgs Chaning Sheep (see Bron. chitis)................. 317

Dogs Chasing Sheep (see Wounds) 343

Eyes, Sura................. 320

Feet, Sult (see Font Rot in sheep). 336 Filatia Bronchitis:........... 818 Fluke lisease in Sheep ......... $\mathbf{3 2 5}$ Foot Rot in Sheep ............ 336 Fractured Lego. .............. . 329 Garget ................... 334 Grating Teeth (sce Inpaction of

First Stomach). ............ 322 Grub in the Head of Sheep. ..... 325 Gruntiug (see Impaction of First

Stomuch)..... .......... 322 Head, Grub in (see Grub in Head). 325 How to Cut or Castrute Rame.... 330 Impaction of First Stomuch...... 322 Intlanimation of the Lunge....... 310 Intlammation of the Bowoln...... 323 Inftammation of the Milk Bas... . 3\$4 Inflammation of the Teaticles in

Rans................... 39

Lamb Bed Turned Ont. ..........

Lamb, Conatipation in.......... 235

Lainh, Diarrhcea in . . . . . . . . . . ses

Lumb, Weaknesu in. ........... 385

Lambing ................. nt

Lambing, Signs of. ........... 331

Lambing, Troubles Met. With in. 320 Lambs, How to Cut their Tails... 331

Lego Broken................. 28

Livur Disemsed (see Fluke Diseano). 325

Lungs, Inflammatlon of......... a 319

Maggots in Wound of Sheep .... 22

Manure, White Spota in (⿻o Tape. worm!.................

Mitk Bag Mortified (see Infamns. tion of)................. 324

Milk Bag, Inflammation of....... 324 Mortification of Milk Bag (see $\mathbf{~ L}$. famuation of Milk Bagl........ 334 Mouth, Wood or Anything Wloe Caught in ................... g 
Nons, Running at (see Cold in

Head) ................... 316

Old Shoop Lowing Their Teeth.... 320

Pain, Severe (see Colic)........... 3223

l'uin, Severe (see Iuflammation of

Bowels) ................. 323

rieces of Wood or Anything in Mouth).................. 320

l'lacenta or Cleaning Not Coming Away .................. 3333

Pleurisy (see Inflammation of Lungs) ................. 310

Pnenmonia (see Inflammation of Lungs).................. 319

Rpms, How to Cut or Castrate... 330

Running at Nose (see Catarrb).... 316

Soab in Sheep.............. 327

Soowers [see diarrhcea]......... 329

Sheep Choking.............. 320

Sheep Chased by Doga (see Bron. chitis) 317

Sheep, Fluke Disease.......... 325

Sheep Lambing .............. 331

Sheep, Losing Their Teeth ...... 320

Shoep, Maggota in Wound ...... 328

Sheep. Not Eating (see Impaction of First Stomach)........... 322

Sheep, Old, Failing (soe Losing Their Teeth) .............. seo

SL_ep, Scab in Skin. .......... 32;
Sheep, Ticks............... 328

Shoep, Wool Falling Off (see 5 csh

in Sheep)............... 327

Slsecp, Wool Falling Off (see Wool

Falling Uff in Spring)....... 3:27

8igns of Lambing.............. 331

Simple Catarrb.............. 316

Slavering at Month (see Ohoking). 320

Snufting (see Cold in Head)...... 316

Sore Eyes in Sheep............ 329

Sore Foet (see Foot Rot in Sheep). 336

Sore Throat ................. 317

Swelling (see Blosting) ......... 821

Tapew orm in Lambs and Sheep. . 324

Teeth, Troubles of . ........... 320

Testicles, Inflammation of in Rams 330

Thront, Sore............... 317

Throut Swollen (see Soro Throat).. 317

Ticks on Sheep.............. 328

Troubles Mot With in Lambing. . 332

Tympanitis ... ............ 321

Heaknes in Young Lambs ...... 335

Wheezing (see Bronchitis)....... 317

White Sipots in Manure(see Tape-

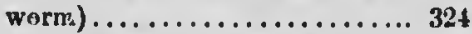

Womb Turned Out (see Lamb Bed

Turned Out)............. 333

Wool Falling 0 f in the Spring... 327

Wounds, Meggots in .......... 328

Young Lambs, Diveases of........ 335

\section{PIGS.}

PAGE

Acute Indigastion ............ 338

Back Buwel Iurned Out ........ 341

Back Broken in Pigs .......... 347

Barking iu Pigs (see Sore Throst). 333

Black Teeth in Young Yigs ...... 3\$5

Blind Staggers.............. 34:

Bloated (see Acute Indigestion)... 338

Boars, How to Castrate....... . . 344

Buund $U_{p}$ (see Constipation in

Pigs) .................. 340

Buwels, Back One Turned Out.... 341

Bowels Not Working (see Consti-

pation)................... 340

Broken Back in Piga ........... 347

Broken Lega in Piga.... ......., 36
RAGR

Castrating ................... 344

Choking................... 337

Chronio Indigestion........... 339

Cunvulsions in Young Pigs (seo

Fits in Young Pigs).......... 351

Constipation in Pigs........... 340

Coughing (see Sore Thront) ...... 338

Coughing (see Choking)........ 337

Cuts or Wound of Any Kind.... 343

Diarrhcea.................. 341

Difficulties With Sowe in Pigging. 348

Diseased Milk Glands (soo Inflam-

mation of the Milk Clands).... 350

Eat Too Much of Any Kind of Food (noo Acuto Indigention). . . 
Fits in Pigs (wre Worms)....... 341

Fits in Young lige From Worms. 3.il

Founder, or Sore Feet in Pigs.... 343

Fracture of a Yig's Leg. . . . . . . . 346

Garget.................. 350

Hog Cholera ................ 347

How to Cut or Cantrate Pigs.... . 344

How to Cut or Castrate Pigs That

Are Ruptured in the Bax...... 345

How to Ring a Pig........... 3il

Indigestion, Acute.......... 33s

Indigestion, Cbronic. . . . . . . . . . 339

Inflammation of the Milk Glands, 350

Leg Broken.......... . .... 346

Lice on Pigs................ 346

Little Piga Sick (see Black Teeth). $\mathbf{3 4 5}$

Little Yigs Sick (see Wornı).... 341

Milk Fever ............... 349

Milk Glands Mortified (see Intam. mation of Milk (Hands) . . . . 350

Paralyzed Pig (seu Broken Back in Piga) ..... . . . . . . . . 347

Paralyaed Pigs (see Blind Staggers) 31:2

Pig Bed Turned Out.......... 350

Pig, Blue Around Head and Kart (see Blind St

Pig, How to $\mathrm{C}$.

....... 342

ate..... 344

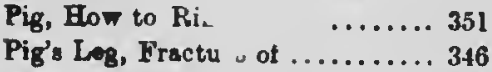

Pigs, Lioe on.. . ........... 346

Pigs, Little Onen Sick (see Black

Teoth)................. 345

Pign, Little Ones Sick (see Worms) 341

Pigging, Vifficulties Met With. . 348

Pig, Not Able to Get Up (nee

Broken Back) ............. 347

Pig, Not Able to Get Up (see

Blind Staggern)............ 342

Pigu Paralyzed (see Blind Staggern) 342

Pigo Paraljzed (see Broken Back). 347

Pige Ruptured, Bow to Castrato.. 345
Pigs Fery Stiff and Sore (see

Founders or Sore Feet)....... 343

Pigs Very S'rupid and Not Fating

(see Plind Staggers) .......... 342

Pigs With Broken Back........ 347

Pigs, Youl: $\delta$ ( ) Fits From

Worms.... . ....... 351

Rectum or Back Bowel Turned Out 341

Ring Pigs, How to........... 35l

Ruptured in the Bag, How to Cas.

tirate Them .............. 345

Scowers (see Diarrhaua) ......... 341

Sore Feet. . . . . . . . . . . . 343

Sores (see Wounds)........... 343

Sors Throat ............. 338

Sows Pigging, Difficulties Met

With ............... 348

Sow's Teats Mortified (see Inflam.

mation of the Milk Glands) . . 350

Sows 'That Won't Five Milk After

Pigging (see Milk Fever)..... 349

Sows Very Sick After Pigging, (Always Look for Milk Fever). 349

(Also, Inflamm tion of Milk

Glands)................ 350

Sow, Very Sore Along the Milk Glands, (see Inflammation of Milk Glands) . ............ 350

Sows With Milt Fever.... . . . . 349

Stiffness and Soreness (see Fonndcr) 343

Stoppage in the Bowelu (see Con.

stipstion) ............... 340

Stunted................... 339

Stupidness (aee Blind Staggers)... 342

Swollen Belly (see Acute In. digestion)............... 338

Water Running Out of the Mouth (see Choking).............. 337

Woinb Turned Out........... 350

Worms.................. 341

Wounds or Cuts of Any hind... 343 


\section{DoGs.}

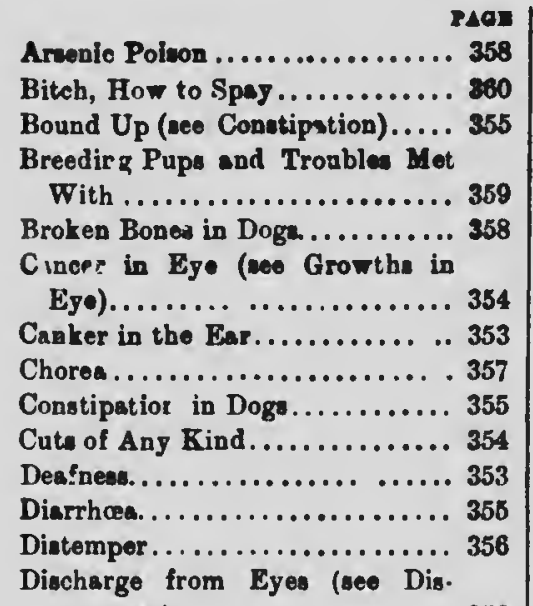

temper)................ 356

Dog Trembling or Jerking (see

Chorea) ................. 357

Dogs, Constipated or Bound Up.. 355

Dogs, How to Cut or Castrato.... 360

Ear, Canker in.............. 353

Enlargement of the Eye........ 354

Eye, Growth in ............... 354

Eyes, Sore................. 354

Eyes, Water Running From (see

listemper)................ 356

Fleas ..................... 353

Fractured Bones in Dogs........ 358

Growthe in the Eye............. 354

Hair Falling Off (see Mange)..... 352

Hard of Hearing (nov Deafness). . . 353

Hide Bonnd (ece Worms)........ 356

How to Castrate a Dog.......... 360

How to Cnt Paps' Tails.......... 360

How to Get Bitch Pups-read.... 359

How to Get Dog Pnpe-read ..... 3. 3.9

How to Spay \& Bitoh ........... 360

Hydrophobla, .................. 357

Itohy, woes .............. 353
rAGE

Itchy (,$\ldots$ Mange) . . . . . . . . . 352

Jarking, Dog (noo Chorea) ....... 357

Lnmpu in the Skin (see Tumors). . 3.55

iog Brolen (see Fractured Bones) $3 . \overline{5}$

iice on Dog (see Fleas)......... 353

3/ad Dog................ 357

Mad Doy (wee Dog Poisoned)...... 358

Mange.................... 352

Poisoned................... 358

Pups, How to Breed............ 359

Pnp's Tailn, How to Cnt........ 360

Pupping, Troubles Mot With

While.................... 359

Rabies..................... 357

Rat Poison................. 3.58

Red Ejes (see Sore Eyes)........ 354

Running Sore in Head (see Canker

in $\mathbf{E a r}) . . \ldots \ldots \ldots \ldots \ldots \ldots$. 3

Scratching ( Fleas) . . . . . . . 353

Scratching (see Mange)......... 352

Scowers (see Diarrhaea)......... 355

Stin Irritated (see Mange)...... 352

Skin Raw (see Mange).......... 352

Sore Eyes.................. 354

Sore in Head (see Canker in Kar)., 353

Sores (see Wounds or Cints)..... 354

Spay - Bitch, How to.......... 360

Straining (sce Constipation) . .... 355

Strangles (see Distemper)....... 356

Strychnine Poison............ 358

Swelling on the Skin (see Tumors) 355

Tails on Pups, How to Cut. .... 360

Trembling Dog :oe Chored)...... 357

Troubles at Pupping Time ....... 35.9

Tumors or Grow ths on Skin ...... 355

Wax in Ear (see Deafness)....... 353

White Spots in Munure (see

Worms)................. $3 \pi$ sin

Worms................. 3.56

Wounds or Cuts of Any Klnd ... 35.t

\section{POULTRY.}

Bis Fand in Turkejw. . . . . . PACE 366

Cankor ....................... 364

Cholera ...................... 364

Crop Bound ................ 365

Dinanes and Treatment of Poultry 362
Gaper................... 365

Hen Lice in Hen house and on

Hens....................... 3i3

Leg i eakness............. 36,j

Roup.................. 362

Scaly Lega................. 3t. 


\section{INDEX PART V.}

\section{MEDICINES AND RECEIPTS.}

\section{MEDICINES.}

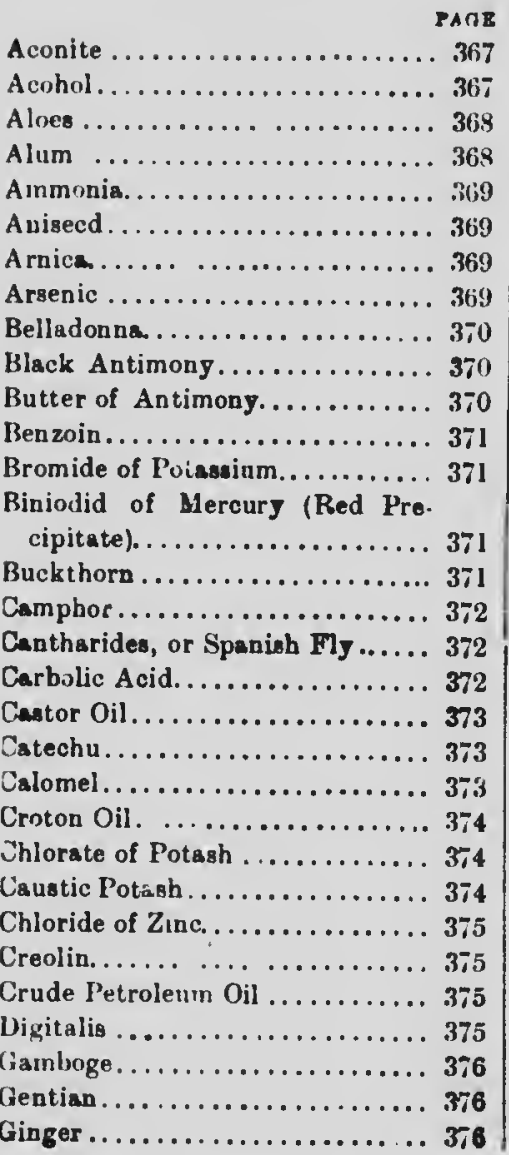

rAsD

Hyposulphite of Sods ......... 3ii

Iodine .................. 37;

Iodide of Potassium .......... 377

Lime.... ............... 377

Linseed .................. 378

Laudanum................. 378

Monsell's Solution of Iron....... 3;

Marshmallows ............... 37!

Mustard.................. 379

Nux Vomica................379

Nitrate of Silver ............ 379

Nitratc of Potash or Saltpetre.... 380

Olive Oil.................... 380

Oil of 'Tar............... 380

Oxide of Zine. ............. 330

Oil of Male Shield Fern......... 380

Pepper................... 381

Quassia Ch:pe.............. 381

Sulphuric Acid............... 381

Sulphuric Ether............ 382

Sulphate of Copper ............ 382

Sulphate of Iron ............. 382

Sulphate of Zino ............. 382

Sugar of Lead ............... $3 \times 3$

Salicylic Acid................ 383

Salt..................... 383

Sweet Spirits of Nitre......... 383

Spirits of Turpentine.......... 384

Salts.................... 384

Sulphur................... 385

Vaseline. ................... 385

Verdigris................... 394 
RECEIPTS.

\begin{tabular}{|c|c|}
\hline PATIE & $\mathbf{P A}$ \\
\hline Liniment. . & List of Medicines to Be Kept on \\
\hline ver and Worms. & Hand \\
\hline lic Oil $\ldots \ldots \ldots \ldots \ldots \ldots \ldots, 388$ & Mercury Bliater... \\
\hline and Indigestion, .......... 390 & Ball for Horsea. \\
\hline dition Powder. ............. 390 & Phyaic Drench for Horses........ 388 \\
\hline oolin Lotion................. 387 & Physic Drench for Cuttle ........ 383 \\
\hline e Wash.................. & Powders to Act ou Kidneys and \\
\hline , Blister.................... & ................ \\
\hline n............ & - $3 \times 6$ \\
\hline ders. . ... & White Lotion. .. . \\
\hline 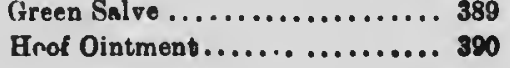 & Worm Powder. \\
\hline
\end{tabular}

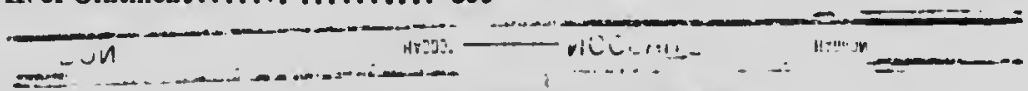

\section{ILLUSTRATIONS.}
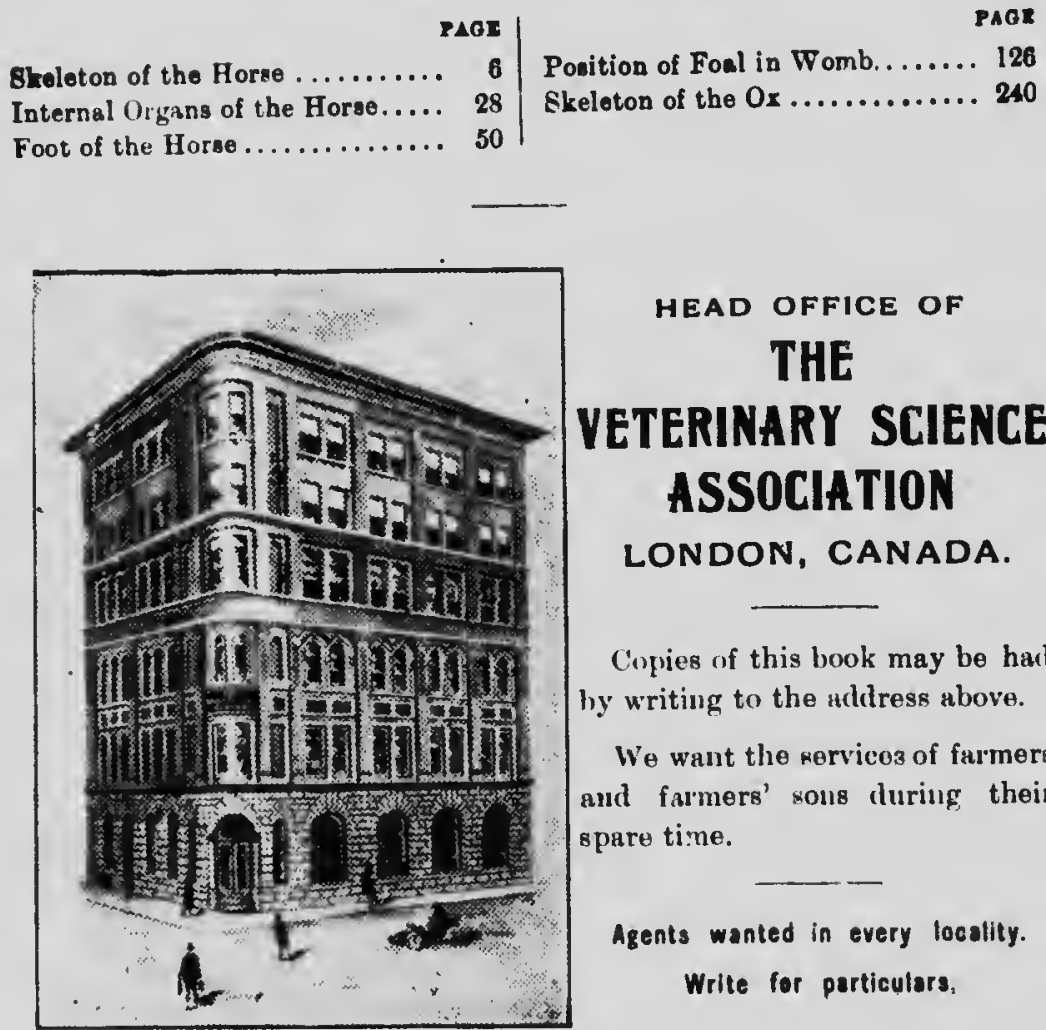

\section{HEAD OFFICE OF THE VETERINARY SCIENCE ASSOCIATION}

LONDON, CANADA.

Copies of this book may be hal hy writing to the uddress above.

We want the services of falmers and farmers' sons during their spare time.

Agents wanted in every locality. Write for particulars, 


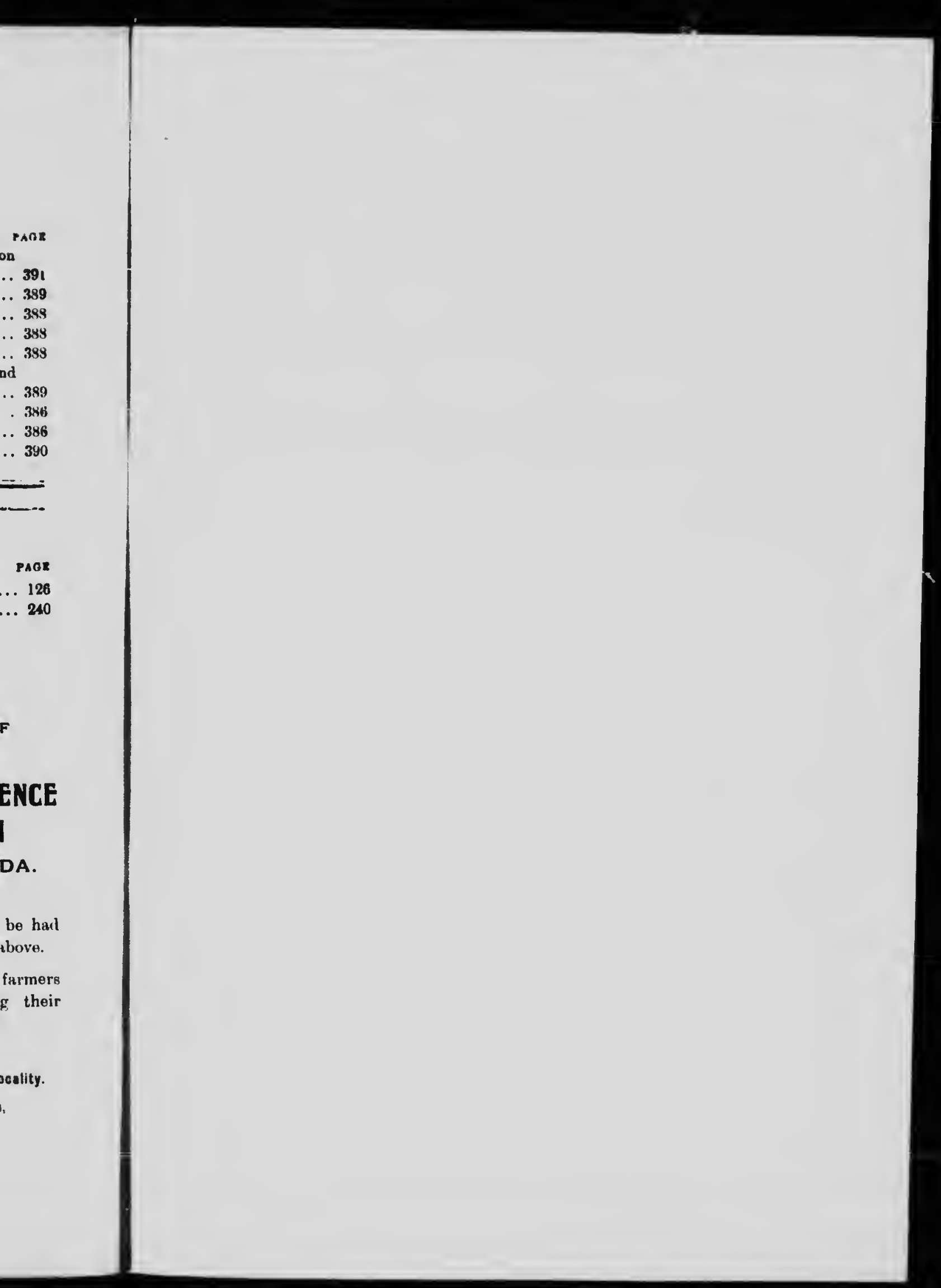




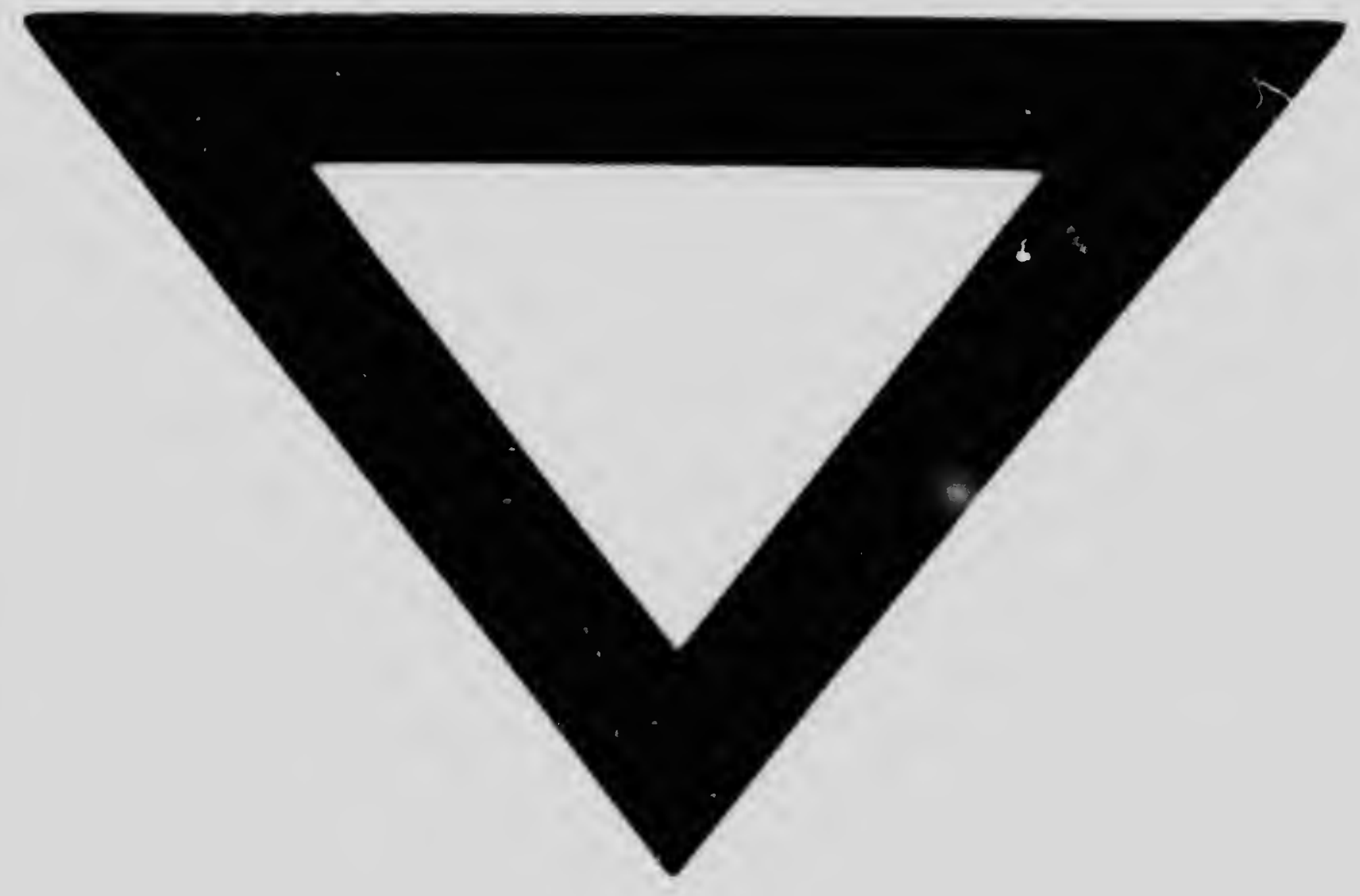

